С.Н. Охулков, А.С. Плехов, Д.Ю. Титов, Ю.В. Шевырёв

\title{
МЕТОДЫ И УСТРОЙСТВА ОСЛАБЛЕНИЯ ВИБРАЦИИ ЭЛЕКТРОМЕХАНИЧЕСКИХ КОМПЛЕКСОВ
}

Библиотека журнала «Вестник научно-технического развития»

The library of the Journal "Bulletin of Science and Technical Development"

(http://www.vntr.ru)

Представлено членом редколлегии, д.ф-м.н.,, академиком РАЕН

В.И. Ерофеевым

BHTP

VESTNIK

MOCKBA

2017 
МИНИСТЕРСТВО ОБРАЗОВАНИЯ И НАУКИ РОССИЙСКОЙ ФЕДЕРАЦИИ

ФЕДЕРАЛЬНОЕ ГОСУДАРСТВЕННОЕ БЮДЖЕТНОЕ ОБРАЗОВАТЕЛЬНОЕ УЧРЕЖДЕНИЕ ВЫСШЕГО ОБРАЗОВАНИЯ «НИЖЕГОРОДСКИЙ ГОСУДАРСТВЕННЫЙ ТЕХНИЧЕСКИЙ УНИВЕРСИТЕТ им. Р.Е. АЛЕКСЕЕВА»

\section{МЕТОДЫ И УСТРОЙСТВА ОСЛАБЛЕНИЯ ВИБРАЦИИ ЭЛЕКТРОМЕХАНИЧЕСКИХ КОМПЛЕКСОВ}

\section{МОНОГРАФИЯ}

Нижний Новгород 2016 


\title{
УДК 628.517.2
}

ББК 34.41

O 92

\author{
А в т о р ы:
}

С.Н. Охулков, А.С. Плехов, Д.Ю. Титов, Ю.В. Шевырёв

Р е це н з е н т

доктор технических наук, профессор М.Х. Прилуцкий

О 92 Методы и устройства ослабления вибрации электромеханических комплексов: монография / С.Н. Охулков, А.С. Плехов, Д.Ю. Титов, Ю.В. Шевырёв; Нижегород. гос. техн. у-т им. Р.Е. Алексеева, 2016. - 254 с.

ISBN 978 - 5 - $502-00825-9$

Рассмотрены проблемы вибрации электромеханических комплексов, обусловленные взаимным влиянием механических колебаний элементов машин и кондуктивных факторов электромагнитной совместимости, таких как реактивная мощность и мощность искажений, потребляемые электрическими машинами.

Рекомендуется для студентов, аспирантов, преподавателей вузов и научных работников, специализирующихся в области виброзащиты.

Монография подготовлена в рамках проектной части государственного задания в сфере научной деятельности - проект № 8.2668.2014/К «Оптимизация энергетических и вибрационных характеристик регулируемых автономных электромеханических систем с новым классом адаптивных полупроводниковых преобразователей».

Рис. 159. Табл. 35. Библиограф.: 134 назв.

УДК 628.517.2

ББК 34.41

ISNB 978 - 5 - 502 - 00825 - 9

(C) НГТУ им. Р.Е. Алексеева, 2016

(C) Охулков С.Н., Плехов А.С., Титов Д.Ю., Шевырёв Ю.В., 2016 


\section{ОГЛАВЛЕНИЕ}

ВВЕДЕНИЕ

ГЛАВА 1. АНАЛИЗ ЭЛЕКТРОМАГНИТНЫХ И ВИБРАЦИОННЫХ ПРОЦЕССОВ В ЭЛЕКТРОМЕХАНИЧЕСКИХ КОМПЛЕКСАХ

1.1. Структура узла нагрузки с электромеханическими комплексами

1.2. Использование активных компенсирующих устройств для виброзащиты машин электромеханического комплекса 15

1.3. Дополнительные причины возникновения вибраций в машинах электромеханического комплекса и методы снижения вибраций .23

ГЛАВА 2. АКТИВНЫЕ КОМПЕНСИРУЮЩИЕ УСТРОЙСТВА КАК РАЗВИТИЕ АКТИВНЫХ ФИЛЬТРОВ ГАРМОНИК 33

2.1. Применение АКУ на основе активных фильтров гармоник в целях ослабления вибраций машин и негативного влияния на сеть

2.2. Анализ свойств активных фильтров, изготавливаемых электротехническими компаниями

2.3. Преобразование координат как инструмент построения алгоритмов вычисления сигналов управления АКУ

ГЛАВА 3. СИЛОВОЙ ПРЕОБРАЗОВАТЕЛЬ АКТИВНОГО КОМПЕНСИРУЮЩЕГО УСТРОЙСТВА 65

3.1. Основные схемы силовой части активных фильтров

3.2. Определение требований к параметрам активного фильтра гармоник

3.3. Учет потерь и генерируемой мощности искажений 
электромеханического фильтра при определении установленной мощности активного компенсирующего устройства. .78

ГЛАВА 4. ОПИСАТЕЛЬНЫЕ И МАТЕМАТИЧЕСКИЕ МОДЕЛИ ЭЛЕКТРОМЕХАНИЧЕСКИХ КОМПЛЕКСОВ КАК

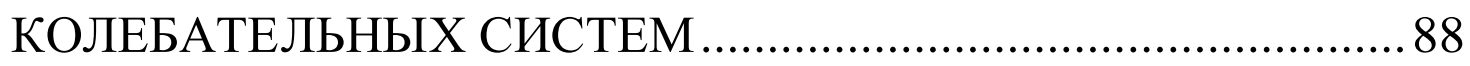

4.1. Математические модели колебательных систем на основе машин с электрическим приводом переменного тока......88 4.2. Оценка деформаций валов асинхронных двигателей в

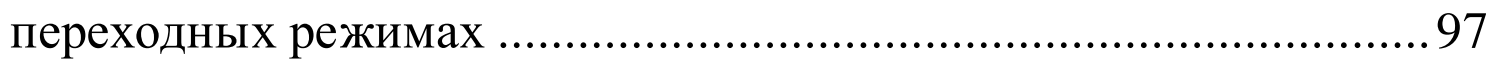

4.3. Математическая модель явления синхронизации ................ 121

4.4. Биения как результат неустойчивой синхронизации двух двигателей на общем вязкоупругом основании ................ 128

4.5. Нормирование вибраций................................................. 141

ГЛАВА 5. ГИДРООПОРЫ С МАГНИТОРЕОЛОГИЧЕСКИМ ТРАНСФОРМАТОРОМ

5.1. Гидроопоры как современные средства виброзащиты машин и силовых агрегатов

5.2. Конструкция индукционных МРТ перестраиваемых гидроопор с внешним расположением возбуждаемых электромагнитов.

5.3. Основы расчета магнитной цепи индукционных МРТ гидроопор 178

5.4. Возбуждение и размагничивание ферромагнитных элементов с остаточной магнитной индукцией в МРТ гидроопор

5.5. Управление гидроопорой с МРТ 207 
ГЛАВА 6. ИМИТАЦИОННОЕ МОДЕЛИРОВАНИЕ И ЭЭСПЕРИМЕНТАЛЬНОЕ ИССЛЕДОВАНИЕ СИСТЕМ ВИБРОЗАЩИТЫ ЭЛЕКТРИЧЕСКИХ И РАБОЧИХ МАШИН......218

6.1. Экспериментальное исследование электромехани-

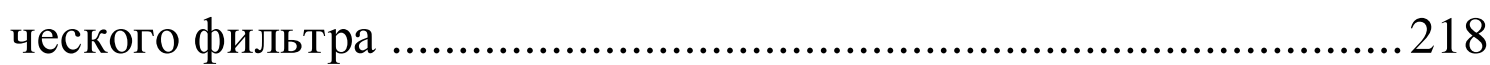
6.2. Моделирование активного фильтра гармоник сетевого тока. 222

6.3. Экспериментальные исследования синхронизации двух электрических машин на упругом основании 226

6.4. Синтез комплексной системы ослабления вибраций электромеханического комплекса 


\section{ВВЕДЕНИЕ}

Монография направлена на исследование и разработку комплексных систем энергосбережения, увеличения ресурсов и резервов электромеханического оборудования на основе новых силовых полупроводниковых преобразователей и активных виброзащитных устройств - гидроопор с магнитореологическими трансформаторами с магнитными жидкостями, управляемыми электромагнитными полями.

Защита от вибрации и шума является актуальной проблемой современного машиностроения, так как надежность и безопасность функционирования оборудования зависят от эффективности мероприятий по виброзащите. Последние тенденции развития силовых установок связаны с увеличением их скорости движения и мощности, что приводит к возрастанию уровней вибрации, а также к расширению спектра колебаний, действующих на машины и механизмы.

Наиболее перспективными устройствами для гашения вибрации считаются магнитореологические гасители колебаний. В них диссипация энергии колебаний происходит в средах с магнитными жидкостями.

Компенсация неактивных составляющих электрической мощности, потребляемой от источников питания переменного тока нагрузками с реактивными элементами и силовыми электронными преобразователями, реализуется путем создания условий неуправляемого или управляемого резонанса для реактивных и искажающих токов или напряжений на месте потребления электроэнергии, а вместе с тем, и для создания «антипульсаций» момента электрической машины.

Проблема управления колебаниями электромагнитного момента электрических машин отражена в работах Онищенко Г.Б., Шрейнера Р.Т., Титова В.Г., Хватова О.С., Шевырёва Ю.В., Фёдорова О.В. и др. Исследованием высших гармоник в сетях электроснабжения занимались: Арриллага Дж., Вагин Г.Я., Кудрин Б.И, Зиновьев Г.С, Жежеленко И.В., Железко И.С., Лоскутов А.Б., Розанов Ю.К. и другие авторы. Проблемы вибрации машин и механизмов широко изучены такими авторами, как Гордеев Б.А., Григорьев Н.В., Кудинов В.А., Фридман В.М., Шубов И.Г., Tinghsu S., Hattori S. и другими.

В монографии рассмотрены вопросы применения активных фильтров гармоник и преобразователей частоты для компенсации реактивных мощностей, приведены экспериментальные исследования эффектов синхронизации электрических машин, предложена интегральная система ослабления вибраций, содержащая виброзащитные гидроопоры. 


\section{ГЛАВА 1. АНАЛИЗ ЭЛЕКТРОМАГНИТНЫХ И ВИБРАЦИОННЫХ ПРОЦЕССОВ В ЭЛЕКТРОМЕХАНИЧЕСКИХ КОМПЛЕКСАХ}

\section{1. Структура узла нагрузки с электромеханическими комплексами}

Электромеханические комплексы являются динамическими системами, в которых наблюдаются колебания электрических параметров режима и вибрации механических частей. Электрические колебания вызывают движения механических элементов, а нагрузки в механической системе влияют на изменение режимов работы электрических подсистем.

Основными характеристиками электрических сетей, от которых зависят режимы работы таких электромеханических комплексов, как электроприводы и установки «тепловой двигатель - электрический генератор» электростанций является их комплексное сопротивление между узлами нагрузки, и последующая посадка напряжения на нем при передаче электроэнергии. При этом при ощутимых значениях реактивного сопротивления линии электропередачи, падение может быть значительным и привести к нештатным ситуациям. Наиболее часто встречающейся проблемой в «слабой» сети (например, в судовой с источником питания в виде синхронного генератора или в системе автономного электроснабжения) является посадка напряжения при пуске мощного асинхронного электродвигателя. Рассчитанный на номинальную нагрузку генератор не может справиться с пусковыми токами, превышающими номинальный в несколько раз, в результате чего происходит падение напряжения судовой сети. Так как момент на валу асинхронного двигателя пропорционален квадрату напряжения, параллельно-работающие машины при определенных обстоятельствах электродвигатели могут остановиться без последующего самостоятельного перезапуска. Для предотвращения такой ситуации приходится, например, заменять один мощный электродвигатель несколькими электродвигателями меньшей мощности, запускаемыми один за другим. Другое возможное решение проблемы заключается в использовании частотно-регулируемого привода, где пусковыми токами, возможно, управлять [85].

В электрической сети промышленного предприятия, как правило, имеется большой запас мощности, и проблема пуска мощных асинхронных двигателей стоит менее остро [21]. Однако потребляемая электродвигателями реактивная мощность загружает питающую электросеть, в результате чего уменьшается резерв мощности установленного оборудования. Использование частотно-регулируемого электропривода, наряду с положительными эффектами, загружает сеть высокочастотными гармони- 
ками, снижающими срок эксплуатации оборудования [97, 109]. Для снижения негативного влияния данных неактивных мощностей серийно выпускаются установки компенсации реактивной мощности [88], а также активные фильтры гармоник, повышающие качество напряжения в питающей сети предприятия. Данные установки, устанавливаются возле устройств ввода и предназначены для снижения уровня реактивной мощности, потребляемой объектом из промышленной сети.

Вместо применения классических частотных преобразователей с неуправляемым выпрямителем, который и является основным источником высокочастотных помех, на больших мощностях все большее распространение получают частотные преобразователи с активным выпрямителем, потребляющие из сети синусоидальный ток с близким к единице коэффициентом мощности. Можно отметить, что такой электроприемник не потребляет неактивной мощности. Однако он не является компенсатором реактивной мощности, потребляемой параллельно включенной нагрузкой.

В настоящий момент все вопросы улучшения качества потребляемой электроэнергии рассматриваются при условиях нахождения системы в установившемся режиме [22, 23]. Рассмотрим математические модели типовых электроприемников.

По форме и энергетической роли потребляемого тока электроприемники можно распределить [58] на четыре базовых группы (рис. 1.1):

- компенсирующие установки;

- несимметричная нагрузка;

- нагрузка потребляющая несинусоидальный ток;

- нагрузка с синусоидальным потреблением.

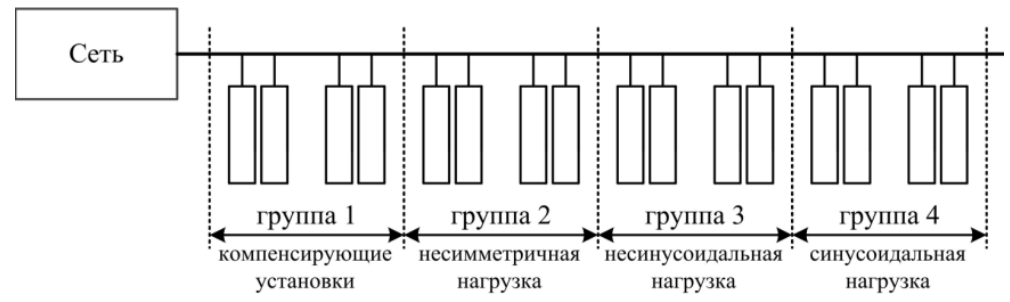

Рис. 1.1. Структурная схема узла нагрузки

Каждый из электроприемников характеризуется факторами воздействия на питающую сеть, а также эффектами от взаимодействия с другими электроприемниками [26, 27].

Для решения задач взаимодействия данных электроприемников рассмотрим отдельные группы структуры сети с организованным энергообменом (рис. 1.1), с помощью которой можно анализировать процессы взаимодействия и получать необходимые характеристики переходных процессов. 
Наиболее распространенным типом такой нагрузки являются трансформаторы и асинхронные электродвигатели с непосредственным подключением. Одной из характеристик такой нагрузки является коэффициент мощности, характеризующий уровень потребляемой реактивной мощности, необходимой для работы устройства. Реактивная мощность не оказывает негативного воздействия на параллельно работающие электроприемники, однако она загружает линии питания дополнительной мощностью, что может привести к перегрузке сети, а также значительным посадкам напряжения при включении мощных электроприемников. Реактивная мощность индуктивного характера компенсируется в узле распределения нагрузки с помощью конденсаторных батарей с полупроводниковыми коммутаторами, регулирующими количество компенсируемой реактивной мощности в данный интервал времени, не меньший периода напряжения питания.

Математическая модель асинхронного электродвигателя, подключенного непосредственно к питающей сети, должна учитывать несимметрию питающего напряжения, а также сопротивление питающих проводов, которые, в пределах, например, электрической сети средней мощности, будут играть существенную роль в переходных процессах.

При составлении уравнений математической модели асинхронной трехфазной машины возможны следующие допущения [63]:

- магнитная цепь АД не насыщена;

- энергия магнитного поля сосредоточена в воздушном зазоре;

- потери в стали и механические потери пренебрежимо малы;

- воздушный зазор равномерен.

Систему дифференциальных уравнений токов ротора и статора удобно записать в векторно-матричной форме [9]:

$$
\frac{d[i]}{d t}=\left[L_{1}\right]^{-1} \cdot\left\{[u]-\left([R]+\left[L_{2}\right] \frac{\omega}{\sqrt{3}}[i]\right)\right\},
$$

где [i] - вектор неизвестных токов (токи статора и ротора); $[u]-$ вектор напряжений; $[R]-$ матрица сопротивлений; $\left[L_{1}\right],\left[L_{2}\right]-$ матрица индуктивностей статора и ротора.

Решением данной системы являются токи во всех фазах статора и ротора. По ним определяется электромагнитный момент двигателя:

$$
m=p_{n} \frac{\sqrt{3}}{2} L_{m}\left[\left(i_{A} i_{c}+i_{B} i_{a}+i_{C} i_{b}\right)-\left(i_{A} i_{b}+i_{B} i_{c}+i_{C} i_{a}\right)\right] .
$$

Уравнение движения асинхронного двигателя выглядит следующим образом: 


$$
\frac{J_{\Sigma}}{p_{n}} \cdot \frac{d \omega}{d t}=M-M_{c}
$$

где $J_{\Sigma}$ - суммарный момент инерции вращающихся масс, приведенных к валу двигателя; $p_{n^{-}}$число пар полюсов; $M_{c^{-}}$статический момент на валу двигателя.

Описанная выше модель позволяет в качестве статического момента использовать любую периодическую функцию, что позволяет симулировать различные механические процессы на валу двигателя.

Средние значения потребляемой активной и реактивной мощностей по первой гармонике рассчитываются по следующей формуле:

$$
\left\{\begin{array}{l}
P=U I_{1} \cos \varphi \\
Q=U I_{1} \sin \varphi
\end{array},\right.
$$

где $\cos \varphi$ - коэффициент мощности электродвигателя.

Из формулы (1.1) видно, что потребление тока уменьшается с увеличением частоты вращения вала машины. На рис. 1.2 отображены графики набора скорости $(a)$ и коэффициента мощности (б) асинхронного двигателя.

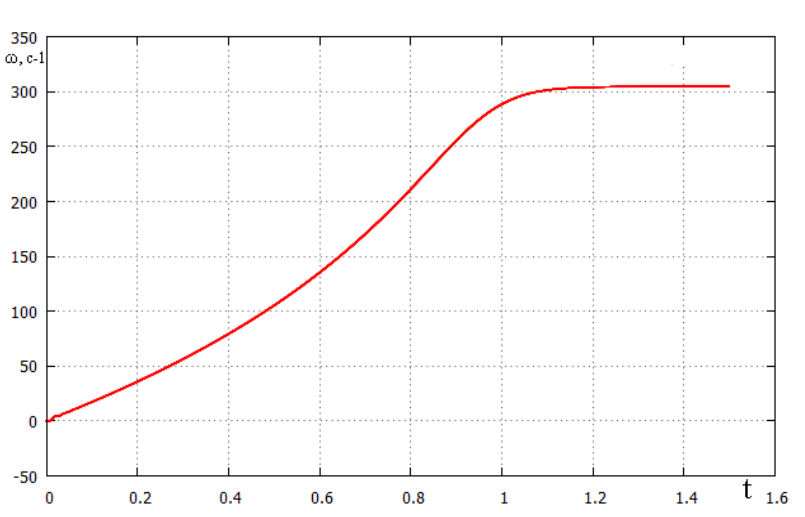

a)

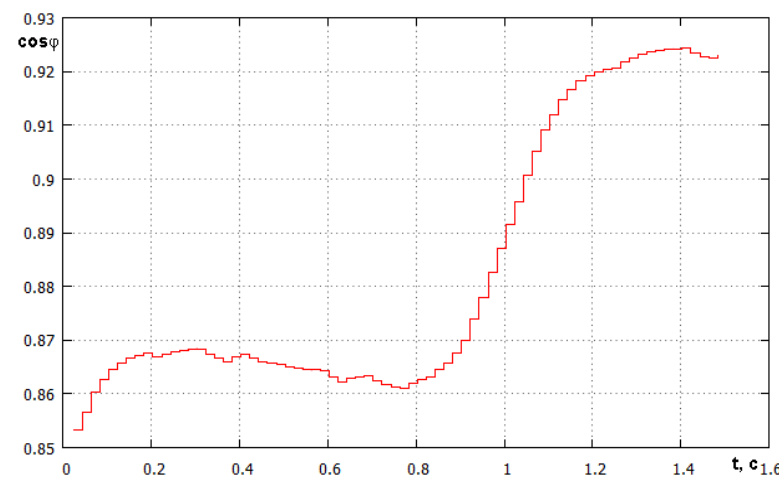

б)

Рис. 1.2. Графики мгновенного значения (a) частоты вращения ротора двигателя; (б) коэффициента мощности при разгоне

При номинальной частоте вращения, когда магнитное сопротивление системы велико, амплитуда потребляемого тока минимальна. В этом режиме коэффициент мощности электродвигателя максимален. Однако при пуске, когда в цепи присутствует только малое активно-индуктивное сопротивление обмотки, коэффициент мощности уменьшается, что сказывается на высоких пусковых токах, большая часть которых является реактивной. 
Математическая модель несимметричной нагрузки сводится к системе, которая описывает трехфазный электроприемник с неравными эквивалентными сопротивлениями в фазах:

$$
\left[\begin{array}{l}
i_{A}(t)=u_{A}(t) \cdot z_{A}(t) \\
i_{B}(t)=u_{B}(t) \cdot z_{B}(t) \\
i_{C}(t)=u_{C}(t) \cdot z_{C}(t)
\end{array}\right],
$$

где $z_{A}(t) \neq z_{B}(t) \neq z_{C}(t) \quad$ - эквивалентные сопротивления фаз электроприемника.

Для четырехпроводной сети электроснабжения математическая модель сводится системе из сумм однофазных электроприемников:

$$
\left[\begin{array}{l}
i_{A}(t)=u_{A}(t) \cdot \sum z_{A}^{i}(t) \\
i_{B}(t)=u_{B}(t) \cdot \sum z_{B}^{i}(t) \\
i_{C}(t)=u_{C}(t) \cdot \sum z_{C}^{i}(t)
\end{array}\right],
$$

где $z_{A}^{i}(t), \quad z_{B}^{i}(t), \quad z_{C}^{i}(t) \quad$ электроприемников фаз.

Одним из последствий несимметрии питающего напряжения являются перенапряжения на других фазах в случае трехпроводной схемы питания. Кроме того, у асинхронных электродвигателей с непосредственным подключением наблюдаются биения момента, которые приводят к вибрациям механизмов, что снижает надежность работы оборудования (рис. 1.3).

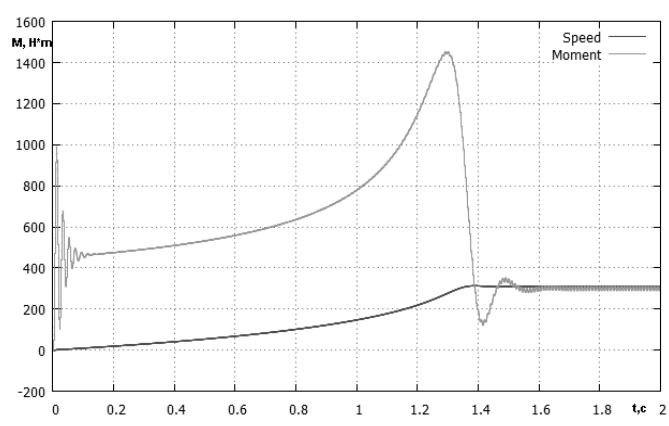

a)

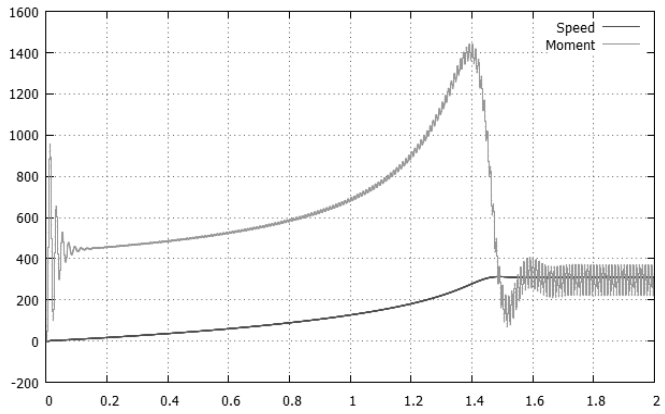

б)

Рис. 1.3. Графики частоты вращения и момента асинхронного двигателя при работе от сети (a) с симметричным напряжением; с пониженным напряжением одной фазы (б)

Единственным способом предотвращения негативного воздействия несимметричной нагрузки на сеть является равномерное распределение однофазных нагрузок по фазам. Однако, несмотря на статистическую 
равномерность, в реальной сети загруженность фаз будет различной. Применение компенсирующих устройств, перераспределяющих нагрузку по фазам, решает данную проблему.

Напряжение в начале линии $U_{l}$ связано с напряжением в ее конце $U_{2}$ соотношением

$$
U_{1}=\sqrt{\left(U_{2}+\Delta U^{\prime}\right)^{2}+\left(\Delta U^{\prime \prime}\right)^{2}},
$$

где $\Delta U^{\prime}$ и $\Delta U^{\prime \prime}$ - продольная и поперечная составляющие вектора падения напряжения, определяемые по формулам

$$
\begin{aligned}
& \Delta U^{\prime}=\frac{P_{2} R+Q_{2} X}{U_{2}}=\Delta U_{p}^{\prime}+\Delta U_{q}^{\prime} \\
& \Delta U^{\prime \prime}=\frac{P_{2} R+Q_{2} X}{U_{2}}=\Delta U_{p}^{\prime \prime}+\Delta U_{q}^{\prime \prime}
\end{aligned} .
$$

Арифметическую разницу между напряжением в начале и конце линии называют потерей напряжения $\Delta U=U_{1}-U_{2}$. Для сетей обычно $X \gg R$, поэтому $\Delta U^{\prime}$ определяется в основном слагаемым $Q_{2} X$, а $\Delta U^{\prime \prime}$ слагаемым $P_{2} R$. Влияние $\Delta U^{\prime \prime}$ на $U_{2}$ мало, так как в (1.2) первое слагаемое подкоренного выражения значительно больше второго.

Поэтому уровни напряжения в узлах энергосистемы практически почти не зависят от передаваемой активной мощности и полностью определяются реактивной составляющей (рис. 1.4) [68].

Следовательно, для стабилизации уровня напряжения на шинах потребителя необходимо искусственно изменять поток реактивной мощности, чтобы выполнялись требования ГОСТа на качество электроэнергии.

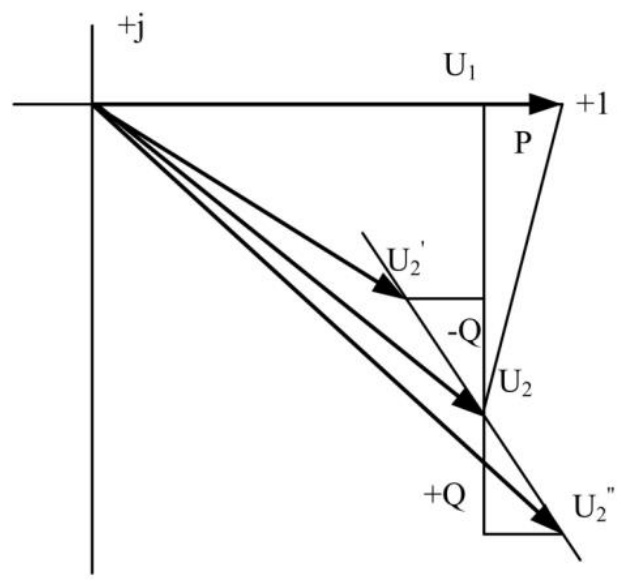

Рис. 1.4. Зависимость напряжения у потребителя от перетоков реактивной мощности

Источниками высшего гармонического состава являются подключенные к электросети потребители с нелинейными входными цепями на 
базе полупроводниковых нелинейных элементов (выпрямительных мостов, диодов, тиристоров и т. д.).

Наиболее распространенными нелинейными приемниками являются:

- статические преобразователи - выпрямители, источники бесперебойного питания, тиристорные регуляторы, преобразователи частоты для питания регулируемого электропривода и т. п.;

- электронные балласты газоразрядных осветительных приборов;

- электродуговые печи постоянного и переменного тока;

- сварочные установки и др.

Наибольшая трудность в математическом описании несинусоидальной нагрузки заключается в том, что большая часть нелинейных процессов происходит в связи с процессами коммутации цепей внутри устройства, таким образом, требуется написать уравнения для каждого из ключевых режимов потребителя. Однако, учитывая, что цепи указанных электроприемников работают синхронно с сетью (мостовые выпрямители, тиристорные регуляторы и проч.) в установившемся режиме работы, подобную систему математических описаний с высокой точностью можно заменить на представление формы итогового сигнала в виде ряда Фурье:

$$
I=\sum_{j=1}^{N} A_{j} \sin \left(j \cdot \omega \cdot t+\varphi_{j}\right),
$$

где $j$ - номер гармоники; $N$ - число учитываемых гармоник; $A_{j}$ - амплитуда гармоники; $\varphi_{j}$ - фаза гармоники.

Например, временная диаграмма напряжений наиболее распространенного в общепромышленных преобразователях 6-пульсного мостового неуправляемого диодного выпрямителя, работающего на активноиндуктивную нагрузку $(a)$ и гармонический состав потребляемого тока (б) представлены на рис. 1.5.

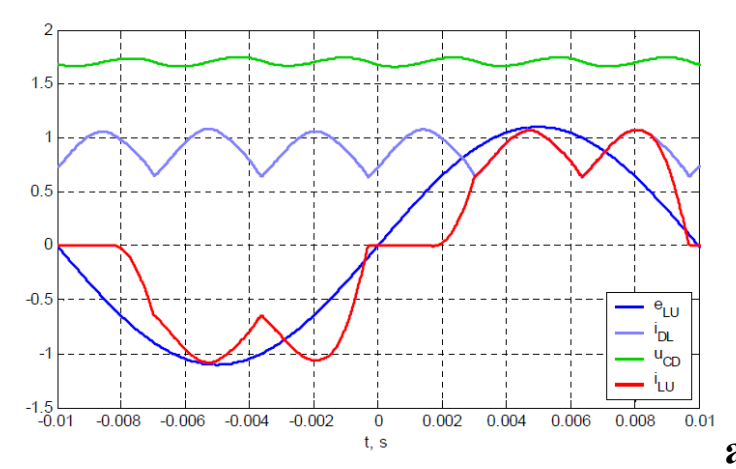

a)

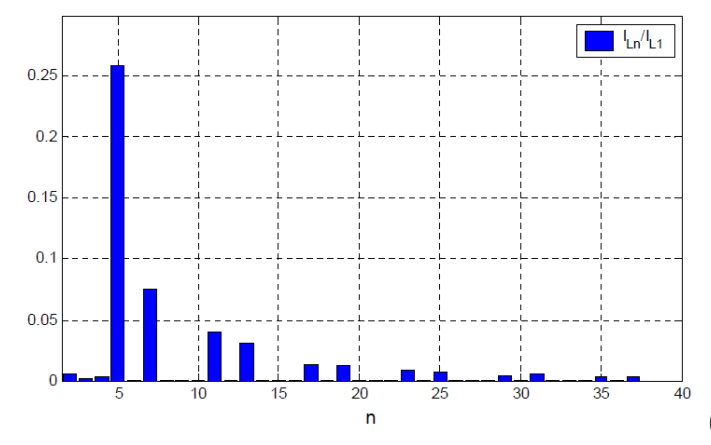

б)

Рис. 1.5. Диаграмма напряжений $(a)$; гармонический состав 6-пульсного мостового диодного выпрямителя, работающего на активно-индуктивную нагрузку (б) 
Таким образом, для математического описания несинусоидальной нагрузки в установившемся режиме достаточно указать набор амплитуд и фаз гармонического спектра, которые можно получить из результатов различных исследований $[50,51,94]$, в том числе ранее проводимых авторами $[59,77]$.

В случае описания динамических процессов, амплитуды и фазы гармоник будут являться некоторыми функциями времени и формула (1.3) примет следующий вид:

$$
I=\sum_{j=1}^{N} A_{j}(t) \sin \left(j \cdot \omega \cdot t+\varphi_{j}(t)\right),
$$

где $A_{j}(t)$ - мгновенное значение амплитуды гармоники, зависящее от потребляемого тока подключенной к выпрямителю нагрузки.

Наличие в сети высокочастотных гармоник может привести к различным эффектам от прохождения высокочастотных токов через параллельно-работающие электроприемники. Наибольшей проблемой является нагрев конденсаторных батарей, которые входят в состав фильтров питания электроники и установок компенсации реактивной мощности.

Активные компенсирующего устройства - это компенсаторы неактивных составляющих потребляемой электрической мощности, которые позволяют исключить из потребляемой мощности такие составляющие, как реактивная мощность, мощность несимметрии и мощность искажений. Как было показано, именно эти составляющие потребляемой мощности и обусловливают механические удары, вибрации и колебания в рабочих машинах.

Полностью управляемое активное компенсирующее устройство (АКУ) [59] - это устройство, способное генерировать в сеть активные и неактивные составляющие мощности в необходимых количествах. К данному типу электроприемников относятся установки компенсации реактивной мощности, а также активные фильтры гармоник, представляющие собой электроприемники, влиянием которых на питающую сеть можно управлять.

Возможно совмещение функций генерации реактивной мощности и выполнения технологической работы, как это реализуется, например, при использовании синхронных двигателей с регулируемым возбуждением, а также при использовании электроприемников с питанием от полупроводниковых преобразователей [10].

Это означает, что, помимо прямой функции питания некоторой технологической нагрузки от источника регулируемого напряжения, имеется 
возможность регулировать уровни потребляемых из сети неактивных составляющих мощности посредством организации обмена генерируемой энергии с электроприемниками, характеризующимися индуктивным характером нагрузки и высокочастотными токами. Данное энергообменное устройство характеризуется величиной запасенной энергии, которое определяет также интенсивность, скорость и длительность процессов компенсации.

Поскольку энергообменное устройство используется для компенсации реактивной мощности, высокочастотного гармонического состава или стабилизации напряжения, математическая модель данного устройства зависит от типа генерируемой мощности и может быть записана как:

$$
\begin{gathered}
i(t)=-\left(i_{Q}(t)+i_{T}(t)\right) \\
|i(t)|<I_{\max }
\end{gathered},
$$

где $i_{Q}(t), i_{T}(t)$ - мгновенные значения неактивных составляющих тока, присутствующих в сети, которые требуется скомпенсировать; $I_{\max }=I_{\text {уст }}$ $I_{P}$ - максимальное значение величины тока, которое возможно передать через оборудование установленной мощности, в том числе одновременно используемое для передачи активной мощности током $I_{P}$ (например, шины питания между генераторами, фидерами и электроприемниками, автоматические выключатели и т. п.).

Соответственно, математическая модель энергообменного устройства зависит от существующих в электрической сети потребителей неактивных мощностей.

\section{2. Использование активных компенсирующих устройств для виброзащиты машин электромеханического комплекса}

В настоящее время для привода главных циркуляционных насосов атомных электростанций (ГЦН АЭС) и в таких энергетических установках переменной частоты вращения, как дизель-генератор и ветровая электростанция, продолжается использование асинхронных машин с фазным ротором.

Наиболее распространенным типом ветрогенераторов является генератор с переменной скоростью вращения (ГПСВ). 75\% ветряков, выпущенных в 2001 г., и более 80\%, выпущенных в 2002 г., используют данный принцип преобразования энергии ветра в электрическую. Современные морские ветроэлектростанции мощностью 0,5-2 ГВт используют, в основном, ветрогенераторы с переменной скоростью вращения.

Популярность ветряков этого типа обусловлена более высокой 
эффективностью преобразования энергии ветра. Они способны вырабатывать электроэнергию при весьма больших диапазонах изменения скорости потока воздуха. С ростом скорости ветра выходная мощность генератора возрастает. Электронная схема инвертора, обслуживающего генератор ГПСВ, несколько сложнее, чем для классического генератора с постоянной скоростью, но это компенсируется прибавкой более чем $10 \%$ мощности.

На рис. 1.6 показана упрощенная схема преобразователя, использующего в качестве генератора асинхронный двигатель с короткозамкнутым ротором. Электронный модуль содержит конвертор, блок конденсаторов шины питания, инвертор и выходные индуктивности. Для того чтобы не возникало терминологической путаницы, условимся называть конвертором преобразователь, соединенный с генератором и осуществляющий функции подмагничивания ротора и выпрямления выходного напряжения генератора, а инвертором - преобразователь, формирующий выходное напряжение, модулированное по синусоидальному закону.

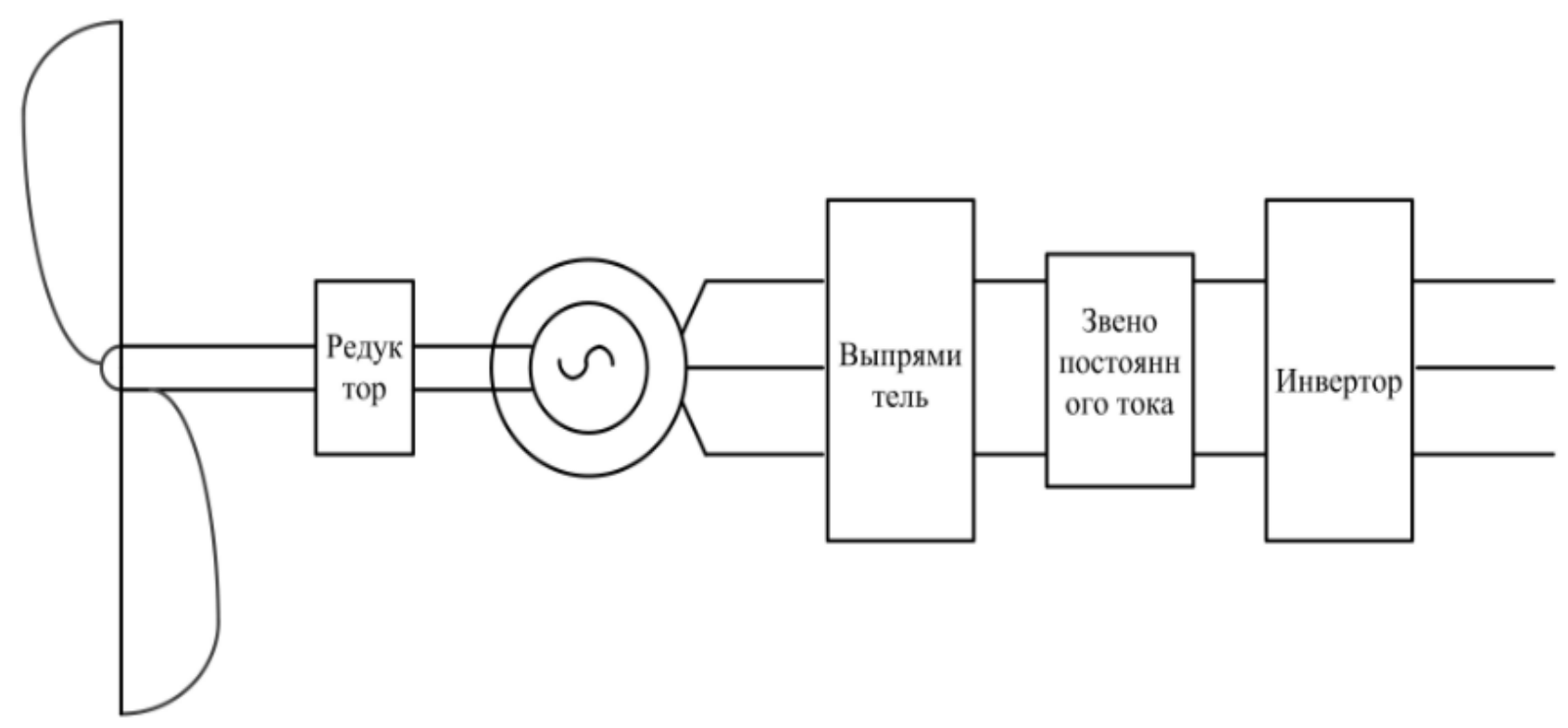

Рис. 1.6. Упрощенная схема ВЭУ, использующего в качестве генератора асинхронный двигатель с короткозамкнутым ротором

Схема, демонстрирующая еще один принцип преобразования энергии, приведена на рис. 1.7. Алгоритм управления данным устройством позволяет компенсировать потери мощности, образующиеся за счет скольжения. В устройстве используется асинхронный двигатель с фазным ротором и кольцевыми токосъемниками, а также электронный блок, содержащий конвертор и инвертор. Данная схема может работать в следующих трех режимах. 


\section{Режим 1}

Статорная обмотка двигателя подключается к сети только тогда, когда скорость ротора близка к синхронной частоте вращения. Ротор постоянно подключен к сети через конвертор и инвертор. При низкой скорости вращения ротора ( $80 \%$ от номинальной), 20\% мощности отбирается ротором из сети. Такая схема иногда называется каскадной.

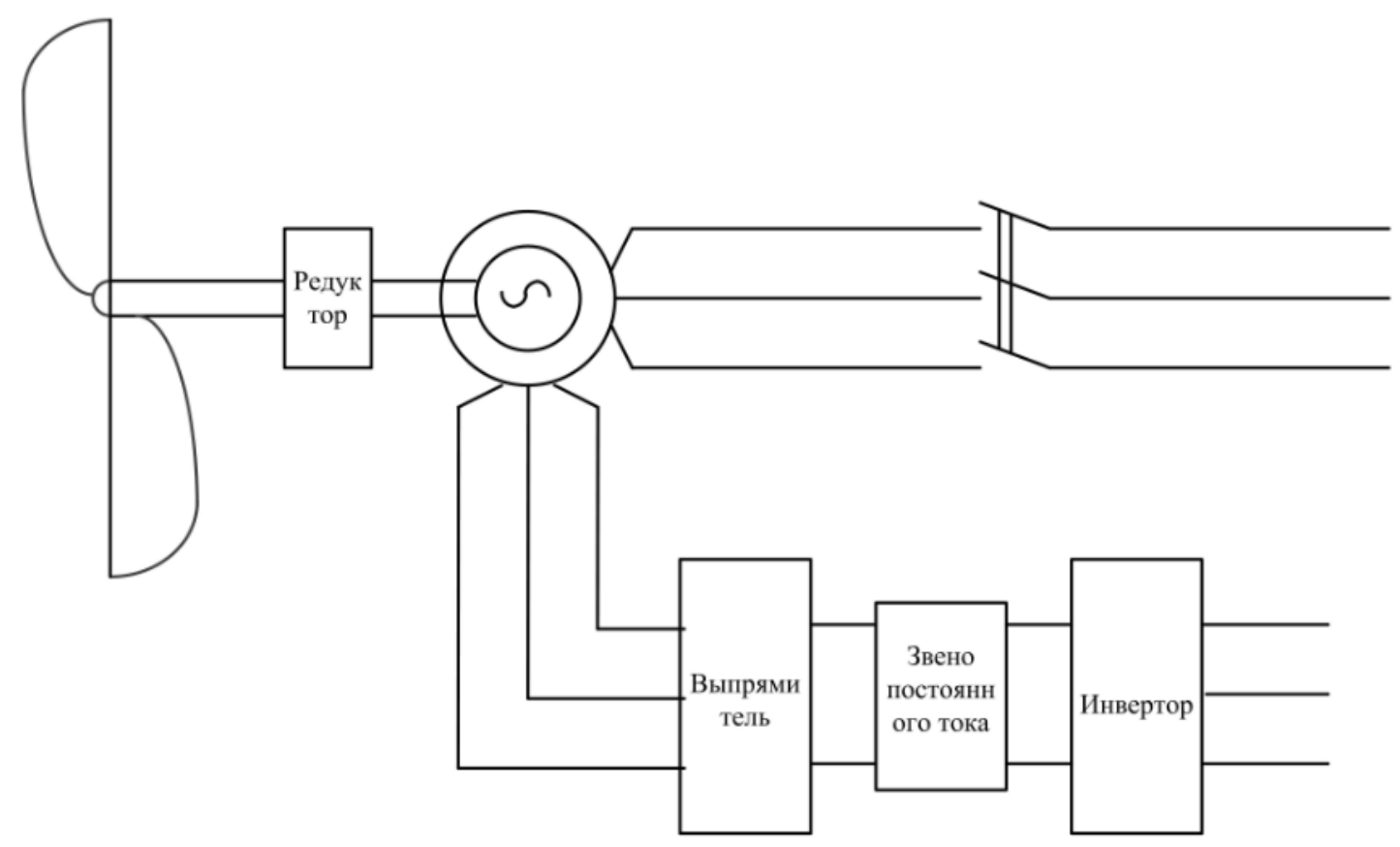

Рис. 1.7. Упрощенная схема ВЭУ, использующего в качестве генератора асинхронный двигатель с фазным ротором

Режим 2

Статор, ротор и электронный блок всегда соединены между собой и отключаются от сети только в момент запуска генератора. Статорная обмотка подключается к сети, когда генерируемое напряжение синхронизировано с сетевым. Конвертор формирует сигнал подмагничивания таким образом, чтобы выходная частота генератора была постоянной и равной сетевой (50 Гц). При этом он работает на низкой частоте, не превышающей несколько десятков Гц. Соединение ротора с конвертором выполняется с помощью токосъемника.

\section{Режим 3}

Аналогичен предыдущему. Двигатель без токосъемника, но со статором, имеющим две 3-фазные обмотки. Одна статорная обмотка подключается к сети, другая соединена с конвертором и инвертором. Передача энергии от ротора к дополнительной статорной обмотке осуществляется за счет трансформаторной связи. Разделение энергии, вырабатываемой ротором и поступающей на ротор, может быть осуществлено за счет 
использования инвертора на разных частотах. Основным преимуществом данной схемы является отсутствие токосъемников, недостатком - необходимость применения статора с двумя обмотками.

При использовании в качестве генератора синхронного электродвигателя отпадает нужда в конверторе, в этом случае можно использовать обычный 3-фазный выпрямительный мост. Синхронный двигатель имеет внешнее возбуждение, следовательно, не нужен источник реактивной мощности, как в предыдущих случаях. В отличие от асинхронных машин, синхронный генератор имеет меньшее выходное напряжение при малых частотах вращения, поэтому после выпрямительного моста необходимо установить повышающий $\mathrm{DC} / \mathrm{DC}$-преобразователь, как показано на рис. 1.8 .

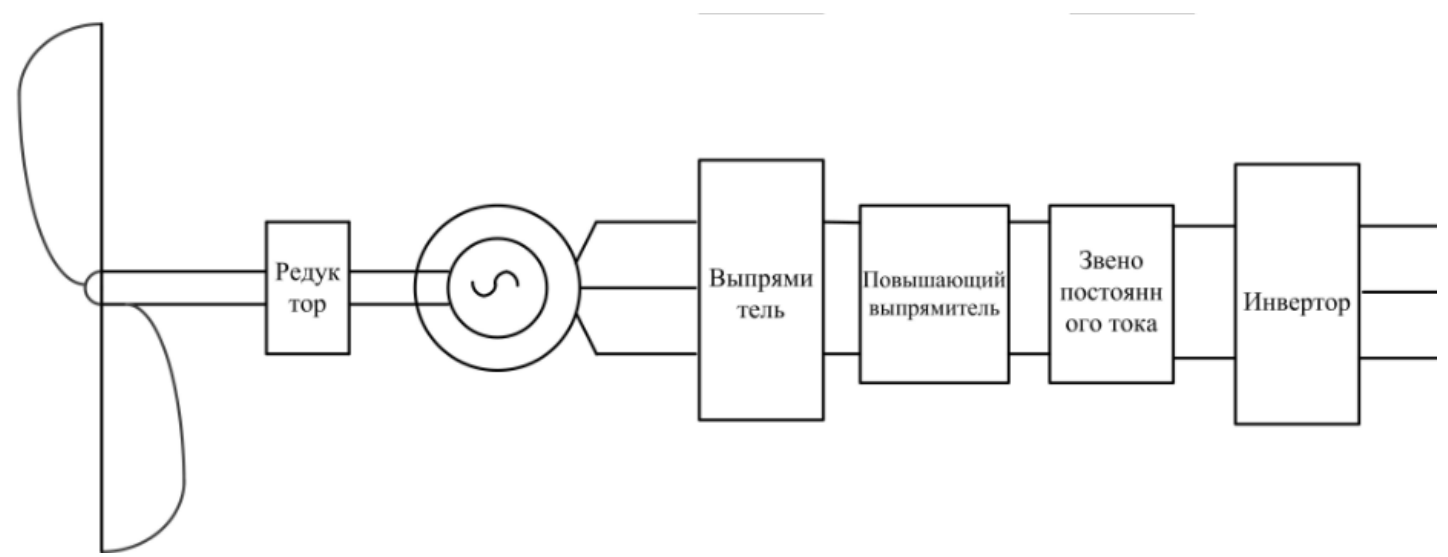

\section{Рис. 1.8. Упрощенная схема ВЭУ, использующего в качестве генератора синхронный двигатель}

В данном случае возможно использование синхронного двигателя с постоянными магнитами. При низкой скорости вращения турбины повышающий преобразователь вырабатывает напряжение, необходимое для питания выходного инвертора. Существует вариант применения синхронного генератора без повышающего конвертора, в этом случае формирование требуемого напряжения осуществляется за счет управления напряжением возбуждения. В описанной схеме может быть использован низкоскоростной многополюсный генератор без редуктора, что является несомненным преимуществом, т.к. повышающий редуктор, как неотъемлемая часть ветрогенератора, создает дополнительные потери и снижает срок службы изделия.

Основные особенности различных вариантов ВЭУ приведены в табл. 1.1. Среди описанных схем наиболее эффективной и широко применяемой является схема с асинхронным генератором и компенсацией потерь на скольжение. Более $50 \%$ работающих сегодня ветряков используют этот принцип работы. 
Особенности различных типов ВЭУ

\begin{tabular}{|c|c|c|}
\hline Тип преобразователя & Преимущества & Недостатки \\
\hline $\begin{array}{l}\text { Асинхронный } \\
\text { генератор, 3-фазный } \\
\text { конвертор и инвертор }\end{array}$ & $\begin{array}{l}\text { Простой асинхронный } \\
\text { двигатель } \\
\text { Нет ограничения по скорости } \\
\text { вращения } \\
\text { Выходное напряжение и } \\
\text { мощность пропорциональны } \\
\text { скорости вращения } \\
\text { Продолжительная работа при } \\
\text { сбоях в энергосистеме } \\
\text { Возможно } \\
\text { выходной мощностью } \\
\end{array}$ & $\begin{array}{l}\text { Два последовательных 3- } \\
\text { фазных преобразователя } \\
\text { Высокое значение dv/dt } \\
\text { на обмотках генератора; } \\
\text { Потери до } 3 \% \\
\text { выходной мощности }\end{array}$ \\
\hline $\begin{array}{l}\text { Асинхронный } \\
\text { мотор/генератор с } \\
\text { токосъемниками и } \\
\text { фазным ротором, } \\
\text { 3-фазный конвертор и } \\
\text { инвертор }\end{array}$ & 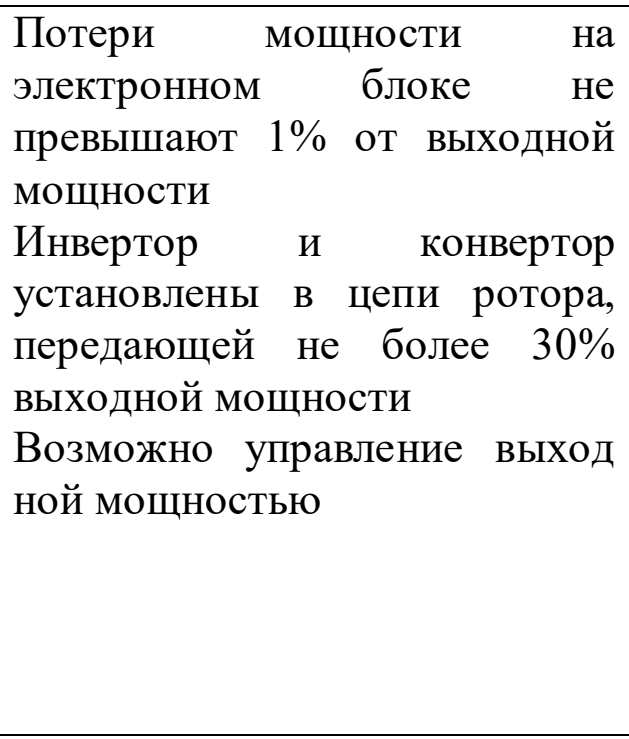 & $\begin{array}{l}\text { Нестандартный } \\
\text { двигатель } \\
\text { токосъемниками (или } 2 \\
\text { статорными обмотками) } \\
\text { и фазным ротором } \\
\text { Ограниченная рабочая } \\
\text { частота ( вращения } \\
\text { турбины }(80 \ldots 120 \%) \\
\text { Конвертор работает на } \\
\text { низкой частоте } \\
\text { Высокое значение dv/dt } \\
\text { на обмотках генератора } \\
\text { Сложный } \\
\text { запуска процесс }\end{array}$ \\
\hline $\begin{array}{l}\text { Синхронный } \\
\text { мотор/генератор, } \\
\text { выпрямитель, } \\
\text { повышающий DC/DC } \\
\text { преобразователь и } \\
\text { 3-фазный инвертор }\end{array}$ & 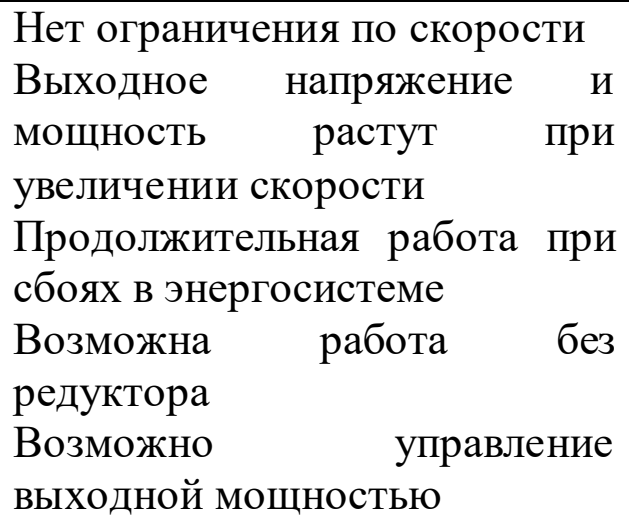 & $\begin{array}{l}\text { Три последовательных } \\
\text { каскада преобразования } \\
\text { Потери до } 3 \% \quad \text { от } \\
\text { выходной мощности }\end{array}$ \\
\hline
\end{tabular}

Электропривод переменного тока с регулируемой скоростью (например на основе синхронных и асинхронных машин) широко используется по причине его надежности, редкости обслуживания, низким уровнем потерь и т.д. $[55,56,60]$. Управление рабочим режимом электрическими двигателями переменного тока такое же, как и двигателями постоянного тока при использовании управления ориентированного по полю. 
Тем не менее, электродвигатели переменного тока вызывают большие или малые колебания момента, например, момента от зубцовых гармоник поля, вызванного явнополюсностью машин, несовершенством элементов систем управления, таких как инверторы, датчики и др., при вращении. Некоторые нагрузки также приводят к колебаниям момента из-за несовершенства их структуры.

Известно [131], что пульсация вращающего момента может быть снижена за счет добавления специального компенсационного возмущения напряжения/тока к питающему напряжению/току для управляющего входа как показано на рис. 1.9. Возмущающий сигнал или данные для компенсации можно приблизительно получить с помощью анализа, который учитывает структуру электрического двигателя, оценивает форму ЭДС и т.д. В итоге, необходимо делать тонкую настройку сигнала компенсации для каждого двигателя, чтобы в полной мере подавлять колебания момента.

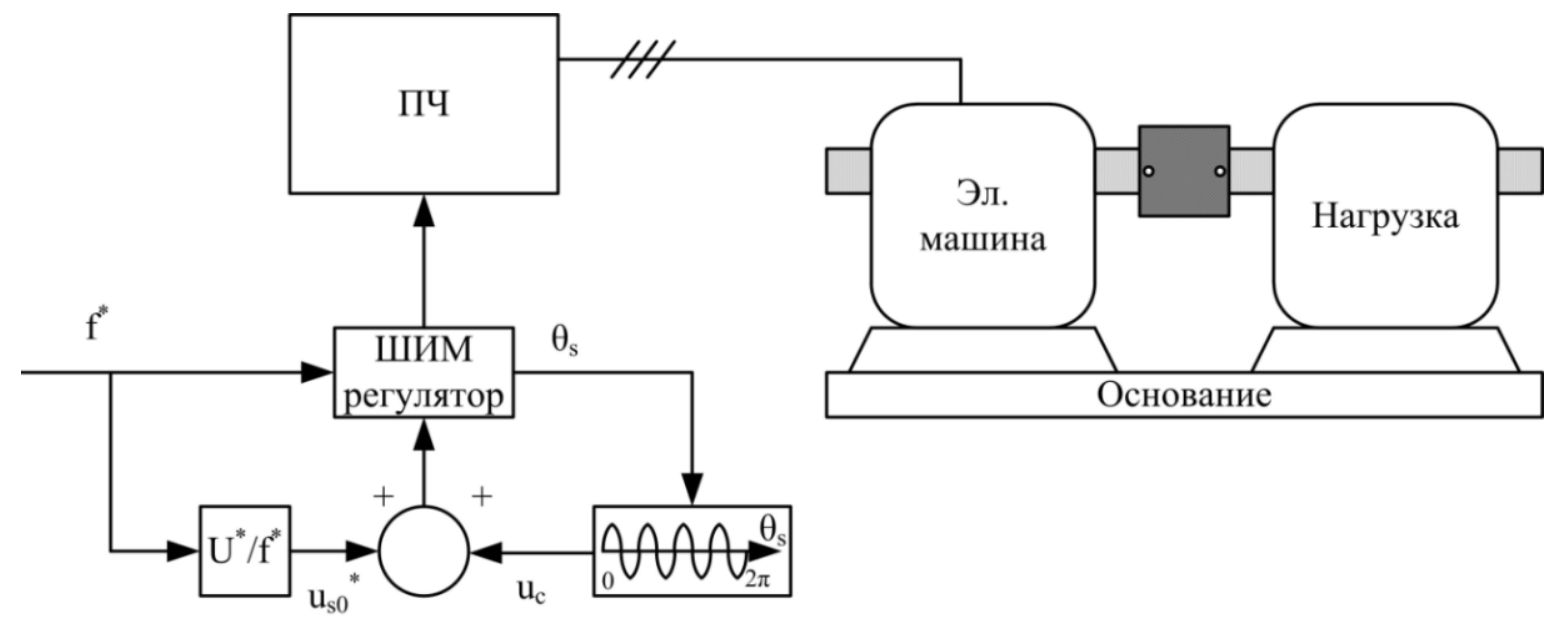

a)

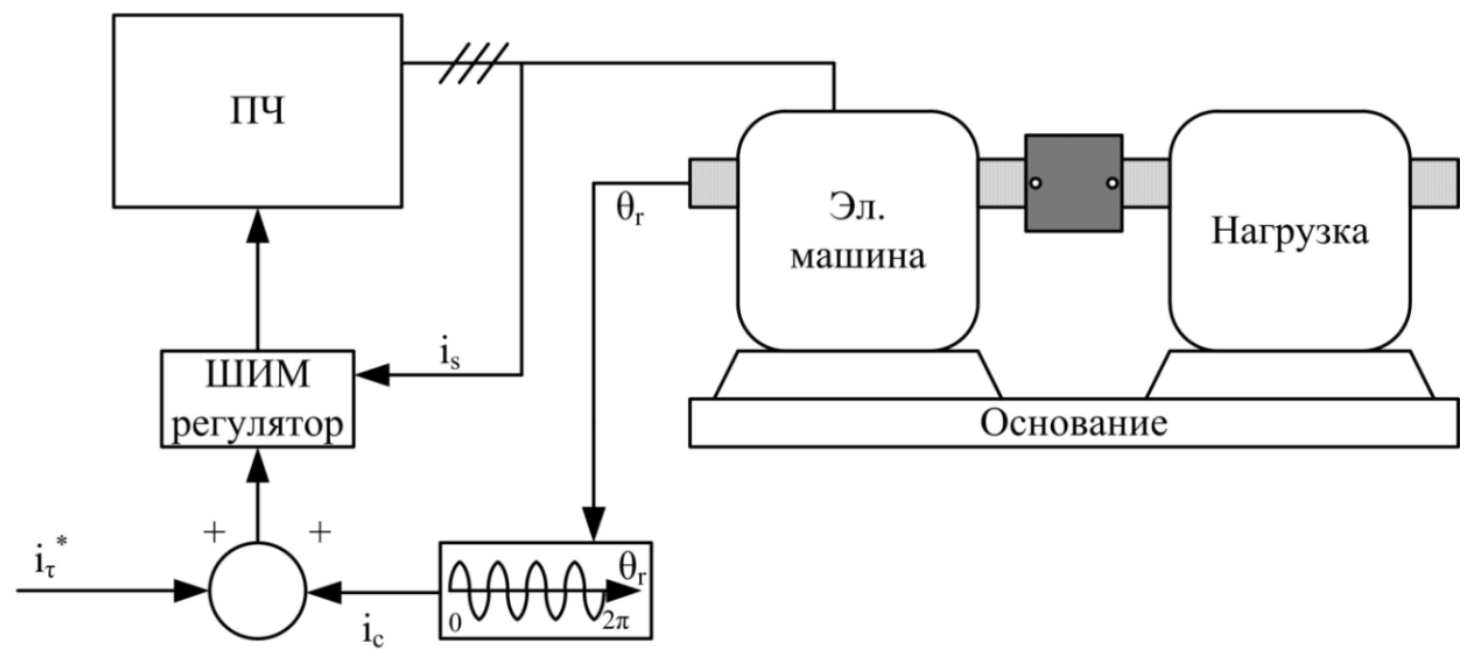

б)

Рис. 1.9. Система управления возмущением для подавления периодических колебаний момента $(a)$ шаговым двигателем; асинхронной машиной с фазным ротором (б) 
В электромеханических комплексах с машиной двойного питания (МДП) искажения сетевых токов оказывают негативное влияние на работу электрических машин в части их нагрева от высших гармоник и снижений коэффициента полезного действия (КПД), а также на работу энергосистемы и ее потребителей. Более серьёзной проблемой для комплексов с МДП являются искажения тока, создаваемые вентильным преобразователем в цепи ротора и приводящие к низкочастотным пульсациям электромагнитного момента электрической машины. Частота этих колебаний линейно связана со скольжением ротора МДП и снижается по мере приближения его к номинальному значению. При этом инерционные механизмы, например ГЦН АЭС, имеют низкие величины собственных частот крутильных колебаний и подвергаются опасным резонансным явлениям в валопроводах. В этих конструкциях целесообразно применение виброзащитных гидроопор с магнитореологическими трансформаторами. На приведенной схеме (рис. 1.10) это решение отражается использованием ПЧ3, который является преобразователем электрической энергии, питающим обмотки МРТ, а также измерителя вибрации ИВ. Бесконтактные датчики момента применяются с начала 80-х годов XX века для ГЦН АЭС с целью обнаружения резонансных зон крутильных колебаний [3].

Современные преобразователи электроэнергии имеют канал для определения среднего и мгновенного значений моментов, вычисленных на основе параметров схемы замещения электрической машины и измерения электрических величин с помощью внутренних датчиков преобразователя частоты. Этот канал метрологически не аттестуется, его информационное значение велико для реализации систем управления предлагаемыми активными электромеханическими фильтрами гармоник.

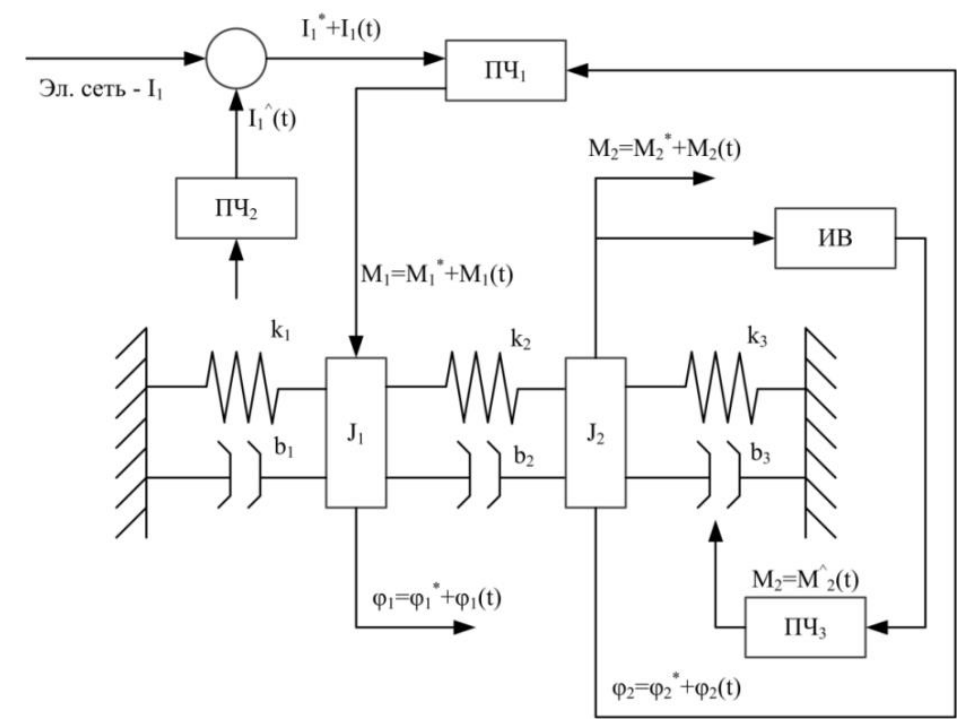

Рис. 1.10. Структура системы с двумя степенями свободы и подсистемами активной виброзащиты 
Наряду с пульсациями момента и искажениями сетевого тока, производственные электроустановки, характеризуются стохастическими коэффициентами использования, резкоизменяющимися уровнями потребления активной и реактивной электроэнергии. Последнее обстоятельство вызывает в электрической сети колебания напряжения. С другой стороны, нелинейность и несимметрия фазных токов производственной системы электропотребления приводит к искажению формы кривой тока, в том числе и «неканоническими» гармониками, и несимметрии напряжения.

Появление «неканонических» гармоник $[95,96]$ может быть вызвано и при периодическом, даже синусоидальном, изменении активной проводимости из-за изменения нагрузки от рабочей машины или установки, например:

$$
Y(t)=Y_{0}\left(1+\sin \left(\omega_{\mathrm{p}} t\right)\right)
$$

где $\omega_{\mathrm{p}}$ - частота регулирования мощности потребителя; $T_{\mathrm{p}}=1 / f_{\mathrm{p}}-$ период повторения, круговая частота сети $\omega=2 \pi f_{\mathrm{p}}>\omega_{\mathrm{p}}$.

При этом $P=U_{2} Y_{0}$, но $S=I U=1,22 \cdot U_{2} Y_{0}$, т.е. нестационарные процессы даже в линейных цепях приводят к появлению несинусоидальных токов, которые содержат дополнительные гармоники, частота которых не кратна частоте сети.

Наиболее применяемыми в настоящее время методами активной виброзащиты являются использование упругих и демпферных опор с нелинейными характеристиками, а также электродинамических антивибраторов с регулируемыми параметрами. В развитии электродинамических антивибраторов используют два подхода: активные электромеханические фильтры гармоник и виброзащитные гидроопоры с магнитореологическими трансформаторами [29-40].

Активные электромеханические фильтры гармоник (АЭМФГ) базируются на теории активных фильтров гармоник тока и напряжения, используемых в узлах подключения электроприемников с нелинейной нагрузкой $[48,80]$. Реализация АЭМФГ предполагает выделение значимой полосы спектра вибраций и генерирование посредством преобразователя частоты (ПЧ) ПЧ1 с ШИМ составляющей электромагнитного момента $M_{1}(t)$, обусловленной вибрациями (см. рис. 1.6).

Это сложное воздействие должно подаваться в противофазе с колебаниями, фиксируемыми измерителями деформации $\varphi_{2}(t)$. Для обеспечения синусоидальности тока, потребляемого при этом из сети, $I^{*}{ }_{1}+I_{1}(t)$ в схему вводится ПЧ2 - активный фильтр гармоник тока. 


\section{3. Дополнительные причины возникновения вибраций в машинах электромеханического комплекса и методы снижения вибраций}

Источниками вибрации являются силовые воздействия, возникающие, например, при вращении неуравновешенных масс либо при биении зубчатых или других механических передач, а также кинематические воздействия, обусловленные погрешностями изготовления и монтажа валов, подшипников, муфт и других вращающихся деталей машин.

Характерными для зубчатых передач возмущающими силами являются силы в зубчатых зацеплениях. К ним относятся силы, возникающие при входе зубьев в зацепление в нерасчетной точке (кромочный удар); силы, возникающие в связи с периодическим изменением числа зубьев, передающих крутящий момент; силы, возникающие при одновременном появлении обоих факторов [107].

Источниками внешних периодических воздействий на упругую систему станка являются:

- центробежные силы быстровращающихся несбалансированных деталей (роторов электродвигателей, шпинделей, валов и т.п.);

- магнитная неуравновешенность электродвигателей;

- пульсация гидравлических приводов;

- пересопряжение зубьев зубчатых колес;

- периодические возмущения от шарикоподшипников;

- возмущения, передаваемые через фундамент станка от посторонних источников воздействия [107].

Основные причины роторных вибраций: несовершенства конструктивные или возникшие при изготовлении, сборке и эксплуатации, а также специфические для роторных систем неконсервативные силы, приводящие при определённых условиях к автоколебаниям. В ряде случаев, решающую роль приобретают неуравновешенности, связанные с переносом рабочего тела из-за неполного заполнения полостей в различных насосах, электромагнитная неуравновешенность, а также неуравновешенности, образующиеся за счет искривления оси из-за возможной тепловой нессимметрии. Отличительная черта роторных вибраций состоит в том, что в большинстве случаев они связаны с поперечными колебаниями роторов, в то время как крутильные колебания или продольные играют меньшую роль [107].

В асинхронных двигателях переменного тока весьма мал зазор между ротором и статором. Поэтому силы одностороннего магнитного притяжения между ротором и статором, возникающие при поперечных колебаниях ротора, оказываются сравнимыми с неуравновешенными центробеж- 
ными силами. В случае недостаточной жесткости вала или опор ротора значительные колебания ротора могут привести к задеванию его за статор, а следовательно, и к выходу из строя двигателя [107]. При малых колебаниях эти силы пропорциональны смещению ротора относительно статора и направлены в сторону смещения, т. е. при малых колебаниях вал ротора можно рассматривать как стержень, лежащий на упругом основании с отрицательным коэффициентом основания [99].

Механические колебания электрических машин могут быть вызваны переменными электромагнитными силами. Эти колебания наблюдаются в машинах, имеющих электромагниты, перемещающиеся при вращении ротора относительно зубцов якоря, образованных пазами для электрической обмотки. В машинах переменного тока электромагниты расположены на роторе, а зубцы имеет сердечник статора. Если число зубцов якоря, приходящееся на $1 / 2 p$ часть окружности, является дробным, т. е. $z / 2 p=(n+1 / q)$, где $\mathrm{z}$ - число зубцов якоря; $2 p$ - число полюсов; $n, q-$ целые числа, то при вращении ротора картина расположения зубцов относительно каждого полюса будет периодически изменяться, повторяясь через период времени $T=2 \pi q / \omega z$, где $\omega$ - частота вращения ротора. Это влечет за собой периодическое изменение магнитного потока под каждым полюсом с периодом $T$ и со сдвигом по фазе для двух соседних полюсов на угол $2 \pi / q$. Наряду с этой частотой изменения магнитного потока существует также пульсация потока под полюсами с еще более высокой «зубцовой» частотой, равной $\omega z$. Снижение этих колебаний достигается скосом зубцов якоря.

Машиностроительные заводы обеспечивают балансировку роторов согласно нормам на виброактивность и на вибростойкость, как в части статического небаланса, так и динамического небаланса. Последний может быть обнаружен только при вращении ротора, то есть из динамического опыта по воздействию создаваемого момента на опоры ротора. Однако при монтаже агрегатов погрешности приводят к небалансу «нового» эквивалентного или составного ротора. Кроме того, этот эквивалентный ротор на рабочих оборотах окажется разбалансированным вследствие появления новых эксцентриситетов из-за упругих деформаций. Нарушения балансировки усиливаются по мере увеличения скорости вращения ротора [107].

Таким образом, методы общей динамики и расчета критических режимов роторов обладают ограниченными возможностями при широком диапазоне рабочих чисел оборотов, а также в тех случаях, когда конструкция рабочей машины уже осуществлена и критический, например, резонансный, режим оказался в диапазоне рабочих чисел оборотов. 
Источники

Источники вибрации электрических машин

\begin{tabular}{|c|c|c|c|}
\hline $\begin{array}{l}\text { Частота вращения, } \\
\text { об/мин }\end{array}$ & Тип машины & Тип подшипника & Источник вибрации \\
\hline До 1000 & $\begin{array}{l}\text { Крупные электро- } \\
\text { двигатели } \\
\text { янного и пере- } \\
\text { ного тока }\end{array}$ & Скольжения & Магнитные силы \\
\hline \multirow[t]{2}{*}{1500} & \multirow{2}{*}{$\begin{array}{l}\text { Электрические } \\
\text { машины постоян- } \\
\text { ного и переменно- } \\
\text { го тока средней и } \\
\text { малой мощности }\end{array}$} & Скольжения & $\begin{array}{l}\text { Магнитные силы, } \\
\text { небаланс }\end{array}$ \\
\hline & & Качения & $\begin{array}{l}\text { Подшипники, } \\
\text { магнитные с силы, } \\
\text { небаланс }\end{array}$ \\
\hline \multirow[t]{2}{*}{3000} & \multirow{2}{*}{$\begin{array}{l}\text { Электрические } \\
\text { машины постоян- } \\
\text { ного и переменно- } \\
\text { го тока средней и } \\
\text { малой мощности }\end{array}$} & Скольжения & $\begin{array}{l}\text { Магнитные силы, } \\
\text { небаланс }\end{array}$ \\
\hline & & Качения & $\begin{array}{l}\text { Подшипники, } \\
\text { магнитные } \\
\text { небаланс }\end{array}$ \\
\hline 3000 & $\begin{array}{l}\text { Крупные } \\
\text { турбогенераторы } \\
100-500 \text { МВт }\end{array}$ & Скольжения & $\begin{array}{l}\text { Магнитные силы, } \\
\text { небаланс }\end{array}$ \\
\hline $1500-3000$ & $\begin{array}{l}\text { Высокочастотные } \\
\text { индукторные } \\
\text { генераторы }\end{array}$ & $\begin{array}{l}\text { Скольжения, } \\
\text { качения }\end{array}$ & Магнитные силы \\
\hline
\end{tabular}

1. Электромагнитные силы действуют в воздушном зазоре между статором и ротором, и имеют характер вращающихся или пульсирующих силовых волн. Величина этих сил зависит от электромагнитных нагрузок, а также от конструктивных и расчётных параметров машины. Вибрация, вызываемая электромагнитными силами, зависит от характеристик статора как колебательной системы. Для большинства типов электрических машин значение магнитной вибрации лежит в диапазоне частот 100-4000 Гц [110].

2. Вибрация от подшипников качения зависит:

- от качества изготовления подшипников (необходимо обеспечить минимальную вибрацию наружного кольца подшипника);

- точности обработки мест под посадку подшипников и замков в щитах для их фиксации относительно корпуса машины.

3. Механическая несбалансированность роторов приводит к ощутимым вибрациям, особенно в быстроходных машинах. Уменьшение небаланса ротора достигается динамическим уравновешиванием ротора. 
Методы борьбы с вибрацией базируются на исследованиях колебаний реальных механических систем или их физических моделей, а также на анализе уравнений, описывающих колебательный процесс в таких системах (рис. 1.11) [61].

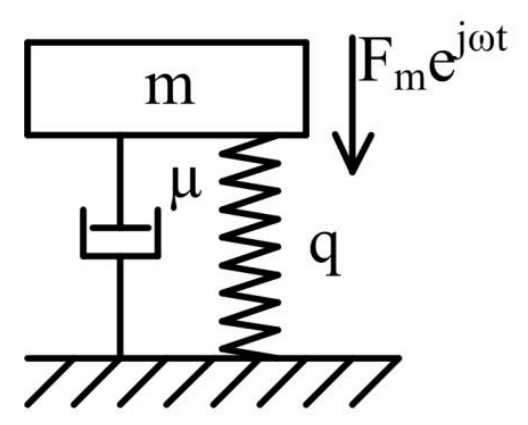

Рис. 1.11. Механическая система с одной степенью свободы, обладающая трением

Уравнение колебаний механической системы, приведенной на рис. 1.11, при воздействии возмущающей силы $F$, изменяющейся по синусоидальному закону, имеет вид:

$$
\mu \frac{d x}{d t}+m \frac{d^{2} x}{d t^{2}}+q x=F_{m} e^{j \omega t}
$$

где $m$ - масса системы, кг; $q$ - коэффициент жесткости, Н/м; $x$ - текущее значение виброперемещения, м; $d x / d t$ - текущее значение виброскорости, $\mathrm{M} / \mathrm{c} ; d^{2} x / d t^{2}$ - текущее значение виброускорения, м/ $\mathrm{c}^{2} ; \mu-$ коэффициент сопротивления (терния), Н·c/м; $F_{m}$ - амплитуда вынуждающей силы, $\mathrm{H} ; \omega-$ круговая частота вынуждающей силы, рад/с.

Система вращательного движения с одной степенью свободы имеет структуру, в которой между массой (моментом инерции) $J$ и фиксированной стенкой расположен безинерционный демпфер с коэффициентом демпфирования $b$ и пружина жесткостью $k$. Демпфер создает силу демпфирования $b \cdot \varphi^{\prime}$, пропорциональную мгновенной угловой скорости. Уравнение движения для вынужденного гармонического движения можно записать в виде

$$
J \cdot \varphi^{\prime \prime}+b \cdot \varphi^{\prime}+k \cdot \varphi=M \cdot e^{j(\omega t-\varphi)},
$$

где $\varphi$ - угловое смещение; $\varphi^{\prime}, \varphi^{\prime \prime}$ - угловая скорость и ускорение соответственно; $M$ - возбуждающий момент; $j=\sqrt{ }-1 ; \omega-$ частота возбуждения.

В итоге, после математических преобразований, решение уравнения (1.4) крутильных колебаний может быть записано в виде 


$$
\varphi=\left[\frac{1}{\sqrt{\left\{1-\left(\frac{\omega}{\omega_{0}}\right)^{2}\right\}^{2}+\left(2 \frac{b \omega}{J \omega_{0}}\right)^{2}}}\right] \cdot \frac{M}{k} \cdot e^{j(\omega t-\theta)} .
$$

Величина в квадратных скобках последнего выражения является модулем комплексной частотной характеристики и является безразмерным отношением между амплитудой смещения $\varphi$ и статическим смещением $M / k$.

Для электромеханических комплексов на основе АКУ характерно наличие не менее двух степеней свободы. Структура такой системы при общепринятых допущениях в теории электропривода приведена на рис. 1.12. Эта система является гетерогенной, в ней имеют различную природу силы (моменты), жесткости и демпферы: $M_{1}-$ мгновенное значение электромагнитного момента на валу электрической машины; $M_{2}-$ механический момент, противодействующий электромагнитному моменту; $k_{1}-$ механический аналог эквивалентной реакции на перетоки составляющих неактивной мощности, потребляемой из сети при создании момента $M_{1} ; k_{2}-$ жесткость валопровода и соединительных элементов; $k_{3}-$ жесткость элементов крепления и вязкоупругого основания; $b_{1}-$ механический аналог эквивалента электрических потерь в электроприводе; $b_{2}-$ коэффициент демпфирования валопровода и соединительных элементов; $b_{3}$ - коэффициент демпфирования вязкоупругого основания [121].

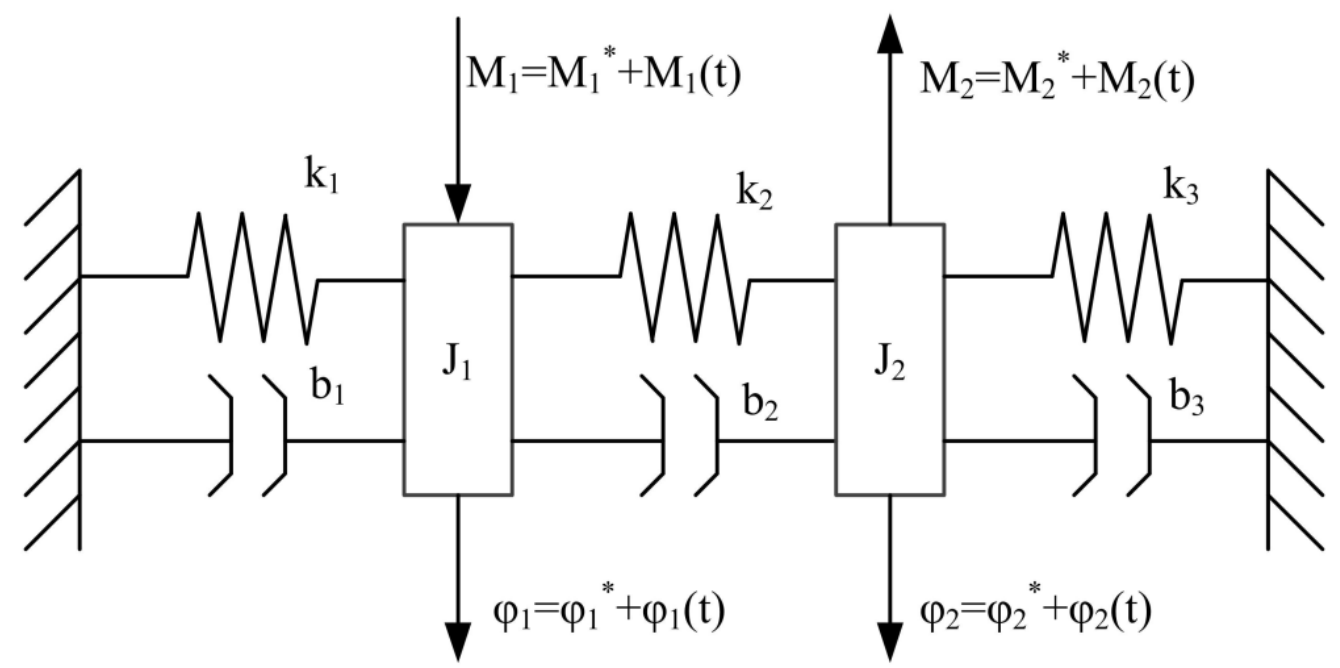

Рис. 1.12. Структура системы с двумя степенями свободы и подсистемами активной виброзащиты 
Анализ такой системы облегчается при допущении линейности элементов и использовании матричного метода:

$$
\left[\begin{array}{cc}
J_{1} & 0 \\
0 & J_{2}
\end{array}\right]\left[\begin{array}{c}
\varphi_{1}^{\prime \prime} \\
\varphi_{2}^{\prime \prime}
\end{array}\right]+\left[\begin{array}{cc}
b_{1}+b_{2} & -b_{2} \\
-b_{2} & b_{1}+b_{2}
\end{array}\right]\left[\begin{array}{c}
\varphi_{1}^{\prime} \\
\varphi_{2}^{\prime}
\end{array}\right]+\left[\begin{array}{cc}
k_{1}+k_{2} & -k_{2} \\
-k_{2} & k_{1}+k_{2}
\end{array}\right]\left[\begin{array}{l}
\varphi_{1} \\
\varphi_{2}
\end{array}\right]=\left[\begin{array}{l}
M_{1} \\
M_{2}
\end{array}\right]
$$

Если $M_{1}$ и $M_{2}$ являются источниками сложных колебаний, то решение осуществляется численными методами для множества реализаций с целью выявления средних статистических значений виброперемещений, виброскорости и виброускорения. При периодическом режиме возбуждения колебаний, когда заданная скорость электропривода $\varphi^{\prime *}$ остается неизменной, а рассматриваются только вибрации, необходимо анализировать гармонический спектр моментов при допущении постоянства их технологических значений $M_{1}^{*}$ и $M_{2}^{*}$.

Исследование этой модели (рис. 1.12) и (1.6), а также других моделей с большей размерностью позволило получить АЧХ электромеханических комплексов, согласующиеся с [110]. На рис. 1.13 показаны АЧХ вибраций электрических машин.
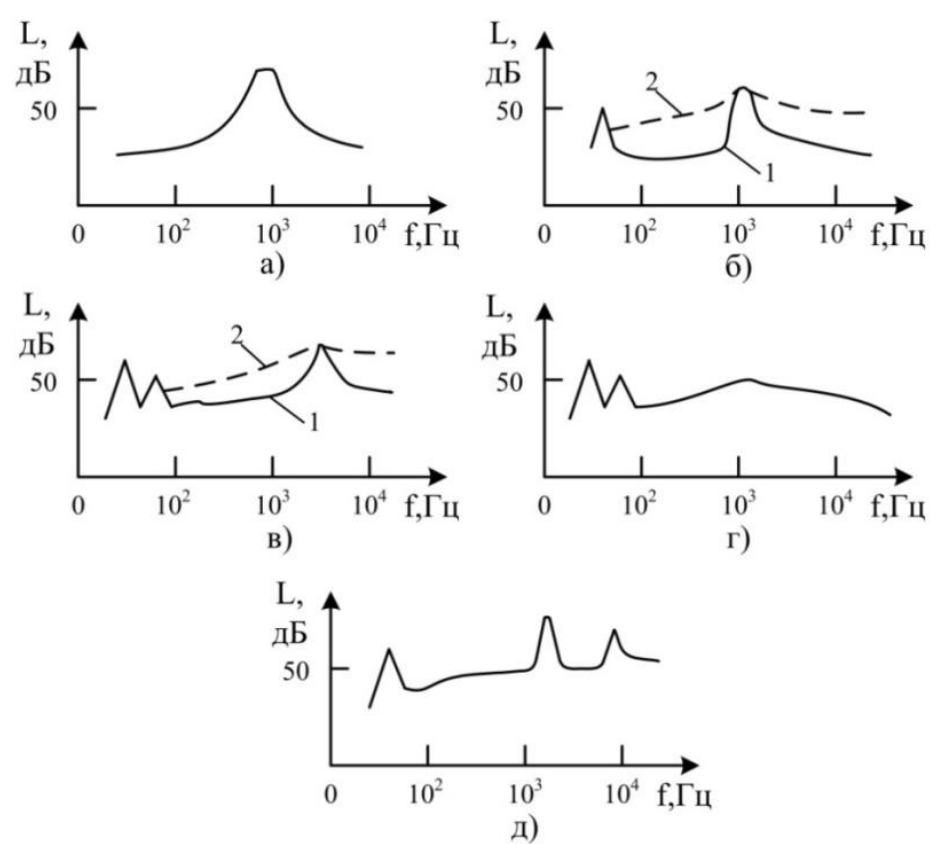

Рис. 1.13. АЧХ вибрации электрических машин:

$a$ - крупные ЭД постоянного и переменного тока частотой вращения до 1000 об/мин; $\sigma$ - ЭД постоянного и переменного тока средней мощности частотой вращения 1500 об/мин: 1 - с подшипником скольжения; 2 - с подшипником качения; 8 - ЭД постоянного и переменного тока средней мощности частотой вращения 3000 об/мин: $1-\mathrm{c}$ подшипником скольжения; 2 - с подшипником качения; 2 - крупные турбогенераторы частотой вращения 3000 об/мин; $\partial$ - высокочастотные индукторные генераторы частотой вращения 1500-3000 об/мин 
В теории динамики машин выделяют два основных класса систем виброзащиты: это системы пассивной виброзащиты (СПВ) и системы активной виброзащиты (CAB). Среди СПВ наиболее простыми, доступными и распространёнными являются упругие элементы. На достаточно высоких частотах они обеспечивают отражение большей части колебательной энергии обратно в источник. Механики представляют работу САВ как введение или изменение эквивалентных параметров пассивного объекта - массы, жесткости и демпфирования [121].

Известны следующие методы борьбы с вибрациями:

- снижение вибраций воздействием на источник возбуждения (посредством снижения или ликвидации вынуждающих колебания сил);

- отстройка от режима резонанса путем рационального выбора массы или жесткости колеблющейся системы;

- вибродемпфирование - увеличение механического импеданса колеблющихся конструктивных элементов объекта путем увеличения диссипативных сил при колебаниях с частотами, близкими к резонансным;

- динамическое гашение вибрации - присоединение к защищаемому объекту дополнительной системы, реакции которой уменьшают размах вибрации объекта в точках присоединения этой системы.

Снижение вибраций воздействием на источник возбуждения. При конструировании машин и проектировании технологических процессов должно быть предусмотрено исключение вибраций или их предельное снижение.

Неуравновешенность вращающихся элементов - один из наиболее распространенных источников возбуждения вибрации в машинах. Для её устранения применяют уравновешивание или статическую и динамическую балансировку.

Отстройка от режима резонанса. Резонансные явления устраняют либо изменением характеристик системы: $m$ - массы или $q$ - жесткости системы (введением, например, ребер жесткости), либо установлением нового рабочего режима (путем отстройки собственных частот агрегата и его отдельных узлов от частоты возмущающей силы на стадии проектирования).

Вибродемпфирование (вибропоглощение) - это процесс уменьшения уровня вибрации защищаемого объекта путем превращения энергии механических колебаний данной системы в тепловую энергию за счет диссипативных сил.

Эффект вибродемпфирования определяется коэффициентом активного сопротивления (трения) системы. Увеличение потерь энергии механических колебаний может производиться за счет: 
a) использования конструктивных материалов с большим внутренним трением, это сплавы: $\mathrm{Cu}$ - Ni, $\mathrm{Ni}$ - Ti, $\mathrm{Ni}$ - Co, композиционные материалы, пластмассы и др.;

б) нанесения на вибрирующие поверхности слоя упруговязких материалов с большим внутренним трением. Это многослойные покрытия, твердые и мягкие пластмассы, резина, мастики, технические масла, смазки;

в) использования искусственных демпферов - устройств в виде поршня, перемещающегося в вязкой среде.

Динамическое гашение вибрации. Для увеличения реактивного сопротивления колебательной системы $(m \omega-q / \omega)$ используют динамические виброгасители (рис. 1.14). Это дополнительная колебательная система с массой $m$ и жесткостью $q$, собственная частота которой $f$ настроена на основную частоту колебаний $f$ вибрирующего агрегата, имеющего массу $M$ и жесткость $Q$, путем подбора характеристик виброгасителя $m$ и $q$.

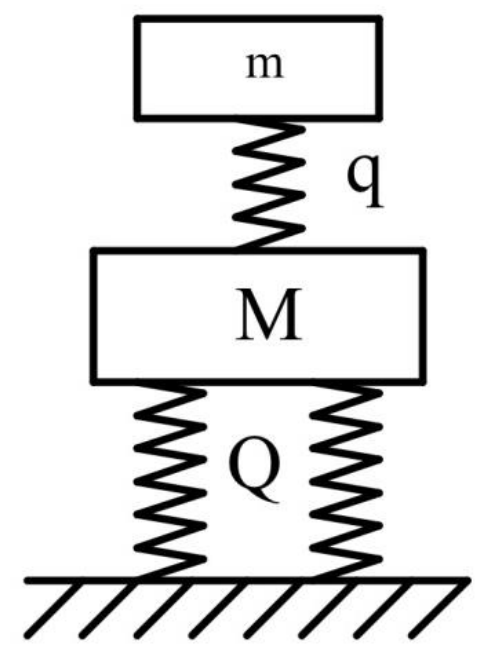

Рис. 1.14. Динамический виброгаситель

Виброгаситель жестко крепится на агрегате, поэтому в нем в каждый момент времени возбуждаются колебания, находящиеся в противофазе с колебаниями агрегата.

Недостатком динамического виброгасителя является то, что он эффективно действует только на резонансной частоте колебательной системы. При отличии собственной частоты колебаний системы от резонансной - эффективность виброгашения резко падает. Динамическое виброгашение применяется для ослабления низкочастотных вибраций.

Динамические виброгасители могут быть основаны на пассивных элементах (массы, пружины) и активных, имеющих собственные источн ики энергии. 
Для снижения вибрации также возможно использование ударных виброгасителей (маятниковых, пружинных), в которых осуществляется переход механической энергии в энергию деформации контактирующих элементов.

В результате энергия распределяется по объему соударяющихся элементов виброгасителя, вызывая их колебания и вместе с тем рассеяние энергии вследствие действия сил внешнего и внутреннего трения.

Виброизоляция. Этот способ защиты от вибрации заключается в снижении передачи колебаний от источника возбуждения защищаемому объекту при помощи устройств, помещаемых между ними.

Виброизоляция осуществляется введением в колебательную систему упругой связи, препятствующей передаче вибраций от машины к основанию и смежным конструкциям [101].

Для виброизоляции источников возбуждения колебаний применяют:

a) пружинные, пружинно-резиновые и резинометаллические виброизоляторы;

б) упругие резиновые прокладки;

в) комбинированные виброизоляторы (установка виброизоляторов на прокладки из упругих материалов типа резины).

Для эффективной виброизоляции фундамент, на котором производится монтаж оборудования на виброизоляторах должен обладать большой массой. При изоляции с помощью пружинных амортизаторов и упругих прокладок происходит в большей степени отражение колебательной энергии и в меньшей степени поглощение энергии в самих изолирующих элементах.

Активные системы виброизоляции. Вибрационная защита с помощью массивных элементов оказывается малоэффективной для низких частот. В таких случаях применяют активные (управляемые) системы виброизоляции. В них внешние силы, вызывающие вибрацию защищаемого объекта компенсируются дополнительным источником энергии.

Активные системы виброизоляции используются для защиты прецизионных станков, стартовых платформ, пилотов от перегрузок и повышения комфортности транспортных средств. Активная система содержит чувствительные элементы (датчики), устройства для создания управляющего воздействия.

В зависимости от предъявляемых требований усилительные и исполнительные устройства могут быть гидравлические, пневматические, электромеханические.

На рис. 1.15 приведена схема активной виброзащиты, где введена активная обратная связь, формирующая управляющее воздействие $V(t)$. 
Цель виброзащиты - уменьшение колебаний объекта с массой $M$ при кинематическом возмущении $\xi(t)$. Управляющее воздействие $V(t)$ приложено к промежуточной массе $m$.

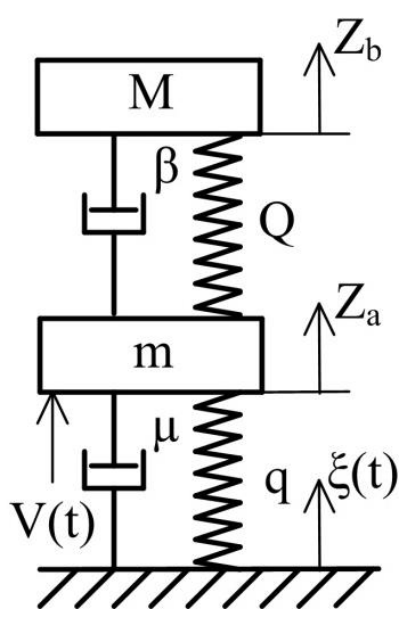

Рис. 1.15. Схема активной виброзащиты

Управление может быть осуществлено:

1. По отношению масс $M$ и $m$. Тогда управляющее воздействие осуществляется перемещением массы $M$ по направлению $Z_{\mathrm{B}}$ :

$V(p)=-k \cdot W(p) \cdot Z_{\mathrm{B}}$

где $k$ - коэффициент усиления; $W(p)$ - передаточная функция цепи, включающей датчик и исполнительное устройство или управляющее воздей-

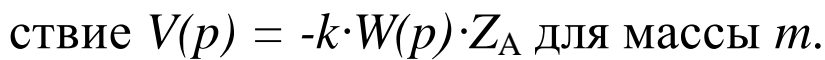

2. По возмущению $\xi(t)$, где управляющее воздействие:

$V(p)=-(\mu \cdot P+q) \cdot \xi(t)=W(p) \cdot \xi(t)$,

где $q$ - коэффициент жесткости; $\mu$ - коэффициент сопротивления (терния). 


\section{ГЛАВА 2. АКТИВНЫЕ КОМПЕНСИРУЮЩИЕ УСТРОЙСТВА КАК РАЗВИТИЕ АКТИВНЫХ ФИЛЬТРОВ ГАРМОНИК}

\section{1. Применение АКУ на основе активных фильтров гармоник в целях ослабления вибраций машин и негативного влияния на сеть}

Развитие современных технологий полупроводников ведёт все к более возрастающему количеству и потребителей, управляемых тиристорными коммутаторами, полупроводниковыми регуляторами напряжения и конверторами. Однако, конверторы увеличивают значение индуктивной реактивной мощности и ухудшают несинусоидальную форму токовой кривой $[5,47,49,59]$.

Назначением любой электроэнергетической системы является бесперебойное обеспечение потребителей (электроприемников) электроэнергией определенного качества и в нужном количестве. Кроме того, во всех возможных режимах системы должно быть обеспечено приведение в действие электроприемников в соответствии с их назначением.

Под режимом понимается состояние системы, определенное множеством различных процессов и зависящее от схемы соединения элементов системы. Каждый из режимов характеризуется потоками мощности к электроприемникам, значениями напряжений в узловых токах, значениями токов в различных элементах. Эти характеристики называют параметрами режима электроэнергетической системы, или ее переменными состояния. При этом процессы определяются и параметрами элементов системы: проводимостями, инерционными постоянными, которые определяют свойства системы. Изменение свойств системы инициирует в ней переходный процесс, изменяющий параметры режима.

В любой момент времени систему можно считать находящейся либо в установившемся, либо в переходном режиме. Переходный режим может включать в себя множество переходных процессов. Установившейся режим, напротив, характеризуется постоянством параметров режима и переменных состояния. Компенсационные устройства обладают ограниченной полосой пропускания, которую надо оценивать при решении задач компенсации в переходных режимах.

Как уже было отмечено, энергообменная сеть состоит из множества различных потребителей электроэнергии, описываемых своей математической моделью (рис. 2.1).

При этом возможны следующие процессы:

- любой электроприемник может быть, как включен, так и выключен в любой момент времени;

- нагрузка электроприемников (например, статический момент на 
валу асинхронного двигателя) может быть непостоянной и является специфичной для каждого оборудования (например, скорость подачи заготовок в механизм, жесткость материала и проч.);

- источник энергии неидеален.

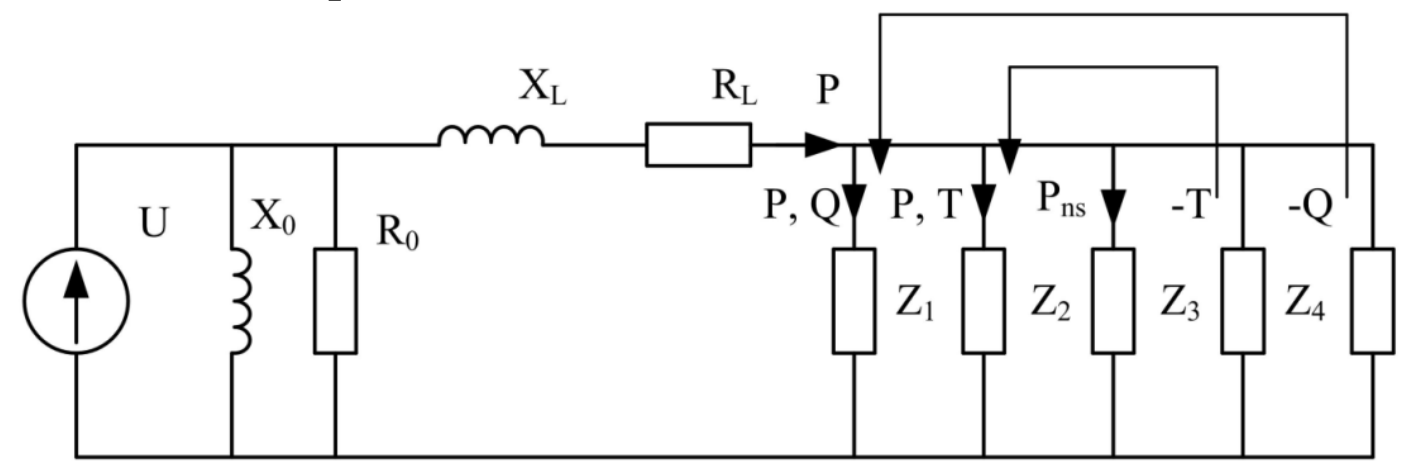

Рис. 2.1. Эквивалентная схема узла нагрузки

На рис. 2.1 представлена питающая цепь в виде идеального источника напряжения $U$, схемы замещения параметров питающей линии $X_{L}, R_{L}$ и элементов схемы замещения питающего трансформатора $X_{0}, R_{0}$. Нагрузку представляют пять различных электроприемников:

- $Z_{1}$ - синусоидальная нагрузка, потребляющая из сети активную $P$ и реактивную мощность $Q$;

- $Z_{2}$ - несинусоидальная нагрузка, потребляющая из сети активную мощность $P$ и мощность искажений $T$;

- $Z_{3}$ - несимметричная нагрузка, нагружающая фазы электроприемниками разной мощности;

- $Z_{4}$ - энергообменное устройство, генерирующее в сеть высокочастотные гармоники в количестве, равном мощности искажений, сгенерированной нагрузкой $Z_{2}$ обратного знака;

- $Z_{5}$ - энергообменное устройство, генерирующее в сеть реактивную мощность в количестве равной реактивной мощности, потребляемой синусоидальной нагрузкой, но противоположного знака.

Нагрузки $Z_{1}-Z_{3}$ работают автономно от системы, решая собственные задачи по передаче энергии потребителю. Вопрос управления представляют энергообменники $Z_{4}$ и $Z_{5}$, работа которых зависит от текущих параметров потребления неактивной мощности электроприемниками узла нагрузки. Информация об уровнях потребляемой активной и неактивной мощности и гармоническом составе собирается с помощью датчиков в узле распределения нагрузки и приводит к изменению задания на компенсацию с задержкой. В статическом режиме имеется возможность стабильной компенсации неактивной мощности в зависимости от возможностей установок. 
Работа этих установок направлена на снижение потоков неактивной мощности от источника питания. Показано, что целевой функцией управления компенсационными устройствами должна быть:

$$
\operatorname{tg} \varphi_{\text {сети }}=\left(\frac{Q_{\text {сети }}-Q_{\text {КУ }}}{P_{\text {сети }}}\right) \rightarrow \min \{u\},
$$

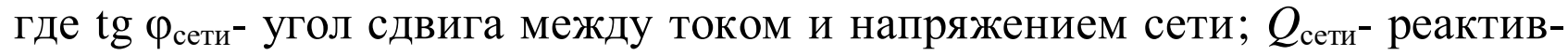
ная мощность по первой гармонике, потребляемая от источника питания;

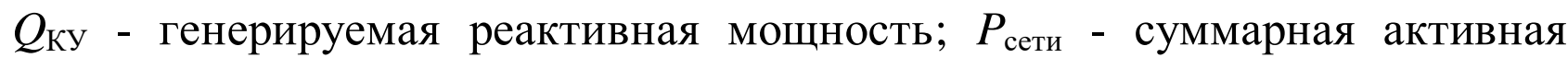
мощность, потребляемая всеми нагрузками; $\{u\}$ - множество сигналов управления, специфичных для разных видов компенсирующих устройств.

В динамическом режиме, когда происходят переключения рабочих режимов электроприемников, возникают различные эффекты от их взаимодействия, указанные выше. Эти помехи в питающей сети ведут к повреждениям и ошибочным включениям оборудования и приборов. Загрязнение сетей переменного тока высшими гармониками может вести к следующим последствиям: снижение срока службы конденсаторов; непредусмотренное срабатывание защитной аппаратуры; выход из строя или ошибочное функционирование микропроцессорных систем управления и компьютеров, приводов двигателей, устройств освещения и других чувствительных потребителей.

Идея компенсации искажений напряжений и токов в сети, т.е. активная фильтрация, основана на введении в сеть последовательно источника напряжения с управляемым искажением или параллельно источника тока с управляемым искажением, причем вносимые искажения находятся в противофазе с имеющимися искажениями и компенсируют их в результирующей кривой напряжения или тока. Эта идея иллюстрируется для активного фильтра напряжения и тока на рис. 2.2, $a, 6$.

Источник напряжений, компенсирующий искажения напряжения сети, (или нагрузки) вводится в сеть последовательно через трансформатор $T$. Если напряжение сети несинусоидально (на рисунке условно трапеция), а напряжение на нагрузке должно быть синусоидальным, то источник

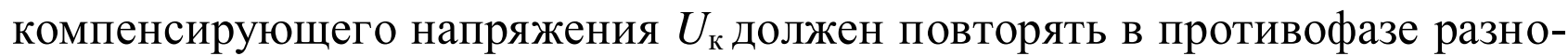
сти мгновенной кривой напряжения сети $U$ и ее первой гармоники $U_{(1)}$ (рис. 2,a).

Аналогично работает и активный фильтр тока. Если нелинейная нагрузка потребляет несинусоидальный ток (на рис. 2.2, б), то компенсатор генерирует ток, равный в противофазе разности мгновенной кривой тока нелинейной нагрузки $i_{\mathrm{H}}$ и ее первой гармоники $i_{\mathrm{H}(1)}[53,54]$. 
$\mathrm{u}$

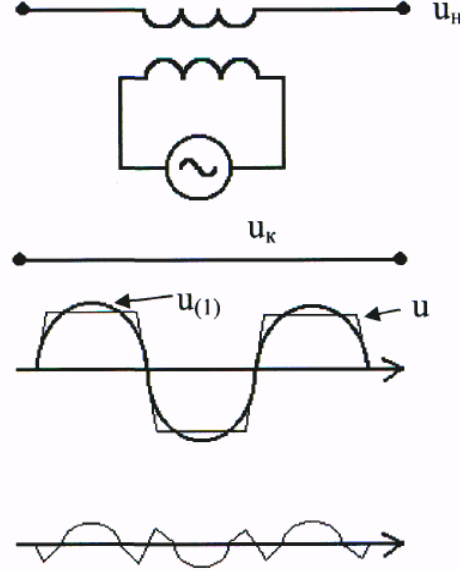

a) $U_{\mathrm{K}}=-\left(u-u_{(1)}\right)$

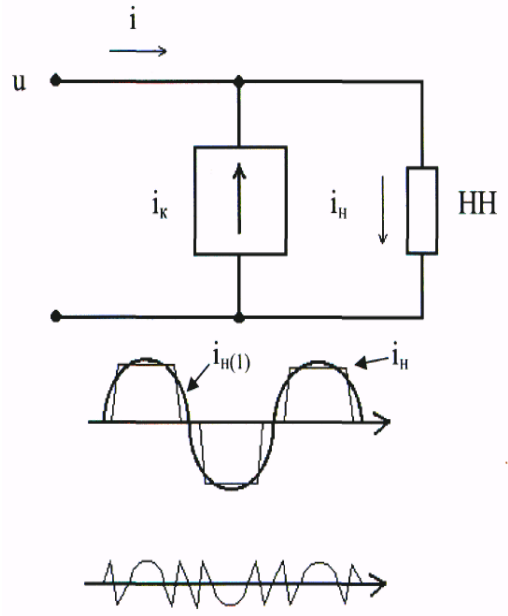

б) $i_{\mathrm{K}}=-\left(i_{\mathrm{H}}-i_{\mathrm{H}(1)}\right)$

Рис. 2.2. Графики работы активных фильтров (a) напряжения и тока (б)

Схемы активных фильтров напряжения и тока обычно выполняют на базе инверторов напряжения с ШИМ. Рассматривая инвертор напряжения как реверсивный широтно-импульсный преобразователь (ШИП), работающий в режиме периодического реверса, и учитывая линейность регулировочной характеристики ШИП, можно воспроизвести на выходе инвер-

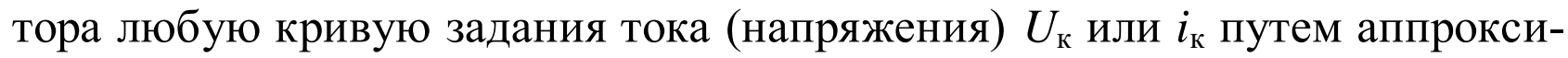
мации ее средними значениями по интервалам тактов коммутации при

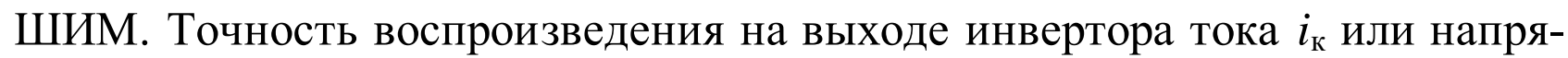

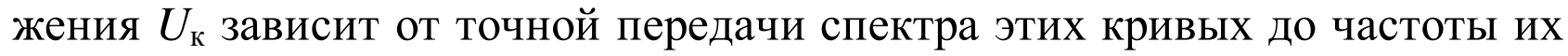
верхней гармоники, определяемой в соответствии с теоремой отсчетов Котельникова половиной частоты коммутации при ШИМ. Так, для подавления в результирующем токе сети всех гармоник входного тока трехфазного мостового выпрямителя вплоть, например до 23-й, относительная величина которой в спектре $1 / 23$, т.е. менее $5 \%$, необходима частота коммутации в интервале не ниже $2 \cdot 23 \cdot 50=2300$ Гц, что вполне допустимо для силовых транзисторов. Техническая реализация такого воспроизведения на выходе инвертора напряжения сигнала задания на его входе легко обеспечивается при использовании управления инвертором по методу слежения.

Более радикальным способом улучшения качества электроснабжения и устранения обратного влияния нелинейного потребителя на питающую сеть является совместное использование активного фильтра напряжения и тока. Возможны два варианта их объединения: параллельнопоследовательное и последовательно-параллельное включения. При этом появилась возможность за счет использования выходных трансформаторов в активных фильтрах объединить их цепи постоянного напряжения общим конденсатором фильтра $C_{d}$. 
Если на такую структуру возложить еще и функцию регулирования величины реактивной мощности и ее знака, то можно будет поддерживать синусоидальное напряжение стабильной величины при колебаниях напряжения в сети при колебаниях нагрузки.

Активные фильтры гармоник можно классифицировать:

1) по количеству силовых преобразователей:

- одноуровневые;

- многоуровневые;

2) способу подключения к нагрузке:

- последовательные;

- параллельные;

- последовательно-параллельные (гибридные);

3) способу подключения к сети:

- однофазные;

- трехфазные трехпроводные;

- трехфазные четырех проводные (с нейтральным проводом);

4) типу накопительного элемента:

- с емкостным накопительным элементом (силовой преобразователь - инвертор напряжения);

- с индуктивным накопительным элементом (силовой преобразователь - инвертор тока).

Способ подключения АФГ определяет фильтруемый параметр, при последовательном соединении фильтруется напряжение сети, а при параллельном - сетевой ток. Основной принцип действия последовательно и параллельного АФГ представлен на рис. 2.3 и рис. 2.4.

Тип накопительного элемента влияет на выбор силовой подсистемы АФГ, с емкостным элементом используется инвертор напряжения, а при индуктивном - инвертор тока.

Силовая часть обеспечивает компенсацию и состоит из блока силовой электроники, силового конденсатора (или дросселя) и высокочастотного фильтра.
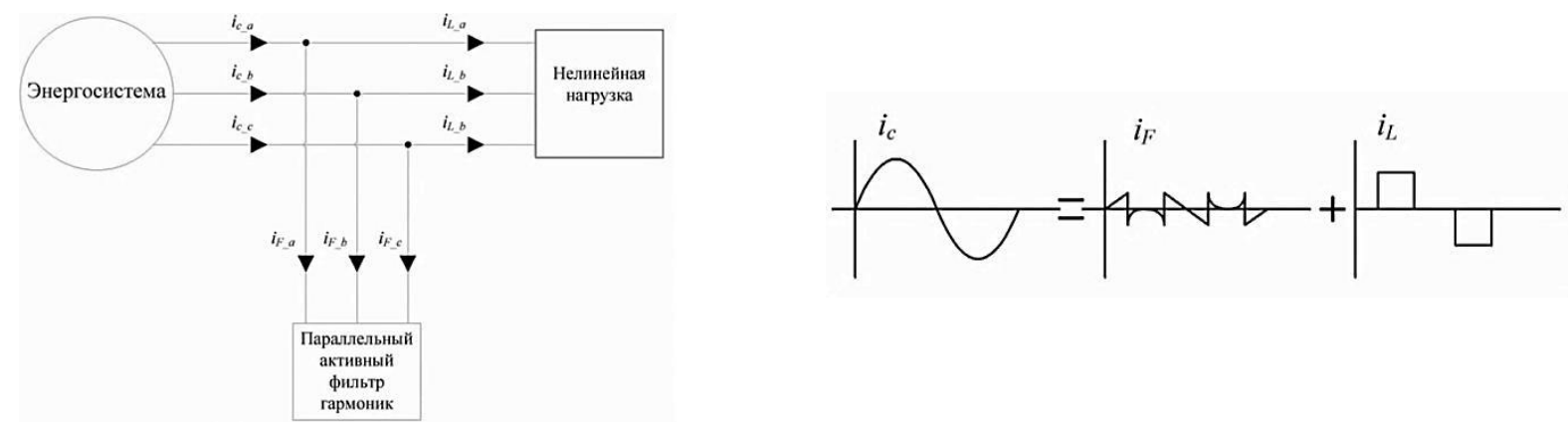

Рис. 2.3. Принцип действия параллельного АФГ 


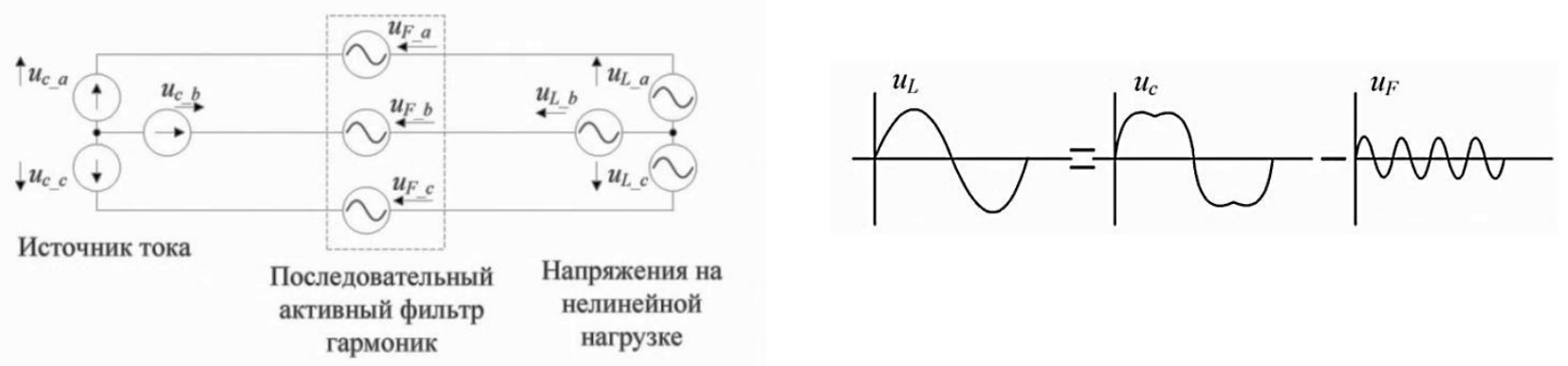

Рис. 2.4. Принцип действия последовательного АФГ

В табл. 2.1 приведено сравнение параллельного и последовательного АФГ.

Таблица 2.1

\section{Сравнение последовательного и параллельного АФГ}

\begin{tabular}{|c|c|c|}
\hline & Параллельный АФГ & Последовательный АФГ \\
\hline $\begin{array}{l}\text { Принципиальная } \\
\text { схема }\end{array}$ & 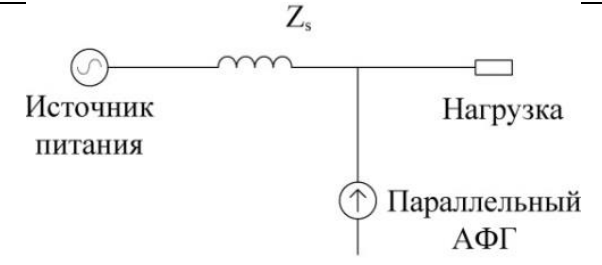 & $\underbrace{Z_{\mathrm{s}}}_{\substack{\text { Источник } \\
\text { питания }}}$ Последовательный \\
\hline $\begin{array}{l}\text { Основной } \\
\text { принцип работы }\end{array}$ & Работает как источник тока & Работает как источник напряжения \\
\hline Тип нагрузки & $\begin{array}{l}\text { Индуктивная или нагрузка } \\
\text { источник тока или источник } \\
\text { гармоник тока, например } \\
\text { тиристорный выпрямитель } \\
\text { привода постоянного тока }\end{array}$ & $\begin{array}{l}\text { Емкостная или нагрузка источник } \\
\text { напряжения или источник гармо- } \\
\text { ник напряжения, например диод- } \\
\text { ный выпрямитель со сглаживаю- } \\
\text { щими конденсаторами для привода } \\
\text { переменного тока }\end{array}$ \\
\hline
\end{tabular}

Электрические сети с низким качеством электроэнергии приводят к финансовым потерям, проблемам с безопасностью и влияют на окружающую среду. Существуют три причины низкого качества электроэнергии:

- гармоническое загрязнение;

- несбалансированность нагрузки в результате асимметрии напряжений;

- реактивная мощность.

Эти причины приводят к частым сбоям оборудования и снижению срока службы оборудования, производственным потерям, снижают уровень безопасности установок, повышают выбросы углерода в атмосферу и другим нежелательным эффектам. 
В дополнение к финансовым потерям возникают расходы, связанные с дополнительными потерями мощности в компонентах сети, таких как трансформаторы, кабели и электродвигатели.

Эти потери каскадно возвращаются в электростанции и, в зависимости от процесса и топлива, из которого генерируется электроэнергия, приводят к увеличению выброса $\mathrm{CO}_{2}$. Атомные электростанции не имеют выбросов $\mathrm{CO}_{2}$, в то время как угольные электростанции производят около 900 до 1000 г/кВтч.

Из-за остановки электроснабжения предприятия несут расходы, которые отражены в табл. 2.2, где представлен обзор финансовых проблем из-за остановки электроснабжения для различных отраслей промышленности. Данные были получены после общеевропейского исследования качества электроэнергии, проведенного Европейским институтом меди в 2002 году [123]. Остальная информация основана на данных АВВ.

Таблица 2.2

Примерные финансовые потери из-за прекращения электроснабжения предприятий

\begin{tabular}{|l|l|}
\hline Сектор экономики & $\begin{array}{l}\text { Финансовые потери на каждый } \\
\text { инцидент (в евро) }\end{array}$ \\
\hline Производство полупроводников & 3,8 миллионов \\
\hline Финансовая торговля & 6 миллионов \\
\hline Дата центр & 750000 \\
\hline Телекоммуникации & 30000 \\
\hline Сталелитейная промышленность & 350000 \\
\hline Стекольная промышленность & 250000 \\
\hline Морская платформа & $250000-750000$ \\
\hline Дноуглубительные работы/ мелиорация земель & $50000-250000$ \\
\hline
\end{tabular}

Исторически сложилось, что пассивные фильтры были первыми предложены для уменьшения гармонических искажений. В низковольтном (HB) оборудовании эти решения становятся все менее и менее применимы $[123,124]$ по следующим причинам:

- НВ оборудование очень динамично и ведет к перегрузке пассивного фильтра;

- современные нагрузки (например, частотно-регулируемый привод, современные системы освещения) уже имеют очень хороший $\cos \varphi$ (возможно даже емкостной), что приводит к перекомпенсации, когда установлен пассивный фильтр;

- пассивные фильтры, применяемые в НВ оборудовании, обычно устраняют гармоники низкого порядка. Однако в настоящее время, гармоники высокой частоты являются проблемой; 
- эффективность фильтрации пассивного фильтра определяется отношением импеданса пассивного фильтра к импедансу сети и поэтому не может быть гарантирована.

По этим причинам существует общемировая тенденция отхода от пассивных фильтров в пользу активных фильтров в установках низкого и среднего напряжений.

\section{2. Анализ свойств активных фильтров, изготавливаемых электротехническими компаниями}

Активные фильтры гармоник серийно изготавливают следующие электротехнические компании [133]:

1) Danfoss;

2) ABB (Asea Brown Boveri).

Компания Danfoss выпускает активные фильтры серии VLT AAF00x. Активный неполноточный фильтр осуществляет мониторинг всех токов трехфазных линий и обрабатывает измеренный токовый сигнал с помощью системы процессора обработки цифровых сигналов. Затем фильтр обеспечивает компенсацию, активно формируя сигналы в противоположной фазе на нежелательные составляющие тока. Сигналы противоположной фазы генерируются с помощью управления ключами IGBT в реальном времени. Форма кривой компенсированного тока выравнивается с помощью встроенного фильтра LCL, что предотвращает воздействие частоты коммутации IGBT на сеть [133].

Фильтр позволяет использовать общий или выборочный режим компенсации гармоник. В общем режиме компенсации все гармоники будут сведены к нулю. В данном режиме фильтр будет также балансировать нагрузку, чтобы уменьшить неравномерность распределения нагрузки между двумя фазами. Производительность установившегося режима позволит компенсировать гармоники до 40-го порядка, но сверхбыстрое нарастание тока позволяет фильтру также компенсировать мерцание и прочие быстрые и кратковременные явления. В выборочном режиме фильтр позволяет пользователю запрограммировать приемлемые индив идуальные уровни гармоник от 5-го до 25-го порядка. В выборочном режиме фильтр не будет уменьшать четные порядки гармоник, а также утраивания и не будет поддерживать балансировку фазной нагрузки и уменьшение мерцания [133].

АФГ, кроме режима компенсации гармоник, также имеет возможность запрограммировать приоритет фильтра на реактивный ток или на компенсацию гармоник. Если компенсация гармоник выбрана основным 
приоритетом, фильтр будет формировать компенсационный ток для уменьшения гармоник, а энергию для корректировки реактивного тока будет использовать только при наличии избыточной энергии. Фильтр будет автоматически и непрерывно распределять энергию между первым и вторым приоритетом, чтобы обеспечить максимально возможное подавление реактивного тока и гармоник. Это обеспечивает непрерывную оптимизацию действительного коэффициента мощности и максимально возможное использование тока питания трансформатора.

Невозможно перегрузить активный фильтр благодаря цепи самозащиты, которая автоматически уменьшает компенсированный ток до уровня, когда фильтр находится в состоянии стабильной температуры. При правильном подборе типоразмера фильтра он уменьшает гармоническое искажение тока до уровня 5\% [133]. Характеристики активных фильтров компании Danfoss приведены в табл. 2.3.

Таблица 2.3

Характеристики активных фильтров компании Danfoss

\begin{tabular}{|l|l|l|}
\hline Группа изделий & AAF & AAF \\
\hline Серия & 005 & 006 \\
\hline Номинальный ток & $190 \mathrm{~A}$ & $190 \mathrm{~A}$ \\
& $250 \mathrm{~A}$ & $250 \mathrm{~A}$ \\
& & $310 \mathrm{~A}$ \\
& & $400 \mathrm{~A}$ \\
\hline Фазы & Три фазы & Три фазы \\
\hline Напряжение сети & $380-480 \mathrm{~B}$ переменного тока & 380-480В переменного тока \\
\hline Фильтр & IP21/Nema тип 1 & IP21/Nema тип 1 \\
& IP54, гибрид & IP54/Nema тип 12 \\
\hline Фильтр ВЧ-помех & Фильтр ВЧ помех класс A2 & Фильтр ВЧ помех класс A2 \\
& Фильтр ВЧ помех класс A1 & Фильтр ВЧ помех класс A1 \\
\hline
\end{tabular}

Фильтры компании АВВ имеют возможности активной фильтрации гармоник сети, компенсации реактивной мощности и распределения нагрузок (устранение небаланса фаз). Фильтр отслеживает ток сети в реальном масштабе времени и с помощью мультипроцессорной системы цифровой обработки сигналов (DSP) преобразует измеряемые параметры в цифровые сигналы. Цифровой контроллер генерирует сигналы широтноимпульсной модуляции (ШИМ), отпирающие IGBT-транзисторы, которые через линейные реакторы подпитывают сеть гармоническими токами в противофазе фильтруемым компонентам. Кроме того, фильтры PQF могут быть интегрированы в информационные промышленные сети связи.

Компания АВВ выпускает следующие серии активных фильтров: 
1) PQFI - применяются для фильтрации гармоник в сетях с тяжелыми промышленными нагрузками.

2) PQFM - применяются для фильтрации гармоник в промышленных сетях ограниченной мощности

3) PQFK - применяются для фильтрации гармоник в сетях с коммерческими нагрузками, включая гармоники нулевой последовательности в нейтральном проводе.

4) PQFS - применяются для фильтрации гармоник в сетях (с нейтральным проводом и без него) с коммерческими, бытовыми и небольшими промышленными нагрузками.

Все серии активный фильтров компании $\mathrm{ABB}$ имеют - силовая часть - ШИМ преобразователь с IGBT-транзисторами; цифровое управление программируемые параметры фильтрации, комплексная настройка выбранных гармоник (включая гармоники нулевой последовательности), невозможность перегрузки, программируемая компенсация коэффициента мощности, функция распределения нагрузки (между фазами или между фазами и нейтральным проводом), возможность компенсации реактивной мощности до нуля. Характеристики активных фильтров компании АВВ приведены в табл. 2.4.

Таблица 2.4

Характеристики фильтров АВВ

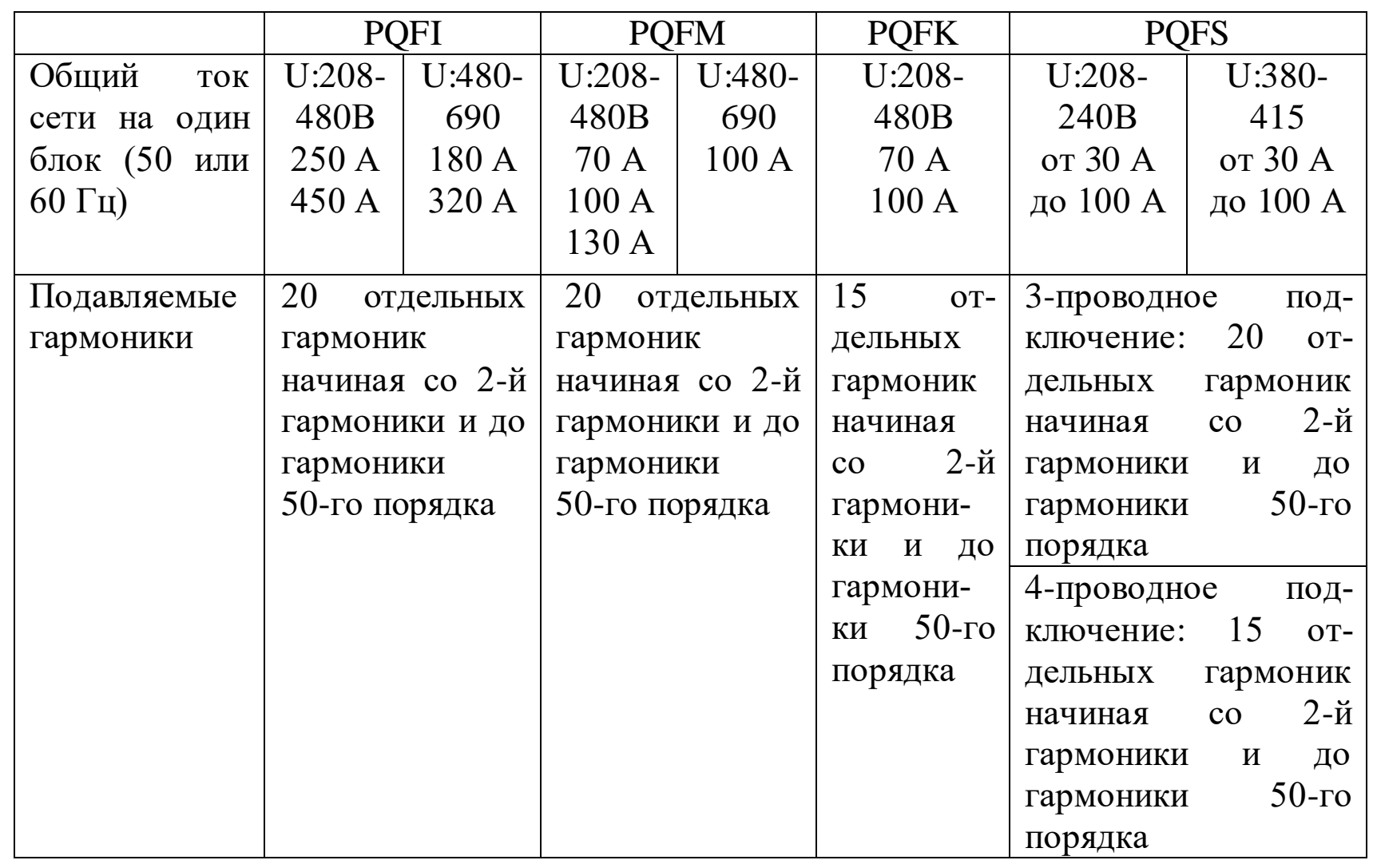


Окончание табл. 2.4

\begin{tabular}{|l|r|r|}
\hline $\begin{array}{l}\text { Степень } \\
\text { фильтрации }\end{array}$ & Задается для всех гармоник в абсолютных единицах \\
\hline $\begin{array}{l}\text { Коэффици- } \\
\text { ент ослабле- } \\
\text { ния гармо- } \\
\text { ник }\end{array}$ & Более 97\% при номинальной нагрузке \\
\hline $\begin{array}{l}\text { Реактивная } \\
\text { мощность }\end{array}$ & $\begin{array}{c}\text { Требуемый коэффициент реактивной мощности задается в пределах } \\
\text { от 0,6 (индуктивный характер) до 0,6 (емкостной характер) }\end{array}$ \\
\hline $\begin{array}{l}\text { Распределе- } \\
\text { ние нагрузки }\end{array}$ & $\begin{array}{c}\text { Программируемое распределе- } \\
\text { ние нагрузки между фазами }\end{array}$ & $\begin{array}{c}\text { Программируемое распределение } \\
\text { нагрузки между фазами и } \\
\text { нейтральным проводом }\end{array}$ \\
\hline $\begin{array}{l}\text { Активная } \\
\text { мощность }\end{array}$ & Обычно менее 3\% мощности устройства \\
\hline $\begin{array}{l}\text { Время } \\
\text { реакции }\end{array}$ & \multicolumn{2}{|c|}{$<0,5$ мс, мгновенное } \\
\hline $\begin{array}{l}\text { Время } \\
\text { отклика }\end{array}$ & \multicolumn{3}{|c|}{40 мс (фильтрация 10-90 \%) } \\
\hline
\end{tabular}

Существующие устройства компенсации неактивных составляющих потребляемой электрической мощности реализуют отдельные функции компенсации реактивной мощности, симметрирования напряжений сети, активной фильтрации высших гармоник и интергармоник для обеспечения электромагнитной совместимости электроприемников с питающей сетью. Однако для исключения вибрации роторов электрических и рабочих машин, факторов, сопровождающих механическую синхронизацию роторов группы асинхронных двигателей, требуются специальные структуры силовых преобразователей с алгоритмами управления и средства активной виброзащиты асинхронных двигателей.

\section{3. Преобразование координат как инструмент построения алгоритмов вычисления сигналов управления АКУ}

Теории, связанные с мгновенной мощностью, могут быть классифицированы в две группы. В одной - теории, основанные на преобразования координат $a b c$ фаз к трем ортогональным осям $\alpha \beta 0$, а в другой группе связанные непосредственно с координатами $a b c$ фаз $[48,81,98,114]$.

Теория, использующая преобразование координат $a b c$ к координатам $\alpha \beta 0$, основана на мгновенных мощностях, определяемых во временной области. Для этой теории нет ограничений, наложенных на форму тока или напряжения, и она может применяться для трехфазных сетей «с» или «без» нейтрального провода. Поэтому она справедлива не только для установившихся режимов, но и для переходных процессов. Эта теория 
очень эффективна и гибка в разработке контроллеров для силовых кондиционеров (активные фильтры гармоник, активные компенсационные выпрямители), основанных на силовых приборах.

В этой теории мгновенной мощности сначала преобразуются токи и напряжения из координат $a b c$ к $\alpha \beta 0$ координатам, и потом определяется мгновенная мощность в новых координатах. Эта теория обычно рассматривает трехфазную систему как целое, а не суперпозицию или сумму однофазных цепей.

Преобразование Кларка или $\alpha \beta 0$ преобразование $[98,114]$ отображает трехфазные мгновенные напряжения из координат $a b c-u_{a}, u_{b}, u_{c}$ в мгновенные напряжения в $\alpha \beta 0$ - осях $u_{\alpha}, u_{\beta}$ и $u_{0}$. Преобразование Кларка и обратное преобразование для трехфазного напряжения:

$$
\begin{aligned}
& {\left[\begin{array}{l}
u_{0} \\
u_{\alpha} \\
u_{\beta}
\end{array}\right]=\sqrt{\frac{2}{3}}\left[\begin{array}{ccc}
\frac{1}{\sqrt{2}} & \frac{1}{\sqrt{2}} & \frac{1}{\sqrt{2}} \\
1 & -\frac{1}{2} & -\frac{1}{2} \\
0 & \frac{\sqrt{3}}{2} & -\frac{\sqrt{3}}{2}
\end{array}\right]\left[\begin{array}{l}
u_{a} \\
u_{b} \\
u_{c}
\end{array}\right],} \\
& {\left[\begin{array}{l}
u_{a} \\
u_{b} \\
u_{c}
\end{array}\right]=\sqrt{\frac{2}{3}}\left[\begin{array}{ccc}
\frac{1}{\sqrt{2}} & 1 & 0 \\
\frac{1}{\sqrt{2}} & -\frac{1}{2} & \frac{\sqrt{3}}{2} \\
\frac{1}{\sqrt{2}} & -\frac{1}{2} & -\frac{\sqrt{3}}{2}
\end{array}\right]\left[\begin{array}{l}
u_{0} \\
u_{\alpha} \\
u_{\beta}
\end{array}\right] \text {. }}
\end{aligned}
$$

Аналогично, трехфазные мгновенные токи $i_{a}, i_{b}, i_{c}$ могут быть преобразованы к $\alpha \beta 0$ - осям:

$$
\begin{aligned}
& {\left[\begin{array}{l}
i_{0} \\
i_{\alpha} \\
i_{\beta}
\end{array}\right]=\sqrt{\frac{2}{3}}\left[\begin{array}{ccc}
\frac{1}{\sqrt{2}} & \frac{1}{\sqrt{2}} & \frac{1}{\sqrt{2}} \\
1 & -\frac{1}{2} & -\frac{1}{2} \\
0 & \frac{\sqrt{3}}{2} & -\frac{\sqrt{3}}{2}
\end{array}\right]\left[\begin{array}{l}
i_{a} \\
i_{b} \\
i_{c}
\end{array}\right],} \\
& {\left[\begin{array}{l}
i_{a} \\
i_{b} \\
i_{c}
\end{array}\right]=\sqrt{\frac{2}{3}}\left[\begin{array}{ccc}
\frac{1}{\sqrt{2}} & 1 & 0 \\
\frac{1}{\sqrt{2}} & -\frac{1}{2} & \frac{\sqrt{3}}{2} \\
\frac{1}{\sqrt{2}} & -\frac{1}{2} & -\frac{\sqrt{3}}{2}
\end{array}\right]\left[\begin{array}{l}
i_{0} \\
i_{\alpha} \\
i_{\beta}
\end{array}\right] .}
\end{aligned}
$$


Одно из преимуществ применений $\alpha \beta 0$ преобразования - это отделение составляющей нулевой последовательности из $a b c$-фазных составляющих, $\alpha$ и $\beta$ - оси не делают вклад в составляющую нулевой последовательности $i_{0}$ или $u_{0}$. Так как не существует нулевой последовательности токов в трехфазной трех проводной системе, то $i_{0}$ может быть устранена из указанных вычислений, что приводит к упрощению матриц. Если трехфазные напряжения сбалансированы в четырех проводных системах, то нулевая последовательность напряжений отсутствует, так что составляющая $u_{0}$ может быть устранена. Однако, когда составляющая нулевой последовательности тока и напряжения существует, нужно рассмотреть полное преобразование.

Если $u_{0}$ может быть устранена из матрицы преобразования, преобразование Кларка и обратное преобразование имеют вид

$$
\left[\begin{array}{l}
u_{\alpha} \\
u_{\beta}
\end{array}\right]=\sqrt{\frac{2}{3}}\left[\begin{array}{ccc}
1 & -\frac{1}{2} & -\frac{1}{2} \\
0 & \frac{\sqrt{3}}{2} & -\frac{\sqrt{3}}{2}
\end{array}\right]\left[\begin{array}{l}
u_{a} \\
u_{b} \\
u_{c}
\end{array}\right],
$$

и

$$
\left[\begin{array}{l}
u_{a} \\
u_{b} \\
u_{c}
\end{array}\right]=\sqrt{\frac{2}{3}}\left[\begin{array}{cc}
1 & 0 \\
-\frac{1}{2} & \frac{\sqrt{3}}{2} \\
-\frac{1}{2} & -\frac{\sqrt{3}}{2}
\end{array}\right]\left[\begin{array}{l}
u_{\alpha} \\
u_{\beta}
\end{array}\right] .
$$

Аналогично и для токов.

Матрицы (2.5) и (2.6) предполагают преобразование осей как показано на рис. 2.5 Оси неподвижны и не должны быть спутаны с понятиями векторного тока или напряжения. Мгновенные значения фазного напряжения или линейного тока, относящиеся к неподвижным $a b c$ координатам, преобразуются к $\alpha \beta$ неподвижным осям или наоборот. Оси $a, b$ и $c$ пространственно сдвинуты на $2 \pi / 3$ рад друг от друга, а $\alpha$ и $\beta$ - оси ортогональны, и $\alpha$ - ось параллельна оси $a$. Направление $\beta$ - оси выбирается таким образом, что если вращать пространственные вектора тока или напряжения на $a b c$ координатах в $a b c$ последовательности, они должные вращать в $\alpha \beta$ последовательности на $\alpha \beta$ координатах [114].

Если $u_{0}$ можно пренебречь, вектор мгновенного напряжения определяется из мгновенных составляющих $\alpha$ и $\beta$ - напряжений, по формуле:

$$
\mathrm{e}=u_{\alpha}+j u_{\beta} .
$$



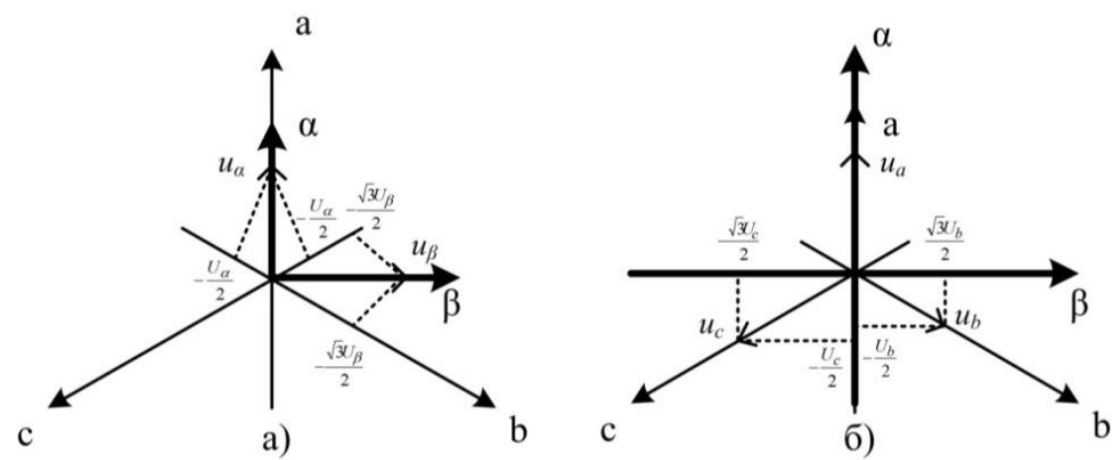

Рис. 2.5. Преобразование Кларка (a); обратное преобразование Кларка (б)

Аналогично, если $i_{0}$ можно пренебречь, то мгновенный вектор тока определяется как:

$$
i=i_{\alpha}+j i_{\beta}
$$

Указанные мгновенные вектора могут быть представлены в комплексной плоскости, где $\alpha$ - ось - реальная ось, и мнимая ось - $\beta$ в преобразовании Кларка. Следует отметить, что вектора определены как функции времени, потому что они состоят из составляющих мгновенных фазных напряжений и линейных токов в трехфазной системе. Поэтому, они не должны интерпретироваться как вектора. Полезность такого векторного определения показано в следующем примере.

Рассмотрим сбалансированные синусоидальные фазные напряжения и линейные токи трехфазной линейной сети:

$$
\left\{\begin{array}{c}
u_{a}(t)=\sqrt{2} U \sin \left(\omega t+\varphi_{u}\right) \\
u_{b}(t)=\sqrt{2} U \sin \left(\omega t+\varphi_{u}-\frac{2 \pi}{3}\right) \\
u_{c}(t)=\sqrt{2} U \sin \left(\omega t+\varphi_{u}+\frac{2 \pi}{3}\right)
\end{array}\right.
$$

и

$$
\left\{\begin{array}{c}
i_{a}(t)=\sqrt{2} I \sin \left(\omega t+\varphi_{i}\right) \\
i_{b}(t)=\sqrt{2} I \sin \left(\omega t+\varphi_{i}-\frac{2 \pi}{3}\right) \\
i_{c}(t)=\sqrt{2} I \sin \left(\omega t+\varphi_{i}+\frac{2 \pi}{3}\right)
\end{array} .\right.
$$

Углы $\varphi_{u}$ и $\varphi_{i}$ - это фазы напряжения и тока.

Указанные токи и напряжения содержат симметричные составляющие в основной положительной последовательности. Поэтому они синусоидальны и сбалансированы. Эти напряжения и токи могут быть преоб- 
разованы к $\alpha \beta$ системе отсчета, используя (2.5) и аналогично для вычисления токов. Указанные трехфазные напряжения и тока преобразуются в $\alpha \beta$ систему отсчета по (2.11) и (2.12):

$$
\left\{\begin{array}{l}
u_{\alpha}=\sqrt{3} U \cos \left(\omega t+\varphi_{u}\right) \\
u_{\beta}=\sqrt{3} U \sin \left(\omega t+\varphi_{u}\right)
\end{array},\right.
$$

И

$$
\left\{\begin{array}{l}
i_{\alpha}=\sqrt{3} I \cos \left(\omega t+\varphi_{i}\right) \\
i_{\beta}=\sqrt{3} I \sin \left(\omega t+\varphi_{i}\right)
\end{array} .\right.
$$

Теперь вектор напряжения $e$ и вектор тока $i$ определяются как:

$$
\mathrm{e}=u_{\alpha}+j u_{\beta} \rightarrow \mid \begin{gathered}
\mathrm{e}=\sqrt{3} U\left[\cos \left(\omega t+\varphi_{u}\right)+j \sin \left(\omega t+\varphi_{u}\right)\right] \\
\mathrm{e}=\sqrt{3} U e^{j\left(\omega t+\varphi_{u}\right)}
\end{gathered},
$$

И

$$
i=i_{\alpha}+j i_{\beta} \rightarrow \mid \begin{gathered}
i=\sqrt{3} I\left[\cos \left(\omega t+\varphi_{i}\right)+j \sin \left(\omega t+\varphi_{i}\right)\right] \\
i=\sqrt{3} I e^{j\left(\omega t+\varphi_{i}\right)}
\end{gathered}
$$

Поэтому в случае трехфазной сбалансированной синусоидальной сети вектора тока и напряжения имеют постоянную амплитуду и вращаются почасовой стрелке или в $\alpha \rightarrow \beta$ последовательности с угловой частотой $\omega$, как показано на рис. 2.6. Тот же результат получается, если мгновенные $a b c$ напряжения и токи взять для составления векторов на комплексной плоскости. Чтобы подтвердить результат, полученный с использованием преобразования Кларка, относительное положения $a, b$ и $c$ осей и $\alpha$ и $\beta$ осей должно соответствовать рис. $2.5, \alpha$ - ось должна совпадать с $a$ - осью и быть реальной осью в комплексной плоскости, $\beta$ - ось - мнимая ось, сдвинута на $\pi / 2$ от реальной оси.

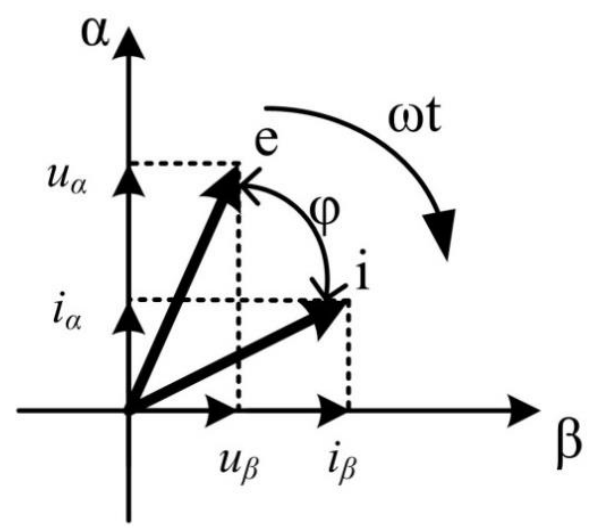

Рис. 2.6. Векторное представление напряжения и тока $\alpha \beta$ в системе отсчета 
Каждая временная функция фазного напряжения из $a b c$ координат умножается на комплексную величину с фазой, соответствующей направлению осей. Поэтому вектор комплексного напряжения состоит

$$
\mathrm{e}_{a b c}=u_{a} e^{j 0}+u_{b} e^{j 2 \pi / 3}+u_{c} e^{-j 2 \pi / 3} .
$$

Перемещая временные функции $u_{a}, u_{b}, u_{c}$ в (2.9) и (2.10) получим следующее выражение:

$$
\mathrm{e}_{a b c}=\frac{3 \sqrt{2}}{2} U\left[\cos \left(\omega t+\varphi_{u}\right)+j \sin \left(\omega t+\varphi_{u}\right)\right]=\frac{3 \sqrt{2}}{2} U e^{j\left(\omega t+\varphi_{u}\right)} .
$$

Отметим, что вектор напряжения $\mathrm{e}_{a b c}$ имеет постоянную амплитуду и вращается в прямом направлении с угловой частотой $\omega$, как определено в (2.13). Следовательно, если е вращается по часовой стрелке, в последовательности $\alpha \rightarrow \beta$ с синхронной угловой скоростью, $\mathrm{e}_{a b c}$ будет также, вращаться последовательно через $a \rightarrow b \rightarrow c$ оси с такой же угловой скоростью. Можно написать следующее отношение:

$$
\mathrm{e}_{a b c}=\sqrt{\frac{2}{3}} \mathrm{e}_{a b c} .
$$

Вектор, представленный трехфазными мгновенными токами и напряжениями, может быть использован в силовой электронике. Например, может использоваться в векторном управлении двигателями переменного тока, в векторной ШИМ силовых преобразователей, а также для управления силовыми кондиционерами.

Преобразование Кларка и обратное преобразование, используемое по (2.1)-(2.4) имеют свойство инвариантности в мощности. Эта особенность очень удобна, когда рассматриваем анализ мгновенной мощности в трехфазных сетях. Все традиционные методы определения мощности, имеют условия, что система находится в установившемся режиме. Для трехфазных систем «с» или «без» нейтрального провода в устойчивом состоянии или переходном процессе трехфазная мгновенная мощность описывается как сумма потоков мгновенных мощностей в секунду.

Трехфазная мгновенная активная мощность $p_{3 \varphi}(t)$ рассчитывается из мгновенных фазовых напряжений и линейных токов как:

$$
p_{3 \varphi}(t)=u_{a}(t) i_{a}(t)+u_{b}(t) i_{b}(t)+u_{c}(t) i_{c}(t),
$$

или

$$
p_{3 \varphi}=u_{a} i_{a}+u_{b} i_{b}+u_{c} i_{c} .
$$

где $u_{a}, u_{b}$ и $u_{c}$ - мгновенные фазные напряжения, $\mathrm{B} ; i_{a}, i_{b}$ и $i_{c}$ - мгновенные линейные токи, А. 
В сетях без нейтрального провода $u_{a}, u_{b}$ и $u_{c}$ - измеряются в общей точке. Иногда, ее называют «земля» (базисная точка). Однако базисная точка может быть выбрана произвольно и $p_{3 \varphi}(t)$, рассчитанная по (2.18) или (2.19), имеет результаты одинаковые для всех базисных точек, выбранных для измерения напряжения. Например, если фаза $b$ выбрана как базисная точка для измерения «фазного напряжения», то трехфазная мгновенная активная мощность считается как:

$$
p_{3 \varphi}=\left(u_{a}-u_{b}\right) i_{a}+\left(u_{b}-u_{b}\right) i_{b}+\left(u_{c}-u_{b}\right) i_{c}=u_{a b} i_{a}+u_{c b} i_{c} .
$$

Это объясняет, почему возможно использовать $(n-1)$ ваттметр для измерения активной мощности в $n$ - проводных сетях.

Трехфазная мгновенная активная мощность может быть посчитана через $\alpha \beta 0$ составляющие, если использовать (2.2) и (2.4) ,чтобы заменить переменные в $a b c$ координатах в (2.16):

$$
p_{3 \varphi}=u_{a} i_{a}+u_{b} i_{b}+u_{c} i_{c} \leftrightarrow p_{3 \varphi}=u_{\alpha} i_{\alpha}+u_{\beta} i_{\beta}+u_{0} i_{0} .
$$

В теории мгновенной мощности разделяются трехфазные системы на «с» или «без» нейтрального провода. Три мгновенных мощности мощность нулевой последовательности $p_{0}$, мгновенная активная мощность $p$, и мгновенная реактивная мощность $q$ - определяются из мгновенных фазных напряжений и линейных токов в $\alpha \beta$ осях как:

$$
\left[\begin{array}{c}
p_{0} \\
p \\
q
\end{array}\right]=\left[\begin{array}{ccc}
u_{0} & 0 & 0 \\
0 & u_{\alpha} & u_{\beta} \\
0 & u_{\beta} & -u_{\alpha}
\end{array}\right]\left[\begin{array}{c}
i_{0} \\
i_{\alpha} \\
i_{\beta}
\end{array}\right] .
$$

В трехфазной трех проводной сети отсутствует нулевая последовательность токов, поэтому $i_{0}=0$. В этом случае определяются в $\alpha \beta$ осях только мгновенные мощности, потому что результат $i_{0} u_{0}$ всегда 0 . Следовательно, в трехфазной трех проводной сети мгновенная реальная мощность $p$ представлена суммой потоков мощности в единицу времени через составляющие $\alpha \beta$. В этом случае $p_{3 \varphi}=p$.

Теория мгновенной мощности для трехфазной трех проводной сети использует вектора напряжения и тока, определенных в (2.7) и (2.8). Мгновенная комплексная мощность $s$ определяется как результат вектора напряжения $e$ и сопряженного вектора тока $i$, представленная в виде комплексных членов:

$$
s=\mathrm{e} \cdot i=\left(u_{\alpha}+j u_{\beta}\right)\left(i_{\alpha}-j i_{\beta}\right)=\left(u_{\alpha} i_{\alpha}+u_{\beta} i_{\beta}\right)+j\left(\left(u_{\beta} i_{\alpha}+u_{\alpha} i_{\beta}\right) .\right.
$$


Мгновенная активная и реактивная мощности, определяемые по (2.22), есть части комплексной мощности $s$, определяемой по (2.23). Поскольку на мгновенное напряжение и токи, которые применяется в расчетах, нет ограничений, то возможно применение этой теории как в установившемся режиме, так и в переходном процессе.

Первоначальное определение $p$ и $q$ основано на следующем выражении:

$$
\left[\begin{array}{l}
p \\
q
\end{array}\right]=\left[\begin{array}{cc}
u_{\alpha} & u_{\beta} \\
-u_{\beta} & u_{\alpha}
\end{array}\right]\left[\begin{array}{c}
i_{\alpha} \\
i_{\beta}
\end{array}\right]
$$

Выражения (2.22) и (2.24) применимы для анализа. Однако используем (2.22), потому что положительное значения мгновенной реактивной мощности $q$ в (2.22) соответствуют результату прямой последовательности напряжения и запаздыванию прямой последовательности токов, что согласовывается с пониманием реактивной мощности.

В дальнейшем токи в координатах $\alpha \beta$ установим в качестве функций напряжений и активных и реактивных мощностей $p$ и $q$. Из (2.22) возможно записать:

$$
\left[\begin{array}{c}
i_{\alpha} \\
i_{\beta}
\end{array}\right]=\frac{1}{u_{\alpha}^{2}+u_{\beta}^{2}}\left[\begin{array}{cc}
u_{\alpha} & u_{\beta} \\
u_{\beta} & -u_{\alpha}
\end{array}\right]\left[\begin{array}{l}
p \\
q
\end{array}\right] .
$$

По правилу правой руки (2.25) можно расширить как:

$$
\left[\begin{array}{c}
i_{\alpha} \\
i_{\beta}
\end{array}\right]=\frac{1}{u_{\alpha}^{2}+u_{\beta}^{2}}\left[\begin{array}{cc}
u_{\alpha} & u_{\beta} \\
u_{\beta} & -u_{\alpha}
\end{array}\right]\left[\begin{array}{c}
p \\
0
\end{array}\right]+\frac{1}{u_{\alpha}^{2}+u_{\beta}^{2}}\left[\begin{array}{cc}
u_{\alpha} & u_{\beta} \\
u_{\beta} & -u_{\alpha}
\end{array}\right]\left[\begin{array}{c}
0 \\
q
\end{array}\right]=\left[\begin{array}{c}
i_{\alpha p} \\
i_{\beta p}
\end{array}\right]+\left[\begin{array}{c}
i_{\alpha q} \\
i_{\beta q}
\end{array}\right] .
$$

Указанные токи могут быть определены:

- по мгновенному активному току по оси $\alpha i_{\alpha p}$ :

$$
i_{\alpha p}=\frac{u_{\alpha}}{u_{\alpha}^{2}+u_{\beta}^{2}} p
$$

- мгновенному реактивному току по оси $\alpha i_{\alpha q}$ :

$$
i_{\alpha q}=\frac{u_{\beta}}{u_{\alpha}^{2}+u_{\beta}^{2}} q
$$

- мгновенному активному току по оси $\beta i_{\beta p}$ : 


$$
i_{\beta p}=\frac{u_{\beta}}{u_{\alpha}^{2}+u_{\beta}^{2}} p,
$$

- мгновенному реактивному току по оси $\beta i_{\beta q}$ :

$$
i_{\beta q}=\frac{-u_{\alpha}}{u_{\alpha}^{2}+u_{\beta}^{2}} q .
$$

Мгновенная мощность в $\alpha$ и $\beta$ координатах определяется как $p_{\alpha}$ и $p_{\beta}$, рассчитывается из мгновенных напряжений и токов в $\alpha \beta$ - осях как:

$$
\left[\begin{array}{l}
p_{\alpha} \\
p_{\beta}
\end{array}\right]=\left[\begin{array}{l}
u_{\alpha} i_{\alpha} \\
u_{\beta} i_{\beta}
\end{array}\right]=\left[\begin{array}{l}
u_{\alpha} i_{\alpha p} \\
u_{\beta} i_{\beta p}
\end{array}\right]+\left[\begin{array}{l}
u_{\alpha} i_{\alpha q} \\
u_{\beta} i_{\beta q}
\end{array}\right] .
$$

Из (2.31) и (2.22) активная мощность может быть представлена как сумма $p_{\alpha}$ и $p_{\beta}$. Поэтому перепишем эту сумму, используя (2.31), что дает

$$
\begin{gathered}
\quad p=u_{\alpha} i_{\alpha p}+u_{\beta} i_{\beta p}+u_{\alpha} i_{\alpha q}+u_{\beta} i_{\beta q}= \\
=\frac{u_{\alpha}^{2}}{u_{\alpha}^{2}+u_{\beta}^{2}} p+\frac{u_{\beta}^{2}}{u_{\alpha}^{2}+u_{\beta}^{2}} p+\frac{u_{\alpha} u_{\beta}}{u_{\alpha}^{2}+u_{\beta}^{2}} q+\frac{-u_{\alpha} u_{\beta}}{u_{\alpha}^{2}+u_{\beta}^{2}} q .
\end{gathered}
$$

В выражении - есть два важных момента. Один - мгновенная активная мощность $p$ - описывается только

$$
u_{\alpha} i_{\alpha p}+u_{\beta} i_{\beta p}=p_{\alpha p}+p_{\beta p}=p .
$$

Второй, что в следующем соотношении существуют члены, зависящие от $q$ :

$$
u_{\alpha} i_{\alpha q}+u_{\beta} i_{\beta q}=p_{\alpha q}+p_{\beta q}=0 .
$$

Указанное выражение предполагает разделение мощностей на следующие типы:

- мгновенная активная мощность по оси $\alpha p_{\alpha p}$

$$
p_{\alpha p}=u_{\alpha} i_{\alpha p}=\frac{u_{\alpha}^{2}}{u_{\alpha}^{2}+u_{\beta}^{2}} p,
$$

- мгновенная реактивная мощность по оси $\alpha p_{\alpha q}$

$$
p_{\alpha q}=u_{\alpha} i_{\alpha q}=\frac{u_{\alpha} u_{\beta}}{u_{\alpha}^{2}+u_{\beta}^{2}} q,
$$


- мгновенная активная мощность по оси $\beta p_{\beta p}$

$$
p_{\beta p}=u_{\beta} i_{\beta p}=\frac{u_{\beta}^{2}}{u_{\alpha}^{2}+u_{\beta}^{2}} p
$$

- мгновенная реактивная мощность по оси $\beta p_{\beta q}$

$$
p_{\beta q}=u_{\beta} i_{\beta q}=\frac{-u_{\alpha} u_{\beta}}{u_{\alpha}^{2}+u_{\beta}^{2}} q
$$

Следует заметить, что ватты (Вт) используются как единицы измерений для всех мощностей $p_{\alpha p}, p_{\alpha q}, p_{\beta p}$ и $p_{\beta q}$, потому что каждая мощность определяется как результат мгновенного напряжения по оси и части мгновенного тока по той же оси.

В указанных выражениях отображены следующие взаимосвязи:

- мгновенный ток $i_{\alpha}$ разделен на составляющие мгновенную активную $i_{\alpha p}$ и мгновенную реактивную $i_{\alpha q}$ как показано в (2.27) и (2.28). Такое же разделение сделано для тока по оси $\beta$;

- сумма мгновенной активной мощности $p_{\alpha p}$ по оси $\alpha(2.35)$ и мгновенной активной мощности по оси $\beta p_{\beta p}$ соответствует мгновенной активной мощности $p$;

- сумма $p_{\alpha q}$ и $p_{\beta q}$ всегда ноль, поэтому ни одна из них не делают вклад ни в мгновенные, ни в средние потоки мощности между источником и нагрузкой в трехфазной цепи, по этой причине они были названы реактивные мощности по $\alpha$ и $\beta$ осям. Мгновенная реактивная мощность $q$ количественно такая же, как мощности $p_{\alpha q}$ и $p_{\beta q}$;

- так как сумма $p_{\alpha q}$ и $p_{\beta q}$ всегда ноль, их компенсация не нужна.

Если переменные $\alpha \beta$ мгновенной реактивной мощности $q$ определены как в (2.22), заменим их эквивалентным выражением, используя (2.5) и аналогично для токов, получим следующее:

$$
q=u_{\beta} i_{\alpha}+u_{\alpha} i_{\beta}=\frac{1}{\sqrt{3}}\left[\left(u_{a}-u_{b}\right) i_{c}+\left(u_{b}-u_{c}\right) i_{a}+\left(u_{c}-u_{a}\right) i_{b}\right] \text {. }
$$

Отметим, что $q$ в $\alpha \beta$ системе отсчета, определяется как сумма произведений напряжений и токов по разным осям. Также реактивная мощность $q$, которая считается из фазных напряжений и линейных токов в координатах $a b c$, есть результат суммы произведений линейных напряжений и линейных токов в различных фазах. Это эквивалентно тому, что реализовано в некоторых инструментах для измерений трехфазной реактивной 
мощности. В этих инструментах используется различные вектора тока и напряжения. Здесь вместо них используется мгновенное значение токов и напряжений.

Реактивная мощность $q$ пропорциональная количеству энергии, соответствующей обмену между фазами сети. Рис. 2.7 объясняет изложенное об активной и реактивной мощности.

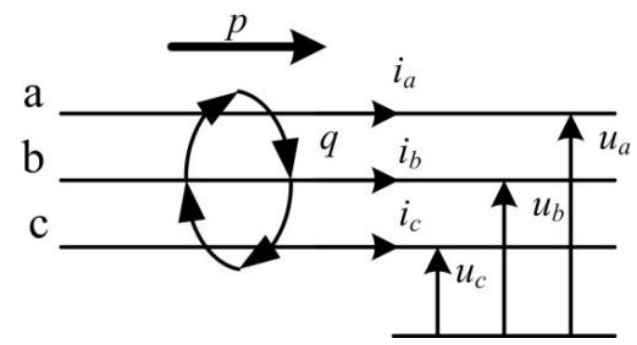

Рис. 2.7. Физическое значение мгновенной активной и реактивной мощности

Для лучшего понимания значения $p$ и $q$, нужно привести некоторые примеры. Первый - линейная цепь с синусоидальными токами и напряжениями и другие с синусоидальными напряжениями и нелинейной нагрузкой.

Синусоидальные напряжения и токи

Представим трехфазный идеальный источник напряжения, передающий мощность к трехфазному сбалансированному полному сопротивлению. Фазные напряжения:

$$
\left\{\begin{array}{c}
u_{a}(t)=\sqrt{2} U \sin (\omega t) \\
u_{b}(t)=\sqrt{2} U \sin \left(\omega t-\frac{2 \pi}{3}\right) \\
u_{c}(t)=\sqrt{2} U \sin \left(\omega t+\frac{2 \pi}{3}\right)
\end{array}\right.
$$

и линейные токи:

$$
\left\{\begin{array}{c}
i_{a}(t)=\sqrt{2} I \sin (\omega t) \\
i_{b}(t)=\sqrt{2} I \sin \left(\omega t-\frac{2 \pi}{3}\right) \\
i_{c}(t)=\sqrt{2} I \sin \left(\omega t+\frac{2 \pi}{3}\right)
\end{array}\right.
$$

После преобразования Кларка напряжение

$$
\left\{\begin{array}{c}
u_{\alpha}=\sqrt{3} U \sin (\omega t) \\
u_{\beta}=-\sqrt{3} U \sin (\omega t)
\end{array},\right.
$$


и ТОК

$$
\left\{\begin{array}{c}
i_{\alpha}=\sqrt{3} I \sin (\omega t+\varphi) \\
i_{\beta}=-\sqrt{3} I \sin (\omega t+\varphi)
\end{array} .\right.
$$

По двум указанным выражениям можно рассчитать реальную и реактивную мощности:

$$
\left\{\begin{array}{c}
p=3 U I \cos \varphi \\
q=-3 U I \sin \varphi
\end{array} .\right.
$$

Обе мгновенные мощности постоянны в этом примере. Активная мощность $p$ равна традиционному определению трехфазной активной мощности $p_{3 \phi}$, реактивная мощность $q$ так же равна традиционному определению реактивной мощности $q_{3 \phi}$. Этот пример показывает связь между теорией мгновенной мощности и традиционной теорией в случае синусоидальных сбалансированных токов и напряжений нагрузки.

Если нагрузка имеет индуктивный характер, то реактивная мощность $q$ - имеет положительное значение, и если нагрузка емкостная, то $q$ отрицательная, в согласии с общим определением реактивной мощности.

Сбалансированное напряжение и емкостная нагрузка

Рассмотрим две ситуации:

1) трехфазное сбалансированное напряжение с трехфазной сбалансированной емкостной нагрузкой (емкость $C$ );

2) несбалансированная нагрузка (конденсатор соединен между двумя фазами).

В первом случае нагрузка сбалансирована под условиями установившегося режима. Получим следующие активные и реактивные мощности:

$$
\left\{\begin{array}{c}
p=0 \\
q=-3 \frac{U^{2}}{X_{c}}
\end{array}\right.
$$

где $X_{c}$ - реактивное сопротивление конденсатора.

В этом случае нет потока мощности от источника к нагрузке, реактивная мощность постоянна.

В другом случае конденсатор соединен между фазами $a$ и $b$. Тогда мгновенная активная

$$
p=3 \frac{U^{2}}{X_{c}} \sin \left(2 \omega t+\frac{\pi}{3}\right)
$$


и реактивная мощность

$$
q=-3 \frac{U^{2}}{X_{c}}\left[1+\cos \left(2 \omega t+\frac{\pi}{3}\right)\right]
$$

Каждая мощность в (2.46) и (2.47) не имеет постоянной составляющей и представлена только колебательной составляющей. Из традиционной теории это должно быть нормально только для реактивной мощности (средняя реактивная мощность), а не для активной мощности. Причина, по которой активная мощность не равна нулю, - напряжение на зажимах конденсатора меняется синусоидально и поэтому он заряжается и разряжается, согласно с потоком мощности $p$. Фактически, если рассматривать это как турбину генератора, то она имеет положительный крутящий момент, когда конденсатор заряжается, или отрицательный, когда разряжается. Этот крутящий момент должен пульсировать на валу. В предыдущем примере было три сбалансированных конденсатора, один конденсатор разряжался, пока другие заряжались. В установившемся режиме нет потоков мощности от источника к нагрузке [114].

Мгновенная реактивная мощность так же меняется со временем, и ее среднее значение не равно нулю, что показано в предыдущем случае со сбалансированными трехфазными конденсаторами. Это пример того, что при условии несбалансированной нагрузки теория мгновенной мощности показывает некоторое важное понимание, которое невозможно увидеть в традиционной частотной теории при условии несбалансированной нагрузки.

Синусоидальное сбалансированное напряжение $u$ нелинейная нагрузка

Предположим, что есть трехфазный источник напряжения, сбалансированный и чисто синусоидальный, как в (2.40) и (2.41), и нагрузка тиристорный выпрямитель, работающий с углом управления 30 гр. эл. Угол коммутации предположим равным нулю и сглаживающий реактор со стороны постоянного тока достаточно большим, чтобы убрать колебания в выпрямленном токе. На рис. 2.8 показана схема.

На рис. 2.9, a показана форма выходного напряжения $u_{d}$, а на рис. 2.9, б показаны идеальное напряжение и ток фазы $a$. Хорошо известно, что трехфазный ток содержит, кроме основной гармоники, и другие $(6 n \pm 1 ; n=1,2,3 \ldots) .(6 n-1)$ - это гармоники обратной последовательности, а $(6 n+1)$ - гармоники прямой последовательности. Линейные токи шести пульсного тиристорного выпрямителя, работающего с углом в 30 гр. представлены как: 


$$
\left\{\begin{array}{c}
i_{a}(t)=\sqrt{2}\left(I_{1} \sin \left(\omega t-\frac{\pi}{6}\right)-I_{5} \sin \left(5 \omega t-\frac{\pi}{6}\right)+\right. \\
\left.+I_{7} \sin \left(7 \omega t-\frac{\pi}{6}\right)-\ldots\right) ; \\
i_{b}(t)=\sqrt{2}\left(I_{1} \sin \left(\omega t-\frac{2 \pi}{3}-\frac{\pi}{6}\right)-I_{5} \sin \left(5 \omega t+\frac{2 \pi}{3}-\frac{\pi}{6}\right)+\right. \\
\left.+I_{7} \sin \left(7 \omega t-\frac{2 \pi}{3}-\frac{\pi}{6}\right)-\ldots\right) ; \\
i_{c}(t)=\sqrt{2} I\left({ }_{1} \sin \left(\omega t+\frac{2 \pi}{3}-\frac{\pi}{6}\right)--I_{5} \sin \left(5 \omega t-\frac{2 \pi}{3}-\frac{\pi}{6}\right)+\right. \\
\left.+I_{7} \sin \left(7 \omega t+\frac{2 \pi}{3}-\frac{\pi}{6}\right)-\ldots\right) .
\end{array}\right.
$$

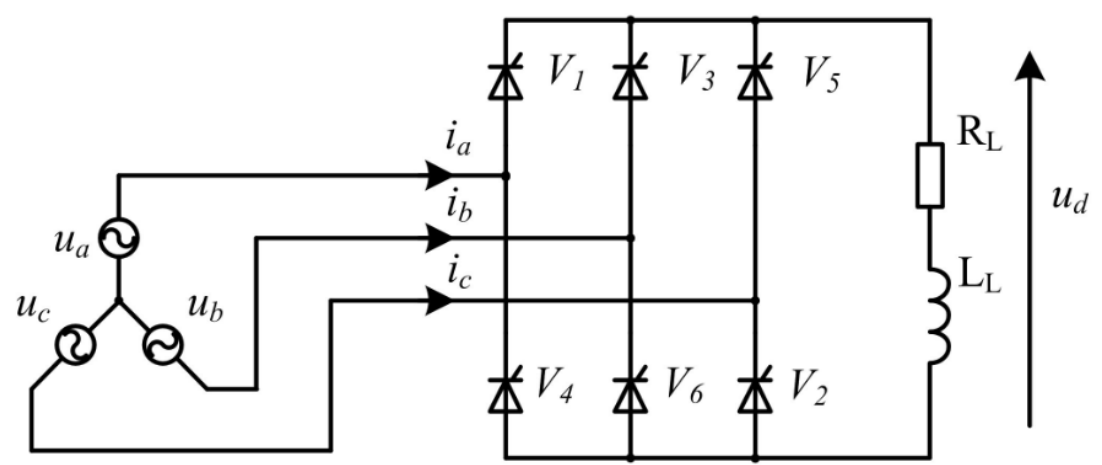

Рис. 2.8. Трехфазный источник напряжения и тиристорный выпрямитель

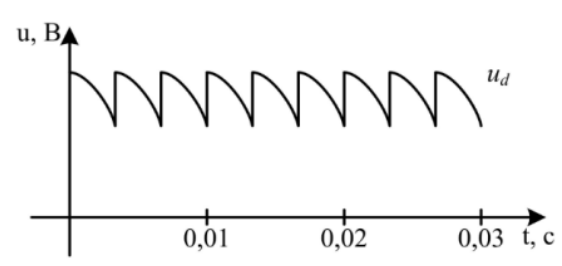

a)

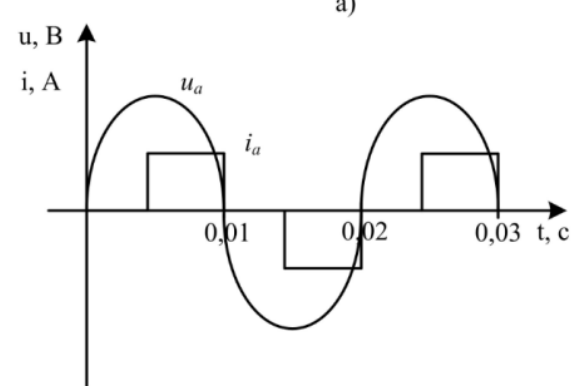

б)

Рис. 2.9. Осциллограмма токов и напряжений (a) выпрямленное напряжение; ток и напряжение в фазе $\boldsymbol{a}($ б)

На рис. 2.10 показана (a) активная мощность $p$ и (б) реактивная мощность $q$. Активная мощность рассчитана с использованием тока и напряжения со стороны переменного тока и это значение будет таким же, 
если мы перемножим выпрямленное напряжение $u_{d}$ на выпрямленный ток. Мгновенная мощность, входящая со стороны переменного тока в выпрямитель, равна выходной мощности со стороны постоянного тока, если нет потерь в выпрямителе. Реактивная мощность определяется только для многофазной цепи переменного тока, так что может быть посчитана только со стороны переменного тока.
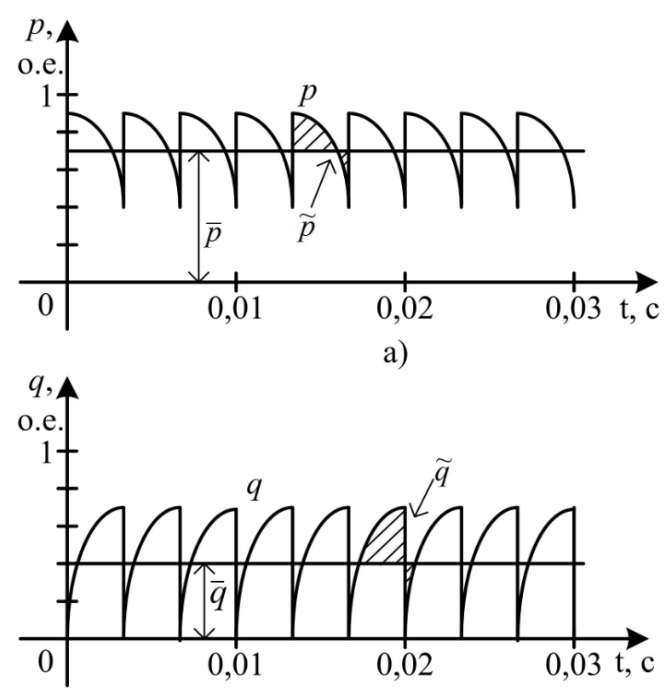

б)

Рис. 2.10.Осциллограмма мощностей $(a)$ активная мощность; реактивная мощность (б)

Две мощности имеют постоянную составляющую и колебательную составляющую. Поэтому, разделим $p$ и $q$ на две части:

$$
\begin{aligned}
& p=\bar{p}+\tilde{p}, \\
& q=\bar{q}+\tilde{q},
\end{aligned}
$$

где $\bar{p}$ - средняя часть $p$, Вт; $\tilde{p}$ - вариационная часть $p$, Вт; $\bar{q}$ - средняя часть $q$, Вт; $\tilde{q}$ - вариационная часть $q$, Вт.

Активная мощность $p$ представляет суммарный энергетический поток в единицу времени в цепи. Среднее значение $\bar{p}$ представляет поток в единицу времени в прямом направлении. Если рассчитать $\bar{p}$ и $\bar{q}$ в $a b c$ из (2.40), (2.41) и (2.48), получим:

$$
\left\{\begin{array}{l}
\bar{p}=3 U I_{1} \cos \frac{\pi}{6} \\
\bar{q}=3 U I_{1} \sin \frac{\pi}{6}
\end{array} .\right.
$$

Колеблющаяся часть $\tilde{p}$ - это колебания энергии в единицу времени, среднее значение которых равно нулю. Ее можно представить как допол- 
нительный поток мощности в сети без эффективного вклада в передачу энергии от источника к нагрузке и наоборот.

Реактивная мощность $q$ дает величину мгновенной реактивной мощности $p_{\alpha q}$ и $p_{\beta q}$ или величину соответственной мощности в координатах $a b c$. Хотя мощности $p_{\alpha q}$ и $p_{\beta q}$ существует в каждой оси, их сумма равна нулю в любое время. Среднее значение реактивной мощности $\bar{q}$ не делает вклад в передачу энергии, однако вносит вклад в увеличение полного тока, потребляемого электроприемником, отражая его реактивную составляющую. Колебательная составляющая реактивной мощности $\tilde{q}$ так связана с мощностью, что происходит обмен между тремя фазами без передачи энергии между источником и нагрузкой. В представленном примере, колебания активной мощности $\tilde{p}$ и реактивной мощности $\tilde{q}$ связаны с присутствием гармоник исключительно в токе нагрузке.

На рис. 2.11 показана составляющая тока фазы а отвечающая за среднюю активную мощность $\bar{p}$ и среднюю реактивную мощность $\bar{q}$. Для примера, построим на этом же рисунке напряжение фазы $a$. Эти токи могут быть рассчитаны по (2.27) и (2.29) для $p=\bar{p}$ и (2.28) и (2.30) для $q=\bar{q}$, с последующим преобразованием от $\alpha \beta$ координат к аbc координатам. Ток $i_{a \bar{p}}$ в фазе с напряжением $u_{a}$, а ток $i_{a \bar{q}}$ отстает от напряжения на 90 гр., действуя как индуктивная нагрузка, что хорошо известно для линейно-коммутируемого тиристорного выпрямителя.

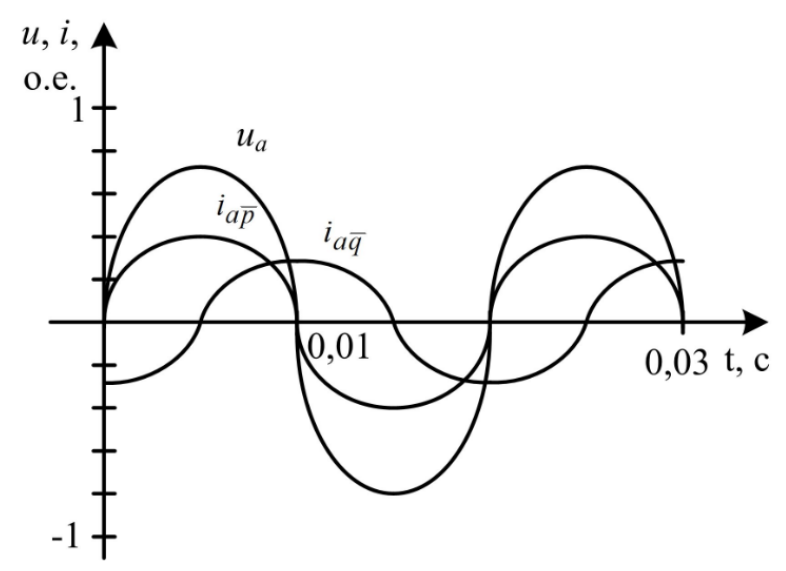

Рис. 2.11. Напряжение в фазе $a$, токи $i_{a \bar{p}}$ и $i_{a \bar{q}}$

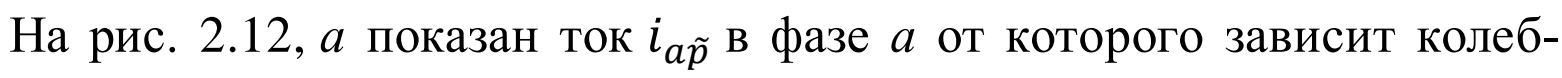
лющаяся мощность $\tilde{p}, 2.12, \sigma$ - ток $i_{a \tilde{q}}$ от которого зависит колеблющаяся мощность $\tilde{q}$ и 2.12, с - сумма $i_{a \tilde{p}}$ и $i_{a \tilde{q}}$. Эти токи были посчитаны, как и в предыдущем случае, с использованием (2.27) и (2.29) для $p=\tilde{p}$ и (2.28) и (2.30) для $q=\tilde{q}$, и в дальнейшем преобразованы из $\alpha \beta$ к $a b c$. Сумма четыpex компонентов $i_{a \bar{p}}+i_{a \bar{q}}+i_{a \tilde{p}}+i_{a \tilde{q}}$ равна прямоугольному сигналу тока, изображенному на рис. $2.9, \sigma$. 
Теория мгновенной мощности имеет преимущество, позволяющие производить полный анализ и вычисления в реальном времени различных мощностей и соответствующих токов в трехфазной цепи. Знание в реальном времени нежелательных токов в цепи позволяет уменьшить их. Для примера, если колебания мощности нежелательны, то компенсируя токи $i_{a \widetilde{p}}$ и $i_{a \tilde{q}}$ в нагрузке и связанные с ними токи в фазах $b$ и $c$, компенсируя искаженный ток, ток в сети станет синусоидальным. Можно легко показать, что $i_{a}-\left(i_{a \widetilde{p}}+i_{a \tilde{q}}\right)$ будет чистая синусоида.

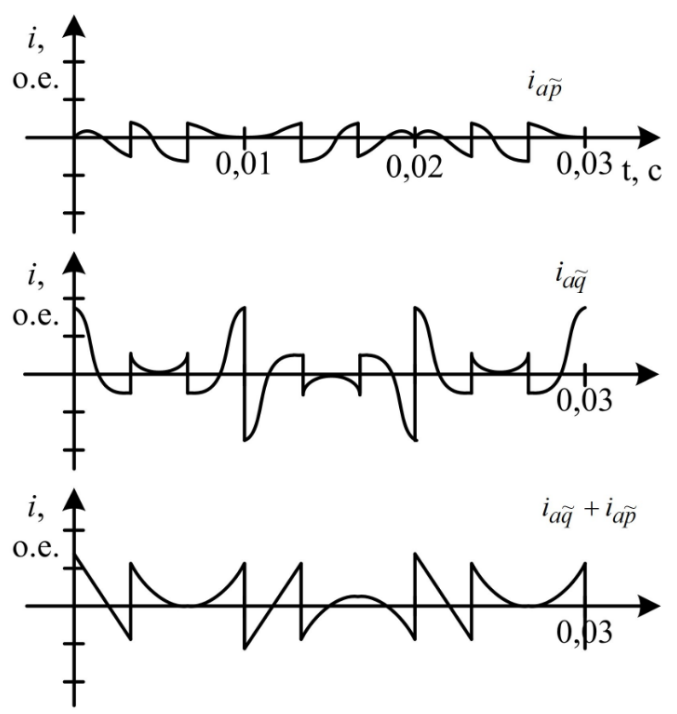

Рис. 2.12. Осциллограммы токов ток $\boldsymbol{i}_{a \widetilde{p}}(a)$, ток $\boldsymbol{i}_{a \widetilde{q}}(\widetilde{\sigma})$, суммарный

$$
\text { ток } \boldsymbol{i}_{a \widetilde{p}}+\boldsymbol{i}_{a \widetilde{q}}(c)
$$

Одно из важных применений теории мгновенной мощности - это компенсация нежелательных токов. Рис. 2.13 показывает основную идею параллельного компенсатора тока. На нем показан источник (система генерации энергии) подключенный к нелинейной нагрузке, которая компенсируется параллельным компенсатором. Для упрощения предположим, что параллельный компенсатор ведет себя как трехфазный управляемый источник тока, который может генерировать любой выбранный ток $i_{C a}^{*}, i_{C b}^{*}$ и $i_{C c}^{*}$.

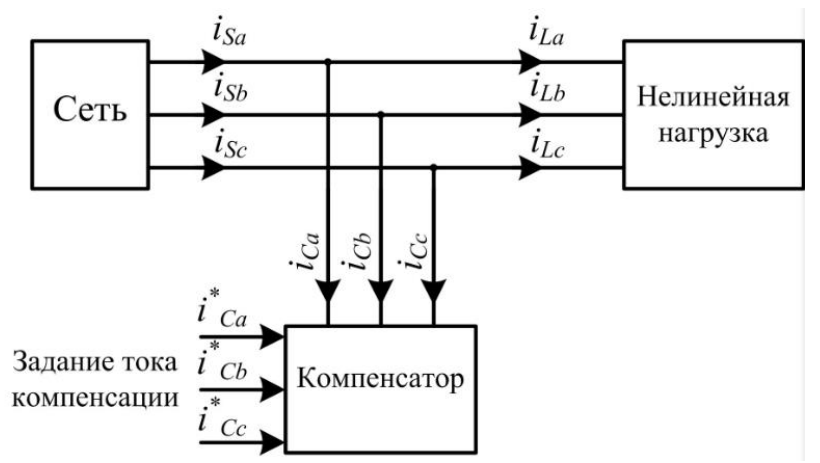

Рис. 2.13. Основной принцип параллельной токовой компенсации 
Рис. 2.14 показывает основной метод управления параллельным компенсатором. Вычисленная активная мощность $p$ нагрузки разделяется на среднюю $\bar{p}$ и колеблющуюся части $\tilde{p}$. Также, реактивная мощность нагрузки $q$ разделяется на среднюю $\bar{q}$ и колеблющуюся части $\tilde{q}$. Затем для компенсации выбираются нежелательные части активной и реактивной мощности нагрузки. Мощности для компенсации представлены как $-p_{c}^{*}$ и $-q_{c}^{*}$ на рис. 2.14. Причина для появления отрицательного знака в компенсируемых мощностях в том, что компенсатор должен вырабатывать компенсационный ток, который генерирует инверсную от нежелательной мощность. Заметим, что принятое условное обозначение тока на рис. 2.13 такое же, как компенсированный ток, - это сумма тока нагрузки и тока компенсации. Поэтому обратное преобразование от $\alpha \beta$ к $a b c$ применяется для расчета мгновенных значений трехфазного тока компенсации $i_{C a}^{*}, i_{C b}^{*}$ и $i_{C c}^{*}$.

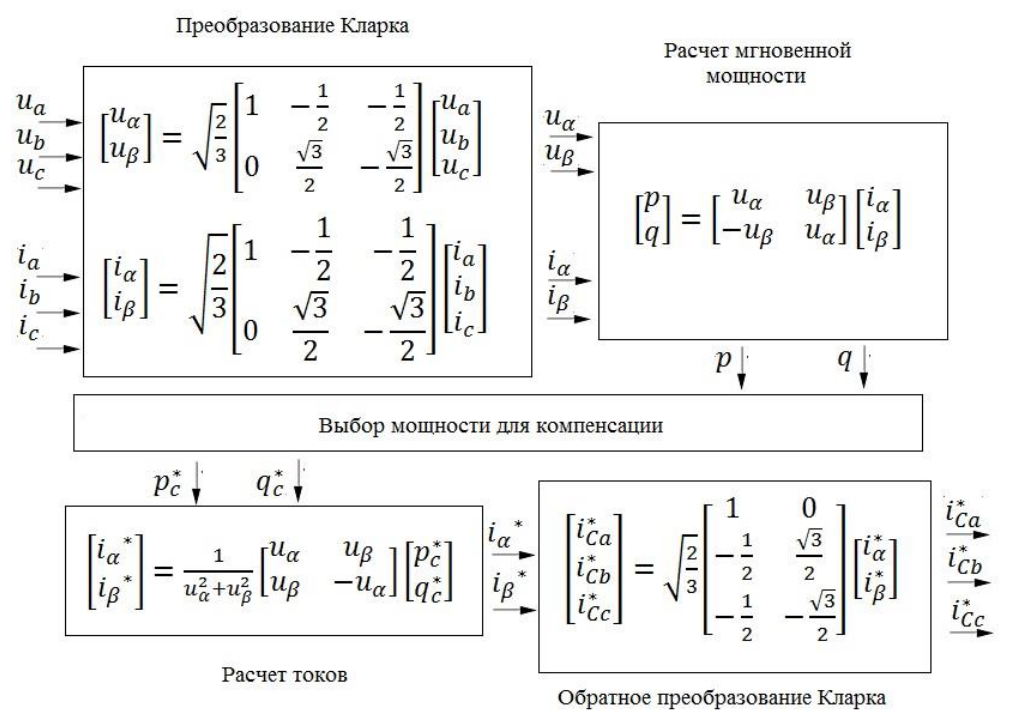

Рис. 2.14. Метод управления параллельной токовой компенсацией

На рис. 2.15 - рис. 2.19 показаны различные результаты компенсации, содержащие такую же нелинейную нагрузку, как на рис. 2.8. Каждый рисунок показывает ток, который должен быть устранен в нагрузке, компенсированный ток и $p_{s}$ и $q_{s}$ в фазе $a$. Заметим, что компенсатор должен генерировать инверсный ток для компенсации, который не показан на упомянутых рисунках. Идеальный ток компенсации может быть просто посчитан вычитанием устраненного тока из тока нагрузки. Эти результаты будут такими же, если метод управления, показанный на рис. 2.14, используется для генерирования компенсированного тока, который вырабатывает инверсные мощности $\left(-p_{\mathrm{c}}^{*}\right.$ и $\left.-q_{\mathrm{c}}^{*}\right)$. Поэтому эти токи компенсации суммируются с током нагрузки. Мощности $p_{s}$ и $q_{s}$ связаны с новыми мощностями, поставляемые от источника после компенсации. 
Рис. 2.15 показывает компенсацию реактивную мощности нагрузки $q$. В этом случае, все составляющие тока, которые не делают переноса энергии, хотя они могут вызывать потери в сети, должны быть устранены. Активная мощность $p_{s}$, вырабатываемая током компенсации равна вырабатываемой током нагрузки, в то время как реактивная мощность $q_{s}$ равна нулю в источнике. Когда компенсатор работает как управляемый потребитель тока (сток тока), компенсированный ток зависит только от $q$, так что нет потока энергии от или в компенсатор. Эта особенность, в принципе, означает, что такому компенсатору не нужен источник тока или элемент хранения энергии, чтобы реализовать компенсацию $q$. Поскольку компенсатор вырабатывает токи, которые связаны с реактивной мощностью нагрузки $q$, включая все гармоники $q=\bar{q}+\tilde{q}$, этот компенсатор должен иметь бесконечную частотную характеристику (АЧХ).

На рис. 2.16 показана такая же компенсация, как и в предыдущем случае, за исключением, использования только средней реактивной мощности $\bar{q}$. В этом случае, ток компенсации $i_{a \bar{q}}$ не имеет гармонических составляющих и поэтому компенсатор генерирует синусоидальный ток с частотой линии. Как и ожидалось, активная мощность $p_{s}$ со стороны источника равна активной мощности $p$ нагрузки. Реактивная мощность $q_{s}$ имеет только колебательную часть, так как среднее значение $\bar{q}$ реактивной мощности нагрузки было скомпенсировано.

На рис. 2.17 показан случай компенсации только $\tilde{p}$. Взяв токи, связанные с этой мощностью как токи компенсации для компенсатора, сделаем постоянной (без колебаний) трехфазную мгновенную активную мощность, которая равна посчитанной активной мощности. Реактивная мощность будет такой же, как в нагрузке. Если первичный источник мощности содержит турбогенератор (генератор с турбиной), то компенсация мощности устранит пульсации вращающего момента по роторной оси, как результат - нет нежелательных вибраций вала. Компенсированный ток содержит гармонический состав, эти гармоники не влияют на активную мощность. Компенсатор снабжает колеблющуюся активную мощность $\tilde{p}$, которая устраняется в источнике. Поэтому он должен иметь возможность снабжать и запасть энергию, но с нулевым средним значением. Этому компенсатору требуется элемент хранения энергии.

На рис. 2.18 показан случай компенсации $\tilde{p}$ и $\tilde{q}$. Этот способ устраняет ток, показанный на рис. 2.12. Теперь источник тока чисто синусоидальный. Этот способ компенсации применяется, когда устранение гармоник - важнейшая проблема. Хотя результирующие активная и реактивная мощности не имеют пульсаций, ток, связанный со средней реактивной 
мощностью $\bar{q}$, по-прежнему течет из сети, делая коэффициент мощности меньше чем единица, т.е. реактивный ток не скомпенсирован.

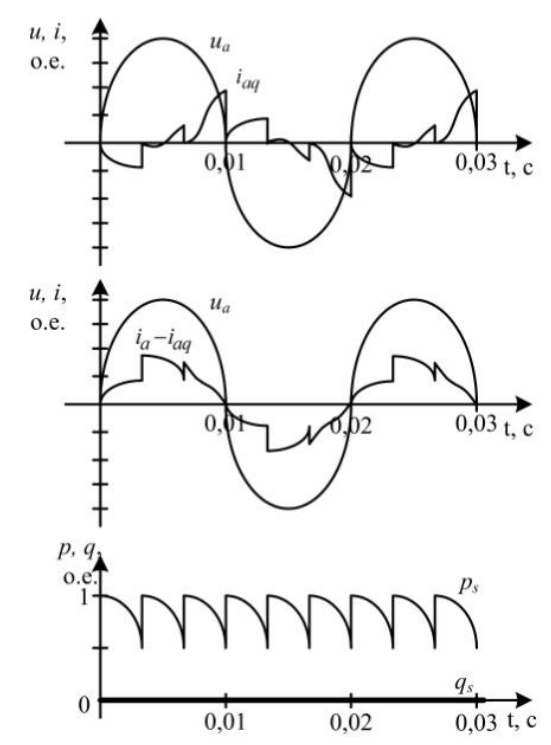

Рис. 2.15. Устраняемый ток $i_{a q}$, компенсированный ток $i-i_{a q}$ и активная и реактивная мощность, выработанная компенсированным током

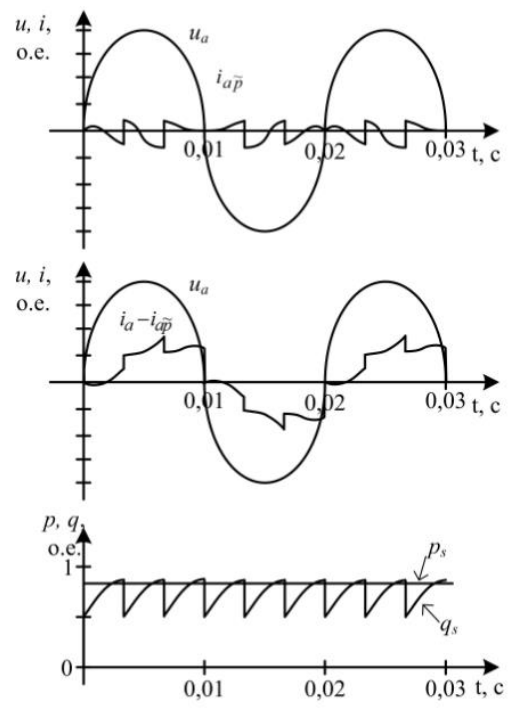

Рис. 2.17. Устраняемый ток $\boldsymbol{i}_{a \widetilde{p}}$, компенсированный ток $i-i_{a \widetilde{p}}$ и активная и реактивная мощность, выработанная компенсированным током

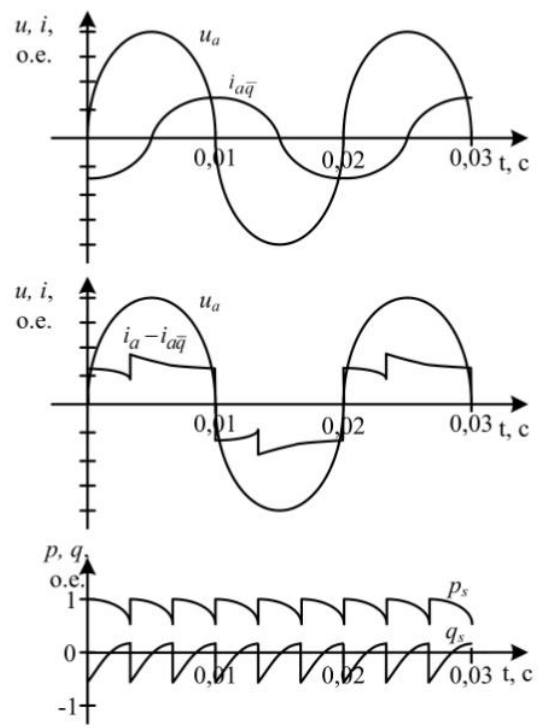

Рис. 2.16. Устраняемый ток $\boldsymbol{i}_{a \bar{q}}$, компенсированный ток $i-i_{a \bar{q}}$ и активная и реактивная мощность, выработанная компенсированным током

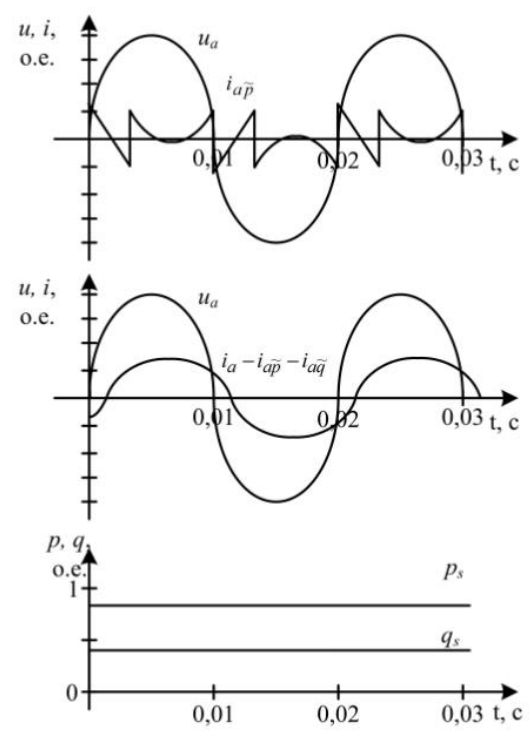

Рис. 2.18. Устраняемый ток $i_{a \widetilde{p}}+i_{a \widetilde{q}}$, компенсированный ток $i-\left(i_{a \widetilde{p}}+i_{a \widetilde{q}}\right)$ и активная и реактивная мощность, выработанная компенсированным током

На рис. 2.19 показан случай компенсации $\tilde{p}$ и $q$. Этот способ, при котором все нежелательные составляющие тока нагрузки должны быть 
устранены. Компенсированный ток синусоидальный - вырабатывает постоянную активную мощность и не генерирует реактивную мощность. Нелинейная нагрузка и компенсатор формируют идеальную, линейную чисто активную нагрузку. Источник тока имеет минимальное среднеквадратичное значение, чтобы передать энергию как первоначальный ток нагрузки, который создаст среднее значение мощности $\bar{p}$. Это лучшая компенсация, которая может быть сделана с точки зрения потока мощности, потому что сглаживает генерируемую мощность от генератора. Кроме того, устраняет все гармоники тока. Однако нужно отметить, что это особая ситуация, в которой искажения или дисбаланс представлены в системе напряжений.

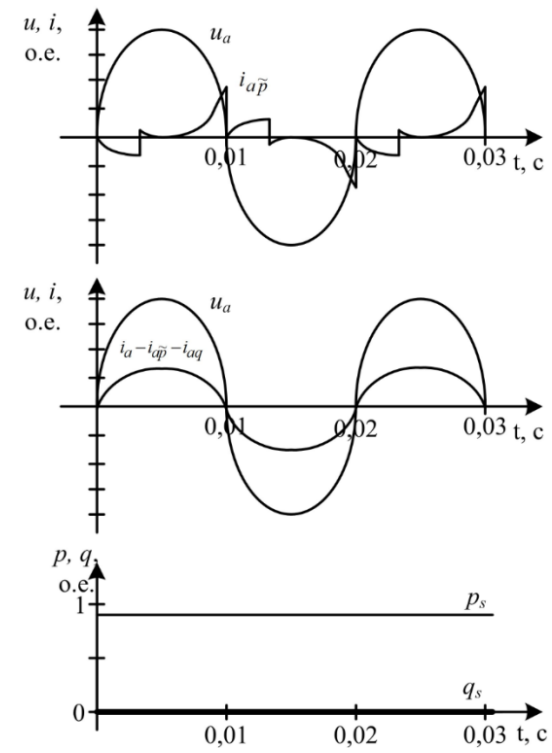

Рис. 2.19. Устраняемый ток $i_{a \widetilde{p}}+i_{a q}$, компенсированный ток $i-\left(i_{a \widetilde{p}}+i_{a q}\right)$ и активная и реактивная мощность, выработанная компенсированным током

Изложенные рассуждения представлены в табл. 2.5, показывающей, какие результаты дает компенсация тех или иных составляющих мощности.

Таблица 2.5

Результаты компенсации разных составляющих

\begin{tabular}{|c|c|c|c|l|}
\hline \multicolumn{2}{|c|}{$\begin{array}{c}\text { Составляющие } \\
\text { мощности, } \\
\text { подлежащие } \\
\text { компенсации }\end{array}$} & \multicolumn{2}{|c|}{ Результат компенсации } \\
\hline $\bar{p}$ & $\tilde{p}$ & $\bar{q}$ & $\tilde{q}$ & \\
\hline- & - & + & + & $\begin{array}{l}\text { Компенсация реактивной мощности, в результате коэффициент } \\
\text { мощности равен 1. Компенсация ВГ тока, связанных с состав- } \\
\text { ляющей } \tilde{q}\end{array}$ \\
\hline
\end{tabular}


Окончание табл. 2.5

\begin{tabular}{|c|c|c|c|l|}
\hline- & - & + & - & $\begin{array}{l}\text { Компенсация реактивной мощности, в результате коэффициент } \\
\text { мощности равен 1 }\end{array}$ \\
\hline- & + & - & - & $\begin{array}{l}\text { Компенсация ВГ тока, связанных с составляющей } \\
\tilde{p} . \text { Если первичный источник мощности содержит турбогенера- } \\
\text { тор, то компенсация устранит пульсации электромагнтного } \\
\text { (вращающего) момента на роторной оси электрической машины }\end{array}$ \\
\hline- & + & - & + & $\begin{array}{l}\text { Компенсация ВГ, в результате компенсированный ток синусои- } \\
\text { дален }\end{array}$ \\
\hline- & + & + & + & $\begin{array}{l}\text { Компенсация ВГ и реактивной мощности, ток сети синусоида- } \\
\text { лен, компенсатор и нелинейная нагрузка представляют собой } \\
\text { чисто активную нагрузку }\end{array}$ \\
\hline
\end{tabular}




\section{ГЛАВА З. СИЛОВОЙ ПРЕОБРАЗОВАТЕЛЬ АКТИВНОГО КОМПЕНСИРУЮЩЕГО УСТРОЙСТВА}

\section{1. Основные схемы силовой части активных фильтров}

Можно свести активные фильтры к следующему обобщенному типу. Активные фильтры состоят из двух основных подсистем - это:

- сигнальная часть;

- силовая часть.

Сигнальная часть выполняет анализ гармонических искажений в сети, формирует компенсационный сигнал и сигнал управления ключами преобразователя. Сигнальная часть состоит из датчиков тока и напряжения, которые измеряют ток и напряжение в сети, цифрового сигнального процессора, рассчитывающего сигнал компенсации.

Силовая часть обеспечивает компенсацию и состоит из блока силовой электроники, силового конденсатора (или дросселя) и высокочастотного фильтра.

Активный фильтр может выполнять следующие функции:

- компенсация гармонических искажений;

- компенсация реактивной мощности;

- виброзащита - динамическая коррекция пульсаций момента на валу нагрузки - рабочей машины.

Современные преобразователи частоты (ПЧ) могут:

- изменять частоту выходного напряжения и тока $f_{\text {вых }}$ относительно частоты входного напряжения $f_{\text {вх }}$;

- плавно изменять амплитуду первой гармоники выходного напряжения $U_{m \text { вых; }}$;

- изменять в общем случае фазовый угол нагрузки входного сетевого источника $\varphi_{\text {вх }}$ по сравнению с фазовым углом нагрузки $\varphi_{\text {вых, }}$ присоединенной к выходу ПЧ.

Сдвиг по фазе входного тока относительно напряжения питающей сети, в зависимости от типа ПЧ, может быть либо функцией параметров нагрузки на выходе, либо может регулироваться в определенных пределах независимо от этих параметров.

Мы рассматриваем двухзвенные преобразователи частоты (ДПЧ) со звеном постоянного тока, которые обладают свойством пропускать поток энергии через себя в обоих направлениях. Такой идеальный ПЧ, обладающий функциональной гибкостью и имеющий в некотором приближении синусоидальные напряжение и ток на входе и на выходе, подобен трансформатору, способному преобразовывать напряжение $U_{m \text { вх }}$, также часто-

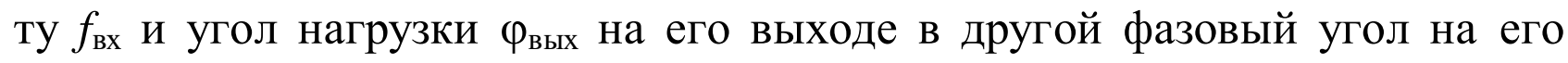


входе [86], как показано на рис. 3.1. Здесь многофазный источник синусоидального напряжения $u_{\mathrm{Bx}}=U_{m \text { вх }} \sin \left(\omega_{\mathrm{Bx}} t\right)$ присоединен к входу ПЧ. Это напряжение преобразуется в выходное (в общем случае - многофазное) напряжение $u_{\text {вых }}=U_{m \text { вых }} \sin \left(\omega_{\text {вых }} t\right)$, которое прикладывается к нагрузке $Z_{\mathrm{H}}$. В частном случае, это может быть нагрузка постоянного тока. Идеальный ПЧ не имеет потерь, так как активная мощность на его входе равна активной мощности на его выходе.

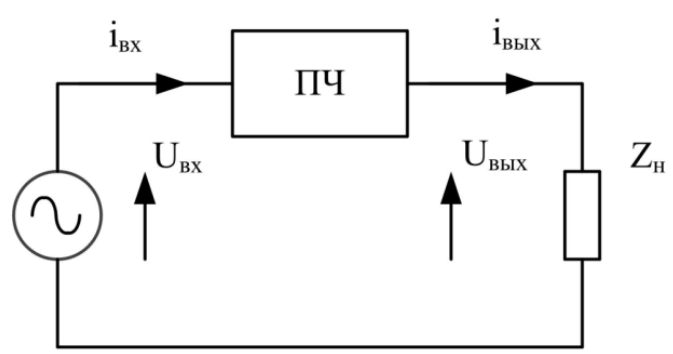

\section{Рис. 3.1. Схема включения идеального ПЧ}

Со стороны выхода преобразователь частоты вместе с входным источником переменного напряжения $u_{\text {вх }}$ можно рассматривать как эквива-

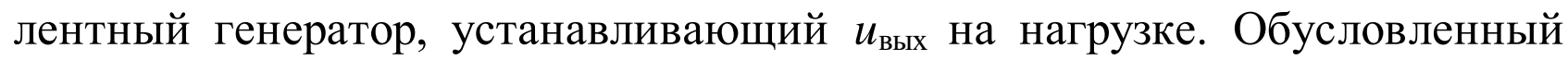
эти напряжением выходной ток $i_{\text {вых }}=I_{m \text { вых }} \sin \left(\omega_{\text {вых }} t+\varphi_{\text {вых }}\right)$ протекает через $Z_{\text {н }}$, при этом комплексная величина $Z_{\text {н }}$ определяет величины $I_{m \text { вых }}$ и $\varphi_{\text {вых}}$.

Если и процессы преобразования частоты рассматривать в обратном направлении - от выхода к входу, то ПЧ преобразует выходной ток с частотой $f_{\text {выx }}$ во входной ток с частотой $f_{\text {вx }}: i_{\mathrm{BX}}=I_{m \text { вх }} \sin \left(\omega_{\mathrm{BX}} t+\varphi_{\mathrm{BX}}\right)$.

Независимо от схемы ПЧ активные мощности на входе

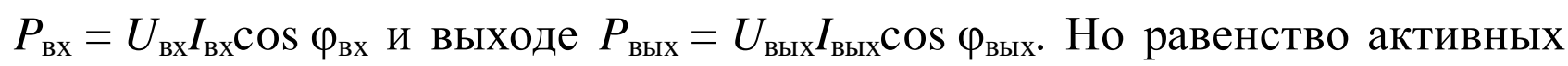
мощностей на входе и выходе ПЧ не определяет однозначно $I_{m \text { вх }}$ и $\varphi_{\text {вх }}$, так как эти величины зависят от передаточной функции для тока или полного сопротивления. Таким образом, со стороны входа такой идеальный ПЧ может рассматриваться как полное сопротивление, потребляющее от источника питания с напряжением $u_{\mathrm{Bx}}$ активную мощность $P_{\mathrm{Bx}}$, равную активной мощности нагрузки $P_{\text {вых }}$ при фазовом угле $\varphi_{\text {вх }}$, который может устанавливаться независимо.

В настоящее время продолжаются разработки и промышленный выпуск активных выпрямителей и активных фильтров гармоник на их основе. Принцип работы активного выпрямителя базируется на использовании свойств автономного инвертора напряжения (тока), который дополнен диодами для преобразования переменного напряжения сети в постоянное и заряда конденсатора (обеспечения тока через дроссель). Заряженный конденсатор или индуктивность с «неизменным» током становится источником питания инвертора. Такой инвертор преобразует постоянное 
напряжение на конденсаторе (ток через индуктивность) в переменное регулируемое по величине амплитуды и по фазе напряжение (ток) по отношению вектора сетевого напряжения, реализуя векторное управление противо - ЭДС на своих зажимах.

Подсистемы силовой части активного фильтра гармоник, основанные на инверторе тока и инверторе напряжения с широтно-импульсной модуляцией (ШИМ). Со стороны цепи постоянного тока к силовому преобразователю подключен элемент хранения энергии (конденсатор для инвертора напряжения и индуктивность для инвертора тока) $[78,79]$.

Рассмотрим силовые схемы активных фильтров.

1. Однофазный активный фильтр:

- Однофазный параллельный активный фильтр с емкостным накопителем энергии (рис. 3.2) [129].

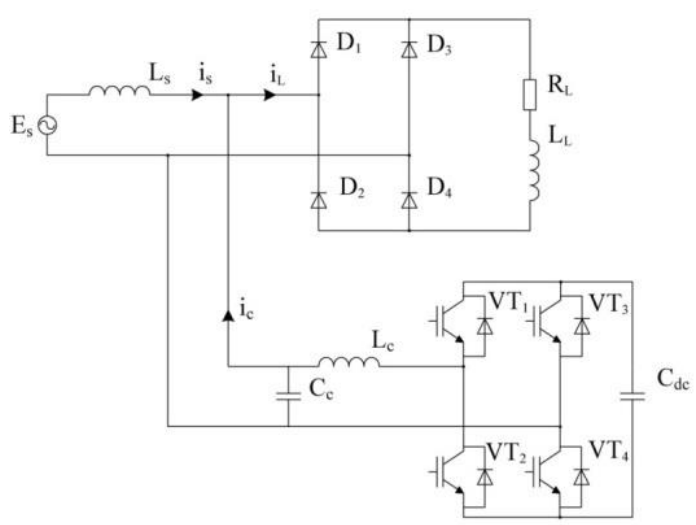

Рис. 3.2. Однофазный параллельный активный фильтр с емкостным накопителем энергии

- Однофазный параллельный активный фильтр с индуктивным накопителем энергии (рис. 3.3) [128].

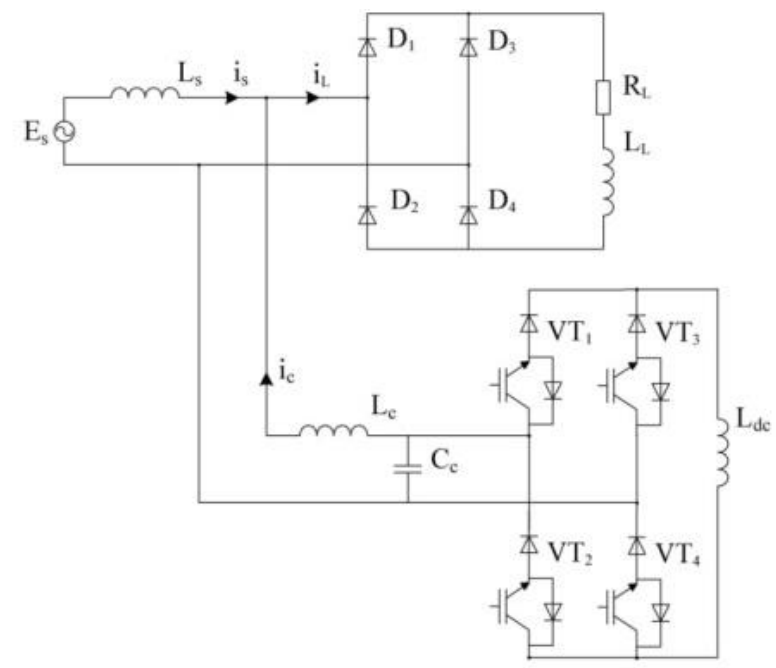

Рис. 3.3. Однофазный параллельный активный фильтр с индуктивным накопителем энергии 
- Однофазный последовательный активный фильтр с емкостным накопителем энергии (рис. 3.4) [120].

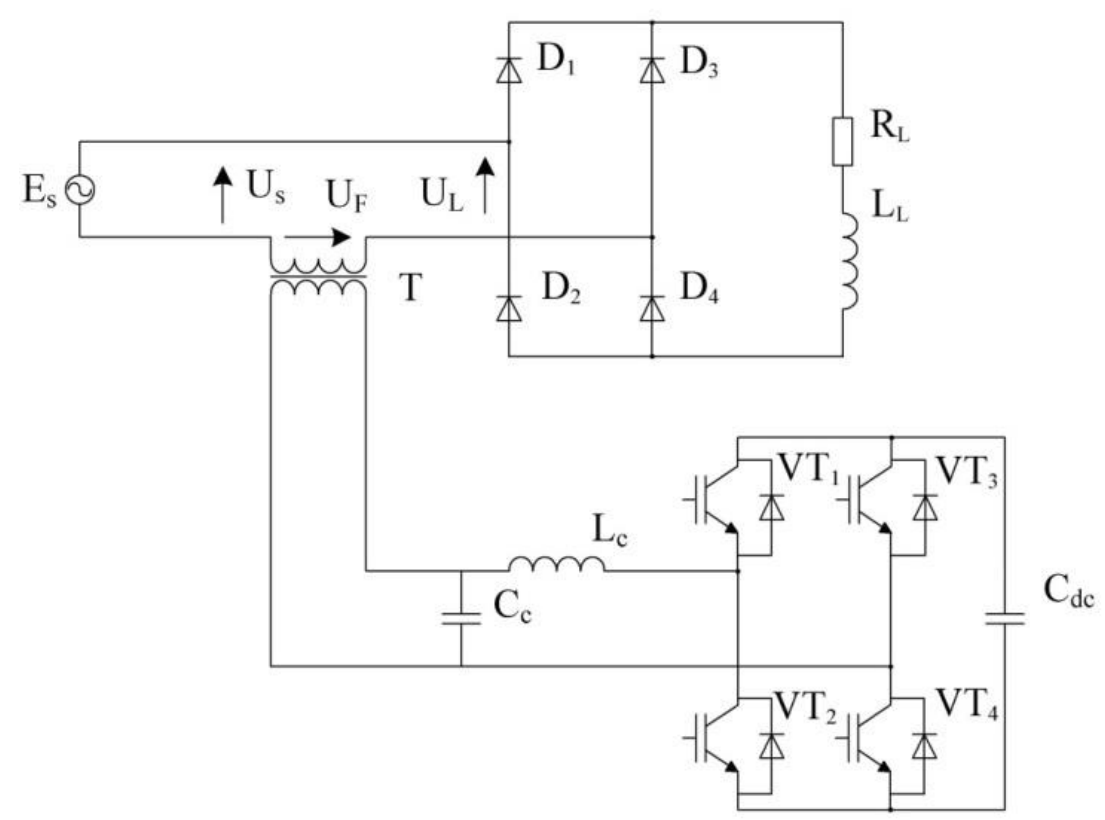

Рис. 3.4. Однофазный последовательный активный фильтр с емкостным накопителем энергии

- Однофазный последовательный активный фильтр с индуктивным накопителем энергии (рис. 3.5) [113].

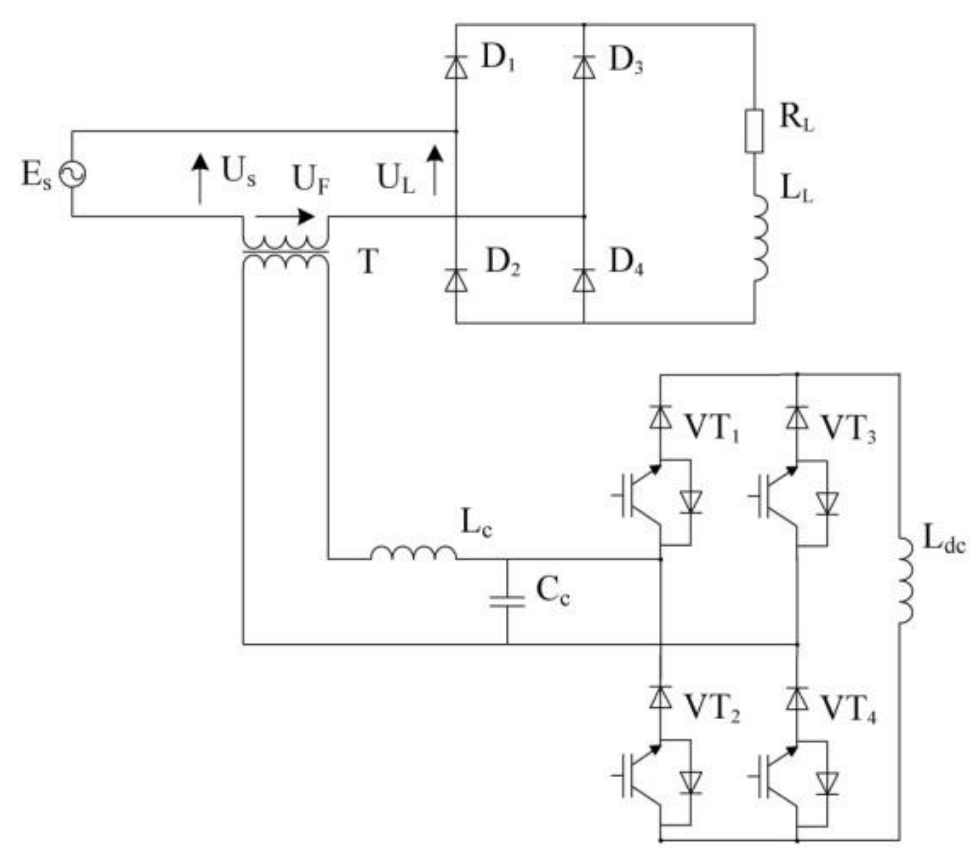

Рис. 3.5. Однофазный последовательный активный фильтр с индуктивным накопителем энергии

- Однофазный последовательно - параллельный (гибридный) активный фильтр (рис. 3.6) [118]. 


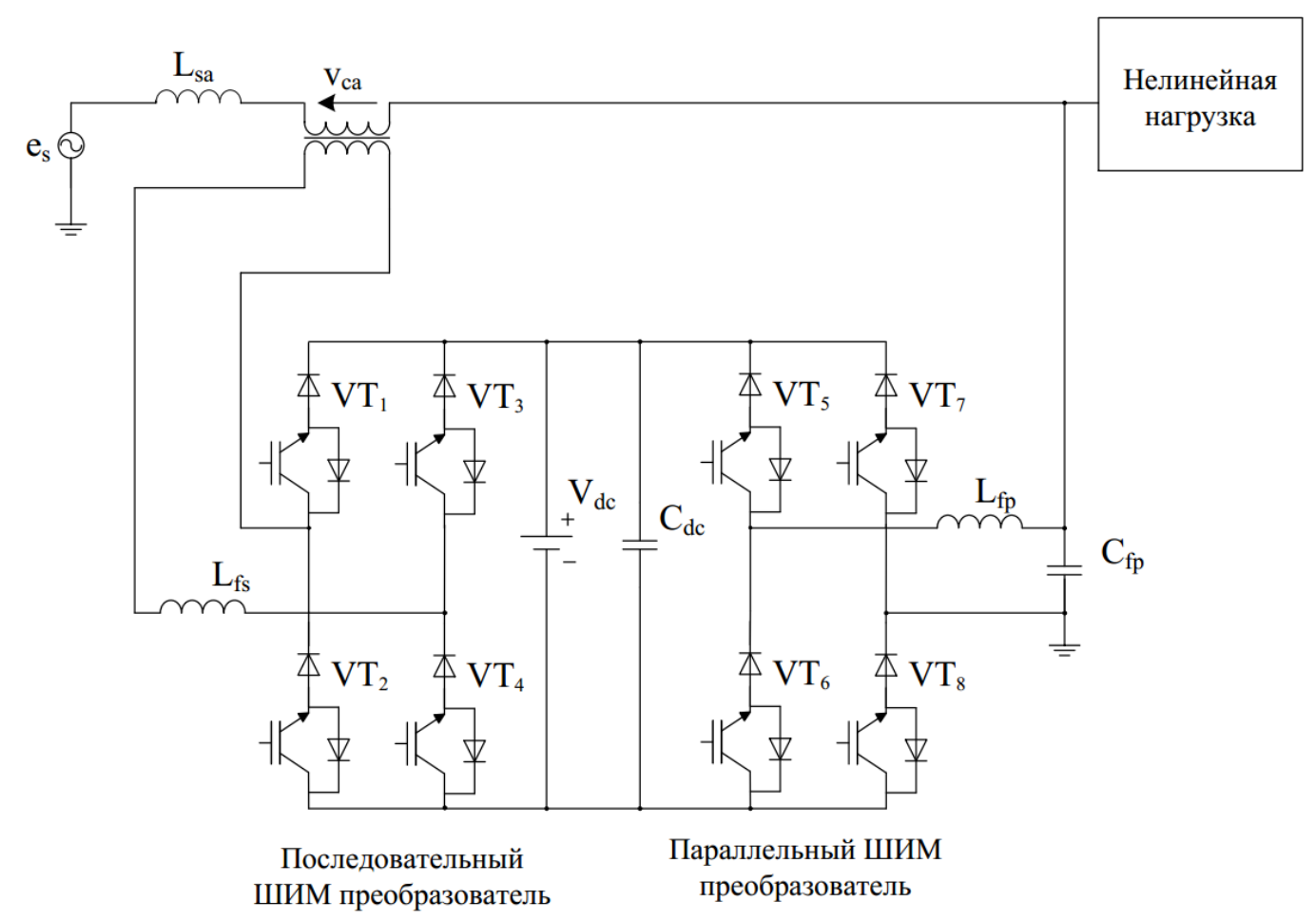

Рис. 3.6. Однофазный последовательно - параллельный (гибридный) активный фильтр

2. Трехфазный активный фильтр:

- Трехфазный трехпроводной параллельный активный фильтр с емкостным накопителем энергии (рис. 3.7) [126].

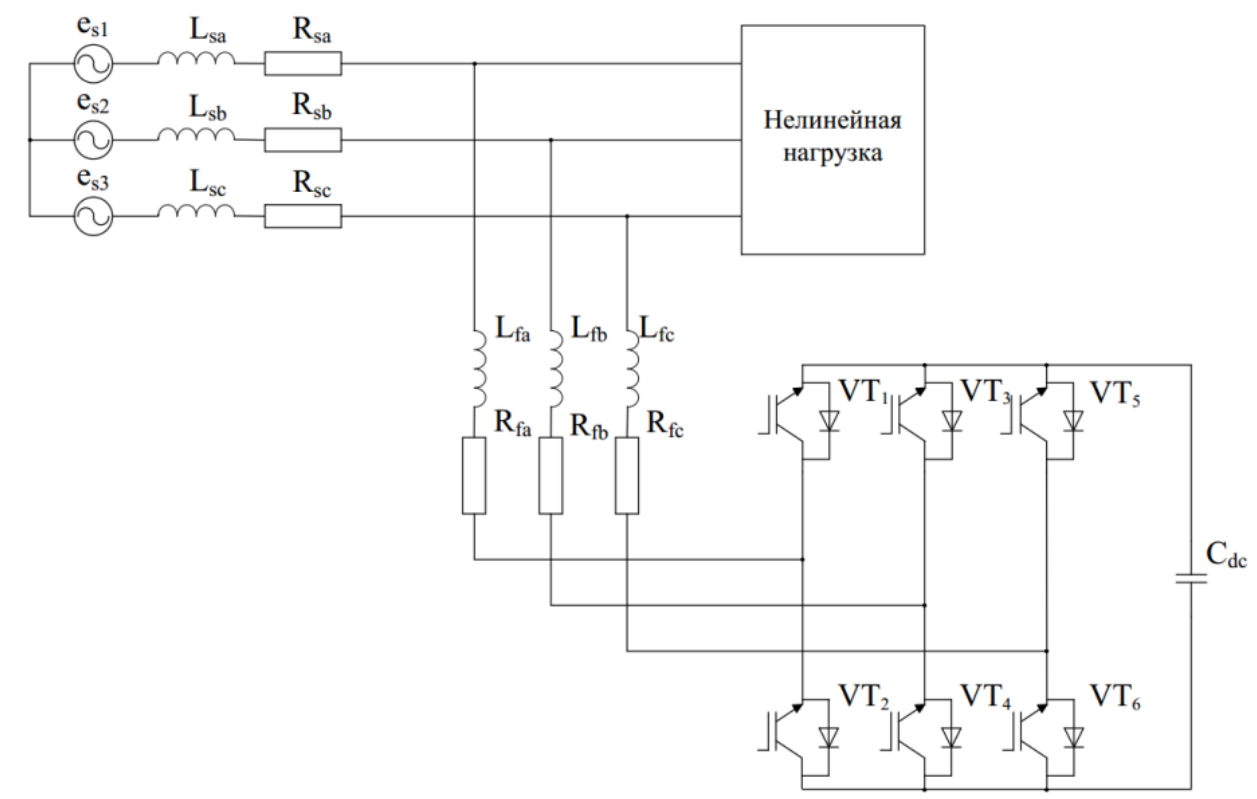

Рис. 3.7. Трехфазный трехпроводной параллельный активный фильтр с емкостным накопителем энергии

- Трехфазный трехпроводной параллельный активный фильтр с индуктивным накопителем энергии (рис. 3.8) [130]. 


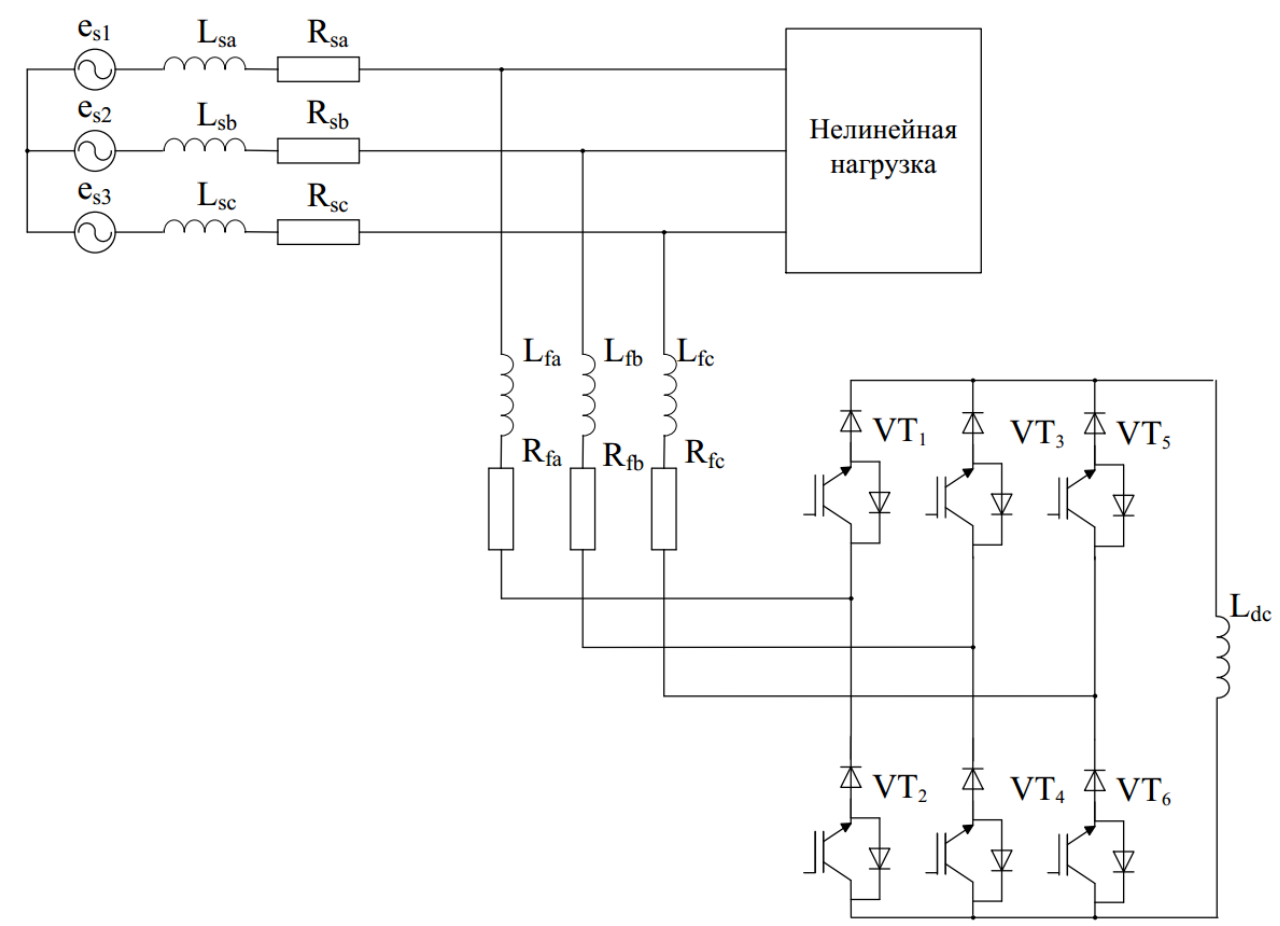

Рис. 3.8. Трехфазный трехпроводной параллельный активный фильтр с индуктивным накопителем энергии

- Трехфазный трехпроводной последовательный активный фильтр [134] (рис. 3.9).

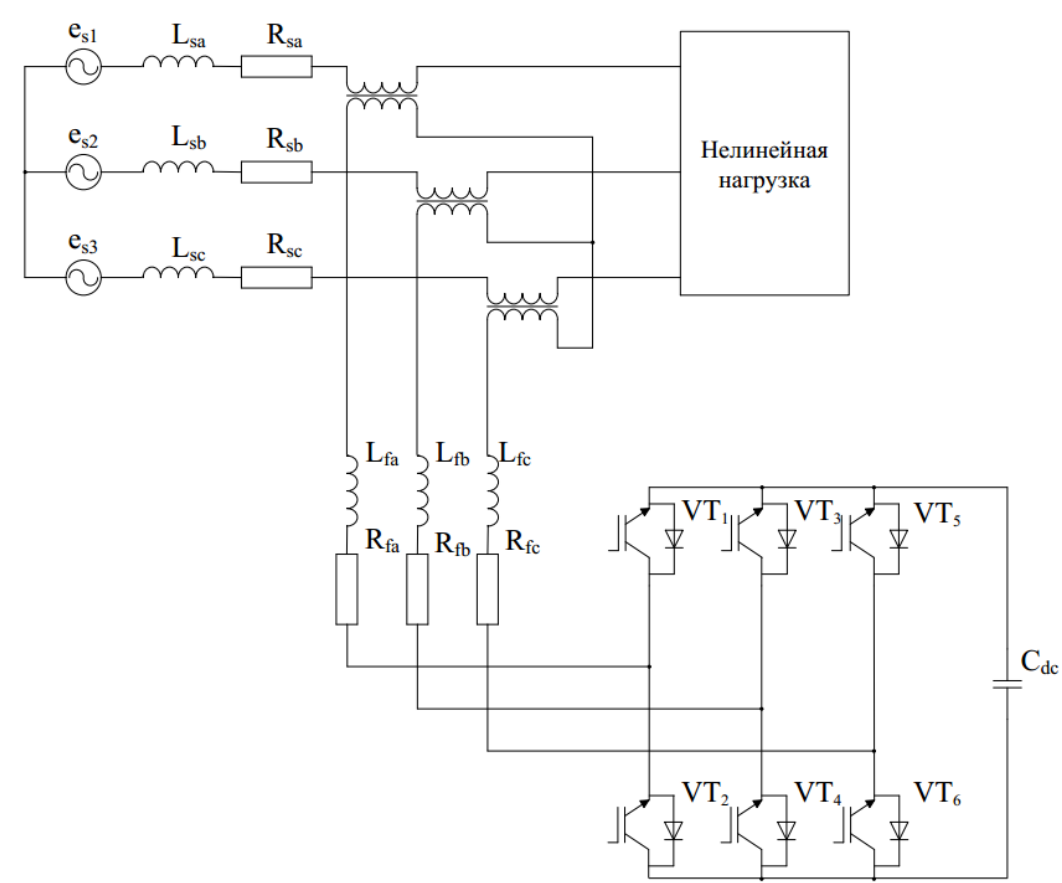

Рис. 3.9. Трехфазный трехпроводной последовательный активный фильтр с емкостным накопителем энергии

- Трехфазный трёхпроводной последовательно-параллельный (гибридный) активный фильтр гармоник с емкостным накопителем энергии (рис. 3.10) [119]. 


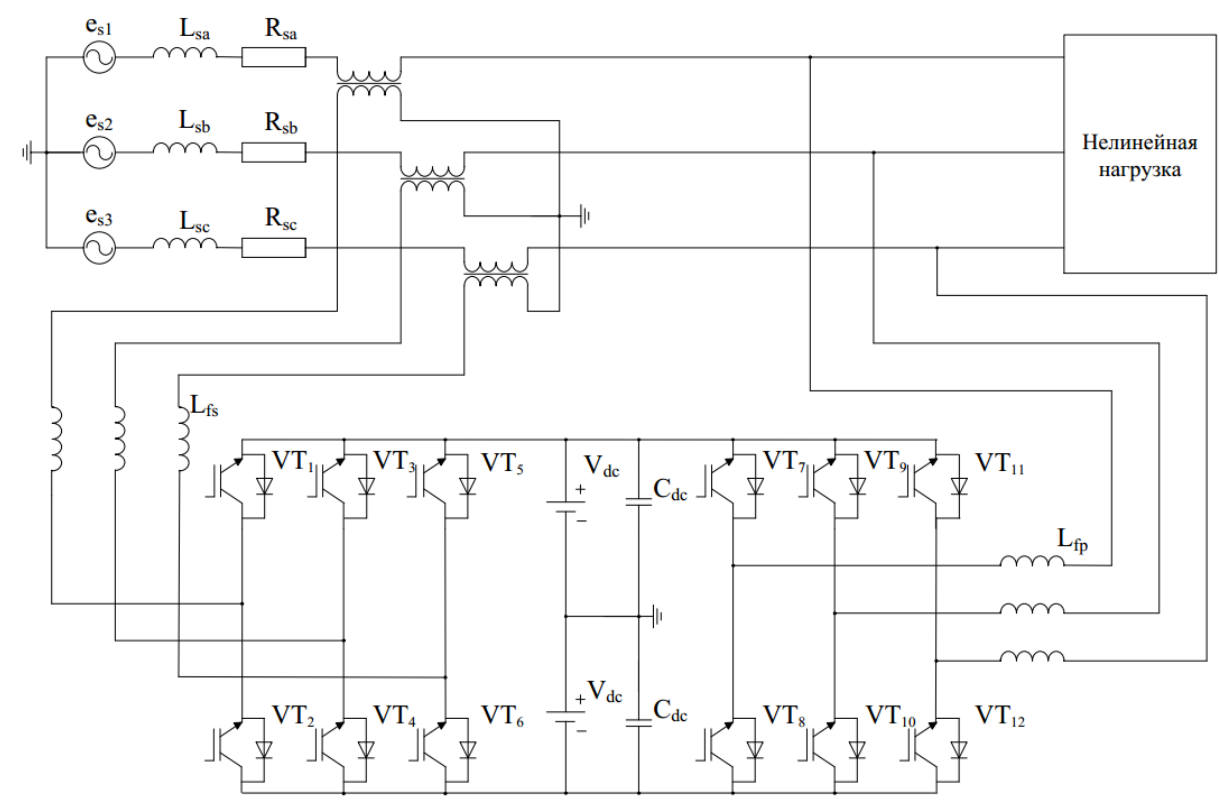

Рис. 3.10. Трехфазный трехпроводной последовательно-параллельный активный фильтр с емкостным накопителем энергии

• Трехфазный трёхпроводной гибридный активный фильтр гармоник с индуктивным накопителем энергии (рис. 3.11) [125].

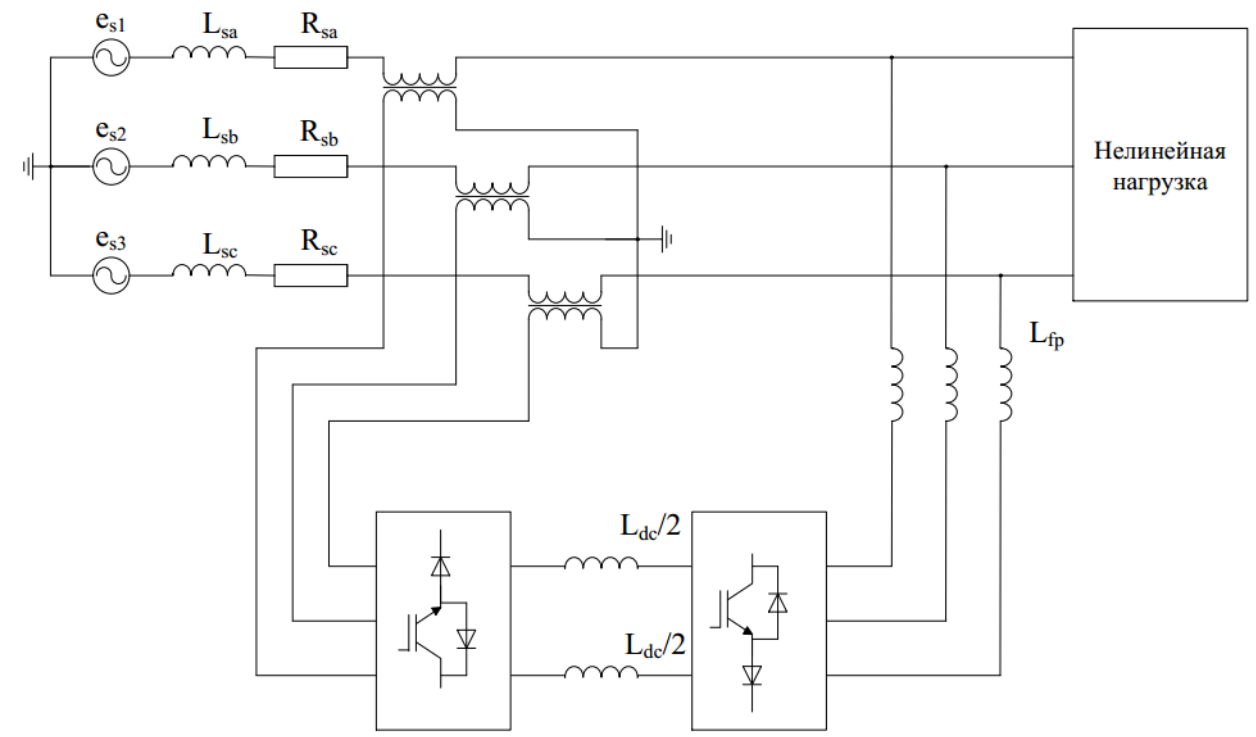

Рис. 3.11. Трехфазный трехпроводной активный фильтр с индуктивным накопителем энергии

Данные схемы используются для устранения искажений сетевого тока и напряжения в узле нагрузки, создаваемых электроприёмниками с нелинейной характеристикой, например выпрямителем с большой индуктивностью на стороне постоянного тока. Это свойство может быть обусловлено выходным фильтром либо индуктивностью системы возбуждения синхронного двигателя или двигателя постоянного тока. Преимуществом использования инверторов напряжения в силовой части АФГ является высокое быстродействие и меньшая стоимость. ШИМ регулято- 
ры тока или напряжения в обоих случаях имеют одинаковую функциональность, чтобы преобразователь вел себя как управляемый источник тока, или соответственно, напряжения.

ШИМ-преобразователи создают нежелательные гармоники тока с частотами переключения ключей и кратные им. Если частота переключения ШИМ-преобразователя достаточно высока, эти нежелательные гармоники тока можно легко отфильтровать, используя пассивный фильтр верхних частот, представленный как $R$ и $C$.

Регуляторы параллельного активного фильтра гармоник вычисляют в реальном времени компенсационный ток и управляют силовым преобразователем таким образом, чтобы ток был компенсирован точно. Контроллеры параллельного активного фильтра работают с обратной связью, непрерывно измеряя ток нагрузки $i_{n}$, и рассчитывая мгновенные значения компенсационного тока $i^{*}$ д для широтно-импульсного модулирования. В случае высокой частоты модуляции преобразователь с ШИМ может рассматриваться как линейный усилитель мощности, в котором компенсационный ток $i_{C}$ соответствует току задания $i^{*}{ }_{C}$.

\section{2. Определение требований к параметрам активного фильтра гармоник}

Структурная схема АФГ показана на рис. 3.12. АФГ предназначен для компенсации высших гармонических составляющих и интергармоник тока и напряжения в эквивалентных элементах нагрузки $Z_{\text {эab }}, Z_{\text {эbc }}, Z_{\text {эса }}$ основных электроприемников, требующих синусоидального напряжения питания, а также в элементах $Z_{\text {ла }}, Z_{\text {ль }}, Z_{\text {лс }}$, отображающих параметры источников энергии и линии связи системы электроснабжения.

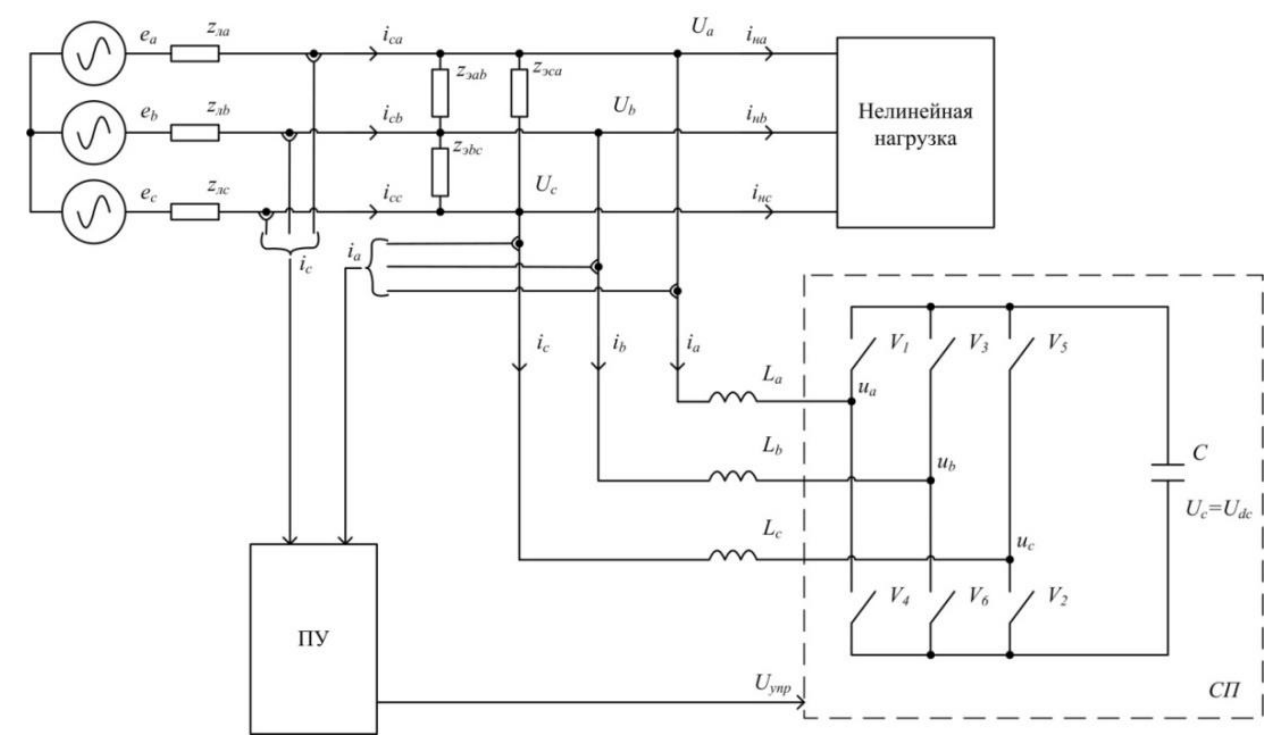

Рис. 3.12. Структурная схема активного фильтра гармоник 
Компенсационный ток зависит от состояний каждого из силовых ключей, которые приведены в табл. 3.1.

Состояние ключей силовой подсистемы АФГ

Таблица 3.1

\begin{tabular}{|c|c|c|c|c|c|c|c|c|c|}
\hline \multirow{2}{*}{$\begin{array}{c}\text { № состоя- } \\
\text { ния } k\end{array}$} & \multicolumn{7}{|c|}{ Силовые ключи } & \multicolumn{3}{|c|}{$\begin{array}{c}\text { Коэффициенты пере- } \\
\end{array}$} & $V_{1}$ & $V_{2}$ & $V_{3}$ & $V_{4}$ & $V_{5}$ & $V_{6}$ & $k_{a}$ & $k_{b}$ & $k_{c}$ \\
\hline 0 & 0 & 1 & 0 & 1 & 0 & 1 & 0 & 0 & 0 \\
\hline 1 & 0 & 0 & 0 & 1 & 1 & 1 & $-1 / 3$ & $-1 / 3$ & $2 / 3$ \\
\hline 2 & 0 & 1 & 1 & 1 & 0 & 0 & $-1 / 3$ & $2 / 3$ & $-1 / 3$ \\
\hline 3 & 0 & 0 & 1 & 1 & 1 & 0 & $-2 / 3$ & $1 / 3$ & $1 / 3$ \\
\hline 4 & 1 & 1 & 0 & 0 & 0 & 1 & $2 / 3$ & $-1 / 3$ & $-1 / 3$ \\
\hline 5 & 1 & 0 & 0 & 0 & 1 & 1 & $1 / 3$ & $-2 / 3$ & $1 / 3$ \\
\hline 6 & 1 & 1 & 1 & 0 & 0 & 0 & $1 / 3$ & $1 / 3$ & $-2 / 3$ \\
\hline 7 & 1 & 0 & 1 & 0 & 1 & 0 & 0 & 0 & 0 \\
\hline
\end{tabular}

Преобразователь с ШИМ должен иметь ключи с высокой частотой переключения - $f_{P W M}$ для того, чтобы точно отрабатывать задание на создание тока компенсации. Приемлемым считается $f_{P W M}>10 f_{h \max }$, где $f_{h \max }-$ частота высшей гармоники тока, которая должна быть компенсирована, исходя из этого условия, рассмотрим различные типы силовых ключей относительно применимости их в силовой подсистеме, табл. 3.2 [82].

Таблица 3.2

\section{Сравнительные характеристики ключевых приборов}

\begin{tabular}{|c|c|c|}
\hline $\begin{array}{c}\text { Тип силового } \\
\text { ключа }\end{array}$ & Преимущества & Недостатки \\
\hline $\begin{array}{l}\text { IGCT (тиристор c } \\
\text { интегрированным } \\
\text { управлением) }\end{array}$ & $\begin{array}{l}\text { Малое падение напряжения в } \\
\text { проводящем состоянии } 2.7 \text { В } \\
\text { Встроенный блок управления } \\
\text { Средняя частота переключения } \\
500 \text { Гц }\end{array}$ & $\begin{array}{l}\text { Низкие частотные свойства } \\
d u / d t=100-300 \mathrm{~B} / \text { мкс } \\
d i / d t=100-300 \mathrm{~A} / \text { мкс }\end{array}$ \\
\hline $\begin{array}{l}\text { IGBT } \\
\text { (биполярный } \\
\text { транзистор } \quad \mathrm{c} \\
\text { изолированным } \\
\text { затвором) }\end{array}$ & $\begin{array}{l}\text { Встроенный блок управления } \\
\text { Рабочая частота до } 100 \text { кГц } \\
\text { Простая система управления } \\
-d u / d t=1000-2000 \mathrm{~B} / \text { мкс } \\
-d i / d t=1000-2000 \mathrm{~A} / \text { мкс }\end{array}$ & \begin{tabular}{lcr} 
Высокие & потери \\
включенном & \multicolumn{2}{c}{ состоянии } \\
(падение & напряжения в \\
открытом состоянии до 3.2 В)
\end{tabular} \\
\hline
\end{tabular}

Из анализа данных табл. 3.2 следует, что для реализации силовой подсистемы могут в настоящее время использоваться только IGBT приборы.

Энергообменный конденсатор $C$ предназначен для обеспечения компенсационного тока в непосредственной близости от нелинейной нагруз- 
ки, благодаря чему ток, обусловленный высшими гармониками и интергармониками, не будет потребляться от источника $e_{a}, e_{b}, e_{c}$.

Напряжение на конденсаторе на стороне постоянного тока должно быть с минимальными пульсациями и достаточным, чтобы обеспечивать компенсацию неактивных составляющих тока АФГ. Искажение напряжения на конденсаторе вызваны активными потерями в СП и мощностью искажений нелинейной нагрузки. Большая емкость благоприятна, так как позволяет стабилизировать напряжение на конденсаторе в установившемся режиме. Но увеличение емкости приведет к большему объему и большей стоимости конденсатора [83].

В симметричной системе электроснабжения действуют напряжения, для которых справедливо

$$
e_{a}+e_{b}+e_{c}=0
$$

и ток сети

$$
i_{c a}+i_{c b}+i_{c c}=0 .
$$

Поэтому описать работу АФГ можно следующими дифференциальными уравнениями:

$$
\left\{\begin{array}{l}
L_{a} \frac{d i_{a}}{d t}=U_{a}-u_{a} \\
L_{b} \frac{d i_{b}}{d t}=U_{b}-u_{b} \\
L_{c} \frac{d i_{c}}{d t}=U_{c}-u_{c}
\end{array}\right.
$$

гдеи $u_{a}, u_{b}, u_{c}$ - выходные напряжения АФГ - вычисляются как $u_{a}=k_{a} U_{c}$, $u_{b}=k_{b} U_{c}, u_{c}=k_{c} U_{c}$, где $k_{a}, k_{b}, k_{c}$ - коэффициенты переключения.

Как видно из табл. 3.1, при любом состоянии $k$ сумма $k_{a}+k_{b}+k_{c}=0$. Таким образом, выходные напряжения АФГ соответствуют требованиям к симметричной системе трехфазных напряжений.

Включение-выключение коммутационного прибора в АФГ определяется знаком $\Delta i_{a}$ в текущий момент. Например, для фазы $A, k_{a}<0$, когда $\Delta i_{a a}>0$; и, наоборот, $k_{a}>0$, когда $\Delta i_{a a}<0$. Таким образом, ошибка между рассчитанным током и фактическим током может быть снижена, и компенсационный ток будет приближен к рассчитанному току.

Рассмотрим случай, когда номер состояния силовой подсистемы $k=5$, тогда ток фазы $A$ и фазы $C$ должен уменьшаться, а в фазе $B$ увеличиваться. Ключ $V_{1}$ фазы $A$, ключ $V_{5}$ фазы $C$ и ключ $V_{6}$ фазы $B$ - замкнуты. Коэффициент переключения каждого плеча моста может быть учтен из таблицы $1: k_{a}=1 / 3, k_{b}=-2 / 3, k_{c}=1 / 3$. Тогда (3.1) можно записать как: 


$$
\left\{\begin{array}{l}
L_{a} \frac{d i_{a}}{d t}=U_{a}-\frac{1}{3} U_{d c} \\
L_{b} \frac{d i_{b}}{d t}=U_{b}+\frac{2}{3} U_{d c} \\
L_{c} \frac{d i_{c}}{d t}=U_{c}-\frac{1}{3} U_{d c}
\end{array}\right.
$$

Управляемые токи $i_{a}, i_{c}$ должны уменьшаться и $i_{b}$ увеличиваться. Дифференциальные токи АФГ должны удовлетворять следующим выражениям [83]:

$$
\frac{d i_{a}}{d t} \leq 0, \frac{d i_{b}}{d t} \geq 0, \frac{d i_{c}}{d t} \leq 0 .
$$

Мощность искажения $T_{u}$, которая вызывает изменение напряжения на конденсаторе на стороне постоянного тока, может быть рассчитана следующим выражением [106, 114]:

$$
T_{u}=\sqrt{3} U \sum_{n=2}^{\infty} I_{n}=\mp \sqrt{3} U \sum_{n=2}^{\infty} I_{n H} \cos \left[(n \pm 1) \omega \cdot t+\varphi_{n}\right]
$$

где $U$ - действующее значение напряжения 1 -й гармоники источника.

Номера гармоник $n$ прямой последовательности вычисляются согласно выражению $n=6 k+1$, где $k$ - ряд натуральных чисел $(k=1,2,3 .$.$) .$ Номера гармоники $n$ обратной последовательности $n=6 k-1$.

В (3.2) верхний знак используется, если рассчитываются гармоники обратной последовательности, и нижний знак, если - прямой.

Рассмотрим случай, когда нелинейная нагрузка (рис. 3.12) - неуправляемый трехфазный мостовой выпрямитель. Спектр высших гармоник генерируемых выпрямителем определяется выражением $n=m k \pm 1$, где $m-$ пульсность выпрямителя.

Шестипульсный выпрямитель генерирует 5, 7, 11, 13, 17 и 19 гармоники. Тогда искажение напряжения на конденсаторе, вызванное этими гармониками может быть рассчитано из (3.2):

$$
\begin{aligned}
& T_{u} \approx \sqrt{3} U \cdot\left(-I_{5 H} \cos \left[6 \omega \cdot t+\varphi_{5}\right]+I_{7 H} \cos \left[6 \omega \cdot t+\varphi_{7}\right]-\right. \\
& -I_{11 H} \cos \left[12 \omega \cdot t+\varphi_{11}\right]+I_{13 H} \cos \left[12 \omega \cdot t+\varphi_{13}\right]- \\
& \left.-I_{17 H} \cos \left[18 \omega \cdot t+\varphi_{17}\right]+I_{19 H} \cos \left[18 \omega \cdot t+\varphi_{19}\right]\right) .
\end{aligned}
$$

Это искажение зависит главным образом от 5-й гармоники, т.е. от гармоники, имеющей наибольший период и наибольшую амплитуду. 
Поэтому период, на котором стабилизируется напряжение на конденсатоpe, должен составлять $T / 12$, где $T$-период сетевого напряжения. Мощность искажения $T_{u}$ компенсируется током АФГ, поэтому энергия на интервале $T / 12$, отдаваемая конденсатором $C$, за счет изменения напряжения $\Delta U_{d c}$, должна быть не менее энергии искажения на этом периоде. Емкость может быть рассчитана [108] с учетом (3.3) согласно выражению:

$$
\int_{0}^{T / 12} T_{u} d t=\frac{1}{2} C\left[U_{d c}+\Delta U_{d c}\right]^{2}-\frac{1}{2} C U_{d c}^{2} .
$$

С другой стороны, мощность искажения можно определить [93] как $T_{u}=S_{1} \cdot T H D_{i}$, где $S_{1}$ - полная мощность первой гармоники нелинейной нагрузки; $T H D_{i}$ - суммарное гармоническое искажение.

В $[93,94]$ определено $T H D_{i}$ для различных типов нелинейных нагрузок. Если нагрузка специфична, то величина $T H D_{i}$ определяется посредством измерений.

Ток, протекая по элементам силовой цепи преобразователя, вызывает дополнительные потери активной мощности. Поэтому необходимо учесть потери в инверторе АФГ. IGBT модули инвертора состоят из IGBT транзистора и параллельного диода. Потери на IGBT состоят из потерь в открытом состоянии $P_{s s}$ и потерь при переключении $P_{s w 1}$, потери на диоде складываются из потерь в открытом состоянии $P_{D}$ и потерь на выключение $P_{s w 2}$. Сумма потерь на IGBT модуле может быть выражена

$$
P_{A}=P_{s s}+P_{s w 1}+P_{s w 2}+P_{D}
$$

Потери IGBT в открытом состоянии

$$
P_{s S}=I_{C P} \cdot V_{C E}(s a t) \cdot\left(\frac{1}{8}+\frac{D}{3 \pi} \cdot \cos \varphi\right),
$$

где $I_{C P}$ - максимальное значение тока на выходе фазы; $V_{C E}(s a t)$ - падение напряжения насыщения IGBT ключа при максимальном токе $I_{C P}$ и температуре $T=125^{\circ} \mathrm{C} ; D$ - коэффициент модуляции; $\varphi$ - фазный угол между выходным напряжением и током.

Потери при переключении IGBT:

$$
P_{S w 1}=\left(E_{S W(O N)}+E_{S W(O F F)}\right) \cdot f_{S W} \cdot \frac{1}{\pi},
$$

где $E_{S W(O N)}$ и $E_{S W(O F F)}$ - энергии включения и выключения ключа за импульс при пиковой амплитуде тока и температуре $T=125^{\circ} \mathrm{C} ; f_{S W}$ - частота переключений. 
Потери диода в открытом состоянии

$$
P_{D}=I_{E P} \cdot V_{E C} \cdot\left(\frac{1}{8}-\frac{D}{3 \pi} \cdot \cos \varphi\right),
$$

где $I_{E P}$ - максимальное значение тока на выходе фазы; $V_{E C}$ - прямое падение напряжения при токе $I_{E P}$.

Потери при выключении диода

$$
P_{s w 2}=0,125 \cdot I_{r r} \cdot t_{r r} \cdot V_{C E}(p k) \cdot f_{S W},
$$

где $I_{r r}$ - пиковый ток восстановления диода; $t_{r r}$ - время обратного восстановления диода; $V_{C E}(p k)$ - пиковое напряжение диода.

В табл. 3.3 приведен расчет потерь $P_{A}$ в СП АФГ, выполненной на IGBT модулях CM75DU-24F, при мощности нелинейной нагрузки 320кBA и частоте коммутаций 10 кГц.

Таблица 3.3

Потери в СП АФГ

\begin{tabular}{|c|c|c|c|}
\hline$P_{s s}, \mathrm{BT}$ & $P_{s w 1}, \mathrm{BT}$ & $P_{D}, \mathrm{BT}$ & $P_{s w 2}, \mathrm{BT}$ \\
\hline 134,16 & 266,64 & 27 & 145,38 \\
\hline
\end{tabular}

С учетом (3.5) емкость может быть рассчитана:

$$
\int_{0}^{T / 12}\left(T_{u}+P_{A}\right) d t=\frac{1}{2} C\left[U_{d c}+\Delta U_{d c}\right]^{2}-\frac{1}{2} C U_{d c}{ }^{2},
$$

Следовательно,

$$
C=2 \frac{\int_{0}^{T / 12}\left(T_{u}+P_{A}\right) d t}{\Delta U_{d c}\left(\Delta U_{d c}+2 U_{d c}\right)} .
$$

Формула (3.6) позволила получить следующие зависимости емкости конденсатора (мФ) от мощности преобразователя (кВА) (сплошная линия, левая ось ординат) и емкости конденсатора, необходимой для компенсации потерь в СП АФГ (штриховая линия, правая ось ординат).

На рис. 3.13 показана зависимость емкости накопительного конденсатора от мощности преобразователя нагрузки. С одной стороны, емкость конденсатора линейно зависит от компенсируемой мощности нелинейной нагрузки, а с другой, емкость конденсатора, необходимая для компенса- 
ции потерь в IGBT модуле, зависит от параметров модуля и частоты коммутации, и мало зависит от величины компенсационного тока. Эта емкость незначительна, ее можно не учитывать при проектировании АФГ.

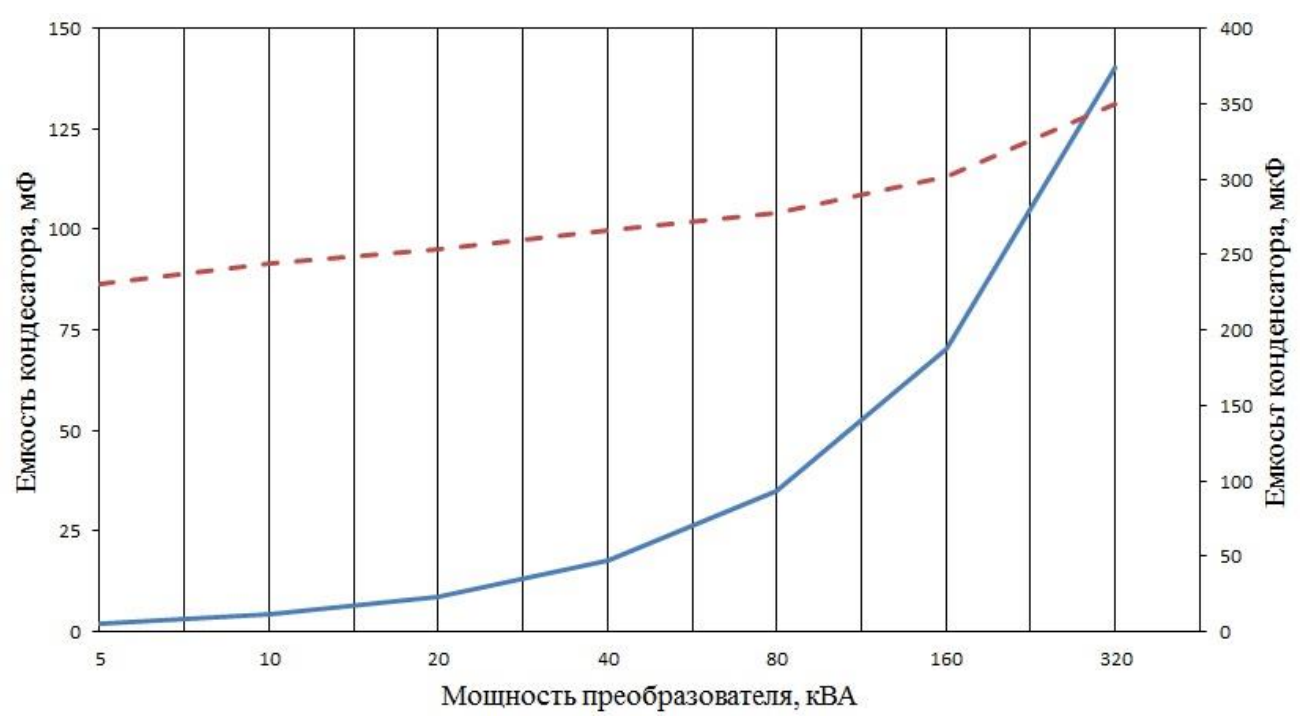

Рис. 3.13. Зависимость емкости накопительного конденсатора от мощности преобразователя нагрузки

\section{3. Учет потерь и генерируемой мощности искажений электромеханического фильтра при определении установленной мощности активного компенсирующего устройства}

Мощность искажений, генерируемая при создании виброгасящих пульсаций электромагнитного момента двигателя, либо генератора автономной электростанции, определяемая высшими гармоническими составляющими тока, должна быть учтена при нахождении допустимых величин активной и реактивной мощностей, потребляемых из сети, которые равны соответствующим мощностям на входе АКУ. В роли АКУ в первом случае выступает автономный инвертор напряжения или тока, питающий приводной двигатель, а во втором случае - генераторный инвертор, обеспечивающий необходимые параметры электроэнергии автономной электростанции.

Компенсация неактивных составляющих мощности и намеренное формирование искажений выходного тока с целью гашения вибраций являются одной из форм влияния рассматриваемых преобразователей на сеть. Это влияние зависит от степени регулирования выпрямленного напряжения на выходе звена постоянного тока [10]. При этом полная мощность, потребляемая преобразователем из сети, коэффициент мощности преобразователя и активная мощность на входе АКУ находятся в соотношениях 


$$
S=m U_{\phi} I_{\phi}, k_{\mathrm{M}}=\frac{\sqrt{6} N}{2 \pi k_{\phi}} C_{p}, P_{(1)}=m U_{\phi} I_{\phi(1)} \cos \varphi,
$$

где $m$ - число фаз сети; $U_{\phi}$ - действующее значение фазного напряжения сети; $I_{\phi}$ - действующее значение тока фазы сети; $N$ - число 3 фазных схем с нулевым выводом, на которые можно разложить преобразователь; $k_{\phi}=I_{\phi} / I_{d}$ - коэффициент формы тока; $C_{\mathrm{p}}=U_{d} / U_{d 0}$ - степень регулирования выпрямленного напряжения; $I_{\phi(1)}$ - действующее значение первой гармоники сетевого тока; $\cos \varphi$ - коэффициент сдвига первой гармоники сетевого тока относительно напряжения сети.

Коэффициент мощности $k_{\mathrm{M}}$ зависит, с одной стороны, от степени регулирования выходного напряжения выпрямителя $C_{\mathrm{p}}$, с другой, - от коэффициента сдвига $\cos \varphi$ и коэффициента искажений сетевого тока $k_{\text {и }}$ :

$$
k_{\mathrm{M}}=\frac{\sqrt{6} N}{2 \pi k_{\phi}} C_{p}=\frac{I_{\phi(1)}}{I_{\phi}} \cos \varphi=k_{\mathrm{и}} \cos \varphi
$$

учитывая, что

$$
k_{\text {и }}=\frac{I_{\phi(1)}}{I_{\phi}}=\frac{I_{\phi(1)}}{\sqrt{I_{\phi(1)}^{2}+\sum_{k=2}^{40} I_{\phi(k)}^{2}}}=\frac{1}{\sqrt{1+T H D_{\text {o.e. }}^{2}}},
$$

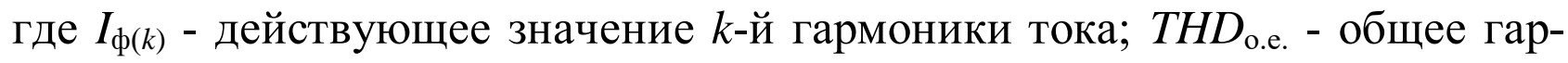
моническое искажение, выраженное в относительных единицах.

Многие авторы, в том числе [52], отмечают, что мощность искажения есть всегда и мало зависит от способа управления преобразователем. Однако следует принять во внимание, что высшие гармонические составляющие трудно учитывать, они более подвержены влиянию случайных факторов из-за колебаний напряжения сети и нагрузки.

Для характеристики качества преобразования тока достаточно регрессионных оценок. В качестве такой оценки удобно использовать $T H D_{\text {о.е. }}$ :

$$
T H D_{\text {o.e. }}=\frac{\sqrt{\sum_{k=2}^{\infty} I_{(k)}^{2}}}{I_{(1)}},
$$

где $I_{(k)}$ и $I_{(1)}$ - действующие (или амплитудные) значения $k$-й и 1-й гармоник тока. 
В отечественной практике для оценки гармонического состава тока используют коэффициент искажения $k_{\mathrm{r}}$ :

$$
k_{\mathrm{H}}=\frac{I_{(1)}}{I} 100 \% \text {. }
$$

где $I$ - действующее значение тока фазы.

$T H D$ и $k_{\text {и }}$ в относительных единицах $\left(T H D_{\text {о.е. }}\right.$ и $\left.k_{\text {ио.е. }}\right)$ связаны соотношением [94]

$$
T H D_{\text {о.е. }}=\frac{\sqrt{1-k_{\text {и о.е. }}^{2}}}{k_{\text {и о.е. }}} .
$$

Таким образом, мощность искажения $T$ с учетом (3.11)

$$
T=U I \sqrt{1-k_{\text {и о.е. }}^{2}}=S_{(1)} \frac{1}{k_{\text {и o.e. }}} \sqrt{1-k_{\text {и о.e. }}^{2}}=S_{(1)} \sqrt{1-\frac{1}{k_{\text {и о.e. }}^{2}}}=S_{(1)} T H D_{\text {o.e. }},
$$

где $S_{(1)}=\sqrt{P_{(1)}^{2}+Q_{(1)}^{2}}$ - полная мощность первой гармоники тока и напряжения.

Для повышения точности расчетов установленной мощности АКУ необходимо, помимо расчетов мощности гармонических искажений, рассчитывать приблизительное значение потерь мощности на электродвигателе:

$$
S_{\text {уст }} \geq \sqrt{P_{(1)}^{2}+Q_{(1)}^{2}+\left(S_{\text {уст }} \cdot T H D_{\text {o.e. }}\right)^{2}+\Delta P^{2}},
$$

где $\Delta P$ - суммарные потери в асинхронном двигателе.

Обычно асинхронные двигатели конструируют так, чтобы при номинальном режиме они имели КПД и $\cos \varphi$, близкие к максимальным. Кроме того, максимум КПД достигается, когда постоянные потери механические и в стали равны переменным потерям в обмотках [58].

Из рис. 3.14 видно, что при снижении напряжения питания больше чем в два раза от номинального при неизменной нагрузке значение КПД начинает резко снижаться. На этом же рисунке приведены кривые зависимостей КПД от напряжения сети для двух значений потребляемой мощности двигателя. Каждой нагрузке соответствует оптимальное напряжение, при котором постоянные потери равны переменным. Чем меньше нагрузка, тем меньше оптимальное значение напряжения. 
Таким образом, желательно при частичных нагрузках снижать напряжение питания, для того чтобы КПД поддерживать на высоком уровне. Изложенное относится к нерегулируемым асинхронным двигателям и справедливо для двигателей в составе частотно- регулируемого электропривода при номинальной угловой скорости, поскольку для этого режима и рассматривается установленная мощность преобразователя.

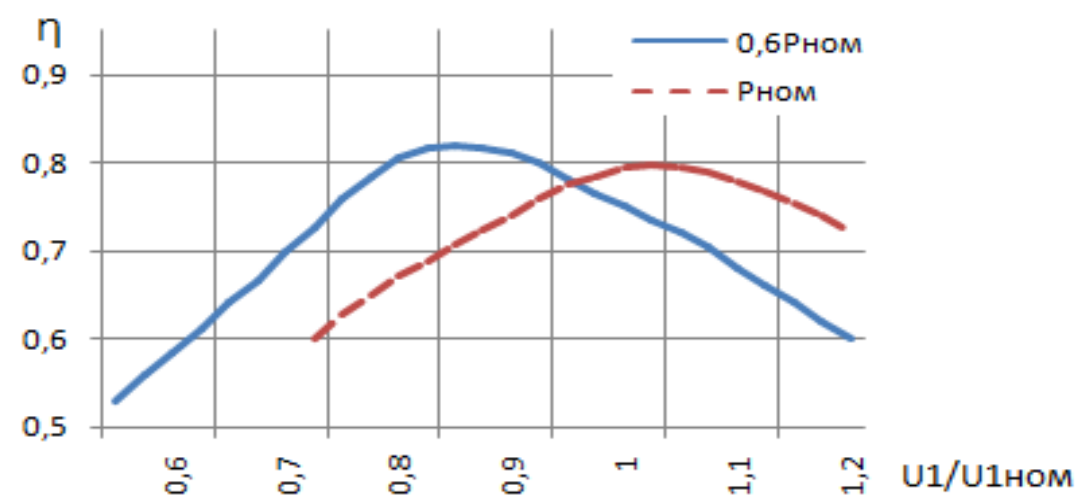

Рис. 3.14. Зависимость КПД асинхронного двигателя от питающего напряжения

Для расчета суммарных потерь в асинхронном двигателе выполним расчет параметров схемы замещения асинхронного двигателя на основании каталожных данных по методике В.Я. Беспалова [9].

Для примерного расчета была использована серия асинхронных электродвигателей серии 4А со степенью защиты IP44, способ охлаждения ICA0141. В частности, рассматриваем двигатель 4A180S2Y3, каталожные данные которого взяты из [88].

$P_{\text {ном }}=22$ кВт; $s_{\text {ном }}=2 \% ; \eta=92 \% ; \cos \varphi=0,91 ; b_{\text {ном }}=2,2-$ кратность момента; $k_{i}=7,5$ - кратность пускового тока; $U_{1 \phi}=220 \mathrm{~B} ; f_{\text {ном }}=50$ Гц; $p=2 ; k_{\text {и }}=U_{1} / U_{1 \phi} ; k_{f}=f / f$.

Используем расчетные формулы [64]:

- номинальный ток статора

$$
I_{1 \text { ном }}=\frac{P_{2 \text { ном }}}{3 U_{1 \phi} \eta_{\text {ном }} \cos \varphi_{\text {ном }}},
$$

- номинальная угловая скорость магнитного поля статора

$$
\omega_{0 \text { ном }}=\frac{\pi \cdot f_{\text {ном }}}{p},
$$

- номинальная угловая скорость ротора

$$
\omega_{2 \text { ном }}=\left(1-s_{\text {н }}\right) \omega_{0 \text { ном }},
$$


- номинальный момент

$$
M_{\text {ном }}=\frac{P_{2 \mathrm{HOM}}}{\omega_{2 \mathrm{HOM}}}
$$

Изначально принимаем модуль жесткости линеаризованной механической характеристики асинхронного двигателя $\beta=1.3$, в этом случае:

- критическое скольжение

$$
s_{\mathrm{K}}=\frac{s_{\mathrm{H}} \sqrt{b_{\mathrm{HOM}}^{2}-\left(1-2 s_{\mathrm{H}} \beta\left(b_{\mathrm{HOM}}-1\right)\right)}}{1-2 s_{\mathrm{H}} \beta\left(b_{\mathrm{HOM}}-1\right)},
$$

- ток намагничивания

$$
I_{0 \mathrm{HOM}}=I_{1 \mathrm{HOM}}\left(\sin \varphi_{\mathrm{H}}-\frac{\cos \varphi_{\mathrm{H}}}{b_{\mathrm{HOM}}+\sqrt{b_{\mathrm{HOM}}^{2}-1}}\right),
$$

- расчетный коэффициент

$$
C_{1}=\frac{I_{0}}{2 k_{i} I_{1 \mathrm{Hом}}}+1
$$

- номинальный ток ротора, приведенный к статору

$$
I^{\prime}{ }_{0 \mathrm{Hом}}=I_{1 \mathrm{Hом}} \cos \varphi_{\mathrm{H}},
$$

-сопротивление ротора, приведенное к статору

$$
R_{2}^{\prime}=\frac{M_{\mathrm{HOM}} \omega_{0 \mathrm{HOM}} s_{\mathrm{H}}}{3 I_{2 \mathrm{HOM}}^{\prime 2}}
$$

Примем коэффициент загрузки равным $k_{z}=75 \%$.

Тогда согласно [9]:

- номинальные потери двигателя

$$
\Delta P_{2}=\frac{P_{2 \text { ном }}(1-\eta)}{\eta},
$$

- номинальные переменные потери в статоре

$$
\Delta P_{\text {пер2ном }}=\frac{\Delta P_{\text {ном }}}{1+k_{z}^{2}},
$$


- активное сопротивление статора

$$
R_{1}=\frac{\Delta P_{\text {пер2ном }}}{3 I_{2 \text { ном }}^{2}} \text {. }
$$

Определим индуктивные сопротивления Т-образной схемы замещения:

$$
\Delta P_{\text {пост }}=\Delta P_{\text {ном }}-\Delta P_{\text {пер1ном }} \text {. }
$$

Примем допущения [63]:

- номинальные механические потери

$$
\Delta P_{\text {мех.ном }}=0,08 \Delta P_{\text {ном }},
$$

- номинальные механические потери

$$
\Delta P_{\text {доп } 2}=0,01 \Delta P_{\text {ном }},
$$

- потери в стали

$$
\Delta P_{\text {ст }}=\Delta P_{\text {пост }}-\left(\Delta P_{\text {мех.ном }}+\Delta P_{\text {доб } 2}\right),
$$

- эквивалентное сопротивление потерь в стали

$$
R_{\mu 1}=\frac{\Delta P_{\mathrm{cT}}}{3 I_{0 \mathrm{HOM}}^{2}}
$$

a

$$
\sin \varphi_{0}=\sqrt{\frac{1-\left(R_{\mu 1}+R_{1}\right) I_{0 \text { ном }}}{U_{\phi}}} .
$$

Рассчитаем параметрические коэффициенты асинхронного двигателя [9]:

$$
\begin{gathered}
A_{0}=\frac{I_{1 \mathrm{HOM}} \cos \varphi_{\mathrm{H}}-I_{0} \cos \varphi_{0}}{U_{\phi}}, \\
A_{1}=\frac{m U_{\phi}^{2}\left(1-s_{\mathrm{H}}\right)}{2 C_{1} b_{\mathrm{Hом}} P_{2 \mathrm{Hом}}}, \\
B=\frac{1}{s_{\mathrm{H}}}+\frac{1}{s_{\mathrm{K}}}+\frac{2 A_{0} A_{1}}{s_{\mathrm{H}}},
\end{gathered}
$$




$$
C=\frac{1}{s_{\mathrm{K}} s_{\mathrm{H}}}-\left(\frac{1}{s_{\mathrm{H}}^{2}}+\frac{1}{s_{\mathrm{K}}^{2}}\right) A_{0} A_{1} .
$$

Уточняем коэффициент $\beta$ - модуль жесткости линеаризованной механической характеристики асинхронного двигателя:

$$
\begin{gathered}
\beta=\frac{-B}{2}+\sqrt{\frac{B^{2}}{4}-C}, \\
\gamma=\sqrt{\frac{1}{s_{\mathrm{K}}^{2}} \beta^{2}}, \\
X_{\mathrm{H}}=\gamma \cdot C_{1} R_{2}^{\prime} .
\end{gathered}
$$

Индуктивное сопротивление фаз ротора и статора

$$
\begin{aligned}
& X_{2 \sigma}=\frac{0.58 \cdot X_{\mathrm{H}}}{C_{1}}, \\
& X_{1 \sigma}=0.42 \cdot X_{\mathrm{H}} .
\end{aligned}
$$

Расчет потерь двигателя производим в последовательности, предлагаемой ниже. Из энергетических диаграмм следует [77], что потребляемая из сети мощность равна

$$
\begin{gathered}
P_{1}=P_{2 \text { ном }}+\Delta P+\Delta P_{2}-\Delta P_{\text {мех }}, \\
\Delta P=\Delta P_{1}+\Delta P_{2}+\Delta P_{\mathrm{Mex}},
\end{gathered}
$$

- потери в статоре

$$
\Delta P_{1}=\Delta P_{1 \text { ном }}\left(\frac{I_{1}}{I_{1 \text { ном }}}\right)^{2},
$$

- номинальные потери в статоре

$$
\Delta P_{\text {1ном }}=3 I_{1 \text { ном }}^{2} R_{1},
$$

- механические потери двигателя

$$
\Delta P_{\text {мех }}=\frac{\Delta P_{\text {мех.ном }} k_{f}(1-s)}{1-s_{\mathrm{H}}},
$$

- потери в роторе 


$$
\Delta P_{2}=P_{a} s .
$$

При учете $k_{u}=k_{f}$ и постоянного момента сопротивления на валу, получим [77]

$$
s=\frac{s_{\mathrm{K}}}{k_{f}\left(\frac{b_{\mathrm{HOM}} k_{u}^{2}}{k_{f}^{2}}+\sqrt{\left(\frac{b_{\mathrm{HOM}} k_{u}^{2}}{k_{f}^{2}}\right)^{2}-1}\right)} .
$$

Активная мощность, потребляемая из сети

$$
P_{a}=\frac{3 U_{1}^{2} \frac{R_{2}^{\prime}}{s}}{\left(R_{1}+C_{1} \frac{R_{2}^{\prime}}{s}\right)^{2}+\left(X_{1 \sigma}+C_{1} X_{2}^{\prime}\right)^{2}},
$$

- ток статора

$$
I_{1}=\sqrt{\left(I_{0}+I_{2}^{\prime} \sin \varphi^{\prime}\right)^{2}+\left(I_{2}^{\prime} \cos \varphi^{\prime}\right)^{2}},
$$

где

$$
\sin \varphi^{\prime}=\frac{1}{\sqrt{\frac{2 b_{\mathrm{HOM}} k_{u}^{2}}{k_{f}^{2}}\left(\frac{2 b_{\mathrm{HOM}} k_{u}^{2}}{k_{f}^{2}}+\sqrt{\left(\frac{2 b_{\mathrm{HOM}} k_{u}^{2}}{k_{f}^{2}}\right)^{2}-1}\right)}},
$$

- ток ротора

$$
I_{2}^{\prime}=\frac{U_{1}}{\sqrt{\left(R_{1}+\frac{C_{1} R_{2}^{\prime}}{s_{\mathrm{H}}}\right)^{2}+k_{f}\left(X_{1}+C_{1} X_{2}^{\prime}\right)^{2}}} .
$$

Для определения тока намагничивания воспользуемся характеристикой (рис. 3.15) холостого хода асинхронного двигателя [64]. Вычислительными средствами аппроксимируем кривую и выразим значение $I_{0}$ (рис. 3.16). 


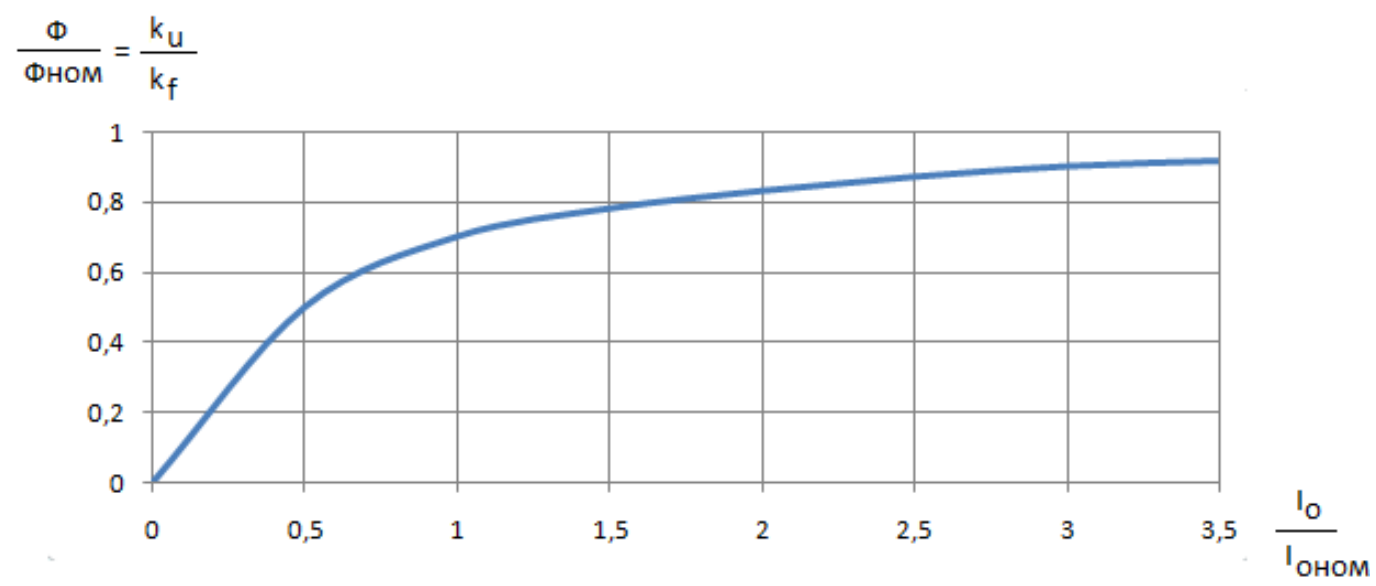

Рис. 3.15. Характеристика холостого хода асинхронного двигателя

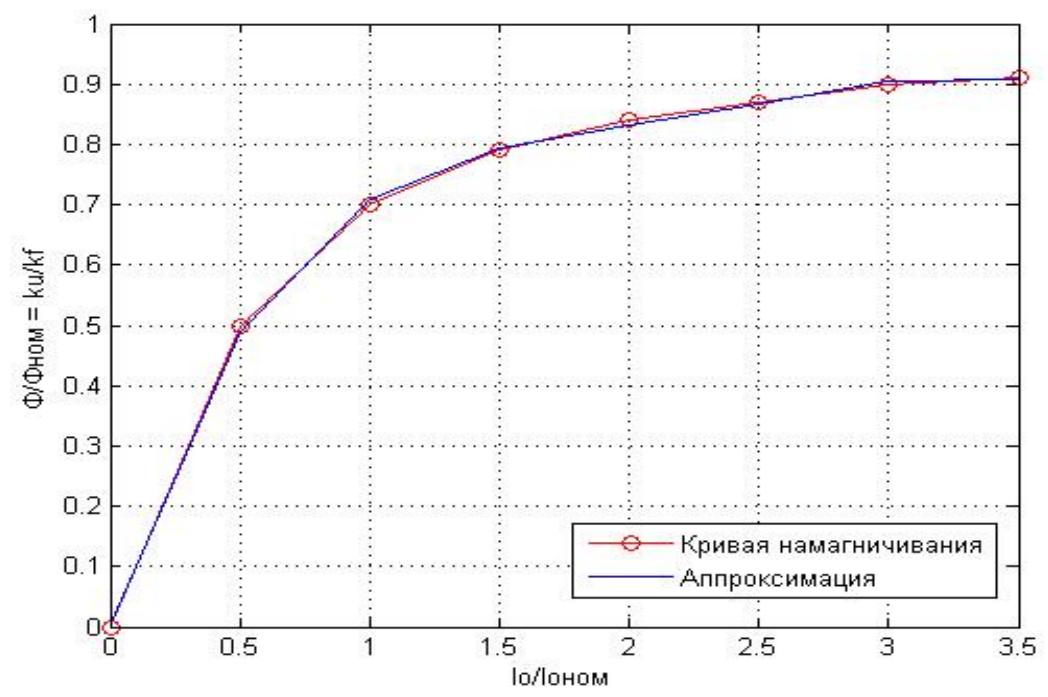

Рис. 3.16. Характеристика холостого хода асинхронного двигателя и линия аппроксимации

$$
I_{0}=I_{0 \text { ном }} f\left(\frac{k_{u}}{k_{f}}\right) \text {, }
$$

$f\left(\frac{k_{u}}{k_{f}}\right)=-0.0283\left(\frac{k_{u}}{k_{f}}\right)^{4}+0.2595\left(\frac{k_{u}}{k_{f}}\right)^{3}-0.8726\left(\frac{k_{u}}{k_{f}}\right)^{2}+1.348\left(\frac{k_{u}}{k_{f}}\right)+0.003$.

По приведенным выражениям рассчитаем потери и КПД двигателя (рис. 3.17) при различном напряжении $U$ на интервале $20-240$ В с учетом условия $U / f=$ const.

Значение потерь двигателя рассчитаем по формуле (3.37), а значение КПД

$$
\eta=\frac{P_{a}-\Delta P}{P_{a}}
$$




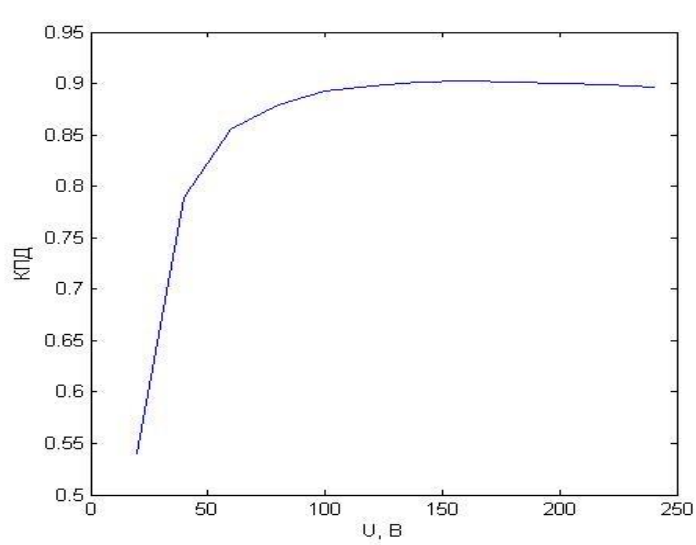

a)

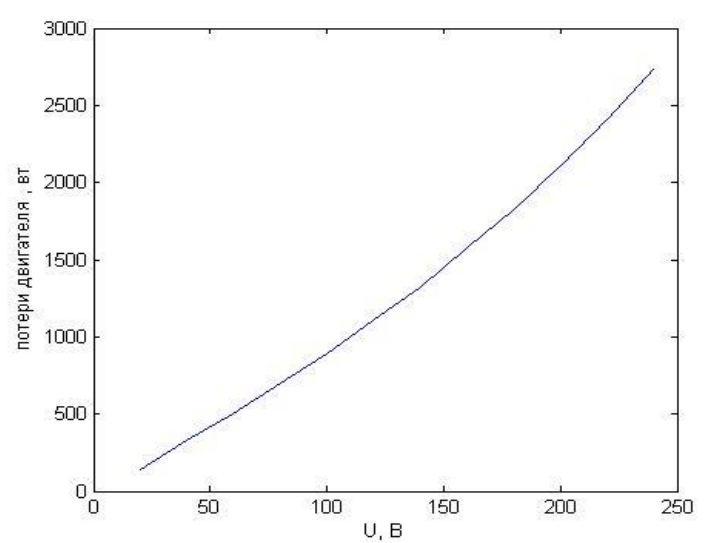

б)

Рис. 3.17. Изменение КПД (a), потерь двигателя 4A180S2Y3 при изменении напряжения питания (б)

Подобные расчеты проведены для двигателей 4А255М2Y3 мощностью 55кВт, 4A280S2Y3 - 110кВт, 4A3155S2Y3 - 160 кВт, 4A355S2Y3 250 кВт. По результатам расчета построена поверхность зависимости потерь двигателей от изменения напряжения питания и мощности, потребляемой электрической машиной.

С другой стороны, по данным моделирования изменения мощности

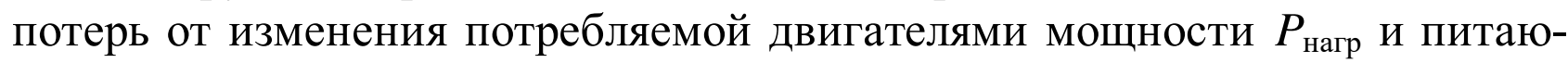
щего напряжения на статоре двигателя $U_{1}$ было определено уравнение регрессии:

$$
\Delta P=42.1654-5.11 \cdot U_{1}+5.4853 \cdot P_{\text {нагр }}+0.3144 \cdot U_{1}^{2}-0.0335 \cdot P_{\text {нагр }}^{2} .
$$

Для расчета суммарных потерь в асинхронном двигателе была написана программа в математическом пакете Matlab [84, 91, 92]. Расчеты проведены для двигателей 4A255M2Y3 мощностью 55кВт, 4A280S2Y3 $110 \kappa, 4 \mathrm{~A} 3155 \mathrm{~S} 2 \mathrm{Y} 3$ - 160 кВт, 4A355S2Y3 - 250 кВт. По результатам расчета построена поверхность (рис. 3.18) зависимости потерь двигателей от изменения напряжения питания и мощности, потребляемой электрической машиной.

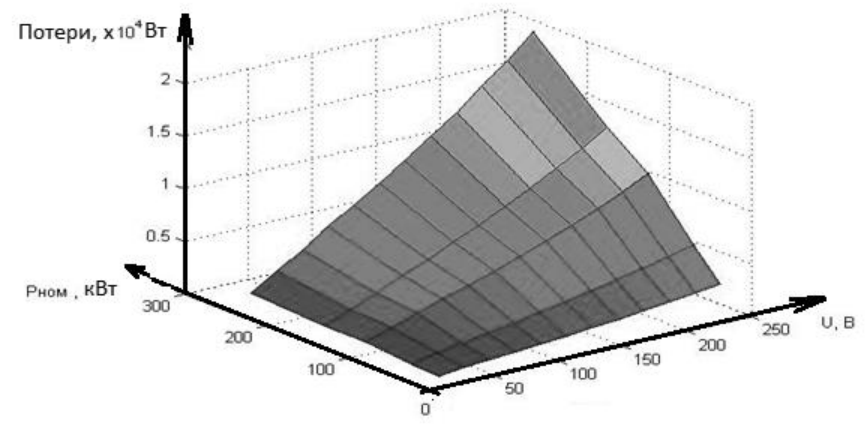

Рис. 3.18. Изменение потерь в двигателе по данным расчета 


\section{ГЛАВА 4. ОПИСАТЕЛЬНЫЕ И МАТЕМАТИЧЕСКИЕ МОДЕЛИ ЭЛЕКТРОМЕХАНИЧЕСКИХ КОМПЛЕКСОВ КАК КОЛЕБАТЕЛЬНЫХ СИСТЕМ}

\section{1. Математические модели колебательных систем на основе машин с электрическим приводом переменного тока}

Моделирование и анализ механических систем сложны, поскольку рассматриваются системы со многими степенями подвижности, обладающие рядом резонансных частот. Поэтому нередко для исследований применяют принцип аналогий, например, используют электромеханическую аналогию колебаний. Исследование электрических моделей вместо механических более целесообразно в силу простоты их построения, и в тоже время механические колебания и колебания в электрических цепях (колебательном контуре) описываются одними и теми же дифференциальными уравнениями [110].

Методика расчета вибрации электрической машины зависит от характера сил и мест их приложения. Физическая модель машины как колебательной системы зависит от того, какие силы являются причиной возбуждения вибрации.

Динамическая модель машины при возбуждении вибрации электромагнитными силами может быть представлена в виде совокупности радиальных каналов (рис. 4.1), по которым колебания распространяются от точек приложения сил к выбранным точкам наблюдения. Анализ динамического состояния машины производится рассечением системы статора на ряд независимых подсистем.
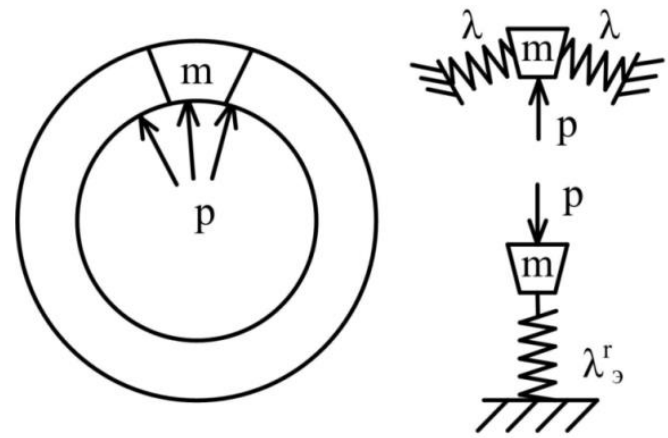

Рис. 4.1. Колебательная модель статора электрической машины

Наибольшую интенсивность имеет вибрация, возбуждаемая основной волной вращающегося магнитного поля, частота этой вибрации равна удвоенной частоте питающей сети [110].

Рассмотрим одномассовую колебательную систему.

К колебаниям поступательной системы могут быть приведены: 
- вибрация, возбуждаемая остаточным небалансом ротора, амортизированной электрической машины на фундаменте бесконечной массы и жесткости;

- вибрация сердечника статора, возбуждаемая электромагнитными силами.

К колебаниям крутильной системы могут быть приведены:

- крутильные колебания ротора электрической машины, сочленённого с ротором, имеющим бесконечный момент инерции;

- колебания, возбуждаемые при внезапном коротком замыкании.

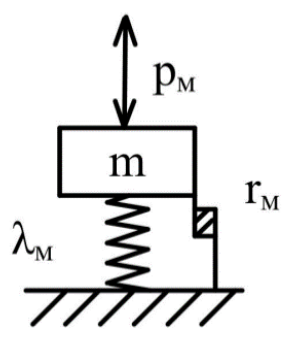

a)

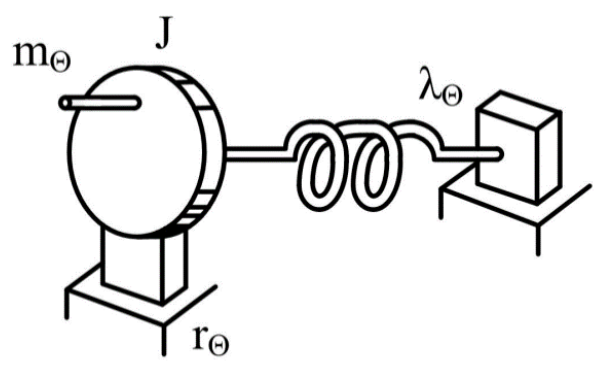

б)

Рис. 4.2. Поступательная и крутильная колебательные системы

Уравнения равновесия сил и моментов могут быть записаны в следующем виде:

- для механической поступательной системы

$$
m \frac{d^{2} y}{d t^{2}}+r_{\mathrm{M}} \frac{d y}{d t}+\frac{y}{\lambda_{\mathrm{M}}}=P_{\mathrm{M}} e^{j \omega t}
$$

где $m \frac{d^{2} y}{d t^{2}}-$ сила инерции; $r_{\mathrm{M}} \frac{d y}{d t}-$ сила трения; $\frac{y}{\lambda_{\mathrm{M}}}-$ сила упругости; $P_{\mathrm{M}} e^{j \omega t}-$ приложенная к системе сила.

- для механической крутильной системы

$$
J \frac{d^{2} \varphi}{d t^{2}}+r_{\Theta} \frac{d \varphi}{d t}+\frac{\varphi}{\lambda_{\Theta}}=M_{\Theta} e^{j \omega t}
$$

где $J \frac{d^{2} \varphi}{d t^{2}}-$ момент сил инерции вращающегося маховика; $r_{\Theta} \frac{d \varphi}{d t}-$ момент сил трения; $\frac{\varphi}{\lambda_{\Theta}}-$ момент сил упругости; $M_{\Theta} e^{j \omega t}-$ внешний момент, приложенный к системе.

Решения уравнений (4.1) и (4.2) имеют вид 
- для механической поступательной системы скорость поступательного перемещения $\dot{y}$ :

$$
\dot{y}=\frac{P_{\mathrm{M}} e^{j \omega t}}{r_{\mathrm{M}}+j \omega m-\frac{j}{\omega \lambda_{\mathrm{M}}}}=\frac{P_{\mathrm{M}}}{z_{\mathrm{M}}},
$$

где $z_{\mathrm{M}}=r_{\mathrm{M}}+j \omega m-\frac{j}{\omega \lambda_{\mathrm{M}}}$.

- для механической крутильной системы скорость вращательного перемещения $\dot{\varphi}$ :

$$
\dot{\varphi}=\frac{M_{\Theta} e^{j \omega t}}{r_{\Theta}+j \omega m-\frac{j}{\omega \lambda_{\Theta}}}=\frac{m_{\Theta}}{z_{\Theta}},
$$

где $z_{\Theta}=r_{\Theta}+j \omega m-\frac{j}{\omega \lambda_{\Theta}}$.

На рис. 4.3 показан пример одномассовых колебательных систем, соответствующих амортизированной машине, установленной на вибрирующем фундаменте, и ротору генератора, приводимого во вращение двигателем дизеля.

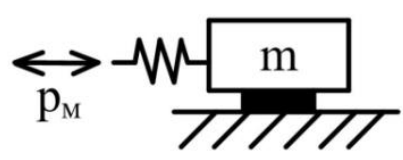

a)

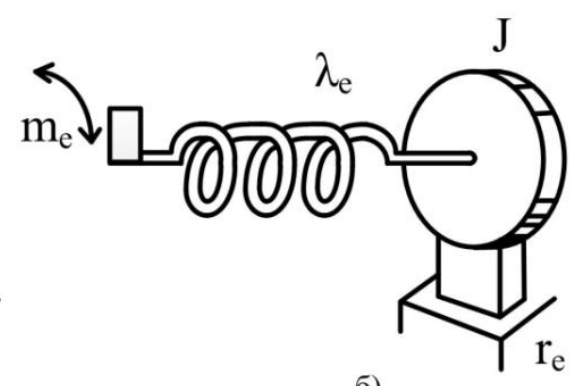

б)

Рис. 4.3. Колебательная система: амортизированная машина на вибрирующем фундаменте (a), крутильные колебания ротора, возбуждаемые дизелем (б)

В этом случае скорости перемещений будут равны:

- для механической поступательной системы:

а) линейная скорость массы $m$

$$
\dot{y}_{3}=\frac{P_{\mathrm{M}}}{r_{\mathrm{M}}+j \omega m} ;
$$

б) линейная скорость в точке приложения силы 


$$
\dot{y}_{1}=\frac{P_{\mathrm{M}}\left(r_{\mathrm{M}}+j \omega m+\frac{1}{j \omega \lambda_{\mathrm{M}}}\right)}{\left(r_{\mathrm{M}}+j \omega m\right) \frac{1}{j \omega \lambda_{\mathrm{M}}}} ;
$$

в) скорость между линейными скоростями двух концов пружины

$$
\dot{y}_{2}=\dot{y}_{1}-\dot{y}_{3}=P_{\mathrm{M}} j \omega \lambda_{\mathrm{M}} .
$$

- для механической крутильной системы:

a) угловая скорость маховика с моментом инерции $J$

$$
\dot{\varphi}_{3}=\frac{m_{\Theta}}{r_{\Theta}+j \omega J} ;
$$

б) суммарная угловая скорость в точке приложения момента:

$$
\dot{\varphi}_{3}=\frac{m_{\Theta}\left(r_{\Theta}+j \omega J+\frac{1}{j \omega \lambda_{\Theta}}\right)}{\left(r_{\Theta}+j \omega J\right) \frac{1}{j \omega \lambda_{\Theta}}} ;
$$

в) разность угловых скоростей на двух концах пружины:

$$
\dot{\varphi}_{2}=\dot{\varphi}_{1}-\dot{\varphi}_{3}=m_{\Theta} j \omega \lambda_{\Theta} .
$$

К двухмассовым колебательным системам приводятся:

1) машина массой $m_{1}$, установленная на двойной каскад амортизаторов, первый из которых имеет податливость $\lambda_{1}$ и второй $\lambda_{2}$ с промежуточной массой $m_{2}$, машина возбуждается силами $p_{0}$ (рис. 4.4).
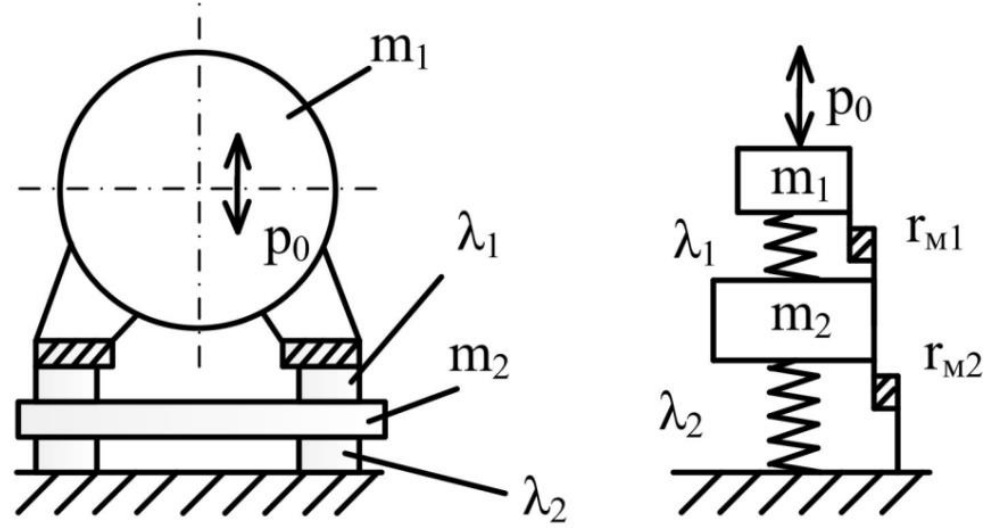

Рис. 4.4. Машина, установленная на двойной каскад амортизаторов

Сопротивления отдельных участков эквивалентной системы:

$$
z_{\mathrm{M} 1}=j \omega m_{1}, z_{\mathrm{M} 2}=r_{\mathrm{M} 1}+\frac{1}{\omega \lambda_{1}}, z_{\mathrm{M} 3}=r_{\mathrm{M} 2}+j \omega m_{2}+\frac{j}{\omega \lambda_{2}} .
$$


Колебательные скорости имеют вид

$$
\begin{gathered}
\dot{y}_{0}=\frac{p_{0}\left(z_{\mathrm{M} 2}+z_{\mathrm{M} 3}\right)}{H_{\mathrm{M}}} ; \\
\dot{y}_{1}=\frac{p_{0} z_{\mathrm{M} 3}}{H_{\mathrm{M}}} ; \\
\dot{y}_{2}=\frac{p_{0} z_{\mathrm{M} 2}}{H_{\mathrm{M}}} ;
\end{gathered}
$$

где $H_{\mathrm{M}}=z_{\mathrm{M} 2} \cdot z_{\mathrm{M} 3}+z_{\mathrm{M} 2} \cdot z_{\mathrm{M} 1}+z_{\mathrm{m} 3} \cdot z_{\mathrm{M} 1}$

2) машина массой $m_{1}$, установленная на амортизаторы податливостью $\lambda_{1}$ с динамическим поглотителем колебаний $\left(m_{2}, \lambda_{2}\right)$, машина возбуждается силами $p_{0}$ (рис. 4.5).
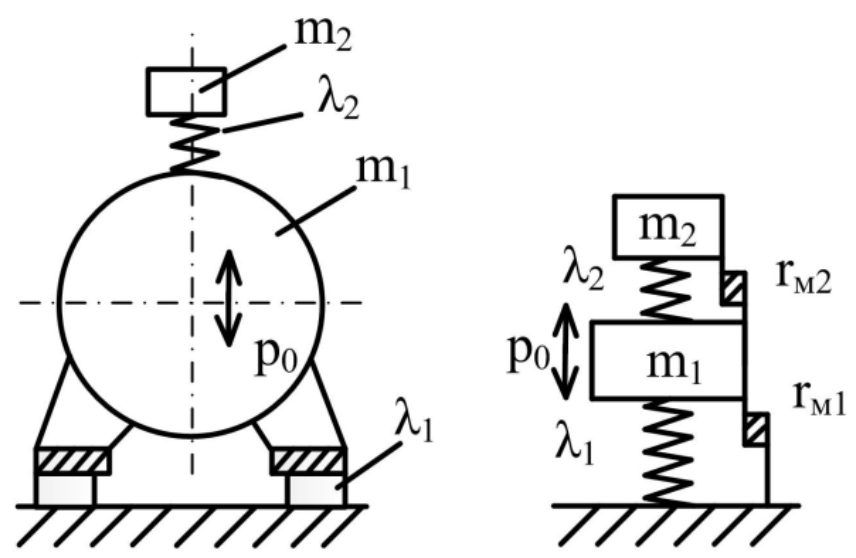

Рис. 4.5. Амортизированная машина с динамическим поглотителем колебаний

Сопротивления отдельных участков эквивалентной системы:

$$
z_{\mathrm{M} 1}=r_{\mathrm{M} 1}+j \omega m_{1}+\frac{j}{\omega \lambda_{1}}, z_{\mathrm{M} 2}=r_{\mathrm{M} 2}+\frac{1}{\omega \lambda_{2}}, z_{\mathrm{M} 3}=j \omega m_{3} .
$$

Колебательные скорости имеют вид

$$
\begin{gathered}
\dot{y}_{0}=\frac{p_{0}\left(z_{\mathrm{M} 2}+z_{\mathrm{M} 3}\right)}{H_{\mathrm{M}}} ; \\
\dot{y}_{1}=\frac{p_{0} z_{\mathrm{M} 3}}{H_{\mathrm{M}}} ; \\
\dot{y}_{2}=\frac{p_{0} z_{\mathrm{M} 2}}{H_{\mathrm{M}}} ;
\end{gathered}
$$

где $H_{\mathrm{M}}=z_{\mathrm{m} 2} \cdot z_{\mathrm{m} 3}+z_{\mathrm{m} 2} \cdot z_{\mathrm{m} 1}+z_{\mathrm{m} 3} \cdot z_{\mathrm{M} 1}$;

3) пакет железа статора массой $m_{1}$ и податливостью $\lambda_{1}$, упруго подвешенный в корпусе массой $m_{2}$ и податливостью $\lambda_{2}$, на пружинах податливостью $\lambda_{3}$, пакет возбуждается радиальными магнитными силами $p_{0}$ (рис. 4.6). 

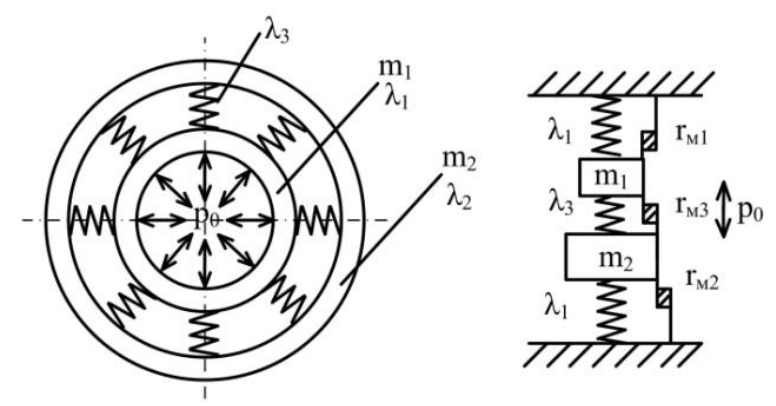

Рис. 4.6. Статор с упругой подвеской пакета железа в корпусе

Сопротивления отдельных участков эквивалентной системы:

$$
z_{\mathrm{M} 1}=r_{\mathrm{M} 1}+j \omega m_{1}+\frac{j}{\omega \lambda_{1}}, z_{\mathrm{M} 2}=r_{\mathrm{M} 3}+\frac{1}{\omega \lambda_{3}}, z_{\mathrm{M} 3}=r_{\mathrm{M} 2}+j \omega m_{2}+\frac{j}{\omega \lambda_{2}} .
$$

Колебательные скорости имеют вид

$$
\begin{gathered}
\dot{y}_{0}=\frac{p_{0}\left(z_{\mathrm{M} 2}+z_{\mathrm{M} 3}\right)}{H_{\mathrm{M}}} ; \\
\dot{y}_{1}=\frac{p_{0} z_{\mathrm{M} 3}}{H_{\mathrm{M}}} ; \\
\dot{y}_{2}=\frac{p_{0} z_{\mathrm{M} 2}}{H_{\mathrm{M}}} ;
\end{gathered}
$$

где $H_{\mathrm{M}}=z_{\mathrm{M} 2} \cdot z_{\mathrm{M} 3}+z_{\mathrm{M} 2} \cdot z_{\mathrm{M} 1}+z_{\mathrm{M} 3} \cdot z_{\mathrm{M} 1} \cdot$

Рассмотрим двухмассовую кинематическую схему, содержащую упругий элемент. Эта схема показана на рис 4.7.

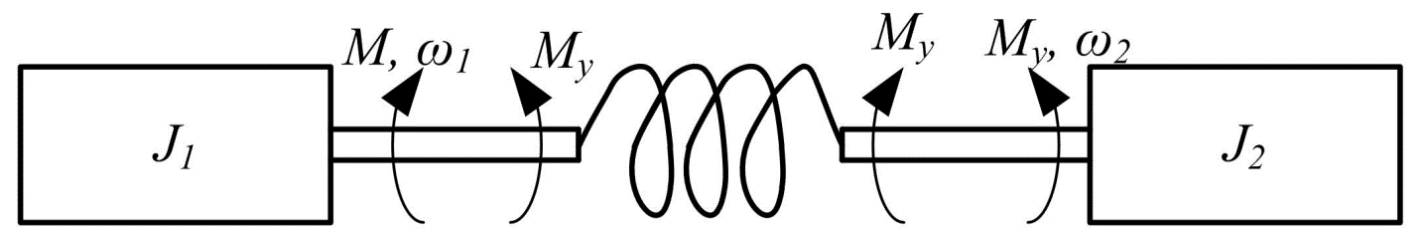

Рис. 4.7. Двухмассовая кинематическая схема с упругой связью

Схема (рис. 4.7) учитывает люфты и зазоры в зубчатых передачах и соединениях, так же применима при рассмотрении высокоточных электроприводов и приводов, работающих в интенсивных динамических режимах $[11,12]$.

Для анализа механических систем с двумя степенями подвижности используем уравнение Лагранжа второго рода:

$$
\frac{d}{d t}\left(\frac{\partial L}{\partial \dot{q}_{i}}\right)-\frac{\partial L}{\partial q_{i}}=\sum Q_{i},
$$

где $L=W_{\text {к }}-W_{\text {п }}-$ функция Лагранжа, равная разности $W_{\text {к }}-$ кинетической и $W_{\text {п }}$ - потенциальной энергии, которыми обладает электромеханическая 
система при движении по всем координатам $i ; q_{i}$ - перемещение; $\dot{q}_{i}-$ скорость перемещения; $Q_{i}$ - внешние силы, действующие по каждой степени подвижности.

Тогда для рис. 4.7 можно составить следующую функцию Лагранжа:

$$
L=\frac{J_{1} \omega_{1}}{2}+\frac{J_{2} \omega_{2}}{2}+\frac{C \Delta \varphi^{2}}{2}
$$

где $J_{1}$ - момент инерции первой массы; $J_{2}$ - момент инерции второй массы; $C$ - жесткость упругого элемента; $\Delta \varphi=\varphi_{1}-\varphi_{2}-$ угол закручивания упругого элемента. Моменты инерции приведены к скорости вала двигателя.

Так как система по рис. 4.7 обладает двумя степенями подвижности то по (4.3) получим следующую систему:

$$
\left\{\begin{array}{c}
\frac{d}{d t}\left(\frac{\partial L}{\partial \omega_{1}}\right)-\frac{\partial L}{\partial \varphi_{1}}=M \\
\frac{d}{d t}\left(\frac{\partial L}{\partial \omega_{2}}\right)-\frac{\partial L}{\partial \varphi_{2}}=-M_{c}
\end{array},\right.
$$

где $M$ - момент двигателя; $M_{c}-$ статический момент.

Считая производные, получим

$$
\begin{gathered}
\frac{d}{d t}\left(\frac{\partial L}{\partial \omega_{1}}\right)=\frac{d J_{1} \omega_{1}}{d t}=J_{1} \frac{d \omega_{1}}{d t} ; \\
\frac{d}{d t}\left(\frac{\partial L}{\partial \omega_{2}}\right)=\frac{d J_{2} \omega_{2}}{d t}=J_{2} \frac{d \omega_{2}}{d t} ; \\
\frac{\partial L}{\partial \varphi_{1}}=-C \Delta \varphi ; \\
\frac{\partial L}{\partial \varphi_{2}}=C \Delta \varphi .
\end{gathered}
$$

Подставляя найденные производные в (4.4), получим

$$
\left\{\begin{array}{c}
M-M_{\mathrm{y}}=J_{1} \frac{d \omega_{1}}{d t} \\
M_{\mathrm{y}}-M_{c}=J_{2} \frac{d \omega_{2}}{d t}
\end{array},\right.
$$

где $M_{\mathrm{y}}=C \Delta \varphi-$ момент в упругом звене. 
Для получения передаточной функции двухмассовой системы выразим уравнение (4.5) в операторной форме:

$$
\left\{\begin{array}{l}
M-\frac{C}{p}\left(\omega_{1}-\omega_{2}\right)=J_{1} p \omega_{1} \\
\frac{C}{p}\left(\omega_{1}-\omega_{2}\right)-M_{c}=J_{2} p \omega_{2}
\end{array}\right.
$$

По системе уравнений (4.6) можно составить структурную схему, показанную на рис. 4.8 .

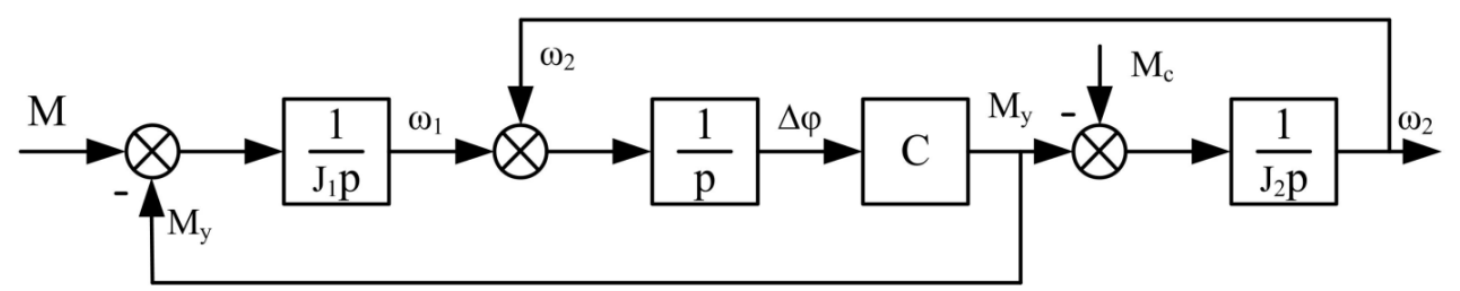

Рис. 4.8. Структурная схема двухмассовой механической системы

Преобразованная структурная схема с рис. 4.8 показана на рис. 4.9.

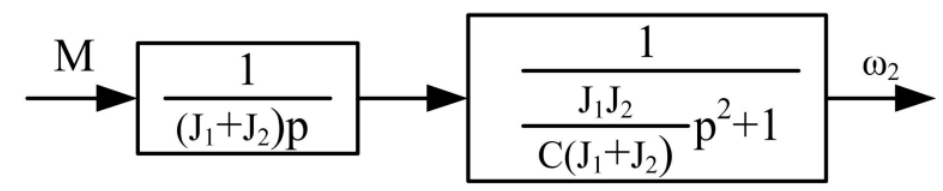

Рис. 4.9. Преобразованная структурная схема двухмассовой механической системы

Передаточная функция двухмассовой механической системы с упругим звеном имеет вид

$$
W(p)=\frac{1}{\left(J_{1}+J_{2}\right) p} \frac{1}{\frac{J_{1} J_{2}}{C\left(J_{1}+J_{2}\right)} p^{2}+1} .
$$

Выполним расчет амплитудо-частотных характеристик с учетом передаточной функции (4.7) для трех насосных агрегатов типа К.

Насосы центробежные консольные типа К и агрегаты электронасосные на их основе предназначены для перекачивания технической воды (кроме морской), а также других жидкостей, сходных с водой по плотности, вязкости, химической активности с $p H$ от 6 до 9, с содержанием твердых включений не более $0,1 \%$ и температурой перекачиваемой жидкости не более $85^{\circ} \mathrm{C}$.

Условное обозначение насосов типа К показано на рис. 4.10. 


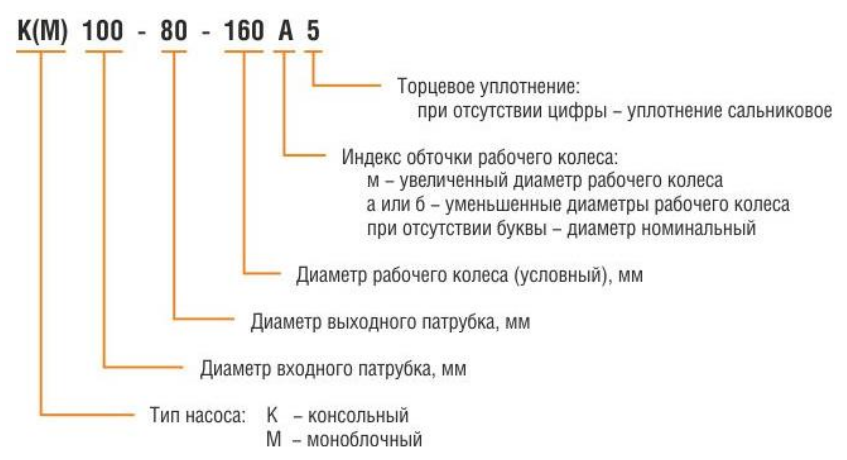

Рис. 4.10. Условное обозначение насосов типа К

Насосы для расчета показаны в табл. 4.1.

Таблица 4.1

Параметры насосов

\begin{tabular}{|c|c|c|c|c|c|}
\hline Насос & $\begin{array}{c}\text { Мощность элек- } \\
\text { тродвигателя, кВт }\end{array}$ & $\begin{array}{c}\text { Тип двига- } \\
\text { теля }\end{array}$ & Об/мин & $\begin{array}{c}\text { Масса } \\
\text { насоса, кг }\end{array}$ & $\begin{array}{c}\text { Масса } \\
\text { агрегата, } \\
\text { кг }\end{array}$ \\
\hline К100-65-250 & 37 & АИР200M2 & 2900 & 78 & 350,5 \\
\hline К200-150-400 & 90 & АИР250M4 & 1450 & 250 & 980 \\
\hline К125-100-315 & 110 & АИР280S2 & 3000 & 300 & 1300 \\
\hline
\end{tabular}

На рис. 4.11 - рис. 4.13 показаны АЧХ насосных агрегатов.
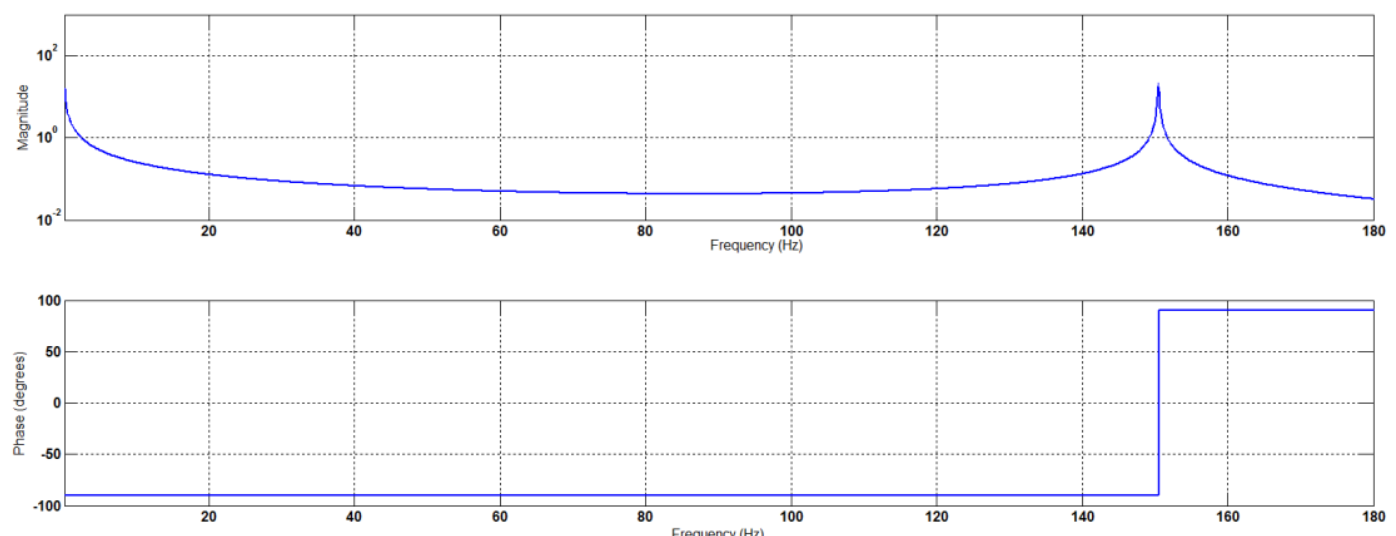

Рис. 4.11. АЧХ для агрегата К100-65-250
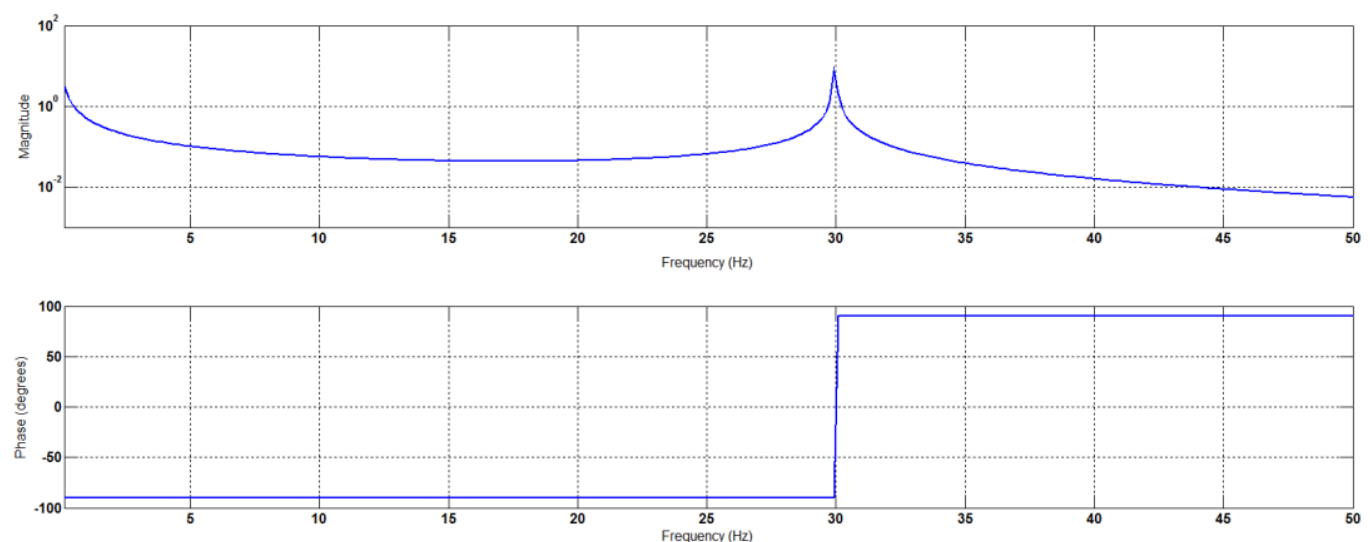

Рис. 4.12. АЧХ для агрегата К200-150-400 

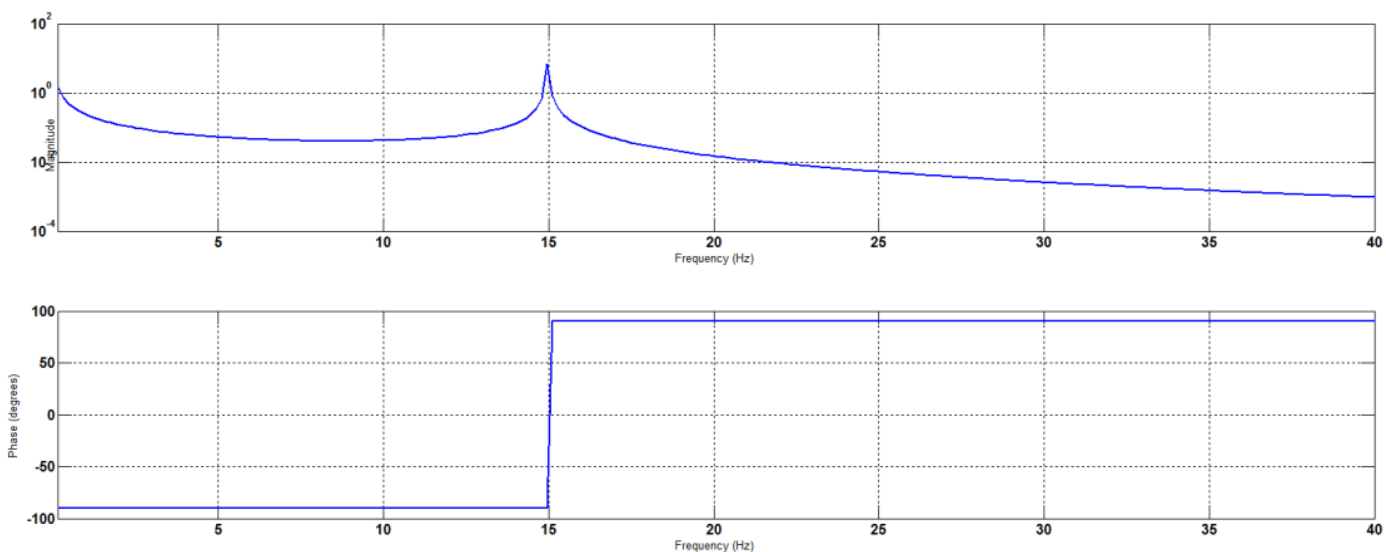

Рис. 4.13. АЧХ для агрегата К125-100-315

По рис. 4.11 - рис. 4.13 определены резонансные частоты, соответственно 150, 30 и 15 Гц.

\section{2. Оценка деформаций валов асинхронных двигателей в переходных режимах}

Конструкции современных асинхронных электродвигателей электромеханических комплексов характеризуются высокими динамическими нагрузками в переходных режимах. Часто именно динамические нагрузки являются причиной различных дефектов. Более того, именно динамическое совершенство конструкции асинхронного электродвигателя определяет долговечность и ресурс двигателя в целом. Контроль динамического состояния конструкции электродвигателя ведется при испытаниях в процессе измерений вибрационных сигналов, поступающих с датчиков, установленных в различных точках на корпусе двигателя. Обрабатывая эти сигналы, получают информацию о динамическом состоянии электродвигателей. Анализ вибрационных сигналов позволяет также вести контроль технического состояния электрических машин, прогнозировать появление возможных дефектов [19, 107, 110].

Механические колебания - вибрации в электрических машинах специфичны вследствие наличия переменного магнитного поля. В случае возникновения эксцентриситета воздушного зазора между ротором и статором, вследствие статического или динамического эксцентриситета ротора, электромагнитное поле вызывает одностороннюю радиальную силу, приложенную к центру ротора и направленную в сторону наименьшего воздушного зазора. Эта сила получила название - одностороннее магнитное притяжение (unbalanced magnetic pull - UMP) [122]. Одностороннее магнитное притяжение является источником вынужденных колебаний - вибраций в гидрогенераторах и асинхронных электродвигателях. В гидрогенераторах большое влияние электромагнитных сил на вибрации 
ротора объясняется как многополюсностью, так и относительно меньшим радиальным зазором между ротором и статором. В асинхронных двигателях переменного тока весьма мал зазор между ротором и статором, поэтому UMP оказывается сравнимым с неуравновешенными силами $[19,107$, 110]. Кроме того, влияние UMP на роторную динамику проявляется и в других типах электрических машин [127]. В связи с этим, учет UMP является важной задачей в анализе роторной динамики электромашин.

Так, не подверженное действию внешних сил тело, вращающееся с постоянной угловой скоростью $\omega$ вокруг одной из своих главных центральных осей инерции, находится в состоянии динамического равновесия, характеризующегося равенством нулю главных вектора и момента неуравновешенных сил [1]:

$$
\begin{gathered}
\sum F_{i}=\omega^{2} \sum m_{i} r_{i}=\omega^{2} \sum D_{i}=\omega^{2} D_{i}=\omega^{2} m_{\mathrm{p}} e_{\text {ст }}=0, \\
\sum M_{i}=\sum z_{i} \cdot F_{i}=\omega^{2} \sum z_{i} \cdot m_{i} r_{i}=\omega^{2} \sum D_{i} \cdot z_{i}=\omega^{2} M_{D}=0,
\end{gathered}
$$

где $m_{i}, r_{i}, D_{i}$ - соответственно неуравновешенная точечная масса, ее эксцентриситет и дисбаланс; $m_{\mathrm{p}}=\sum m_{i}$ - масса; $e=\sum r_{i} m_{i} / m_{\mathrm{p}}$ - эксцентриситет ротора; $D, M_{D}$ - главный вектор и главный момент дисбалансов.

Для выполнения условия (4.8) необходимо и достаточно, чтобы ось вращения ротора проходила через его центр масс $\left(e_{\text {ст }}=0\right)$.

Для выполнения условия (4.9) необходимо и достаточно, чтобы ось вращения ротора совпадала с одной из его главных осей инерции, т. е. чтобы были равны нулю его центробежные моменты инерции.

При вращении ротора электрической машины вокруг оси, не совпадающей с главной центральной осью инерции, он становится неуравновешенным.

Неуравновешенность - это состояние ротора, характеризующееся таким распределением масс, которое во время вращения вызывает переменные нагрузки на опорах ротора и его изгиб.

Мерой неуравновешенности считают дисбаланс $D$, Для сопоставления роторов различных масс вводят дисбаланс, численно равный эксцентриситету:

$$
e_{\mathrm{cт}}=D / m_{\mathrm{p}}
$$

Виды неуравновешенности:

- статическая неуравновешенность;

- моментная неуравновешенность;

- динамическая неуравновешенность (рис. 4.14) [107]. 


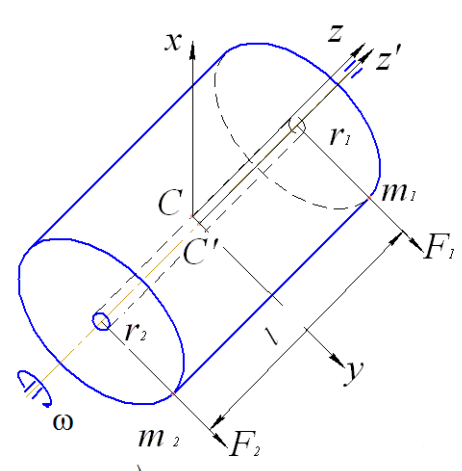

a)

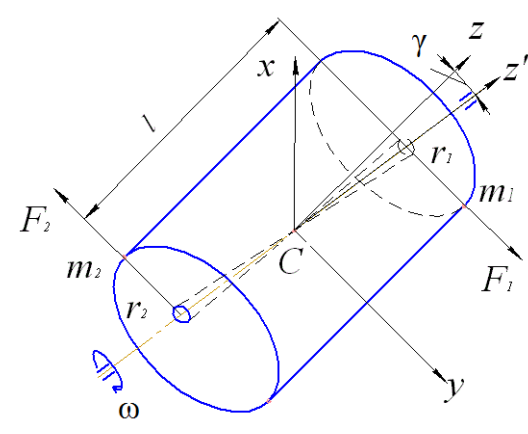

б)

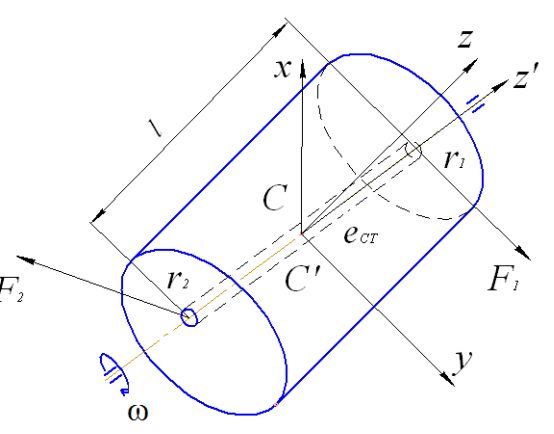

в)

Рис. 4.14. Виды неуравновешенности ротора: статическая неуравновешенность $(a)$; моментная неуравновешенность (б); динамическая неуравновешенность (в)

1. Для статической неуравновешенности ротора (рис. 4.14,a) справедливо

$$
\sum F_{i}=2 m_{1} r_{1} \omega^{2}=m_{\mathrm{p}} e_{\mathrm{c \tau}} \omega^{2} \neq 0,
$$

при $\lambda=F_{1} / F_{2}=1, \varphi_{1}=\varphi_{2}=0$.

Здесь и ниже через $\varphi_{1}$ и $\varphi_{2}$ обозначены углы между векторами эквивалентных сил неуравновешенности $F_{1}$ и $F_{2}$ и некоторой начальной осью, которая в рассматриваемом случае совмещена с вектором $F_{1}$.

При статической неуравновешенности оси z и z' параллельны. Эта неуравновешенность полностью определяется главным вектором дисбалансов $D$ или эксцентриситетом $e_{\text {ст. }}$.

2. Для моментной неуравновешенности ротора (рис. 4.14,б) справедливо

$$
\begin{gathered}
\sum F_{i}=\omega^{2} m_{\mathrm{p}} e_{\mathrm{cT}}=0, \\
\sum M_{i}=\sum z_{i} \cdot F_{i}=m_{1} r_{1} l \omega^{2}=J_{x z} \neq 0,
\end{gathered}
$$

при $\lambda=-1, \varphi_{1}=0, \varphi_{2}=\pi$.

При моментной неуравновешенности ось ротора и его главная центральная ось инерции пересекаются в центре масс (рис. 4.14, б). Моментная неуравновешенность полностью определяется главным моментом дисбалансов ротора $M_{D}$ или его центробежными моментами инерции.

3. Для динамической неуравновешенности ротора (рис. $4.14,8$ ) справедливо:

$$
\sum F_{i}=m_{1} r_{1} \omega^{2} \cdot \sqrt{1-\lambda^{2}+2 \lambda \cos \varphi_{2}} \neq 0,
$$

при $|\lambda| \neq 1, \varphi_{1}=\varphi_{2}=0$ или $|\lambda|=1, \varphi_{1}=0, \varphi_{2}=0$ либо $\varphi_{2}=\pi$ или $|\lambda| \neq 1$, $\varphi_{1}=0, \varphi_{2}=a, a \neq 0 \neq \pi$. 


$$
A=\left[m_{1} r_{1} \lambda \sin \left(\varphi_{2}-\varphi_{C}\right)\right]^{2}+\left[\frac{\sum F_{i} \lambda \cos \left(\varphi_{2}-\varphi_{C}\right)-\cos \varphi_{C}}{2 \varphi^{2} \lambda \cos \left(\varphi_{2}-\varphi_{C}\right)+\cos \varphi_{C}}\right]^{2} .
$$

При динамической неуравновешенности, состоящей из статической и моментной, ось ротора и его главная центральная ось инерции пересекаются не в центре масс ротора или перекрещиваются (рис. 4.14, в). Динамическая неуравновешенность определяется главными вектором и моментом дисбалансов ротора.

В любом из вариантов неуравновешенности ротора при его вращении возникают дополнительные перегрузки в подшипниках, являющиеся причиной возникновения вибраций, передающихся на опоры.

В этом параграфе описывается построение математической модели деформаций сдвига ротора асинхронного двигателя в переходных режимах. Оценка максимальных деформаций сдвига при моментной неуравновешенности вращающихся валов асинхронных двигателей необходима для последующего определения их торсионных крутящих моментов, возникающих при их совместной работе в случае их синхронизации и захвата частоты вращения одним из двигателей. Установлено, что возникновение переменных торсионных крутящих моментов вращающихся валов при синхронизации частоты вращения роторов асинхронных двигателей понижает ресурс их работы и ведет к их разрушению, вследствие возрастания эксцентриситета валов и возникающей вибрации [19].

Задача оценки максимальных деформаций сдвига для определения и снижения переменных торсионных (крутящих) моментов вращающихся валов в стационарных и переходных режимах работы асинхронных двигателей всегда актуальна и отвечает современным запросам машиностроения $[19,110]$. При оценке максимальных деформаций сдвига вращающихся валов асинхронных двигателей, вызванных торсионными крутящими моментами используется метод конечных элементов.

В машиностроении часто представляют интерес переходные нестационарные процессы, при которых возможны резкие изменения напряжений и деформаций вращающихся валов силовых агрегатов и достижение недопустимо больших их величин $[19,110]$. Такие процессы могут возникать, например, при возрастании торсионных крутящих моментов вращающихся валов при синхронизации и захвате частоты вращения при совместной работе асинхронных двигателей и резком изменении режима их вибрации [41].

Аналитические расчеты переходных процессов, как правило, невозможны. В этих случаях используются численные методы [69, 87]. Ниже 
рассмотрен подход к решению задачи оценки максимальных деформаций сдвига вращающихся валов, возникающих в их поперечных сечениях для последующего определения торсионных крутящих моментов.

Схему ротора и вала асинхронного двигателя с их геометрическими и массовыми параметрами можно представить как на (рис. 4.15). На рис. 4.15 показано $d_{1}$ - радиус вала электродвигателя; $d_{2}$ - диаметр ротора; $b_{0}$ - приведенная длина ротора; $L$ - длина вала электродвигателя; $L_{1}$ - длина участков вала электродвигателя; $m_{1}, m_{2}, I_{1}, I_{2}$ - массы и моменты инерции вала и ротора электродвигателя соответственно.

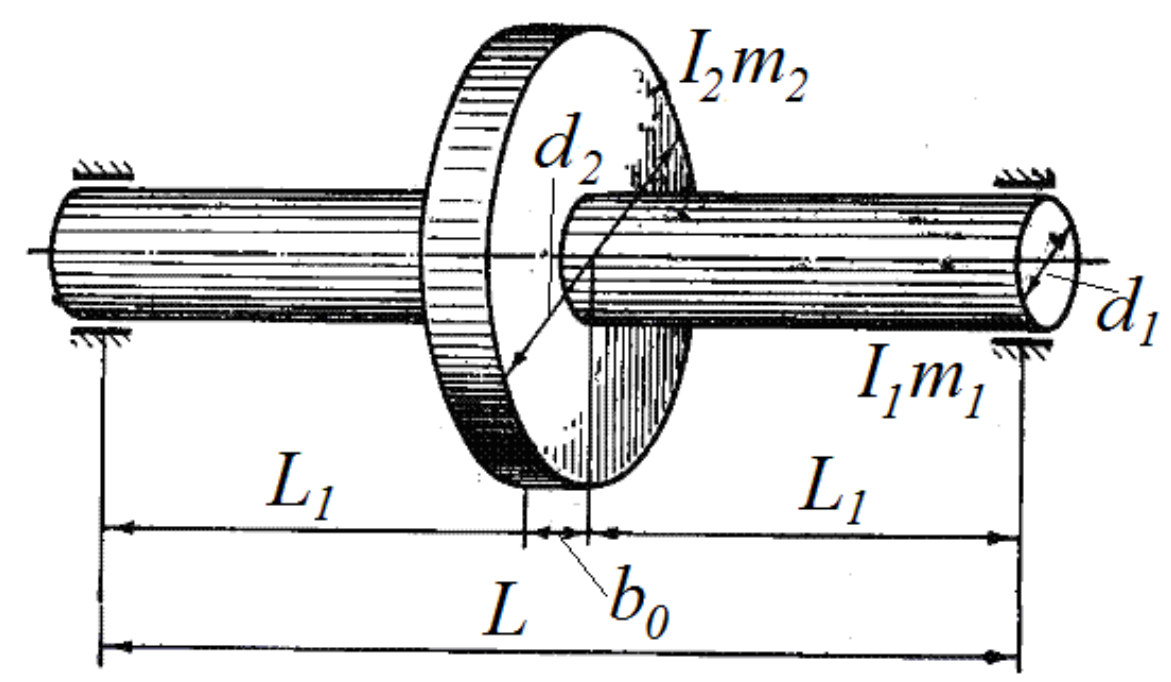

Рис. 4.15. Типовая схема однодискового ротора в виде диска между опорами

Для оценки максимальных деформаций сдвига вращающегося вала асинхронного двигателя отойдём от схемы однодискового ротора, представленной на (рис. 4.15), и будем рассматривать вал отдельно без ротора.

Определение переменных торсионных (крутящих) моментов вращающегося вала основано на оценке деформации сдвига по его сечению при приложении к валу переменных крутящих моментов. Для оценки деформации сдвига по сечению вала при приложении к валу переменных крутящих моментов необходимо знать, как движутся сечения вала относительно друг друга и как рассчитать это движение в любой текущий момент времени. Для упрощения задачи необходимо представить вращающийся вал как упругий торсион [69, 87]. Упругий торсион - деформируемый элемент (ДЭ), - как правило, является участком контролируемого стального вала прямоугольного сечения, закрепленным по торцам и установленным в разрыв вала машинного агрегата и являющийся частью некой кинематической цепи (рис. 4.16) [69].

Для определения внутренних деформации сдвига, возникающих в поперечных сечениях ДЭ вала под действием внешних моментов, используется метод сечений [69, 87]. 


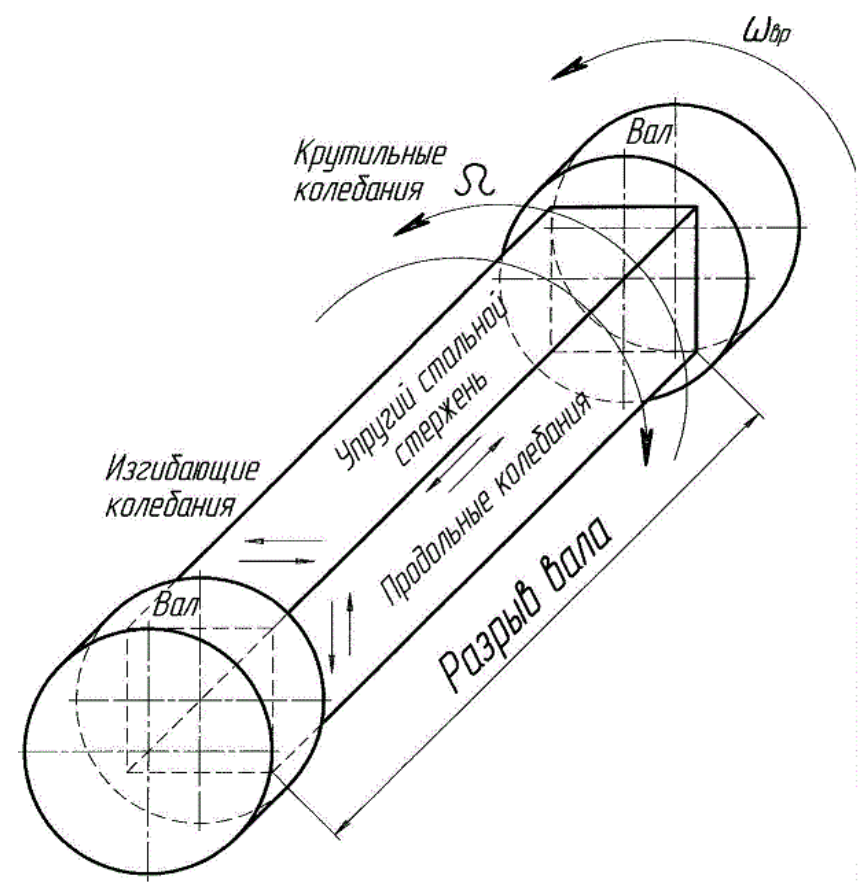

Рис. 4.16. Участок контролируемого стального вала прямоугольного сечения

Разобьем упругий прямоугольный торсион на элементы длины $h$ и пронумеруем их (рис. 4.17).

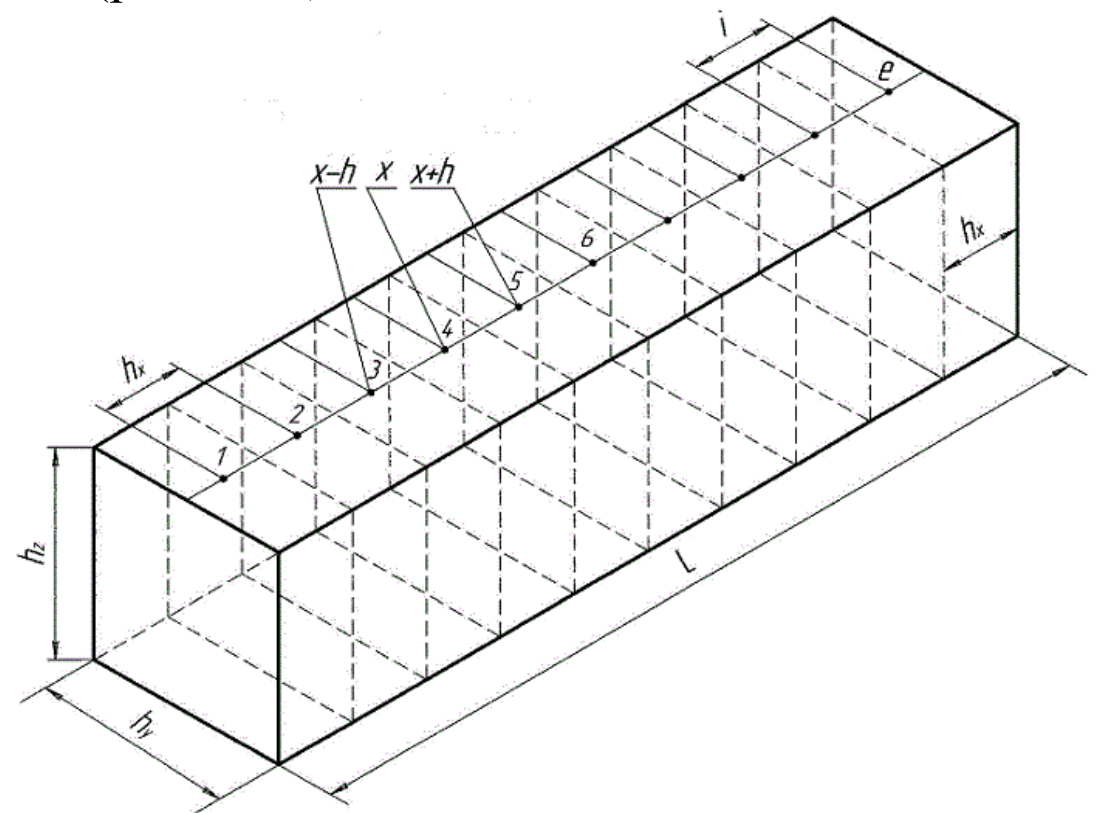

Рис. 4.17. Упругий прямоугольный торсион, разбитый на элементы длины $h$

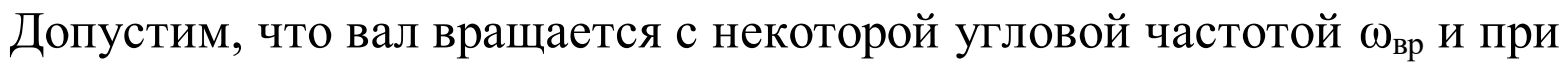
вращении возникают крутильные колебания с частотой $\Omega_{\text {кр}}$, при действии крутящих моментов $M_{x}^{+}$и $M_{x}^{-}$. Эти моменты создаются упругими напряжениями, моментами инерционных сил или моментами внешних сил по отношению к ДЭ вала - упругому торсиону. Гипотеза о распределении деформаций по сечению ДЭ состоит в предположении, что форма сечения не меняется и происходит только поворот сечения на угол $\varphi_{x}$ [69]. 
Таким образом, функция $\varphi_{\mathrm{x}}$ зависит только от координаты $x$ и не зависит от $y$ и $z$ (рис. 4.18).

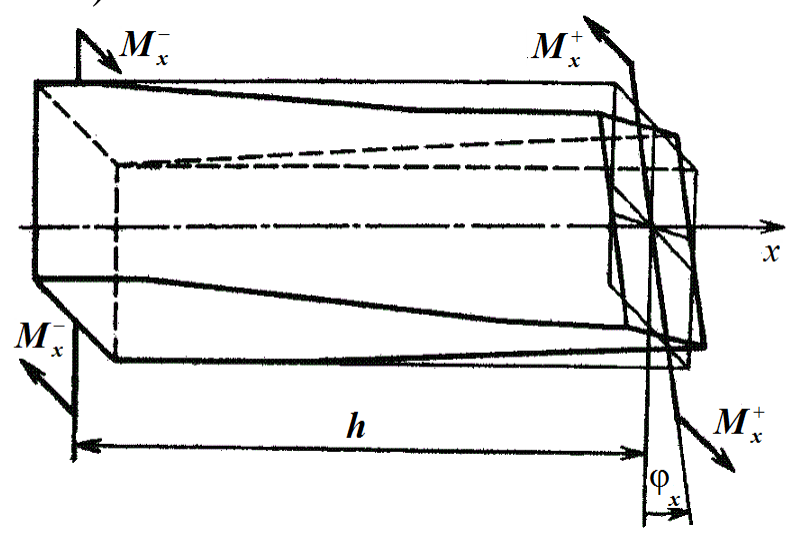

Рис. 4.18. Форма сечения торсиона не меняется и только его сечение повёрнуто на угол $\varphi_{\mathrm{x}}$

Если вращающийся вал совершает колебания вокруг оси вращения, то сечения торсиона также колеблются относительно оси вращения, причем величины закручивания элементов ДЭ не остаются постоянными и равными $\varphi_{\mathrm{x}}$, а изменяются. В одно время угол $\varphi_{\mathrm{x}}$ уменьшается, в другое, наоборот, становится больше. Вдоль ДЭ, вследствие эксцентриситета вала, распространяются упругие колебания - крутильные колебания [69].

При остановке вращения вала колебательный процесс в ДЭ вала постепенно затухает. В конечном счете, все элементы ДЭ вала приходят в исходное состояние, т.е. в положение равновесия. Это и есть одна из картин крутильных колебаний упругого ДЭ вала асинхронного двигателя.

Как же поворачиваются сечения ДЭ относительно друг друга и как рассчитать этот поворот? В общем случае можно отметить: поворот происходит таким образом, что все элементы ДЭ в каждый момент времени находятся в динамическом равновесии.

Произведём замену упругого торсиона в виде прямоугольного сечения, разбитого на элементы длины $h$ (рис. 4.17), на упругий торсион круглого сечения, также разбитого на элементы одинаковой длины $h$. Элементы одинаковой длины $h$ пронумеруем.

Выберем произвольный элемент с номером “ $i$ “ и запишем уравнение его динамического равновесия в виде [69]

$$
M_{x}^{+}-M_{x}^{-}=J_{m} \frac{d^{2} \varphi_{x}}{d t^{2}}
$$

где $J_{m}$ - момент инерционных сил элемента (момент инерции элемента).

Крутящие моменты следует выразить через касательные напряжения (рис. 4.19): 


$$
M_{x}^{+}=\int_{S} \sigma_{i+0,5} r d S
$$

где $r$ - расстояние элемента площади до центра ДЭ вала.

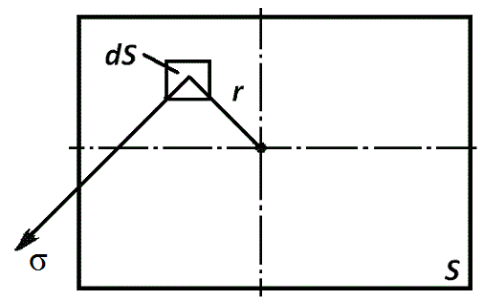

Рис. 4.19. Крутящие моменты выражены через касательные напряжения $\sigma$, изменяющиеся по поверхности $S$ как по значению, так и по направлению

Касательные напряжения $\sigma$ изменяются по поверхности $S$ как по значению, так и по направлению. Значения напряжений $\sigma$ определяют

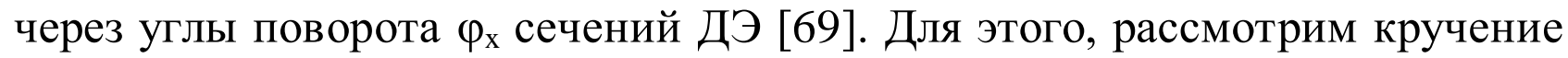
цилиндра, вырезанного из ДЭ вала (рис. 4.20).

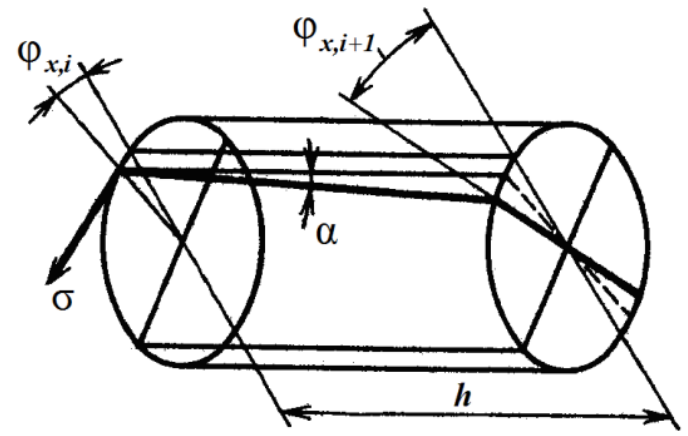

Рис.4.20. Кручение цилиндра, вырезанного из ДЭ вала

Деформация сдвига определяется как $\operatorname{tg} \alpha$ :

$$
\operatorname{tg} \alpha=\frac{\left(\varphi_{x, i+1}-\varphi_{x, i}\right) r}{h},
$$

а касательные напряжения пропорциональны $\operatorname{tg} \alpha$ :

$$
\sigma=G r \frac{\varphi_{x, i+1}-\varphi_{x, i}}{h}
$$

где $G$ - модуль сдвига материала ДЭ вала.

Теперь выражение для крутящего момента можно записать в виде

$$
M_{x}^{+}=G \frac{\varphi_{x, i+1}-\varphi_{x, i}}{h} \int_{S} \sigma_{i+0,5} r^{2} d S
$$


Интеграл в выражении (4.20) определяет полярный момент инерции сечения ДЭ вала. У ДЭ вала постоянного сечения полярный момент инерции сечения постоянен по длине ДЭ и не зависит от $x$ :

$$
J=\int_{S} r^{2} d S .
$$

Аналогично можно записать выражение для крутящего момента $M_{x}$. В него войдут углы $\varphi_{\mathrm{x}, i}$ и $\varphi_{\mathrm{x}, i-1}$. В результате уравнение равновесия примет вид [69, 87]

$$
J G \frac{\varphi_{x, i+1}-2 \varphi_{x, i}+\varphi_{x, i-1}}{h^{2}}=J_{m} \frac{d^{2} \varphi_{x}}{d t^{2}} .
$$

Момент инерционных сил пропорционален полярному моменту инерции сечения вала:

$$
J_{m}=J \rho h,
$$

где $\rho$ - плотность материала ДЭ вала.

Разделив левую и правую части уравнения (4.21) на $J$, получим

$$
G \frac{\varphi_{x, i+1}-2 \varphi_{x, i}+\varphi_{x, i-1}}{h^{2}}=\rho h \frac{d^{2} \varphi_{x}}{d t^{2}} .
$$

Запишем это уравнение в разностной форме, введя дискретизацию не только по координате $x$, но и по времени $t$, тогда получим следующее уравнение [69, 87]:

$$
G \frac{\varphi_{x, i+1}-2 \varphi_{x, i}+\varphi_{x, i-1}}{h^{2}}=\rho h \frac{\varphi_{x, i+1}-2 \varphi_{x, i}+\varphi_{x, i-1}}{\tau^{2}},
$$

где $j$ - номер шага времени; $\tau$ - шаг по времени.

Элементы длины $h$ и величины времени $\tau$, определяющие дискретизацию по координате $x$ и по времени $t$ являются для упругого ДЭ вала физическими постоянными, т.е. константами $h=$ const и $\tau=$ const [5].

Если в уравнении (4.23) устремить шаги по координатам и времени к нулю, то вторые разности по координатам и времени превратятся во вторые производные [69, 87]:

$$
G \frac{d^{2} \varphi_{x}}{d x^{2}}=\rho \frac{d^{2} \varphi_{x}}{d t^{2}} .
$$


Уравнение (4.24) есть дифференциальное уравнение в частных производных для крутильных колебаний, и представляет приближенную математическую модель процесса радиальных колебаний вала асинхронного двигателя.

Уравнение (4.24) можно записать и в следующем виде:

$$
\begin{aligned}
\frac{d^{2} \varphi_{x}}{d t^{2}} & =\frac{G}{\rho} \cdot \frac{d^{2} \varphi_{x}}{d x^{2}}, \\
\frac{d^{2} \varphi_{x}}{d t^{2}} & =a^{2} \cdot \frac{d^{2} \varphi_{x}}{d x^{2}},
\end{aligned}
$$

где $a=\sqrt{G / \rho}$.

Уравнения (4.25) и (4.26) называются дифференциальными уравнениями свободных крутильных колебаний цилиндрических валов постоянного сечения. Это есть дифференциальные уравнения в частных производных второго порядка гиперболического типа. Они еще называется волновыми уравнениями $[87,112]$.

В дальнейшем процесс угловых колебаний вала при его балансировке исследуется путем замены переменных в уравнениях (4.25) и (4.26) с использованием метода конечных элементов [69].

Определение переменных торсионных (крутящих) моментов вращающегося вала основано на оценке деформации сдвига по его сечению при приложении к валу переменных крутящих моментов. При оценке деформации сдвига $\varepsilon_{\max }$ по сечению вала (рис. 4.21) при действии переменных крутящих моментов на валу $M_{x}^{+}$и $M_{x}^{-}$необходимо провести вычисление перемещений всех точек ДЭ вала в любой текущий момент времени. При вращении вала из-за действия крутящих моментов $M_{x}^{+}$и $M_{x}^{-}$возникают

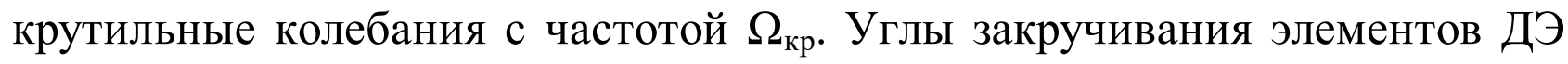
не остаются постоянными и равными $\varphi_{\mathrm{x}}$, а линейные перемещения точки с радиусом $r$ изменяются с линейной скоростью $v_{\text {л }}=\Omega_{\text {кр }} r$.
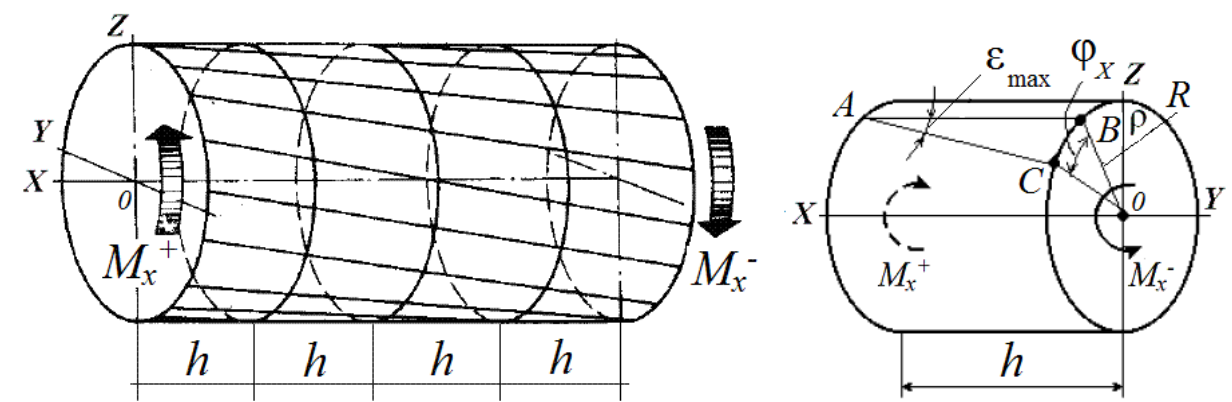

Рис. 4.21. Стальной вал круглого сечения разбитый на элементы длины $h$ 
Допустим, что в начальный момент $(t=0)$ правая часть ДЭ вала остается неподвижной, а к левой части приложен некоторый вращающий момент (рис. 4.21). Задача состоит в расчете перемещений во времени во всех точках ДЭ вала. Введем дискретизацию по координате и времени для ДЭ вала, т.е. выберем шаги сетки $h$ и $\tau$, разобьем область решения на дискретные элементы $h$ х $\tau$ и пронумеруем их [69].

Тогда для дискретной области уравнение движения примет вид (4.22), а в разностной форме (4.23).

Предположим, что по координате выбрано шесть узлов $i=1, \ldots, 6$ (рис. 4.22). Начальные условия представлены в виде угловых перемещений и линейных скоростей всех точек ДЭ вала, при $t=0$ на круговой диаграмме угловых перемещений всех точек узлов ДЭ вала.

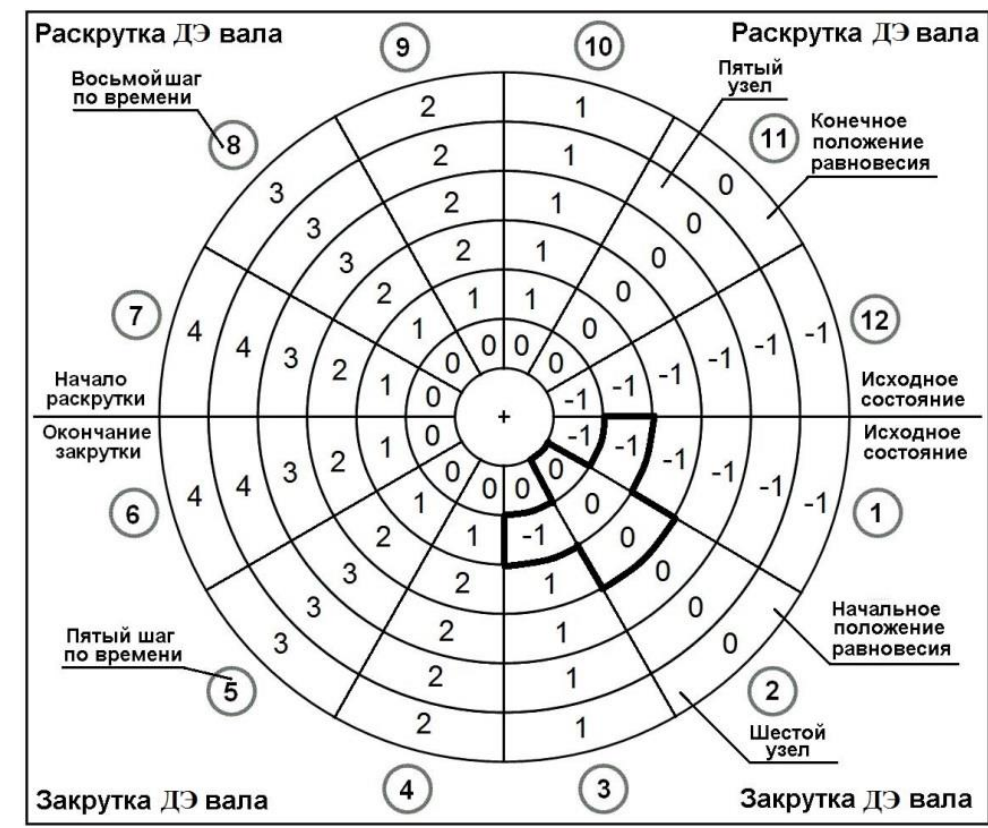

\section{Рис. 4.22. Круговая диаграмма угловых перемещений всех точек узлов ДЭ вала}

В разностной постановке эти начальные условия вводим следующим образом (рис. 4.22): в первом шаге во времени $j=1$ все центры элементов ДЭ вала помещаем на один и тот же угол $\varphi_{x}$ от начального положения, т.е. на

$$
\varphi_{i, 1}=-v_{\mathrm{\Omega}} \tau=-1,
$$

тогда в следующем шаге, на круговой диаграмме угловых перемещений всех точек узлов ДЭ вала (рис. 4.22), когда ДЭ вала начинает закручиваться под действием крутящего момента $(t=0)$, и все точки приходят в начальное состояние $\varphi_{i, 2}=0$.

Таким образом, задаются начальные угловые перемещения всех точек равными нулю (задаем систему отсчета), а линейные скорости всех точек равными $v_{\text {л }}$ Результаты расчета представлены в табл. 4.2. 
Таблица 4.2

Вычисления перемещений средних точек элементов ДЭ упругого вала

\begin{tabular}{|c|c|c|c|c|c|c|}
\hline $\boldsymbol{i}, \boldsymbol{j}$ & \multicolumn{7}{|c|}{$\boldsymbol{i}$} \\
\hline $\boldsymbol{j}$ & $\mathbf{1}$ & $\mathbf{2}$ & $\mathbf{3}$ & $\mathbf{4}$ & $\mathbf{5}$ & $\mathbf{6}$ \\
\hline 1 & -1 & -1 & -1 & -1 & -1 & -1 \\
\hline 2 & 0 & 0 & 0 & 0 & 0 & 0 \\
\hline 3 & 0 & -1 & 1 & 1 & 1 & 1 \\
\hline 4 & 0 & 1 & 2 & 2 & 2 & 2 \\
\hline 5 & 0 & 1 & 2 & 3 & 3 & 3 \\
\hline 6 & 0 & 1 & 2 & 3 & 4 & 4 \\
\hline 7 & 0 & 1 & 2 & 3 & 4 & 4 \\
\hline 8 & 0 & 1 & 2 & 3 & 3 & 3 \\
\hline 9 & 0 & 1 & 2 & 2 & 2 & 2 \\
\hline 10 & 0 & 1 & 1 & 1 & 1 & 1 \\
\hline 11 & 0 & 0 & 0 & 0 & 0 & 0 \\
\hline 12 & -1 & -1 & -1 & -1 & -1 & -1 \\
\hline
\end{tabular}

Первые две строки этой таблицы и есть начальные условия задачи [69]. Далее определяются граничные условия. Нижний конец ДЭ вала не закручивается. Поэтому в левом столбце записываются нули. На верхнем, свободном конце ДЭ вала отсутствуют напряжения, а значит, равны нулю и деформации сдвига:

$$
\frac{\varphi_{6, j}-\varphi_{5, j}}{h}=0,
$$

т.е. угловые перемещения в пятом и шестом элементах должны быть одинаковыми:

$$
\varphi_{6, j}=\varphi_{5, j} .
$$

Далее производятся вычисления деформаций сдвига средних точек ДЭ вала с помощью уравнения $(4.23)[69,87]$.

В уравнении $(4, .23)$ в разностной форме входят пять значений угловых перемещений $(i ; j),(i+1 ; j),(i-1 ; j),(i ; j+1),(i ; j-1)$, которые должны быть записаны в пяти соседних ячейках диаграммы угловых перемещений точек узлов ДЭ вала и табл. 4.2.

Если, например, $i=2$ и $j=2$, то пять клеток будут расположены в верхнем левом углу табл. 4.2, или заштрихованные сегменты (рис. 4.22). Они образуют так называемый пятиточечный шаблон. В четырех клетках шаблона угловые перемещения известны. Остается неизвестной только 
одна величина $\varphi_{i, j+1}$. Ее можно легко вычислить по формуле, приведенной ниже [69].

Для удобства вычислений уравнения решается относительно неизвестной $\varphi_{i, j+1}$ :

$$
\varphi_{i, j+1}=A\left(\varphi_{i+1 ; j}-2 \varphi_{i ; j}+\varphi_{i+1 ; j}\right)+2 \varphi_{i ; j}-\varphi_{i ; j-1},
$$

где $A=G \tau^{2} / \rho h^{2} ; G$ - модуль сдвига; $\rho$ - плотность материала ДЭ вала.

Эта формула, в которой значение неизвестной функции на следующем временном слое $j+1$ явным образом выражено через значения функции на предыдущих слоях, совместно с начальными и граничными условиями называется явной разностной схемой.

Величина безразмерного коэффициента $A$ зависит от выбранных шагов $h$ и $\tau$. Самые простые вычисления получаются при $A=1$. При этом разностная формула приобретает простой вид [69]:

$$
\varphi_{i ; j+1}=\varphi_{i+1 ; j}+\varphi_{i-1 ; j}-\varphi_{i ; j-1}
$$

Подставив в (4.28) значения $\varphi_{3,2}=0, \varphi_{1,2}=0, \varphi_{2,1}=-1$, получим $\varphi_{2,3}=1$.

Запишем это значение в табл. 4.2, переставим шаблон на одну клетку и вычислим $\varphi_{3,3}=1$. Далее, вычисляя $\varphi_{x}$ в последующих узлах, заполняем строку $j=3$. Значение $\varphi_{6,3}$ берется таким же, как и $\varphi_{5,3}$ в соответствии с (4.27). Переставим шаблон на одну строку вниз и произведем вычисления в строке $j=4$.

Продолжим вычисления последовательно по временным слоям $j$ на требуемое число шагов.

На круговой диаграмме угловых перемещений всех точек узлов ДЭ вала (рис. 4.22) показаны положения центров элементов ДЭ вала в каждом шаге по времени. После закручивания ДЭ вала (поворота) поверхности при $j=2$ первый узел $i=1$ прекращает поворачиваться, а последующие продолжают поворот. Затем при $j=3$ прекращает поворачиваться второй узел и т.д. В шестом шаге по времени все узлы ДЭ вала останавливаются. При этом весь ДЭ вала оказывается равномерно сжат (закручен).

Деформации во всех элементах между узлами одинаковы, кроме последнего элемента между узлами $i=5$ и $i=6$, в котором они остаются равными нулю.

Таким образом, весь процесс сжатия (закрутки) ДЭ вала длится четыре шага. Это объясняется тем, что в модели ДЭ вала пять шагов по координате, и за каждый шаг по времени закручивается один элемент 
длиной $h$, причем последний элемент не сжимается (не закручивается). Если бы шаги были поменьше, то количество шагов $n$ по времени при сжатии приближалось бы к количеству шагов по координате, укладывающихся по длине ДЭ вала, и тогда время закрутки определялось бы по формуле [69]

$$
T_{\text {сж }}=n \tau=\frac{L}{h} \tau \text {. }
$$

После завершения закрутки ДЭ вала начинается процесс раскручивания, так как ДЭ вала не находится в положении равновесия. Деформации сжатия (закрутки) теперь определяют начальные условия. Задается новая система отчета. Теперь последний элемент ДЭ вала является первым, расчет перемещений идет от последнего элемента к первому. Начиная с восьмого шага по времени (рис. 4.22), ДЭ вала начинает раскручиваться и за тоже время приходит в исходное недеформированное состояние.

На шаге $j=11$ все точки ДЭ вала вновь оказываются в положении равновесия. После этого шага $j=11$ процесс повторяется вновь уже с прежними нулевыми граничными условиями (рис. 4.22), т.е. прежняя заданная система отчета восстановлена и опять начался процесс сжатия и так далее.

В соответствии с выражением $A=G \tau^{2} / \rho h^{2}=1$ шаг по времени

$$
\tau=h \sqrt{\frac{\rho}{G}},
$$

где $G$ - модуль сдвига; $\rho$ - плотность материала, тогда

$$
T_{\text {сж }}=L \sqrt{\frac{\rho}{G}} .
$$

Известно [69, 87], что скорость распространения механических колебаний в твердых телах определяется из соотношения

$$
V=\sqrt{\frac{E}{\rho}},
$$

где $E$ - модуль упругости.

Механические колебания в ДЭ вала являются волнами кручения, и они чистопоперечные и недисперсионные, то есть их скорость не зависит от длины волны $[87,112]$. Поэтому, если твердое тело закручивается, в 
нашем случае ДЭ вала, то скорость распространения механических колебаний в нём определяется из выражения

$$
V=\sqrt{\frac{G}{\rho}}=\sqrt{\frac{E}{2 \rho(1+\mu)}},
$$

где $\mu$ - коэффициент Пуансона.

Поэтому время закрутки $T_{3}$ ДЭ вала представляет собой отношение [69]:

$$
T_{3}=L / V=T_{\text {сж}},
$$

которое определяет время прохода ультразвуковой волны по длине ДЭ вала. Это время не зависит от скорости закрутки ДЭ вала $v_{\text {л }}$ и выбранных шагов $h$ и $\tau$.

Распространение волны кручения в ДЭ вала кругло сечения показано на рис. 4.23.

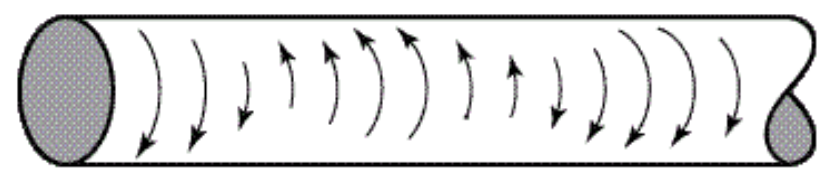

Рис. 4.23. Распространение волны кручения по длине ДЭ вала круглого сечения

Максимальные деформации во всех элементах ДЭ вала получаются одинаковыми и равными [69]

$$
\varepsilon_{\max }=\frac{v_{\text {Л }} \tau}{h}=v_{\text {Л }} \sqrt{\frac{2 \rho(1+\mu)}{E}}=\frac{v_{\text {Л }}}{V},
$$

а напряжения:

$$
\sigma=G \varepsilon_{\max }=\frac{G v_{\text {Л }}}{V}=v_{\text {Л }} \sqrt{\frac{2 \rho(1+\mu)}{E}} .
$$

Как видим, максимальные деформации и напряжения упругого ДЭ вала определяемые выражениями (4.35) и (4.36) и они прямо пропорциональны линейной скорости, т.е. при приложении переменных крутящих моментов являются функциями:

$$
\varepsilon=f\left(v_{\pi}\right)
$$

и

$$
\sigma=f\left(v_{\pi}\right),
$$

а так как $v_{\text {л }}=\Omega_{\text {кр }} r$, то искомые величины являются и функциями частоты крутильных колебаний ДЭ вала т.е. $\varepsilon=f\left(\Omega_{\text {кр }}\right)$ и $\sigma=f\left(\Omega_{\text {кр }}\right)$. 
Чтобы определить, в каком масштабе измеряется перемещение сечений ДЭ вала, нужно воспользоваться равенством $v_{\pi} \cdot \tau=1$.

Например, для вала асинхронного электродвигателя при частоте крутильных колебаний $\Omega_{\text {кр }}=0,628$ рад/с и радиусе вала $r=0,017$ м линейная скорость закручивания элементов вала будет равна

$$
v_{\text {л }}=\Omega_{\text {кр }} r=10,676 \cdot 10^{-3} \mathrm{M} / \mathrm{c} .
$$

Если, например, материал вала электродвигателя имеет характери-

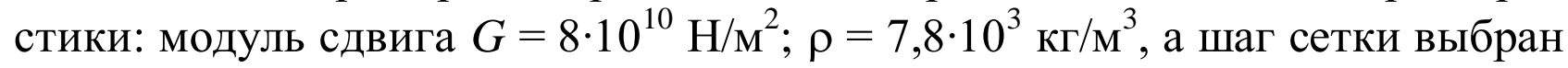
равным $h=0,01 \mathrm{м}$, то в соответствии с (4.31) шаг по времени получается равным

$$
\tau=0,01 \sqrt{\frac{7,8 \cdot 10^{3}}{8 \cdot 10^{10}}} \approx 3,122 \cdot 10^{-6} \mathrm{c} .
$$

Если элементы вала закручиваются со скоростью $v_{\text {Л }}=1,0676 \mathrm{~m} / \mathrm{c}$, то из выражения (4.35) получаем максимальные деформации во всех элементах вала равными:

$$
\varepsilon_{\max }=\frac{10,676 \cdot 10^{-3} \cdot 3,122 \cdot 10^{-6}}{0,01} \approx 3,333042 \cdot 10^{-6} .
$$

Таким образом, максимальные деформации во всех элементах вала получаются малыми. Поэтому и каждая единица для элементов вала в табл. 4.2 равна 3,3330472 микрон. Максимальные напряжения во всех элементах вала получаются равными [69]:

$$
\sigma=G \varepsilon_{\max }=8 \cdot 10^{10} \cdot 3,333042 \cdot 10^{-6}=266,64 \cdot 10^{3} \mathrm{H} / \mathrm{M}^{2} .
$$

Деформация сдвига во всех элементах вала определяется как $\operatorname{tg} \alpha$ по (4.18).

Тогда максимальный взаимный поворот сечений всех элементов вала электродвигателя относительно друг друга находим из выражения (4.18), заменяя $\operatorname{tg} \alpha$ максимальными деформациями $\varepsilon_{\max }$, то есть $\operatorname{tg} \alpha=\varepsilon_{\max }$ :

$$
\begin{gathered}
\varepsilon_{\max }=\operatorname{tg} \alpha=\frac{\left(\varphi_{x, i+1}-\varphi_{x, i}\right) r}{h}, \\
\Delta \varphi_{\max }=\left(\varphi_{x, i+1}-\varphi_{x, i}\right)=\frac{\varepsilon_{\max } h}{r} .
\end{gathered}
$$

Воспользуемся данными примера: $\varepsilon_{\max }=3,333042 \cdot 10^{-6} ; r=0,017$ м; $h=0,01$ м, тогда максимальный взаимный поворот сечений всех элементов вала относительно друг друга составит величину: 


$$
\Delta \varphi_{\max }=\left(\varphi_{x, i+1}-\varphi_{x, i}\right)=\frac{\varepsilon_{\max } h}{r}=\frac{3,3330472 \cdot 10^{-6} \cdot 0,01 \mathrm{M}}{0,017 \mathrm{M}}=1,960616 \cdot 10^{-6} \text { рад . }
$$

В угловых единицах максимальные деформации во всех элементах вала составят углам поворота сечений $\Delta \varphi_{\max } \approx 0,404406^{\prime \prime}$ - угловых секунд или $\Delta \varphi_{\max } \approx 0,0067041^{\prime}$ - угловые минуты.

Максимальный угол закрутки вала электродвигателя длиной 0,3 м составит

$$
\Delta \varphi_{\text {в. max }}=30 \cdot \frac{\varepsilon_{\max } h}{r}=30 \cdot 1,960616 \cdot 10^{-6}=58,81848 \cdot 10^{-6} \text { рад } .
$$

В угловых единицах максимальная деформация вала электродвигателя длиной 0,3 м составит величину $\Delta \varphi_{\text {в } \max } \approx 30 \cdot 0,404406^{\prime \prime}=12,13218^{\prime \prime}$ угловых секунд или $\Delta \varphi_{\text {в } \max } \approx 30 \cdot 0,0067041^{\prime}=0,202203^{\prime}$ - угловые минуты.

Максимальное время закрутки вала электродвигателя длиной $0,3 \mathrm{M}$ при $\Omega_{\text {кр }}=0,628$ рад/с и $T_{\text {кр }}=0,1$ с составит величину

$$
t_{\text {см. } \max }=\frac{\Delta \varphi_{8 \cdot \max }}{2 \pi} \cdot T_{\text {кр }}=\frac{58,81848 \cdot 10^{-6}}{2 \pi} \cdot 0,1 \mathrm{c}=0,9366 \cdot 10^{-6} \mathrm{c} .
$$

Допустимый номинальный крутящий момент на валу электродвигателя определяется выражением

$$
M_{\text {кр.н }}=\frac{\Delta \varphi}{L} G \int_{S} R^{2} d S .
$$

Интеграл в выражении (4.39) полярный момент инерции сечения вала электродвигателя радиусом $R$. У вала электродвигателя постоянного сечения полярный момент инерции сечения постоянен по длине вала и не зависит от длины его базового участка (база $L=0,3 \mathrm{M}$ ):

$$
J_{\mathrm{p}}=\int_{S} R^{2} d S .
$$

Для круглого сечения вала электродвигателя (рис. 4.23) с радиусом $R=0,0171$ м полярный момент инерции определяется выражением [13, 87]:

$$
J_{\mathrm{p}}=\pi \cdot R^{4} / 2 \text {. }
$$

Модуль сдвига вала электродвигателя $G=8 \cdot 10^{10} \mathrm{H} / \mathrm{M}^{2}$; плотность материала вала электродвигателя $\rho=7,8 \cdot 10^{3} \quad \kappa \Gamma / \mathrm{m}^{3}, \quad$ жёсткость $G J_{\mathrm{p}}=10,7447 \cdot 10^{3} \mathrm{H} \cdot \mathrm{M}^{2}$. 
Крутящий момент от действия крутильных колебаний на валу электродвигателя, при частоте крутильных колебаний $\Omega_{\text {кр }}=0,628$ рад/с определяем по выражению

$$
\begin{aligned}
M_{\text {кр.н }} & =\frac{\Delta \varphi_{\text {в. } \max }}{L} G J_{p}=\frac{58,81848 \cdot 10^{-6}}{0,3 \mathrm{M}} 10,7447 \cdot 10^{3} \mathrm{H} \cdot \mathrm{M}^{2}= \\
& =2106,623 \cdot 10^{-3}=2,106623 \mathrm{H} \cdot \mathrm{M}
\end{aligned}
$$

Далее можно перейти к расчёту максимальных деформаций реальных вращающихся реальных валов асинхронных двигателей.

При расчетах крутильных колебаний валов электрических машин, как правило, встречаться валы переменного сечения. Чаще всего сечение изменяется уступом, переходя от одного диаметра $D_{1}$ к другому $D_{2}$ (рис. 4.24).

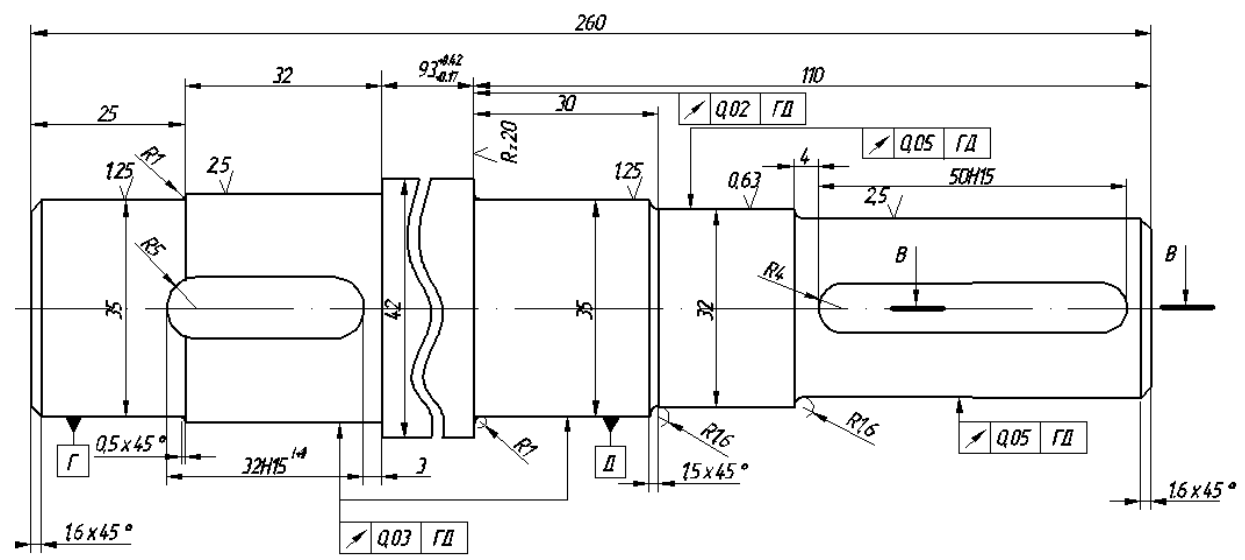

Рис. 4.24. Чертёж реального вала асинхронного электродвигателя

Поэтому при переходе к расчёту максимальных деформаций вращающихся реальных валов электрических машин необходимо их привести к эквивалентному валу простого круглого сечения. В реальных конструкциях валов в местах соединения участков вала различной длины и диаметра наличествуют галтели - округления углов на деталях, как представлено на чертеже реального вала асинхронного электродвигателя (рис. 4.24). Галтели повышают прочность и снижают внутренние напряжения при переходе от меньших сечений к большим сечениям. Для таких соединений необходимо применять метод приведения к эквивалентному участку вала $[13,87,90]$.

При аналитическом решении возникает трудность в подборе формул для описания колебаний валов, которые помимо общих требований удовлетворения уравнениям и начальным и граничным условиям должны еще удовлетворять промежуточным граничным условиям на стыке валов. Формулы для участков малого и большего диаметров валов на стыке 
должны давать одно и то же значение углов поворота и крутящих моментов. Эти требования называют «сшиванием» решения по промежуточным граничным условиям. При поиске аналитических решений такое «сшивание» представляет собой существенную трудность.

При разностном решении задачи такая трудность не возникает, но появляется необходимость в дополнительном уравнении движения для элемента стыка участков валов.

Для участков малого и большего диаметров валов дифференциальное уравнение равновесия в частных производных для крутильных колебаний:

$$
G \frac{d^{2} \varphi_{x}}{d x^{2}}=\rho \frac{d^{2} \varphi_{x}}{d t^{2}}
$$

записывают в разностной форме:

$$
J G \frac{\varphi_{x, i+1}-2 \varphi_{x, i}+\varphi_{x, i-1}}{h^{2}}=J_{m} \frac{d^{2} \varphi_{x}}{d t^{2}} .
$$

Для стыка в уравнение динамического равновесия вращающегося реального вала в виде

$$
M_{x}^{+}-M_{x}^{-}=J_{m} \frac{d^{2} \varphi_{x}}{d t^{2}},
$$

где $J_{m}$ - момент инерционных сил элемента (момент инерции элемента), нужно учесть, что моменты $M_{x}^{+}$и $M_{x}^{-}$относятся к участкам вала разного диаметра.

Проще всего поместить центр промежуточного элемента участка вала - узел сетки - на границе раздела (рис. 4.25).

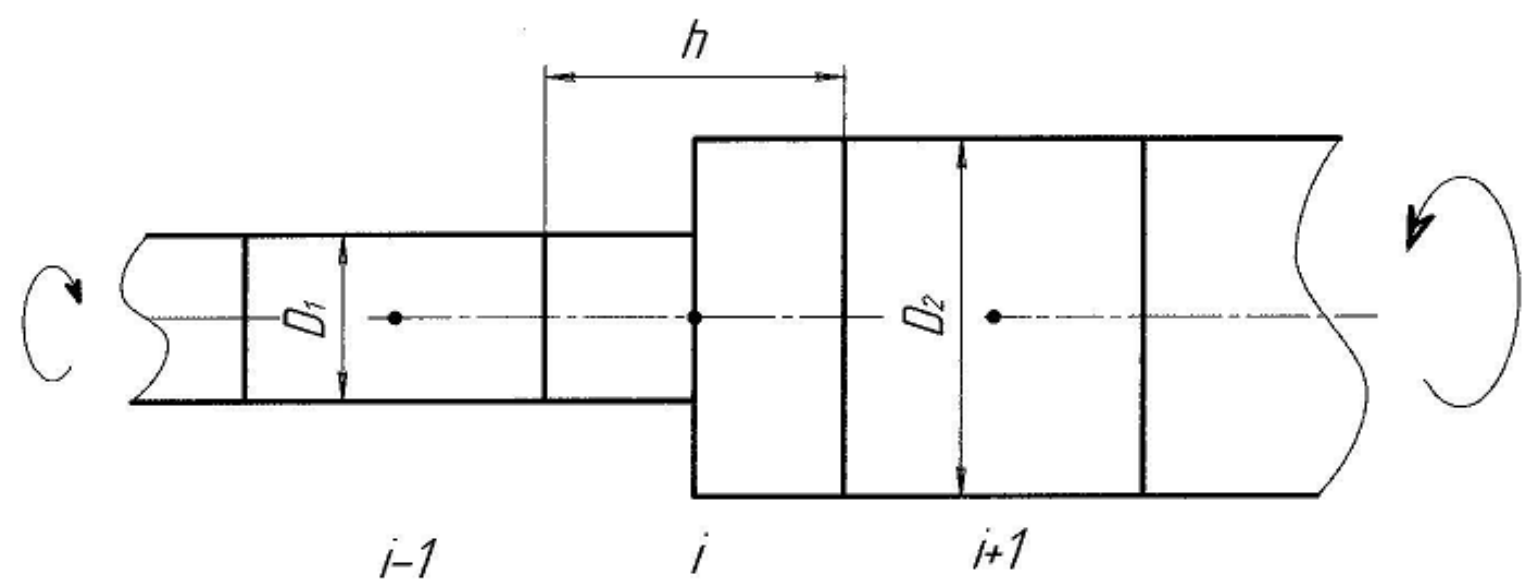

Рис. 4.25. Центр промежуточного элемента участка вала - узел сетки помещён на гранище раздела 
Тогда вместо уравнения (4.43) нужно записать

$$
J_{2} G_{2} \frac{\varphi_{x, i+1, j}-\varphi_{x, i, j}}{h}-J_{1} G_{1} \frac{\varphi_{x, i, j}-\varphi_{x, i-1, j}}{h}=J_{m c p} \frac{\varphi_{x, i, j-1}-2 \varphi_{x, i, j}+\varphi_{x, i, j+1}}{\tau^{2}} .
$$

Произвести сокращение в данном случае не удается и нужно вычислить оба центральных момента инерции и момент инерционных сил $J_{m с p}$.

Например:

$$
\begin{gathered}
J_{1}=\int_{S_{1}} r_{1}^{2} d S \\
J_{2}=\int_{S_{2}} r_{2}^{2} d S \\
J_{m c p}=\frac{h}{2} \int_{S_{1}} \rho_{1} r_{1}^{2} d S+\frac{h}{2} \int_{S_{2}} \rho_{2} r_{2}^{2} d S .
\end{gathered}
$$

В случае валов круглого сечения вычисление интегралов в формулах (4.46) не представляет труда, если воспользоваться цилиндрической системой координат (рис. 4.26).

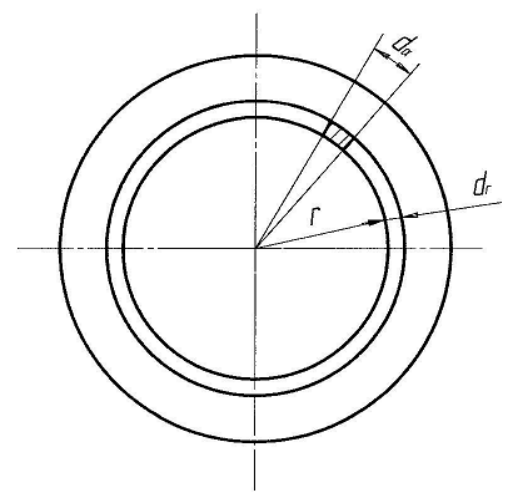

Рис. 4.26. Поперечный разрез вала в цилиндрической системе координат Например, $d S=r d \alpha d r$ и

$$
J_{1}=\int_{0}^{2 \pi} d \alpha \int_{0}^{R} r^{3} d r=\pi \frac{R r^{4}}{2} .
$$

Подставив численные значения в уравнения (4.45), получим явную формулу наподобие $A=G \tau^{2} / \rho h^{2}, G$ - модуль сдвига, $\rho$ - плотность материала реального вала.

Для расчета вала, показанного на рис. 4.25, в качестве конечного принимается элемент постоянного сечения (рис. 4.27). На рис. 4.27 показано: $l$ - конечная длина элемента; $z$ - координата вдоль оси элемента; $\varphi_{i}$, $\varphi_{\gamma}-$ угловые повороты элемента. 


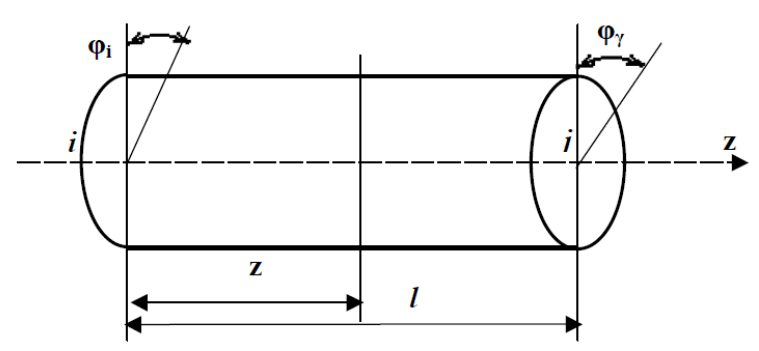

Рис. 4.27. Конечный элемент вала

Так как каждый узел имеет одну степень свободы, то функция перемещений для конечного элемента вала имеет вид

$$
\varphi=\alpha_{0}+\alpha_{1} z
$$

Коэффициенты $\alpha_{0}$ и $\alpha_{1}$ определяем через перемещения $\varphi_{i}, \varphi_{j}$ узлов. При $z=0, \varphi=\varphi_{i}$, а при $z=l, \varphi=\varphi_{j}$. Подставив эти значения в выражение (4.48), получим $\varphi_{i}=\alpha_{0}, \varphi_{j}=\alpha_{0}+\alpha_{1} l=\varphi_{i}+\alpha_{1} l$, откуда

$$
a_{1}=\frac{\varphi_{j}-\varphi_{i}}{l} .
$$

Подставляем значения $\alpha_{0}$ и $\alpha_{1}$ в выражение (4.48)

$$
\varphi=\varphi_{i}+\frac{\varphi_{j}-\varphi_{i}}{l} z=\left(1-\frac{z}{l}\right) \varphi_{i}+\frac{z}{l} \varphi_{j} .
$$

Не вызывает принципиальных трудностей при расчетах крутильных колебаний и наличие в конструкции сосредоточенных масс, например укрепленных на валах шкивов, шестерен, рычагов. Для соответствующих узлов сетки записывают уравнения (4.45), в правой части которых учитывают моменты этих дополнительных деталей.

Механизмы электромеханических комплексов имеют привод, несущими элементами которого являются валы, зубчатые колеса, муфты, гибкие звенья (цепи, ремни). В процессе эксплуатации валопровода привода из-за податливости материала, из которого изготовлены несущие элементы, в них возникает упругая деформация кручения, способствующая возникновению и росту моментов сил упругости. Моменты сил упругости будут доминирующей нагрузкой в валопроводе привода всех электромеханических комплексов. Для динамического исследования таких электромеханических систем необходимо определить численные значения некоторых параметров, важнейшим из которых является крутильная жесткость упругого элемента (вала). Приводные и трансмиссионные валы электромеханических комплексов механизмов передвижения мобильных машин, как правило, имеют ступенчатую конфигурацию, что значительно 
усложняет задачу определения численного значения крутильной жесткости валов валопроводов. Сначала определяется жесткость каждого участка вала, затем вычисляется общая крутильная жесткость всего вала по формуле, определяющую жесткость упругих элементов при последовательном соединении. В таких случаях бывает целесообразно ступенчатый вал (рис. 4.28,a) заменить гладким валом эквивалентной жесткости (рис. 4.28, б). При этом изменится общая длина вала, которая теперь, будет называться приведенной длиной $\ell$. Диаметр гладкого вала постоянный по всей длине теперь, будет называться приведенным диаметром $d$. Диаметр и длина вала - основные геометрические размеры вала для определения численного значения крутильной жесткости.

Приведенный диаметр вала можно определить по формуле

$$
d=\frac{d_{1} \ell_{1}+d_{2} \ell_{2}+d_{3} \ell_{3}+d_{4} \ell_{4}}{\ell_{1}+\ell_{2}+\ell_{3}+\ell_{4}}
$$

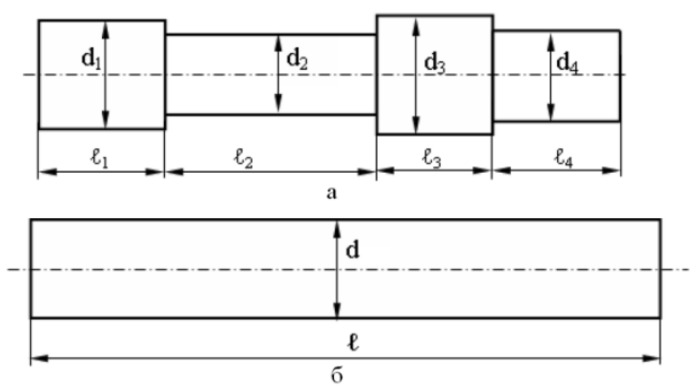

Рис. 4.28. Эскизы реального (а) и приведенного валов (б)

Для определения приведенной длины рассмотрим ступенчатый вал, работающий на кручение (рис. $4.28, a$ ) Ступенчатый вал можно рассматривать как последовательно соединенные дискретные тела с соответствующими диаметрами и длинами. Податливость такого вала определяется суммированием податливостей е участков вала: $\mathrm{e}=\mathrm{e}_{1}+\mathrm{e}_{2}+\mathrm{e}_{3}+\mathrm{e}_{4}$.

Поскольку крутильная жесткость вала есть величина обратная его податливости е $=1 / C$, то её можно определить, используя формулу

$$
\frac{1}{C}=\frac{1}{C_{1}}+\frac{1}{C_{2}}+\frac{1}{C_{3}}+\frac{1}{C_{4}}
$$

Крутильная жесткость каждого участка вала

$$
C_{i}=\frac{\pi G d_{i}^{4}}{32 \ell_{i}},
$$

где $i=1,2,3,4$.

Подставив это выражение в формулу (4.50), получим 


$$
\frac{32 \ell}{\pi G d^{4}}=\frac{32 \ell_{1}}{\pi G d_{1}^{4}}+\frac{32 \ell_{2}}{\pi G d_{2}^{4}}+\frac{32 \ell_{3}}{\pi G d_{3}^{4}}+\frac{32 \ell_{4}}{\pi G d_{4}^{4}},
$$

где $\ell$ - приведенная длина вала; $d$ - приведенный диаметр вала.

Таким образом, используя уравнение (4.51), получим формулу для определения приведенной длины вала:

$$
\left\{\begin{array}{l}
\frac{\ell}{d^{4}}=\frac{\ell_{1}}{d_{1}^{4}}+\frac{\ell_{2}}{d_{2}^{4}}+\frac{\ell_{3}}{d_{3}^{4}}+\frac{\ell_{4}}{d_{4}^{4}} \\
\ell=\ell_{1}\left(\frac{d}{d_{1}}\right)^{4}+\ell_{2}\left(\frac{d}{d_{2}}\right)^{4}+\ell_{3}\left(\frac{d}{d_{3}}\right)^{4}+\ell_{4}\left(\frac{d}{d_{4}}\right)^{4} .
\end{array}\right.
$$

Определим, для примера, используя формулы (4.49) и (4.52) приведенную длину и приведенный диаметр вала асинхронного электродвигателя (рис. 4.29). Ступенчатый вал электродвигателя имеет четыре ступени.

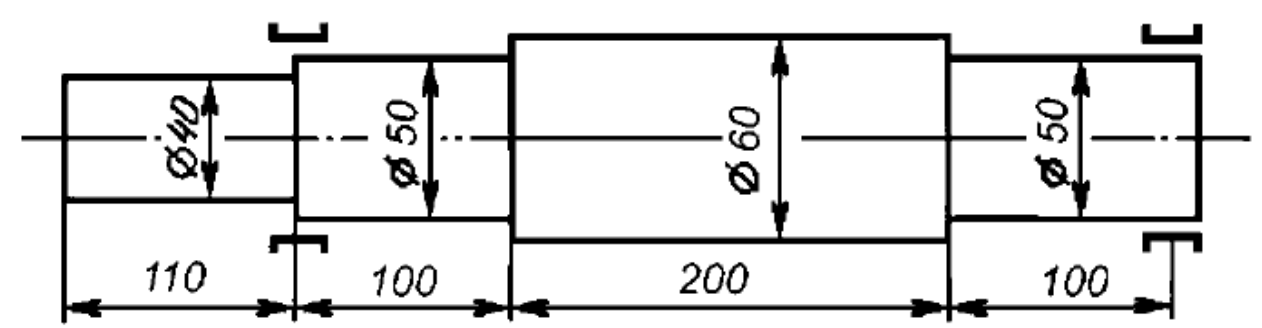

Рис. 4.29. Эскиз ступенчатого вала асинхронного электродвигателя

Геометрические размеры ступенчатого вала электродвигателя:

- диаметры $d_{1}=40 \mathrm{MM}, d_{2}=50 \mathrm{MM}, d_{3}=60 \mathrm{Mм}, d_{4}=50 \mathrm{Mm}$;

- длины участков $\ell_{1}=110 \mathrm{MM}, \ell_{2}=100 \mathrm{MM}, \ell_{3}=200 \mathrm{MM}, \ell_{4}=100 \mathrm{Mм}$.

Приведенный диаметр вала электродвигателя $d$ вычисляется по выражению (4.49)

$$
d=\frac{40 \cdot 110+50 \cdot 100+60 \cdot 200+50 \cdot 100}{110+100+200+100} \cong 51,8 \mathrm{Mм} .
$$

Приведенная длина ступенчатого вала электродвигателя $\ell$ вычисляется по выражению (4.51)

$$
\begin{gathered}
\ell=110\left(\frac{51,8}{40}\right)^{4}+100\left(\frac{51,8}{50}\right)^{4}+200\left(\frac{51,8}{60}\right)^{4}+100\left(\frac{51,8}{50}\right)^{4}= \\
=309,4+115,2+111,1+115,2 \cong 651 \text { мм. }
\end{gathered}
$$

В рассматриваемом примере приведенная длина оказалась больше реальной длины вала электродвигателя (рис. 4.30). За приведенный диаметр можно, в сущности, принять диаметр любой ступени вала электро- 
двигателя, что несколько облегчит вычисление значения приведенной длины вала.

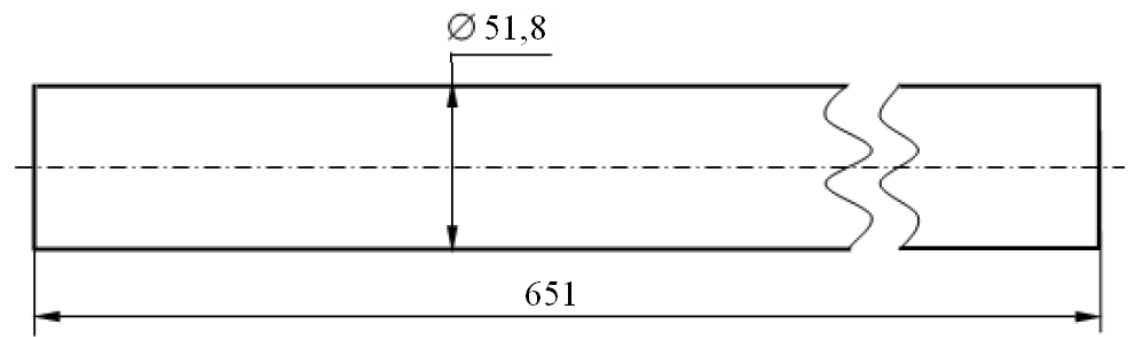

Рис. 4.30. Эскиз приведенного вала с крутильной жесткостью эквивалентной жесткости ступенчатого вала электродвигателя

Используя значения приведенной длины и приведенного диаметра электродвигателя, находим жесткость вала электродвигателя:

$$
C=\frac{\pi G d^{4}}{32 \ell}=\frac{3,14159 \cdot 8,1 \cdot 10^{4} \cdot 51,8^{4}}{32 \cdot 651}=0,88 \cdot 10^{8} \mathrm{H} \cdot \text { мм. }
$$

В системе СИ: $C=0,88 \cdot 10^{5} \mathrm{H} \cdot \mathrm{M}, G=8,1 \cdot 10^{4} \mathrm{MПа} \cdot-$ модуль сдвига.

Жесткости валов и при кручении, и при растяжении, и изгибе также удобно определять, используя такие параметры, как приведенная длина вала и приведенный диаметр вала.

Аналогичные формулы можно получить для ступенчатого вала, работающего на растяжение (сжатие). Приведенный диаметр определяется по формуле (4.49). Обозначим площади поперечных сечений ступеней вала $S_{1} \ldots S_{2} \ldots S_{3} \ldots S_{n}$.

Податливость ступенчатого вала при растяжении (сжатии)

$$
\mathrm{e}=\frac{\ell}{E S}=\frac{\ell_{1}}{E S_{1}}+\frac{\ell_{2}}{E S_{2}}+\frac{\ell_{3}}{E S_{3}}+\ldots+\frac{\ell_{n}}{E S_{n}},
$$

а его приведенная длина

$$
\ell==\frac{\ell}{E S}=\ell_{1} \frac{S}{S_{1}}+\ell_{2} \frac{S}{S_{2}}+\ell_{3} \frac{S}{S_{3}}+\ldots+\ell_{\mathrm{n}} \frac{S}{S_{n}},
$$

где $S$ - площадь поперечного сечения приведенного вала; $E$ - модуль упругости при растяжении (модуль Юнга).

Таким образом, используя такие понятия, как приведенная длина вала и приведенный диаметр вала, можно значительно упростить вычисление параметров для составления динамической модели исследуемого объекта. После определение диаметра и длины приведённого вала электродвигателя приступают к оценке максимальных деформаций сдвига и торсионных крутящих моментов вращающегося ступенчатого вала электродвигателя, используя метод конечных элементов, в основе которого лежит метод сечений. 
Не вызывает принципиальных трудностей при расчетах крутильных колебаний и наличие в конструкции сосредоточенных масс, например укрепленных на валах шкивов, шестерен, рычагов. Для соответствующих узлов сетки записывают уравнения (4.45), в правой части которых учитывают моменты этих дополнительных деталей.

\section{3. Математическая модель явления синхронизации}

Явление синхронизации, физически осознанное ещё во времена Гюйгенса, интенсивно изучается математически только с середины XX века, параллельно с существенными успехами в радиоэлектронике $[1,2$, $116,132]$. Фундаментальные результаты по теме синхронизации с точки зрения качественной теории дифференциальных уравнений и теории бифуркаций [4] доказывают резонансную природу этого явления. Эта теории широко используются для решения насущных практических задач в широком диапазоне деятельности, от микроэлектроники до энергообеспечения [17, 76, 117].

В настоящее время интересы исследователей в передовых областях теории синхронизации сконцентрированы, по-видимому, в связи с бурным развитием новых технологий, на изучении сложных систем с хаотической динамикой, дискретных объектов и систем с временным запаздыванием. В традиционных областях деятельности человека, какими, к примеру, являются энергетика и транспорт, также заметен рост интереса к этому явлению, в целях поиска путей эффективного сбережения электроэнергии и целостности силовых агрегатов. Поступательное развитие науки постоянно совершенствует и расширяет наши представления о явлении синхронизации, как об устойчивом когерентном динамическим процессе. Он возникает, как правило, благодаря весьма малым, почти незаметным связям между отдельными элементами системы, которые, тем не менее, качественно меняют динамическое поведение объекта.

Основное уравнение теории фазовой синхронизации пары осцилляторов (ротаторов) выглядит так $\frac{d \psi}{d \tau}=\Delta+q \sin \psi$, где $\Delta$ - расстройка по частоте (или угловым скоростям), $q$ - параметр глубины модуляции фазы. Это уравнение имеет общее решение:

$$
\psi(\tau)=2 \arctan \left(\frac{1}{\Delta}\left(\tan \left(\frac{\tau}{2} \sqrt{\Delta^{2}-q^{2}}+\frac{C}{2} \sqrt{\Delta^{2}-q^{2}}\right) \sqrt{\Delta^{2}-q^{2}}-q\right)\right)
$$

с произвольной константой интегрирования $C$. Из этого решения вытекает условие устойчивой фазовой синхронизации, которое можно выразить 
следующим образом:

$$
\Delta^{2}-q^{2}<0
$$

Оно свидетельствует, что фазовая расстройка должна быть мала, либо, соответственно, должен быть достаточно велик параметр модуляции, иначе будет уход системы из режима синхронизации.

При более детальном математическом изучении классической проблемы устойчивости синхронизации в задаче двух роторов на упругом фундаменте выяснился тот факт, что приведённая модель неполна. А именно - в модели отсутствует какое-либо описание элемента системы, посредством которого собственно и осуществляется взаимодействие роторов. Оказалось, что структура уточнённой модели такова:

$$
\frac{d A}{d \tau}=\left(q_{2}-\eta\right) A, \frac{d \psi}{d \tau}=\Delta+q \sin \psi+q_{1} A^{2},
$$

где переменная $A$ - мера изменения амплитуды колебаний упругого основания.

Это дополнительное уравнение появляется вследствие возникновения фазовой модуляции угловых частот роторов из-за колебаний основания. Возмущенные таким образом роторы, в свою очередь, вызывают резонансное возбуждение колебаний основания. Отсюда и появляется дополнительное уравнение. При изучении уточнённой модели выяснилось, что для устойчивой синхронизации, помимо выполнения вышеуказанного условия $\Delta^{2}-q^{2}<0$, также необходимо условие, чтобы коэффициент резонансного возбуждения колебаний основания $q_{2}$ не превышал коэффициента диссипации энергии $\eta$, т.е. $q_{2}<\eta$. Последнее ограничение существенно изменяет область устойчивости режима синхронизации в пространстве параметров системы, что, собственно, и демонстрируется на конкретных расчётных примерах.

Математическая модель движения двух двигателей, закреплённых на упругой платформе представляется следующей системой дифференциальных уравнений $[17,18,76,117]$ :

$$
\left\{\begin{array}{c}
m \ddot{y}+p y-m_{1} r_{1}\left(\ddot{\varphi}_{1} \sin \varphi_{1}+\dot{\varphi}_{1}^{2} \cos \varphi_{1}\right)-m_{2} r_{2}\left(\ddot{\varphi}_{2} \sin \varphi_{2}+\dot{\varphi}_{2}{ }^{2} \cos \varphi_{2}\right)=0 \\
I_{1} \ddot{\varphi}_{1}+H_{1}\left(\varphi_{1}, \dot{\varphi}_{1}\right)-L_{1}\left(\varphi_{1}, \dot{\varphi}_{1}\right)-m_{1} r_{1} \ddot{y} \sin \varphi_{1}=0 \\
I_{2} \ddot{\varphi}_{2}+H_{2}\left(\varphi_{2}, \dot{\varphi}_{2}\right)-L_{2}\left(\varphi_{2}, \dot{\varphi}_{2}\right)-m_{2} r_{2} \ddot{y} \sin \varphi_{2}=0
\end{array},\right.
$$

где $m$ - масса платформы, абсолютно твердого тела с одной степенью свободы, характеризуемой линейным горизонтальным смещением $y ; p-$ коэффициент упругости платформы, связанной с неподвижным фундаментом (землей); $m_{i}$ - массы эксцентриков с эксцентриситетами $r_{i}$ (радиу- 
сы инерции); $I_{i}$ - моменты инерции роторов в отсутствие дисбаланса; $L_{i}\left(\varphi_{i}, \dot{\varphi_{i}}\right)$ - движущие моменты; $H_{i}\left(\varphi_{i}, \dot{\varphi_{i}}\right)$ - моменты сил сопротивления вращению роторов.

На платформе установлена пара асинхронных двигателей (неуравновешенных роторов), ось которых перпендикулярна направлению колебаний. Углы поворота ротора $\varphi_{i}$ отсчитывается от направления оси $y$ против хода часовой стрелки. Допустим, что моментная характеристика каждого двигателя и момент сопротивления имеют простейший линеаризованный вид $L_{i}\left(\varphi_{i}, \dot{\varphi_{i}}\right)=M_{i}-k_{i} \dot{\varphi_{i}}, H_{i}\left(\varphi_{i}, \dot{\varphi_{i}}\right)=k_{i} \dot{\varphi_{i}}$. Здесь $M_{i}$ и $k_{i}-$ постоянные параметры, пусковой момент и коэффициент сопротивления двигателя, соответственно. Индекс «1» относится к первому двигателю, а «2» - ко второму. Если принять простейшую линейную модель моментной статической характеристики двигателей, то в безразмерной форме уравнения (4.53) перепишутся так:

$$
\left\{\begin{array}{c}
\ddot{x}+x-\mu \kappa_{1}\left(\ddot{\varphi}_{1} \sin \varphi_{1}+\dot{\varphi}_{1}^{2} \cos \varphi_{1}\right)-\mu \kappa_{2}\left(\ddot{\varphi}_{2} \sin \varphi_{2}+\dot{\varphi}_{2}^{2} \cos \varphi_{2}\right)=0 \\
\ddot{\varphi}_{1}+a_{1} \dot{\varphi}_{1}-b_{1}-\mu \kappa_{1} c_{1} \ddot{x}_{\operatorname{xin}} \sin \varphi_{1}=0 \\
\ddot{\varphi}_{2}+a_{2} \dot{\varphi}_{2}-b_{2}-\mu \kappa_{2} c_{2} \ddot{x} \sin \varphi_{2}=0
\end{array},\right.
$$

где $\mu=\left(m_{1}+m_{2}\right) / m$ - малый параметр задачи.

Введены новые обозначения: $k_{i}=m_{i} /\left(m_{1}+m_{2}\right), \quad a_{i}=\left(k_{0}+k_{i}\right) / I \omega_{0}$, $b_{i}=M_{0} / I \omega_{0}^{2}, \mu c_{i}=I_{i} / I(i=1,2)$. Здесь $I_{i}$ обозначает момент инерции эксцентриков; $\omega_{0}=\sqrt{p / m}$ - частота колебаний платформы без двигателя; $x=2 y /\left(r_{1}+r_{2}\right)-$ новая безразмерная линейная координата, измеряемая в долях радиуса инерции эксцентрика. Дифференцирование в уравнениях, в отличие от системы исходных уравнений, теперь осуществляется по безразмерному времени $\tau=\omega_{0} t$.

Задача допускает эффективное исследование методом малого параметра. Для использования этого метода систему (4.54) требуется привести к стандартной форме шести уравнений, разрешённых относительно старшей производной. Промежуточные представления:

- вводятся новые переменные $y, \varpi_{1}, \varpi_{2}$, связанные с исходными искомыми переменными дифференциальными соотношениями $d x / d t=y$, $d \varphi_{1} / d t=\varpi_{1}, d \varphi_{2} / d t=\varpi_{2} ;$

- отыскивается порождающее решение вновь полученной линеаризованной подсистемы (полагая в уравнениях $\mu=0$ ), на основании которого осуществляется замена переменных (для применения метода вариации произвольных постоянных): $\rho(t)=A(t), \varphi(t)=t+\alpha(t), \varpi_{1}(t)=v_{1}(t) \exp \left(-a_{1} t\right)$, $\varpi_{2}(t)=v_{2}(t) \exp \left(-a_{2} t\right), \quad \varphi_{1}(t)=\Omega_{1} t+B_{1}(t), \quad \varphi_{2}(t)=\Omega_{2} t+B_{2}(t), \quad$ где 
$x(t)=A(\tau) \sin (\varphi(\tau)), y(t)=A(\tau) \cos (\varphi(\tau))$. Здесь $A(t), \alpha(t), v_{1}(t), v_{2}(t), B_{1}(t), B_{2}(t)-$ шесть новых переменных задачи;

- в этих новых переменных $A(t), \alpha(t)$ - амплитуда и фаза колебаний основания, соответственно; $v_{1}(t), v_{2}(t)$ - угловые ускорения и $B_{1}(t), B_{2}(t)$ угловые скорости двигателей, образ системы уравнений (4.54) представляется в эквивалентной стандартной форме, пригодной для дальнейшего анализа.

Далее решение системы в стандартной форме отыскивается в виде разложений в ряд по малому параметру $\mu$ :

$$
\left\{\begin{array}{c}
A(t)=A(\tau)+\mu A^{(1)}(t)+\mu^{2} A^{(2)}(t)+\ldots \\
\alpha(t)=\alpha(\tau)+\mu \alpha^{(1)}(t)+\mu^{2} \alpha^{(2)}(t)+\ldots \\
v_{1}(t)=v_{1}(\tau)+\mu v_{1}^{(1)}(t)+\mu^{2} v_{1}^{(2)}(t)+\ldots \\
v_{2}(t)=v_{2}(\tau)+\mu v_{2}^{(1)}(t)+\mu^{2} v_{2}^{(2)}(t)+\ldots \\
B_{1}(t)=B_{1}(\tau)+\mu B_{1}^{(1)}(t)+\mu^{2} B_{1}^{(2)}(t)+\ldots \\
B_{2}(t)=B_{2}(\tau)+\mu B_{2}^{(1)}(t)+\mu^{2} B_{2}^{(2)}(t)+\ldots
\end{array}\right.
$$

Здесь ядро разложения зависит от $\tau=\mu^{2} t$ - медленного времени, характеризующего протекание медленных резонансных процессов, а переменные с верхним индексом обозначают малые быстро осциллирующие добавки к этому основному эволюционному решению.

При изучении стандартной формы, прежде всего, необходимо выявить резонансные условия. Резонанс в системе (4.54) имеет место, в первом приближении теории возмущений, когда $\Omega_{1} \sim 1$, а также когда $\Omega_{2} \sim 1$, или если одновременно $\Omega_{1} \sim \Omega_{2} \sim 1$. Все эти случаи требуют отдельного изучения. Сейчас нас интересует явление фазовой синхронизации в системе (4.54). Этот случай, в частности, реализуется, когда $\Omega_{2} \sim \Omega_{1}$, но когда обе парциальные угловые скорости вращения достаточно далеки от единицы. В этом случае в первом порядке теории возмущений резонанс в системе (4.54) отсутствует. Резонанс проявится во втором приближении.

После подстановки представления (4.55) в стандартную форму уравнений и разделения быстрых и медленных движений в первом порядке по малому параметру $\mu$, получим следующую информацию о решении системы. В первом приближении медленные стационарные движения (когда $t \rightarrow \infty)$ таковы же, как и в порождающем решении: $A=$ const, $\alpha=$ const, $v_{1}=$ const, $v_{2}=$ const, $B_{1}=$ const, $B_{2}=$ const.

Это означает, что медленно меняющиеся функции $A, \alpha, v_{1}$ и $v_{2}, B_{1}$ и $B_{2}$ не зависят в первом приближении ни от физического времени $t$, ни от 
медленного времени $\tau$. Решения для малых нерезонансных поправок таковы с учетом $1+\Omega_{1}=l, 1-\Omega_{1}=m, 1+\Omega_{2}=n, 1-\Omega_{2}=p$ :

$$
\begin{aligned}
& \varpi_{1}^{(1)}(t)=\frac{\mu c_{1} \kappa_{1} A}{2\left(a_{1}^{2}+l^{2}\right)\left(a_{1}^{2}+m^{2}\right)}\left(\begin{array}{l}
-m\left(a_{1}^{2}+l^{2}\right) \sin \left(-m t+\varphi_{1}-\alpha-\frac{\Omega_{1}}{a_{1}}\right)+ \\
+a_{1}\left(a_{1}^{2}+l^{2}\right) \cos \left(-m t+\varphi_{1}-\alpha-\frac{\Omega_{1}}{a_{1}}\right)- \\
-\left(l \sin \left(l t+\varphi_{1}+\alpha-\frac{\Omega_{1}}{a_{1}}\right)\right)+ \\
+a_{1}\left(a_{1}^{2}+m^{2}\right) \cos \left(l t+\varphi_{1}+\alpha-\frac{\Omega_{1}}{a_{1}}\right)
\end{array}\right) \\
& \varpi_{2}^{(1)}(t)=\frac{\mu c_{2} \kappa_{2} A}{2\left(a_{2}^{2}+n^{2}\right)\left(a_{2}^{2}+p^{2}\right)}\left(\begin{array}{l}
-p\left(a_{2}^{2}+n^{2}\right) \sin \left(-p t+\varphi_{2}-\alpha-\frac{\Omega_{2}}{a_{2}}\right)+ \\
+a_{2}\left(a_{2}^{2}+n^{2}\right) \cos \left(-p t+\varphi_{2}-\alpha-\frac{\Omega_{2}}{a_{2}}\right)- \\
-\left(n \sin \left(n t+\varphi_{2}+\alpha-\frac{\Omega_{2}}{a_{2}}\right)\right)+ \\
+a_{2}\left(a_{2}^{2}+p^{2}\right) \cos \left(n t+\varphi_{2}+\alpha-\frac{\Omega_{2}}{a_{2}}\right)
\end{array}\right) \\
& \alpha^{(1)}(t)=-\frac{\mu}{2 A}\left(\begin{array}{c}
\left.-\frac{\kappa_{2} \Omega_{2}^{2} \cos \left(-p t+\varphi_{2}-\alpha-\frac{\Omega_{2}}{a_{2}}\right)}{-p}+\frac{\kappa_{1} \Omega_{1}^{2} \cos \left(l t+\varphi_{1}+\alpha-\frac{\Omega_{1}}{a_{1}}\right)}{l}+\right) \\
\left.+\frac{\kappa_{2} \Omega_{2}^{2} \cos \left(n t+\varphi_{2}+\alpha-\frac{\Omega_{2}}{a_{2}}\right)}{n}+\frac{\kappa_{1} \Omega_{1}^{2} \cos \left(-m t+\varphi_{1}-\alpha-\frac{\Omega_{1}}{a_{1}}\right)}{-m}\right)
\end{array}\right)
\end{aligned}
$$

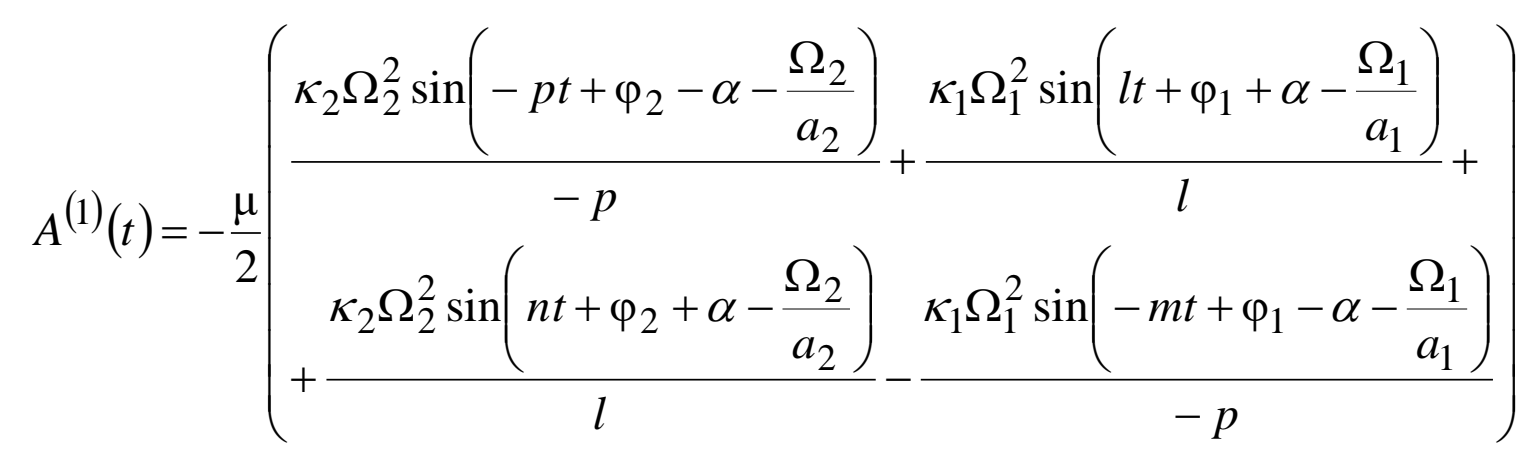




$$
\begin{gathered}
B_{1}^{(1)}(t)=\frac{\mu c_{1} \kappa_{1}}{2 a_{1}}\left(-\frac{\sin \left(-m t+\varphi_{1}-\alpha-\frac{\Omega_{1}}{a_{1}}\right)}{-m}+\frac{\sin \left(n t+\varphi_{2}+\alpha-\frac{\Omega_{2}}{a_{2}}\right)}{n}\right) \\
B_{2}^{(1)}(t)=\frac{\mu c_{2} \kappa_{2}}{2 a_{2}}\left(-\frac{\sin \left(-p t+\varphi_{2}-\alpha-\frac{\Omega_{2}}{a_{2}}\right)}{-p}+\frac{\sin \left(l t+\varphi_{1}+\alpha-\frac{\Omega_{1}}{a_{1}}\right)}{l}\right)
\end{gathered}
$$

Это решение (4.56) описывает малое возмущенное движение фундамента с теми же частотами, что и угловые скорости вращения двигателей, что проявляется в возникновении комбинационных частот в выражении для поправок к амплитуде $A^{(1)}(t)$ и фазе $\alpha^{(1)}(t)$. Поправки к угловым ускорениям и скоростям $\varpi_{1}{ }^{(1)}(t), \varpi_{2}{ }^{(1)}(t), B_{1}{ }^{(1)}(t), B_{2}{ }^{(1)}(t)$ также содержат аналогичные гармоники малой амплитуды на комбинационных разностных и суммарных частотах.

Теперь решение первого приближение построено. Это решение пока непригодно для описания эффекта синхронизации, а потому требуется продолжить процедуру вывода уравнений методом малого параметра. Используя это решение (4.56) в (4.55), можно получить искомые уравнения второго приближения, описывающие явление синхронизации пары двигателей на упругом основании.

Итак, после вторичной подстановки модифицированного представления (4.55) в стандартную форму и разделения движений на медленные и быстрые движения, получаются следующие эволюционные уравнения.

$$
\begin{gathered}
\frac{d A}{d \tau}=\left(q_{2}-\eta\right) A \\
\frac{d \psi}{d \tau}=\Delta+q \sin \psi+q_{1} A^{2}
\end{gathered}
$$

где $\psi(\tau)=\psi_{1}(\tau)-\psi_{2}(\tau)-\mu^{2} \Delta \tau-$ новая медленная переменная, а $\Delta=\left(\Omega_{1}-\Omega_{2}\right) / \mu^{2}$ - малая расстройка парциальных угловых скоростей.

Коэффициенты уравнений (4.57) таковы:

$$
\begin{gathered}
q_{1}=\frac{\kappa_{1} \kappa_{2}}{2}\left[\frac{c_{1}}{a_{1}}\left(\frac{\Omega_{2}^{2}\left(\Omega_{2}^{2}-2\right)}{1-\Omega_{2}^{2}}\right)+\frac{c_{2}}{a_{2}}\left(\frac{\Omega_{1}^{2}\left(\Omega_{1}^{2}-2\right)}{1-\Omega_{1}^{2}}\right)\right] ; \\
q=\frac{c_{1}^{2} \kappa_{1}^{2} \Omega_{1}\left(\Omega_{1}^{2}+a_{1}^{2}+3\right)}{4 m^{2}\left(a_{1}^{2}+m^{2}\right)\left(a_{1}^{2}+l^{2}\right)}+\frac{c_{2}^{2} \kappa_{2}^{2} \Omega_{2}\left(\Omega_{2}^{2}+a_{2}^{2}+3\right)}{4 p^{2}\left(a_{2}^{2}+p^{2}\right)\left(a_{2}^{2}+n^{2}\right)} ;
\end{gathered}
$$




$$
q_{2}=-\frac{a_{1} c_{1} \kappa_{1}^{2}\left(3 \Omega_{1}^{2}+a_{1}^{2}+1\right)}{4 m^{2}\left(a_{1}^{2}+m^{2}\right)\left(a_{1}^{2}+l^{2}\right)}-\frac{a_{2} c_{2} \kappa_{2}^{2}\left(3 \Omega_{2}^{2}+a_{2}^{2}+1\right)}{4 p^{2}\left(a_{2}^{2}+p^{2}\right)\left(a_{2}^{2}+n^{2}\right)} .
$$

Уравнения (4.57) представляют собой обобщение стандартного основного уравнения теории фазовой синхронизации [102], структура которого выглядит следующим образом:

$$
\frac{d \psi}{d \tau}=\Delta+q \sin \psi
$$

Формально это уравнение вытекает из обобщённой модели, если положить $\rho=0$. Уравнение (4.58) имеет общее решение:

$$
\psi(\tau)=2 \arctan \left(\frac{1}{\Delta}\left(\tan \left(\frac{\tau}{2} \sqrt{\Delta^{2}-q^{2}}+\frac{C}{2} \sqrt{\Delta^{2}-q^{2}}\right) \sqrt{\Delta^{2}-q^{2}}-q\right)\right),
$$

где $C$ - произвольная константа интегрирования. Из этого решения вытекает условие устойчивой фазовой синхронизации $\Delta^{2}-q^{2}<0$ (4.54), которое свидетельствует, что для возникновения устойчивого режима синхронизации фазовая расстройка должна быть мала, по сравнению с параметром фазовой модуляции. При нарушении этого условия наблюдается уход системы из режима синхронизации.

С другой стороны, уточнённая модель (4.57) свидетельствует, что для устойчивой синхронизации выполнения вышеуказанного условия недостаточно. Необходимо также условие, чтобы коэффициент резонансного возбуждения колебаний основания $q_{2}$ не превышал коэффициента диссипации энергии $\eta$, т.е. $q_{2}<\eta$. Последнее ограничение существенно изменяет область устойчивости режима синхронизации в пространстве параметров системы, что, собственно, и демонстрируется далее на конкретных расчётных примерах.

В табл. 4.3 приводятся расчёт различных теоретических реализаций устойчивых и неустойчивых режимов синхронизации в отсутствие диссипации энергии в упругом основании, т.е. $\eta=0$.

Пример 1 (см. первую строчку набора параметров в таблице). Это устойчивый режим синхронизации при малой расстройке по угловым скоростям двигателей $\delta=0.1$.

Пример 2 (см., соответственно, вторую строчку набора параметров в таблице, и т.д.). Это неустойчивый режим синхронизации при малой расстройке по угловым скоростям двигателей $\delta=0.1$. Достичь устойчивого режима синхронизации в этом примере можно, добавив демпфирующий элемент с коэффициентом диссипации $\eta \geq 0.008$. 
Пример 3. Это устойчивый режим синхронизации при малых различиях в эксцентриках $\left(k_{1}-k_{2}=0.2\right)$ и равных угловых скоростях.

Пример 4. Это неустойчивый режим синхронизации при малых различиях в эксцентриках $\left(k_{1}-k_{2}=0.2\right)$ и малой расстройке по угловым скоростям двигателей $\delta=0.1$. Достичь устойчивого режима синхронизации и в этом примере можно, добавив демпфирующий элемент с коэффициентом диссипации $\eta \geq 0.009$.

Пример 5. Это неустойчивый режим синхронизации при малых различиях в эксцентриках. Достичь устойчивого режима синхронизации и в этом примере невозможно, даже добавив любой демпфирующий элемент.

Пример 6. Это неустойчивый режим синхронизации при разных угловых скоростях. Достичь устойчивого режима синхронизации также невозможно.

Параметры режимов синхронизации рассмотренных ранее сведены в табл. 4.3.

Таблица 4.3

Параметры устойчивых и неустойчивых режимов синхронизации

\begin{tabular}{|l|l|l|l|l|l|l|l|l|l|l|l|}
\hline № & $\mu$ & $c_{1}$ & $c_{2}$ & $k_{1}$ & $k_{2}$ & $a_{1}$ & $a_{2}$ & $\Omega_{1}$ & $\Omega_{2}$ & $\Delta^{2}-q_{11}{ }^{2}$ & $q_{21}$ \\
\hline 1 & 0.1 & 1 & 1 & 0.5 & 0.5 & 1 & 1 & 0.751 & 0.75 & -0.244 & -0.204 \\
\hline 2 & 0.1 & 1 & 1 & 0.5 & 0.5 & 1 & 1 & 0.251 & 0.25 & -0.072 & 0.008 \\
\hline 3 & 0.1 & 1 & 1 & 0.6 & 0.4 & 1 & 1 & 0.25 & 0.25 & -0.075 & -0.001 \\
\hline 4 & 0.1 & 1 & 1 & 0.6 & 0.4 & 1 & 1 & 0.251 & 0.25 & -0.075 & 0.009 \\
\hline 5 & 0.1 & 1 & 1 & 0.6 & 0.4 & 1 & 1 & 1.25 & 1.25 & 0.239 & -0.085 \\
\hline 6 & 0.1 & 1 & 1 & 0.5 & 0.5 & 1 & 1 & 0.26 & 0.25 & 0.998 & -0.007 \\
\hline
\end{tabular}

\section{4. Биения как результат неустойчивой синхронизации двух двигателей на общем вязкоупругом основании}

В системах со многими источниками вибраций всегда возможна синхронизация на одной или нескольких частотах $[16,62]$. Вопросы синхронизации и захвата частоты при испытаниях механических систем с локальными источниками шума и вибрации приобретают все большую актуальность в современном машиностроении. Синхронизация и захват частоты при переходных режимах работы могут приводить к вредным последствиям, вплоть до разрушения силовых агрегатов [16, 62].

Эти процессы усугубляются влиянием внешних вибрационных полей, способствующих значительному увеличению времени переходных процессов в энергоемком оборудовании. Возрастание времени переходных процессов, в частности, приводит к увеличению энергопотребления и дополнительному росту вредных вибраций, возникновению опасных низкочастотных биений. Эти процессы понижают ресурс работы силовых 
агрегатов и ведут к разрушению инженерных конструкций. Поэтому задача снижения уровней вибрации в стационарных и переходных режимах работы энергоемких машин всегда актуальна [19]. Захват угловой скорости вращения ротора электродвигателя и его синхронизация внешними источниками вибрации происходит во время разгона ротора из состояния покоя. Переходный процесс может сопровождаться рядом нежелательных явлений. К примеру, угловая скорость вращения ротора может и не достичь своего номинального значения, а останется в установившемся режиме гораздо меньшей. Это свидетельствует о вредном действии вибрационного момента на вал ротора, от чего необходимо освободиться либо, по возможности, свести к минимуму.

Отмеченные явления существенно осложняются действием внешнего вибрационного поля даже тогда, когда частоты внешних возмущений не совпадают с номинальной угловой скоростью вращения ротора [100, 105]. Из эффективных способов снижения уровня вибраций частей электрических машин является использование гидравлических опор в качестве демпферов.

Синхронизация используется с пользой во многих горных машинах сепараторах, грохотах. Однако если синхронизация возникла в системе нескольких электродвигателей, которые создают повышенную нагрузку на платформу, где они установлены, то синхронизация, естественно, явление вредное.

Экспериментальные исследования эффектов синхронизации, возникающей при работе двух электродвигателей проводились на закрепленных на общем неподвижном основании и на общем вязкоупругом основании. Общее вязко-упругое основание установлено на четырёх гидравлических опорах (рис. 4.31).

На стальных крепежных пластинах жестко закреплены электродвигатели типа АИР 63 В4 0,37 1500, мощностью в 370 Вт с одинаковыми механическими и частотными характеристиками (рис. 4.31). Крепежные пластины, в свою очередь, жестко закреплены на стальной платформе (основание). Вся система установлена на вибростенде. Между вибростендом и платформой установлены гидроопоры.

Рассмотрены два основных варианта: синхронизация на вязкоупругом основании; синхронизация при вибрирующем основании за счет сторонних внешних воздействий. Проведен анализ спектров и выявлены информативные гармонические составляющие, позволяющие судить о наличии биений.

Физическую модель системы двух двигателей, закрепленных на вязкоупругом основании с одной степенью свободы [19] представим как 
систему двух двигателей, закрепленных на платформе, установленной на вязкоупругих гидроопорах (рис. 4.32).

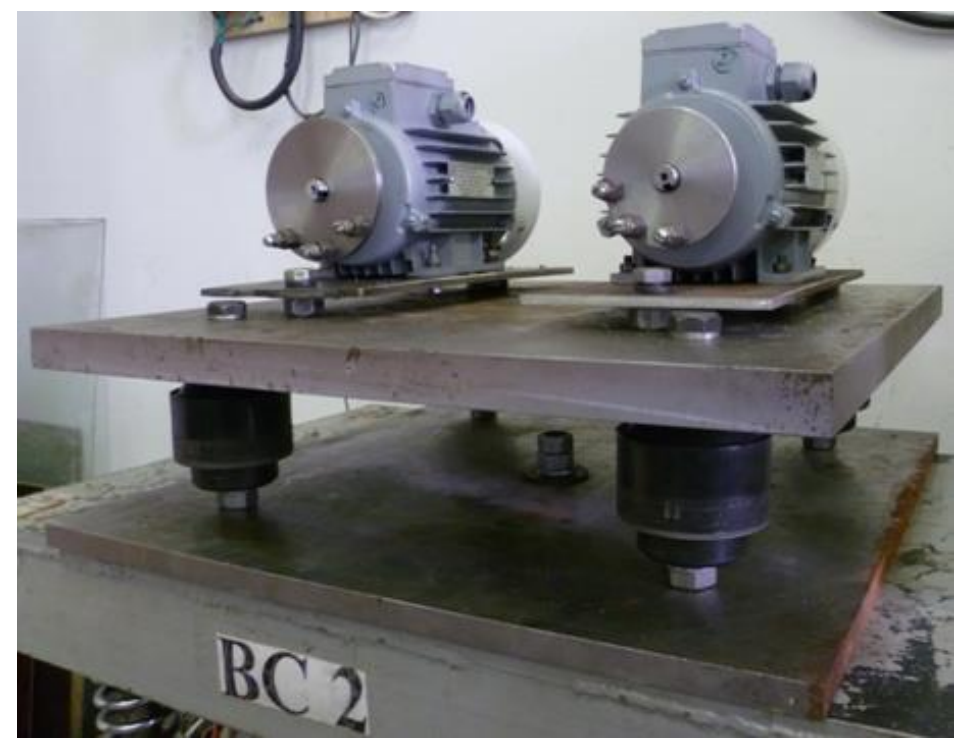

Рис. 4.31. Электромеханическая система двух асинхронных двигателей, установленных на общем вязкоупругом основании

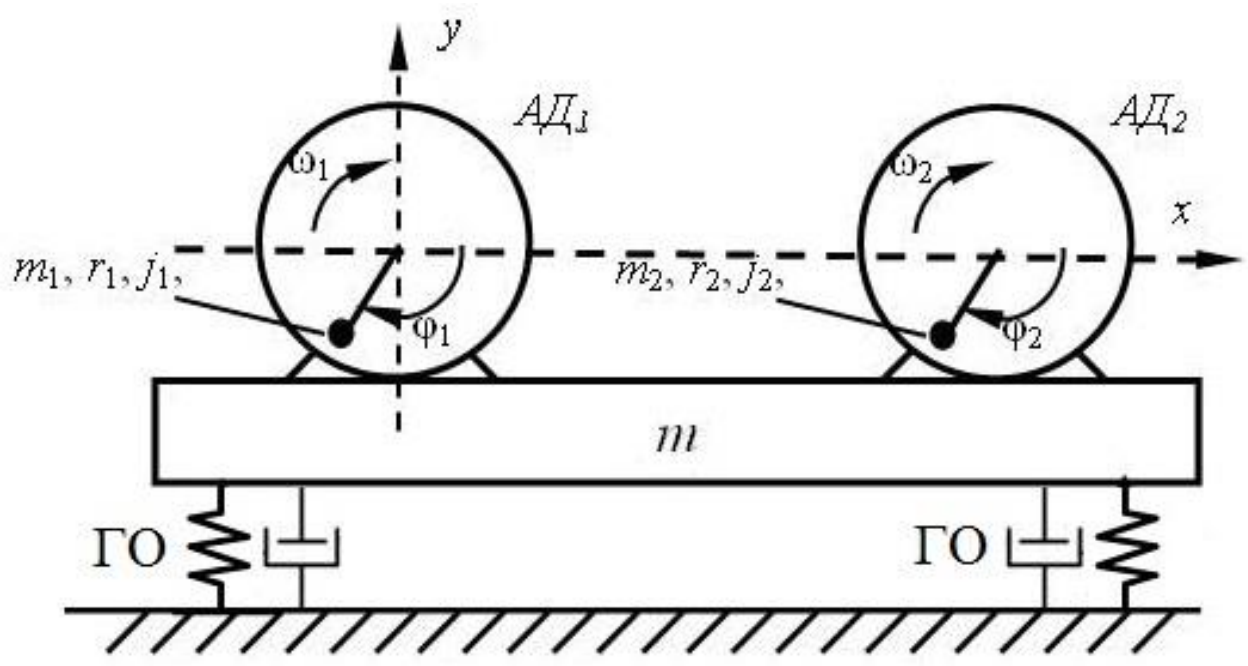

Рис. 4.32. Физическая модель системы двух двигателей, вращающихся в одном направлении, закрепленных на платформе, установленной на вязкоупругие гидравлические опоры (ГО)

Для электромеханической системы на рис. 4.32 заданы: суммарная жесткость обечаек гидроопор - $C$; массы первого и второго двигателей $m_{1}, m_{2}$; масса платформы - $m$; моменты инерции роторов $-I_{1}, I_{2} ;$ радиусы эксцентриков $-r_{1}$ и $r_{2}$; крутящие моменты приложенные к валам двигателей $-M_{1}, M_{2} ; \varphi_{1}, \varphi_{2}$ - углы поворота роторов отсчитываемые от направления оси $x$.

Для электромеханической системы также задаются коэффициенты вязкого сопротивления вертикальному движению корпусов двигателей $\eta_{1.1}, \eta_{1.2}$; коэффициенты вязкого сопротивления вращению роторов $-\eta_{2.1}$, 
$\eta_{2.2}$. Источники вибрации - двигатели с неуравновешенными роторами, обладающие моментами инерции $I_{j}$.

Неуравновешенные роторы двигателей генерируют под действием центробежных сил вынуждающие силы, действующие на вязкоупругое основание [62]:

$$
F_{1}=F_{01} \sin \left(\Omega_{1} t+\varphi_{1}\right) ; F_{2}=F_{02} \sin \left(\Omega_{2} t+\varphi_{2}\right) ;
$$

где $F_{01}=m_{1} \cdot \Omega_{1}^{2} \cdot r_{1}, F_{02}=m_{2} \cdot \Omega_{2}^{2} \cdot r_{2}$ - центробежные силы, $m_{1}, m_{2}-$ массы эксцентриков с радиусами $r_{1}$ и $r_{2}$ соответственно, $\Omega_{1}, \Omega_{2}$ и $\varphi_{1}, \varphi_{2}-$ угловые частоты и начальные фазы вращения неуравновешенных роторов первого, второго двигателей соответственно.

При этом предполагается, что значения $\Omega_{1}, \Omega_{2}$ заданы и не зависят от процесса колебаний вязкоупругой платформы, на которой установлены двигатели с неуравновешенными роторами.

Если используются двигатели, обладающие небольшой мощностью, то процесс колебаний вязкоупругой электромеханической системы заметно влияет на величины $\Omega_{1}, \Omega_{2}$ и последние также колеблются около некоторого среднего значения. Вследствие влияния колебаний вязкоупругой платформы на угловые скорости вращения роторов двигателей их работа в некотором диапазоне угловых скоростей становится неустойчивой [19].

При эксплуатации двигателей, установленных на вязкоупругом основании, необходимо учитывать эти явления. Такие явления можно наблюдать у мотор-компрессора локомотива, энергетическая установка которого находятся в общем корпусе, расположенном на вязкоупругом основании [30]. При составлении системы дифференциальных уравнений введем обобщенные координаты. За обобщенные координаты выбираем углы поворота роторов - $\varphi_{1}, \varphi_{2}$ и вертикальные перемещения платформы с двигателями - $y$. По теореме о движении центров масс для первого и второго двигателей дифференциальные уравнения движения центров масс записываются в виде

$$
\left\{\begin{array}{l}
\left(m+m_{1}\right) \cdot \frac{d V_{c m 1}}{d t}=-\eta_{1.1} \dot{y}_{1}-c y_{1}+\left(m+m_{1}\right) g, \\
\left(m+m_{2}\right) \cdot \frac{d V_{c m 2}}{d t}=-\eta_{1.2} \dot{y}_{2}-c y_{2}+\left(m+m_{2}\right) g .
\end{array} .\right.
$$

где $V_{c m 1}$ и $V_{c m 2}$ - линейная скорость центра масс двигателей электромеханической системы; $g$ - ускорение свободного падения.

Ускорения центра масс первого и второго двигателей определим по формулам 


$$
\left\{\begin{array}{l}
\frac{d V_{c m 1}}{d t}=\ddot{y}_{1}-\frac{m \cdot r_{1}}{m+m_{1}} \cdot\left(\dot{\Omega}_{1} \cdot \sin \varphi_{1}+\Omega_{1}^{2} \cdot \cos \varphi_{1}\right), \\
\frac{d V_{c m 2}}{d t}=\ddot{y}_{2}-\frac{m \cdot r_{2}}{m+m_{2}} \cdot\left(\dot{\Omega}_{2} \cdot \sin \varphi_{2}+\Omega_{2}^{2} \cdot \cos \varphi_{2}\right)
\end{array} .\right.
$$

Подставляя (4.59) в (4.60), получим первые дифференциальные уравнения движения для первого и второго двигателей:

$$
\left\{\begin{array}{l}
\left(m+m_{1}\right) \cdot \ddot{y}_{1}-m \cdot r_{1} \cdot\left(\ddot{\varphi}_{1} \cdot \sin \varphi_{1}+\dot{\varphi}_{1}^{2} \cdot \cos \varphi_{1}\right)=-\eta_{1.1} \dot{y}_{1}-c y_{1}+\left(m+m_{1}\right) g, \\
\left(m+m_{2}\right) \cdot \ddot{y}_{2}-m \cdot r_{2} \cdot\left(\ddot{\varphi}_{2} \cdot \sin \varphi_{2}+\dot{\varphi}_{2}^{2} \cdot \cos \varphi_{2}\right)=-\eta_{1.2} \dot{y}_{2}-c y_{2}+\left(m+m_{2}\right) g .
\end{array}\right.
$$

Запишем дифференциальные уравнения вращательного движения эксцентриков для первого и второго двигателей с эксцентриситетами $r_{1}$ и $r_{2}$ :

$$
\left\{\begin{array}{l}
I_{1} \cdot \ddot{\varphi}_{1}=M_{1}-\eta_{2.1} \cdot \dot{\varphi}_{1}+m \cdot r_{1} \cdot \ddot{y}_{1} \cdot \sin \varphi_{1}-m \cdot g \cdot r_{1} \cdot \sin \varphi_{1}, \\
I_{2} \cdot \ddot{\varphi}_{2}=M_{2}-\eta_{2.2} \cdot \dot{\varphi}_{2}+m \cdot r_{2} \cdot \ddot{y}_{2} \cdot \sin \varphi_{2}-m \cdot g \cdot r_{2} \cdot \sin \varphi_{2} .
\end{array}\right.
$$

Отправной пункт дальнейших рассуждений состоит в том, что механические колебания массы $m$ влияют на угловую скорость роторов двигателей $\Omega_{1}, \Omega_{2}$, и что моменты $M_{1}, M_{2}$, передаваемые статорами на роторы, зависят от угловых скоростей $\Omega_{1}, \Omega_{2}$ :

Зависимости $M_{1}=M\left(\Omega_{1}\right)$ и $M_{2}=M\left(\Omega_{2}\right)$ являются характеристиками двигателей и определяются их конструкцией и параметрами.

Во многих случаях характеристику электродвигателей можно принять в виде линейных функций:

$$
\left\{\begin{array}{l}
M_{1}=M_{01}-b_{1} \Omega_{1} \\
M_{2}=M_{02}-b_{2} \Omega_{2}
\end{array}\right.
$$

где $b_{1}$ и $b_{2}=$ const.

Величины $M_{01}$ и $M_{02}$ зависят от рабочего питающего напряжения двигателей. Изменяя рабочие питающие напряжения можно изменять характеристики двигателей.

С учетом (4.63), обозначая

$$
\eta_{1.1}=b_{1}+\eta_{2.1} \text { и } \eta_{1.2}=b_{2}+\eta_{2.2},
$$

преобразуем (4.62) к виду 


$$
\left\{\begin{array}{l}
I_{1} \cdot \ddot{\varphi}_{1}=M_{01}-\eta_{1.1} \cdot \dot{\varphi}_{1}+m \cdot r_{1} \cdot \ddot{y}_{1} \cdot \sin \varphi_{1}-m \cdot g \cdot r_{1} \cdot \sin \varphi_{1}, \\
I_{2} \cdot \ddot{\varphi}_{2}=M_{02}-\eta_{1.2} \cdot \dot{\varphi}_{2}+m \cdot r_{2} \cdot \ddot{y}_{2} \cdot \sin \varphi_{2}-m \cdot g \cdot r_{2} \cdot \sin \varphi_{2} .
\end{array}\right.
$$

Уравнения (4.61) и (4.64) представляют собой систему дифференциальных уравнений движения конструкции электромеханической системы, изображенной на (рис. 4.32).

Далее рассмотрим вопрос о трансформации энергии в данной электромеханической колебательной системе (рис. 4.32). В таких колебательных системах часто наблюдается явление трансформации энергии одного вида колебаний в другой или от одного тела системы к другому. В первом случае происходит периодическое затухание колебания одного вида и возникновение вследствие этого колебания другого вида. Во втором случае возникают биения, проявляющиеся в периодической амплитудной модуляции вибросигналов генерируемых двигателями системы $[7,90]$.

Рассмотрим данную электромеханическую систему, имеющую две обобщенные координаты $q_{1}$ и $q_{2}$, отсчитываемыми от положения устойчивого равновесия системы. Исходим из того, что электромеханическая система совершает малые колебания с номинальными частотами вращения роторов первого, второго двигателей $\Omega_{1}$ и $\Omega_{2}$ около положения устойчивого равновесия.

Взаимное воздействие двух двигателей друг на друга в колебательной электромеханической системе определяется через отношение обобщенных координат, равное отношению амплитуд колебаний $\mu_{1}$ и $\mu_{2}$.

Действие первого двигателя на второй двигатель определяется через отношение обобщенных координат, равное отношению амплитуд колебаний $\mu_{1}$ :

$$
\frac{q_{2}}{q_{1}}=\frac{A_{2}}{A_{1}}=\frac{F_{02}}{F_{01}}=\mu_{1}
$$

откуда

$$
q_{1}=F_{01} \sin \left(\Omega_{1} t+\varphi_{1}\right) ; q_{2}=\mu_{1} \cdot q_{1}=\mu_{1} \cdot F_{01} \sin \left(\Omega_{1} k t+\varphi_{1}\right) .
$$

Действие второго двигателя на первый двигатель определяется через отношение обобщенных координат, равное отношению амплитуд колебаний $\mu_{2}$ :

$$
\frac{q_{1}}{q_{2}}=\frac{A_{1}}{A_{2}}=\frac{F_{01}}{F_{02}}=\mu_{2},
$$

откуда

$$
q_{2}=F_{02} \sin \left(\Omega_{2} t+\varphi_{1}\right) ; q_{1}=\mu_{2} \cdot q_{2}=\mu_{2} \cdot F_{02} \sin \left(\Omega_{2} t+\varphi_{1}\right) .
$$


Угловые частоты $\Omega_{1}$ и $\Omega_{2}$ являются частотами свободных колебаний электромеханической системы. Соответствующие этим частотам колебания называют главными колебаниями системы. Меньшую из частот $\Omega_{1}$ или $\Omega_{2}$ называют основной частотой, а первое главное колебание, имеющее эту частоту, - основным колебанием. Колебание с меньшей частотой является основным в результирующем колебании системы [90].

Величины $\mu_{1}$ и $\mu_{2}$, представляющие собой отношение обобщенных координат или амплитуд колебаний в каждом из главных колебаний, характеризуют формы главных колебаний и их называют коэффициентами распределения. Формы главных колебаний электромеханической системы не зависят от частоты колебаний и определяются только параметрами колебательной системы.

В электромеханической колебательной системе каждый из двух дв игателей может совершать биения. При упрощающем предположении $A_{1}=A_{2}=Y_{m}$ и $\varphi_{01}=\varphi_{02}$ в результате сложения двух гармонических колебаний с близкими частотами возникают биения:

$$
\begin{aligned}
& y_{\text {рез }}=y_{1}+y_{2}=Y_{m}\left[\sin \left(\Omega_{1} t\right)+\sin \left(\Omega_{2} t\right)\right]= \\
& =2 \cdot Y_{m} \cdot \cos \left(\frac{\Omega_{1}-\Omega_{2}}{2} t\right) \cdot \sin \left(\frac{\Omega_{1}+\Omega_{2}}{2} t\right)
\end{aligned}
$$

Если частоты $\Omega_{1}$ и $\Omega_{2}$ очень близки друг к другу, то в электромеханической колебательной системе движение можно рассматривать как гармоническое колебание с амплитудой и фазой, медленно изменяющимися во времени $[7,90]$. Период изменения амплитуды колебаний двигателей и период биений определяются по формулам

$$
\begin{aligned}
& T_{Y}=\frac{4 \pi}{\Omega_{1}+\Omega_{2}} \\
& T_{б}=\frac{2 \pi}{\Omega_{1}-\Omega_{2}}
\end{aligned}
$$

Период биений равен половине периода изменения амплитуды биений. В процессе биений за время, равное половине периода $T_{6}$, двигатели обмениваются энергией.

В электромеханической системе на каждом из двигателей типа АИР 63 В4 0,37 1500, в 370 Вт жестко закреплены диски, с эксцентриситетами (рис. 4.31). На левом и правом дисках закреплены грузики, создающие моменты инерции $J_{1}=10,125 \cdot 10^{-5} \mathrm{\kappa} \cdot \mathrm{M}^{2}, J_{2}=6,125 \cdot 10^{-5} \mathrm{\kappa} \cdot \mathrm{M}^{2}$ соответственно. Круговая частота вращения роторов обоих двигателей 
$\Omega_{1}=\Omega_{2}=157$ рад/с, или $f_{\text {вр }}=25$ Гц. Круговая частота вибростенда $\Omega_{\mathrm{Bc}}=113,1 \mathrm{paд} / \mathrm{c}$.

Измерения уровней вибрации при работе двух электродвигателей, закрепленных на общем неподвижном основании и на общем вязкоупругом основании проводились виброанализатором «ОКТАВА - 110ВМ», предназначенным для измерения среднеквадратичных, эквивалентных и пиковых уровней виброускорения, а также октавных и третьоктавных уровней виброускорения в децибелах низкочастотной широкополосной вибрации. Акселерометры закреплялись на платформе между двигателями. Измеряемые прибором виброускорения в децибелах (дБ) затем переводились в линейные виброускорения $\left(A, \quad \mathrm{~m} / \mathrm{c}^{2}\right)$ и линейные виброперемещения $(S$, м).

Виброускорения в линейных единицах получают из соответствующих уровней по формулам, которые взяты из руководства по применению измерителя общей и локальной вибрации ОКТАВА-110В/101BМ. Соответствующие формулы для уровней определяют взаимосвязи между уровнями виброускорения, скорости и смещения в $L_{A}\left(\right.$ ДБ), $L_{V}(д Б)$ и $L_{S}($ ДБ):

$$
L_{A}=L_{V}+20 \lg (f)-10 ; L_{V}=L_{S}+20 \lg (f)-60 ; L_{S}=L_{A}-20 \lg (f)+70 \text {. }
$$

Виброускорение, скорость и перемещения в линейных единицах могут быть получены из соответствующих уровней по формулам

$$
A=10^{\frac{L_{a}-120}{20}}, V=10^{\frac{L_{V}-146}{20}}, S=10^{\frac{L_{S}-222}{20}} .
$$

Амплитудно-частотные спектры виброускорений, полученные после обработки вибросигналов от акселерометров при проведении замеров вибрационного воздействия на первый и второй двигатели, закреплённых на платформе, установленной на гидроопоры, выявляют (рис. 4.33) преобладающие частоты колебаний в спектре вибрационного воздействия и уровни виброускорений.

Для представленных на рис. 4.33 при частоте 25 Гц уровни виброускорений в 102,10 дБ и 102,35 дБ для работающих левого и правого двигателей при выключенном вибростенде виброперемещения составят величину $\approx 0,137 \cdot 10^{-3}$ м, определяемую как:

$$
L_{S}=102,1-20 \lg (25)+70=144,76 \text { дБ }
$$

И

$$
S=10^{\frac{L_{S}-222}{20}}=10^{\frac{144,76-222}{20}} \approx 0,137 \text { MM. }
$$




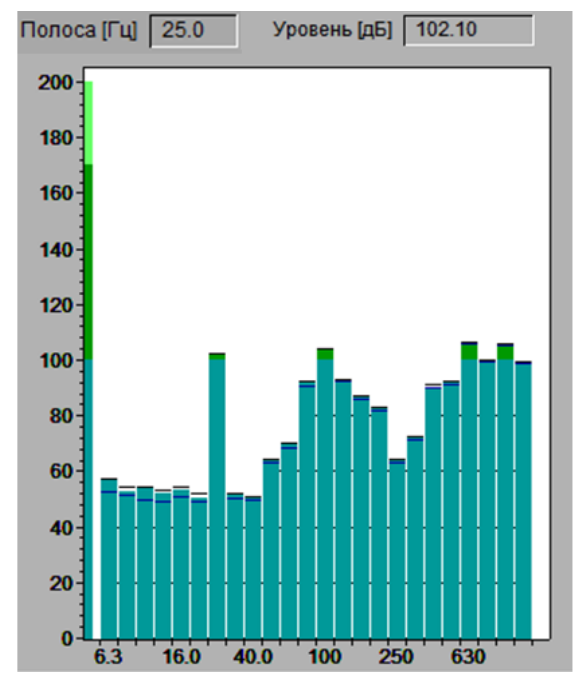

a)

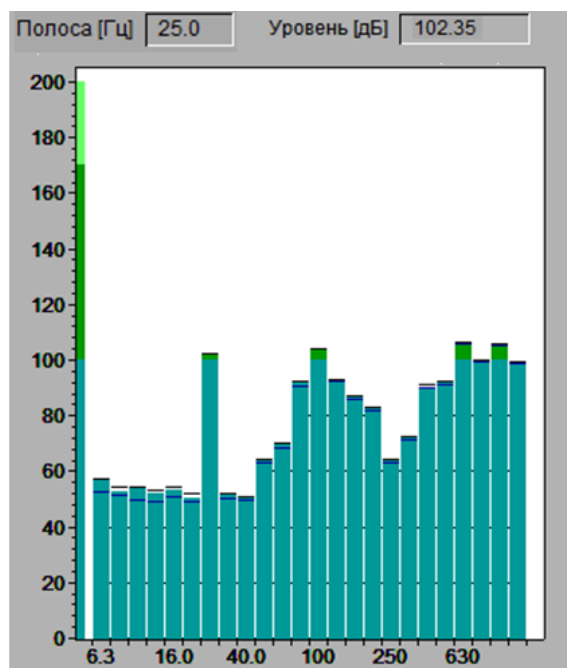

б)

Рис. 4.33. Спектры виброускорений (1/3 октавы) при неподвижном вязкоупругом основании: при работе левого двигателя (a), при работе правого двигателя (б)

На рис. 4.34 представлен спектр виброускорений на неподвижном вязкоупругом основании и одновременной работе левого и правого двигателей (на частоте 25 Гц уровень виброускорения составляет 103,07 дБ).

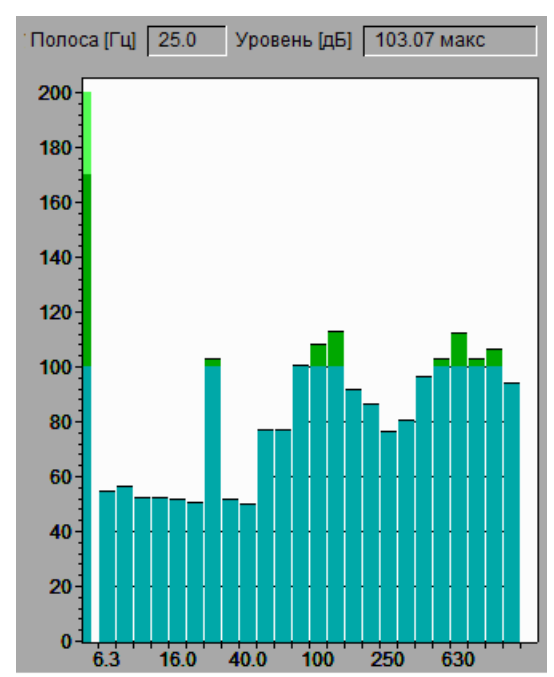

Рис. 4.34 Спектр виброускорений (1/3 октавы) при одновременной работе левого и правого двигателей и неподвижном вязкоупругом основании

Амплитудно-частотный спектр виброускорений (рис. 4.34), полученный после обработки вибросигналов от вибрационного воздействия при первом и втором работающих двигателях и выключенном вибростенде не является равномерным. Здесь спектр виброускорений во всей полосе повторяет спектры отдельно работающих двигателей. Это указывает, что периодического перетока энергии колебательного движения в электромеханической системе от одного двигателя к другому двигателю нет, т.е. данная энергия периодически не оказывается как бы сосредоточенной то в 
одном, то в другом двигателе $[19,62]$.

На рис. 4.35 представлены спектры виброускорений при вибрирующем вязкоупругом основании и работе левого и правого двигателей. При частоте 20 Гц уровень виброускорения составляет 132,5 дБ при работающем левом и 132,57 дБ правом двигателях.

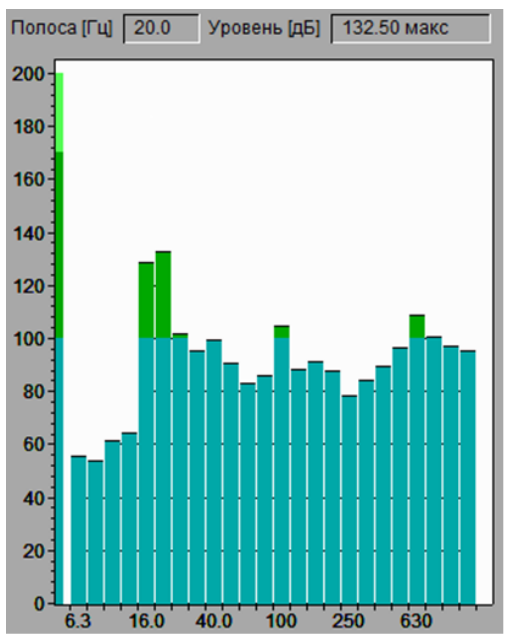

a)

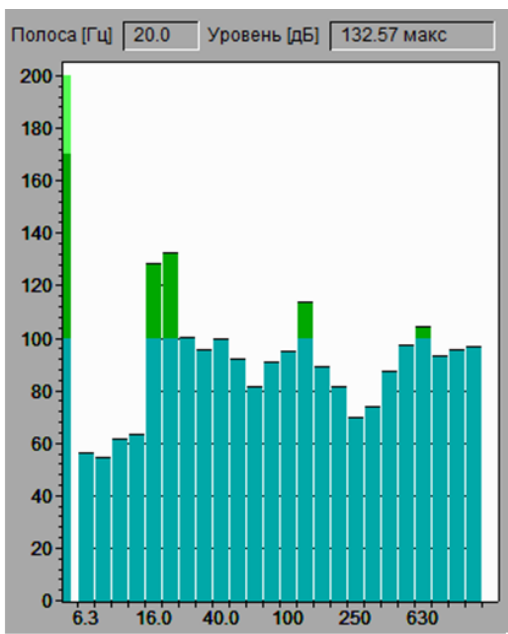

б)

Рис. 4.35. Спектры виброускорений (1/3 октавы) при вибрирующем вязкоупругом основании: при работе левого двигателя $(a)$, при работе правого двигателя (б)

На рис. 4.36 представлен спектр виброускорений при вибрирующем вязкоупругом основании и одновременной работе левого и правого двигателей (на частоте 20 Гц уровень виброускорения составляет 132,62 дБ).

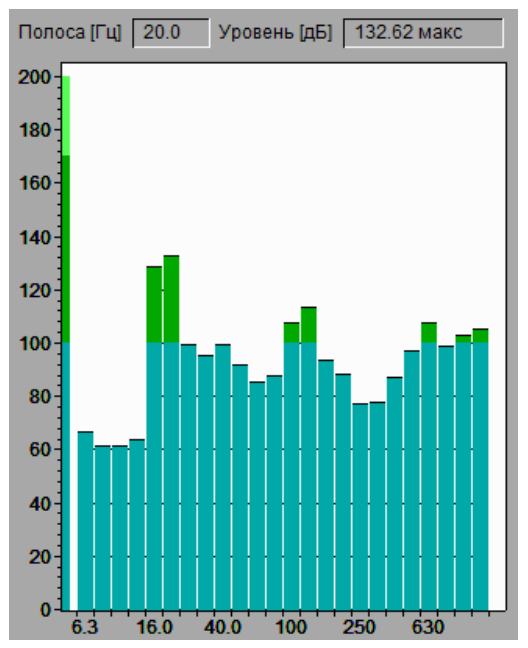

Рис. 4.36. Спектр виброускорений (1/3 октавы) при одновременной работе левого и правого двигателей и вибрирующем вязкоупругом основании

Амплитудно-частотный спектр виброускорений (рис. 4.36), полученный после обработки вибросигналов от вибрационного воздействия при первом и втором работающих двигателях и включенном вибростенде, не является равномерным, и в основном данный спектр также повторяет 
спектры отдельно работающих двигателей (рис. 4.35). На рис. 4.36 амплитуды спектральных составляющих виброускорений во всей полосе повышены по сравнению с амплитудами спектра виброускорений на (рис. 4.35). Это можно объяснить только возросшим уровнем возбуждаемой вибростендом вибрации.

Кроме того, в спектре (рис. 4.36), а также и в спектрах виброускорений отдельно работающих двигателей (рис. 4.35) наблюдается рядом стоящие с полосой частот 20 Гц и спектральные составляющие в полосе частот 16 Гц. Их средняя частота равна частоте возбуждения вибростенда $f_{\mathrm{Bc}}=\left(f_{16}+f_{20}\right) / 2=18$ Гц.

В электромеханической системе (рис. 4.31) возникает взаимное действие вибростенда и работающих двигателей. В этом случае может наблюдаться переток энергии колебательного движения в электромеханической системе от одного двигателя к другому через платформу вибростенда, за счёт возбуждаемой им вибрации. В результате чего в электромеханической системе могут возникать биения, когда частоты $\Omega_{1}$ и $\Omega_{2}$ главных колебаний двигателей близки друг к другу.

Для представленных на рис. 4.35 и рис. 4.36 в полосе частот 20 Гц уровней виброускорений в 132,50 дБ, 132,57 дБ и 132,62 дБ максимальные уровни виброперемещений работающих левого и правого двигателей при включенном вибростенде и совместно составят величину $\approx 4,99 \cdot 10^{-3} \mathrm{M}$, определяемую как $L_{S}=132,62-20 \lg (20)+70=175,979$ дБ:

$$
S=10^{\frac{L_{S}-222}{20}}=10^{\frac{175,979-222}{20}} \approx 4,99 \mathrm{MM} .
$$

Для оценки распределения энергии колебательного движения в электромеханической системе от одного двигателя к другому через платформу вибростенда, по возникающим биениям, когда частоты $\Omega_{1}$ и $\Omega_{2}$ главных колебаний двигателей близки друг к другу необходимо моделирование гармонических колебаний по данным полученным в ходе эксперимента.

Выполним моделирование процессов сложения колебаний от двух работающих двигателей, а также как частный случай выделим биения этих колебаний.

При моделировании процессов сложения двух гармонических колебаний по данным, полученным в ходе эксперимента, удобно эти гармонические колебания двигателей представить по формулам

$$
y_{1}=A_{1} \cos \left(\Omega_{1} t+\varphi_{1}\right) ; y_{2}=A_{2} \cos \left(\Omega_{2} t+\varphi_{2}\right) .
$$

При действии вибрации вибростенда на работающие левый и правый двигатели их уровни виброускорений в полосе спектра виброускоре- 
ний 25 Гц примем 102,35 дБ, что соответствует их равным амплитудам виброперемещений $A_{1}=A_{2}=Y_{m}=0,137 \cdot 10^{-3} \mathrm{M}$, (рис. 4.33) и (рис. 4.36). Пусть при действии вибрации вибростенда имеем растройки двигателей по частоте $\Delta f_{\text {дв.1 }}=f_{1.1}-f_{1.2}=1$ Гц и $\Delta f_{\text {дв.2 }}=f_{2.1}-f_{2.2}=1$ Гц.

Тогда круговые частоты главных колебаний двигателей при включённом вибростенде равны $\Omega_{1}=2 \pi f_{1}=157,0795 \mathrm{paд} / \mathrm{c} \quad$ и $\Omega_{2}=2 \pi f_{2}=150,796$ рад $/ \mathrm{c}$.

При таких условиях для результирующего колебания, применяя формулу для суммы косинусов, получим:

$$
y_{\text {рез }}=2 \cdot A_{1} \cdot \cos \left(\frac{\Omega_{1}-\Omega_{2}}{2} t\right) \cdot \cos \left(\frac{\Omega_{1}+\Omega_{2}}{2} t+\frac{\pi}{2}\right),
$$

где $a=\left|2 \cdot A_{1} \cdot \cos \left(\frac{\Omega_{1}-\Omega_{2}}{2} t\right)\right|$ определяет закон изменения амплитуды результирующего колебания со временем. Так как множитель $a$ может изменяться от $-2 \mathrm{~A}$ до $+2 \mathrm{~A}$, берем его абсолютную величину.

На (рис. 4.37) - (рис. 4.40) и представлены результаты моделирования гармонических колебаний по данным, полученным в ходе эксперимента.

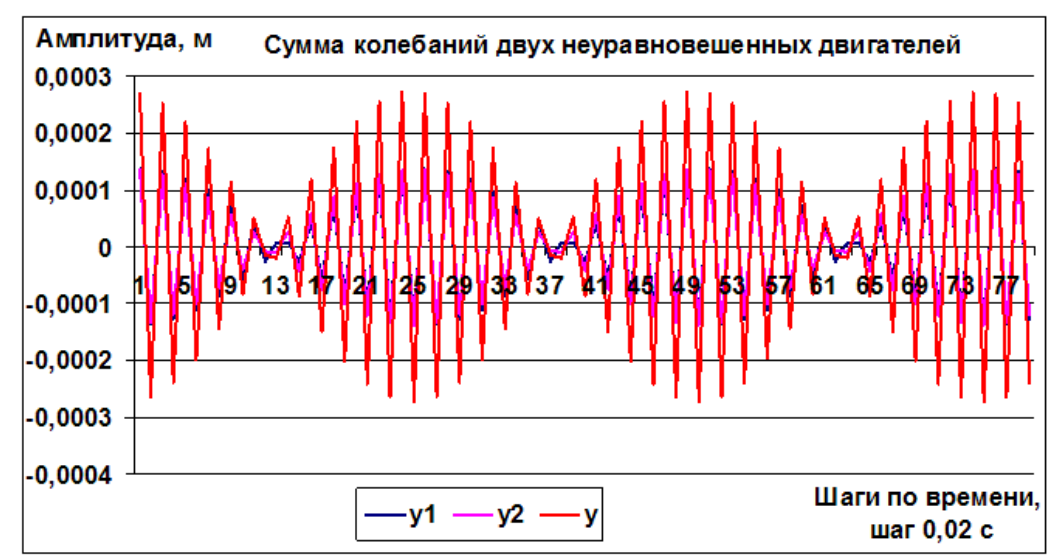

Рис. 4.37. Сумма колебаний двух неуравновешенных двигателей при $\Delta f_{\text {дв.1 }}=1$ Гц

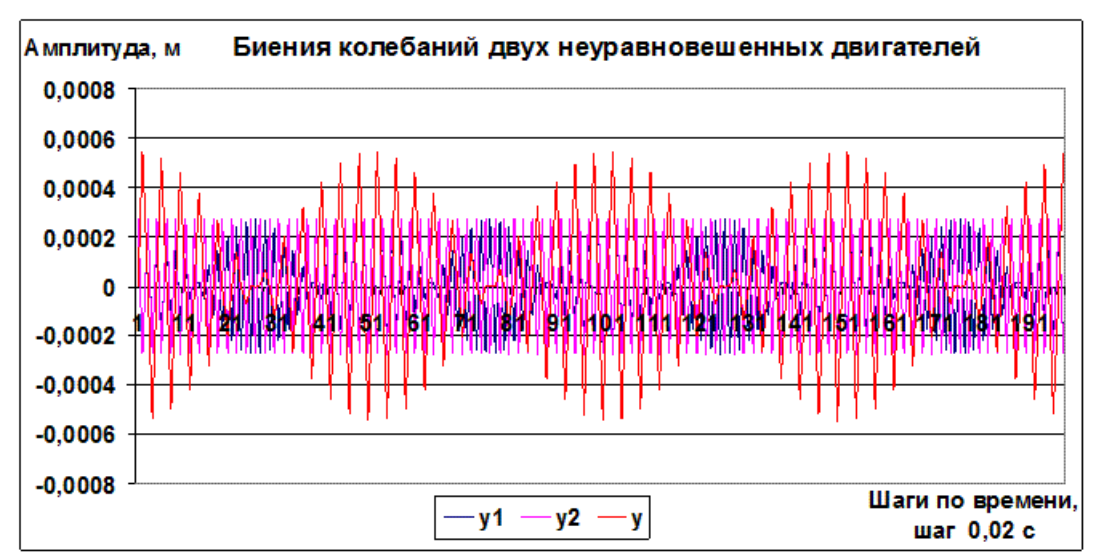

Рис. 4.38. Биения колебаний двух неуравновешенных двигателей при $\Delta f_{\text {дв.1 }}=1$ Гц 


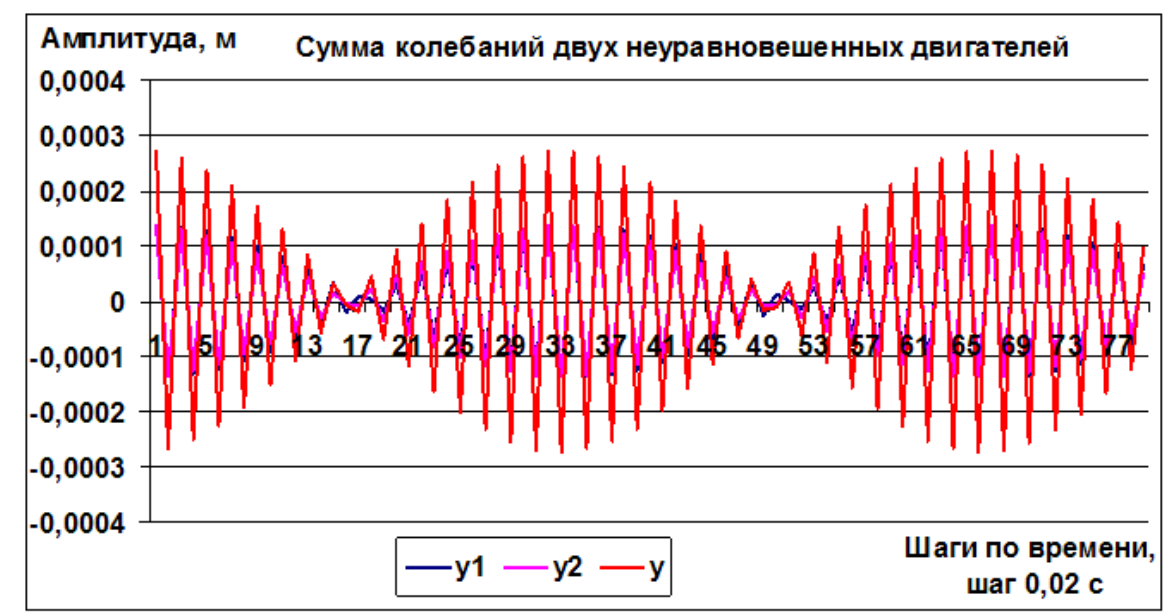

Рис. 4.39. Сумма колебаний двух неуравновешенных двигателей при $\Delta f_{\text {дв. } 2}=0,75$ Гц

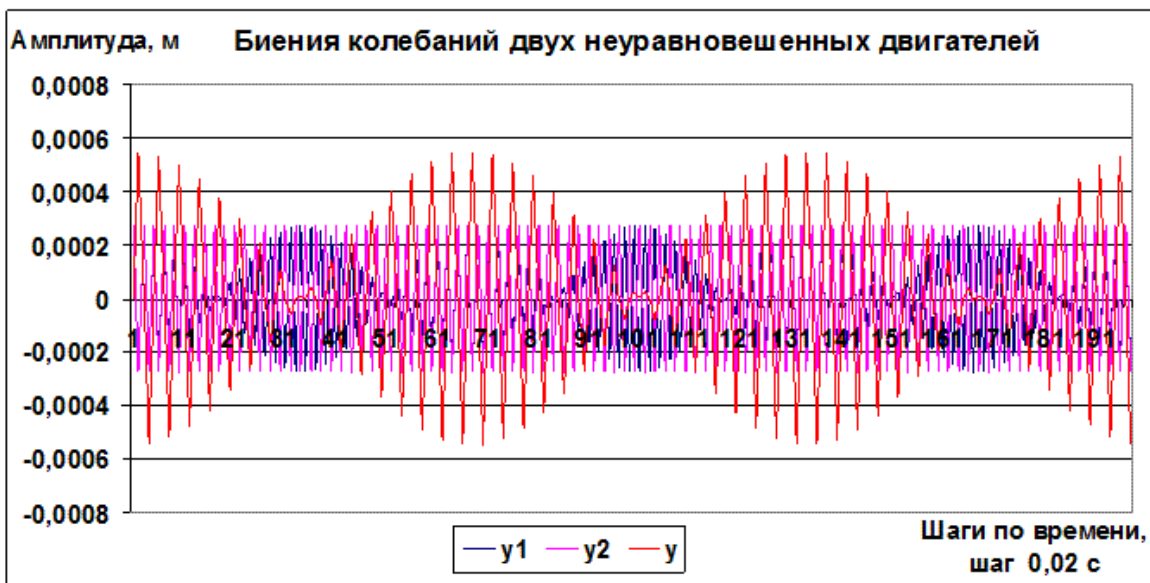

Рис. 4.40. Биения колебаний двух неуравновешенных двигателей при $\Delta f_{\text {дв. } 2}=0,75$ Гц

В результате эксперимента было выявлено, что синхронизация осуществляется по тому двигателю, который ранее достиг стационарного режима. Обнаружено возрастание амплитуд низкочастотных гармоник спектра при синхронизации двигателей на вибрирующем основании. При этом за счет зависимости амплитуды колебаний от частоты нарушается линейность всей электромеханической системы, что вызывает низкочастотные биения. Следовательно, в данном случае синхронизация нарушается.

Выражение (4.64) дает возможность определить разностную частоту низкочастотных биений, которую невозможно замерить без сложных акустических приборов. Эти значения позволят сравнить их с диапазоном возможных резонансных частот и принять решение по подавлению виброколебаний.

Факт нарушения синхронизации при дополнительном вибровозмущении вязкоупругого основания предоставляет еще одну возможность нивелировать это отрицательное явление взаимной синхронизации. 


\section{5. Нормирование вибраций}

Вибрацией называют наиболее распространенный вид механических колебаний, обусловленный работой машин и агрегатов. Вибрация возникает при работе механических машин, агрегатов, транспортных средств и различных приборов и устройств.

В соответствии с широко распространенным мнением считается, что колебания, генерируемые машинами и механизмами, целесообразно рассматривать по отдельным диапазонам: диапазон низких частот (от единиц до 200 - 300 Гц), диапазон средних частот (от 200 - 300 до 1000 2000 Гц); диапазон высоких частот (свыше 1000 - 2000 Гц) [25].

Необходимость такого деления вызвана тем, что каждому диапазону свойственны свои возмущающие силы; для каждого диапазона характерны своя физическая модель машины как колебательной упругой системы и соответствующие ей математические методы описания колебательных процессов; для каждого диапазона можно выделить и свои характерные методы борьбы с колебаниями в источнике и на путях распространения. Наиболее вероятиями причинами низкочастотных колебаний являются:

- неуравновешенность вращающихся масс;

- несоосности приводов отдельных агрегатов (в совокупности с соединительными муфтами);

- нарушение геометрии узлов шип - подшипник;

- периодические силы, создаваемые рабочим процессом [25].

Гармоники колебаний этого диапазона определяют динамическую прочность элементов машин и несут подавляющую долю колебательной энергии; эти колебания хорошо распространяются на большие расстояния из-за слабого демпфирования.

Динамическая модель машины для исследования колебаний низкочастотного диапазона представляет собой комбинацию пластинчатых, балочных элементов, а также точечных масс, сосредоточенных или распределенных упруго демпферных элементов. Наиболее простые модели состоят из сосредоточенных масс, связанных между собой упругими безынерционными элементами.

Силы в этих моделях носят обычно детерминированный характер. Вся машина рассматривается как единая упругая система, исследование свойств которой производится обычно методами прикладной теории колебаний.

Колебания среднечастотного диапазона обычно генерируются:

- высшими гармониками сил, порожденных неуравновешенностью ротора и обусловленных наличием нелинейных элементов в системе 
ротор - статор;

- нарушением геометрии кинематических пар;

- динамическим взаимодействием элементов ротора и статора (типа «зубцовой» частоты в электромашинах, «лопаточной» - в насосах). Эти возмущения часто вызывают резонансные колебания элементов корпуса, деталей амортизации и фундаментов [25].

В диапазоне средних частот машина описывается совокупностью каналов распространения колебаний от точек приложения сил к выбранным точкам наблюдения. Конкретный анализ динамического состояния машины производится обычно с помощью рассечения общей системы на ряд независимых подсистем и описания их свойств в точках взаимодействия этих подсистем обобщенными динамическими характеристиками типа динамической жесткости, импеданса, механической проводимости.

В диапазоне высоких частот механические колебания машин представляют собой упругие волны, распространяющиеся по элементам конструкции. Их расчет следует вести обычными акустическими методами, развитыми для сложных по геометрии и структуре сплошных сред. Для колебаний этих частот характерным является то, что они несут небольшую часть колебательной энергии всего спектра и при распространении хорошо демпфируются.

Рассмотрим влияние вибрации на детали машин и механизмов. Колебания в зубчатых передачах приводят к возрастанию уровня контактных и изгибных напряжений в зубцах колес, а также к усталостной поломке валов. При повышенной податливости ободьев зубчатых колес возможно возникновение в них изгибных колебаний, приводящих к усталостной поломке ободьев и выходу из строя всей передачи [107].

Колебания в металлорежущих станках оказывают влияние на точность и качество обрабатываемых поверхностей, на срок службы инструмента и элементов конструкции станка (направляющих, подшипников), определяющих точность обработки [107].

Роторы и валы являются главными элементами большинства энергетических, электрических и транспортных машин. Выполняя в машинах функции передачи крутящего момента или кругового движения, роторы представляют собой основной источник вредных вибраций [107].

Эксплуатационные характеристики и долговечность силовых установок тяжелых машин (транспортных и энергетических) с двигателями внутреннего сгорания (ДВС) в значительной степени определяются динамическими процессами, возникающими при разных условиях работы [107].

Вибрация машин в основном оказывает негативное воздействие. Она 
ускоряет износ деталей машин, служит основной причиной их поломок и аварий, снижает технико-эксплуатационные характеристики машин. Вибрация выступает как вредное явление по отношению к машинам, так как снижает их эксплуатационные характеристики, увеличивает износ и шум. Вибрация машины всегда порождает шум, который является вредным фактором для человека-оператора и для окружающей среды.

Вибрация, распространяясь через упругие элементы и фундаменты, оказывает отрицательное воздействие на станки и агрегаты, расположенные близи от источника вибрации, разрушая или влияя на их работу.

В случае контакта человека с вибрирующими объектами возникает ряд проблем, обусловленных действием вибрации на здоровье и работоспособность людей. Доказано, что длительное воздействие вибрации на организм человека приводит к повышению его утомляемости, снижению производительности и качества его труда, а также к возникновению профессионального заболевания, называемого вибрационной болезнью [57].

Проблема снижения вибрации и шума на производстве включает две главные задачи:

1) снижение вибрации и шума, создаваемой различными механическими, аэрогидродинамическими и электромагнитными источниками;

2) снижение вибрационных и шумовых характеристик машин и оборудования [20].

Для количественной оценки уравнений вибрации по смещению $x$, скорости $\dot{x}$, ускорению $\ddot{x}$ используется относительная логарифмическая шкала. Оценка уровней вибрации в этом случае производится энергетически в децибелах (дБ), представляющих десять логарифмов отношения рассматриваемых величин к начальным, условно принятым пороговым значениям [25]:

$$
\begin{aligned}
& L_{x}=10 \lg \frac{x^{2}}{x_{0}^{2}}=20 \lg \frac{x}{x_{0}} ; \\
& L_{\dot{x}}=10 \lg \frac{\dot{x}^{2}}{\dot{x}_{0}^{2}}=20 \lg \frac{\dot{x}}{\dot{x}_{0}} ; \\
& L_{\ddot{x}}=10 \lg \frac{\ddot{x}^{2}}{\ddot{x}_{0}^{2}}=20 \lg \frac{\ddot{x}}{\ddot{x}_{0}} .
\end{aligned}
$$

Числители этих выражений представляют абсолютные значения оцениваемых величин, а знаменатели - их пороговые (условно нулевые) значения: 
- по смещению $x_{0}=8 \cdot 10^{-10} \mathrm{~cm}$;

- скорости $\dot{x}_{0}=5 \cdot 10^{-6} \mathrm{~cm} / \mathrm{c}$;

- ускорению $\ddot{x}_{0}=3 \cdot 10^{-2} \mathrm{~cm} / \mathrm{c}^{2}$.

Стандартом ГОСТ 23941-2002 «Шум машин. Методы определения шумовых характеристик. Общие требования» установлены следующие шумовые характеристики машин:

- корректированный по частотной характеристике $A$ шумомера (далее - корректированный по $A$ ) уровень звуковой мощности $L_{W A}$ или эквивалентный корректированный по $A$ уровень звуковой мощности $L_{W A e q}$, дБА;

- уровни звуковой мощности в октавных полосах частот $L_{W}$, дБ;

- уровень звука излучения $L_{p A}$ или эквивалентный уровень звука излучения $L_{p A e q}$, дБА;

- корректированный по частотной характеристике $C$ шумомера пиковый уровень звукового давления излучения $L_{p C, p e a k}$, дБС.

ГОСТ 26043-83 «Вибрация. Динамические характеристики стационарных машин. Основные положения» позволяет получить данные о динамических нагрузках машин, необходимых для проектирования несущих строительных конструкций, а также виброизоляции машин с целью обеспечения вибробезопасности на рабочих местах.

В связи с развитием автономных электростанций на основе возобновляемых источников энергии, таких как ветрогенераторы, солнечные электростанции любых видов, параллельно с которыми работают дизельгенераторы из-за нестабильных потоков энергии основного источника, было выяснено, что дизель-генераторы целесообразно эксплуатировать с переменной частотой вращения $[103,104]$. Защита этих агрегатов от вибрации очень сложна, как и очень актуальна. Однако в настоящее время нельзя привести численные значения норм допустимой вибрации этих машин. Отправной точкой для оценки этих норм можно рассмотреть аналогичные показатели для гидрогегнераторов.

ГОСТ 5616-89 предусматривает следующие нормы вибрации допустимая вибрация (размах колебаний) в горизонтальной плоскости крестовины гидрогенератора со встроенными в них направляющими подшипниками при вертикальном исполнении или вибрация подшипников в вертикальной плоскости при горизонтальном исполнении гидрогенератора во всех рабочих установившихся режимах работы не должна быть более:

- 0.18 мм для гидрогенераторов с номинальной частотой вращения до 100 об/мин;

- 0.15 мм для гидрогенераторов с номинальной частотой вращения св. 100 до 187,5 об/мин; 
- 0.1 мм для гидрогенераторов с номинальной частотой вращения св. 187,5 до 375 об/мин;

- 0.07 мм для гидрогенераторов с номинальной частотой вращения св. 375 до 750 об/мин.

Размах вертикальной вибрации грузонесушей крестовины вертикального гидрогенератора и вибрации в осевом направлении опорной конструкции подпятника горизонтального гидроагрегата не должен превышать значений, указанных в табл. 4.3

Таблица 4.3

Размах вертикальной вибрации

\begin{tabular}{|c|c|}
\hline Частота вибрации, Гц & Допустимый размах вибрации, мм \\
\hline 1 и менее & 0,18 \\
\hline 3 & 0,15 \\
\hline 6 & 0,12 \\
\hline 10 & 0,08 \\
\hline 16 & 0,06 \\
\hline 30 и более & 0,04 \\
\hline
\end{tabular}

Допустимая вибрация (размах колебаний частотой 100 Гц во всем диапазоне нагрузок в симметричном режиме) не должна превышать:

- сердечника статора - 0.03 мм;

- лобовых частей обмотки статора генераторов мощностью свыше $300 \mathrm{MB} \cdot \mathrm{A}$ и генераторов-двигателей мощностью свыше $100 \mathrm{MB} \cdot \mathrm{A}$ в тангенциальном и радиальном направлениях - 0.1 мм.

РД 34.20.501-95 «Правила технической эксплуатации электрических станций и сетей Российской Федерации» содержит сведения об ограничении вибрации гидроагрегата в зависимости от частоты его вращения (табл. 4.4).

Таблица 4.4

Вибрация гидроагрегата (ветрогенератора) в зависимости от частоты его вращения

\begin{tabular}{|c|c|}
\hline $\begin{array}{c}\text { Частота вращения ротора гидроагрегата, } \\
\text { об/мин. }\end{array}$ & $\begin{array}{c}\text { Допустимое значение вибрации, } \\
\text { мм }\end{array}$ \\
\hline 60 и менее & 0,18 \\
\hline 150 & 0,16 \\
\hline 300 & 0,12 \\
\hline 428 & 0,10 \\
\hline 600 & 0,08 \\
\hline
\end{tabular}

У синхронных компенсаторов с номинальной частотой вращения 750 и 1000 об/мин двойная амплитуда вибрации должна быть не выше 80 мкм. 
Вертикальная и поперечная составляющие вибрации (среднее квадратическое значение виброскорости или удвоенная амплитуда колебаний), измеренные на подшипниках электродвигателей, сочлененных с механизмами, не должны превышать значений, указанных в заводских инструкциях. При отсутствии таких указаний в технической документации вибрация подшипников электродвигателей, сочлененных с механизмами, не должна быть выше значений, указанных в табл. 4.5.

Таблица 4.5

Нормы вибрации подшипников электродвигателей

\begin{tabular}{|c|c|}
\hline $\begin{array}{c}\text { Синхронная частота вращения, } \\
\text { об/мин }\end{array}$ & $\begin{array}{c}\text { Удвоенная амплитуда колебаний подшипни- } \\
\text { ков, мкм }\end{array}$ \\
\hline 3000 & 30 \\
\hline 1500 & 60 \\
\hline 1000 & 80 \\
\hline 750 и менее & 95 \\
\hline
\end{tabular}

ГОСТ 25364-97 «Агрегаты паротурбинные стационарные» устанавливает, что вибрацию следует измерять на всех опорах валопровода в трех взаимно перпендикулярных направлениях: вертикальном, горизонтальнопоперечном и горизонтально-осевом по отношению к оси вращения валопровода, а также дает нормы вибрации опор валопровода для оценки вибрационного состояния турбоагрегата, которые приведены в табл. 4.6.

Таблица 4.6

Нормы вибрации опор валопровода

\begin{tabular}{|c|c|}
\hline $\begin{array}{c}\text { Максимальное среднее квадратическое } \\
\text { значение виброскорости, мм· }{ }^{-1}\end{array}$ & Ограничения на эксплуатацию \\
\hline До 4,5 & Без ограничений \\
\hline Св. 4,5 до 7,1 & Не более 30 сут \\
\hline Св. 7,1 до 11,2 & Не более 7 сут \\
\hline Св. 11,2 & Не допускается \\
\hline
\end{tabular}

ГОСТ 609-84 «Машины электрические вращающиеся» устанавливает допускаемую вибрацию (среднеквадратическое значение скорости вибрации) подшипников компенсатора на уровне оси вала при всех режимах работы и при номинальной частоте вращения не должна превышать 2,2 мм с $^{-1}$. Допускаемая вибрация сердечника статора на частоте 100 Гц и при симметричной нагрузке не должна превышать $9,5 \mathrm{Mм} \cdot \mathrm{c}^{-1}$.

ГОСТ 16264.0-85 «Машины электрические малой мощности. Двигатели. Общие технические условия» регламентирует, что двигатели по среднему квадратическому значению виброскорости изготавливают трех категорий: нормальной $(\mathrm{N})$, с пониженной вибрацией $(\mathrm{R})$ и с жесткими 
требованиями по вибрации (S). Среднее квадратическое значение виброскорости для двигателей с номинальной частотой вращения до $4000 \mathrm{Mин}^{-1}$ устанавливают в технических условиях на конкретные типы двигателей в соответствии с требованиями табл. 4.7.

Таблица 4.7

Среднее квадратическое значение виброскорости для двигателей с номинальной частотой вращения до 4000 мин $^{-1}$

\begin{tabular}{|c|c|c|c|c|c|c|}
\hline \multirow{5}{*}{$\begin{array}{l}\text { Высота } \\
\text { оси } \\
\text { враще- } \\
\text { ния, мм }\end{array}$} & \multicolumn{6}{|c|}{ Среднее квадратическое значение виброскорости, мм/с } \\
\hline & \multicolumn{6}{|c|}{ Категория двигателя } \\
\hline & \multicolumn{2}{|c|}{$\mathrm{N}$} & \multicolumn{2}{|c|}{$\mathrm{R}$} & \multicolumn{2}{|c|}{$\mathrm{S}$} \\
\hline & \multicolumn{6}{|c|}{ Двигатели, питаемые от } \\
\hline & $\begin{array}{l}\text { многофаз- } \\
\text { ной сети }\end{array}$ & $\begin{array}{l}\text { однофаз- } \\
\text { ной сети } \\
\text { постоян- } \\
\text { ного и } \\
\text { перемен- } \\
\text { ного тока }\end{array}$ & $\begin{array}{l}\text { многофаз- } \\
\text { ной сети }\end{array}$ & $\begin{array}{l}\text { однофаз- } \\
\text { ной сети } \\
\text { постоян- } \\
\text { ного и } \\
\text { перемен- } \\
\text { ного тока }\end{array}$ & $\begin{array}{l}\text { многофаз- } \\
\text { ной сети }\end{array}$ & $\begin{array}{l}\text { однофаз- } \\
\text { ной сети } \\
\text { постоян- } \\
\text { ного и } \\
\text { перемен- } \\
\text { ного тока }\end{array}$ \\
\hline До 25 & 1,12 & 1,80 & 0,45 & 0,71 & 0,28 & 0,45 \\
\hline $\begin{array}{l}\text { Св. } 25 \\
\text { до } 45\end{array}$ & 1,80 & 2,80 & 0,71 & 1,10 & 0,45 & 0,71 \\
\hline 45 & 2,80 & 4,50 & 1,12 & 2,80 & 0,71 & 1,10 \\
\hline
\end{tabular}

Для двигателей с номинальной частотой вращения 4000 мин $^{-1}$ и выше, а также для многоскоростных двигателей переменного тока среднее квадратическое значение виброскорости не должно превышать 7,1 мм/с.

Среднее квадратическое значение виброскорости $\left(v_{e}\right)$ однофазных асинхронных и синхронных двигателей определяют по результатам измерений по формуле

$$
v_{e}=\sqrt{v_{e n}^{2}-v_{e 2 n}^{2}}
$$

где $v_{e n}$ - измеренный общий уровень виброскорости двигателей, мм/с; $v_{e 2 n}$ уровень виброскорости, измеренный на частоте, равной двойной частоте питающей сети, мм/с.

ГОСТ 20815-93 «Машины электрические вращающиеся. Механическая вибрация некоторых видов машин с высотой оси вращения 56 мм и более. Измерение, оценка и допустимые значения» устанавливает следующие значения вибраций (табл. 4.8).

Критерием, принятым для оценки интенсивности вибрации машин с частотой вращения 600 об/мин и выше, является среднее квадратическое значение виброскорости $v_{e}(\mathrm{~mm} / \mathrm{c}) . v_{e}$ определяют непосредственным измерением или по результатам спектрального анализа в диапазоне от частоты вращения, на которой проводят измерения, до 2000 Гц по формуле 


$$
v_{e}=\sqrt{\sum_{i=1}^{n} v_{e i}^{2}},
$$

где $v_{e i}$ - среднее квадратическое значение виброскорости, полученное при спектральном анализе для $i$-й полосы фильтра, $i=1,2 \ldots n$, при этом первая и $n$-я полосы фильтра должны включать соответственно нижнюю и верхнюю граничные частоты заданной для измерения полосы частот.

Таблица 4.8

\section{Нормы вибрации машин с высотой оси вращения 56 мм и более}

\begin{tabular}{|c|c|c|c|c|c|c|}
\hline \multirow{3}{*}{$\begin{array}{l}\text { Кате- } \\
\text { гория } \\
\text { ма- } \\
\text { шины }\end{array}$} & \multirow{3}{*}{$\begin{array}{l}\text { Номинальная } \\
\text { частота } \\
\text { вращения, } \\
\text { об/мин }\end{array}$} & \multicolumn{5}{|c|}{$\begin{array}{l}\text { Максимальное среднее квадратическое значение виброс- } \\
\text { корости машины, мм/с, для высот оси } H \text {, мм, установлен- } \\
\text { ной }\end{array}$} \\
\hline & & \multicolumn{4}{|c|}{ в свободно повешенном состоянии } & \multirow{2}{*}{$\begin{array}{l}\text { В жестко } \\
\text { скреплён- } \\
\text { ном состо- } \\
\text { янии } \\
H>400\end{array}$} \\
\hline & & $\begin{array}{l}56 \leq H \leq \\
71\end{array}$ & $\begin{array}{l}71 \leq H \leq \\
132\end{array}$ & $\begin{array}{l}132 \leq H \leq \\
225\end{array}$ & $H \geq 225$ & \\
\hline \multirow[t]{2}{*}{$\mathrm{N}$} & $600 \leq n \leq 1800$ & 1,12 & 1,8 & 1,8 & 2,8 & 2,8 \\
\hline & $\begin{array}{l}1800 \leq n \leq \\
6000\end{array}$ & 1,12 & 1,8 & 2,8 & 4,5 & 2,8 \\
\hline \multirow[t]{2}{*}{$\mathrm{R}$} & $600 \leq n \leq 1800$ & 0,71 & 0,71 & 1,12 & 1,8 & - \\
\hline & $\begin{array}{l}1800 \leq n \leq \\
6000\end{array}$ & 0,71 & 1,12 & 1,8 & 2,8 & - \\
\hline \multirow[t]{2}{*}{$S$} & $600 \leq n \leq 1800$ & 0,45 & 0,45 & 0,71 & 1,12 & - \\
\hline & $\begin{array}{l}1800 \leq n \leq \\
6000\end{array}$ & 0,45 & 0,71 & 1,12 & 1,8 & - \\
\hline
\end{tabular}




\section{ГЛАВА 5. ГИДРООПОРЫ С МАГНИТОРЕОЛОГИЧЕСКИМ ТРАНСФОРМАТОРОМ}

\section{1. Гидроопоры как современные средства виброзащиты машин и силовых агрегатов}

В настоящее время основными направлениями по решению проблемы виброзащиты машин и агрегатов являются внедрение систем виброизоляции с гидроопорами. Она заключается в установке между виброактивным и виброизолируемым объектами упругоинерционных элементов, настроенных на определенные частоты $[37,40,115]$. С конструктивнокомпоновочной точки зрения эту проблему удалось решить в интегральных гидроопорах (рис. 5.1). Отечественная гидроопора поршневого типа “Агрон” ОГ - 90, разработанная в Институте проблем машиностроения РАН рассчитана на статическую нагрузку 900 Н (рис. 5.1).

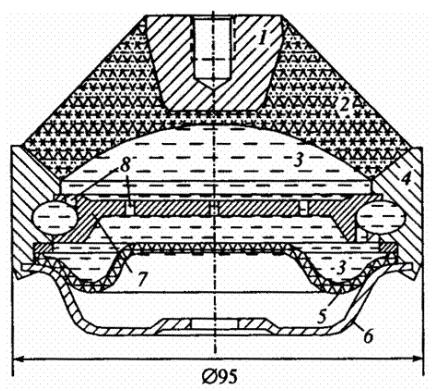

a.

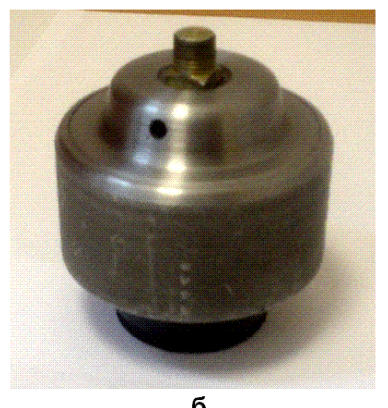

6.

Рис. 5.1. Гидроопора ОГ -90:

$a$ - конструкция гидроопоры - 1 - плата; 2 - обечайка; 3 - жидкостные камеры; 4 корпус; 5 - мембрана; 6 - поддон; 7 - перегородка; 8 - перепускные каналы; 6 внешний вид гидроопоры

Основные конструкции интегральных гидроопор обычно содержат не менее двух камер, рабочую и компенсационную, заполненные рабочей жидкостью $[37,40]$. Упругие свойства гидроопоры формируются в основном, за счет эластичной обечайки, к которой добавляется гидравлическая система. При этом жидкость выступает качестве масс - инерционной и диссипативной компоненты гидроопоры.

Демпфирование колебаний в опоре (рис. 5.1) происходит, в основном, за счет сил инерции колеблющейся жидкости в полостях 3 , деформации подвижной гофрированной мембраны 5 и упругой перегородки 7, а также за счет дросселирования определенного количества жидкости через перепускные каналы 8 .

Испытания выявили значительные преимущества гидроопор Института проблем машиностроения РАН по сравнению с обычными резинометаллическими и их зарубежными аналогами (рис.5.2). 


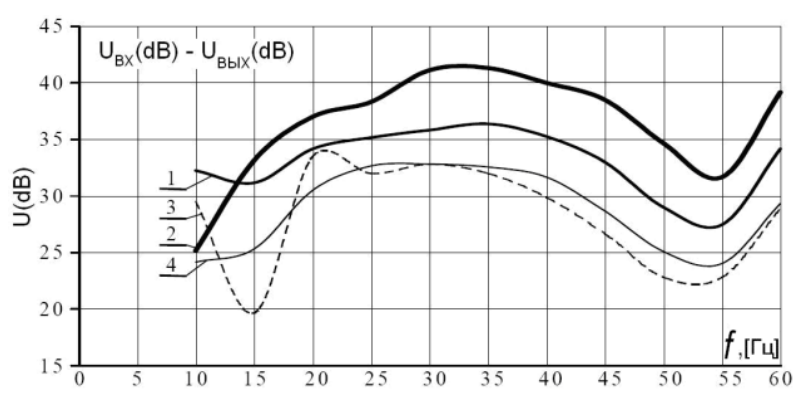

Рис. 5.2. АЧХ гидроопор:

1, 2 - гидроопоры №1,2 Института проблем машиностроения РАН с антикавитационными рабочими полостями; 3 - стандартная виброопора ОАО «ГАЗ»; 4 гидроопора фирмы FREIDENBERG

Из графиков АЧХ гидроопор видно, что гидроопора №1 Института проблем машиностроения РАН с антикавитационными рабочими полостями, в среднем, эффективнее импортной и стандартной виброопоры ОАО «ГАЗ» на 3 - 4 дБ [37].

Дальнейшее развитие гидроопор с инерционным трансформатором (ИТ) связано с использованием инерционных магнитореологических трансформаторов (МРТ) в системах виброизоляции для гашения вибрации и шума. Такое развитие гидроопор предполагает использование МРТ, настроенных на определенные частоты, которые являются их основными элементами [33, 34, 37, 40]. В этом случае МРТ включается в систему автоматического регулирования (САР).

МРТ по сути являются дроссельными каналами, соединяющими рабочие и компенсационные камеры гидроопоры. Настройка МРТ связана с проведением большого объема экспериментальных работ, а при эксплуатации гидроопоры собственные частоты настройки всегда смещаются. Смещение собственных частот настройки гидроопоры вызвано интенсивной диссипацией энергии колебаний, приводящей к нагреванию магнитореологической жидкости (МРЖ) на десятки градусов, что влечет к снижению её вязкости на порядок и более [40].

Следует отметить, что особенностью гидроопор с ИТ и МРТ является независимость частот внутренних резонансов автономной гидроопоры от динамических свойств, присоединенных к ней конструкций. Это свойство имеет важное практическое значение, так как позволяет переносить экспериментальные результаты изучения автономной гидроопоры на систему в целом.

На рис. 5.3 представлена конструкция гидроопоры с МРТ, с электромагнитной системой возбуждающих электромагнитов (ВЭ) $[73,45]$.

Гидроопора с МРТ (рис. 5.3, $a$ ) содержит герметично закрытые рабочую и компенсационную камеры 4 . Камеры 4 ограничены общим корпусом 3 с закрепленной в нем разделительной ферромагнитной перегород- 
кой 7, 8,9 с диамагнитными тангенциальными дроссельными каналами малого внутреннего диаметра 8, порядка 1,5-2,0 мм, расположенных в её поверхностном слое по её образующей между полюсами ВЭ 12. Диамагнитные дроссельные каналы 8 соединяют рабочую и компенсационную камеры 4. Рабочая камера ограничена опорной платой 2 и эластичной обечайкой поршневого действия 1 , а компенсационная - мембраной 5 . Металлическая перегородка 9 выполнена в виде кольца из ферромагнитного материала с высокой магнитной проницаемостью, с отверстиями для встраиваемых диамагнитных дроссельных каналов 8 и является частью магнитопровода кольцевой электромагнитной системы.

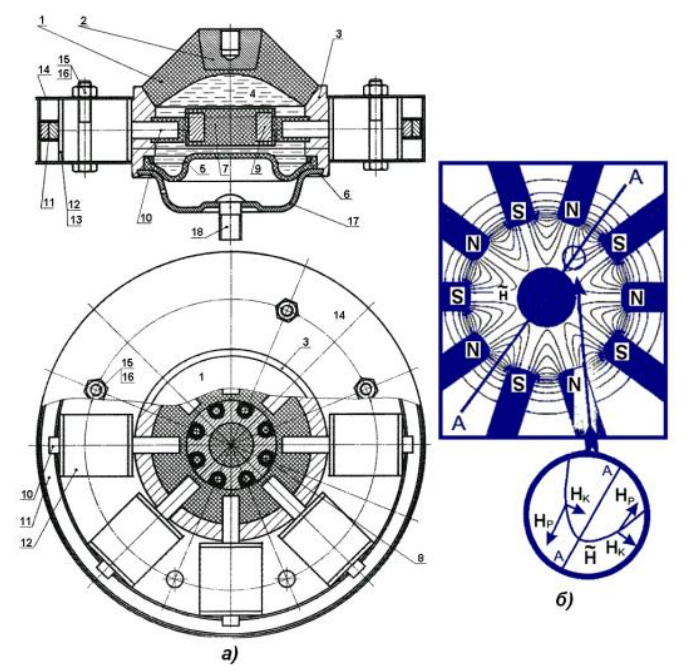

Рис. 5.3. Гидроопора с МРТ с электромагнитной системой возбуждающих электромагнитов:

$a-1$ - эластичная обечайка; 2 - опорная плата; 3 - общий корпус; 4 - рабочая и компенсационная камеры; 5 - мембрана; 6 - поддон; 7,8,9 - ферромагнитная перегородка; 8 - дроссельные каналы; 10 - ферромагнитные сердечники; 11 - внешнее ферромагнитное ярмо; 12,13 - возбуждающие электромагниты; 14 - защитные фланцы электромагнитной системы; 6 - места размещения дроссельных каналов

Кольцевая электромагнитная система МРТ состоит из набора ВЭ 12 с ферромагнитными сердечниками в виде цилиндрических стержней $10 \mathrm{c}$ явно выраженными полюсами, внутренней ферромагнитной перегородки 9 и внешним ферромагнитным ярмом-кольцом 11. Здесь, у сердечников 10 ВЭ и перегородки 9 точка Кюри $767^{\circ} \mathrm{C}$, что в 5 (пять) раз выше нагрева МРЖ $\left(150{ }^{\circ} \mathrm{C}\right)$. Считаем магнитную проницаемость $\mu_{\mathrm{c}}$ сердечников 10 ВЭ перегородки 9 постоянной. Полюса ВЭ 12 расположены поочередно (рис. 5.3, б), т.е. чередуются между собой на полюса $S$ и $N$. Катушки 13 ВЭ соединяются параллельно так, чтобы соседние полюса имели разную полярность и подключаются к источнику намагничивающего тока ВЭ.

Внутренние камеры гидроопоры с МРТ 4 заполнены МРЖ, которая представляет устойчивый коллоидный раствор. Его получение обеспечи- 
вается двумя условиями: мелкими размерами частиц наполнителя (40100 нм) и использованием специальных веществ - стабилизаторов. Так как частицы магнитного наполнителя могут сильно взаимодействовать между собой, адсорбционно-сольватный слой молекул стабилизатора на поверхности частиц препятствует их объединению и коагуляции. Получение магнитных частиц требуемого размера достигается путем осаждения солей двух- и трехвалентного железа в щелочной среде по методу Элмора $[44,111]$ :

$$
\begin{aligned}
& \mathrm{FeSO}_{4} 7 \mathrm{H}_{2} \mathrm{O}+2 \mathrm{FeCl}_{3} 6 \mathrm{H}_{2} \mathrm{O}+8 \mathrm{NH}_{4} \mathrm{OH}= \\
& =\mathrm{Fe}_{3} \mathrm{O}_{4} \downarrow+6 \mathrm{NH}_{4} \mathrm{Cl}+\left(\mathrm{NH}_{4}\right)_{2} \mathrm{SO}_{4}+23 \mathrm{H}_{2} \mathrm{O} .
\end{aligned}
$$

В результате реакции образуется магнетит - осадок черного цвета, обладающий магнитными свойствами. Возникающий в сердечниках 10 ВЭ МРТ магнитный поток действует в зоне разнополярных полюсов сердечников $S$ и $N$ на рабочую МРЖ (рис. $5.3, \sigma$ ), протекающую в тангенциальных индукционных дроссельных каналах 8 изменяя её вязкость пропорционально действующему вибрационному воздействию, и тем самым осуществляя жидкостное демпфирование в гидроопоре с МРТ.

Так, гидроопора с МРТ (рис. 5.3, a) с МРЖ содержит, например, восемь индукционных дроссельных каналов 8 с МРЖ. Под воздействием электромагнитного поля осуществляется управление потоками МРЖ через эти дроссельные каналы 8 , изменяя тем самым пропускную способность разделительной дроссельной ферромагнитной перегородки 7, 8, 9 [45, 73].

В конструкции гидроопор с МРТ нет трущихся частей с фрикционным сухим контактом. Изменение объемов рабочих полостей с МРЖ происходит за счет изменения формы гидроопоры при ее деформации. В качестве компонентов трения выступает конструкционное трение в эластичных обечайке и внутренней мембране и магнитогидравлическое вязкое сопротивление рабочей жидкости в индукционных дроссельных каналах [44-46].

Гидроопоры с МРТ позволяют совместить частотные характеристики виброзащитной системы и возбудителей. В результате большая часть частот виброзащитной системы, состоящая из гидроопор с МРТ находится в какой-либо из зон частотного спектра возбудителей.

Гидроопоры с МРТ включаются в замкнутую систему автоматической регулировки (САР) с микропроцессорной системой для цифрового управления МРТ с целью оптимального демпфирования вибрационных воздействий путём настройки МРТ на заданные резонансные частоты [45, 46, 75].

Физическая модель активной виброзащиты с МРТ в контуре САР 
показана на (рис. 5.4). Так, гидроопора с МРТ, установленная на основании содержит, наряду с обычно применяемыми пружиной и демпфером, инерционный трансформатор с приведенной массой $m_{u m}=L A^{2}[40,46,73]$.

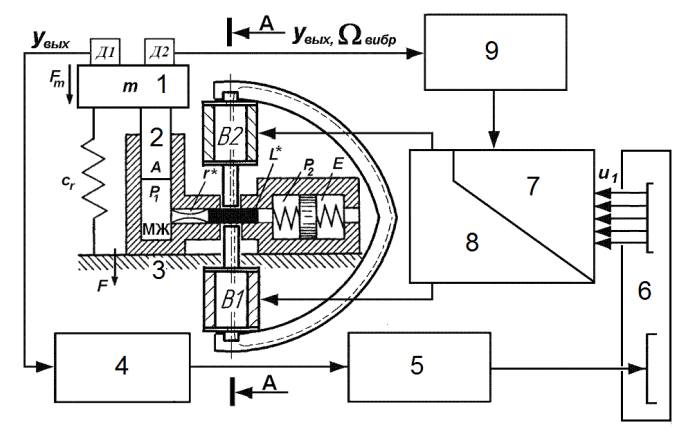

Рис. 5.4. Физическая модель активной виброзащиты с МРТ в контуре САР:

1 - нагрузка с массой $m$, кг; 2 - поршень - обечайка; 3 - основание; 4 - полосовой усилитель; 5 - амплитудный детектор; 6 - микропроцессорная система; 7 - цифровые ключи; 8 - источники намагничивающего тока; 9 - блок формирования напряжения возбуждения; $B 1, B 2$ - возбуждающие электромагниты; Д1, Д2 - акселерометры; $c_{r}$ жесткость упругой обечайки, Н/м; $A$ - площадь поршневого действия обечайки, $\mathrm{m}^{2}$; $r^{*}$ и $L^{*}$ - гидравлическое и инерционное сопротивления дроссельных каналов, $\mathrm{Hc} / \mathrm{M}$; $E$ - емкость дополнительной камеры; $P_{1}, P_{2}$ - давления в рабочих камерах гидроопоры; $F_{m}, F$ - силы, действующие на гидроопору и на основание соответственно, $\mathrm{H}$

Демпфирование колебаний в гидроопоре с MPТ (рис. 5.3, a) и (рис. 5.4), происходит, в основном, во-первых, за счет деформации резиновой обечайки - поршня 1 (на рис. 5.4 - поршень 2), деформации подвижной мембраны 5 и во-вторых, за счет сил инерции колеблющейся рабочей МРЖ в жидкостных объемах 4 опоры, коммутации управляемых индукционных дроссельных каналов 8 в ферромагнитной перегородке 7 (рис. 5.4 - коммутация цифровыми ключами 7). В результате приведенная масса $m_{u m}=L A^{2}$ рабочей МРЖ в дроссельных каналах 8 превосходит свою реальную массу в рабочей и компенсационной камерах 4 гидроопоры.

Под действием неоднородного и ортогонального магнитного поля в дроссельных каналах 8 (рис. 5.3, б) можно достичь объемных пондеромоторных сил в МРЖ на несколько порядков, превышающих силу тяжести, и тем самым, увеличивая вязкость МРЖ в их дроссельных каналах [46].

Настройка на заданные частоты вибросигналов МРТ гидроопоры (рис. 5.4) осуществляется посредством выделения полосовым усилителем 4 первой гармоники вибросигнала, детектирования амплитудным детектором 5 текущих экспериментальных значений демпфирующих амплитудночастотной характеристики (АЧХ) гидроопоры с МРТ, формирования напряжения возбуждения в блоке 9, включения - выключения ВЭ для управления потоками МРЖ в дроссельных каналах. Включение и выключение ВЭ достигается при помощи комбинаций $u_{1}$ “открыто - закрыто" 
цифровыми ключами 7, коммутирующими источники намагничивающего тока ВЭ 8 по заранее заданной программе, записанной в микропроцессорной системе 6 , и задаваемой экспериментальными или расчётными демпфирующими АЧХ динамической жесткости гидроопоры [73].

В результате изменяется динамическая жесткость перестраиваемого МРТ относительно статической жесткости без потери последней. Надлежащим выбором цифровых кодов коммутации ВЭ для МРТ гидроопоры одного типоразмера производится настройка передаточных характеристик в требуемом частотном диапазоне вибросигналов [73]. Установлено, что изменением геометрии дроссельных отверстий и их числа можно изменять положение переходной зоны в частотной области АЧХ [40].

САР гидроопоры с МРТ должна работать в режиме самонастройки [75]. Построение оптимального регулятора связано с выявлением внутренних зависимостей параметров системы, параметров режима объекта регулирования и управляющих сигналов, выявления зависимости для определения оптимальных фазовых сдвигов между сигналами с датчика обратной связи и управляющими сигналами электромагнитной системы ВЭ МРТ гидроопоры.

Схема включения гидроопоры как линейного механического четырехполюсника представлена на рис. 5.5.

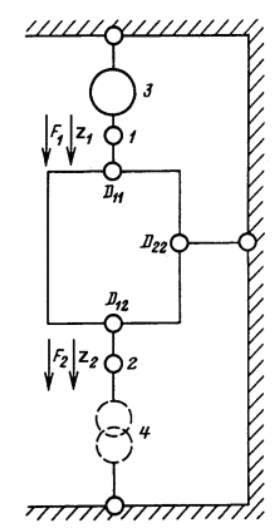

Рис. 5.5. Схема включения гидроопоры как линейного механического четырехполюсника:

1 - контакт со стороны объекта; 2 - контакт со стороны основания; 3 - генератор силы $F_{1} ; 4$ - генератор перемещения $Z_{2}$

Рассмотрим задачу без учета диссипативных характеристик с целью более упрощенного анализа полюсов и нулей частотных функций [8]. Рабочая жидкость принята несжимаемой. Рассмотрим линейный механический четырехполюсник (рис. 5.5). Для такой системы справедливы следующие отношения [32-40]:

$$
F_{1}(s)=D_{11}(s) z_{1}(s)-D_{12}(s) z_{2}(s),
$$




$$
F_{2}(s)=-D_{21}(s) z_{1}(s)+D_{22}(s) z_{2}(s),
$$

где $s$ - переменная преобразования Лапласа; $z_{1}$ и $z_{2}$ - перемещения в точках 1 и $2 ; D_{11}(s)$ и $D_{22}(s)$ - главные динамические жесткости; $D_{12}(s)=D_{21}(s)$ передаточные динамические жесткости.

Из системы (5.1) следует, что если точка 2 жестко закреплена $\left(z_{2}=0\right)$, или точка $l$ свободна $(F=0)$, то абсолютная передаточная функция:

$$
T(s)=-\left.\frac{F_{2}(s)}{F_{1}(s)}\right|_{z_{2}=0}=-\left.\frac{z_{1}}{z_{1}}\right|_{F_{1}=0}=\frac{D_{12}}{D_{11}} .
$$

Результат иллюстрирует известное свойство равенства коэффициентов передачи при силовой и кинематической виброизоляции [40].

Для анализа важна также передаточная функция по относительному перемещению при $F_{l}=0$ :

$$
R(s)=\frac{z_{2}-z_{1}}{z_{2}}=1-T(s) .
$$

Функции $D_{11}(s), D_{12}(s), T(s)$ и $R(s)$ можно представить в виде отношений полиномов

$$
D_{11}(s)=\frac{p(s)}{q(s)}, D_{12}(s)=-\frac{N(s)}{q(s)}, T(s)=\frac{N(s)}{p(s)}, R(s)=\frac{p(s)-N(s)}{p(s)},
$$

где $p(s)$ - полином, корни которого являются резонансными частотами; $q(s)$ - полином, корни которого являются антирезонансными частотами; $N(s)$ - полином, корни которого являются частотами нулей передаточной динамической жесткости и передаточной функции (нулей передачи).

Запишем совместную систему механических и гидравлических уравнений $[19,25,61]$ :

$$
\left\{\begin{array}{rl}
F_{1} & =c_{r} z_{1}+p_{1} A \\
Q & =A z_{1} s \\
L Q s & =p_{1}-p_{2} \\
Q & =E p_{2} s \\
p_{1} & =\frac{F_{1}-c_{r} z_{1}}{A} \\
p_{2} s & =\frac{Q}{E} \\
p_{2} s & =\frac{A z_{1} s}{E} \\
p_{2} & =\frac{A z_{1}}{E}
\end{array} .\right.
$$


Выполним алгебраические преобразования над выражением $L Q s=p_{1}-p_{2}$ и получим

$$
\begin{gathered}
L Q s=p_{1}-p_{2}=L A z_{1} s^{2}=\frac{F_{1}-c_{r} z_{1}}{A}-\frac{A z_{1}}{E} \mid \cdot \frac{A}{z_{1}} ; \\
L A^{2} s^{2}=\frac{F_{1}}{z_{1}}-c_{r}-\frac{A^{2}}{E} ; \\
\frac{F_{1}}{z_{1}}=L A^{2} s^{2}+c_{r}+\frac{A^{2}}{E} ; \\
D_{11}(s)=L A^{2} s^{2}+c_{r}+\frac{A^{2}}{E} .
\end{gathered}
$$

В формуле (5.3) $m_{u m}=L A^{2}$ - приведенная масса; $L=\rho l / A_{T}$, где $\rho\left[\right.$ кг/м $\left.{ }^{3}\right]$ - плотность жидкости, $l[\mathrm{M}]$ - длина трубки; $A_{T}\left[\mathrm{M}^{2}\right]$ - площадь поперечного сечения трубки; $c_{r}$ - жесткость резиновой обечайки; $c_{\mathrm{M}}=A^{2} / E$ - эквивалентная жесткость учитывающая взаимодействие мембраны и дополнительной камеры.

Выполнив необходимые алгебраические преобразования над (5.1) и (5.2), получим

$$
\begin{gathered}
D_{11}(s)=D_{12}(s)=L A^{2} s^{2}+c_{r}+\frac{A^{2}}{E}, \\
T(s)=\frac{F_{2}(s)}{F_{1}(s)}=1, \text { при } R(s)=0 .
\end{gathered}
$$

Отсюда следует, что система имеет одну частоту резонанса:

$$
\omega_{\mathrm{p}}=\sqrt{\frac{c_{r}+\left(A^{2} / E\right)}{L A^{2}}} .
$$

Добавив инерционную нагрузку на вход системы (массу $m$ ), получим

$$
\begin{gathered}
D_{11}(s)=\left(m+L A^{2}\right) s^{2}+c_{r}+\left(A^{2} / E\right), \\
D_{12}(s)=L A^{2} s^{2}+c_{r}+\left(A^{2} / E\right), \\
T(s)=\frac{L A^{2} s^{2}+c_{r}+\left(A^{2} / E\right)}{\left(m+L A^{2}\right) s^{2}+c_{r}+\left(A^{2} / E\right)},
\end{gathered}
$$




$$
R(s)=\frac{m s^{2}}{\left(m+L A^{2}\right) s^{2}+c_{r}+\left(A^{2} / E\right)} .
$$

Для такой системы получим две характерные частоты: частоту нуля $\omega_{0}$, совпадающую с (5.6) и частоту резонанса:

$$
\omega_{\mathrm{p}}=\sqrt{\frac{c_{r}+\left(A^{2} / E\right)}{m+L A^{2}}} .
$$

Здесь резонансная частота гидроопоры без нагрузки перешла в частоту нуля гидроопоры с нагрузкой. Вместо массы $m$ может быть более сложная динамическая нагрузка, но частота нуля передаточной функции не изменится.

Если задача рассматривается с учетом диссипативных характеристик, то динамическая жесткость ненагруженной гидроопоры представлена как [37, 40]:

$$
D(j \omega)=-\omega^{2} m_{u m}+j \omega b+c .
$$

Если на гидроопору устанавливается масса $m$ (рис. 5.4), то суммарная динамическая жесткость при действии на массу силы $F_{m}$ будет равна

$$
D_{c}=-m \omega^{2}+D(j \omega)=-\left(m+m_{u m}\right) \omega^{2}+j \omega b+c .
$$

В выражениях (5.12) и (5.13): $b=r A^{2}-$ приведенное демпфирование или гидравлический коэффициент трения, $\mathrm{Hc} / \mathrm{M} ; c$ - эквивалентная жесткость, учитывает взаимодействие мембраны и дополнительной камеры и сжимаемости жидкости в рабочей камере; $\omega$ - круговая частота; $j$ - мнимая единица.

Эффективность виброизоляции гидроопорой с приведенной массой $m_{u m}$, создающей силу $\boldsymbol{F}_{u m}=m_{u m}(\ddot{x}-\ddot{V})$ на относительных ускорениях, оценивают по её передаточной функции через коэффициент передачи [37]:

$$
T(j \omega)=K(j \omega)=\frac{F_{u m}(j \omega)}{F_{m}(j \omega)}=\frac{F_{2}(j \omega)}{F_{1}(j \omega)}<1 .
$$

Тогда передаточная функция гидроопоры по силе (рис. 5.5) будет равна

$$
T(j \omega)=\frac{F_{2}(j \omega)}{F_{1}(j \omega)} \cdot \frac{z_{1}}{z_{2}}=\frac{-m_{u m} \omega^{2}+b j \omega+c}{-\left(m+m_{u m}\right) \omega^{2}+b j \omega+c} .
$$


Если $V \neq 0$, а сила $F=0$, то передаточная функция гидроопоры от кинетического воздействия (рис. 5.5) определяется из условия равенства сил:

$$
\begin{gathered}
-m \omega^{2} z=\left(-m_{u m} \omega^{2}+b j \omega+c\right) \cdot(z-V), \\
T(j \omega)=\frac{z}{V}(j \omega)=\frac{-m_{u m} \omega^{2}+b j \omega+c}{-\left(m+m_{u m}\right) \omega^{2}+b j \omega+c} .
\end{gathered}
$$

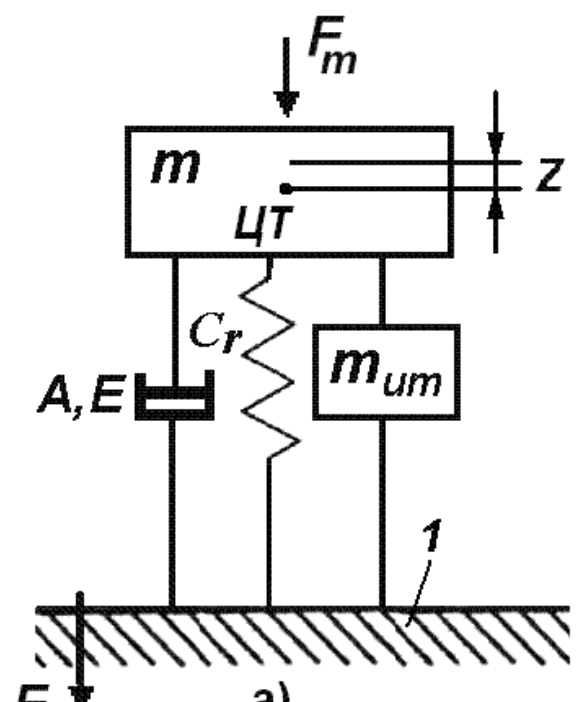

$F \square$ a)

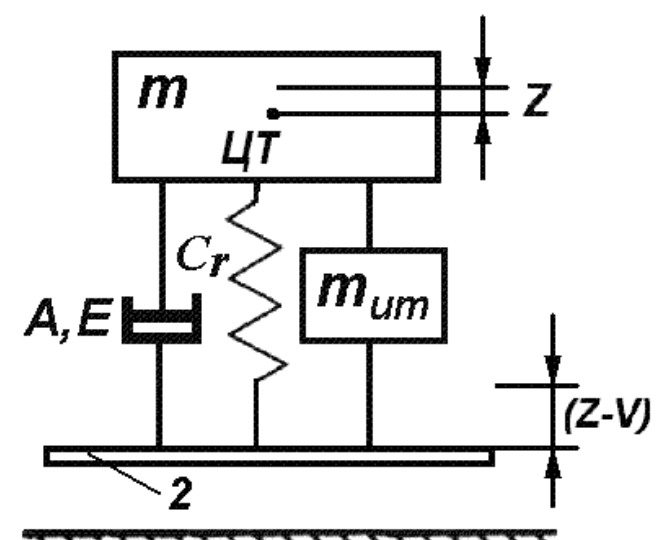

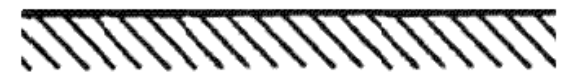

б)

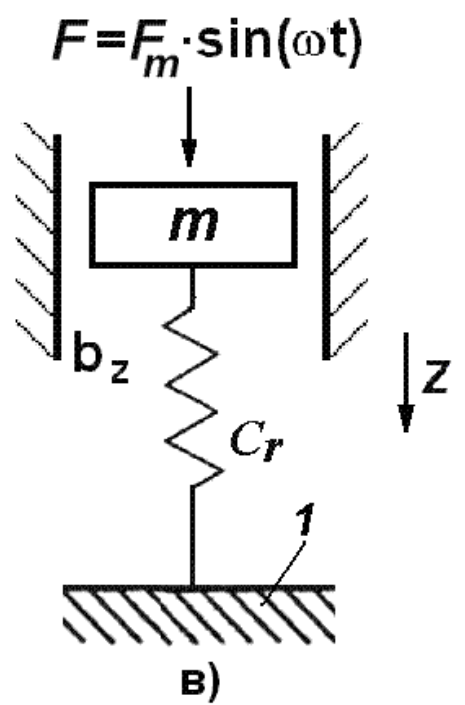

Рис. 5.6. Физические модели одномассовых систем виброизоляции с одной степенью свободы по координате $Z$ масса $m$ сосредоточена в центр тяжести:

$a$ - для силового возбуждения на неподвижном 1 основании; $\sigma$ - для кинетического возбуждения на подвижном 2 основании; в - без рабочей жидкости, где элементы упругости, массы и трения отделены друг от друга

Передаточная функция по силе и кинематическая передаточная функция гидроопоры оказываются одинаковыми. Общий результат для этого равенства получен из анализа этих систем как четырехполюсников [37].

Анализируя формулу (5.17), можно сделать следующий вывод: виброизоляция может быть осуществлена путём настройки гидроопор на частоты их внутренних динамических резонансов, совпадающих с резонансными вибрациями машин и агрегатов. Этого можно достичь изменением динамической жесткости гидроопоры и тем самым осуществить её настройку на резонансные вибрации машин и агрегатов в условиях меняющейся нагрузки.

C точки зрения виброзащиты гидроопоры необходимо рассматривать как системы виброизоляции с одной степенью свободы (рис. 5.6, $a, \sigma$ ).

Здесь полезно рассмотреть гидроопору без рабочей жидкости в составе системы виброизоляции в виде сосредоточенной массы $m$ покоя- 
щейся на резиновой обечайке - пружине, другой конец пружины жестко закреплен к основанию (рис. 5.6, в). Система, кроме того, обладает трением $b_{z}, \mathrm{Hc} / \mathrm{M}$. В этой системе элементы упругости, массы и трения отделены друг от друга. Для простоты анализа будем считать, что на систему воздействует переменная возмущающая сила, изменяющаяся по синусоидальному закону [37].

Уравнение колебательного движения тела с массой $m$ в этом случае имеет вид

$$
m z^{\prime \prime}+b_{z} z^{\prime}+c z=F_{m} \cdot \sin \omega t
$$

где $m$ - масса системы, кг; $c$ - жесткость пружины, численно равная силе, которую необходимо приложить к пружине, чтобы вызвать её единичную деформацию, $\mathrm{H} / \mathrm{m} ; Z$ - текущее значение колебательного смещения пружины, м; $\mathrm{z}^{\prime}=d z / d t$ - текущее значение колебательной скорости, м/с; $\mathrm{z}^{\prime \prime}=d v / d t$ - текущее значение колебательного ускорения $\mathrm{M} / \mathrm{c}^{2} ; b_{z}$ - постоянная которая называется коэффициентом вязкого сопротивления, Нc/м; $F_{m}$ амплитуда возмущающей силы, $\mathrm{H}$; $\omega$ - частота возмущающей силы, рад/сек.

Решение этого уравнения даёт соотношение между амплитудами колебательной скорости $V_{m}$ и возмущающей силы $F_{m}$ :

$$
V_{m}=\frac{F_{m}}{\sqrt{b_{z}^{2}+\left(\omega m-\frac{c}{\omega}\right)^{2}}} .
$$

Знаменатель этого выражения характеризует сопротивление, которое оказывает система возмущающей переменной силе и называется полным механическим сопротивлением или импедансом колебательной системы.

Величина $b_{z}$ составляет активную, а величина $(\omega m-c / \omega)$ - реактивную часть этого сопротивления. Реактивное сопротивление, в свою очередь, состоит их двух сопротивлений: упругого $c / \omega$ и инерционного $\omega m$.

Применительно к гидроопорам соотношение (5.19) между амплитудами колебательной скорости $V_{m}$ и возмущающей силы $F_{m}$ :

$$
V_{m}=\frac{F_{m}}{\sqrt{b_{z}^{2}+b_{z}^{2}(j \omega)+\left[\left(m+m_{u m}\right) \omega-\frac{c}{\omega}\right]^{2}}} .
$$

Из формулы (5.20) видно, что с введением в систему виброгашения 
рабочей жидкости, создающей дополнительную приведенную массу $m_{u m}$, можно изменять реактивное сопротивление и амплитуды колебательной скорости $V_{m}$ и тем самым добиваться наилучшей виброизоляции. При этом гидравлическая система виброгашения, кроме коэффициента вязкого сопротивления $b_{z}$, обладает и гидравлическим коэффициентом трения $b_{z}(j \omega)$ в дроссельных каналах рабочей жидкости.

Снижение вибрации при помощи гидроопор достигается как и их эластичной резиновой обечайкой, так и гидравлическим инерционным трансформатором с приведенной массой $m_{u m}[37]$.

Динамической жесткостью механической системы называют отношение амплитуды внешней гармонической силы к комплексной амплитуде колебаний.

Для системы с одной степенью свободы динамическая жесткость:

$$
c(\eta)=\frac{F(j \omega)}{x(j \omega)}=\frac{F_{0}}{\tilde{A}}=a\left(1-\eta^{2}+i \frac{\vartheta}{\pi} \cdot \eta\right)
$$

где $c(\eta)$ - динамическая жесткость; $\eta$ - коэффициент потерь; $i$ - мнимая единица. При резонансе система обладает минимальной динамической жесткостью [37, 40].

Гидроопоры, обладая рядом преимуществ перед обычными виброопорами, имеют существенный недостаток. Нет строгой концепции расчета их динамических характеристик. Каждое новое поколение гидроопор с заданными техническими требованиями дорабатывается, в основном экспериментально.

Актуальной является задача предварительной настройки гидроопор на заданные резонансные частоты, при условиях меняющейся нагрузки $[38,45,46]$.

Концепция перестройки гидроопор на заданные частоты включает построение физической модели гидроопоры и установление вида ее передаточной функций - отношения вибрационной силы на её выходе к смещению или скорости на её входе [73]. В концепцию входит также определение полюсов и нулей её передаточных функций $T(s)$ на всех частотах вибрации $\omega_{\text {вi}}$, где $i-$ номер частоты возбуждения гидроопоры.

Учитывая то, что дальнейшее решение проблемы виброзащиты машин и агрегатов связано с внедрением гидроопор с магнитореологическими трансформаторами и системами автоматического регулирования (САР) в управление гидроопорами, то должно учитываться, что гидроопора работает в САР в цепи обратной связи.

Кроме того, при настройке гидроопор на заданные резонансные частоты необходимо знать и рассчитать их вибрационные амплитудно- 
частотные характеристики без активного воздействия обратной связи, т.е. в разомкнутой системе регулирования.

Гидроопора принадлежит к семейству конечных линейных систем с сосредоточенными параметрами. Передаточная функция гидроопоры (5.15) полностью характеризует собственное движение её составных элементов, а также количество и диаметр каналов дроссельной перегородки, т.е. определяет жёсткость гидроопоры и так же характеризуют преобразование входных воздействий гидроопоры в её вынужденное движение [73].

Определение передаточных функций $T(s)$ гидроопор на всех частотах вибрации далее проводиться с учётом того, что гидроопора работает без активного воздействия обратной связи.

Существует тесная связь между передаточной функцией $T(s)$ гидроопоры и её дифференциальным уравнением динамического состояния. Выходную реакцию гидроопоры как системы 2-го порядка можно определить через входное воздействие не зависящее от времени, решая линейное дифференциальное уравнение 2-го порядка, которое имеет вид:

$$
\left(m+m_{u m}\right) \frac{d^{2} y}{d t^{2}}+b \frac{d y}{d t}+C y=m_{u m} \frac{d^{2} x}{d t^{2}}+b \frac{d x}{d t}+C x .
$$

Из выражения (5.15) следует, что передаточные функции $T(j \omega)$ гидроопоры, есть дробно - рациональные функции комплексной величины $s=j \omega$, которые имеют один и тот же знаменатель, где $s=\sigma+j \omega$ представляет собой комплексную частоту.

Передаточная функция гидроопоры является рациональной, а любая рациональная функция вида полностью определена (с точностью до действительной постоянной) корнями полинома знаменателя - полюсами $S_{p i}$ и числителя - нулями $S_{z i}$ функции $T(s)$. Расположение полюсов и нулей на комплексной плоскости обуславливается как типом системной передаточной функции, так и элементами, входящими в состав гидроопоры.

Положение полюсов и нулей содержит значительную информацию как качественного, так и количественного характера - относительно свойств гидроопоры, включая, в частности, основные особенности её АЧХ.

Из диаграмм полюсов (рис. 5.7) видно, что передаточная функция гидроопоры является устойчивой, полюса такой функции располагаются в виде комплексно-сопряжённых пар симметрично оси $R e$ в левой $S$ - полуплоскости.

Проведя анализ расположения полюсов и нулей (рис. 5.7) функций 
$T(s)$ вида (5.15), можно идентифицировать и определить основные параметры гидроопоры. Полюса и нули функций $T(s)$ являются объединяющими параметрами физической модели гидроопоры, несущими информацию о гидравлическом коэффициенте трения $b_{z}(j \omega)$, и динамической жесткости гидроопоры $D(j \omega)$.

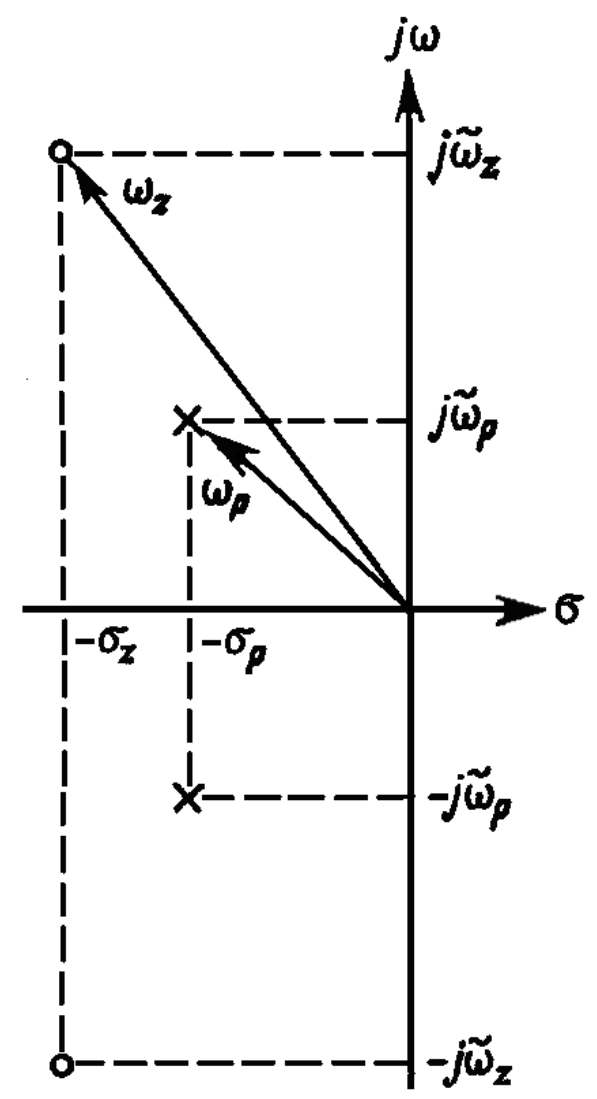

Рис. 5.7. Диаграмма полюсов и нулей передаточной функции гидроопоры

Такая информация заложена для гидравлического коэффициента трения гидроопоры $b_{z i}(j \omega)$ в реальной части полюсов $S_{p i}$ функций $T(s)$, а для динамической жесткости гидроопоры $D_{j i}(j \omega)$ в их мнимой части (рис. 5.7).

По заданным техническим требованиям на АЧХ можно синтезировать и рассчитать такую передаточную функцию $T(s)$ гидроопоры, для которой частотная характеристика $|T(j \omega)| e^{j \omega \omega}$ удовлетворяет этим требованиям.

АЧХ и ФЧХ, соответствующей передаточной функции $T(s)$ гидроопоры, можно получить графически, исходя из диаграммы ее полюсов и нулей (рис. 5.7).

В общем гидроопора характеризуется передаточной функцией вида [73]:

$$
T(s)=K\left(s^{2}+2 \sigma_{z} s+\omega_{z}^{2}\right) /\left(s^{2}+2 \sigma_{p} s+\omega_{p}^{2}\right) .
$$


Для случая $\omega_{\mathrm{p}}=\omega_{\mathrm{z}} \mathrm{AЧX}$ (частотно-заграждающая) диаграмма полюсов и нулей изображена на рис. 5.8, $a$, а АЧХ - на рис. 5.8, б.

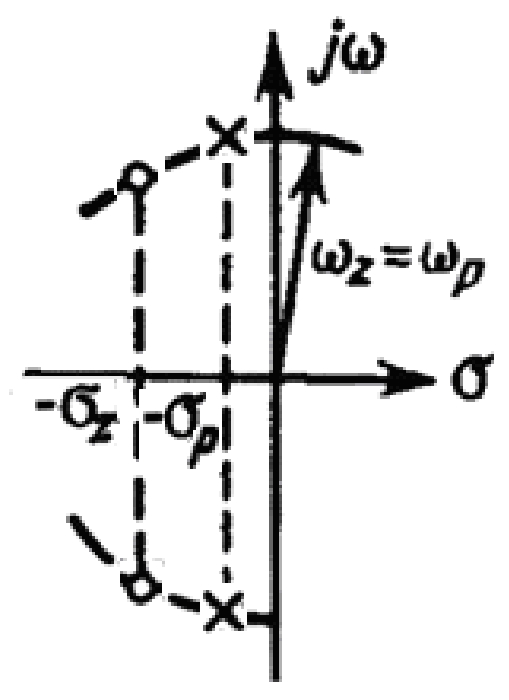

a

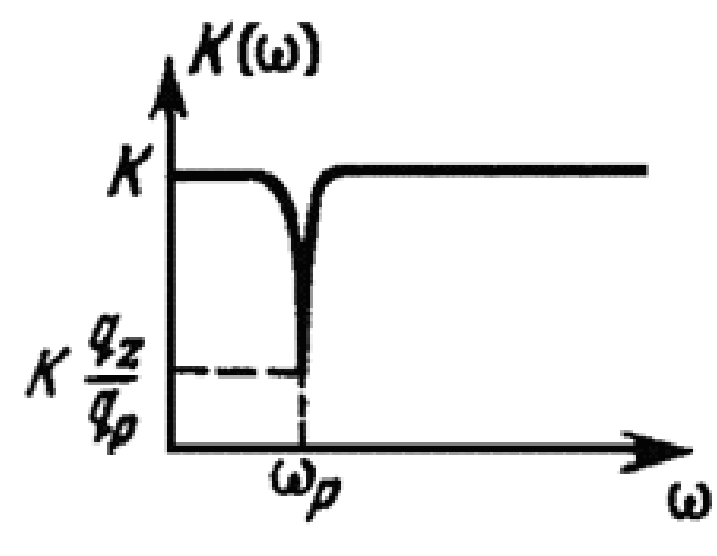

6

Рис. 5.8. Диаграмма полюсов и нулей передаточной функции гидроопоры $(a)$; идеальная заграждающая амплитудно-частотная характеристика гидроопоры (б)

Далее будем считать, что базовая линейная система виброизоляции является системой с одной степенью свободы с сосредоточенными параметрами и они не зависят от времени. Поэтому дифференциальное уравнение для такой системы виброизоляции будут уравнениями с постоянными коэффициентами (5.24):

$$
\left(m+m_{u m}\right) \frac{d^{2} y}{d t^{2}}+b_{z i} \frac{d y}{d t}+C_{z i} y=m_{u m} \frac{d^{2} x}{d t^{2}}+b_{z i} \frac{d x}{d t}+C_{z i} x,
$$

где $x(t)=z_{1}$ и $y(t)=z_{2}$ - входной и выходной сигналы.

Дифференциальные уравнения состояния наиболее просто решаются операционным методом с использованием преобразования Лапласа, которое позволяет провести синтез гидравлических виброопор в частотной области, что важно при их разработке, проектировании и испытании.

Выполняя преобразование по Лапласу при нулевых начальных условиях над левой и правой частями дифференциального уравнения состояния гидроопоры (5.24) и произведя замену $z$ на $Y$, а коэффициенты $\left(m+m_{u m}\right) ; b_{z i}$ и $C_{z i}$ - на соответствующие производным коэффициенты - на $a_{2} ; a_{1 i}$ и $a_{0 i}$ В левой части выражения. В правой же части выражения произведём замену коэффициентов $m_{u m} ; b_{z i}$ и $C_{z i}$ на коэффициенты - $b_{2} ; b_{1 i}$ и $b_{0 i}$. При такой замене коэффициентов получим выражение для дифференциального уравнения состояние гидроопоры, при $x=z_{1}$ и $y=z_{2}$, которое имеет 
вид выражения (5.26):

$$
\begin{gathered}
\left(m+m_{u m}\right) \cdot \ddot{y}+b_{z i} \cdot \dot{y}+C_{z i} \cdot y=m_{u m} \cdot \ddot{x}+b_{z i} \cdot \dot{x}+C_{z i} \cdot x, \\
a_{2} \cdot \ddot{y}+a_{1 i} \cdot \dot{y}+a_{0 i} \cdot y=b_{2} \cdot \ddot{x}+b_{1 i} \cdot \dot{x}+b_{0 i} \cdot x .
\end{gathered}
$$

Выполним преобразование Лапласа над частями уравнения (5.26):

$$
\begin{gathered}
L\left[a_{2} \cdot \ddot{y}+a_{1 i} \cdot \dot{y}+a_{0 i} \cdot y\right]=L\left[b_{2} \cdot \ddot{x}+b_{1 i} \cdot \dot{x}+b_{0 i} \cdot x\right], \\
a_{2} L[\ddot{y}]+a_{1 i} L[\dot{y}]+a_{0 i} L[y]=b_{2} L[\ddot{x}]+b_{1 i} L[\dot{x}]+b_{0 i} L[x] .
\end{gathered}
$$

Преобразование по Лапласу при нулевых начальных условиях линейного дифференциального уравнения состояния гидроопоры с постоянными коэффициентами заключается в замене оператора дифференцирования $P=d / d t$ комплексной величиной $S=\sigma+j \omega$, т.е. применяя к выражению (5.28) имеем

$$
\left(a_{2} s^{2}+a_{1 i} s+a_{0 i}\right) \cdot Y=\left(b_{2} s^{2}+b_{1 i} s+b_{0 i}\right) \cdot X .
$$

где $Y$ и $X$ - изображения по Лапласу функций времени $y(t), x_{0}(t)$.

Из выражения (5.29) теперь можно определить системную передаточную функцию гидроопоры без активного воздействия обратной связи. Такая функция имеет вид отношения двух квадратных уравнений с постоянными коэффициентами:

$$
T(s)_{i}=\frac{Y(s)_{i}}{X(s)_{i}}=\frac{b_{2} s^{2}+b_{1 i} s+b_{0 i}}{a_{2} s^{2}+a_{1 i} s+a_{0 i}} .
$$

Передаточная функция $T(s)_{i}$ гидроопоры определяется относительно входного воздействия, при этом предполагается, что все остальные входные воздействия на гидроопору равны нулю. Из выражения (5.30) очевидна независимость передаточных функций гидроопоры $T(s)_{i}$ от того какой функцией времени является её входное воздействие. Передаточная функция $T(s)_{i}$ зависит лишь от вида дифференциального уравнения состояния гидроопоры и значений её коэффициентов $a_{i}$ и $b_{i}$, т.е. от динамических свойств и параметров гидроопоры как системы, которые могут быть определены экспериментально.

Системная передаточная функцию гидроопоры (5.30), полученная операционным методом с использованием преобразования Лапласа, совпадает с передаточной функцией гидроопоры, полученной при решении 
совместной системы механических и гидравлических уравнений (5.15). Заменяя комплексную частоту $j \omega$ в (5.15) комплексной величиной $s=j \omega$ передаточную функцию гидроопоры можно представить в виде

$$
T(s)=\frac{F(s)}{F_{m}(s)}=\frac{m_{u m} s^{2}+b_{z i} s+c}{\left(m+m_{u m}\right) s^{2}+b_{z i} s+c} .
$$

Передаточная функция гидроопоры вида (5.30) и (5.31) является рациональной и полностью определена (с точностью до действительной постоянной) корнями полинома знаменателя $D(s)$ - полюсами $S_{p i}$ и корнями полинома числителя $N(s)$ - полюсами $S_{z i}$ функции $T(s)$.

Гидроопора с такой (5.31) передаточной функцией является устойчивой системой виброизоляции. Передаточная функция гидроопоры является основной характеристикой, отражающей способность гидроопоры к виброгашению в заданном частотном диапазоне вибросигналов.

В ходе эксперимента при виброиспытаниях для построения АЧХ гидроопор были получены зависимости переходной жёсткости гидроопор от их частоты возбуждения (рис. 5.9) [73].
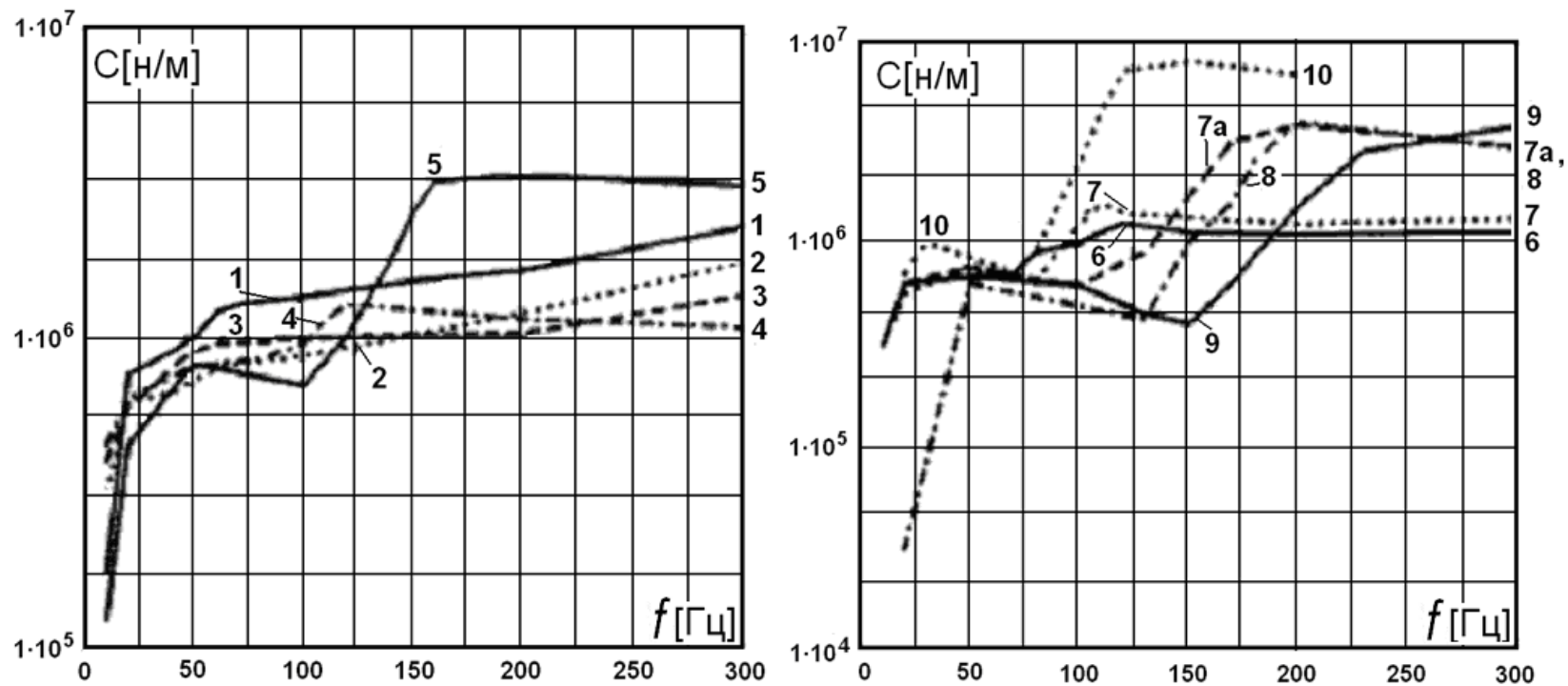

Рис. 5.9.Экспериментальные зависимости динамической жесткости гидроопор от частоты возбуждения

На рис. 5.9 представлены следующие экспериментальные зависимости: Переходная жесткость ОГ-90 с обечайкой и металлическим поршнем с отверстием. № сборок со следующими параметрами перегородок: 1 - 5 отверстий диаметром 2,5 мм; 2 - 7 отверстий диаметром 2,5 мм; 3 - 7 отверстий диаметром 2,5 мм по периметру; 4 - 9 отверстий диаметром 3 мм со взаимным поворотом; 5 - 9 отверстий диаметром 3 мм с взаимным поворотом; 6 - 13 отверстий диаметром 3,0 мм; 7 - 13 отверстий 
диаметром 2,5 мм; 7a. - 6 отверстий диаметром 3,0 мм; 8 - 15 отверстий диаметром 2,5 мм; 9 - 19 отверстий диаметром 2,5 мм; 10 - 21 отверстий диаметром 2,0 мм.

Для гидроопоры, содержащей, пять параллельных инерционных трубок (характеристика 1 на рис. 5.9), включением - выключением индукционных клапанов с помощью комбинаций “открыто - закрыто” может быть проведена настройка на 32 различных частоты настройки в диапазоне 18-50 Гц.

Следующим этапом при определении АЧХ гидропор является определение полюсов и нулей передаточных функций.

Для определения полюсов и нулей передаточных функций $W(s)_{i}$ необходимо определить коэффициенты полиномов $X(s)_{i}$ и $Y(s)_{i}$ на всех

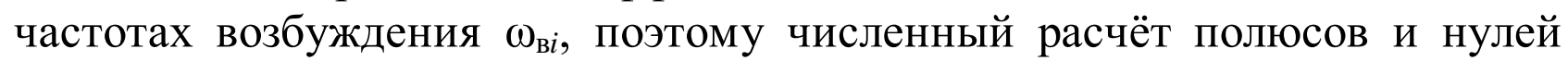
передаточных функций выполняется в два этапа:

1. Коэффициенты полиномов $X(s)_{i}$ функций $W(s)_{i}$.

Как видно из выражения для системной передаточной функции $W(s)_{i}$ (5.30): полиномом $X(s)$ функции $W(s)_{i}$ является знаменатель, т.е.

$$
X(s)_{i}=a_{2} s^{2}+a_{1 i} s+a_{0 i}
$$

где $a_{2}=\left(m+m_{\text {um }}\right) ; a_{1 i}$ и $a_{0 i}$ - коэффициенты.

Коэффициент $a_{2}=\left(m+m_{\text {иm }}\right)$ является постоянным для всего диапазона частот возбуждения $\omega_{\text {вi }}$. Коэффициенты: $a_{1 i}=b_{z i}$ обобщённый гидравлический коэффициент трения; $a_{0 i}=c_{z i}-$ переходная динамическая жёсткость; $i=1,2,3 \ldots n-$ номера частот возбуждения $\omega_{в i}$.

2 . Коэффициенты полиномов $X(s)_{i}$ функций $W(s)_{i}$.

Полиномом $Y(s)$ функции $W(s)_{i}$ является числитель, т.е.

$$
Y(s)_{i}=b_{2} s^{2}+b_{1 i} s+b_{0 i} .
$$

где $b_{2}=m_{u m}, b_{1 i}$ и $b_{0 i}-$ коэффициенты.

Коэффициент $b_{2}=m_{\text {um }}$ является постоянным для всего диапазона частот возбуждения $\omega_{\text {ві }}$. Коэффициенты: $b_{1 i}=b_{z i}$ - обобщённый гидравлический коэффициент трения; $b_{0 i}=c_{z i}-$ переходная динамическая жёсткость; $i=1,2,3 \ldots n$ - номера частот возбуждения $\omega_{\mathrm{в} i}$.

Определение коэффициентов полиномов $X(s)_{i}$ и $Y(s)_{i}$ функций $W(s)_{i}$ прежде всего сводится к расчёту величин $m_{u m},\left(m+m_{u m}\right), b_{z i}=b^{(1)}{ }_{z i}+b^{(2)}{ }_{z i}$ и $c_{z i}$ на всем диапазоне частот возбуждения $\omega_{в i}$. Далее проводится расчёт величин $m_{u m},\left(m+m_{u m}\right), b_{z i}=b^{(1)}{ }_{z i}+b^{(2)}$ и $c_{z i}$ для всего диапазона частот

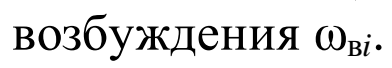

По коэффициентам полиномов осуществляется построение ампли- 
тудно-частотные характеристики, можно оценить устойчивость системы и установить изменение положения полюсов передаточных функций на комплексной $s-$ плоскости при изменении величины жёсткости.

Приведенная масса инерционного трансформатора $m_{u m}$, превосходящая реальную массу жидкости в цилиндрическом зазоре может быть определена из выражения

$$
m_{u m}=\rho l \frac{S_{\Pi}^{2}}{S_{\mathrm{K}}},
$$

где $\rho$ - плотность рабочей жидкости, кг $/ \mathrm{M}^{3} ; l$ - длина цилиндрического зазора, м; $S_{\Pi}$ - площадь поршневого действия штока-поршня, м ${ }^{2} ; S_{K}-$ площадь поперечного сечения цилиндрического зазора, м $^{2}$.

При расчёте обобщённого гидравлического коэффициента трения применяют методику для расчёта резиновых деталей при циклических нагрузках и определяют гидравлический коэффициента трения рабочей жидкости в цилиндрическом зазоре:

$$
b_{\mathrm{zi}}^{(2)}=\omega_{\mathrm{B} i} \cdot S_{\Pi}^{2} \cdot \rho \cdot A / \ell,
$$

где $A$ - коэффициент пропорциональности, зависящий от характеристик гидравлической системы; $\ell$ - длина цилиндрического зазора, м; $\rho$ - плотность рабочей жидкости, кг $/ \mathrm{M}^{3}$.

При расчёте коэффициента трения в эластичной обечайке $b^{(1)}{ }_{z i}$ используется эмпирическая зависимость

$$
b^{(1)}{ }_{z i}=m A\left(\omega_{\mathrm{Bi}}\right)^{1-p} / 2 \pi, \text { при } \mathrm{A}=28 ; \mathrm{p}=1,1 \ldots 1,2 \ldots
$$

где $A$ и р - реологические параметры резины, определяемые через гистерезис при циклическом нагружении эластичной обечайки; $\omega_{\mathrm{B} i}=2 \pi f_{\mathrm{в} i}$ круговая частота возбуждения.

Определение гидравлического коэффициента трения рабочей жидкости в цилиндрическом зазоре $b^{(2)}{ }_{z i}$ производится по формуле (5.30). Общий коэффициент трения есть сумма, состоящая из коэффициента трения эластичной обечайки $-b^{(1)}{ }_{z i}$ и переменного на каждой $i$-й частоте возбуждения гидравлического коэффициента трения в цилиндрическом зазоре $k_{j} \cdot b_{z i}^{(2)}$, зависящего от температуры рабочей жидкости и её динамической вязкости:

$$
\eta_{j}^{(t)}=\rho \cdot \varsigma_{j}^{(t)},
$$

где $\varsigma_{j}^{(t)}$ - кинематическая вязкость. 
Численные значения обобщенного коэффициента трения при температурах рабочей жидкости $20^{\circ} \mathrm{C}$ и $40^{\circ} \mathrm{C} b_{z i}^{(2)}$ приведены в табл. 5.1 и табл. 5.2.

Нормирование коэффициентов полиномов $Y(s)$ и $X(s)$ функции $W(s)$ необходимо для последующего расчёта полюсов передаточной функции. Нормирование полиномов $Y(s)$ и $X(s)$ осуществляется таким образом, чтобы в собственном операторе $X(s)$ и операторе воздействия $Y(s)$ коэффициенты при максимальной степени $s$ были равны единице. Выражение для нормированной передаточной функции имеет вид

$$
W(s)_{H 1,0}=\frac{Y(s)_{H 1,0}}{X(s)_{H 1,0}}=\frac{\frac{b_{2} s^{2}}{b_{2}^{\prime}}+\frac{b_{1,0} s}{b_{2}^{\prime}}+\frac{b_{01,0}}{b_{2}^{\prime}}}{\frac{a_{2} s^{2}}{a_{2}^{\prime}}+\frac{a_{1,0} s}{a_{2}^{\prime}}+\frac{a_{01,0}}{a_{2}^{\prime}}} .
$$

Численные значения нормированных коэффициентов полиномов $Y(s)$ и $X(s)$ передаточной функции $W(s)$ при температурах рабочей жидкости $20^{\circ} \mathrm{C}$ и $40^{\circ} \mathrm{C}$ приведены в табл. 5.3 и табл. 5.4.

\section{Обобщённый коэффициент трения при $T=20^{\circ} \mathrm{C}$}

Таблица 5.1

\begin{tabular}{|c|c|c|c|c|c|}
\hline$i$ & $f_{i}, \Gamma_{\amalg}$ & $\omega_{i}, \mathrm{paz} / \mathrm{c}$ & $b_{z i}^{(1)}, \mathrm{paz} \cdot \kappa \Gamma / \mathrm{c}$ & $b_{z i}^{(2)}$, рад·кг $/ \mathrm{c}$ & $b_{z i}$, рад $\cdot \kappa г / \mathrm{c}$ \\
\hline 0 & 8 & 50,265 & 222,859 & 16,414 & 239,273 \\
\hline 1 & 25 & 157,080 & 187,846 & 51,294 & 239,140 \\
\hline 2 & 50 & 314,159 & 169,296 & 102,589 & 271,885 \\
\hline 3 & 75 & 471,230 & 159,307 & 153,880 & 313,188 \\
\hline 4 & 100 & 628,319 & 152,578 & 205,178 & 357,757 \\
\hline 5 & 125 & 785,398 & 147,556 & 256,473 & 404,029 \\
\hline 6 & 150 & 942,477 & 143,575 & 307,767 & 451,342 \\
\hline 7 & 175 & 1099,557 & 140,293 & 359,062 & 499,355 \\
\hline 8 & 200 & 1256,630 & 137,511 & 410,354 & 547,866 \\
\hline 9 & 225 & 1413,710 & 135,103 & 461,649 & 596,752 \\
\hline
\end{tabular}

Обобщённый коэффициент трения при $\boldsymbol{T}=\mathbf{4 0}{ }^{\circ} \mathrm{C}$

Таблица 5.2

\begin{tabular}{|c|c|c|c|c|c|}
\hline$i$ & $f_{i}, \Gamma \amalg$ & $\omega_{i}, \mathrm{paд} / \mathrm{c}$ & $b^{(1)}{ }_{i i}, \mathrm{paд} \cdot \kappa \Gamma / \mathrm{c}$ & $b^{(2)}{ }_{z i}, \mathrm{paд} \cdot \kappa \Gamma / \mathrm{c}$ & $b_{z i}, \mathrm{рад} \cdot \kappa г / \mathrm{c}$ \\
\hline 0 & 8 & 50,265 & 222,859 & 6,887 & 229,746 \\
\hline 1 & 25 & 157,080 & 187,846 & 21,522 & 209,368 \\
\hline 2 & 50 & 314,159 & 169,296 & 43,044 & 212,341 \\
\hline 3 & 75 & 471,230 & 159,307 & 64,565 & 223,872 \\
\hline 4 & 100 & 628,319 & 152,578 & 86,088 & 238,667 \\
\hline 5 & 125 & 785,398 & 147,556 & 107,611 & 255,167 \\
\hline
\end{tabular}


Окончание табл. 5.2

\begin{tabular}{|l|l|l|l|l|l|}
\hline 6 & 150 & 942,477 & 143,575 & 129,133 & 272,708 \\
\hline 7 & 175 & 1099,557 & 140,293 & 150,655 & 290,949 \\
\hline 8 & 200 & 1256,630 & 137,511 & 172,176 & 309,688 \\
\hline 9 & 225 & 1413,710 & 135,103 & 193,699 & 328,802 \\
\hline
\end{tabular}

Таблица 5.3

Коэффициенты $Y(s)$ и $X(s)$ функции $W(s)$ при $T=20^{\circ} \mathrm{C}$

\begin{tabular}{|c|c|c|c|c|c|c|}
\hline \multirow{3}{*}{$i$} & \multirow{3}{*}{$f_{i}, \Gamma ц$} & \multirow{3}{*}{$\begin{array}{l}\omega_{i}, \\
\text { рад/с }\end{array}$} & $Y(s)$ & $X(s)$ & $Y(s)$ & $X(s)$ \\
\hline & & & $b_{z i}$, рад $\cdot \kappa г / c$ & $a_{z i}$, рад $\cdot \kappa г / c$ & $b_{0 i}, \kappa \Gamma / \mathrm{c}^{2}$ & $a_{0 i}, \mathrm{\kappa} \Gamma / \mathrm{c}^{2}$ \\
\hline & & & $b_{z i} / b_{2}$, рад/c & $a_{z i} / a_{2}$, рад/c & $b_{z i} / b_{2}, 1 / \mathrm{c}^{2}$ & $a_{0 i} / a_{2}, 1 / \mathrm{c}^{2}$ \\
\hline \multirow{2}{*}{0} & \multirow{2}{*}{8} & \multirow{2}{*}{50,265} & 239,273 & 239,273 & 562500 & 562500 \\
\hline & & & 22,566 & 2,3783 & 53051,023 & 5591,284 \\
\hline \multirow{2}{*}{1} & \multirow{2}{*}{25} & \multirow{2}{*}{157,080} & 239,140 & 239,140 & 898750 & 898750 \\
\hline & & & 22,554 & 2,377 & 84763,746 & 8933,630 \\
\hline \multirow{2}{*}{2} & \multirow{2}{*}{50} & \multirow{2}{*}{314,159} & 271,885 & 271,885 & 1100000 & 1100000 \\
\hline & & & 25,642 & 2,702 & 103744,223 & 10934,067 \\
\hline \multirow{2}{*}{3} & \multirow{2}{*}{75} & \multirow{2}{*}{471,230} & 313,188 & 313,188 & 2100000 & 2100000 \\
\hline & & & 29,537 & 3,113 & 198057,153 & 20874,129 \\
\hline \multirow{2}{*}{4} & \multirow{2}{*}{100} & \multirow{2}{*}{628,319} & 357,757 & 357,757 & 2128000 & 2128000 \\
\hline & & & 33,741 & 3,556 & 200697,915 & 21152,450 \\
\hline \multirow{2}{*}{5} & \multirow{2}{*}{125} & \multirow{2}{*}{785,398} & 404,029 & 404,029 & 2475000 & 2475000 \\
\hline & & & 38,105 & 4,016 & 233424,502 & 24601,652 \\
\hline \multirow{2}{*}{6} & \multirow{2}{*}{150} & \multirow{2}{*}{942,477} & 451,342 & 451,342 & 2662000 & 2662000 \\
\hline & & & 42,567 & 4,486 & 251061,020 & 26460,443 \\
\hline \multirow{2}{*}{7} & \multirow{2}{*}{175} & \multirow{2}{*}{1099,55} & 499,355 & 499,355 & 3083000 & 3083000 \\
\hline & & & 47,095 & 4,963 & 290766,764 & 30645,209 \\
\hline \multirow{2}{*}{8} & \multirow{2}{*}{200} & \multirow{2}{*}{1256,63} & 547,866 & 547,866 & 3250000 & 3250000 \\
\hline & & & 51,670 & 5,445 & 306517,023 & 32305,199 \\
\hline \multirow{2}{*}{9} & \multirow{2}{*}{225} & \multirow{2}{*}{1413,70} & 596,752 & 596,752 & 3500000 & 3500000 \\
\hline & & & 56,281 & 5,931 & 330095,256 & 34790,215 \\
\hline
\end{tabular}

Таблица 5.4

Коэффициенты $Y(s)$ и $X(s)$ функции $W(s)$ при $T=40^{\circ} \mathrm{C}$

\begin{tabular}{|c|c|c|c|c|c|c|}
\hline \multirow{3}{*}{$i$} & \multirow{3}{*}{$f_{i}, \Gamma_{ц}$} & \multirow{3}{*}{$\begin{array}{l}\omega_{i}, \\
\text { рад/с }\end{array}$} & $Y(s)$ & $X(s)$ & $Y(s)$ & $X(s)$ \\
\hline & & & $b_{z i}$, рад $\cdot к \Gamma / c$ & $a_{z i}$, рад $\cdot к г / \mathrm{c}$ & $b_{0 i}, \kappa \Gamma / \mathrm{c}^{2}$ & $a_{0 i}, \mathrm{\kappa} \Gamma / \mathrm{c}^{2}$ \\
\hline & & & $b_{z i} / b_{2}$, рад/c & $a_{z i} / a_{2}$, рад/c & $b_{z i} / b_{2}, 1 / \mathrm{c}^{2}$ & $a_{0 i} / a_{2}, 1 / \mathrm{c}^{2}$ \\
\hline \multirow{2}{*}{0} & \multirow{2}{*}{8} & \multirow{2}{*}{50,265} & 229,746 & 229,746 & 562500 & 562500 \\
\hline & & & 21,668 & 2,283 & 53051,023 & 5591,284 \\
\hline \multirow{2}{*}{1} & \multirow{2}{*}{25} & \multirow{2}{*}{157,080} & 209,368 & 209,368 & 898750 & 898750 \\
\hline & & & 19,746 & 2,081 & 84763,746 & 8933,630 \\
\hline \multirow{2}{*}{2} & \multirow{2}{*}{50} & \multirow{2}{*}{314,159} & 212,341 & 212,341 & 1100000 & 1100000 \\
\hline & & & 20,026 & 2,110 & 103744,223 & 10934,067 \\
\hline \multirow{2}{*}{3} & \multirow{2}{*}{75} & \multirow{2}{*}{471,230} & 223,872 & 223,872 & 2100000 & 2100000 \\
\hline & & & 21,114 & 2,225 & 198057,153 & 20874,129 \\
\hline
\end{tabular}


Окончание табл. 5.4

\begin{tabular}{|c|c|c|c|c|c|c|}
\hline \multirow{2}{*}{4} & \multirow{2}{*}{100} & \multirow{2}{*}{628,319} & 238,667 & 238,667 & 2128000 & 2128000 \\
\hline & & & 22,509 & 2,372 & 200697,915 & 21152,450 \\
\hline \multirow{2}{*}{5} & \multirow{2}{*}{125} & \multirow{2}{*}{785,398} & 255,167 & 255,167 & 2475000 & 2475000 \\
\hline & & & 24,065 & 2,536 & 233424,502 & 24601,652 \\
\hline \multirow{2}{*}{6} & \multirow{2}{*}{150} & \multirow{2}{*}{942,477} & 272,708 & 272,708 & 2662000 & 2662000 \\
\hline & & & 25,719 & 2,710 & 251061,020 & 26460,443 \\
\hline \multirow{2}{*}{7} & \multirow{2}{*}{175} & \multirow{2}{*}{1099,55} & 290,949 & 290,949 & 3083000 & 3083000 \\
\hline & & & 27,440 & 2,892 & 290766,764 & 30645,209 \\
\hline \multirow{2}{*}{8} & \multirow{2}{*}{200} & \multirow{2}{*}{1256,63} & 309,688 & 309,688 & 3250000 & 3250000 \\
\hline & & & 29,207 & 3,078 & 306517,023 & 32305,199 \\
\hline \multirow{2}{*}{9} & \multirow{2}{*}{225} & \multirow{2}{*}{1413,71} & 596,752 & 596,752 & 3500000 & 3500000 \\
\hline & & & 56,281 & 5,931 & 330095,256 & 34790,215 \\
\hline
\end{tabular}

Численное определение полюсов и нулей передаточной функции проводится для построения графиков динамических жесткостей.

В соответствии с табл. 5.3 числовое выражение $W(s)_{\mathrm{H} 1,0}$ для частоты возбуждения 8 Гц при температуре рабочей жидкости $20^{\circ} \mathrm{C}$ имеет вид

$$
\mathrm{W}(\mathrm{s})_{\mathrm{H} 1,0}=\frac{\mathrm{s}^{2}+22,566 \mathrm{~s}+53051,023}{\mathrm{~s}^{2}+2,3783 \mathrm{~s}+5591,284} .
$$

- числитель функции $W(s)_{1,0}=s^{2}+22,566 s+6219,228=0$, так как это выражение является квадратным уравнением, его корни равны $s_{\mathrm{p} .1,2}=-11,283 \pm j 230,051$;

- знаменатель функции $W(s)_{1,0}=s^{2}+2,378 s+5591,12=0$, аналогично его корни равны $s_{\mathrm{p} .1,2}=-1,189 \pm j 74,765$.

Результаты численного расчёта полюсов передаточной функции $W(s)_{1 ; i}$ МР-демфера для диапазона частот возбуждения $f_{i}=8 \div 225$ Гц, при температурах рабочей магнитной жидкости $20^{\circ} \mathrm{C}$ и $40^{\circ} \mathrm{C}$ сведены в табл. 5.5 - табл. 5.12.

Таблица 5.5

Полюса полиномов $X(s)$ функции $W(s)$ при $T=20^{\circ} \mathrm{C}$

\begin{tabular}{|l|l|l|l|l|l|l|}
\hline$i$ & $f_{i}, \Gamma \amalg$ & $\omega_{i}, \mathrm{pa} / \mathrm{c}$ & $a_{z i} / a_{2}, \mathrm{pa} / \mathrm{c}$ & $a_{00} / a_{2}, 1 / \mathrm{c}^{2}$ & $\operatorname{Re} p_{i}$ & $\operatorname{Im} p_{i}$ \\
\hline 0 & 8 & 50,265 & 2,3783 & 5591,284 & $-1,189$ & $\pm \mathrm{j} 74,765$ \\
\hline 1 & 25 & 157,080 & 2,377 & 8933,630 & $-1,188$ & $\pm \mathrm{j} 94,51$ \\
\hline 2 & 50 & 314,159 & 2,702 & 10934,067 & $-1,351$ & $\pm \mathrm{j} 104,557$ \\
\hline 3 & 75 & 471,230 & 3,113 & 20874,129 & $-1,556$ & $\pm \mathrm{j} 144,47$ \\
\hline 4 & 100 & 628,319 & 3,556 & 21152,450 & $-1,778$ & $\pm \mathrm{j} 145,427$ \\
\hline 5 & 125 & 785,398 & 4,016 & 24601,652 & $-2,008$ & $\pm \mathrm{j} 156,836$ \\
\hline 6 & 150 & 942,477 & 4,486 & 26460,443 & $-2,243$ & $\pm \mathrm{j} 162,651$ \\
\hline
\end{tabular}


Окончание табл. 5.5

\begin{tabular}{|l|l|l|l|l|l|l|}
\hline 7 & 175 & 1099,55 & 4,963 & 30645,209 & $-2,481$ & $\pm \mathrm{j} 175,04$ \\
\hline 8 & 200 & 1256,63 & 5,445 & 32305,199 & $-2,722$ & $\pm \mathrm{j} 179,715$ \\
\hline 9 & 225 & 1413,71 & 5,931 & 34790,215 & $-2,965$ & $\pm \mathrm{j} 186,497$ \\
\hline
\end{tabular}

Таблица 5.6

Нули полиномов $\boldsymbol{Y}(s)$ функции $\boldsymbol{W}(s)$ при $\boldsymbol{T}=20^{\circ} \mathrm{C}$

\begin{tabular}{|l|l|l|l|l|l|l|}
\hline$i$ & $f_{i}, \Gamma \amalg$ & $\omega_{i}, \mathrm{pa} / \mathrm{c}$ & $b_{z i} / b_{2}, \mathrm{pa} / \mathrm{c}$ & $b_{0 i} l b_{2}, 1 / \mathrm{c}^{2}$ & $\operatorname{Re} z_{i}$ & $\operatorname{Im} z_{i}$ \\
\hline 0 & 8 & 50,265 & 22,566 & 53051,023 & $-11,283$ & $\pm \mathrm{j} 230,051$ \\
\hline 1 & 25 & 157,080 & 22,554 & 84763,746 & $-11,277$ & $\pm \mathrm{j} 290,9323$ \\
\hline 2 & 50 & 314,159 & 25,642 & 103744,223 & $-12,821$ & $\pm \mathrm{j} 321,838$ \\
\hline 3 & 75 & 471,230 & 29,537 & 198057,153 & $-14,768$ & $\pm \mathrm{j} 444,791$ \\
\hline 4 & 100 & 628,319 & 33,741 & 200697,915 & $-16,87$ & $\pm \mathrm{j} 447,675$ \\
\hline 5 & 125 & 785,398 & 38,105 & 233424,502 & $-19,052$ & $\pm \mathrm{j} 482,764$ \\
\hline 6 & 150 & 942,477 & 42,567 & 251061,020 & $-21,283$ & $\pm \mathrm{j} 500,607$ \\
\hline 7 & 175 & 1099,557 & 47,095 & 290766,764 & $-23,547$ & $\pm \mathrm{j} 538,713$ \\
\hline 8 & 200 & 1256,630 & 51,670 & 306517,023 & $-25,835$ & $\pm \mathrm{j} 553,036$ \\
\hline 9 & 225 & 1413,710 & 56,281 & 330095,256 & $-28,14$ & $\pm \mathrm{j} 573,849$ \\
\hline
\end{tabular}

Таблица 5.7

Модули векторов полиномов $X(s)$ функции $W(s)$ при $T=2^{\circ} \mathrm{C}$

\begin{tabular}{|l|l|l|l|l|l|}
\hline$i$ & $f_{i}, \Gamma_{ц}$ & $\omega_{i}, \mathrm{pa} / \mathrm{c}$ & $\operatorname{Re} p_{i}$ & $\operatorname{Im} p_{i}$ & $A p_{i}\left(\omega_{i}\right)$ \\
\hline 0 & 8 & 50,265 & $-1,189$ & $\pm \mathrm{j} 74,765$ & 74.77445 \\
\hline 1 & 25 & 157,080 & $-1,188$ & $\pm \mathrm{j} 94,51$ & 94.51746 \\
\hline 2 & 50 & 314,159 & $-1,351$ & $\pm \mathrm{j} 104,557$ & 104.56572 \\
\hline 3 & 75 & 471,230 & $-1,556$ & $\pm \mathrm{j} 144,47$ & 144.47837 \\
\hline 4 & 100 & 628,319 & $-1,778$ & $\pm \mathrm{j} 145,427$ & 145.43786 \\
\hline 5 & 125 & 785,398 & $-2,008$ & $\pm \mathrm{j} 156,836$ & 156.84885 \\
\hline 6 & 150 & 942,477 & $-2,243$ & $\pm \mathrm{j} 162,651$ & 162.66646 \\
\hline 7 & 175 & 1099,557 & $-2,481$ & $\pm \mathrm{j} 175,04$ & 175.057581 \\
\hline 8 & 200 & 1256,630 & $-2,722$ & $\pm \mathrm{j} 179,715$ & 179.735612 \\
\hline 9 & 225 & 1413,710 & $-2,965$ & $\pm \mathrm{j} 186,497$ & 186.520567 \\
\hline
\end{tabular}

Модули векторов полиномов $\boldsymbol{Y}(s)$ функции $W(s)$ при $\boldsymbol{T}=\mathbf{2 0}{ }^{\circ} \mathrm{C}$

Таблица 5.8

\begin{tabular}{|l|l|l|l|l|l|}
\hline$i$ & $f_{i}, \Gamma_{\amalg}$ & $\omega_{i}, \mathrm{pa} / \mathrm{c}$ & $\operatorname{Re} z_{i}$ & $\operatorname{Im} z_{i}$ & $A z_{i}\left(\omega_{i}\right)$ \\
\hline 0 & 8 & 50,265 & $-11,283$ & $\pm \mathrm{j} 230,051$ & 230.32752 \\
\hline 1 & 25 & 157,080 & $-11,277$ & $\pm \mathrm{j} 290,9323$ & 291.15077 \\
\hline 2 & 50 & 314,159 & $-12,821$ & $\pm \mathrm{j} 321,838$ & 322.09327 \\
\hline 3 & 75 & 471,230 & $-14,768$ & $\pm \mathrm{j} 444,791$ & 445.03609 \\
\hline 4 & 100 & 628,319 & $-16,87$ & $\pm \mathrm{j} 447,675$ & 447.99274 \\
\hline 5 & 125 & 785,398 & $-19,052$ & $\pm \mathrm{j} 482,764$ & 483.13979 \\
\hline 6 & 150 & 942,477 & $-21,283$ & $\pm \mathrm{j} 500,607$ & 501.05921 \\
\hline 7 & 175 & 1099,557 & $-23,547$ & $\pm \mathrm{j} 538,713$ & 539.22737 \\
\hline 8 & 200 & 1256,630 & $-25,835$ & $\pm \mathrm{j} 553,036$ & 553.63911 \\
\hline 9 & 225 & 1413,710 & $-28,14$ & $\pm \mathrm{j} 573,849$ & 574.53854 \\
\hline
\end{tabular}


Таблица 5.9

Полюса полиномов $X(s)$ функции $W(s)$ при $T=40^{\circ} \mathrm{C}$

\begin{tabular}{|l|l|l|l|l|l|l|}
\hline$i$ & $f_{i}, \Gamma_{\amalg}$ & $\omega_{i}, \mathrm{pa} / \mathrm{c}$ & $a_{z i} / a_{2}, \mathrm{pa} / / \mathrm{c}$ & $a_{01} / a_{2}, 1 / \mathrm{c}^{2}$ & $\operatorname{Re} p_{i}$ & $\operatorname{Im} p_{i}$ \\
\hline 0 & 8 & 50,265 & 2,283 & 5591,284 & $-1,141$ & $\pm \mathrm{j} 74,766$ \\
\hline 1 & 25 & 157,080 & 2,081 & 8933,630 & $-1,04$ & $\pm \mathrm{j} 94,512$ \\
\hline 2 & 50 & 314,159 & 2,110 & 10934,067 & $-1,055$ & $\pm \mathrm{j} 104,56$ \\
\hline 3 & 75 & 471,230 & 2,225 & 20874,129 & $-1,112$ & $\pm \mathrm{j} 144,474$ \\
\hline 4 & 100 & 628,319 & 2,372 & 21152,450 & $-1,186$ & $\pm \mathrm{j} 145,433$ \\
\hline 5 & 125 & 785,398 & 2,536 & 24601,652 & $-1,268$ & $\pm \mathrm{j} 156,844$ \\
\hline 6 & 150 & 942,477 & 2,710 & 26460,443 & $-1,355$ & $\pm \mathrm{j} 162,661$ \\
\hline 7 & 175 & 1099,557 & 2,892 & 30645,209 & $-1,446$ & $\pm \mathrm{j} 175,051$ \\
\hline 8 & 200 & 1256,630 & 3,078 & 32305,199 & $-1,539$ & $\pm \mathrm{j} 179,729$ \\
\hline 9 & 225 & 1413,710 & 3,268 & 34790,215 & $-1,634$ & $\pm \mathrm{j} 186,514$ \\
\hline
\end{tabular}

Таблица 5.10

Нули полиномов $\boldsymbol{Y}(s)$ функции $W(s)$ при $\boldsymbol{T}=40^{\circ} \mathrm{C}$

\begin{tabular}{|l|l|l|l|l|l|l|}
\hline$i$ & $f_{i}, \Gamma \amalg$ & $\omega_{i}, \mathrm{pa} / \mathrm{c}$ & $b_{z i} / b_{2}, \mathrm{paz} / \mathrm{c}$ & $b_{0 i} / b_{2}, 1 / \mathrm{c}^{2}$ & $\operatorname{Re} z_{i}$ & $\operatorname{Im} z_{i}$ \\
\hline 0 & 8 & 50,265 & 21,668 & 53051,023 & $-10,834$ & $\pm \mathrm{j} 230,073$ \\
\hline 1 & 25 & 157,080 & 19,7461 & 84763,746 & $-9,873$ & $\pm \mathrm{j} 290,974$ \\
\hline 2 & 50 & 314,159 & 20,026 & 103744,223 & $-10,013$ & $\pm \mathrm{j} 321,937$ \\
\hline 3 & 75 & 471,230 & 21,114 & 198057,153 & $-10,557$ & $\pm \mathrm{j} 444,91$ \\
\hline 4 & 100 & 628,319 & 22,509 & 200697,915 & $-11,254$ & $\pm \mathrm{j} 447,851$ \\
\hline 5 & 125 & 785,398 & 24,065 & 233424,502 & $-12,032$ & $\pm \mathrm{j} 482,99$ \\
\hline 6 & 150 & 942,477 & 25,719 & 251061,020 & $-12,859$ & $\pm \mathrm{j} 500,894$ \\
\hline 7 & 175 & 1099,557 & 27,440 & 290766,764 & $-13,72$ & $\pm \mathrm{j} 539,053$ \\
\hline 8 & 200 & 1256,630 & 29,207 & 306517,023 & $-14,603$ & $\pm \mathrm{j} 553,447$ \\
\hline 9 & 225 & 1413,710 & 31,010 & 330095,256 & $-15,505$ & $\pm \mathrm{j} 574,329$ \\
\hline
\end{tabular}

Модули векторов полиномов $X(s)$ функции $W(s)$ при $T=40^{\circ} \mathrm{C}$

\begin{tabular}{|l|l|l|l|l|l|}
\hline$i$ & $f_{i}, \Gamma \amalg$ & $\omega_{i}, \mathrm{pa} / \mathrm{c}$ & $\operatorname{Re} p_{i}$ & $\operatorname{Im} p_{i}$ & $A p_{i}\left(\omega_{i}\right)$ \\
\hline 0 & 8 & 50,265 & $-1,141$ & $\pm \mathrm{j} 74,766$ & 74,77470 \\
\hline 1 & 25 & 157,080 & $-1,04$ & $\pm \mathrm{j} 94,512$ & 94,51772 \\
\hline 2 & 50 & 314,159 & $-1,055$ & $\pm \mathrm{j} 104,56$ & 104,56532 \\
\hline 3 & 75 & 471,230 & $-1,112$ & $\pm \mathrm{j} 144,474$ & 144,47827 \\
\hline 4 & 100 & 628,319 & $-1,186$ & $\pm \mathrm{j} 145,433$ & 145,43783 \\
\hline 5 & 125 & 785,398 & $-1,268$ & $\pm \mathrm{j} 156,844$ & 156,84912 \\
\hline 6 & 150 & 942,477 & $-1,355$ & $\pm \mathrm{j} 162,661$ & 162,66664 \\
\hline 7 & 175 & 1099,557 & $-1,446$ & $\pm \mathrm{j} 175,051$ & 175,05697 \\
\hline 8 & 200 & 1256,630 & $-1,539$ & $\pm \mathrm{j} 179,729$ & 179,73558 \\
\hline 9 & 225 & 1413,710 & $-1,634$ & $\pm \mathrm{j} 186,514$ & 186,52115 \\
\hline
\end{tabular}

Таблица 5.12

Модули векторов полиномов $Y(s)$ функции $W(s)$ при $T=40^{\circ} \mathrm{C}$

\begin{tabular}{|l|l|l|l|l|l|}
\hline$i$ & $f_{i}, \Gamma \amalg$ & $\omega_{i}, \mathrm{pa} / \mathrm{c}$ & $\operatorname{Re} z_{i}$ & $\operatorname{Im} z_{i}$ & $A z_{i}\left(\omega_{i}\right)$ \\
\hline 0 & 8 & 50,265 & $-10,834$ & $\pm \mathrm{j} 230,073$ & 230,32794 \\
\hline
\end{tabular}


Окончание табл. 5.12

\begin{tabular}{|l|l|l|l|l|l|}
\hline 1 & 25 & 157,080 & $-9,873$ & $\pm \mathrm{j} 290,974$ & 291,14145 \\
\hline 2 & 50 & 314,159 & $-10,013$ & $\pm \mathrm{j} 321,937$ & 322,09267 \\
\hline 3 & 75 & 471,230 & $-10,557$ & $\pm \mathrm{j} 444,91$ & 445,03523 \\
\hline 4 & 100 & 628,319 & $-11,254$ & $\pm \mathrm{j} 447,851$ & 447,99237 \\
\hline 5 & 125 & 785,398 & $-12,032$ & $\pm \mathrm{j} 482,99$ & 483,13984 \\
\hline 6 & 150 & 942,477 & $-12,859$ & $\pm \mathrm{j} 500,894$ & 501,05903 \\
\hline 7 & 175 & 1099,557 & $-13,72$ & $\pm \mathrm{j} 539,053$ & 539,22757 \\
\hline 8 & 200 & 1256,630 & $-14,603$ & $\pm \mathrm{j} 553,447$ & 553,63962 \\
\hline 9 & 225 & 1413,710 & $-15,505$ & $\pm \mathrm{j} 574,329$ & 574,53825 \\
\hline
\end{tabular}

На рис. 5.10 и рис. 5.11 приведены зависимости расчетной АЧХ МРдемпфера при значениях температуры рабочей жидкости $20^{\circ} \mathrm{C}$ и $40^{\circ} \mathrm{C}$.

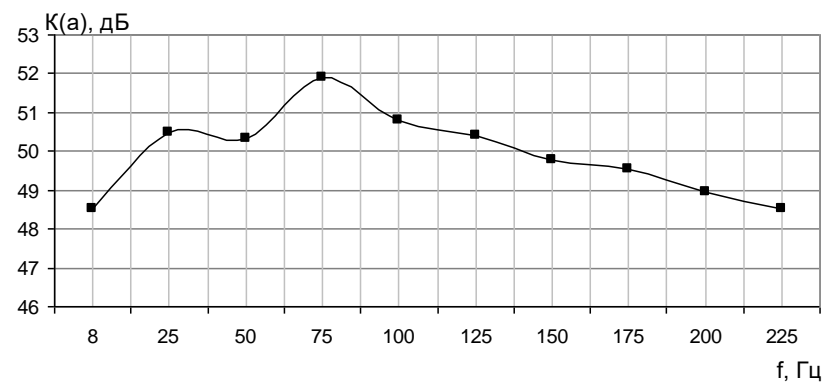

Рис. 5.10. Амплитудно-частотная характеристика при $T=20^{\circ} \mathrm{C}$

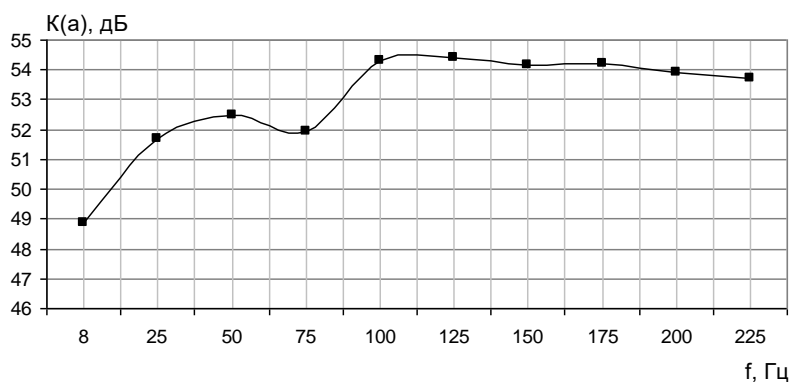

Рис. 5.11. Амплитудно-частотная характеристика при $T=40^{\circ} \mathrm{C}$

\section{2. Конструкция индукционных МРТ перестраиваемых гидроопор с внешним расположением возбуждаемых электромагнитов}

В большинстве конструкций индукционных МРТ перегородкой служит ферромагнитная (стальная) перегородка с диамагнитными дроссельными каналами малого внутреннего диаметра, порядка 1,5-2,0 мм, которые расположены в её поверхностном слое по её образующей между полюсами возбуждающих электромагнитов (ВЭ) и перегородкой МРТ. Перегородка МРТ может быть выполнена, в виде: сплошного кольца диска из ферромагнитного материала с высокой магнитной проницаемостью, с высверленными для дроссельных каналов отверстиями. Ферромагнитная перегородка встраивается в МРТ так, чтобы через неё по ин- 
дукционным дроссельным каналам полностью или частично осуществлялось протекание МРЖ.

К недостаткам проектируемых МРТ относят увеличение тока и мощности ВЭ. Это связано с большой МДС ВЭ, необходимой для проведения через дроссельные каналы магнитного потока возбуждения. С увеличением диаметра дроссельных каналов потребляемые ток и мощность ВЭ возрастают.

Расположение полюсов ВЭ индукционных МРТ перестраиваемых гидроопор, симметричное. По числу полюсов ВЭ индукционные МРТ разделяются на двухполюсные и многополюсные - кольцевые [73].

Простейшие симметричные двухполюсные индукционные МРТ, например, строятся из двух внешних дугообразных ВЭ, установленных неподвижно, с зазором, по отношению к ферромагнитной перегородке (рис. 5.12).

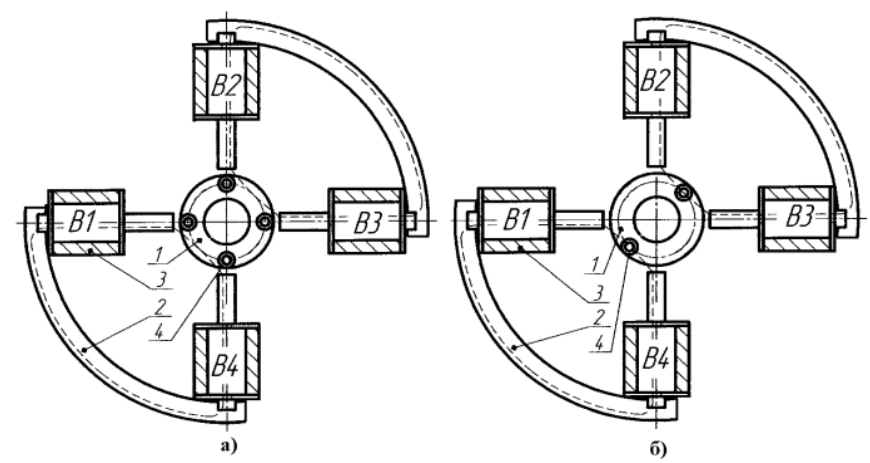

Рис. 5.12. Симметричные двухполюсные индукционные МРТ перестраиваемых гидроопор (a) четырехканальный; двухканальный (б)

На рис. 5.12 показано: 1 - ферромагнитная перегородка гидроопоры; 2 - внешнее дугообразное ярмо магнитопровода; 3 - возбуждающие электромагниты; 4 - индукционные диамагнитные дроссельные каналы.

На рис. 5.12, а четыре индукционных дроссельных канала МРТ расположены напротив полюсов, около зазоров между магнитной перегородкой и двумя полюсами дугообразных ВЭ перестраиваемой гидроопоры. На рис. 5.12, б два индукционных дроссельных канала расположены по середине между полюсами ВЭ, в теле ферромагнитной перегородки между двумя полюсами дугообразных ВЭ МРТ гидроопоры.

Как видно из рис. 5.12, внешние дугообразные ВЭ В1, В2 и В3, В4 симметричных двухполюсных индукционных МРТ являются составными и состоят каждый из двух катушек индуктивности, размещенных на своём отдельном магнитопроводе, замкнутом через ферромагнитную перегородку и индукционные дроссельные каналы.

Для устранения гистерезисных явлений, связанных с остаточной намагниченностью при использовании магнитопровода из ферромагнит- 
ного материала, стержневые стальные сердечники ВЭ и сама ферромагнитная перегородка должны одновременно размагничиваться при работе гидроопоры. На обмотку ВЭ подается изменяющееся двухполярное напряжение возбуждения $U_{\mathrm{B}}$ с изменяющейся круговой частотой $2 \pi f_{\mathrm{B}}$.

Более совершенным является симметричный кольцевой индукционный МРТ на основе тордуктора [73] (рис. 5.13). Такой индукционный МРТ состоит из восьми ВЭ с сердечниками в виде цилиндрических стержней с явно выраженными полюсами. Разно полярные полюса ВЭ индукционного МРТ расположены поочередно. Катушки ВЭ соединяются обычно параллельно так, чтобы соседние полюса имели разную полярность и подключаются к источнику двухполярного изменяющегося напряжения возбуждения $U_{\mathrm{B}}$ с изменяющейся круговой частотой $2 \pi f_{\mathrm{B}}$.

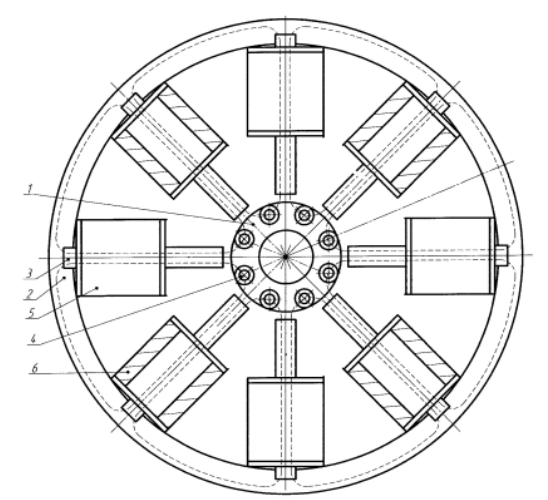

Рис. 5.13. Схема кольцевого симметричного индукционного МРТ перестраиваемой гидроопоры на основе тордуктора (общий вид с верху):

1,2 - внутреннее и внешнее ферромагнитные (стальные) кольца; 3 - стальные сердечники ВЭ; 4 - индукционные дроссельные каналы; 5 - катушки ВЭ; 6 - обмотки ВЭ

На рис. 5.14 показано полное возбуждение индукционных дроссельных каналов переменным магнитным полем электромагнитов на развертке боковой поверхности перегородки кольцевого индукционного МРТ в гидроопоре с внешним расположением ВЭ.

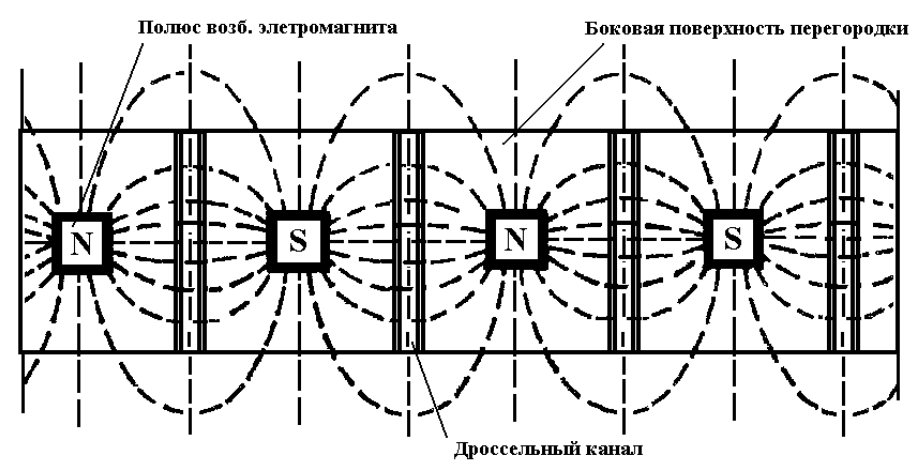

Рис. 5.14. Полное возбуждение дроссельных каналов переменным магнитным полем ВЭ на развертке боковой поверхности перегородки кольцевого индукционного МРТ в гидроопоре с внешним расположением ВЭ 
Из рис. 5.14 видно, что при возбуждении индукционных дроссельных каналов переменным магнитным полем ВЭ магнитные силовые линии поля полностью захватывают дроссельные каналы дроссельной перегородки и со стороны её боковой поверхности.

В кольцевом МРТ сердечники ВЭ могут выполняться из низкоуглеродистой стали. Посередине индукционного кольцевого МРТ (рис. 5.13) расположена ферромагнитная перегородка в виде внутреннего ферромагнитного кольца 4, по краям - внешнее ферромагнитное кольцо 2. Внутреннее и внешнее ферромагнитные (стальные) кольца 2 и 4, сердечники полюса ВЭ 3, и индукционные дроссельные каналы 1 образуют собой магнитную систему МРТ. На стержнях ВЭ 5 размещаются катушки ВЭ 6.

Важным достоинством кольцевого индукционного МРТ по сравнению с МРТ на двухполюсных дугообразных ВЭ является повышенная чувствительность.

Исходными данными для проектирования перестраиваемых индукционных МРТ являются геометрические размеры гидроопоры и условия ее работы. Важнейшим параметром, определяющим габаритные и другие конструктивные размеры МРТ гидроопоры, является диаметр перегородки - $D$ или внешний диаметр ферромагнитного кольца - стакана, используемого в качестве ферромагнитной перегородки (рис. 5.15).

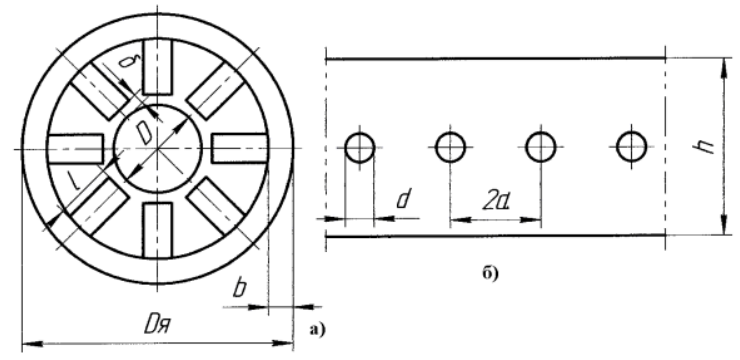

Рис. 5.15. Основные размеры кольцевого индукционного МРТ:

$a$ - общий вид; $\sigma$ - проекция полюсов и ярма на поверхность перегородки (без катушек ВЭ)

В индукционном МРТ гидроопоры диаметр ферромагнитной перегородки связан с числом полюсов ВЭ $p$ и полюсным делением $2 a$ соотношением

$$
2 a=\pi D / p
$$

При уменьшении расстояния $a$ возрастает количество полюсов и катушек ВЭ, усложняется конструкция индукционного МРТ гидроопоры. Увеличение полюсного деления $a$ вызывает повышение тока возбуждения и мощности, потребляемой ВЭ. Кроме того, возрастают габариты и масса МРТ гидроопоры. 
Диаметры полюсов ВЭ $-d$ выбираются из условий снижения тока и мощности возбуждения, с одной стороны, и возможного размещения полюсов, с катушками ВЭ и уменьшения массы индукционного МРТ - с другой (рис. 5.15). Из проведённых оценок и экспериментов при проектировании МРТ гидроопоры установлены оптимальные значения $d=6,0 \div 10,0$ мм.

Внешний диаметр ярма $D_{я}$ индукционного МРТ определяется диаметром ферромагнитной перегородки $D$, величиной зазора $\delta$ для дроссельных каналов, длиной полюсов $l$ и толщиной ярма $b$ (рис. 5.15):

$$
D_{Я}=D+2(\delta+l+b) .
$$

Зазор $\delta$ для индукционных дроссельных каналов между полюсами ВЭ и ферромагнитной перегородкой является одним из важнейших параметров индукционного МРТ, определяющим его ток и мощность возбуждения, габариты ВЭ, расход меди и т. Д. Для уменьшения тока и мощности следует выбирать зазор по возможности меньшим. Рекомендуемый зазор $\delta=3,5 \div 4,5$ мм, где большие значения относятся к ферромагнитным перегородкам больших диаметров (до 50 мм) [73].

Длина $l$ полюсов ВЭ (рис. 5.15) выбирается с учетом размещения на них катушек и ограничивается их габаритами, которые находятся в прямой зависимости от значения $\delta$. При малых $\delta l=70 \div 100$ мм, при больших $\delta$ и $l$ увеличивается до 120 - 140 мм. Дальнейшее увеличение $l$ нежелательно из-за увеличения магнитного сопротивления полюсов (в случае выполнения их массивными) и повышения рассеяния, что вызывает возрастание МДС обмотки возбуждения и дополнительное увеличение габаритов катушек ВЭ. Толщина ярма $b$ выбирается из конструктивных соображений, чтобы обеспечить жесткость конструкции ярма.

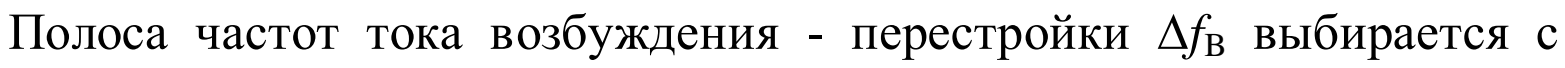
учетом требуемых динамических характеристик МРТ и гидроопоры и в зависимости от их назначения. Напряжение возбуждения ВЭ выбирают, исходя из условий полосы перестройки $\Delta f_{\mathrm{B}}$ МРТ гидроопоры [73].

В Институте проблем машиностроения РАН разработаны различные варианты конструкций магнитореологических гидроопор, основанных на других технических решениях [73]. Эти конструкции и технические решения направлены на создание жидкостного магнитного демпфирования, превосходящего конструкционное демпфирование резины. В магнитогидравлических виброопорах происходит формирование внутренних динамических свойств реактивного характера за счет ускоренного движения столбов рабочей МРЖ и изменения её вязкости в дроссельных каналах под действием магнитного поля. 


\section{3. Основы расчета магнитной цепи индукционных МРТ гидроопор}

При отсутствии МРЖ в гидроопоре с МРТ ферромагнитная дроссельная перегородка представляет собой изотропную среду, в которой распределение электромагнитного поля определяется геометрическими параметрами ВЭ. Здесь необходимо уточнение: будем считать, что гидроопора с МРТ не заполнена рабочей МРЖ (пустая гидроопора).

При заполненной рабочей МРЖ гидроопоре дроссельная перегородка становится магнитно-анизотропной средой за счет протекания в дроссельных каналах МРТ рабочей МРЖ. При этом происходит перераспределение электромагнитного поля в дроссельной перегородке гидроопоры и увеличение её магнитной проницаемости.

При проектировании гидроопоры с МРТ необходимо установить связь характеристик МРТ с его основными параметрами: дроссельными каналами дроссельной перегородки гидроопоры, расстоянием между осями полюсов ВЭ, характеристиками ферромагнитных материалов дроссельной перегородки и магнитопроводов ВЭ. Также необходимо установить: связь со значениями напряжения и тока в катушках ВЭ, числом витков катушек ВЭ и т. д.

Представляется, возможность решения основных задач проектирования МРТ гидроопоры - определения магнитного потока ВЭ, требуемой напряженности магнитного поля в дроссельной перегородке, расчета МДС катушек ВЭ, числа их витков, сечения провода и т. д.

В отсутствии рабочей МРЖ (пустая гидроопора) дроссельная перегородка гидроопоры представляет собой ферромагнитную электропроводящую среду, магнитная проницаемость $\mu$ которой во много раз выше магнитной проницаемости диэлектрических зазоров $\mu_{0}$ дроссельных каналов гидроопоры $[15,40,65,67]$. Магнитная проницаемость $\mu$ зависит от напряженности магнитного поля Н. В первом приближении анализ электромагнитного поля в дроссельной перегородке может быть проведен без учета зависимости $\mu(H)$, считая $\mu=$ const. Принимается также постоянной и удельная электрическая проводимость $\gamma$ материала дроссельной перегородки [15, 67, 74].

Геометрические размеры дроссельной перегородки в применяемых конструкциях гидроопор с МРТ во много раз превышают эквивалентную глубину проникновения электромагнитной волны $[15,40,67,74]$ :

$$
\Delta=\sqrt{2 / \mu \gamma \omega_{B}} .
$$

где $\omega_{\mathrm{B}}=2 \pi f_{\mathrm{B}}-$ угловая частота изменяющегося однополярного электромагнитного поля в дроссельной перегородки гидроопоры. 
Так, при частоте 60 Гц значения $\Delta$ составляют около 4 мм, а при больших частотах еще меньше [15, 67]. Это позволяет рассматривать дроссельную перегородку МРТ пустой гидроопоры как проводящее полупространство с высокой магнитной проницаемостью, в которое через полюсы ВЭ втекают изменяющиеся по периодическому закону магнитные потоки, выражаемые комплексами $\dot{\Phi}_{1}, \dot{\Phi}_{2}, \ldots \dot{\Phi}_{N}$ (рис. 5.16, a) $[15,67,74]$.
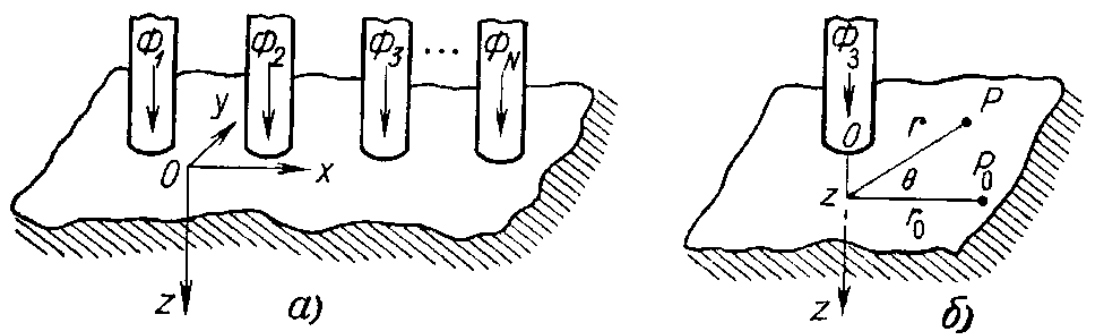

Рис. 5.16. Размещение полюсов ВЭ у проводящего полупространства: $a$ - система $\mathrm{N}$ полюсов; $\sigma$ - уединенный полюс

Электромагнитное поле в дроссельной перегородке МРТ пустой гидроопоры можно определить, суммируя поля, созданные каждым из полюсов. Поля описываются векторным дифференциальным уравнением в комплексной форме [15, 67, 74]

$$
\nabla^{2} \dot{\mathbf{H}}=\mathrm{j} \mu \gamma \omega_{\mathrm{B}} \dot{\mathbf{H}} .
$$

Для поля уединенного цилиндрического полюса с диаметром $d$ удобно использовать цилиндрическую систему координат $r, \theta, z$, в которой начало координат $O$ лежит на плоскости раздела сред (поверхности перегородки), а ось $O z$ совмещена с осью полюса и направлена в глубь проводящего полупространства (рис. 5.16, б) [67, 74]. Из условий симметрии $\dot{\mathbf{H}}$ не зависит от $\theta, \dot{\mathbf{H}}_{\boldsymbol{\theta}}=\mathbf{0}$. При этом векторное уравнение (5.35) распадается на два дифференциальных уравнения, связывающих комплексы радиальной $\dot{\mathbf{H}}_{\mathbf{r}}$ и аксиальной $\dot{\mathbf{H}}_{\mathbf{z}}$ составляющих вектора $\dot{\mathbf{H}}[6,15,67,74,112]$ :

$$
\begin{gathered}
\frac{\partial^{2} \dot{\mathbf{H}}_{z}}{\partial r^{2}}+\frac{1}{r} \frac{\partial \dot{\mathbf{H}}_{z}}{\partial r}+\frac{\partial^{2} \dot{\mathbf{H}}_{z}}{\partial z^{2}}=j \mu \gamma \omega_{B} \dot{\mathbf{H}}_{z}, \\
\frac{\partial^{2} \dot{\mathbf{H}}_{r}}{\partial r^{2}}+\frac{1}{r} \frac{\partial \dot{\mathbf{H}}_{r}}{\partial r}+\frac{\partial^{2} \dot{\mathbf{H}}_{r}}{\partial z^{2}}-\frac{\dot{\mathbf{H}}_{r}}{r^{2}}=j \mu \gamma \omega_{B} \dot{\mathbf{H}}_{r} .
\end{gathered}
$$

Решение системы уравнений (5.36) - (5.37) должно удовлетворять следующим граничным условиям:

а) при $r \rightarrow \infty$ или $z \rightarrow \infty, \dot{\mathbf{H}}_{\mathbf{r}} \rightarrow \infty$ и $\dot{\mathbf{H}}_{\mathbf{z}} \rightarrow \infty$;

б) при $r \leq d / 2$ и $z=0$ при равномерном распределении магнитного потока в зазоре $\Phi_{\delta}$ по поперечному сечению полюса: 


$$
\dot{\mathbf{H}}_{\mathrm{z}}=4 \dot{\Phi}_{\delta} / \pi \mathrm{d}^{2} \mu
$$

при $r>d / 2 \dot{\mathbf{H}}_{\mathbf{z}}=0$.

Используя результаты [67], получаем общие интегралы в виде:

$$
\begin{aligned}
\dot{\mathbf{H}}_{\mathrm{z}}(\mathrm{r}, \mathrm{z}) & =\frac{2 \dot{\Phi}_{\delta}}{\pi \mathrm{d} \mu} \int_{0}^{\infty} \mathbf{J}_{1}\left(\frac{\mathrm{d}}{2} \rho\right) \mathbf{J}_{0}(\mathrm{r} \rho) \exp (-\mathrm{sz}) \mathrm{d} \rho, \\
\dot{\mathbf{H}}_{\mathrm{r}}(\mathrm{r}, \mathrm{z}) & =\frac{2 \dot{\Phi}_{\delta}}{\pi \mathrm{d} \mu} \int_{0}^{\infty} \frac{\mathrm{s}}{\rho} \mathbf{J}_{1}\left(\frac{\mathrm{d}}{2} \rho\right) \mathbf{J}_{1}(\mathrm{r} \rho) \exp (-\mathrm{sz}) \mathrm{d} \rho .
\end{aligned}
$$

где $\boldsymbol{J}_{0}$ и $\boldsymbol{J}_{1}-$ функции Бесселя первого рода, нулевого и первого порядков;

$$
s=\sqrt{\rho^{2}+j \mu \gamma \omega_{B}},
$$

где $\rho$ - вещественная переменная $[15,67]$.

Исследования показали, что при $r>(d / 2+2,5 \Delta)$ и любом $z$ выражения (5.38), (5.39) могут быть существенно упрощены:

$$
\begin{gathered}
\dot{\mathbf{H}}_{\mathrm{z}}(\mathrm{r}, \mathrm{z})=\frac{\dot{\Phi}_{\delta}}{\pi \sqrt{2} \mu \Delta} \frac{\mathrm{z}}{\mathrm{r}^{2}+\mathrm{z}^{2}} \exp \left(-\frac{\sqrt{\mathrm{r}^{2}+\mathrm{z}^{2}}}{\Delta}+\mathrm{j} \frac{\sqrt{\mathrm{r}^{2}+\mathrm{z}^{2}}}{\Delta}\right), \\
\dot{\mathbf{H}}_{\mathrm{r}}(\mathrm{r}, \mathrm{z})=\frac{\dot{\Phi}_{\delta}}{\pi \sqrt{2} \mu \Delta \mathrm{r}} \exp \left[-\frac{\mathrm{z}}{\Delta}+\mathrm{j}\left(\frac{\pi}{4}-\frac{\mathrm{z}}{\Delta}\right)\right] .
\end{gathered}
$$

За пределами области дроссельной перегородки МРТ, находящейся под полюсом ВЭ, для расчета $\dot{\mathbf{H}}$ практически всегда можно пользоваться упрощенными выражениями (5.38a), (5.39a). При этом для любых значений $r$ и $z \dot{\mathbf{H}}_{\mathbf{z}} \ll<\dot{\mathbf{H}}_{\mathrm{r}}$, т.е. электромагнитное поле дроссельной перегородке можно рассматривать как натуральную (неполяризованную) волну, векторы $\mathbf{H}$ которой имеют лишь радиальную составляющую и лежат в плоскостях $z=$ const, перпендикулярных направлению распространения волны. В отличие от плоской (поляризованной) волны $[15,65]$ в данном поле значения $\dot{\mathbf{H}}$ для разных точек плоскости $z=$ const различны. Однако картины магнитных полей во всех плоскостях $z=$ const подобны.

Электромагнитное поле в дроссельной перегородке при отсутствии МРЖ (пустой гидроопоре) - вихревое, однако если в него внести «перегородки» [15] в виде плоскостей $z=$ const и плоскости $\theta=0$, то в каждом бесконечно тонком слое полупространства, параллельном плоскости раздела сред, магнитное поле можно характеризовать скалярным магнитным потенциалом. Его величина в точке $P(r, \theta, z)$ : 


$$
\dot{U}=\int_{\mathrm{P}}^{\mathrm{P}_{0}} \dot{\mathbf{H}} \mathrm{d} \mathbf{l}=\int_{\mathrm{r}}^{\mathrm{r}_{0}} \dot{\mathbf{H}}_{\mathrm{r}} \mathrm{dr}=\frac{\dot{\Phi}_{\delta}}{\pi \sqrt{2} \mu \Delta} \ln \frac{\mathrm{r}_{0}}{\mathrm{r}} \exp \left[-\frac{\mathrm{z}}{\Delta}+\mathrm{j}\left(\frac{\pi}{4}-\frac{\mathrm{z}}{\Delta}\right)\right],
$$

где $P_{0}\left(r_{0}, 0, z\right)$ - точка, в которой принято $U=0$ (рис. $\left.5.16, \sigma\right)$.

Магнитное поле МРТ пустой гидроопоры в каждом слое полупространства можно представить как плоскопараллельное поле заряженной оси с линейной плотностью заряда $[15,67]$ :

$$
\dot{q}(\mathrm{z})=\dot{\Phi}_{\delta} \exp \left[-\frac{\mathrm{z}}{\Delta}+\mathrm{j}\left(\frac{\pi}{4}-\frac{\mathrm{z}}{\Delta}\right)\right],
$$

в среде с эквивалентной проницаемостью

$$
\chi=\sqrt{\mu / \gamma \omega_{\mathrm{B}}} .
$$

Величина $\dot{q}$ является функцией координаты $z$, величина $\chi$ одинакова для всех слоев полупространства при $\mu=$ const и зависит от свойств проводящей среды - материала дроссельной перегородки МРТ и частоты электромагнитного поля $[15,67]$.

Как видно из формул (5.41), (5.42), линейная плотность заряда $\dot{q}$ имеет размерность магнитного потока (Вб), а эквивалентная проницаемость - размерность индуктивности (Гн), при этом выражение скалярного потенциала магнитного поля, созданного в дроссельной перегородке уединенным полюсом МРТ пустой гидроопоры, принимает вид:

$$
\dot{U}=-\frac{\dot{q}}{2 \pi \chi} \ln \frac{\mathrm{r}}{\mathrm{r}_{0}} .
$$

Функция потока, которая, как и потенциал, используется для описания плоскопараллельных полей, в данном случае равна

$$
\dot{V}=\frac{\dot{q}}{2 \pi} \theta .
$$

Здесь, в отличие от общепринятой функции потока $\dot{V}_{\mathrm{M}}$, которая характеризует распределение потока вектора $\mathbf{H}[15,67]$, используется пропорциональная ей функция

$$
\dot{V}=\chi \dot{V}_{\mathrm{M}}
$$

Эта функция, имеющая размерность магнитного потока (Вб) и не зависящая от эквивалентной проницаемости среды, характеризует распре- 
деление (растекание) магнитного потока в плоскостях $z=$ const проводящего полупространства.

Электромагнитное поле в дроссельной перегородке МРТ пустой гидроопоры, созданное системой $N$ полюсов, через которые втекают изменяющиеся магнитные потоки $\dot{\Phi}_{1}, \dot{\Phi}_{2}, \ldots \dot{\Phi}_{N}$ (рис. 5.16, б), при оговоренных ранее условиях также может рассматриваться как натуральная волна, векторы $\dot{\mathbf{H}}$ которой лежат в плоскостях $z=$ const. При $\mu=$ const, т. е. в линейном проводящем полупространстве, составляющие вектора $\dot{\mathbf{H}}$, а также скалярный потенциал $\dot{U}$ и функция потока $\dot{V}$ при любом значении $z=$ const определяются с помощью соотношений (5.39a), (5.43), (5.44) методом наложения [15, 65, 67].

Если магнитные потоки полюсов ВЭ по модулю равны $\dot{\Phi}_{\delta}$, а по фазе совпадают или отличаются на $\pi$, выражения $\dot{V}$ и $\dot{U}$ для любого многополюсного ВЭ могут быть сведены к виду

$$
\begin{gathered}
\dot{V}(\mathrm{x}, \mathrm{y}, \mathrm{z})=\frac{\dot{q}(\mathrm{z})}{2 \pi} \operatorname{arctg} \mathrm{F}_{10}(\mathrm{x}, \mathrm{y}), \\
\dot{U}(\mathrm{x}, \mathrm{y}, \mathrm{z})=-\frac{\dot{q}(\mathrm{z})}{4 \pi \chi} \operatorname{lnF}_{20}(\mathrm{x}, \mathrm{y}) .
\end{gathered}
$$

где $F_{10}(x, y)$ и $F_{20}(x, y)$ - безразмерные функции координат $x, y$, зависящие от числа полюсов и их взаимного расположения [67].

Для полей, созданных двумя полюсами разной полярности и бесконечным рядом равноотстоящих полюсов чередующейся полярности, которые соответствуют полям в симметричном двухполюсном и кольцевом многополюсном МРТ, выражения для $F_{10}(x, y)$ и $F_{20}(x, y)$ в отсутствии МРЖ пустой гидроопоре приведены в табл. 5.13.

Таблица 5.13

Выражения $F_{10}(x, y)$ и $F_{20}(x, y)$ для симметричного двухполюсного и кольцевого магнитореологических трансформаторов

\begin{tabular}{|c|c|c|}
\hline $\begin{array}{c}\text { Расположение проекций возбуж- } \\
\text { дающих полюсов }\end{array}$ & $F_{10}(x, y)$ & $F_{20}(x, y)$ \\
\hline & $\frac{-2 \mathrm{ay}}{\mathrm{x}^{2}+\mathrm{y}^{2}-\mathrm{a}^{2}}$ & $\frac{(\mathrm{x}+\mathrm{a})^{2}+\mathrm{y}^{2}}{(\mathrm{x}-\mathrm{a})^{2}+\mathrm{y}^{2}}$ \\
\hline & $\frac{\operatorname{sh} \frac{\pi \mathrm{y}}{2 \mathrm{a}}}{\cos \frac{\pi \mathrm{x}}{2 \mathrm{a}}}$ & $\frac{\pi \mathrm{y}}{2 \mathrm{a}}+\sin \frac{\pi \mathrm{x}}{2 \mathrm{a}}$ \\
\hline
\end{tabular}


В этих выражениях $a$ - половина расстояния между осями соседних полюсов, $\dot{V}(0,0, z)=\dot{U}(0,0, z)$. Представленные выражения позволяют рассчитать магнитное поле в любой точке дроссельной перегородки, в частности на его внешней боковой поверхности при $z=0$.

Для расчета МРТ пустой гидроопоры нужно знать связь магнитного потока возбуждения $\dot{\Phi}_{\mathrm{B}}$, проходящего через дроссельную перегородку уединенным полюсом МРТ, с напряженностью магнитного поля $\dot{\mathbf{H}}_{\mathbf{H}}$ в точке с координатами $(0,0)$ на поверхности $z=0$ (рис. 5.17).

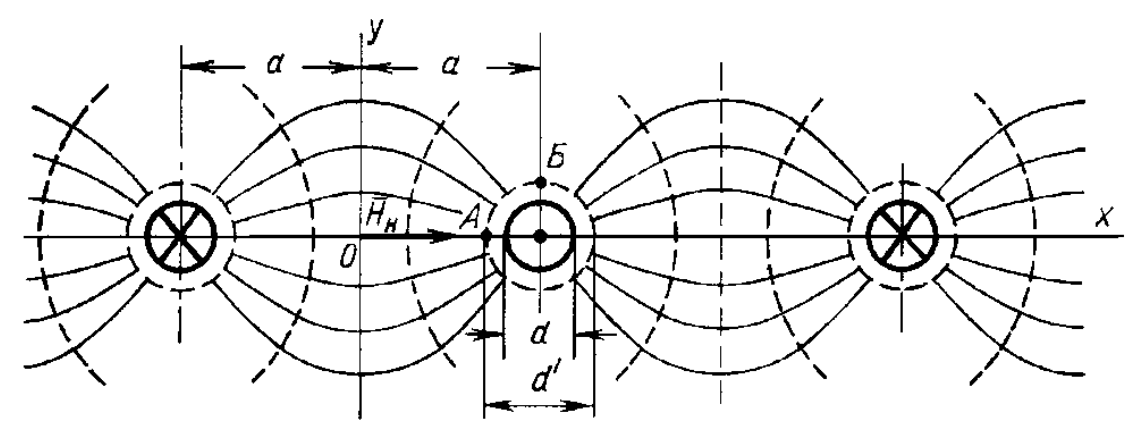

Рис. 5.17. Линии напряженности и равного потенциала магнитного поля на плоскости раздела сред

Эта связь получается из (5.41) и (5.47), исходя из того, что в кольцевых МРТ пустых гидроопор $\Phi_{\mathrm{B}}=\Phi_{\delta} / 2$, а в симметричных двухполюсных $\Phi_{\mathrm{B}}=\Phi_{\delta}$, а $\dot{\mathbf{H}}_{\mathbf{H}}$ связано с потенциалом магнитного поля соотношением $[15,67]$ :

$$
\dot{\mathbf{H}}_{\mathrm{H}}=\dot{\mathbf{H}}_{\mathrm{HX}}=-\left.\frac{\partial \dot{U}}{\partial \mathrm{x}}\right|_{\substack{\mathrm{x}=0 \\ \mathrm{y}=0 \\ \mathrm{z}=0}}=\frac{\dot{q}(0)}{4 \pi \chi}\left(\frac{1}{\mathrm{~F}_{20}} \frac{\partial \mathrm{F}_{20}}{\partial \mathrm{x}}\right)_{\substack{\mathrm{x}=0 \\ \mathrm{y}=0}} .
$$

Использование выражений $F_{10}(x, y)$ из табл. 5.13 приводит к формулам [67, 74]:

- для кольцевых МРТ

$$
\dot{\Phi}_{\mathrm{B}}=2 a \chi \dot{\mathbf{H}}_{\mathrm{H}} \exp \left(-\mathrm{j} \frac{\pi}{4}\right),
$$

- для симметричных двухполюсных МРТ

$$
\dot{\Phi}_{\mathrm{B}}=\pi a \chi \dot{\mathbf{H}}_{\mathrm{H}} \exp \left(-\mathrm{j} \frac{\pi}{4}\right) \text {. }
$$

Соотношения (5.41) и (5.47) дают возможность также рассчитать комплексное магнитное сопротивление участков в дроссельной перегородке МРТ пустой гидроопоры между соседними полюсами ВЭ $[67,74]$ : 


$$
\dot{Z}_{\mathrm{B}}=\frac{2 \dot{U}\left(a-d^{\prime} / 2,0,0\right)}{\dot{\Phi}_{\mathrm{B}}} \approx \frac{2 \dot{U}\left(a, d^{\prime} / 2,0\right)}{\dot{\Phi}_{\mathrm{B}}},
$$

где $\dot{U}\left(a-d^{\prime} / 2,0,0\right)$ и $\dot{U}\left(a, d^{\prime} / 2,0\right)$ - потенциалы соответственно в точках $A$ и $Б$ внешней боковой поверхности дроссельной перегородки (рис. 5.17), находящихся на границе проекции полюсов ВЭ на плоскость раздела сред. Следует учитывать, что вследствие потоков выпучивания расчетный диаметр $d$ полюса ВЭ превышает истинный (конструктивный) диаметр $d$ $[67,74]$.

При $d \leq 0,5 a$, что характерно для реальных конструкций,

- в случае кольцевого МРТ

$$
\dot{Z}_{\mathrm{B}}=\frac{2}{\pi \chi} \ln \frac{8 a}{\pi d^{\prime}} \exp \left(\mathrm{j} \frac{\pi}{4}\right) ;
$$

- в случае симметричного двухполюсного МРТ

$$
\dot{Z}_{\mathrm{B}}=\frac{1}{\pi \chi} \ln \frac{4 a}{d^{\prime}} \exp \left(\mathrm{j} \frac{\pi}{4}\right) .
$$

Представленные формулы выведены без учета зависимости $\mu(H)$. Непостоянство Н на плоскости раздела сред и резкое снижение Н по мере углубления в проводящее полупространство вследствие затухания электромагнитной волны вызывают различия $\mu$ в разных точках дроссельной перегородки и изменение значений $\dot{Z}_{\mathrm{B}}$ и $\dot{\Phi}_{\mathrm{B}}$. При достаточно сильном поле, когда $\mathbf{H}_{e}>\mathbf{H}_{\mathrm{M}}\left(\mathbf{H}_{\mathrm{M}}-\right.$ напряженность поля, при которой $\mu$ достигает максимума, - рис. 5.18), $\zeta=0,86, \theta=59^{0}$ для всех ферромагнитных материалов. При слабых полях $\left(\mathbf{H}_{e}<\mathbf{H}_{\mathrm{M}}\right) \zeta$ приближается к 1 , а $\theta-$ к $45^{0}$.

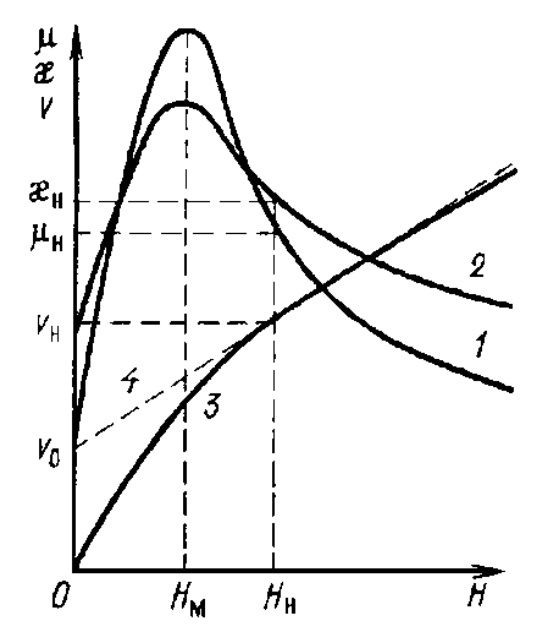

Рис. 5.18. Зависимости от напряженности магнитного поля:

$1-\mu(H) ; 2-\chi(H) ; 3-v\left(H_{e}\right) ; 4-$ линейная аппроксимация $v\left(H_{e}\right)$ 
Анализ влияния зависимости $\mu(H)$ при затухании поля в ферромагнитной среде при отсутствии электропроводной жидкости в гидроопоре $[15,65,67]$ показывает, что в формулы магнитного сопротивления должны быть внесены поправки в виде коэффициента $\zeta$ при модуле этой величины и в виде фазового угла $\theta$ вместо угла $\pi / 4$, который получается при $\mu=$ const. Значения $\zeta$ и $\theta$ зависят от напряженности магнитного поля $\mathbf{H}_{e}$ на плоскости раздела сред [15, 67].

Таким образом, изменение магнитной проницаемости, вызванное уменьшением напряженности магнитного поля в глубине ферромагнитного полупространства при отсутствии МРЖ в гидроопоре, оказывает заметное влияние на магнитное сопротивление. Но еще большее влияние на магнитное сопротивление оказывает изменение напряженности магнитного поля на плоскости раздела сред из-за неоднородности поля. Особенно сильно влияет насыщение участков внешней боковой поверхности дроссельной перегородки вблизи проекций полюсов ВЭ.

Приближенный метод учета влияния этого фактора на магнитное сопротивление ферромагнитного тела, изложенный в [67], основан на использовании величины

$$
v=\chi \mathbf{H}_{\mathrm{e}},
$$

которая пропорциональна магнитному потоку, проходящему по ферромагнитному полупространству через силовую трубку единичной ширины. Являясь дифференциальной характеристикой поля, величина $v$ зависит от напряженности $\mathbf{H}_{e}$ и может быть рассчитана с помощью магнитной характеристики материала дроссельной перегородки $\mu(H)$ по (5.45) и (5.54) (рис. 5.18).

Аналитический метод учета влияния насыщения на магнитное сопротивление ферромагнитного тела использует кусочно-линейную аппроксимацию кривой $v\left(H_{e}\right)$. Удовлетворительное совпадение с экспериментом дает замена кривой $v\left(H_{e}\right)$ участком прямой:

$$
v=v_{0}+\chi_{\mathrm{H}}\left(1-\beta_{0}\right) \mathbf{H}_{\mathrm{e}},
$$

проходящей через точку с координатами $\left(\mathbf{H}_{e}=\mathbf{H}_{\mathrm{H}}, v_{\mathrm{H}}\right)$, где $v_{\mathrm{H}}=\chi_{\mathrm{H}} \mathbf{H}_{\mathrm{H}}$ a $\chi_{\mathrm{H}}$ определяется по (5.45) для $\mu_{\mathrm{H}}$, соответствующей напряженности $\mathbf{H}_{\mathrm{H}}, v_{0}-$ отрезок, отсекаемый на оси ординат аппроксимирующей прямой $v\left(H_{e}\right)$ (рис. 5.18); $\beta_{0}=v_{0} / v_{\mathrm{H}}-$ коэффициент, характеризующий степень насыщения дроссельной перегородки гидроопоры.

Учет влияния непостоянства $\mu$ приводит к следующим выражениям магнитных сопротивлений [67]:

- для кольцевых МРТ 


$$
\dot{Z}_{\mathrm{B}}=\frac{2 \zeta}{\pi \chi_{\mathrm{H}}\left(1-\beta_{0}\right)}\left[\ln \frac{8 a}{\pi d^{\prime}}-\beta_{0} \frac{\pi}{2}\left(1-\frac{d^{\prime}}{2 a}\right)\right] \exp (\mathrm{j} \theta) ;
$$

- для симметричных двухполюсных МРТ

$$
\dot{Z}_{\mathrm{B}}=\frac{\zeta}{\pi \chi_{\mathrm{H}}\left(1-\beta_{0}\right)}\left[\ln \frac{4 a}{d^{\prime}}-2 \beta_{0}\left(1-\frac{d^{\prime}}{2 a}\right)\right] \exp (\mathrm{j} \theta) .
$$

При $\mu=$ const: $\chi=$ const, $v_{0}=0, \beta_{0}=0, \zeta=1, \theta=\pi / 4$ и формулы (5.56) и (5.57) совпадают с (5.52) и (5.53). При насыщении дроссельной перегородки $\beta_{0} \neq 0$ и значения $\dot{Z}_{\mathrm{B}}$ по сравнению с рассчитанными без учета насыщения могут возрасти в 2-3 раза.

Формулы, связывающие $\dot{\Phi}_{\mathrm{B}}$ с $\dot{\mathbf{H}}_{\mathrm{H}}$ при учете непостоянства $\mu$, принимают вид

- для кольцевых МРТ

$$
\dot{\Phi}_{B}=\frac{2}{\zeta} a \chi_{\mathrm{H}} \dot{\mathbf{H}}_{\mathrm{H}} \exp (-\mathrm{j} \theta)
$$

- для симметричных двухполюсных МРТ

$$
\dot{\Phi}_{B}=\frac{\pi}{\zeta} a \chi_{\mathrm{H}} \dot{\mathbf{H}}_{\mathrm{H}} \exp (-\mathrm{j} \theta)
$$

Как пример использования изложенной методики расчета на рис. 5.19 показаны линии вектора магнитной индукции $\dot{\mathbf{B}}$ и линии равного потенциала на поверхности стального дроссельной перегородки в пустой гидроопоре без МРЖ [74].

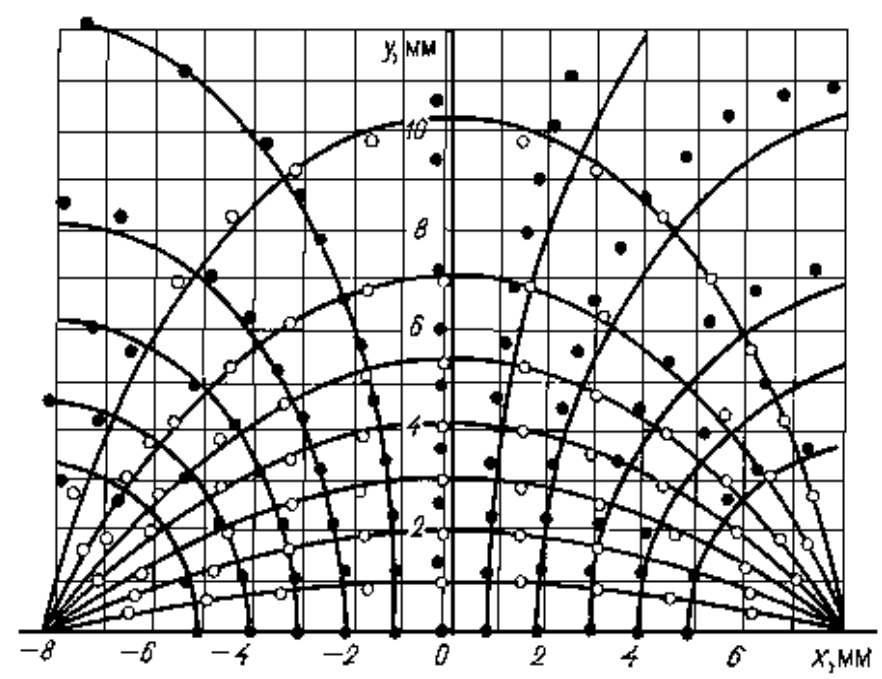

Рис. 5.19. Картины магнитного поля на поверхности дроссельной перегородки МРТ пустой гидроопоры 
На рис. 5.19 для сравнения показаны экспериментально снятые точки линий вектора $\dot{\mathbf{B}}$ и линий $\dot{U}=$ const. Первые можно определить методом игольчатых электродов, вторые - с помощью жесткого потенциалометра. Близкое совпадение расчетных и опытных данных свидетельствует об удовлетворительности представленного математического описания электромагнитного поля [15, 67].

Проектирование индукционного МРТ гидроопоры включает в себя расчет магнитной цепи, цель которого - определение числа витков и тока катушек ВЭ $[15,67,74]$. Исходными данными для расчетов являются выбранные геометрические параметры $p, a, \delta, d, h, l, D_{я}, b$, частота возбуждения $\omega_{\mathrm{B}}=2 \pi f_{\mathrm{B}}$ и напряжение $U_{\mathrm{B}}$ возбуждения (питания) ВЭ, удельные электрические проводимости $\gamma$ и магнитные характеристики $\mu(H)$ ферромагнитных материалов, из которых изготовляются ферромагнитная перегородка, ярмо и сердечники ВЭ.

Задача проектирования индукционного МРТ гидроопоры сводится к определению магнитного потока, обеспечивающего требуемую напряженность и индукцию магнитного поля, расчета магнитодвижущей силы (МДС) катушек возбуждения ВЭ, числа их витков, сечения и диаметра обмоточного провода. Рассмотрены вопросы управления внешним электромагнитным полем при изменении динамических характеристик входного вибросигнала.

В МРТ гидроопоры ферромагнитные стержни ВЭ и ферромагнитная перегородка представляют собой ферромагнитную электропроводящую среду, магнитная проницаемость $\mu=$ const и во много раз выше магнитной проницаемости диэлектрических зазоров $\mu_{0}$ дроссельных каналов.

Магнитная цепь индукционного МРТ гидроопоры рассчитывается из условия получения требуемой напряженности магнитного поля на внешней боковой поверхности ферромагнитной дроссельной перегородки $H_{\mathrm{H}}=(1,3 \div 1,5) H_{\mathrm{m}}$, где $H_{\mathrm{M}}-$ максимальное значение напряженности магнитного поля в магнитопроводе индукционного МРТ $[15,74]$.

Выбрав значение $H_{\mathrm{м}}$, можно определить магнитный поток возбуждения $\dot{\Phi}_{\mathrm{B}}$, проходящий по ферромагнитной дроссельной перегородке гидроопоры.

Зная $\dot{\Phi}_{\mathrm{B}}$ и $\dot{Z}_{\mathrm{B}}-$ комплексное магнитное сопротивление участков ферромагнитной дроссельной перегородки между соседними полюсами ВЭ МРТ гидроопоры, - можно определить комплексное значение МДС $\dot{F}_{\mathrm{B}}$, необходимое для создания на внешней боковой поверхности перегородки требуемой напряженности магнитного поля $\dot{F}_{\mathrm{B}}=\dot{\Phi}_{\mathrm{B}} \dot{Z}_{\mathrm{B}}$.

Расчет магнитной цепи производится по приведенной эквивалентной схеме, позволяющей рассчитать магнитные потоки и МДС в элементах 
разветвленной магнитной цепи индукционного МРТ гидроопоры (рис. 5.20).

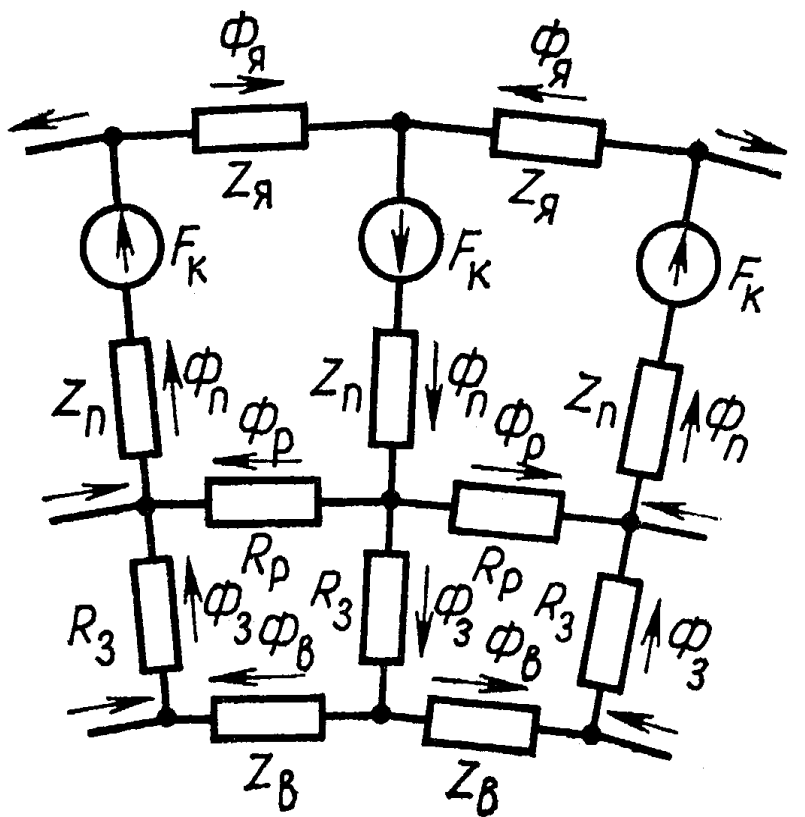

Рис. 5.20. Расчетная эквивалентная схема магнитной цепи индукционного МРT

На рис. 5.20 показано: $\dot{F}_{\text {К }}$ МДС катушки ВЭ; $\dot{\Phi}_{\mathrm{B}}$ - магнитный поток возбуждения; $\dot{\Phi}_{П}-$ магнитный поток в полюсе ВЭ; $\dot{\Phi}_{Я}-$ магнитный поток ярма; $\dot{\Phi}_{\delta}$ - магнитный поток в зазоре; $\dot{\Phi}_{P^{-}}$магнитный поток рассеяния; $\dot{Z}_{\Pi}$ - комплексное магнитное сопротивление полюса; $\dot{Z}_{Я}$ - комплексное магнитное сопротивление ярма; $\dot{Z}_{\mathrm{B}}$ - комплексное магнитное сопротивление участков перегородки между соседними полюсами ВЭ; $R_{\delta}$ - магнитное сопротивление зазора.

Магнитный поток $\Phi_{\delta}$ в зазоре однозначно связан с потоком в дроссельной перегородке $\Phi_{\delta}=k_{N} \dot{\Phi}_{\mathrm{B}}$. Значения коэффициента $k_{N}$ для кольцевого МРТ $k_{N}=2$, а для двухполюсного $k_{N}=1$.

Магнитное сопротивление зазора $R_{3}=R_{\delta}$ можно определить с помощью графически построенной картины поля в зазоре, а также используя предложенные А. Г. Сливинской формулы [89]. Для круглых полюсов

$$
\mathrm{R}_{\delta}=1 / \mu_{0} d\left(\frac{\pi d}{4 \delta}+\frac{0,36 d}{1,2 d+\delta}+0,96\right) .
$$

Магнитный поток в полюсе ВЭ $\dot{\Phi}_{\Pi}=\dot{\Phi}_{\delta}+k_{N} \dot{\Phi}_{\mathrm{P}}$, где $\dot{\Phi}_{\mathrm{P}}-$ поток рассеяния, который не проходит в дроссельную перегородку, а замыкается через диэлектрический зазор между полюсами ВЭ МРТ гидроопоры.

Для определения $\dot{\Phi}_{\mathrm{P}}$ необходимо рассчитать магнитное сопротивление путей рассеяния $R_{\mathrm{P}}$, используя известные графические или графоаналитические методы [89]. Когда угловой сдвиг осей соседних полюсов ВЭ 
невелик, поле рассеяния можно принять плоскопараллельным и рассчитывать по методике [89].

МДС, определяющая поток рассеяния,

$$
\dot{F}_{\mathrm{P}} \approx \dot{F}_{\mathrm{B}}+2 \dot{\Phi}_{\delta} R_{\delta}
$$

Магнитное сопротивление массивного полюса ВЭ должно определяться с учетом поверхностного эффекта и может быть рассчитано по формуле [15, 67, 89]:

$$
\dot{Z}_{\Pi}=\zeta \frac{l}{S_{\Pi}} \sqrt{\frac{\omega_{B} \gamma}{\mu_{\Pi}}} \exp (j \theta) .
$$

где $S_{\Pi}-$ периметр поперечного сечения полюса. Если полюсы имеют продольные разрезы, величина $S_{\Pi}$ равна суммарному периметру фигур, образующихся в поперечном сечении полюса. Магнитная проницаемость $\mu_{\Pi}$ на поверхности полюса (рис. 5.21, a) соответствует напряженности $\mathbf{H}_{П}$, которая может быть определена с помощью, рассчитанной для материала полюса зависимости v $\left(H_{e}\right)$ по значению:

$$
v_{\Pi}=\zeta \dot{\Phi}_{\Pi} / S_{\Pi}
$$
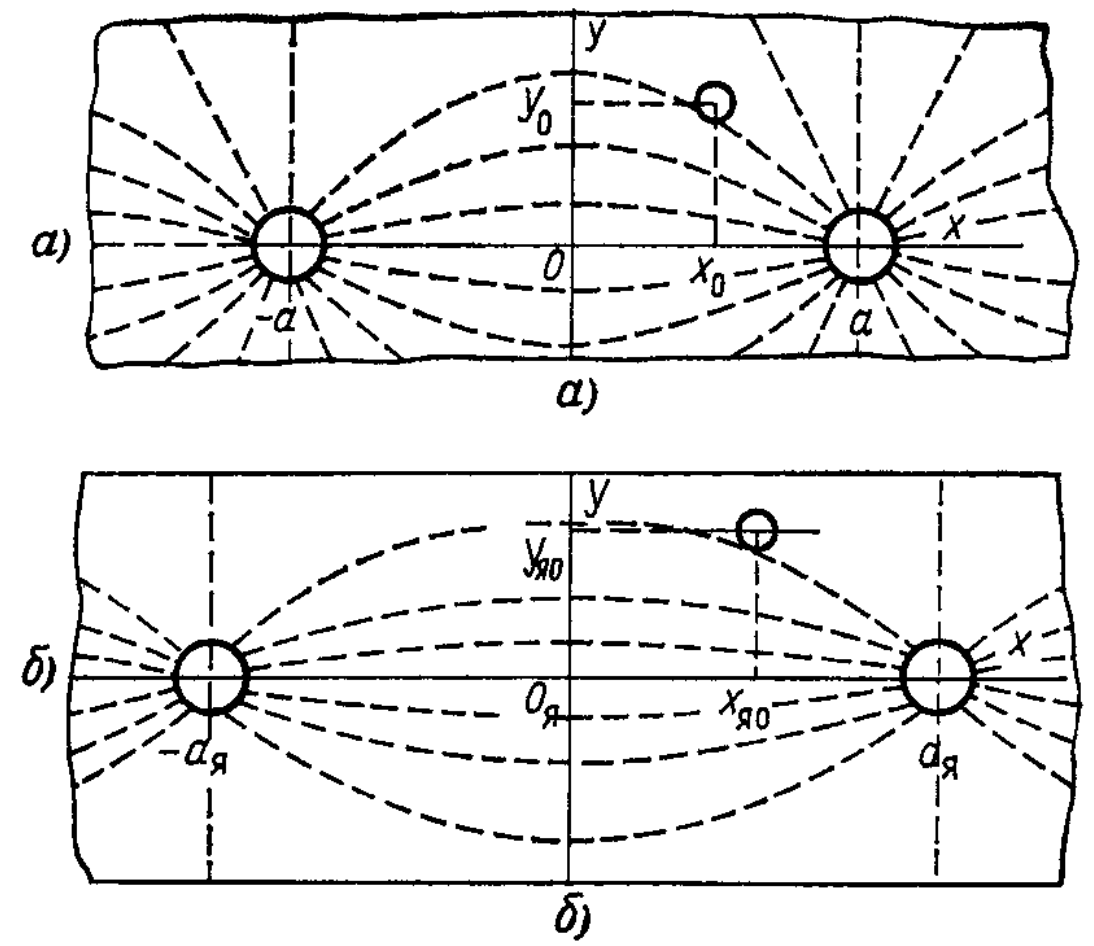

Рис. 5.21. Проекции полюсов ВЭ кольцевого МРТ гидроопоры:

$a$ - на внешнюю боковую поверхность дроссельной перегородки; $\sigma$ - на внутреннюю поверхность ярма 
Магнитное сопротивление массивного полюса ВЭ должно определяться с учетом поверхностного эффекта и может быть рассчитано по формуле [15, 67].

Магнитный поток в ярме $\dot{\Phi}_{Я}=\dot{\Phi}_{\Pi} / k_{N}$.

Анализ растекания магнитного потока в полосе с учетом поверхностного эффекта и насыщения по изложенной выше методике позволяет определить значения $v$ и напряженности магнитного поля в любой точке ярма [15]. Для массивного ярма кольцевого МРТ гидроопоры значение $v_{я н}$ в точке $O_{я}$, лежащей на внутренней поверхности ярма посередине дуги окружности, проходящей через оси соседних полюсов ВЭ (рис. 5.21, б), выражается так:

- при $h \geq 2,5 a_{\text {Я }}$

$$
v_{\text {ЯH }}=\zeta \frac{\dot{\Phi}_{Я}}{2 a_{\text {Я }}}\left[1+4 \exp \left(-\frac{\pi h}{2 a_{\text {Я }}}\right)\right] ;
$$

- при $h<2,5 a_{\text {Я }}$

$$
v_{Я H}=\zeta \frac{\dot{\Phi}_{Я}}{h}\left[\frac{2}{\operatorname{th}\left(\pi a_{Я} / h\right)}-1\right],
$$

где $a_{\text {я }}$ половина дуги окружности, проходящей по внутренней поверхности ярма через оси соседних полюсов ВЭ (рис. 5.21, б). Используя рассчитанную для материала ярма зависимость $v\left(H_{e}\right)$, по $v_{\text {ян }}$ можно определить значение напряженности магнитного поля $\mathbf{H}_{я}$ в точке $0_{\text {я. }}$

Магнитное сопротивление массивного ярма следует определять с учетом поверхностного эффекта, насыщения и ограниченной длины ярма $h$, при этом можно использовать изложенную выше методику учета насыщения ферромагнитных тел и формулы для магнитных сопротивлений, полученные на основе анализа электромагнитного поля в полосе с высокой проницаемостью [67]. Для кольцевого МРТ гидроопоры

- при длинном ярме $\left(h \geq 2,5 a_{\text {Я }}\right)$

$$
\begin{aligned}
\dot{Z}_{\text {Я }}= & \frac{\zeta \exp (j \theta)}{\pi \chi_{\text {ЯН }}\left(1-\beta_{\text {Я0 }}\right)}\left\{2 \ln \frac{8 a_{Я}}{\pi d}+8 \exp \left(-\frac{\pi h}{2 a_{\text {Я }}}\right)-\right. \\
& \left.-\pi \beta_{\text {Я }}\left(1-\frac{d}{2 a_{\text {Я }}}\right)\left[1+4 \exp \left(-\frac{\pi h}{2 a_{\text {Я }}}\right)\right]\right\}
\end{aligned}
$$

- при коротком ярме $\left(h<2,5 a_{я}\right)$ 


$$
\dot{Z}_{Я}=\frac{\zeta \exp (\mathrm{j} \theta \mathrm{x}}{\chi_{Я \mathrm{H}}\left(1-\beta_{\text {Я0 }}\right)}\left\{\frac{2 a_{Я}}{h}-\frac{2}{\pi} \ln \frac{\pi d}{h}-\beta_{\text {Я0 }} \frac{2 a_{Я}-d}{h}\left(\frac{2}{\operatorname{th}\left(\pi a_{Я} / h\right)}-1\right)\right\} .
$$

В выражениях (5.64) и (5.65): $\chi_{я н}-$ эквивалентная проницаемость в точке $O_{я}$, определяемая с помощью рассчитанной для материала ярма зависимости $\chi(H)$ при $\mathbf{H}=\mathbf{H}_{я} ; \beta_{я 0}=v_{я 0} / \chi_{я н} \mathbf{H}_{Я}-$ коэффициент, характеризующий степень насыщения ярма; $v_{я 0-}$ отрезок, отсекаемый на оси ординат аппроксимирующей прямой $v\left(H_{e}\right)$ для материала ярма, при этом аппроксимирующая прямая должна проходить через точку $\left(\mathbf{H}_{я}, v_{я н}\right)$ и быть как можно ближе к кривой $v\left(H_{e}\right)$ на участке $\mathbf{H}_{Я}<\mathbf{H}_{e}<(2,5 \div 3,5) \mathbf{H}_{я}$.

При выполнении полюсов и ярма из листовой электротехнической стали можно принимать $\dot{Z}_{\Pi}=\dot{Z}_{\text {Я }}=0$.

По закону Кирхгофа для эквивалентной расчетной схемы кольцевого индукционного МРТ гидроопоры МДС катушки ВЭ определяется как $[15,67,74]$ :

$$
\dot{F}_{\mathrm{K}}=\dot{\Phi}_{\delta} \dot{R}_{\delta}+\dot{\Phi}_{\Pi} \dot{Z}_{\Pi}+0.5\left(\dot{\Phi}_{\mathrm{B}} \dot{Z}_{\mathrm{B}}+\dot{\Phi}_{Я} \dot{Z}_{\text {Я }}\right) .
$$

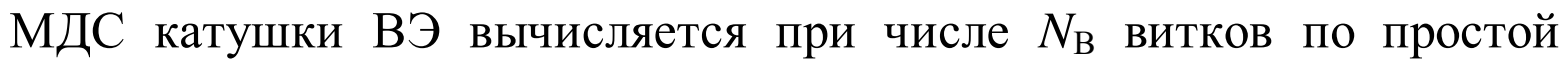
формуле

$$
F_{\mathrm{K}}=I_{\mathrm{K}} N_{\mathrm{B}}
$$

Возбуждающий электромагнит будет тем сильнее и его магнитный поток, тем больше, чем больше будет число ампер-витков А $\bullet$ в $[15,35,39,42]$.

Число витков катушки ВЭ, при частоте $f_{\mathrm{B}}$ и напряжении $U_{\mathrm{K}}$ возбуждения, определяется из выражения

$$
N_{\mathrm{B}} \approx \frac{U_{\mathrm{K}}}{2 \pi f_{\mathrm{B}} \Phi_{\Pi}} .
$$

Из выражения (5.37) определим магнитный поток в полюсе ВЭ:

$$
\Phi_{\Pi} \approx \frac{U_{\mathrm{K}}}{2 \pi f_{\mathrm{B}} N_{\mathrm{B}}} .
$$

Напряжение на катушке ВЭ $U_{\mathrm{K}}$, которое определяется напряжением питания $U_{\mathrm{B}}$ и схемой соединения катушек, будет определяться из выражения

$$
U_{\mathrm{K}} \approx 2 \pi f_{\mathrm{B}} N_{\mathrm{B}} \Phi_{\Pi}
$$


Магнитный поток в полюсе ВЭ определяется только магнитным потоком $\Phi_{\delta}$ в зазоре между полюсом ВЭ и внешней боковой поверхности дроссельной перегородки, т.е. $\Phi_{\Pi}=\Phi_{\delta m}$. Магнитный поток также можно определить как:

$$
\Phi_{\Pi}=\Phi_{\delta}+k_{N} \Phi_{\mathrm{P}} \rightarrow \Phi_{\Pi}=\Phi_{\delta m}=L_{\ni} I_{\ni} .
$$

где $L_{\ni}$ - индуктивность катушек двух соседних ВЭ; $I_{\ni}$ - ток возбуждения.

Для МРТ гидроопоры МГО-90-2, разработанной в Институте проблем машиностроения РАН, можно воспользоваться упрощенной схемой возбуждения индукционных дроссельных каналов. Такая схема возбуждения состоит из двух симметричных двухполюсных ВЭ включённых по Побразной схеме с катушками индуктивности $L_{1}+L_{2}=L_{\text {э }}$ (рис. 5.22) [35, 39, 42].

Совместную индуктивность катушек двух соседних ВЭ вычисляют по формуле [35, 39, 42, 72]:

$$
L_{\ni}=\frac{N_{B}^{2} S_{\delta}}{\frac{l_{e}}{\mu_{e}}+2 \delta^{\prime}} 4 \pi \cdot 10^{-7} \Gamma \mathrm{H},
$$

где $2 \delta^{\prime}$ - суммарная ширина зазоров магнитопровода двух соседних ВЭ (рис. 5.22); $\mu_{e}$ - относительная магнитная проницаемость магнитопровода; $l_{e}$ - длина средней магнитной линии в магнитопроводе двух соседних ВЭ.
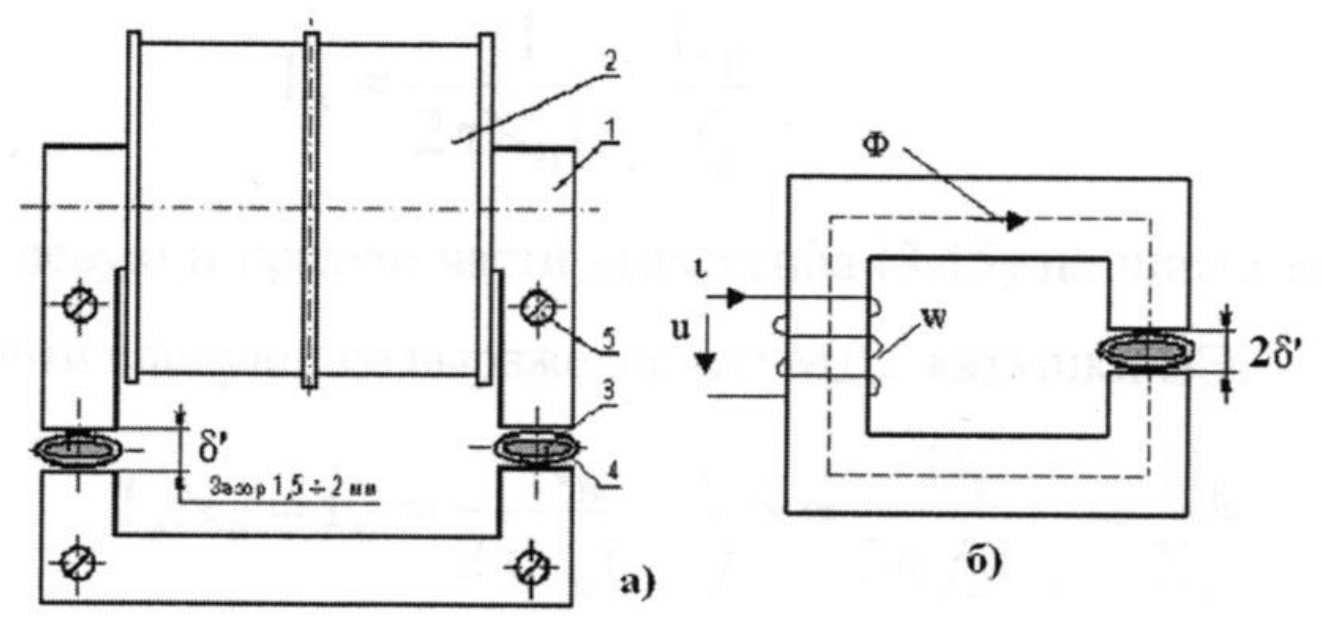

a)

б)

Рис. 5.22. Упрощенная схема возбуждения двух дроссельных каналов ВЭ в МРТ (a); приведенная магнитная цепь к одному полюсному зазору $2 \delta^{\prime}($ б):

1 - сердечник из шихтованного железа; 2 - совместная катушка индуктивности ВЭ; 3 - индукционный дроссельный канал; 4 - трубка индукционного дроссельного канала; 5 - винты крепления; $\delta^{\prime}$ - зазор в полюсе и $2 \delta^{\prime}$ - двойной суммарный полюсной зазор в магнитопроводе ВЭ 
Формула (5.72) для расчёта совместной индуктивности катушек двух соседних ВЭ получена при условии независимости, магнитной проницаемости от индукции, когда ВЭ работает в области индукций, где проницаемость падает с ростом напряжённости магнитного поля. Здесь имеет место обратное явление - действительная индуктивность получается меньше вычисленной. Однако расхождение вычисленной индуктивности с действительной, которая вызвана указанной причиной, обычно не превосходит 1-2\% и поэтому не имеет практического значения, так как индуктивность зависит лишь от величины зазоров в полюсе.

Если ВЭ работает в области индукций, где проницаемость растёт с повышением индукции, концентрация магнитного потока со стороны коротких силовых линий возрастает и действительная индуктивность получается выше вычисленной по формуле (5.72).

Ток катушки ВЭ определяется выражениями (5.69) и (5.71) для магнитного потока в полюсе

$$
\Phi_{\Pi} \approx L_{\ni} I_{\ni} \approx \frac{U_{\mathrm{K}}}{2 \pi f_{\mathrm{B}} N_{\mathrm{B}}} .
$$

Тогда ток $I_{\ni}$ катушки ВЭ определяется выражением

$$
I_{\ni} \approx \frac{1}{2 \pi N_{\mathrm{B}} L_{\ni}} \frac{U_{\mathrm{K}}}{f_{\mathrm{B}}} .
$$

Умножая левую и правую части выражения (5.73) на число витков катушки ВЭ $N_{\mathrm{B}}$, получим следующее выражение для МДС катушки ВЭ:

$$
I_{\ni} N_{\mathrm{B}}=F_{\mathrm{K}} \approx \frac{N_{\mathrm{B}}}{2 \pi N_{\mathrm{B}} L_{\ni}} \frac{U_{\mathrm{K}}}{f_{\mathrm{B}}}=\frac{U_{\mathrm{K}}}{2 \pi f_{\mathrm{B}} L_{\ni}}=\frac{U_{\mathrm{K}}}{X_{L_{\ni}}},
$$

т.е. с увеличением индуктивного сопротивления $X_{L \ni}$ ВЭ должно увеличиваться и его напряжение возбуждения $U_{\kappa}$.

Также из выражения (5.74) вытекает, что с увеличением индуктивного противления $X_{L}$ ВЭ на переменном токе при одновременном увеличении его напряжения возбуждения $U_{\mathrm{K}}$ ток возбуждения и МДС ВЭ должны оставаться постоянными.

Используя выражение (5.74) для МДС катушки ВЭ, можно провести связь числа витков $N_{\mathrm{B}}$ ВЭ с активным $R_{\ni}$ и индуктивным $X_{L}$ сопротивлениями катушки ВЭ индукционного МРТ при его перестройке по частоте. Разделив левую и правую части выражения (5.74) на ток возбуждения $I_{\ni}$, получаем

$$
\frac{N_{\mathrm{B}} I_{\ni}}{I_{\ni}}=\frac{F_{\mathrm{K}}}{I_{\ni}} \approx \frac{U_{\mathrm{K}}}{2 \pi f_{\mathrm{B}} L_{\ni} I_{\ni}}=\frac{U_{\mathrm{K}}}{X_{L_{\ni}} I_{\ni}}=\frac{Z_{\ni}}{X_{L}}=N_{\mathrm{B}} .
$$


Из выражения (5.75) видно, что количество витков $N_{\text {В }}$ ВЭ на переменном токе определено отношением полного сопротивления катушки ВЭ к его активному сопротивлению, т.е. $Z_{\ni} / X_{L}$. При условии, что $Z_{\ni}=R_{\ni}+X_{L}$ и $X_{L} \gg R_{\ni}$ выражение (5.75) можно переписать в виде

$$
N_{\mathrm{B}}=\frac{U_{\mathrm{K}}}{X_{L_{\ni}} I_{\ni}}=\frac{Z_{\ni}}{X_{L}},
$$

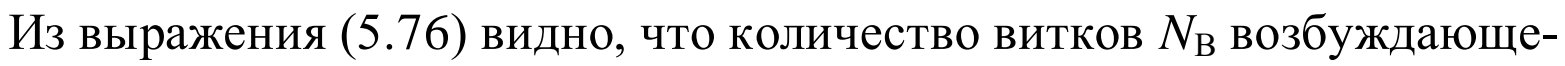
го электромагнита на переменном токе определено отношением $Z_{\Im} / X_{L}$.

Как видно из выражения (5.73), при выбранных управляющих параметрах перестройки индукционного МРТ - частоте $f_{\mathrm{B}}$ и напряжении на катушке ВЭ $U_{\kappa}$, отношение управляющих параметров перестройки $U_{\kappa} / f_{\mathrm{B}}$ должно быть величиной постоянной и определяться выражением

$$
\frac{U_{\mathrm{K}}}{f_{\mathrm{B}}} \approx 2 \pi N_{\mathrm{B}} \Phi_{\Pi} \approx 2 \pi N_{\mathrm{B}} L_{\ni} I_{\ni}=\text { const }
$$

Это очень важный факт, позволяющий создавать постоянный магнитный поток удержания в полюсе ВЭ и перестраивать индукционный MPT по частоте $f_{\mathrm{B}}$ и тем самым при перестройке удерживать магнитным полем МЖ в дроссельных каналах, за счет изменения её вязкости и намагниченности $M(H)$.

\section{4. Возбуждение и размагничивание ферромагнитных элементов с остаточной магнитной индукцией в МРТ гидроопор}

Активные системы виброгашения - гидроопоры нового поколения, содержат в себе элементы адаптивной настройки и электромеханического преобразования. Основой такого преобразования являются рабочие МРЖ жидкости, движением которых можно управлять с помощью внутренних и внешних электромагнитных полей [33-40].

При этом конструкция гидроопор изменяется путем введения новых управляющих элементов - индукционных МРТ. В этом случае возникает сложная техническая задача: управляющее магнитное поле должно изменяться синфазно с изменением частоты внешнего вибросигнала, изменяя полярность.

Перед разработчиками стоят две противоречивые проблемы: с одной стороны, необходимо усиливать напряженность управляющего магнитного поля, с другой стороны, менять его полярность с частотой до 500 Гц. Но при напряженности магнитного поля порядка 140 кА/м в дорогостоя- 
щих ферритовых сердечниках, входящих в состав индукционных МРТ, остаточная магнитная индукция в них может достигать $30 \%$ от первоначальной [73].

Остаточная магнитная индукция $\mathrm{B}_{r}$ ферритовых сердечников (рис. 5.23) недопустима, так как она влечёт задержку между функциями $H$ и $B$ по времени, искажает форму функции $B$ и влияет на переходные процессы в магнитной среде при смене полярности внешнего магнитного поля. Задержка $B$ не должна превышать длительности периода высшей гармоники входного вибросигнала [73]. Фазовый сдвиг между функциями $H$ и $B$ обусловлен в основном гистерезисом сердечников ВЭ.

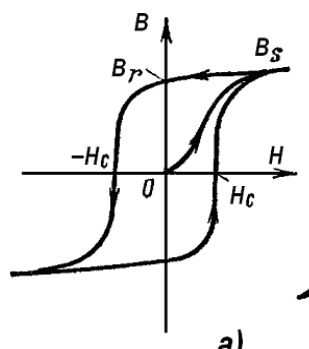

a)

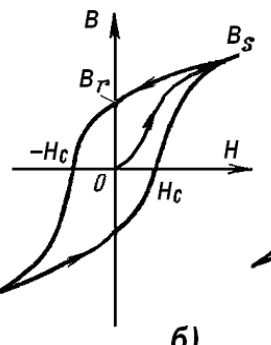

б)

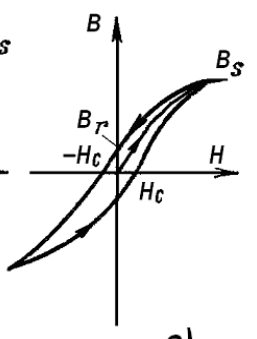

6)

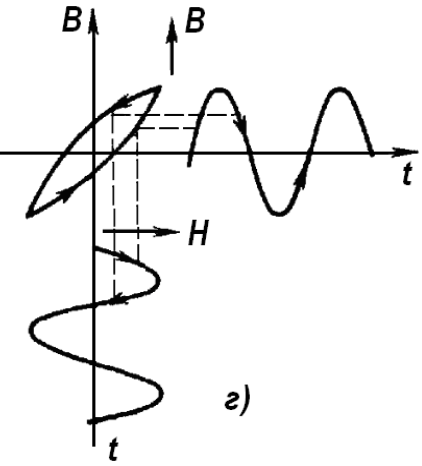

Рис.5.23. Гистерезисные петли различных ферромагнитных материалов:

$a$ - низкоуглеродистые стали 10 и 40; $\sigma$ - холоднокатанная сталь типа 27КХ, 49К2ФА, или электротехническая сталь марки $1521 ;$ в - феррит $\mathrm{CuFe}_{2} \mathrm{O}_{4}$ с кубической структурой, где $B_{S}-$ индукция насыщения; $B_{r}-$ остаточная индукция; $H_{c}-$ коэрцитивная сила по индукции; 2 - искажение формы электромагнитной волны, из-за гистерезиса в сердечниках МРT

Оценку времени переходных процессов в магнитной среде при смене полярности внешнего магнитного поля с учётом гистерезиса в сердечниках МРТ гидроопоры можно произвести при следующем подходе:

a) при некотором увеличении амплитуды перемагничивающего поля появляется сдвиг по фазе ф между периодическими функциями $H=H_{m} \sin \omega t$ и $B=B_{m} \sin (\omega t-\varphi)$ (рис. 5.23, , );

б) так, если остаточная магнитная индукция в сердечнике ВЭ достигает $5 \%$ от первоначальной, то сдвиг по фазе $\varphi$ между периодическими функциями $H$ и $B$ также будет составлять $5 \%$, или $\Delta \varphi=0,1 \cdot \pi=18^{\circ}$.

При фазовом сдвиге $\varphi=5 \%$ между функциями $H$ и $B$ для сигнала возбуждения с частотой $f_{\mathrm{B}}=20$ Гц, при $T_{\text {п }}=50 \cdot 10^{-3} \mathrm{c}-$ периоде повторения сигнала возбуждения задержка будет равна

$$
t_{3.8}=\frac{\Delta \varphi}{2 \pi} T_{\Pi}=\frac{0,1 \cdot \pi}{2 \pi} 50 \cdot 10^{-3}=0,05 \cdot 50 \cdot 10^{-3}=2,5 \cdot 10^{-3} \mathrm{c} .
$$


Для сигнала размагничивания с частотой $f_{\mathrm{P}}=200$ Гц, при $T_{\mathrm{p}}=5 \cdot 10^{-3} \mathrm{c}$ - периоде повторения сигнала размагничивания и фазовом сдвиге $\varphi=5 \%$ между $H$ и $B$ задержка во времени будет равна

$$
t_{3 . p}=\frac{\Delta \varphi}{2 \pi} T_{\Pi}=\frac{0,1 \cdot \pi}{2 \pi} 5,0 \cdot 10^{-3}=0,05 \cdot 5,0 \cdot 10^{-3}=0,25 \cdot 10^{-3} \mathrm{c} .
$$

Такие временные задержки между функциями $H$ и $B$ переменного магнитного поля, обусловленные гистерезисом сердечников ВЭ МРТ не допустимы и их необходимо устранять (размагничивать сердечники ВЭ).

Остаточную магнитную индукцию необходимо погасить перед сменой полярности магнитного поля. Для этого применяются электромагнитные поля с относительно высокой частотой (относительно вибросигналов) до 5 кГц. Более высокие частоты для магнитомягких материалов применять нецелесообразно, так как возникает скин-эффект, который препятствует проникновению магнитного поля внутрь материала. Поэтому сложной задачей при управлении потоком МРЖ является создание магнитных полей с минимальной остаточной магнитной индукцией $B_{r}$.

Геометрические размеры дроссельной перегородки и сердечников ВЭ в МРТ гидроопор во много раз превышают эквивалентную глубину проникновения электромагнитной волны. Для определения, насколько быстро уменьшается амплитуда падающей волны по мере проникновения волны в проводящую среду, вводят понятие глубины проникновения [73]:

$$
\Delta=\sqrt{2 / \mu \gamma \omega_{B}},
$$

где $\omega_{\mathrm{B}}=2 \pi f_{\mathrm{B}}-$ угловая частота изменяющегося однополярного электромагнитного поля в дроссельной перегородке.

При частоте 60 Гц значения $\Delta$ составляют около 1,0 мм, а при больших частотах еще меньше. Это позволяет рассматривать внешнюю боковую поверхность стержней ВЭ и боковую поверхность перегородки с дроссельными каналами индукционного МРТ гидроопоры как проводящее полупространство с высокой магнитной проницаемостью, в которое через полюсы ВЭ втекают изменяющиеся по периодическому закону магнитные потоки.

Под глубиной проникновения $\Delta$ понимают расстояние вдоль направления распространения волны (вдоль оси z), на котором амплитуда падающей волны $E$ (или $H$ ) уменьшается в $e=2,7183$ раз. Уравнением для определения глубины проникновения является выражение

$$
e^{-\kappa \Delta}=e^{-1}
$$


Отсюда следует, что $k \Delta=1$ или $\Delta=1 / k$. Глубина проникновения зависит от свойств, проводящей среды $(\gamma$ и $\mu)$ и от частоты $\omega$.

Для того чтобы охарактеризовать насколько быстро уменьшается амплитуда падающей волны по мере проникновения волны в проводящую среду приводятся для сравнения (оценки) её величины два примера.

Пример 1. Электромагнитная волна имеет частоту $f_{1}=50$ Гц и проникает в проводящую среду, у которой $\gamma=10^{7} \mathrm{OM}^{-1 .} \mathrm{M}^{-1}$ и $\mu=10^{3}$, то:

$$
k_{1}=\sqrt{\frac{\omega_{1} \gamma \mu_{a}}{2}}=\sqrt{\frac{2 \pi \cdot 50 \cdot 10^{3} \cdot 1,256 \cdot 10^{-6} \cdot 10^{7}}{2}}=1404,25(1 / \mathrm{M}) .
$$

Глубина проникновения $\Delta_{1}=0,7 \cdot 10^{-3} \mathrm{M}$, т.е. на расстоянии в $0,7 \cdot 10^{-3} \mathrm{M}$ амплитуды $H$ и $E$ снизятся в 2,7183 раза.

Пример 2. Так, если электромагнитная волна имеет частоту $f_{2}=100$ Гц и проникает в проводящую среду, у которой $\gamma=10^{7} \mathrm{OM}^{-1 .} \mathrm{M}^{-1}$ и $\mu=10^{3}$, то:

$$
k_{2}=\sqrt{\frac{\omega_{2} \gamma \mu_{a}}{2}}=\sqrt{\frac{2 \pi \cdot 100 \cdot 10^{3} \cdot 1,256 \cdot 10^{-6} \cdot 10^{7}}{2}}=1985,91(1 / \mathrm{M}) .
$$

Глубина проникновения $\Delta_{2}=0,5 \cdot 10^{-3}$ м, т.е. на расстоянии в $0,5 \cdot 10^{-3} \mathrm{M}$ амплитуды $H$ и $E$ снизятся в 2,7183 раза.

Чем больше глубина проникновения электромагнитной волны в проводящую среду, тем больше происходит намагничивание ферромагнитного сердечника ВЭ.

Приведённые примеры 1, 2 предназначены для последующей оценки отношения $\Delta_{2} / \Delta_{1}$ глубин проникновения электромагнитной волны в поверхностный слой сердечника ВЭ. Оценив отношение $\Delta_{2} / \Delta_{1}$ глубин проникновения электромагнитной волны в поверхностный слой сердечника ВЭ, для выбранных частот намагничивания проводящей среды $f_{1}=50$ Гц и $f_{2}=100$ Гц можно определить достижимый и допустимый уровни размагничивания ферромагнитных сердечников ВЭ МРТ перестраиваемой гидроопоры перед последующим их намагничиванием.

Если в примере 1 первая электромагнитная волна намагничивания имеет частоту $f_{1}=50$ Гц и проникает в поверхностный слой сердечника ВЭ, у которого $\gamma=10^{7} \mathrm{OM}^{-1} \mathrm{M}^{-1}, \mu=10^{3}$ и $k_{1}=1404,251 / \mathrm{M}$, то глубина её проникновения $\Delta_{1}=0,7 \cdot 10^{-3} \mathrm{M}$.

Если затем после воздействия первой электромагнитной волнынамагничивания частотой $f_{1}=50$ Гц на сердечник ВЭ действует вторая последующая электромагнитная волна размагничивания частотой $f_{2}=100$ Гц (пример 2), тоглубина её проникновения, будет равна $\Delta_{2}=0,5 \cdot 10^{-3} \mathrm{M}$. 
Оценим отношение $\Delta_{2} / \Delta_{1}$ глубин проникновения электромагнитной волны в поверхностный слой сердечника ВЭ. Отношение этих величин $\Delta_{2} / \Delta_{1}=0,7071$.

Из проведенной числовой оценки отношения $\Delta_{2} / \Delta_{1}$ глубин проникновения в поверхностный слой ферромагнитного сердечника ВЭ электромагнитных волн намагничивания и размагничивания с частотами $f_{1}=50$ Гц и $f_{2}=100$ Гц видно, что достижимый уровень последующего размагничивания сердечника ВЭ составляет величину $\Delta_{2} / \Delta_{1}=0,7071$ от уровня его предыдущего намагничивания, если принимать уровень намагничивания сердечника ВЭ $\Delta_{2} / \Delta_{1}=1$.

Если же частота электромагнитных волн размагничивания будет еще больше, то достижимый уровень последующего размагничивания $\Delta_{2} / \Delta_{1}$ сердечника ВЭ будет еще меньше.

Пример 3. Так, если вторая электромагнитная волна размагничивания имеет частоту $f_{2}=500$ Гц, т.е. в 10 раз более высокую, чем частота предыдущего намагничивания, и проникает в поверхностный слой ферромагнитного сердечника ВЭ, у которого $\gamma=10^{7} \mathrm{OM}^{-1 .} \mathrm{M}^{-1}, \mu=10^{3}$, то:

$$
k_{2}=\sqrt{\frac{\omega_{2} \gamma \mu_{a}}{2}}=\sqrt{\frac{2 \pi \cdot 500 \cdot 10^{3} \cdot 1,256 \cdot 10^{-6} \cdot 10^{7}}{2}}=4440,63(1 / \mathrm{M}) .
$$

Глубина проникновения $\Delta_{2}=0,2251 \cdot 10^{-3}$ м. В этом случае можно вести речь о допустимой глубине проникновения электромагнитной волны в поверхностный слой ферромагнитного сердечника ВЭ.

Тогда при предыдущей электромагнитной волне, частотой $f_{1}=50$ Гц намагничивающей поверхностный слой сердечника ВЭ отношение величин $\Delta_{2} / \Delta_{1}=0,316$.

Здесь речь идет о допустимом уровне последующего размагничивания для ферромагнитного сердечника ВЭ, при котором частоту электромагнитной волны размагничивания рекомендуется выбирать в 10 раз более высокой, чем частота предыдущего намагничивания.

Оценка отношения $\Delta_{2} / \Delta_{1}$ глубин проникновения электромагнитной волны в поверхностный слой ферромагнитного сердечника ВЭ для выбранных частот намагничивания и размагничивания проводящей среды $f_{1}=50$ Гц, $f_{2}=100$ Гц и $f_{2}=500$ Гц показала, что достаточный и допустимый уровень размагничивания поверхностного слоя сердечника ВЭ можно достичь при электромагнитной волне частотой $f_{2}=500$ Гц.

Прежде чем устранять гистерезисные явления при протекании рабочих МРЖ в дроссельных каналах индукционного МРТ, связанных с намагничиванием ферромагнитных материалов магнитопроводов ВЭ и 
перегородки гидроопоры и самих рабочих МРЖ, необходимо правильно рассчитать магнитную цепь МРТ.

Выражение (5.77) определяет величину управляющих напряжений

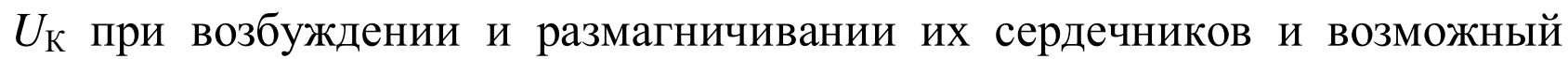
диапазон настройки МРТ по частоте $f_{\mathrm{B}}$. Также выражение (5.77) определяет крутизну подъема зависимостей $U_{\mathrm{K}}\left(f_{\mathrm{B}}\right)=1$ [В/Гц] $f_{\mathrm{B}}$ (рис. 5.17) на частотах возбуждения сердечников ВЭ и их размагничивания $U_{\mathrm{K}}\left(f_{\mathrm{p}}\right)=0,1[\mathrm{~B} / \Gamma ц] f_{\mathrm{p}}$.

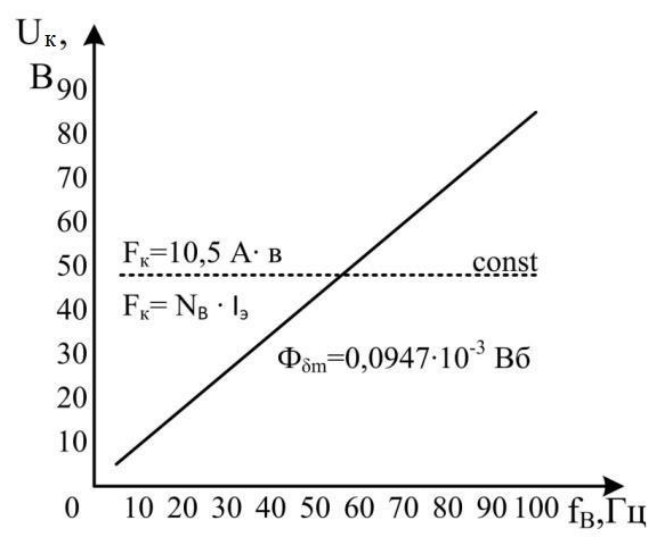

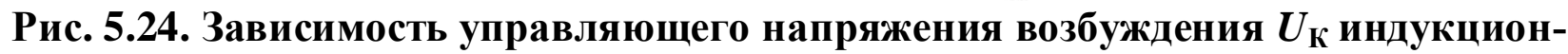
ного МРТ от значений частоты перестройки $f_{\mathrm{B}}$

Для возбуждения сердечников ВЭ примем отношение (5.75) управляющих параметров $U_{\mathrm{K}} / f_{\mathrm{B}}$ равным единице, т.е.:

$U_{\mathrm{K}} / f_{\mathrm{B}}=1\left[\mathrm{~B} / \Gamma_{ц}\right]$ и $U_{\mathrm{K}}=1\left[\mathrm{~B} / \Gamma_{ц}\right] f_{\mathrm{B}}$.

Для размагничивания сердечников ВЭ примем отношение (5.75) управляющих параметров $U_{\mathrm{K}} / f_{\mathrm{B}}$ в десять раз меньше, т.е.:

$U_{\mathrm{K}} / f_{\mathrm{p}}=1\left[\mathrm{~B} / \Gamma_{ц}\right]$ и $U_{\mathrm{K}}=0,1[\mathrm{~B} /$ ц $] f_{\mathrm{p}}$.

Как видим, крутизной подъема зависимостей $U_{\mathrm{K}}\left(f_{\mathrm{B}}\right)$ и $U_{\mathrm{K}}\left(f_{\mathrm{p}}\right)$ на частотах возбуждения сердечников ВЭ и их размагничивания необходимо управлять.

При электромагнитном расчёте ВЭ гидроопоры примем следующее.

1. Рабочий объём гидроопоры заполнен магнитной жидкостью, также ей заполнены и дроссельные каналы МРТ.

2. Для упрощения расчёта ВЭ будем считать, что на гидроопору с МРТ не воздействуют внешние силы и на МЖ, заполняющей индукционные дроссельные каналы не действует перепад давления от действия внешних сил.

3. Примем для расчета полюсной зазор заполненных МЖ индукционных дроссельных каналов равным $\delta^{\prime}=2,5$ мм. Тогда суммарный зазор в магнитной цепи ВЭ индукционного МРТ для двух индукционных дроссельных каналов (рис. 5.22) составит величину равную: $\delta=\delta^{\prime}+\delta^{\prime}=5$ мм. 
При этом положим магнитное сопротивление магнитной цепи ВЭ постоянным.

4. При электромагнитном расчёте ВЭ в качестве примера воспользуемся данными из работы [73] для магнитной жидкости $\left(\mathrm{Fe}_{3} \mathrm{O}_{4}\right)$, представляющей собой коллоидный раствор, величина намагниченности насыщения и магнитная восприимчивость которого пропорциональны концентрации частиц.

5. Для такой магнитной жидкости, содержащей частицы магнетита $\left(\mathrm{Fe}_{3} \mathrm{O}_{4}\right)$ в неоднородном магнитном поле типичного лабораторного постоянного магнита реализованы следующие условия: $H=80-103 \mathrm{~A} / \mathrm{M}$, $M=446 \cdot 10^{3} \mathrm{~A} / \mathrm{M}, T=298 \mathrm{~K}$.

6. Размер частицы МЖ $d$ менее или равен $8,1 \cdot 10^{-9}$ м или 8,1 нм. Действительные размеры частиц устойчивых коллоидов варьируют в пределах примерно до 10 нм.

7. Положим магнитную проницаемость МЖ $\mu=10$, (для $\mu$ это значение достаточно определенно). Также положим электропроводность среды в магнитном поле постоянной, и при изменении напряженности $H$ от 200 до 600 кА/м она не зависит от напряженности магнитного поля.

8. Такая магнитная жидкость на основе $\left(\mathrm{Fe}_{3} \mathrm{O}_{4}\right)$ применима в сильных (2 Тл) полях электромагнитов с железным ярмом. Для реализации стационарного процесса с еще более сильным (20 Тл) полем требуется источник поля с использованием сверхпроводимости. Магнитная жидкость на основе $\left(\mathrm{Fe}_{3} \mathrm{O}_{4}\right)$ в течение долгого времени, порядка нескольких лет, сохраняет свои магнитные свойства, динамические и тепловые характеристики [73].

Из анализа работ по МЖ [24] также выявлено, что намагниченность насыщения МЖ $M(H)$ достигает 500 кА/м в магнитных полях напряженностью 80 кА/м при сохранении их текучести.

Поэтому, в основу расчёта параметров ВЭ МРТ необходимо брать максимальную напряжённость магнитного поля в дроссельных каналах. Она определяется запасом на напряжённость магнитного поля $H$ в зазорах ВЭ МРТ.

В [70] указывается на аналогичное влияние магнитного поля на проводимость и связь проводимости МЖ с поляризационными процессами. Известны значения порогов «открывания/запирания» - (до $H_{\delta}=101,152$ кА/м до $\left.H_{\delta}=141,614 \kappa \mathrm{A} / \mathrm{м}\right)$ в дроссельном канале [39, 42].

Расчёт ВЭ МРТ начинают с определения требуемой напряжённости магнитного поля $H_{m}$, обеспечивающей максимальную намагниченность $M(H)$ МЖ в дроссельном канале, с учётом запаса на напряжённость магнитного поля $H_{\delta}$ в зазорах ВЭ МРТ. Запас на напряжённость магнитного 
поля $H_{\delta}$ в зазорах ВЭ МРТ необходим для целей дополнительной перестройки МРТ гидроопоры по частоте возбуждения (расширения диапазона перестройки), что будет видно в ходе расчёта ВЭ МРТ. Для расчёта ВЭ выбирают максимальную напряжённость магнитного поля в зазоре магнитопровода $H_{\delta}=141,614$ кА/м $[14,15,66]$.

Действующее значение напряженности магнитного поля в зазорах ВЭ $H_{\delta}=141,614$ кА/м определяется как $H_{\delta}=(1,65-1,8) H_{m}$, где $(1,65-1,8)$ запас на напряжённость магнитного поля $H_{\delta}$ в зазорах ВЭ МРТ.

Тогда максимальная напряженность $H_{m}$ магнитного поля в магнитопроводе ВЭ МРТ определяется соотношением:

$$
H_{m}=\frac{H_{\delta}}{1.7}=83.302 \cdot 10^{-3} \mathrm{~A} / \mathrm{M} .
$$

Расчет магнитной цепи ВЭ (см. рис. 5.22, б) состоит в определении МДС - намагничивающей силы $I_{\ni} \cdot N_{B}=H_{m} \cdot l$, необходимой для получения заданного магнитного потока в цепи, размеры участков которой и материалы известны. Расчет производится в следующем порядке:

1) проводят среднюю магнитную линию (см. рис. 5.22, б);

2) разбивают магнитную цепь на однородные участки с неизменными сечениями и определяют сечения $S$ и длины их по средней магнитной линии $l$;

3) по величине заданной магнитной индукции $B_{\delta m}$ и известному сечению $S_{\delta}$ в воздушном зазоре находят магнитный поток $\Phi_{\delta m}$ по формуле

$$
\Phi_{\delta m}=S_{\delta} B_{\delta m}
$$

4) по кривым намагничивания сердечников ВЭ для каждого ферромагнитного участка определяют максимальную магнитную индукцию $B_{m}$. Напряженность поля в воздушном зазоре $H_{m}$ определяют из выражения:

$$
H_{m}=\frac{B_{m}}{\mu_{0}}=0.8 \cdot 10^{6} B_{m}
$$

Но, так как формула (5.72) для расчёта совместной индуктивности катушек двух соседних ВЭ получена при условии независимости магнитной проницаемости от индукции, когда ВЭ работает в области индукций, где проницаемость падает с ростом напряжённости магнитного поля, то расчет магнитной цепи ВЭ следует производить с учётом динамической кривой намагничивания $B(H)$ - зависимости амплитуды магнитной индукции $B_{m}$ от амплитуды напряженности магнитного поля $H_{m}$ при определённой частоте в предположении, что эти величины синусоидальны. 
При расчёте ВЭ МРТ нельзя воспользоваться формулой (5.78), так как магнитное сопротивление участка из ферромагнитного сердечника зависит от величины $\mu$, которая в свою очередь определяется неизвестной еще магнитной индукцией. Задачу можно решить методом последовательных приближений.

Основанием для такого подхода является то, что даже воздушный зазор малого порядка имеет магнитное сопротивление, значительно большее, чем вся остальная магнитная цепь ВЭ. При выбранной максимальной напряженности магнитного поля в магнитопроводе $H_{m}=80 \cdot 10^{3} \mathrm{~A} / \mathrm{M}$ максимальная магнитная индукция в зазорах магнитопровода ВЭ МРТ равна

$$
B_{\delta m}=\mu_{e} \mu_{0} H_{m}=\frac{l_{e}}{\delta} \mu_{0} H_{m}=1.885 T .
$$

Тогда магнитный поток в зазорах ВЭ $\Phi_{\delta m}$, определяется по (5.78):

- для симметричного МРТ - $\Phi_{\delta m \mathrm{C}}=S_{\delta} B_{\delta m}=0.0947 \cdot 10^{-3}$ Вб;

- кольцевого МРТ - $\Phi_{\delta m \kappa}=2 S_{\delta} B_{\delta m}=0.1894 \cdot 10^{-3}$ Вб.

Выберем постоянное отношение управляющих параметров перестройки МРТ гидроопоры по частоте $U_{\mathrm{K}} / f_{\mathrm{B}}$, равное

$$
U_{\mathrm{K}} / f_{\mathrm{B}} \approx 2 \pi N_{\mathrm{B}} \Phi_{\Pi} \approx 0.8506 .
$$

Из последнего выражения находим необходимое количество витков на катушках ВЭ для симметричного и для кольцевого МРТ гидроопоры, которое обеспечивает его перестройку по частоте возбуждения:

- для симметричного МРТ: $N_{\mathrm{C}} \approx 0.8506 / 2 \pi \Phi_{\text {ПС }} \approx 1430$ витков;

- кольцевого МРТ: $N_{\text {К }} \approx 0.8506 / 2 \pi \Phi_{\text {пК }} \approx 715$ витков.

Совместная индуктивность катушек двух соседних ВЭ для симметричного и для кольцевого МРТ вычисляется по формуле (5.72), её значение будет равно $[14,15,66]$ :

$$
\begin{gathered}
L_{\ni \mathrm{C}}=\frac{N_{\mathrm{BC}}^{2} S_{\varnothing \mathrm{C}}}{\frac{l_{e}}{\mu_{e}}+2 \delta^{\prime}} \cdot 4 \pi \cdot 10^{-7}=12.910 \cdot 10^{-3} \Gamma_{\mathrm{H}}, \\
L_{\ni К}=\frac{N_{\mathrm{BC}}^{2} S_{\varnothing \mathrm{C}}}{\frac{l_{e}}{\mu_{e}}+2 \delta^{\prime}} \cdot 4 \pi \cdot 10^{-7}=6.455 \cdot 10^{-3} \Gamma \mathrm{H} .
\end{gathered}
$$

Ток катушек ВЭ вычисляется из выражения

$$
I_{\ni \mathrm{C}}=\frac{B_{\delta m} S_{\delta \mathrm{C}}}{L_{\ni \mathrm{C}}}=\frac{\Phi_{\delta m \mathrm{C}}}{L_{\ni \mathrm{C}}}=7.34 \cdot 10^{-3} \mathrm{~A}
$$




$$
I_{Э К}=\frac{B_{\delta m} S_{\delta К}}{L_{Э К}}=\frac{\Phi_{\delta m К}}{L_{Э К}}=29.34 \cdot 10^{-3} \mathrm{~A} .
$$

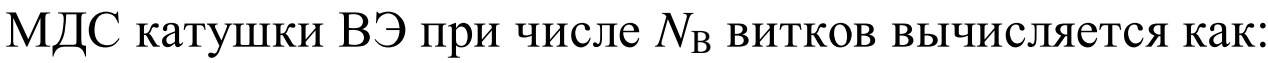

$$
\begin{gathered}
F_{\text {КС }}=N_{\mathrm{BC}} I_{Э \mathrm{C}} \approx 10.5 \mathrm{~A} \cdot \mathrm{B}, \\
F_{\text {КК }}=N_{\text {ВК }} I_{Э К} \approx 21 \mathrm{~A} \cdot \mathrm{B} .
\end{gathered}
$$

Величина управляющих напряжений $U_{\text {K }}$ определяется выражением

$$
U_{\mathrm{K}} \approx 2 \pi N_{\mathrm{B}} \Phi_{\Pi} f_{\mathrm{B}} \approx 0,8506 \cdot f_{\mathrm{B}} .
$$

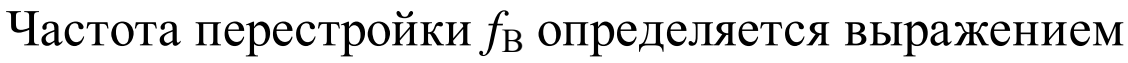

$$
f_{\mathrm{B}} \approx U_{\mathrm{K}} / 0,8506 .
$$

Для того чтобы создавать постоянный магнитный поток удержания МЖ в полюсе ВЭ и перестраивать МРТ гидроопоры по частоте $f_{\mathrm{B}}$ при последовательном возбуждении и его последующем размагничивании на частоте размагничивания $f_{\mathrm{P}}$, необходимо правильно выбрать постоянное отношение управляющих параметров $U_{K} / f_{\mathrm{B}}$ перестройки, которое определяется крутизной подъема зависимости $U_{\mathrm{K}}\left(f_{\mathrm{B}}\right)$.

Крутизна подъема зависимости $U_{\mathrm{K}}\left(f_{\mathrm{B}}\right)$ определяет величину управляющих напряжений $U_{K}$ ВЭ и возможный диапазон перестройки индукционного МРТ заполненной МЖ гидроопоры по частоте $f_{\mathrm{B}}$.

Так, показанная на рис. 5.24 зависимость $U_{K}\left(f_{\mathrm{B}}\right)$ определяет частоты вибросигнала $f_{\mathrm{B}}=10$ Гц и размагничивания $f_{\mathrm{P}}=100$ Гц и позволяет добиться правильной работы гидроопоры на частоте вибросигнала $f_{\mathrm{B}}=10$ Гц с последующим размагничиванием ферромагнитных сердечников ВЭ на частоте размагничивания $f_{\mathrm{P}}=100$ Гц.

На рис. 5.24 также показан закон изменения МДС ВЭ индукционного МРТ гидроопоры, по которому следует, что МДС $F_{\mathrm{K}}=N_{\mathrm{B}} I_{\ni}=$ const.

Но, так как индукционный МРТ гидроопоры необходимо перестраивать по частоте, например: от $f_{\mathrm{B} 1}=10$ Гц до $f_{\mathrm{B} 2}=50$ Гц с последующим размагничиванием на частотах размагничивания $f_{\mathrm{P} 1}=100$ Гц и $f_{\mathrm{P} 2}=500$ Гц, то необходимо крутизну подъема зависимости $U_{\kappa}\left(f_{\mathrm{B}}\right)$, определяющую диапазон перестройки индукционного МРТ по частоте $f_{\mathrm{B}}$ уменьшать. Здесь необходимо сказать о возникающих проблемах, требующих своего разрешения:

1. Уменьшение крутизны подъема зависимости $U_{\mathrm{K}}\left(f_{\mathrm{B}}\right)$ управляющих параметров, определяющий возможный диапазон перестройки индукционного МРТ гидроопоры по частоте $f_{\mathrm{B}}$ влечет за собой уменьшение магнитного потока возбуждения $\Phi_{\delta}$ и МДС ВЭ. 
2. Уменьшение магнитного потока возбуждения $\Phi_{\delta}$ и МДС не обеспечивает запирание индукционных дроссельных каналов и удержание в них рабочих МЖ, так как для этого необходимы большие величины возбуждающих напряжений и соответственно токов ВЭ.

3. Поэтому, для удержания магнитного потока возбуждения, при котором исходит запирание дроссельных каналов и удержание в них рабочей МЖ, необходимо, применять и использовать ферритовые сердечники, выполненные из материала с высокой относительной магнитной проницаемостью, например: $\mu_{r}=1000$.

4. Кроме того, необходимо применять и использовать МЖ с наибольшей чувствительностью к малым магнитным потокам возбуждения $\Phi_{\mathrm{B}}$.

5. Для обеспечения требуемого магнитного потока возбуждения $\Phi_{\mathrm{B}}$ необходимо увеличивать индуктивность катушек ВЭ, т.е. увеличивать число витков их обмоток, или увеличивать ток возбуждения, что влечет за собой увеличение габаритов самих ВЭ.

Уменьшим крутизну подъема зависимости $U_{\mathrm{K}}\left(f_{\mathrm{B}}\right)$, определяющую возможный диапазон перестройки МРТ гидроопоры по частоте от $f_{\mathrm{B} 1}=10$ Гц до $f_{\mathrm{B} 2}=50$ Гц с последующим размагничиванием на частотах размагничивания $f_{\mathrm{P} 1}=100$ Гц и $f_{\mathrm{P} 2}=500$ Гц до значения $U_{\mathrm{K}}\left(f_{\mathrm{B}}\right)=0.1$, т.е.

$$
U_{\mathrm{K}} / f_{\mathrm{B}}=0.1 \mathrm{~B} / \Gamma_{ц} .
$$

Тогда напряжения на катушке ВЭ $U_{K}$ при частотах возбуждения от $f_{\mathrm{B} 1}=10$ Гц до $f_{\mathrm{B} 2}=50$ Гц определяется значениями

$$
U_{\mathrm{K} 1}=0.1 f_{\mathrm{B} 1}=1 \mathrm{~B}, U_{\mathrm{K} 2}=0.1 f_{\mathrm{B} 2}=5 \mathrm{~B} \text {. }
$$

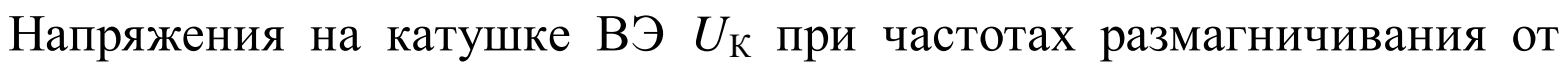
$f_{\mathrm{P} 1}=100$ Гц до $f_{\mathrm{P} 2}=500$ Гц определяется значениями

$$
U_{\mathrm{K} 1}=0.1 f_{\mathrm{P} 1}=10 \mathrm{~B}, U_{\mathrm{K} 2}=0.1 f_{\mathrm{P} 2}=50 \mathrm{~B} .
$$

Здесь применяется индукционный МРТ, выполненный на сердечниках из электротехнической стали, поэтому используем МЖ гидроопор с наибольшей чувствительностью к малым магнитным потокам возбуждения $\Phi_{\delta}$.

Из приведенного примера видно, что при отношении управляющих

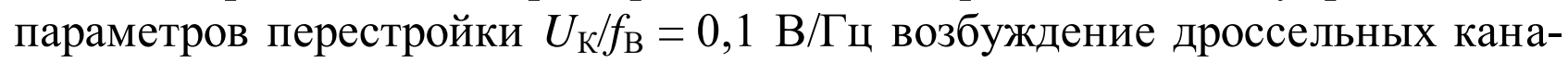

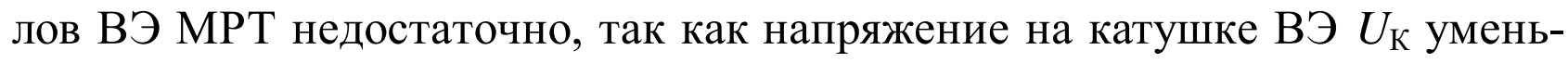
шилось в 10 раз и составляет всего лишь 1,0 В, что недостаточно для обеспечения магнитного потока возбуждения $\Phi_{\delta}$ и МДС ВЭ и следовательно напряжённости магнитного поля в зазорах магнитопровода $H_{\delta}=141,614 \kappa \mathrm{A} / \mathrm{M}$. 
Уйти от такой проблемы, возникающей при совместном возбуждении/размагничивании ВЭ МРТ, позволяет применение в источнике питания ВЭ преобразователя с управляемым коэффициентом усиления, посредством которого осуществляется поочерёдное разделение временных интервалов действия сигналов возбуждения и размагничивания.

Расширения диапазона перестройки МРТ гидроопоры в определённых пределах можно достичь за счёт запаса на напряжённость магнитного поля ВЭ.

Действительно, оптимальное действующее значение напряженности магнитного поля в зазорах ВЭ составляет величину $H_{\delta}=(1,65-1,8) H_{m}$, поэтому запас на напряжённость магнитного поля ВЭ определяется отношениями напряжённостей и возбуждающих напряжений ВЭ МРТ:

$$
\begin{gathered}
K_{H}=\frac{H_{\delta}}{H_{m}}=(1,65 \div 1,8), \\
K_{H}=\frac{H_{\delta}}{H_{m}}=\frac{U_{\mathrm{K} 2}}{U_{\mathrm{K} 1}}=\frac{2 \pi N_{\mathrm{B}} \Phi_{\Pi 2} f_{\mathrm{B} 2}}{2 \pi N_{\mathrm{B}} \Phi_{\Pi 1} f_{\mathrm{B} 1}}=\frac{\Phi_{\Pi 2} f_{\mathrm{B} 2}}{\Phi_{\Pi 1} f_{\mathrm{B} 1}}=(1,65 \div 1,8) .
\end{gathered}
$$

Поэтому если возникает необходимость в расширении диапазона перестройки МРТ гидроопоры в определённых пределах, то задаваемые параметры магнитного поля ВЭ $\left(\Phi_{\Pi 2}\right.$ и $\left.H_{2}\right)$ на требуемой частоте возбуждения ВЭ можно определить из выражений

$$
\begin{gathered}
\Phi_{\Pi 2} f_{\mathrm{B} 2}=K_{H} \Phi_{\Pi 1} f_{\mathrm{B} 1}=(1,65 \div 1,8) \Phi_{\Pi 1} f_{\mathrm{B} 1}, \\
\Phi_{\Pi 2}=K_{H} \Phi_{\Pi 1} \frac{f_{\mathrm{B} 1}}{f_{\mathrm{B} 2}}=\frac{K_{H}}{K_{f}} \Phi_{\Pi 1}=\frac{(1,65 \div 1,8)}{K_{f}} \Phi_{\Pi 1},
\end{gathered}
$$

где $K_{f}=f_{\mathrm{B} 1} / f_{\mathrm{B} 2}$ запас по перестройки МРТ по частоте возбуждения; $f_{\mathrm{B} 1}$ и $f_{\mathrm{B} 2}$ - частоты возбуждения МРТ до и после расширения его диапазона перестройки.

Учитывая, что магнитный поток также можно определить по (5.71) как $\Phi_{\delta m}=L_{3} I_{\ni}$, получаем из последнего выражения для магнитных потоков выражения для токов возбуждения:

$$
L_{\ni} I_{\ni 2}=K_{H} L_{\ni} I_{\ni 1} \frac{f_{\mathrm{B} 1}}{f_{\mathrm{B} 2}}=\frac{K_{H}}{K_{f}} L_{\ni} I_{\ni 1}=\frac{(1,65 \div 1,8)}{K_{f}} L_{\ni} I_{\ni 1} .
$$

Сокращение по индуктивности $L_{э}$ позволяет получить выражение, связывающее частоту возбуждения $f_{\mathrm{B} 1}$ и ток $I_{\ni 1}$ с частотой возбуждения $f_{\mathrm{B} 2}$ 
и током $I_{э 2}$ ВЭ до и после расширения диапазона перестройки МРТ гидроопоры:

$$
I_{\ni 2}=K_{H} I_{\ni 1} \frac{f_{\mathrm{B} 1}}{f_{\mathrm{B} 2}}=\frac{K_{H}}{K_{f}} I_{\ni 1}=\frac{(1,65 \div 1,8)}{K_{f}} I_{\ni 1} .
$$

Это выражение позволяет осуществить перестройку МРТ гидроопоры по току возбуждения ВЭ.

Для симметричного МРТ при токе в $I_{э c}=7,34 \cdot 10^{-3}$ А диаметр медной жилы провода $\varnothing ~ 0,07$ мм, что соответствует марке провода - ПЭЛ 0,085. Для кольцевого МРТ при токе в $I_{э c}=29,34 \cdot 10^{-3}$ А допустимый диаметр медной жилы провода $\varnothing ~ 0,14$ мм, что соответствует марке провода - ПЭЛ 0,16. Выбираем провод с запасом по току марки - ПЭЛ 0,105 и ПЭЛ 0,16.

График изменения напряжения возбуждения $U_{\mathrm{K}}$ индукционного МРТ заполненной МЖ гидроопоры от значений частоты перестройки $f_{\mathrm{B}}$ при постоянном магнитном потоке $\Phi_{\delta m}$ ВЭ представлен на (рис. 5.24).

Результаты вычислений управляющих, электромагнитных параметров ВЭ с заполненными МЖ дроссельными каналами сведены в табл. 5.14 и табл. 5.15.

Таблица 5.14

Управляющие параметры ВЭ

\begin{tabular}{|c|c|c|c|c|c|}
\hline$U_{\mathrm{K}}, \mathrm{B}$ & 4,253 & 8,506 & 12,759 & 17,012 & 21,265 \\
\hline$f_{\mathrm{B}}, \Gamma \mathrm{C}$ & 5,0 & 10,0 & 15,0 & 20,0 & 25,0 \\
\hline$U_{\mathrm{K}}, \mathrm{B}$ & 25,518 & 29,772 & 34,025 & 38,278 & 42,531 \\
\hline$f_{\mathrm{B}}, \Gamma \amalg$ & 30,0 & 35,0 & 40,0 & 45,0 & 50,0 \\
\hline$U_{\mathrm{K}}, \mathrm{B}$ & 46,784 & 51,0375 & 55,290 & 59,544 & 63,797 \\
\hline$f_{\mathrm{B}}, \Gamma \amalg$ & 55,0 & 60,0 & 65,0 & 70,0 & 75,0 \\
\hline$U_{\mathrm{K}}, \mathrm{B}$ & 68,050 & 72,303 & 76,556 & 80,809 & 85,0626 \\
\hline$f_{\mathrm{B}}, \Gamma \amalg$ & 80,0 & 85,0 & 90,0 & 95,0 & 100,0 \\
\hline
\end{tabular}

Таблица 5.15

Электромагнитные параметры ВЭ МРТ гидроопоры

\begin{tabular}{|c|c|c|c|c|c|c|}
\hline \multicolumn{7}{|c|}{ Симметричный МРТ } \\
\hline $\begin{array}{c}\text { Параметры } \\
\text { ВЭ }\end{array}$ & $\begin{array}{c}H_{\delta}, \\
\text { кА/м }\end{array}$ & $H_{\mathrm{m}}, \mathrm{\kappa A} / \mathrm{m}$ & $B_{\delta \mathrm{m}}, \mathrm{T}$ & $\Phi_{\delta \mathrm{mC}, ~ м В б}$ & $I_{э c}, \mathrm{~A}$ & $F_{\mathrm{kC}}, \mathrm{A} \cdot \mathrm{B}$ \\
\hline $\begin{array}{l}\text { Значение } \\
\text { параметра }\end{array}$ & 141,614 & 83,302 & 1,885 & $0,0947 \cdot 10^{-3}$ & $7,34 \cdot 10^{-3}$ & 10,5 \\
\hline $\begin{array}{c}\text { Параметры } \\
\text { ВЭ }\end{array}$ & $N_{\mathrm{BC}}$ & $L_{э c}, \mathrm{M \Gamma \textrm {H }}$ & $S_{\delta \mathrm{C}}, \mathrm{M}^{2}$ & $\begin{array}{c}\text { Диаметр } \\
\text { сердечника, } \\
\text { мм }\end{array}$ & $\begin{array}{c}\text { Диаметр } \\
\text { провода, мм }\end{array}$ & $\begin{array}{c}\text { Марка } \\
\text { провода }\end{array}$ \\
\hline $\begin{array}{l}\text { Значение } \\
\text { параметра }\end{array}$ & 1430 & 12,91 & $50,2 \cdot 10^{-6}$ & 8,0 & 0,09 & $\begin{array}{c}\text { ПЭВ- } \\
0,105\end{array}$ \\
\hline
\end{tabular}


Окончание табл. 5.15

\begin{tabular}{|c|c|c|c|c|c|c|}
\hline \multicolumn{2}{|c|}{ Кольцевой МРТ } \\
\hline $\begin{array}{c}\text { Параметры } \\
\text { ВЭ }\end{array}$ & $H_{\delta}, \mathrm{\kappa A} / \mathrm{M}$ & $H_{\mathrm{m}}, \mathrm{\kappa A} / \mathrm{M}$ & $B_{\delta \mathrm{m}}, \mathrm{T}$ & $\Phi_{\delta \mathrm{mK}}, \mathrm{мB}$ & $I_{\ni \mathrm{K}}, \mathrm{A}$ & $F_{\mathrm{kK}}, \mathrm{A} \cdot \mathrm{B}$ \\
\hline $\begin{array}{l}\text { Значение } \\
\text { параметра }\end{array}$ & 141,614 & 83,302 & 1,885 & $0,1894 \cdot 10^{-3}$ & $29,34 \cdot 10^{-3}$ & 21,0 \\
\hline $\begin{array}{c}\text { Параметры } \\
\text { ВЭ }\end{array}$ & $N_{\mathrm{BK}}$ & $L_{\ni \mathrm{K}}, \mathrm{M \Gamma \textrm {H }}$ & $S_{\delta \mathrm{K}}, \mathrm{M}^{2}$ & $\begin{array}{c}\text { Диаметр } \\
\text { сердечника, } \\
\text { мм }\end{array}$ & $\begin{array}{c}\text { Диаметр } \\
\text { провода, мм }\end{array}$ & $\begin{array}{c}\text { Марка } \\
\text { провода }\end{array}$ \\
\hline $\begin{array}{l}\text { Значение } \\
\text { параметра }\end{array}$ & 715 & 6,445 & $100,4 \cdot 10^{-6}$ & 11,0 & 0,014 & $\begin{array}{c}\text { ПЭВ- } \\
0,16\end{array}$ \\
\hline
\end{tabular}

\section{5. Управление гидроопорой с МРТ}

Для создания рабочего режима намагничивания ферромагнитных сердечников ВЭ в МРТ перестраиваемой по частоте гидроопоры необходимо выбрать рабочий режим ВЭ и устройство создающее режим намагничивания.

Поэтому, рассмотрим физические процессы в ВЭ при воздействии на них синусоидального и несинусоидального (прямоугольной формы) переменных напряжений возбуждения.

Известно, что при синусоидальном напряжении обмотки возбуждения ВЭ основной магнитный поток будет также синусоидален. Если же напряжение возбуждения ВЭ несинусоидально, то основной магнитный поток будет также несинусоидальным.

Далее допустим, что в схеме источника намагничивающего тока к обмотке ВЭ (рис. $5.25, a$ ) непосредственно приложено напряжение, кривая изменения во времени которого имеет прямоугольную форму (рис. 5.25, б).
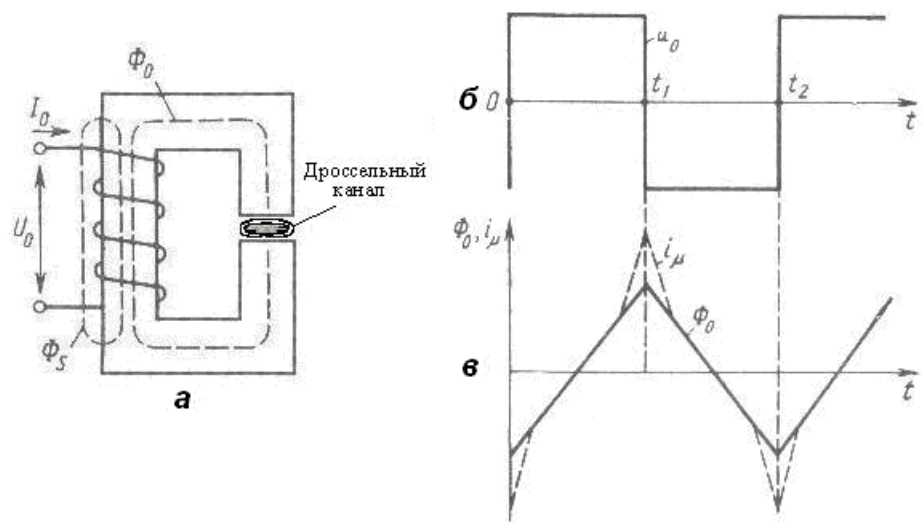

Рис. 5.25. Сердечник ВЭ (a); изменение во времени напряжения возбуждения прямоугольной формы (б); магнитного потока в магнитопроводе (в)

В этом случае, пренебрегая падением напряжения в полном сопротивлении обмотки возбуждения ВЭ (рис. $5.25, a$ ), можно считать, что в любой 
момент напряжение возбуждения $u_{0}$ уравновешивается ЭДС $e_{0}$, индуктируемой основным магнитным потоком $\Phi_{0}$ в сердечнике ВЭ, т. е. $u_{0}=e_{0}$.

Изменение магнитного потока $\Phi_{0}$ во времени показано на рис. $5.25,8$ сплошной линией. Если материал магнитопровода ненасыщен, то магнитный поток пропорционален намагничивающему току $i_{\mu}$, так что кривая $i_{\mu}$ совпадает с зависимостью $\Phi_{0}$. При насыщении материала магнитопровода изменения магнитного потока вызываются большими изменениями намагничивающего тока, и кривая $i_{\mu}$ будет иметь вид, показанный на рис. 5.25, 6 штриховой линией.

Как видим, на рис. 5.25, б, кривая ЭДС $e_{0}$ имеет прямоугольную форму, являясь зеркальным отображением $u_{0}$ относительно оси времени, и производная $d \Phi_{0} / d t$ в течение половины периода от 0 до $t_{1}$ постоянна, т. е. в этом интервале магнитный поток линейно возрастает во времени с равномерной скоростью.

В момент $t_{1}$ напряжение $u_{0}$ изменит знак. На интервале $t_{1}-t_{2}$ производная $d \Phi_{0} / d t$ также постоянна, но изменит знак, и магнитный поток начнет убывать во времени с равномерной скоростью.

Представленное на рис. 5.25, , изменение магнитного потока $\Phi_{0}$ во времени, не обеспечивает необходимый режим намагничивания сердечников ВЭ и соответствует интегрирующему действию ВЭ в индукционном МРТ:

$$
\begin{gathered}
\Phi_{0}(t)=\frac{1}{N_{\mathrm{B}}} \int_{t_{0}}^{t_{1}} u_{0} d t=-\frac{1}{N_{\mathrm{B}}} \int_{t_{0}}^{t_{1}} e_{0} d t \\
i_{0}(t)=\frac{1}{L} \int_{t_{0}}^{t_{1}} u_{0} d t=-\frac{1}{L} \int_{t_{0}}^{t_{1}} e_{0} d t
\end{gathered}
$$

Такое изменение магнитного потока возбуждения $\Phi_{0}$ не позволяет достичь правильного открывания и запирания индукционных дроссельных каналов в МРТ при непосредственном приложении к ВЭ напряжения прямоугольной формы.

Особенностью изменения управляющего напряжения возбуждения $U_{\mathrm{K}}$ при постоянных магнитных потоках $\Phi_{\delta \mathrm{m}}$ в МРТ, заполненных МЖ МРТ гидроопор является его возрастание по линейному закону от значений частоты перестройки $f_{\mathrm{B}}$ (рис. 5.26).

Как видим на рис. 5.26, напряжение возбуждения $U_{\mathrm{K}} \mathrm{MPT}$ линейно возрастает в диапазоне 26 дБ с увеличением значений частоты перестройки $f_{\mathrm{B}}$ : от $U_{\mathrm{K} 1} \approx 4 \mathrm{~B}$ и до $U_{\mathrm{K} 1} \approx 85 \mathrm{~B}$, в полосе частот возбуждения до 100 Гц.

Результирующие АЧХ блока возбуждения МРТ для возбуждения и размагничивания ВЭ и МЖ показаны на рис.5.26, $б$. 

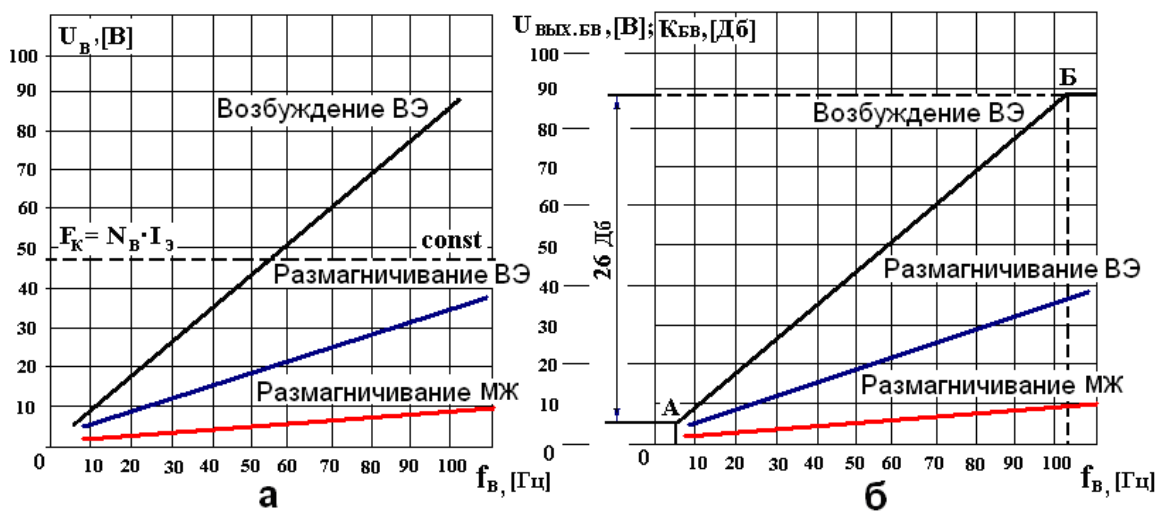

Рис. 5.26. Изменения напряжений возбуждения/размагничивания сердечников ВЭ и МЖ, от значений частоты перестройки $f_{\mathrm{B}}(a)$; результирующие АЧХ блока возбуждения/размагничивания ВЭ и МЖ МРТ (б)

На рис. 5.26, б на оси диапазона напряжений возбуждения МРТ, показаны величины выходного напряжения высоковольтного усилителя мощности, и они должны быть меньше максимального выходного напряжения усилителя мощности, которое должно быть в три раза выше напряжений возбуждения МРТ (до 300 В). Это и есть запас на размагничивание ВЭ и МЖ.

Одним из важных и функциональных узлов перестраиваемой по частоте гидроопоры является устройство для создания рабочего режима намагничивания индукционного магнитореологического трансформатора (МРТ). Правильная работа индукционных дроссельных каналов МРТ при перестройке по частоте возможна только при заданном режиме изменения во времени напряженности или индукции магнитного поля, что эквивалентно поддержанию соответствующей формы кривой намагничивающего тока.

Полупроводниковые преобразователи, создающие необходимый режим намагничивания возбуждающих электромагнитов (ВЭ) обязательно должны входить в устройство возбуждения МРТ гидроопоры.

Для решения задачи снижения вибрации электромеханического комплекса на резонансной частоте необходимо использовать систему автоматического управления МРТ гидроопоры, принцип действия которой поясняется на рис. 5.27.

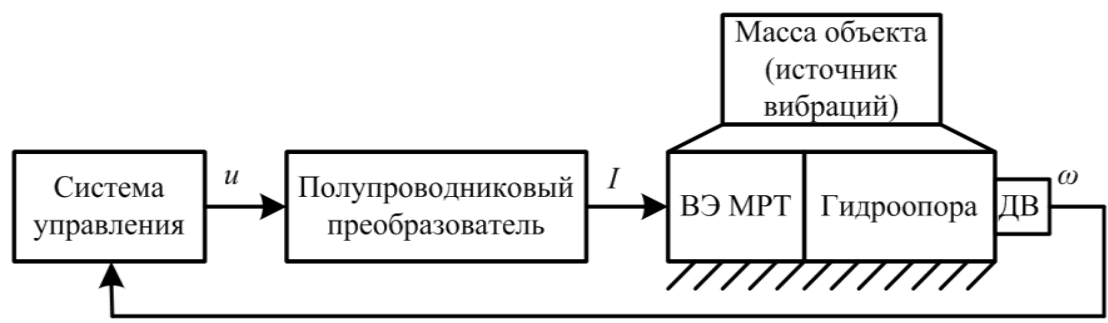

Рис. 5.27. Функциональная схема системы автоматического управления гидроопорой 
На вход системы управления поступает информация о текущих колебаниях $\omega$ с датчика вибрации (ДВ), установленного на гидроопоре. Датчик вибраций может транслировать один из сигналов, которые пропорциональны перемещению, скорости или ускорению. Этот информационный сигнал представляет собой сумму гармонических колебаний на частотах от 5 до 100 Гц. Система управления выполняет преобразование Фурье, определяет наибольшую амплитуду в заданном диапазоне частот и формирует сигнал $u$, управляющий ключами полупроводникового преобразователя. Под действием магнитного поля дроссельные каналы «открываются» и «закрываются», т.е. преобразователь обеспечивает возбуждающий электромагнит (ВЭ МРТ) током намагничивания $I$, который влияет на вязкость магнитной жидкости, протекающей через дроссельные каналы. В процессе управления МРТ гидроопоры на обмотку возбуждающего элек-

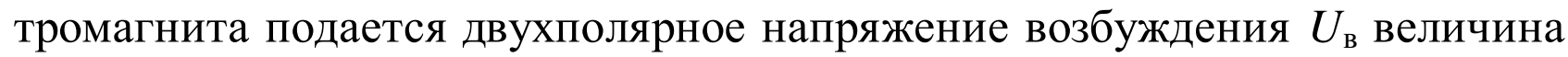

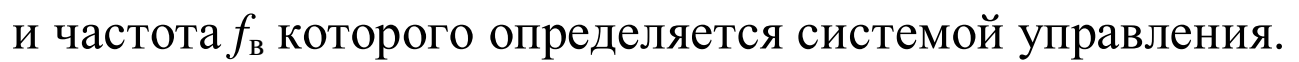

Для устранения гистерезисных явлений, связанных с остаточной намагниченностью, ферромагнитные сердечники ВЭ и перегородка должны размагничиваться при перестройке гидроопоры по частоте, а также в целях компенсации задержки в периодическом процессе изменения вязкости демпфера.

Остаточная магнитная индукция $B_{r}$ ферромагнитных сердечников недопустима, так как она влечёт задержку между зависимостями напряженности $H$ и индукции $B$ магнитного поля во времени, искажает форму кривой $B$ и влияет на переходные процессы в магнитной среде при смене полярности внешнего магнитного поля. Задержка $B(t)$ не должна превышать длительности периода высшей гармоники входного вибросигнала.

Представленные в [43] числовые расчёты и зависимости частотных сдвигов АЧХ, ФЧХ и частотной расстройки между функциями магнитного поля $H$ и $B$, обусловленные гистерезисом ферромагнитных сердечников МРТ, показывают, что гистерезис в сердечниках МРТ оказывает отрицательное действие на работу МРТ гидроопоры - возбуждение дроссельных каналов в МРТ происходит не синхронно с частотой вибросигнала. Это влечёт к частотным сдвигам АЧХ, ФЧХ гидроопоры с МРТ. Поэтому эти частотные сдвиги необходимо учитывать и устранять при настройке гидроопоры с МРТ на заданные частоты размагничивающим импульсным переменным магнитным полем.

Ликвидировать частотные сдвиги между АЧХ, ФЧХ гидроопоры с МРТ и добиться синхронного «закрывания» и «открывания» дроссельных каналов переменным магнитным полем с частотой вибросигнала можно возбуждением и предварительным размагничиванием сердечников МРТ 
при помощи сигнала возбуждения и размагничивания. Этот сигнал состоит из отдельных компонент, формируемых полупроводниковым преобра-

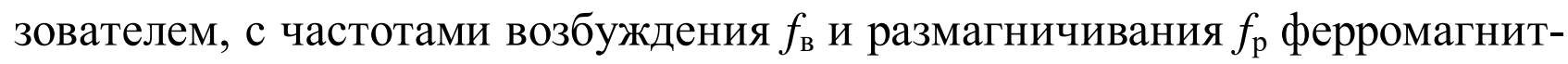
ных сердечников. При этом между частотой возбуждения и размагничивания, как показали эксперименты [43], должно выполняться следующее соотношение:

$$
f_{\mathrm{p}} \geq 10 \cdot f_{\mathrm{B}} .
$$

Отношение этих переменных намагничивания и размагничивания сердечников ВЭ при перестройке МРТ гидроопоры является величиной постоянной, и определяется выражением

$$
\frac{U_{\text {имп. }}}{f_{\mathrm{p}}} \approx 2 \pi N_{\text {в }} \Phi_{\text {имп.р }} \approx 2 \pi N_{\text {в }} L_{\ni} I_{\text {э.имп.р }}=2 \pi N_{\text {в }} \frac{X_{L}}{2 \pi f_{\mathrm{p}}} I_{\text {э.имп.р }}=\mathrm{const}
$$

где $\Phi_{\text {имп.р }}-$ импульсный магнитный поток размагничивания сердечников в

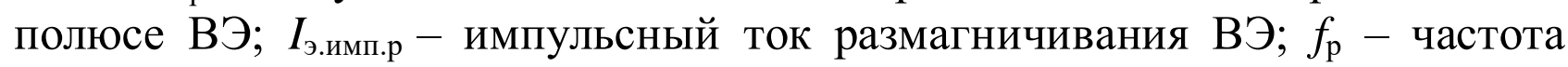

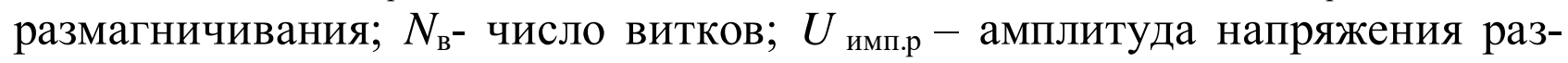
магничивания.

При размагничивающем импульсном переменном магнитном поле с частотой, например $f_{P}=200$ Гц, домены в сердечниках ВЭ не будут успевать выстраиваться из-за быстрой смены полярности переменного магнитного поля и будут находиться в хаотичном порядке, тем самым ликвидируется остаточная магнитная индукция, обусловленная гистерезисом сердечников ВЭ МРТ. Импульсное переменное магнитное поле в дроссельном канале МРТ препятствует его открыванию [44]. Этому будет препятствовать созданное магнитным полем, с частотой $f_{P}=200$ Гц сильное магнитное давление, которое намного больше гидравлического давления от действия инерционной нагрузки.

Таким образом, для достижения одновременного «закрывания» дроссельных каналов и размагничивания сердечников ВЭ требуется правильно выбрать амплитуды и частоты импульсов напряжения возбуждения и размагничивания сердечников ВЭ.

Особенностью изменения управляющего напряжения возбуждения

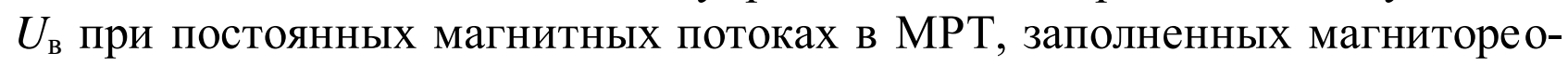
логической жидкостью, является его изменение по линейному закону от значений частоты перестройки $f_{\text {в }}$ (рис. 5.24).

Кроме выбора амплитуд и частот, необходимо правильно подобрать временные интервалы импульсов возбуждения $\tau_{\text {в }}$ и размагничивания $\tau_{\mathrm{p}}$. Эти временные интервалы в периоде действия вибросигнала распределены согласно зависимости 


$$
T_{\mathrm{cc}}=\left[\left(\tau_{\mathrm{B}}+\tau_{\mathrm{p}}\right)+\left(\tau_{\mathrm{B}}+\tau_{\mathrm{p}}\right)\right] .
$$

где $\tau_{\mathrm{B}}=(1,5 / 7) \cdot T_{c}-$ длительность сигналов возбуждения сердечников ВЭ $\mathrm{MPT}, \tau_{\mathrm{p}}=2 T_{c} / 7$ - - длительность сигналов размагничивания сердечников ВЭ МРТ, $T_{c}-$ период вибросигнала. Указанные значения коэффициентов 1,5 / 7 и 2 / 7 представляют собой эмпирически найденную комбинацию, которая позволяет реализовать соотношение (5.81).

На основании вышеизложенного была разработана система управления преобразователя, питающего МРТ, и получены диаграммы токов и напряжений. Система управления формирует требуемые АЧХ и обеспечивает напряжения и частоты сигналов возбуждения и размагничивания для сердечников ВЭ, при возбуждении и последующем размагничивании на временном интервале за период действия вибросигнала.

Функциональная схема системы управления полупроводниковым преобразователем показана на рис. 5.28.

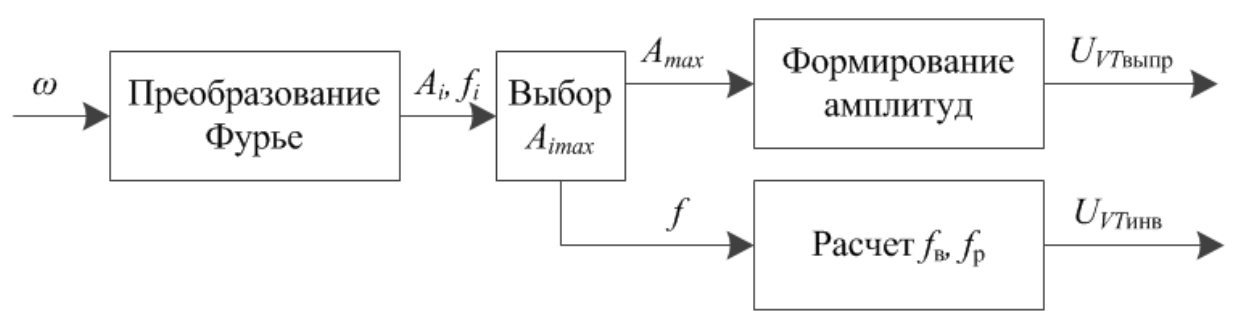

Рис. 5.28. Функциональная схема системы управления

На вход системы управления поступает сложный гармонический сигнал $\omega$ от вибродатчика, над этим сигналом выполняется преобразования Фурье. В результате преобразования Фурье получены значения амплитуд $A_{i}$ и частот $f_{i}$ в диапазоне частот от 5 до 100 Гц. Блок «Выбор $A_{i \max }$ » выполняет поиск наибольшей амплитуды $A_{\max }$ и соответствующей этой амплитуде значения частоты $f$. Значение $A_{\max }$ поступает на блок формирование амплитуды, где происходит расчет необходимого напряжения в звене постоянного тока преобразователя и формируется сигнал управления ключами выпрямителя $U_{V T \text { выпр. }}$ Значение $f$ поступает на блок расчета $f_{\text {в }}$, $f_{\mathrm{p}}$, где происходит вычисление частот и длительностей сигналов возбуждения и размагничивания и формируется сигнал управления ключами инвертора $U_{V T и н в}$.

Возможные схемы преобразователей для питания ВЭ МРТ показаны на рис. 5.29. Основа таких схем - преобразователь частоты, содержащий выпрямитель и инвертор. На рис. 5.29 показано: $R_{L}$ и $L_{L}$ активное и индуктивное сопротивление ВЭ, $L_{f}$ и $C_{f}-$ фильтр в звене постоянного тока. В табл. 5.16 приведены сравнительные характеристики предложенных схем преобразователей. 
Таблица 5.16

Сравнительные характеристики преобразователей для питания ВЭ

\begin{tabular}{|l|l|l|}
\hline Тип схемы & Преимущества & Недостатки \\
\hline $\begin{array}{l}\text { Активный выпрямитель } \\
\text { инвертор }\end{array}$ & $\begin{array}{l}\text { Уиравляемость } \\
\text { ный с переходом сетевого напряжения } \\
\text { через ноль }\end{array}$ \\
\hline $\begin{array}{l}\text { Неуправляемый одно- } \\
\text { фазный выпрямитель и } \\
\text { инвертор }\end{array}$ & $\begin{array}{l}\text { Диапазон частот } \\
f_{\text {в до } 100 \text { Гц }}\end{array}$ & $\begin{array}{l}\text { Высокая частота коммутации ключей } \\
\text { инвертора }\end{array}$ \\
\hline $\begin{array}{l}\text { Активный трехфазный } \\
\text { выпрямитель и инвер- } \\
\text { тор }\end{array}$ & $\begin{array}{l}\text { Диапазон частот } \\
f_{\text {во } 100 \text { Гц }}^{\text {Управляемость }}\end{array}$ & Сложность \\
\hline
\end{tabular}

Авторами разработана модель, содержащая систему управления, полупроводниковый преобразователь, возбуждающий электромагнит гидроопоры.

На рис. 5.30 показано, что при использовании схемы - активный однофазный выпрямитель и инвертор, и настройки МРТ на $f_{\text {в }}=25$ Гц, в моменты времени $t=0.02,0.04,0.06$ и т.д., форма тока питающего ВЭ искажается. С ростом частоты настройки это искажение увеличивается. Этого можно избежать при использовании схемы - активный трехфазный выпрямитель с инвертором.

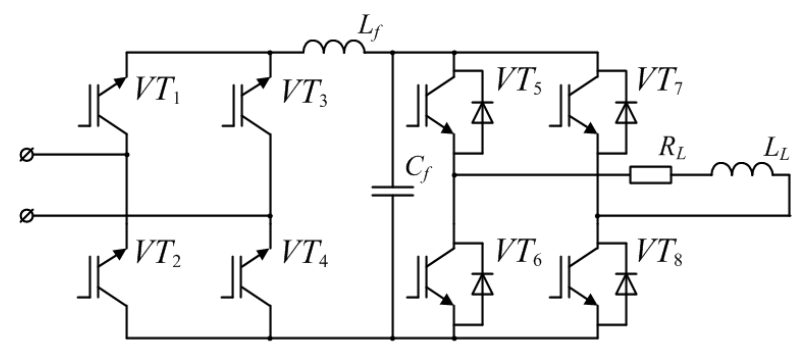

a)

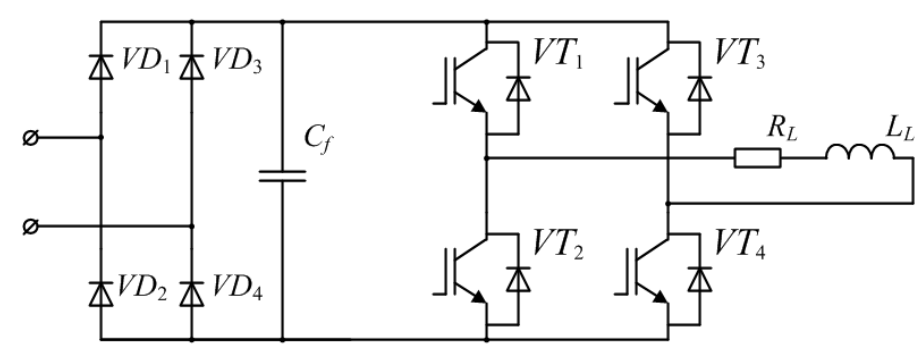

б)

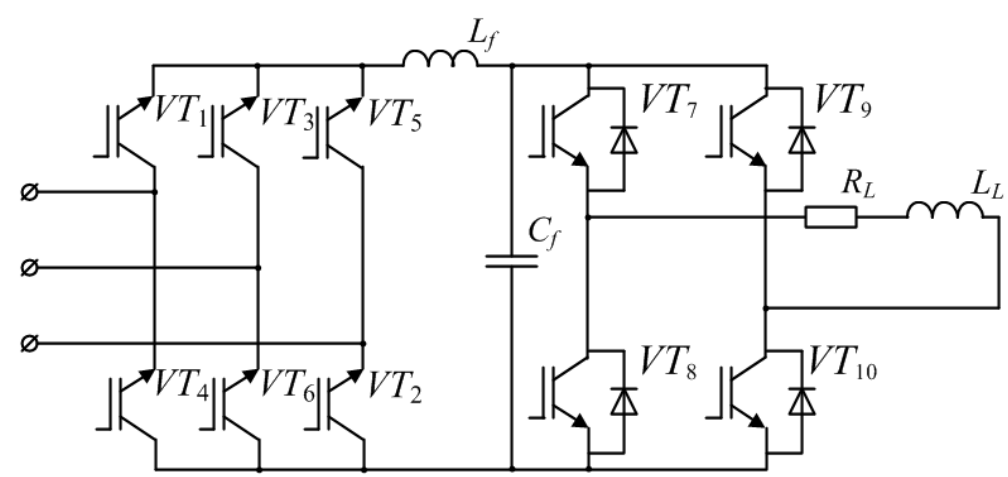

B)

Рис. 5.29. Топология схем для питания возбуждающего электромагнита на основе преобразователей частоты, содержащих активный выпрямитель и инвертор (a); неуправляемый однофазный выпрямитель и инвертор (б); активный трехфазный выпрямитель и инвертор (в) 


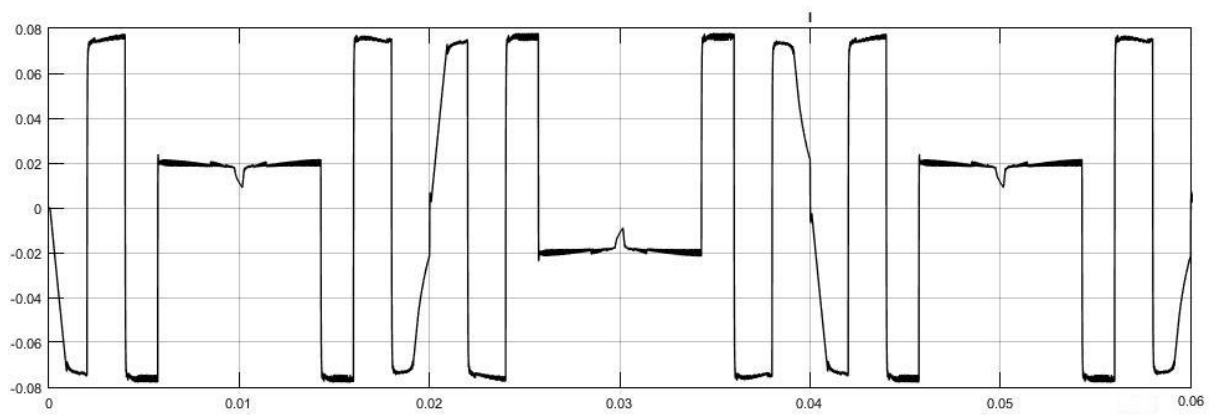

Рис. 5.30. Мгновенное значение тока питающего ВЭ МРТ

Результаты моделирования для схемы активный трехфазный выпрямитель и инвертор при настройке МРТ на $f_{\text {в }}=80$ Гц показаны на рис. 5.31. На рис. 5.31, а изображено напряжение на выходе инвертора. На рис. 5.31, б приведены: 1 - гармонический сигнал, выделенный системой управления после обработки сигнала с вибродатчика (штриховая линия); 2 - ток, питающий ВЭ МРТ, содержащий сигнал возбуждения и размагничивания ВЭ (сплошная линия).

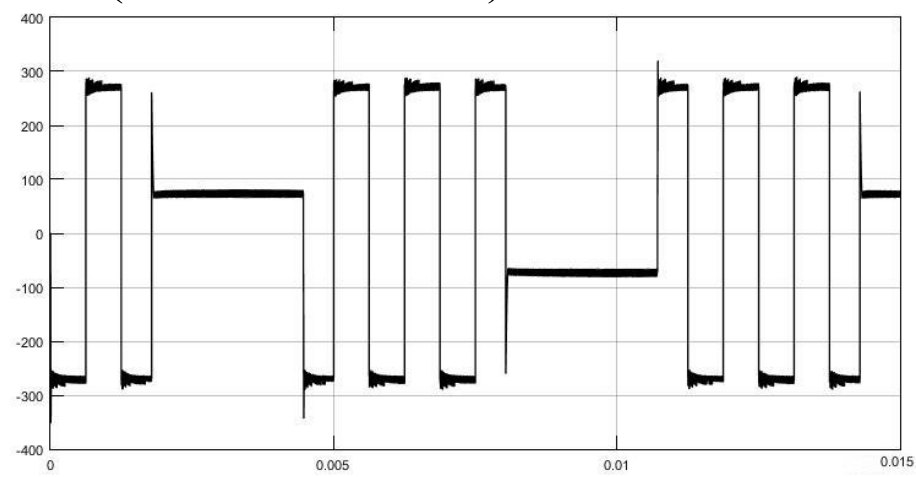

a)

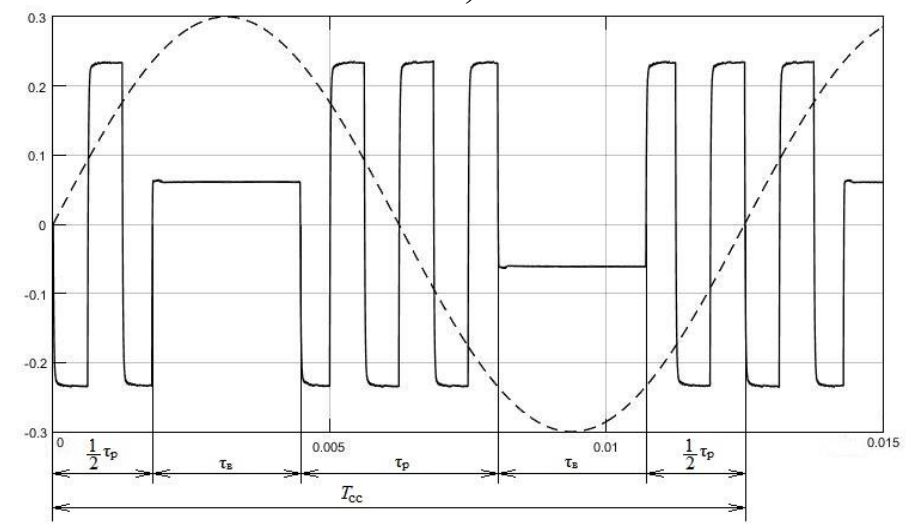

б)

Рис. 5.31. Результаты моделирования напряжение на ВЭ (a); ток через ВЭ (б)

Разработана модель для управления гидроопорой с МРТ, содержащая систему управления однофазным преобразователем частоты, показанная на рис. 5.32. Система управления разработана с применением Altera DSP Builder, который позволяет разрабатывать и моделировать алгоритмы управления, а затем генерировать код для ПЛИС. 
$\mathrm{C}$ помощью технологии hardware in the loop было проведено моделирование системы управления преобразователем частоты, создающим ток намагничивания ВЭ гидроопоры. При таком моделировании из модели на ПЛИС передаются сигналы вибрации и напряжения в звене постоянного тока, а от ПЛИС в модель передаются сигналы управления ключами выпрямителя и инвертора, обеспечивая режим намагничивания и размагничивания ферромагнитных сердечников ВЭ, при котором происходит «открывание» и «запирание» дроссельных каналов в МРТ гидроопоры.

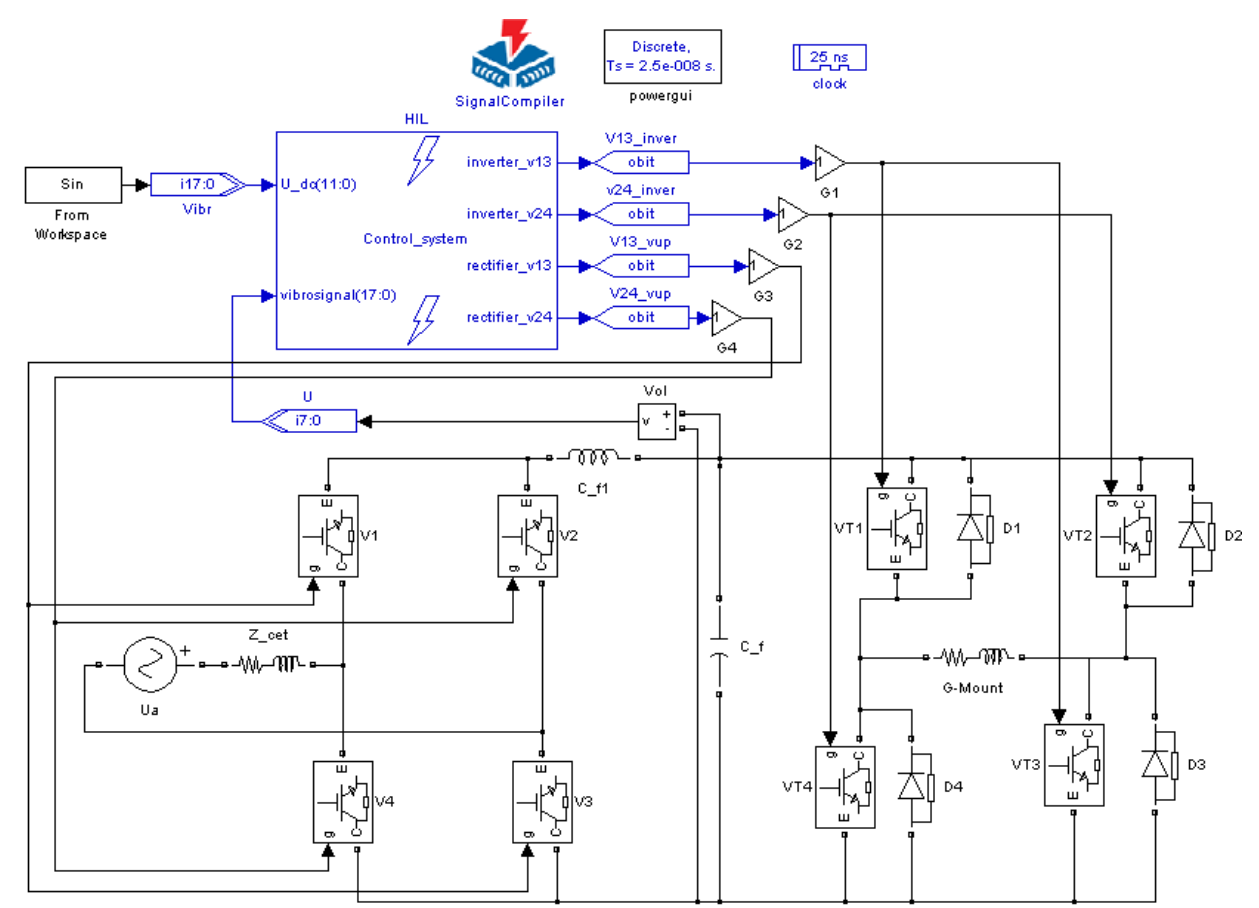

Рис. 5.32. Модель управления гидроопорой с МРТ

Сигнал вибрации, переданный на ПЛИС, показанный на рис. 5.33 Спектр сигнала вибрации, рассчитанный системой управления, показан на рис. 5.34.

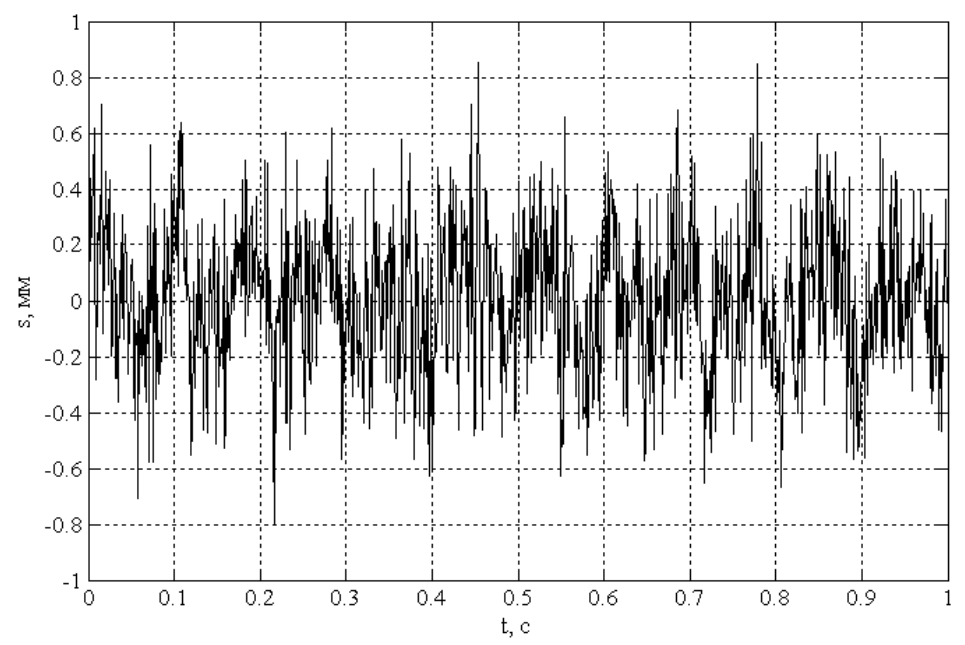

Рис. 5.33. Сигнал вибрации 


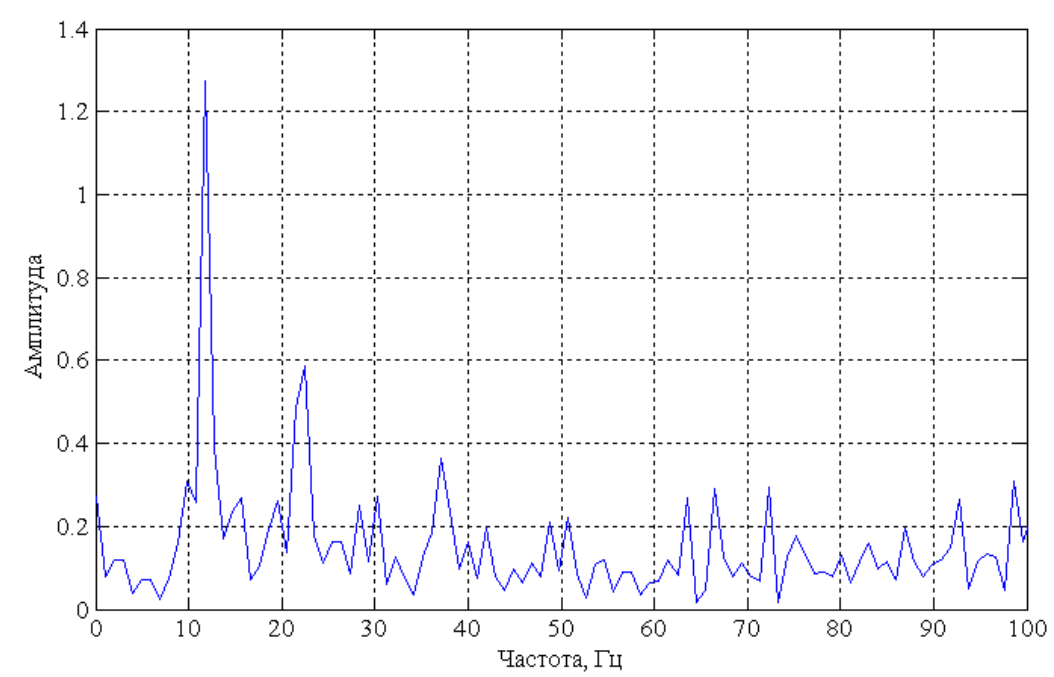

Рис. 5.34. Спектр сигнала вибрации

Система управления формирует задание напряжения в звене постоянного тока преобразователя частоты (рис. 5.35). На рис. 5.36 показано напряжение в звене постоянного тока.

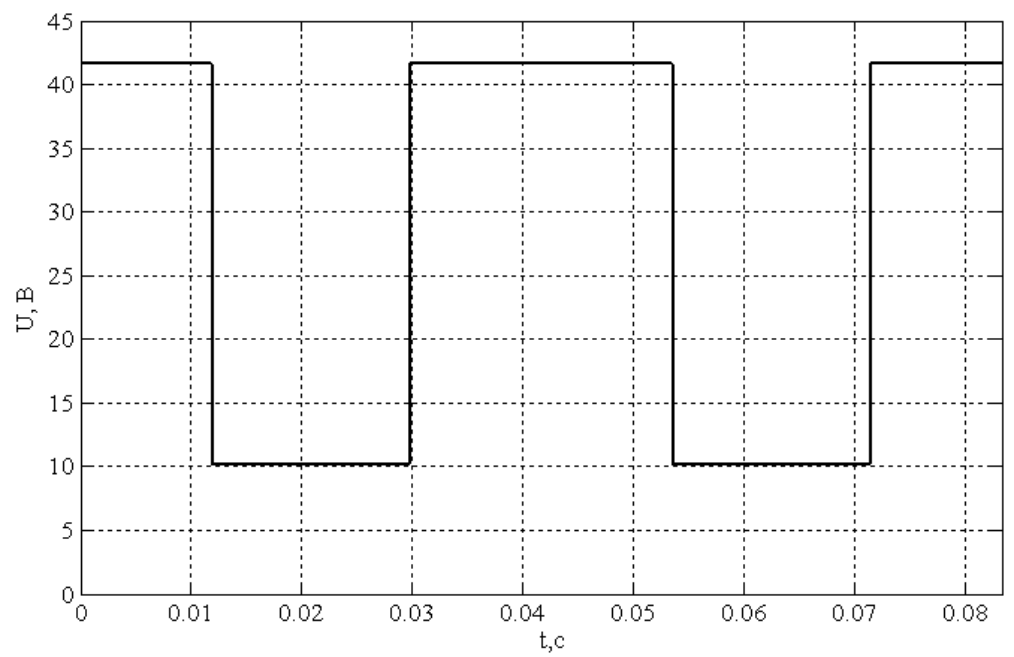

Рис. 5.35. Задание напряжения в звене постоянного тока

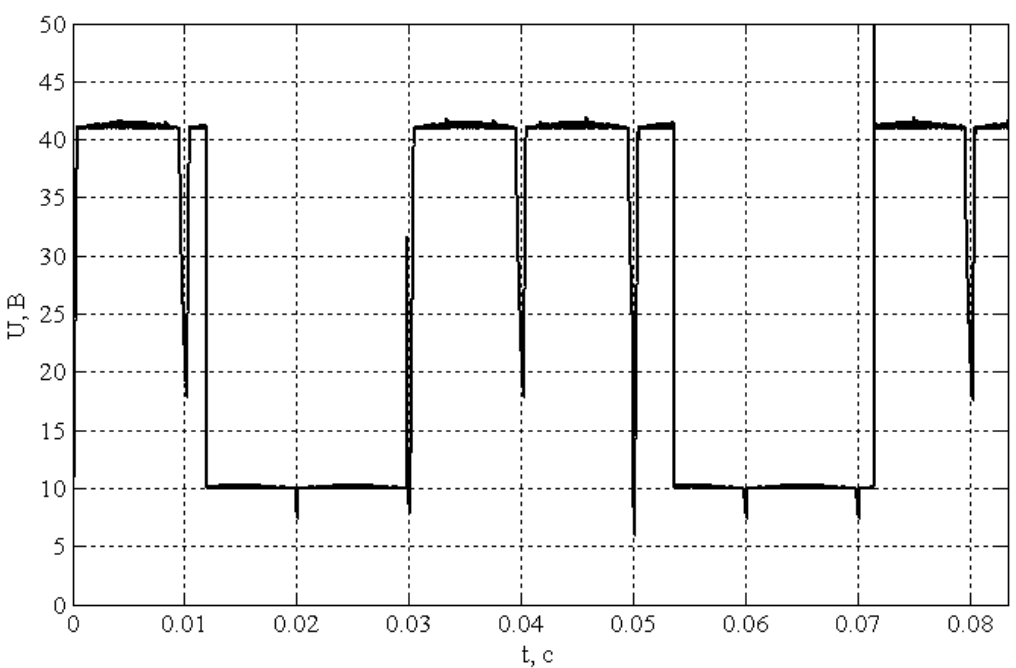

Рис. 5.36. Напряжение в звене постоянного тока 
На рис. 5.37 показано напряжение на МРТ гидроопоры, на рис. 5.38 ток через МРТ.

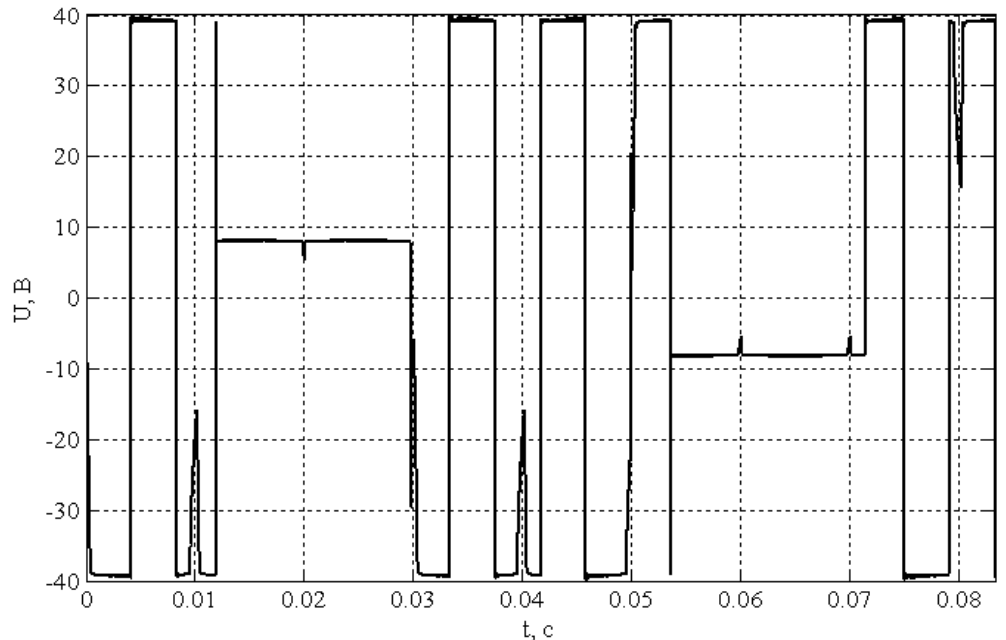

Рис. 5.37. Напряжение на МРТ

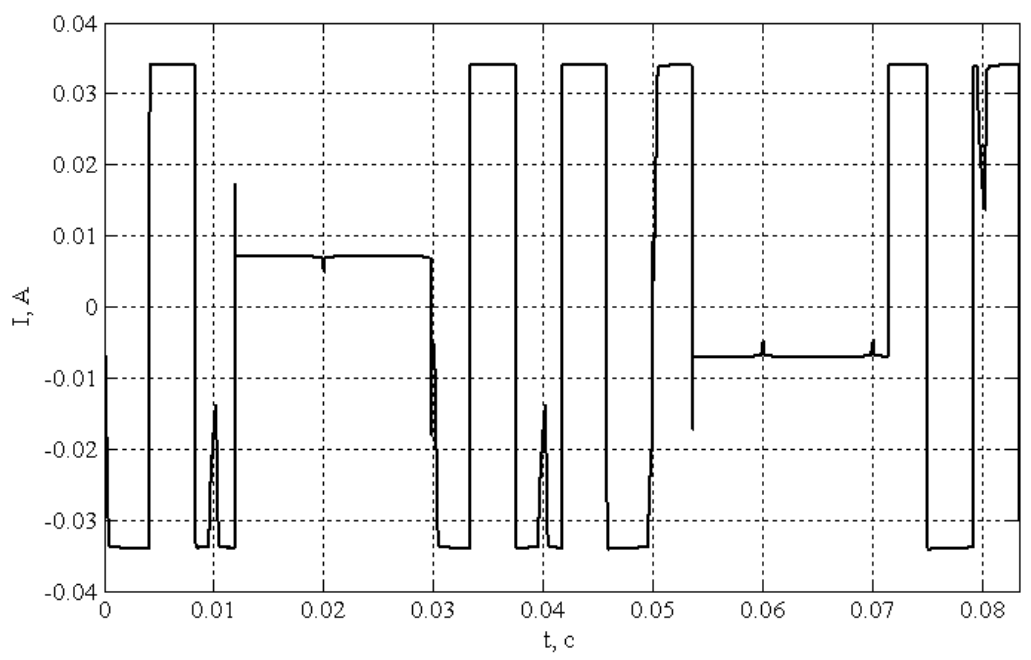

Рис. 5.38. Ток через МРT

Разработанная система управления формирует сигналы управления ключами полупроводникового преобразователя таким образом, чтобы обеспечивался режим намагничивания и размагничивания ферромагнитных сердечников ВЭ, при котором происходит «открывание» и «запирание» дроссельных каналов в МРТ гидроопоры. 


\section{ГЛАВА б. ИМИТАЦИОННОЕ МОДЕЛИРОВАНИЕ И ЭКСПЕРИМЕНТАЛЬНОЕ ИССЛЕДОВАНИЕ СИСТЕМ ВИБРОЗАЩИТЫ ЭЛЕКТРИЧЕСКИХ И РАБОЧИХ МАШИН}

\section{1. Экспериментальное исследование электромеханического фильтра}

Представлены результаты имитационного эксперимента по проверке возможности функционирования электромеханического фильтра на основе активного компенсирующего устройства (АКУ), питающего двигатель постоянного тока, электромагнитный момент которого определяется выходным током АКУ и содержит пульсации, компенсирующие вибрации.

В [131] рассмотрен метод для получения компенсационного сигнала, который подавляет вибрации электрического двигателя с помощью преобразования Фурье в реальном времени и использующий датчик ускорения, прикрепленный к корпусу электрического двигателя или акустического сигнал, формируемого микрофоном, расположенным рядом с корпусом. Датчик используется для получения данных о возмущении для компенсации. Преобразование Фурье (ПФ) применяется к сигналу вибрации, полученного с датчика ускорения до введения в систему управления. Все высшие и низшие порядки гармоник сигнала вибрации будут устранены из результатов ПФ, кроме конкретной частотной составляющей, такой как основная, гармоники второго порядки и т.д. и это позволит улучшить стабильность системы управления.

На рис. 6.1 показаны примеры механических систем. На рис. 6.1, $a$ показано расположение двигателя и исполнительного механизма на общем основании, например компрессор кондиционера воздуха. В этом случае, разница моментов созданных двигателем и исполнительным механизмом приложена к общему основанию, которое вибрирует, если двигатель и/или исполнительный механизм создают несбалансированный крутящий момент. На рис. 6.1, б показан случай, когда корпус мотора и механизма отделены друг от друга, корпус двигателя вибрирует в основном из-за колебаний момента, созданных в двигателе, колебания ротора вызваны моментом двигателя и моментом механизма.

На рис. 6.2 показана схема с датчиком вибрации и ПФ. Управление снижением механической вибрации выполняется с помощью системы управления.

Сигнал вибрации поступает с датчика ускорения на блок ПФ через фильтр нижних частот, который удаляет высокочастотный шум датчика. 
Выходные сигналы с блока ПФ используются только для определенных частот колебаний, который устраняет высшие и низшие порядки гармоник. Сумма выбранных сигналов подается на цифровой фильтр, где параметр $k_{1}$ - пропорциональная часть, для усиления цепи обратной связи, $k_{2}-$ элемент компенсирующий фазовую задержку. Параметры $k_{1}$ и $k_{2}$ определяются для отдельной составляющей частоты вибрации, так что система управления становиться стабильной.
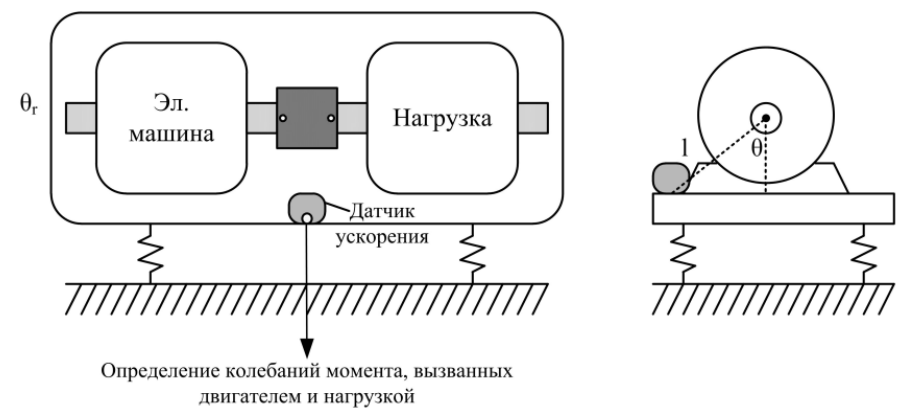

a)

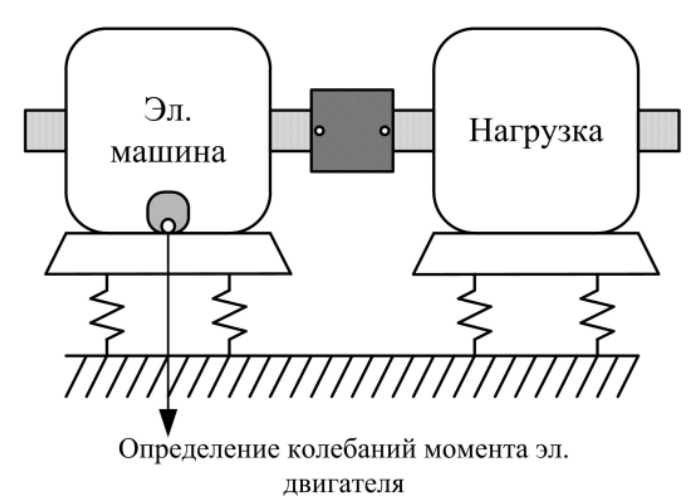

б)

Рис. 6.1. Модель механической системы и определения вибрации двигатель и исполнительный механизм, расположенные на общем основании $(a)$; двигатель и исполнительный механизм, установленные отдельно (б)

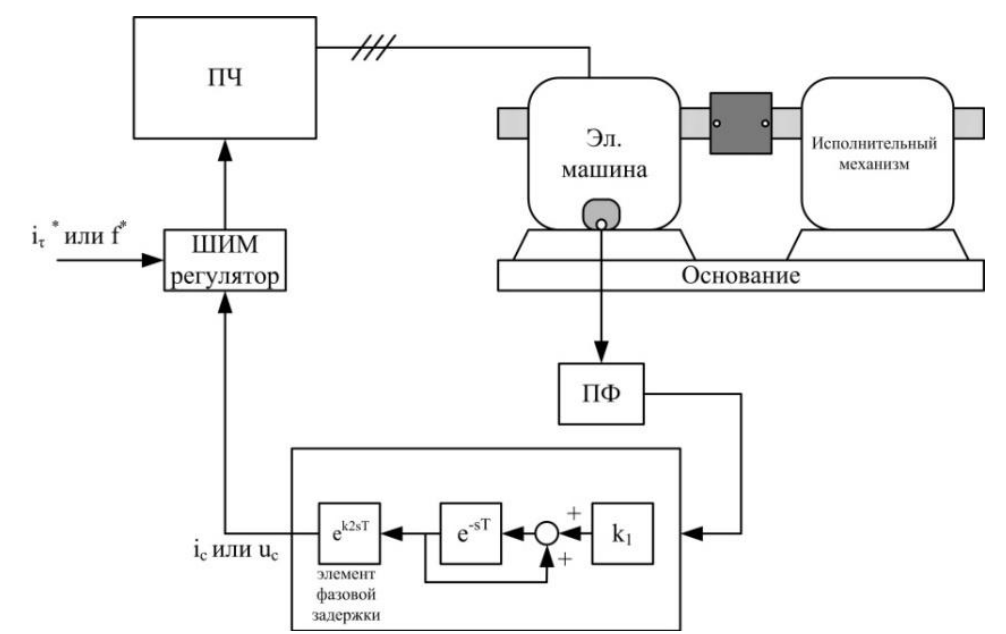

Рис. 6.2. Система получения компенсационных сведений, использующая датчик вибрации и блок ПФ 
Для проверки концепции построения электромеханического фильтра, работающего со спектром частот, был построен экспериментальный макет электромеханического фильтра с преобразованием Фурье. Функциональная схема электромеханического фильтра представляет собой совокупность электропривода, управляемого по моменту, модель механической колебательной системы и датчика ускорения, установленного на корпусе вибрирующей рабочей машины (рис. 6.3). Модель такой системы содержит также управляемый источник вибрации.

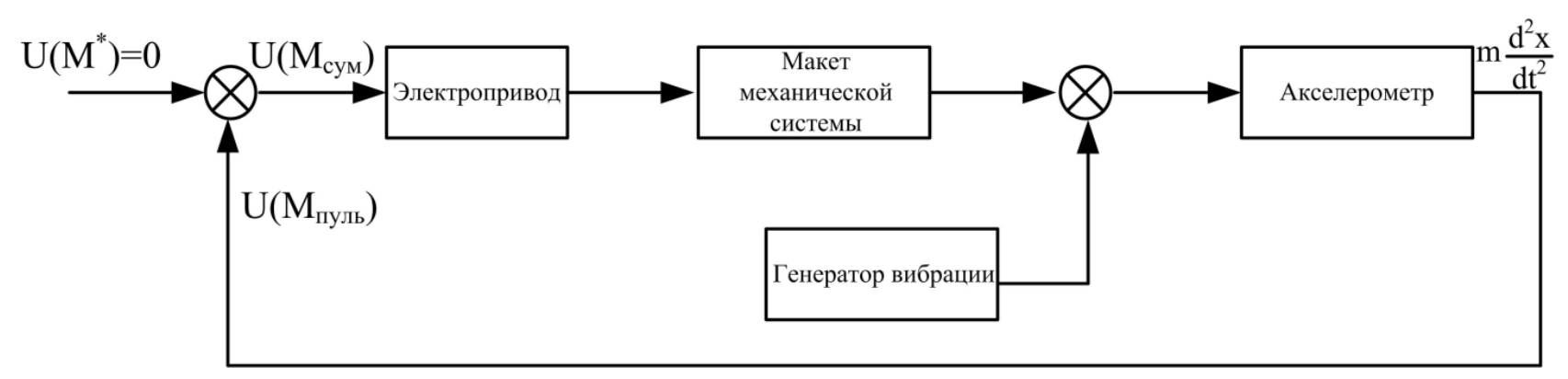

Рис. 6.3. Функциональная схема электромеханического фильтра

Сигнал, задающий нормальный режим работы двигателя электропривода $U\left(M^{*}\right)=0$, т.е. система управления электропривода будет отрабатывать только составляющую пропорциональную моменту «антипульсаций», поскольку $U\left(M_{\text {сум }}\right)=U\left(M^{*}\right)-U\left(M_{\text {пул }}\right)=-U\left(M_{\text {пул }}\right)$. Генератор вибраций, в качестве которого выбран вибростол, обеспечивает появление пульсаций момента, которые измеряются акселерометром, выходной сигнал которого используется в цепи обратной связи $U\left(M_{\text {пул }}\right)=k J \cdot d^{2} x / d t^{2}$.

Структурная схема экспериментальной установки без возмущающего вибростола с использованием двигателя СЛ-621, являющейся основой электропривода приведена на рис. 6.4. Блоки этой схемы представлены передаточными функциями соответственно:

- двигателя, управляемого по моменту - $W_{i u}(s)$ и $W_{M i}(s)$;

- преобразователя электрической энергии с системой управления $U_{d}=\alpha \cdot W_{\Pi \Pi}(s) ; \alpha=U_{\mathrm{y}} \cdot W_{\text {СИФу }}(s) ; U_{\mathrm{y}}=\Delta i \cdot W_{\mathrm{PT}}(s) ; \Delta i=\left(i^{*}+i_{\mathrm{K}}-i_{d}\right) ; i^{*}=\left(\omega^{*}-\omega\right) W_{\mathrm{PT}}(s) ;$

- канала формирования компенсационного тока, обеспечивающего генерацию «антипульсаций» момента $\Delta M_{\mathrm{K}}=-\Delta M_{\mathrm{B}}-$ датчика вибраций $W_{\text {дв }}(s)$ и канала связи, с блоком ПФ $W_{\text {кС }}(s)$.

Результаты экспериментов представлены на рис. 6.5. На приведенных осциллограммах символом $f^{*}$ обозначена базовая частота блока ПФ, в нашем случае она была принята 2,5 Гц с целью охватить результатами преобразования блока ПФ низкочастотный диапазон вибраций экспериментальной установки. 


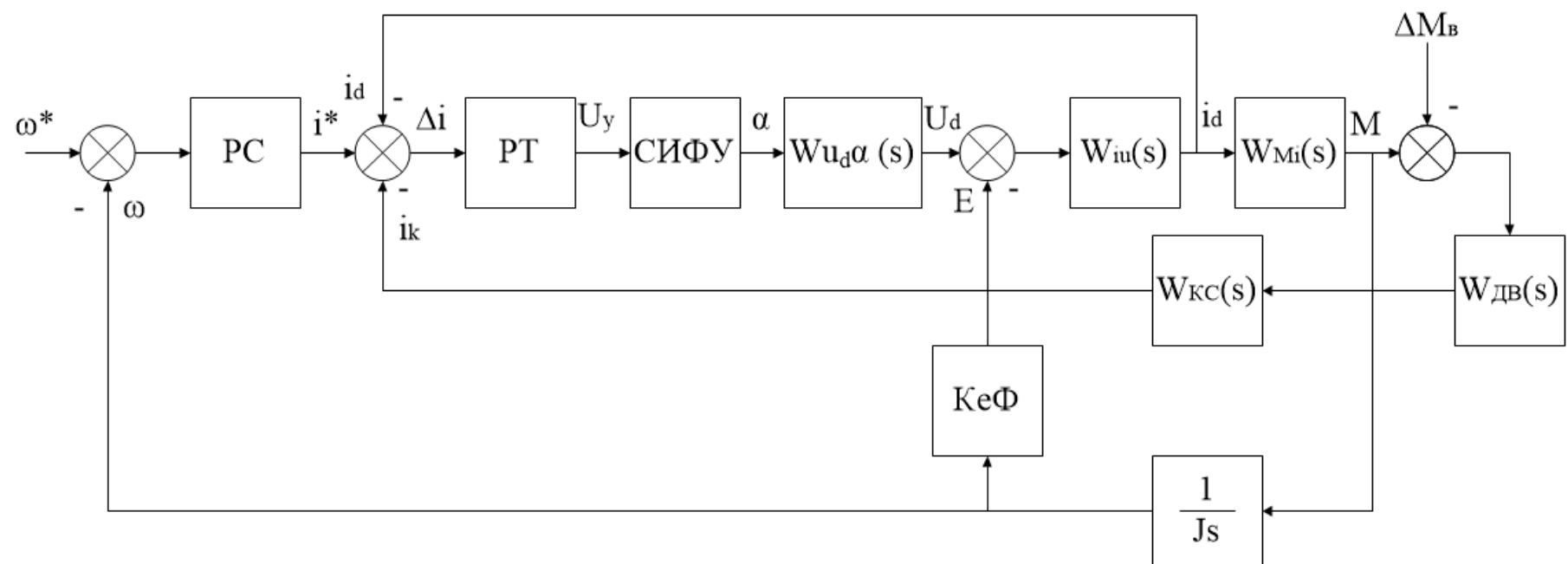

Рис. 6.4. Структурная схема электропривода, входящего в состав экспериментальной установки
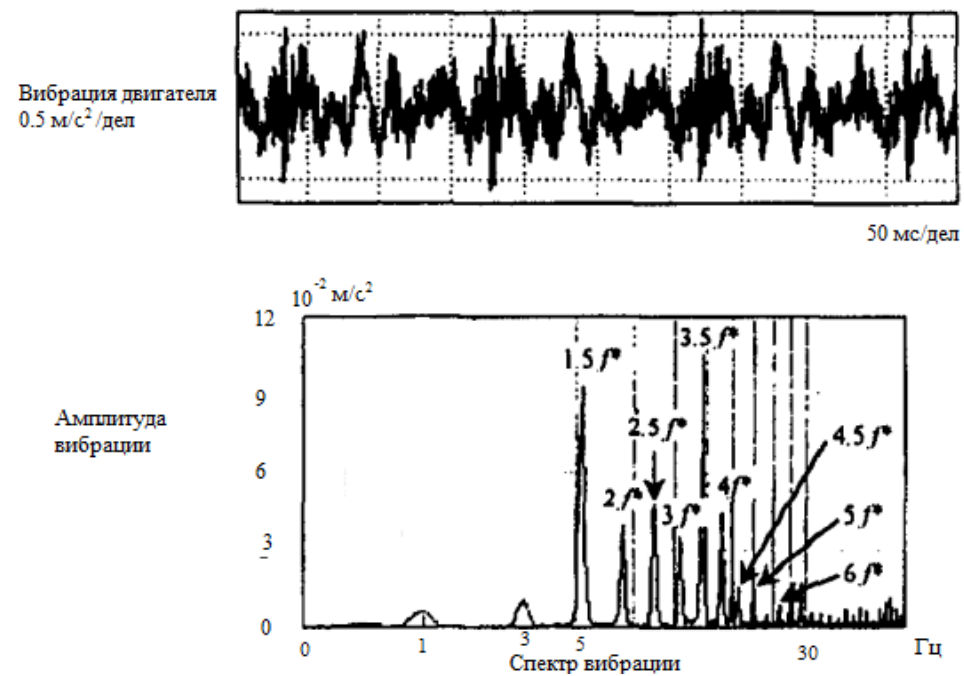

a)
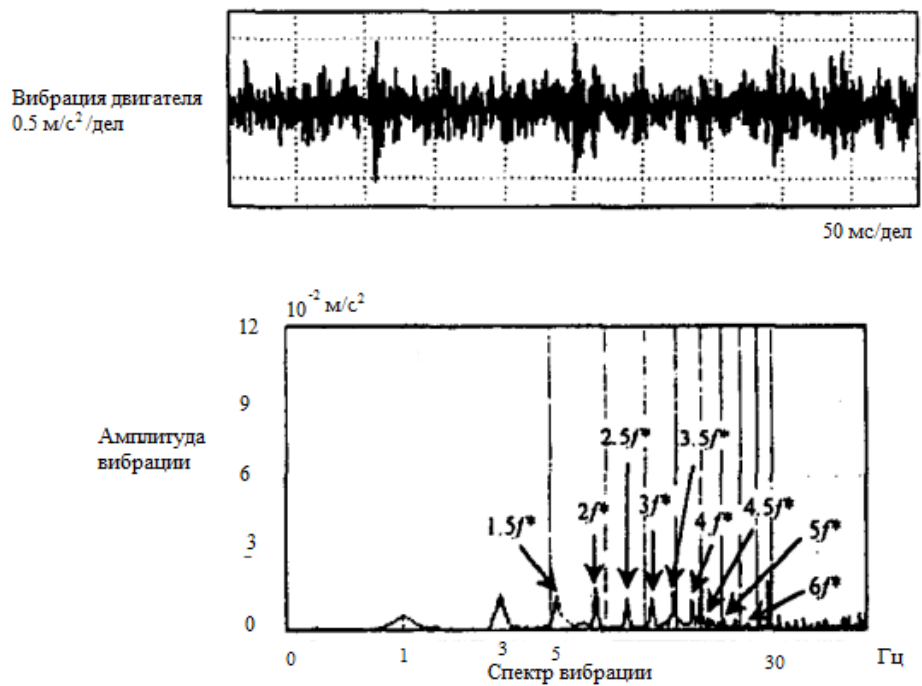

б)

Рис. 6.5. Сигнал с датчика вибраций и спектр сигнала без подавления вибрации (a); подавление отдельных гармоник (б) 


\section{2. Моделирование активного фильтра гармоник сетевого тока}

Ранее было показано, что гармоники сетевого тока создают также пульсации момента двигателя, которые вызывают недопустимые вибрации, в случае если нагрузкой является МДП или электрический двигатель, питаемый от непосредственного преобразователя частоты.

Задачу моделирования [81] активного фильтра гармоник можно разделить на две подзадачи:

- моделирование алгоритмов управления активными фильтрами;

- моделирование работы ШИМ преобразователя.

Рассмотрим алгоритм управления активным фильтром гармоник, основанный на теории мгновенной мощности. Эта теория, основа на преобразовании мгновенных значений электрических переменных в фазах питающей сети к трем ортогональным осям $\alpha \beta 0$. Структурная схема (алгоритм) расчета компенсационного тока, основанная на теории мгновенной мощности приведена на рис. 6.6.

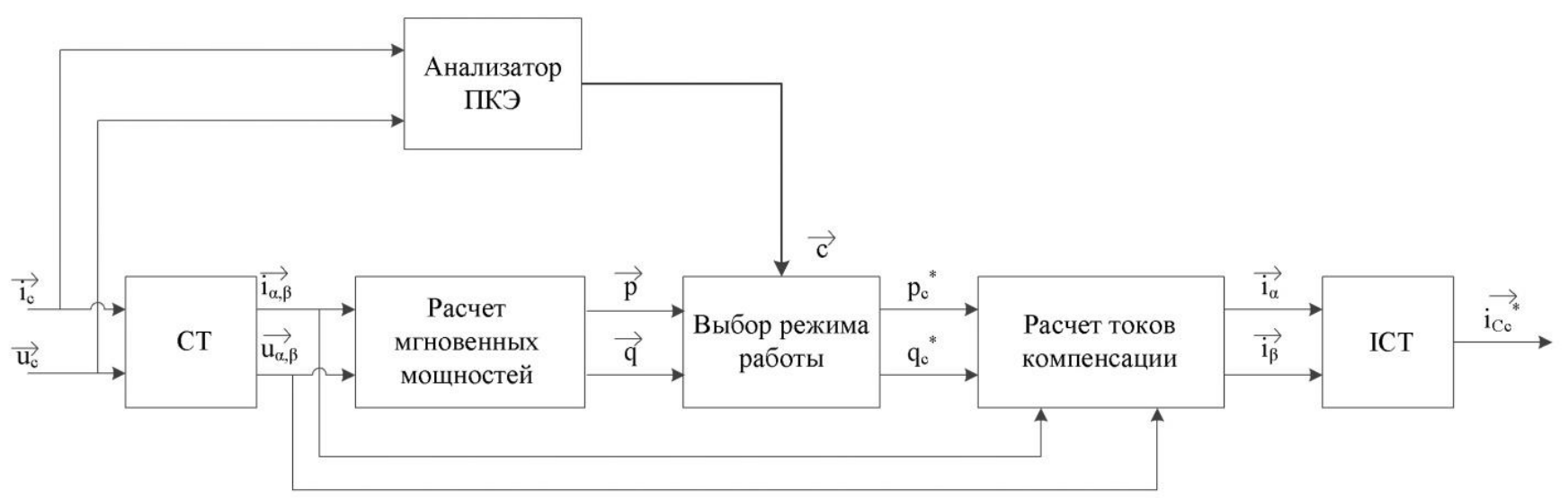

Рис. 6.6. Структурная схема (алгоритм) расчета компенсационного тока, основанная на теории мгновенной мощности

Описание блоков структурной схемы:

1. Блок СТ - прямое преобразование Кларка:

$$
\begin{aligned}
& {\left[\begin{array}{l}
u_{\alpha} \\
u_{\beta}
\end{array}\right]=\sqrt{\frac{2}{3}}\left[\begin{array}{rrr}
1 & -\frac{1}{2} & -\frac{1}{2} \\
0 & \frac{\sqrt{3}}{2} & -\frac{\sqrt{3}}{2}
\end{array}\right]\left[\begin{array}{l}
u_{a} \\
u_{b} \\
u_{c}
\end{array}\right],} \\
& {\left[\begin{array}{l}
i_{\alpha} \\
i_{\beta}
\end{array}\right]=\sqrt{\frac{2}{3}}\left[\begin{array}{ccc}
1 & -\frac{1}{2} & -\frac{1}{2} \\
0 & \frac{\sqrt{3}}{2} & -\frac{\sqrt{3}}{2}
\end{array}\right]\left[\begin{array}{l}
i_{a} \\
i_{b} \\
i_{c}
\end{array}\right] .}
\end{aligned}
$$


2. Блок расчета мгновенных мощностей:

$$
\left[\begin{array}{l}
p \\
q
\end{array}\right]=\left[\begin{array}{cc}
u_{\alpha} & u_{\beta} \\
-u_{\beta} & u_{\alpha}
\end{array}\right]\left[\begin{array}{l}
i_{\alpha} \\
i_{\beta}
\end{array}\right] .
$$

3. Блок выбора режима работы:

Данный блок в зависимости от управляющего сигнала с блока «Анализатор ПКЭ» (ПКЭ - параметры качества электроэнергии) выбирает мощности для компенсации, а именно, $\tilde{p}, \bar{p}, \tilde{q}$ или $\bar{q}$, где $\tilde{p}$ - колебательная составляющая активной мощности; $\bar{p}$ - постоянная составляющая активной мощности; $\tilde{q}$ - колебательная составляющая реактивной мощности; $\bar{q}$ постоянная составляющая реактивной мощности.

Для компенсации мощностей подходящими являются три комбинации:

$-\tilde{p}+\tilde{q}-$ компенсация ВГ;

$-\tilde{q}+\bar{q}-$ компенсация реактивной мощности;

$-\tilde{p}+\tilde{q}+\bar{q}-$ компенсация ВГ и реактивной мощности.

4. Блок расчета токов компенсации:

$$
\left[\begin{array}{c}
i_{\alpha}{ }^{*} \\
i_{\beta}{ }^{*}
\end{array}\right]=\frac{1}{u_{\alpha}^{2}+u_{\beta}^{2}}\left[\begin{array}{cc}
u_{\alpha} & u_{\beta} \\
u_{\beta} & -u_{\alpha}
\end{array}\right]\left[\begin{array}{c}
p_{c}^{*} \\
q_{c}^{*}
\end{array}\right] .
$$

5. Блок ICT - обратное преобразование Кларка

$$
\left[\begin{array}{l}
i_{a}^{*} \\
i_{b}^{*} \\
i_{c}^{*}
\end{array}\right]=\sqrt{\frac{2}{3}}\left[\begin{array}{cc}
1 & 0 \\
-\frac{1}{2} & \frac{\sqrt{3}}{2} \\
-\frac{1}{2} & -\frac{\sqrt{3}}{2}
\end{array}\right]\left[\begin{array}{l}
i_{\alpha}^{*} \\
i_{\beta}^{*}
\end{array}\right] .
$$

Выполнена модель (рис. 6.7) в среде Matlab Simulink, в которой peaлизован данный алгоритм расчета тока компенсации АФГ.

На рис. 6.8 приведены осциллограммы токов в фазе $A$ без компенсации искажений.

Рассмотрим результаты моделирования режимов работы схемы при формировании токов компенсации:

1. Режим компенсации ВГ. На рис. 6.9 показан рассчитанный по теории мгновенной мощности компенсационный ток, а на рис. 6.10 - ток в фазе $A$ после компенсации 


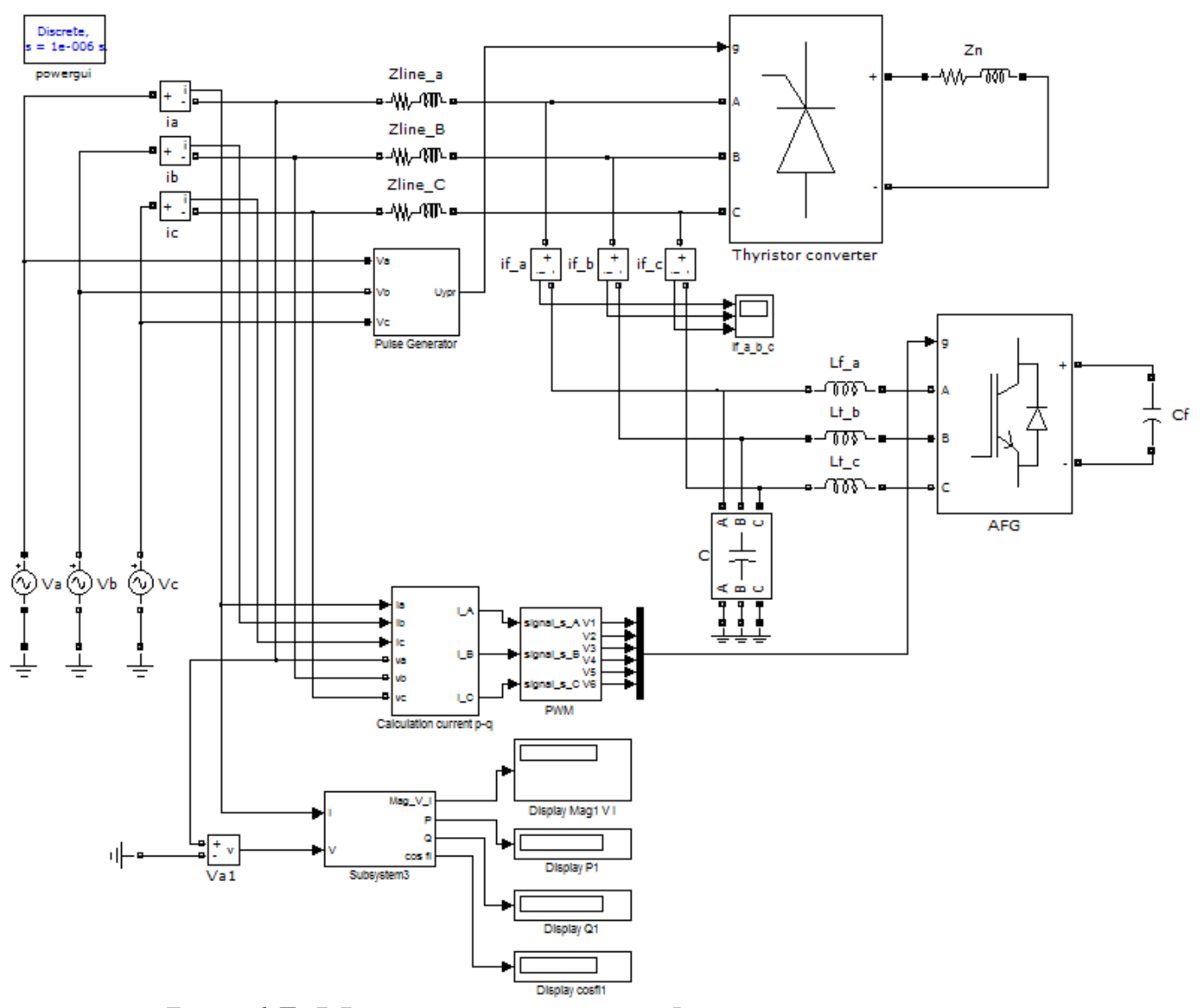

Рис. 6.7. Модель «активный фильтр гармоник - сеть»

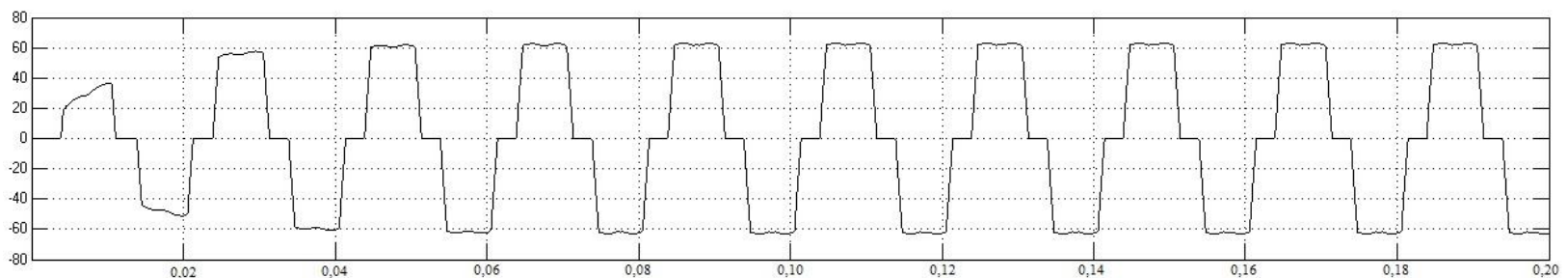

Рис. 6.8. Ток фазы $\boldsymbol{A}$ без компенсации

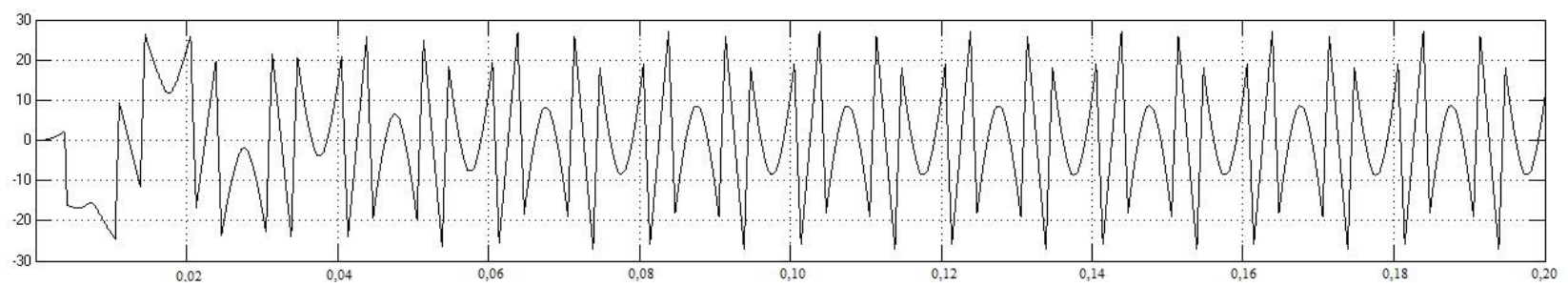

Рис. 6.9. Рассчитанный по теории мгновенной мощности ток компенсации для фазы $\boldsymbol{A}$

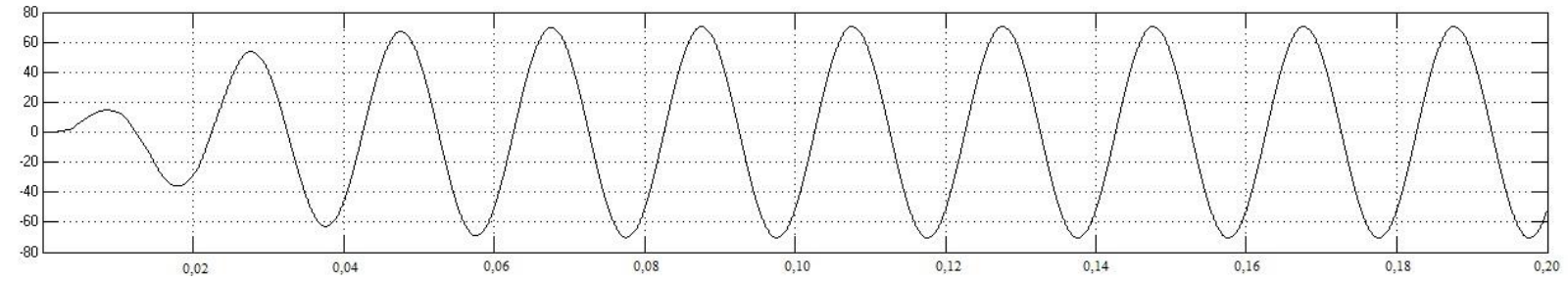

Рис. 6.10. Ток в фазе $\boldsymbol{A}$ после компенсации 
2. Режим компенсации реактивной мощности. На рис. 6.11 показан рассчитанный по теории мгновенной мощности компенсационный ток, а на рис. 6.12 - ток в фазе $A$ после компенсации

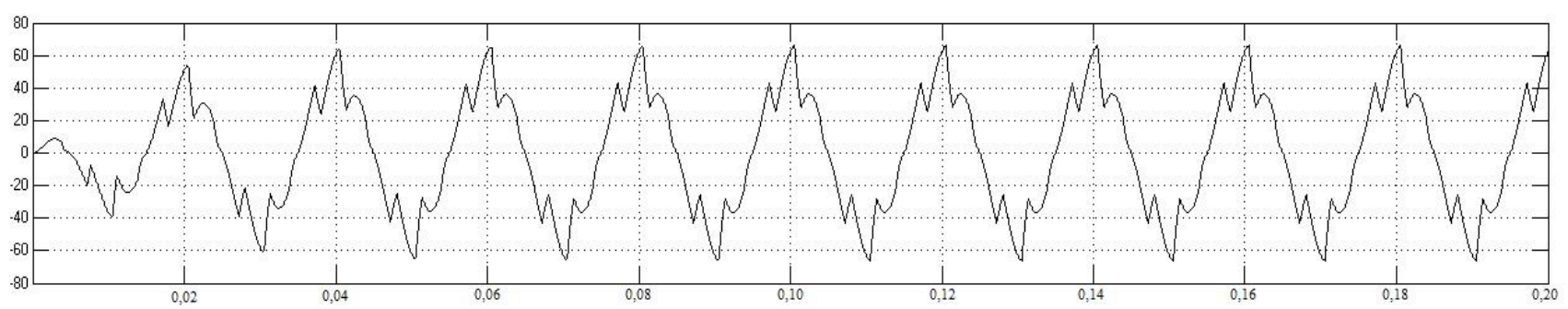

Рис. 6.11. Рассчитанный по теории мгновенной мощности ток компенсации для фазы $A$

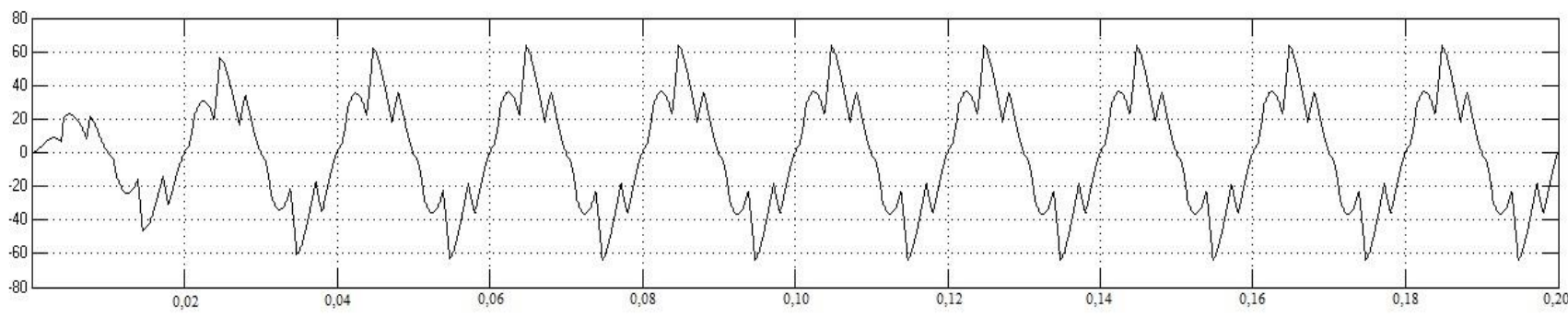

Рис. 6.12. Ток в фазе $\boldsymbol{A}$ после компенсации

3. Комплексный режим компенсации реактивной мощности и ВГ. На рис. 6.13 показан рассчитанный по теории мгновенной мощности компенсационный ток, а на рис. 6.14 - ток в фазе $A$ после компенсации

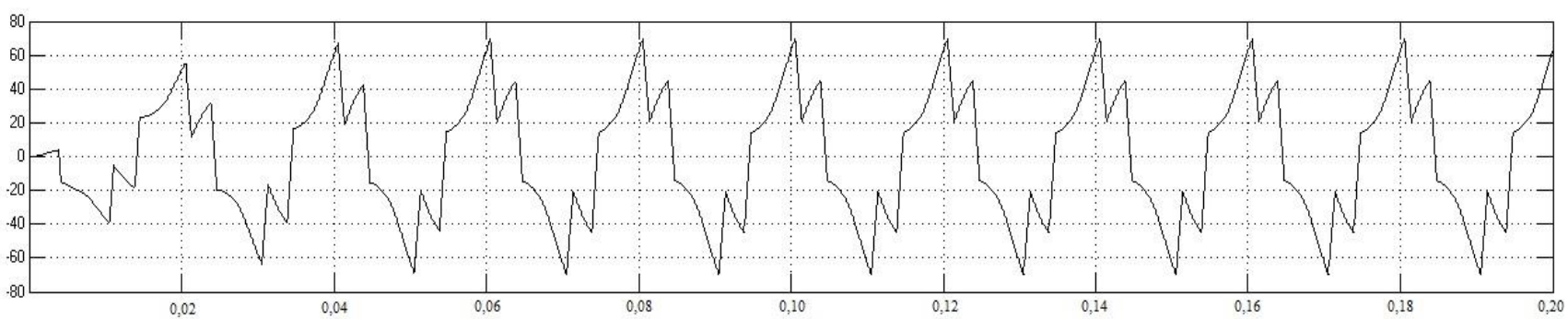

Рис. 6.13. Рассчитанный по теории мгновенной мощности ток компенсации для фазы $\boldsymbol{A}$

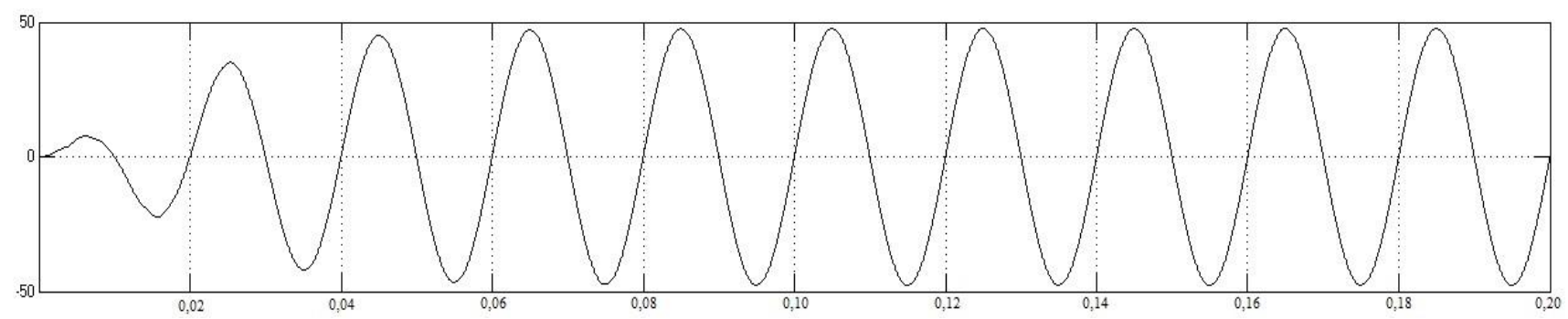

Рис. 6.14. Ток в фазе А после компенсации

Из приведенных диаграмм видно, что в результате компенсации ВГ $\mathrm{THD}_{\mathrm{i}}$ в фазе А снизился с 23,5 до 1\%, коэффициент мощности в результате компенсации реактивной мощности возрос с 0,68 до 0,99 . 


\section{3. Экспериментальные исследования синхронизации двух электрических машин на упругом основании}

В системах со многими источниками вибраций всегда возможна синхронизация на одной или нескольких частотах [105]. Этот процессы усугубляются влиянием внешних вибрационных полей, способствующих значительному увеличению времени переходных процессов в энергоемком оборудовании.

Возрастание времени переходных процессов, в частности, приводит к увеличению энергопотребления и дополнительному росту вредных вибраций, возникновению опасных низкочастотных биений. Эти процессы понижают ресурс работы силовых агрегатов и ведут к разрушению инженерных конструкций. Поэтому задача снижения уровней вибрации в стационарных и переходных режимах работы энергоемких машин всегда актуальна [19]. Захват угловой скорости вращения ротора электродвигателя частотами внешних источников вибрации происходит во время разгона ротора из состояния покоя.

Переходный процесс может сопровождаться рядом нежелательных явлений. К примеру, угловая скорость вращения ротора может и не достичь своего номинального значения, а останется в установившемся режиме гораздо меньшей (так называемое явление «застревания»). Это свидетельствует о вредном действии вибрационного момента на вал ротора, от чего необходимо освободиться либо, по возможности, свести к минимуму.

Отмеченные явления существенно осложняются действием внешнего вибрационного поля даже тогда, когда частоты внешних возмущений не совпадают с номинальной угловой скоростью вращения ротора. Одним из эффективных способов снижения уровня вибраций частей электромашин является использование гидравлических опор в качестве демпферов.

Суть синхронизации состоит в том, что несколько электромеханических объектов, совершающих по отдельности колебательные или вращательные движения с различными частотами и угловыми скоростями, начинают двигаться синхронно - с одинаковыми или соизмеримыми частотами и угловыми скоростями из-за наличия даже весьма слабых связей или взаимодействий. При этом между колебательными и вращательными движениями устанавливаются вполне определенные фазовые соотношения $[16,62,71,100]$. Важно отметить, что подобные режимы движения весьма устойчивы, т.е. они возникают самопроизвольно при подходящих электромеханических параметрах конструкции, причем с прагматической точки зрения их можно трактовать как в положительном, 
так и в отрицательном аспектах. К примеру, синхронизация грубого механического или электрического колебательного контура и весьма стабильного кварцевого генератора широко используется в импульсной технике примерно с середины 50-х годов прошлого столетия. Здесь синхронизация является полезным эффектом. Синхронизация используется с пользой во многих горных машинах - сепараторах, грохотах. Однако если синхронизация возникла в системе нескольких электродвигателей, которые создают повышенную нагрузку на платформу, где они установлены, то синхронизация - явление вредное.

В работах $[28,30,41]$ исследовалась математическая модель системы двух двигателей, установленных на общем упругом основании:

$$
\left\{\begin{array}{c}
m \ddot{y}+p y-m_{1} r_{1}\left(\ddot{\varphi}_{1} \sin \varphi_{1}+\dot{\varphi}_{1}^{2} \cos \varphi_{1}\right)-m_{2} r_{2}\left(\ddot{\varphi}_{2} \sin \varphi_{2}+\dot{\varphi}_{2}{ }^{2} \cos \varphi_{2}\right)=0, \\
I_{1} \ddot{\varphi}_{1}+H_{1}\left(\varphi_{1}, \dot{\varphi}_{1}\right)-L_{1}\left(\varphi_{1}, \dot{\varphi}_{1}\right)-m_{1} r_{1} \ddot{y} \sin \varphi_{1}=0, \\
I_{2} \ddot{\varphi}_{2}+H_{2}\left(\varphi_{2}, \dot{\varphi}_{2}\right)-L_{2}\left(\varphi_{2}, \dot{\varphi}_{2}\right)-m_{2} r_{2} \ddot{y} \sin \varphi_{2}=0 ;
\end{array},\right.
$$

где $m$ - масса платформы, абсолютно твердого тела с одной степенью свободы, характеризуемой линейным горизонтальным смещением $y ; p-$ коэффициент упругости платформы, связанной с неподвижным фундаментом (землей); $m_{i}-$ массы эксцентриков с эксцентриситетами $r_{i}$ (радиусы инерции); $I_{i}-$ моменты инерции роторов в отсутствие дисбаланса; $L_{i}\left(\varphi_{i}, \dot{\varphi}_{i}\right)$ - движущие моменты; $H_{i}\left(\varphi_{i}, \dot{\varphi_{i}}\right)-$ моменты сил сопротивления вращению роторов. Первое уравнение описывает вынужденные колебания платформы, второе и третье уравнения описывают динамику источников возбуждения, т.е. вращения роторов электродвигателей первого и второго соответственно.

В работах [28, 41] выяснено, что в системе происходит частотная синхронизация. При анализе режима синхронизации фазочастотная характеристика показывает, что при уменьшении коэффициента демпфирования обнаружены резкие скачки разности фаз, что нарушает режим синхронизации. При увеличении демпфирования скачки уменьшаются и в итоге не наблюдаются. Также в работах показано, что устойчивая фазовая синхронизация имеет место при синхронно-противофазном режиме - здесь разность фаз равна $\pi$. Для частичной проверки этих результатов был проведен эксперимент.

Рассмотрим следующую электромеханическую систему (рис. 6.15). На стальных крепежных пластинах жестко крепятся двигатели с одинаковыми механическими и частотными характеристиками. Крепежные пластины, в свою очередь, жестко закреплены на стальной платформе (основание). Вся система установлена на вибростенде, между вибростендом и 
платформой - гидроопоры. На каждом из двигателей жестко закреплены диски, с определенными эксцентриситетами, создающими различные моменты инерции. На левом двигателе закреплен больший диск с дополнительными грузами, создающими момент инерции $J_{1}=10,125 \cdot 10^{-5} \kappa^{\circ} \cdot \mathrm{M}^{2}$, а на правом двигателе $-J_{2}=6,125 \cdot 10^{-5} \kappa^{\cdot} \cdot \mathrm{M}^{2}$.

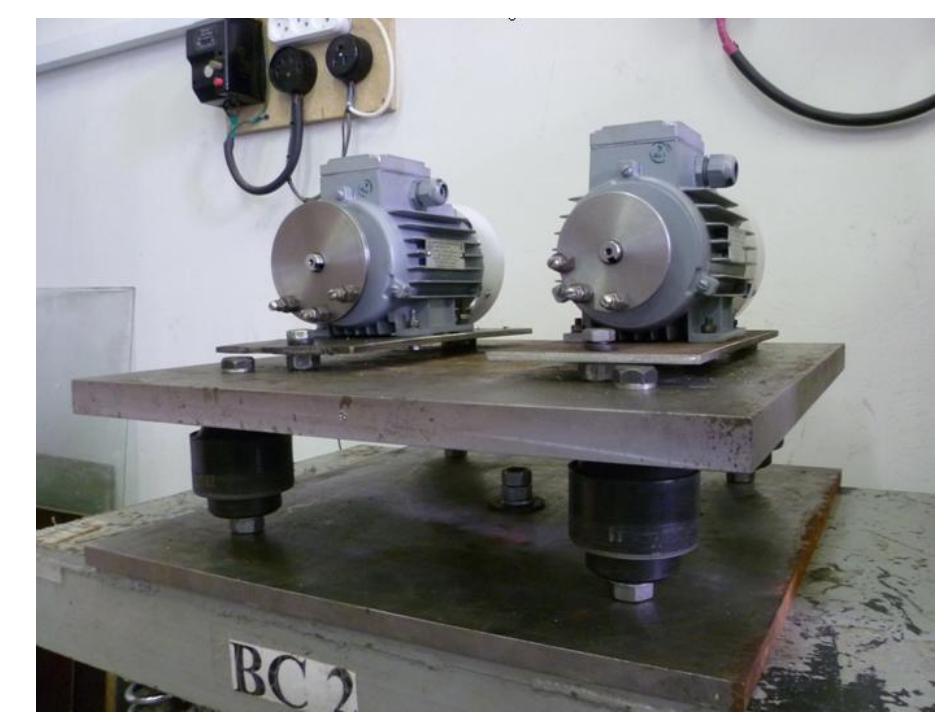

Рис. 6.15. Электромеханическая система

При испытаниях рассматривались следующие ситуации, спектры измерений которых представлены на рисунках: при выключенном вибростенде работает левый двигатель (рис. 6.16), при выключенном вибростенде работает правый двигатель (рис. 6.17), при выключенном вибростенде работают оба двигателя (рис. 6.18). Затем включили вибростенд на частоте $\Omega_{\text {вс }}=18$ Гц и провели те же самые испытания: при включенном вибростенде работает левый двигатель (рис. 6.19), при включенном вибростенде работает правый двигатель (рис. 6.20), при включенном вибростенде работают оба двигателя (рис. 6.21). После этого понизили моменты инерции у обоих двигателей, на левом двигателе момент инерции стал равен $J_{1}=6,48 \cdot 10^{-5} \kappa \Gamma^{\cdot} \mathrm{M}^{2}$, на правом двигателе $-J_{2}=3,92 \cdot 10^{-5} \kappa^{\cdot} \cdot \mathrm{M}^{2}$, и провели такие же испытания: при выключенном вибростенде работает левый двигатель (рис. 6.22), при выключенном вибростенде работает правый двигатель (рис. 6.23), при выключенном вибростенде работают оба двигателя (рис. 6.24), при включенном вибростенде работает левый двигатель (рис. 6.25), при включенном вибростенде работает правый двигатель (рис. 6.26), при включенном вибростенде работают оба двигателя (рис. 6.27). Вибростенд по-прежнему работает на частоте 18 Гц. На каждое испытание приходилось по 7 измерений уровня вибрации. Измерения уровней вибрации проводились прибором «ОКТАВА - 110». Датчики для измерений закреплялись на платформе между двигателями. 


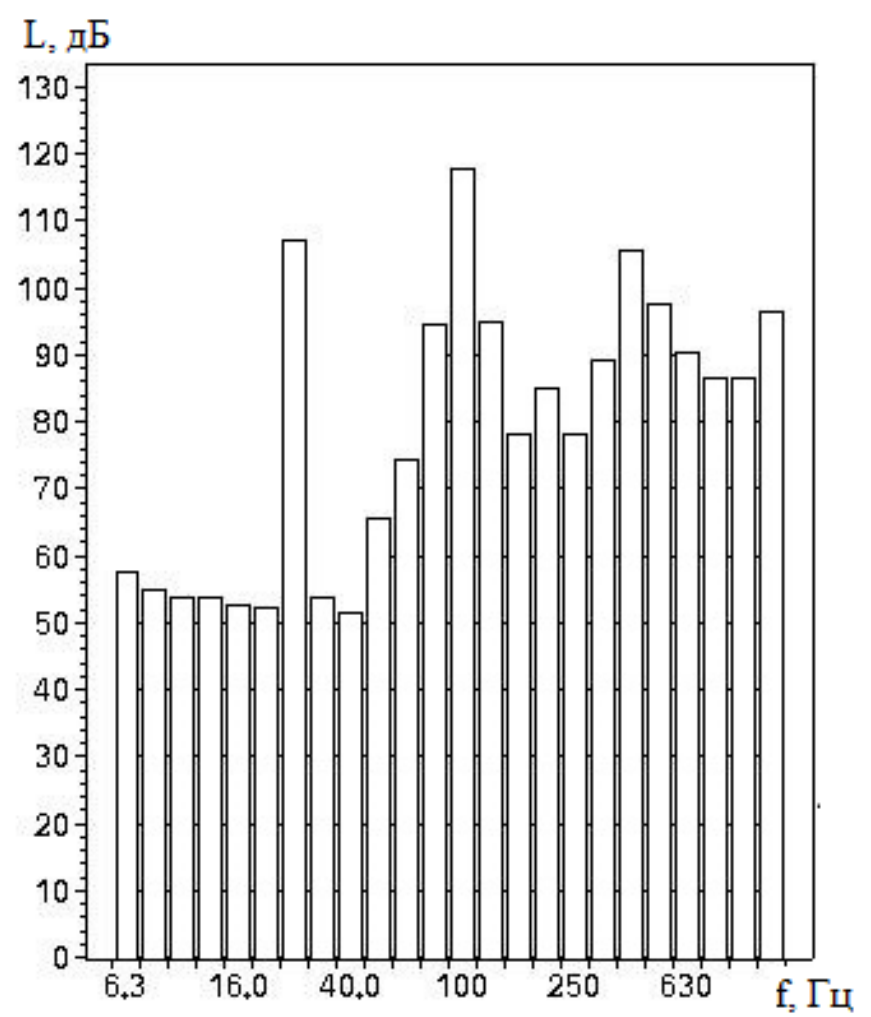

Рис. 6.16. Амплитудный спектр вибросигнала (левый двигатель, стенд выключен)

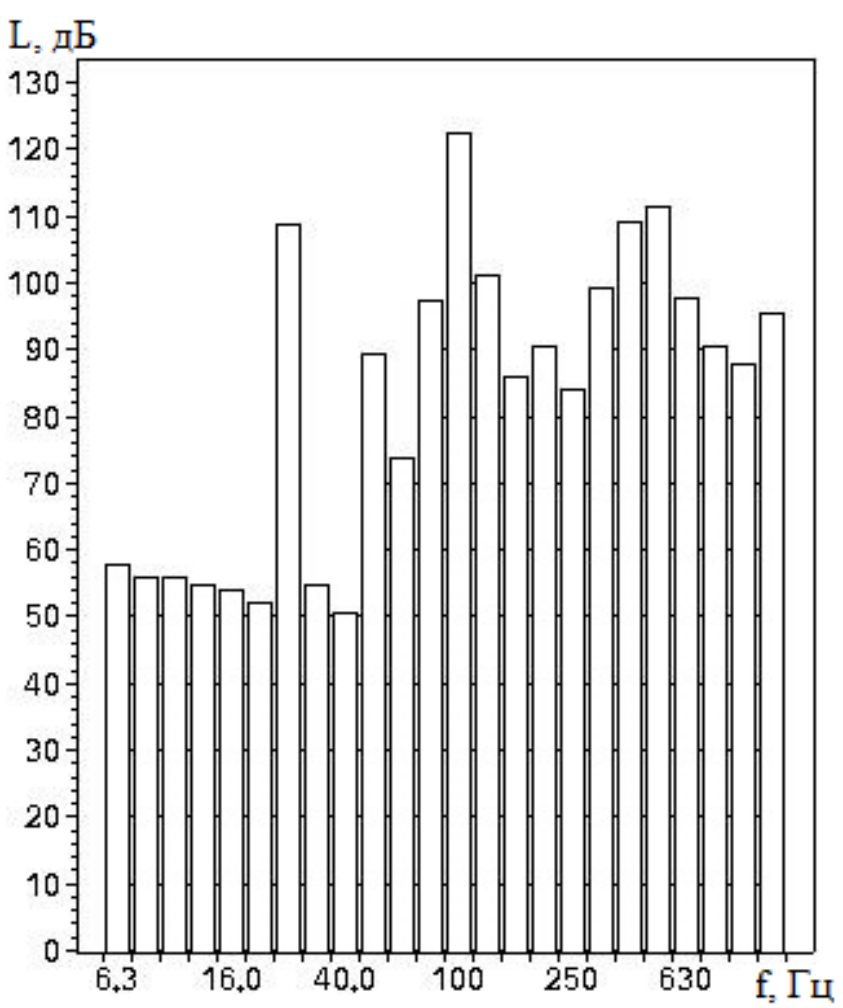

Рис. 6.18. Амплитудный спектр вибросигнала (два двигателя, стенд выключен)

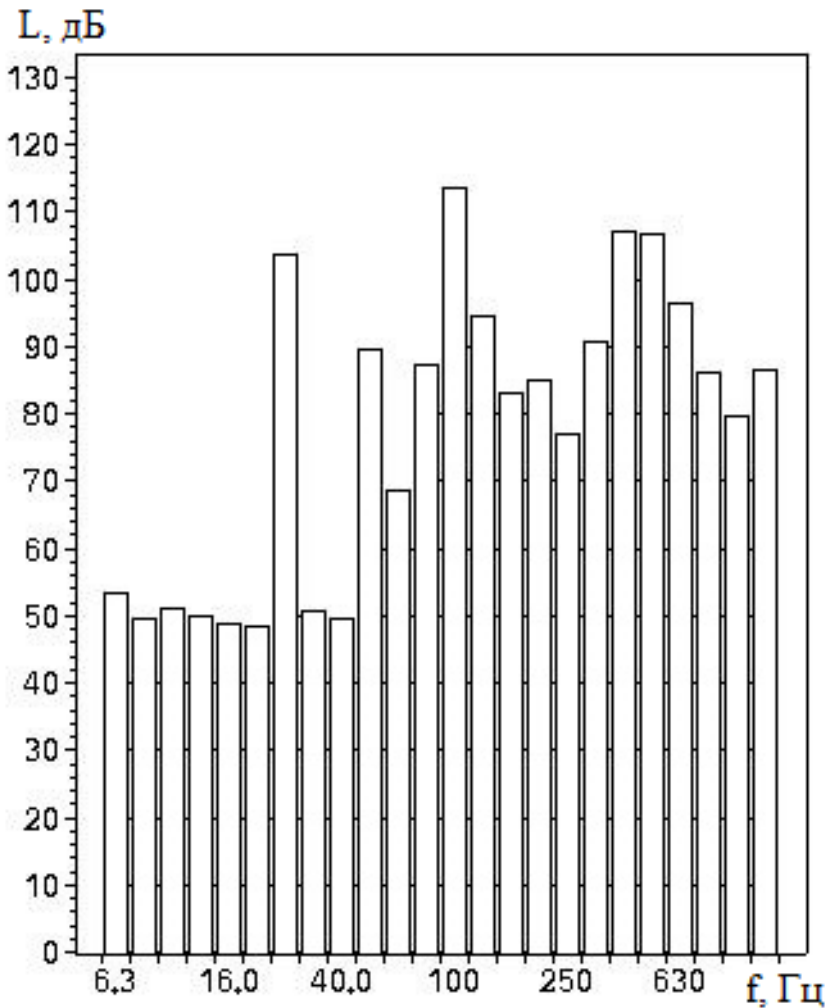

Рис. 6.17. Амплитудный спектр вибросигнала (правый двигатель, стенд выключен)

$\mathrm{L}$, дБ

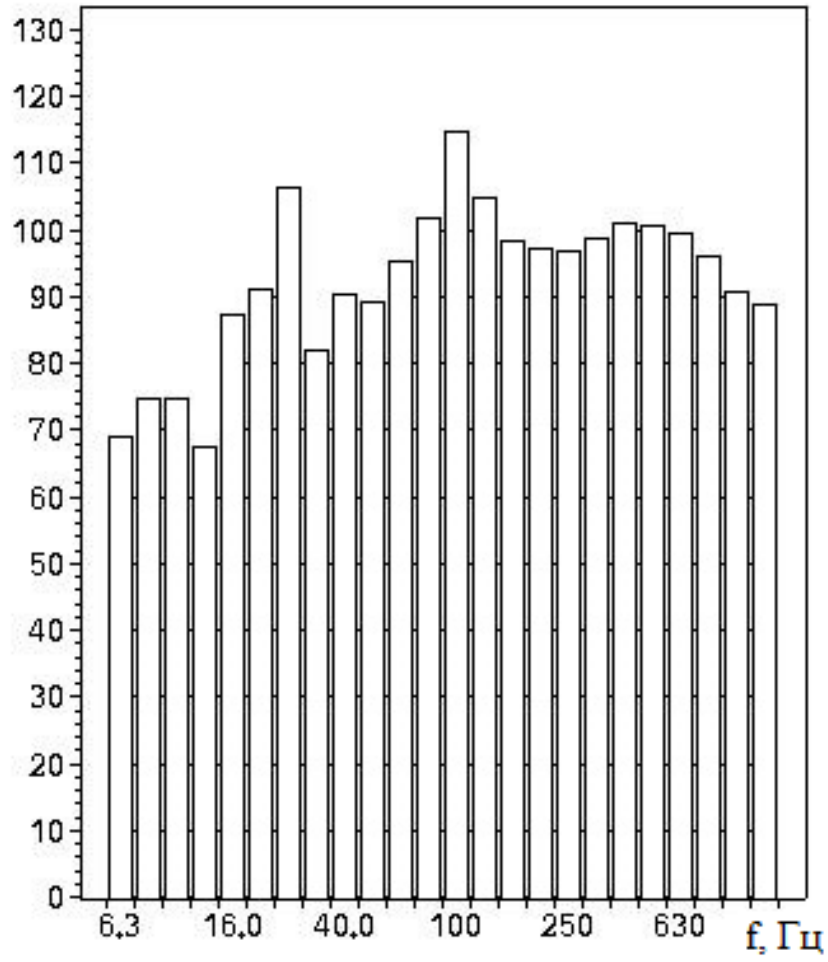

Рис. 6.19. Амплитудный спектр вибросигнала (левый двигатель, $\Omega_{\text {вс }}=18$ Гц) 

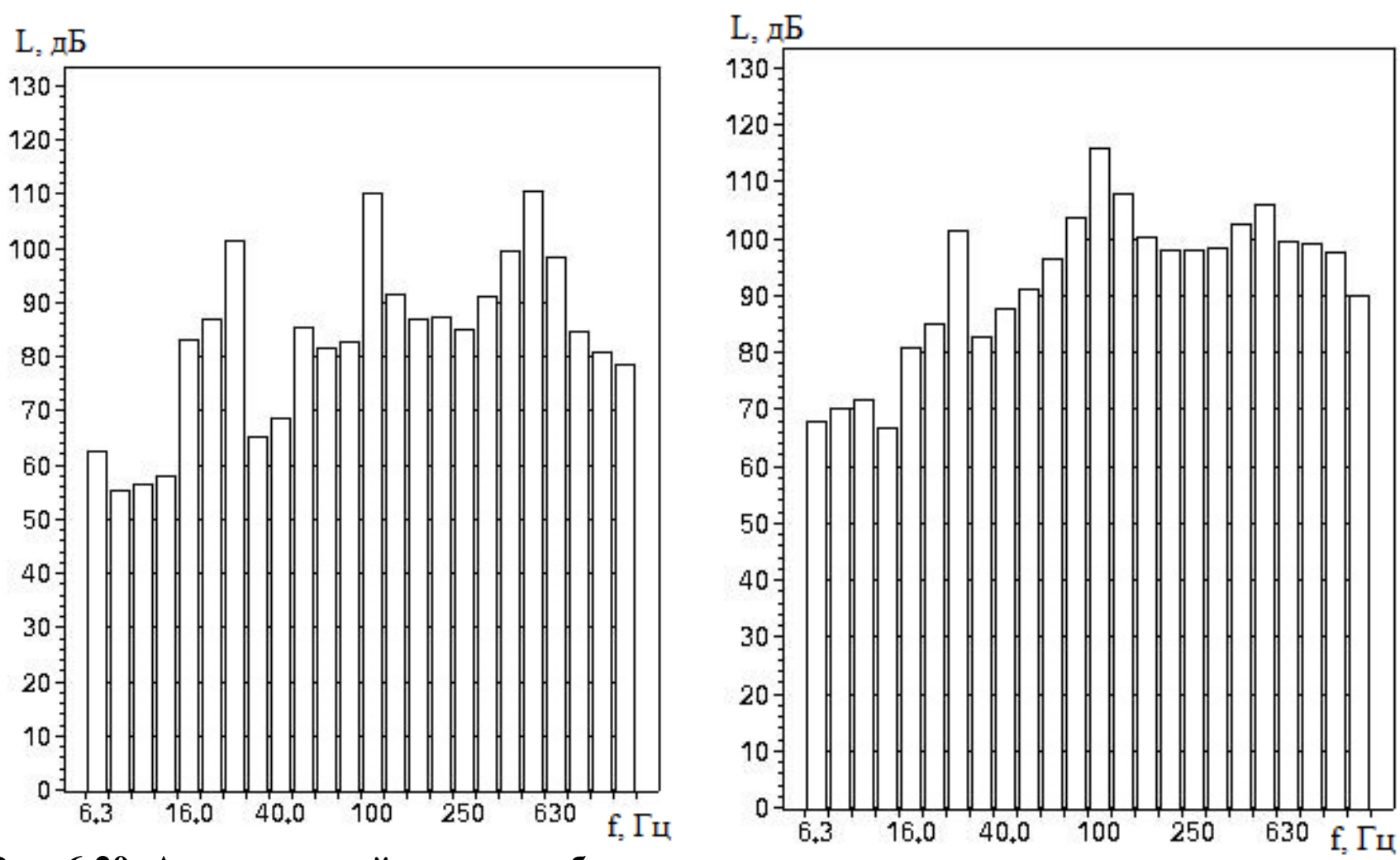

Рис. 6.20. Амплитудный спектр вибросигнала (правый двигатель, $\Omega_{\mathrm{Bc}}=18$ Гц)

Рис. 6.21. Амплитудный спектр вибросигнала (оба двигателя, $\Omega_{\mathrm{вc}}=18$ Гц)
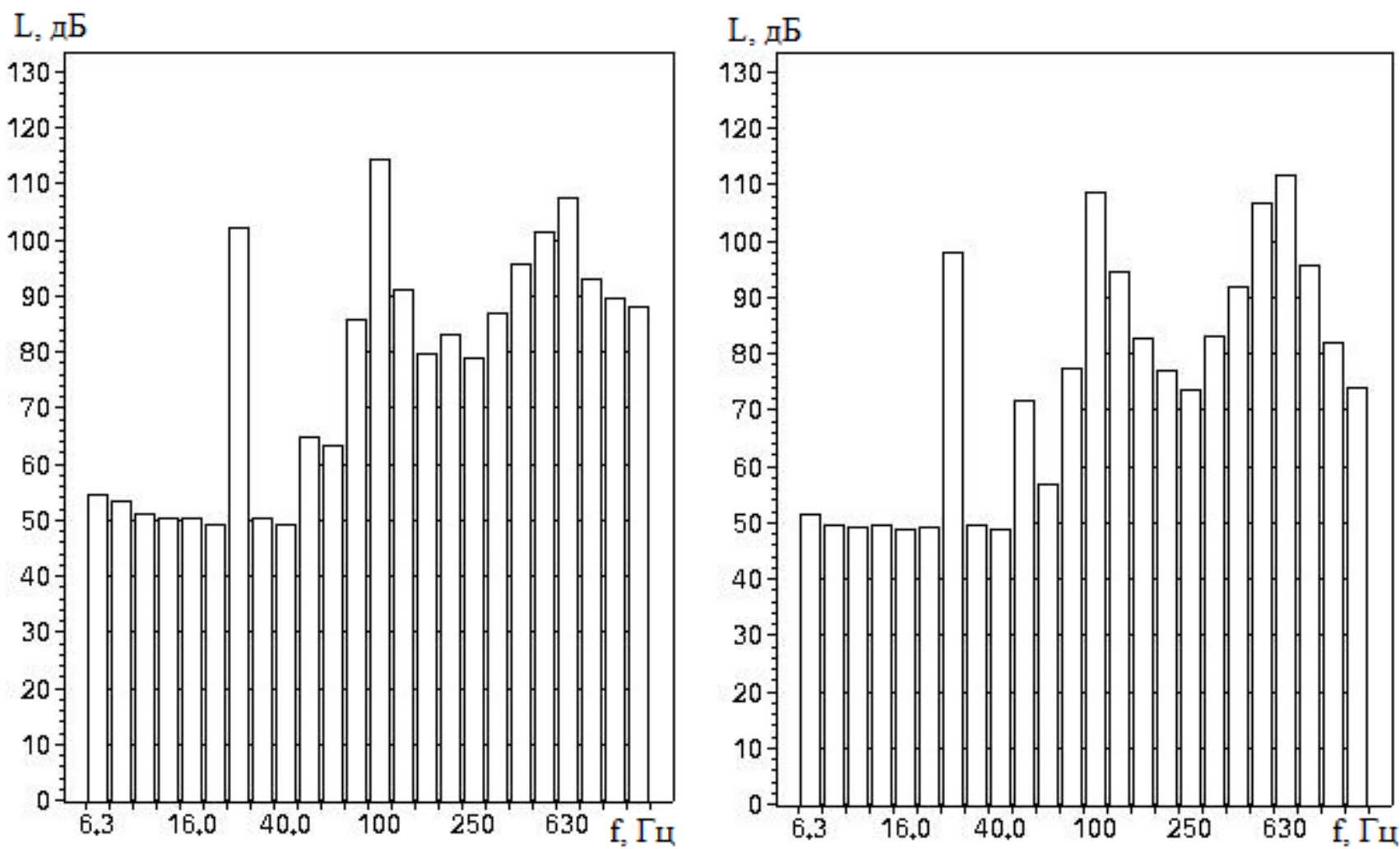

Рис. 6.22. Амплитудный спектр вибросигнала (левый двигатель, стенд выключен) Рис. 6.23. Амплитудный спектр вибросигнала (правый двигатель, стенд выключен) 


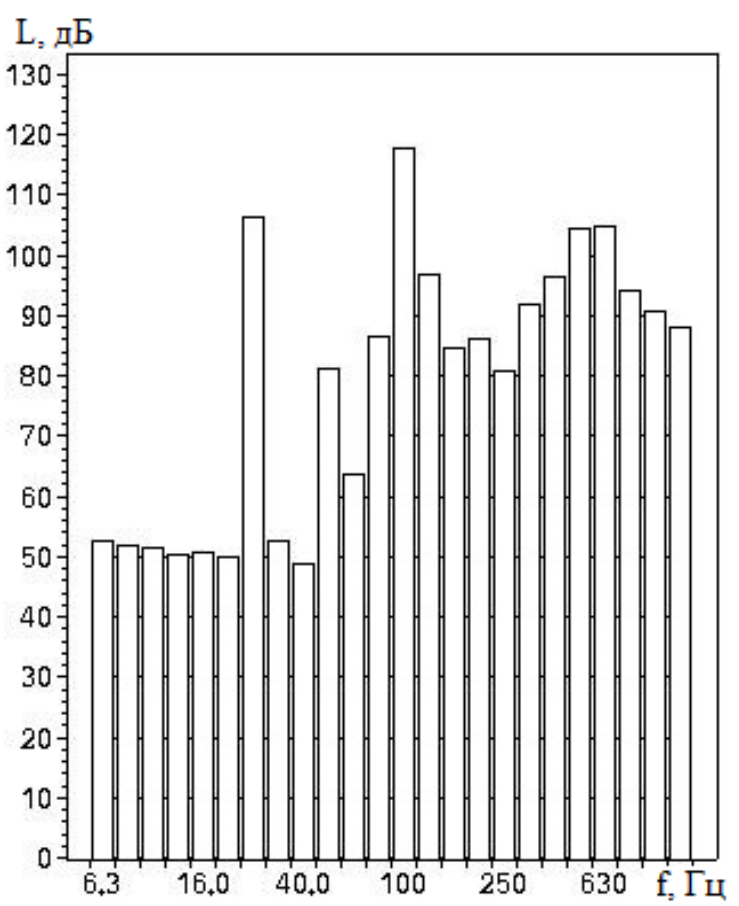

Рис. 6.24. Амплитудный спектр вибросигнала (два двигателя, стенд выключен)

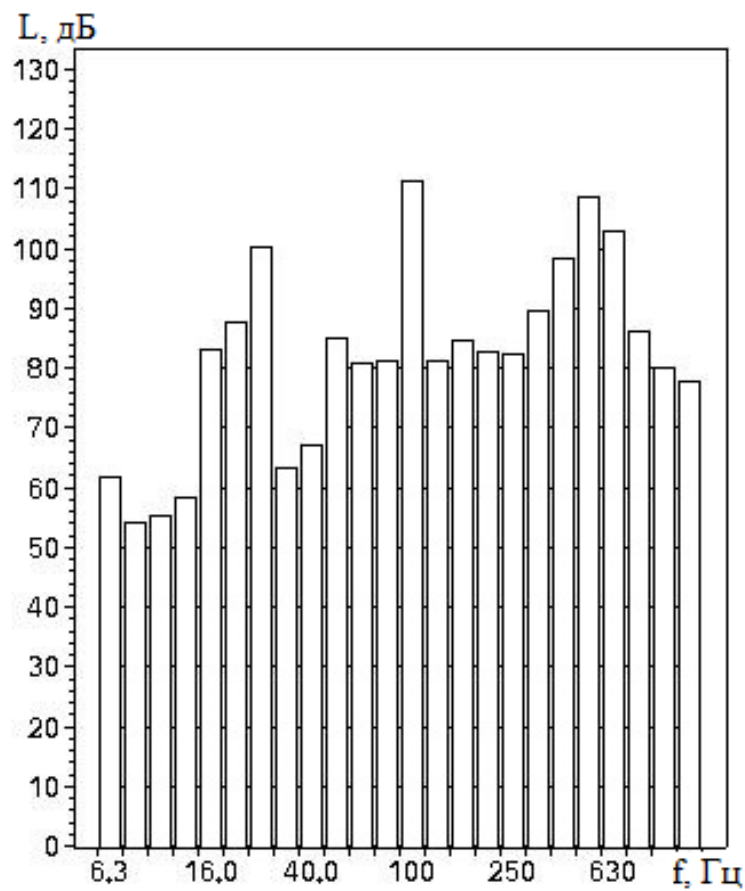

Рис. 6.26. Амплитудный спектр вибросигнала (правый двигатель, $\Omega_{\text {вс }}=18$ Гц)

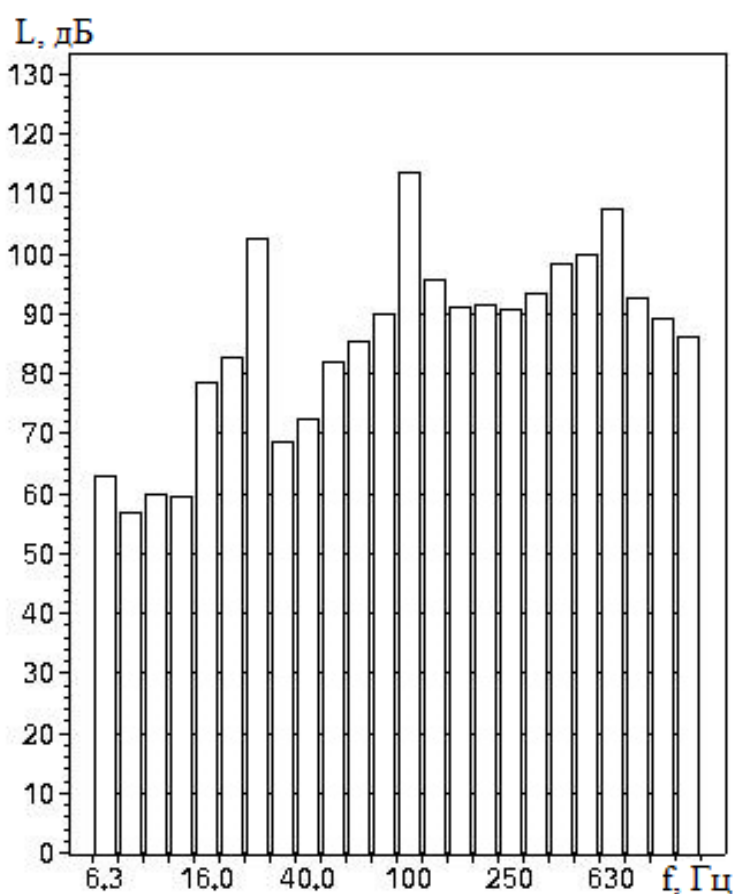

Рис. 6.25. Амплитудный спектр вибросигнала (левый двигатель, $\Omega_{\text {вс }}=18$ Гц)

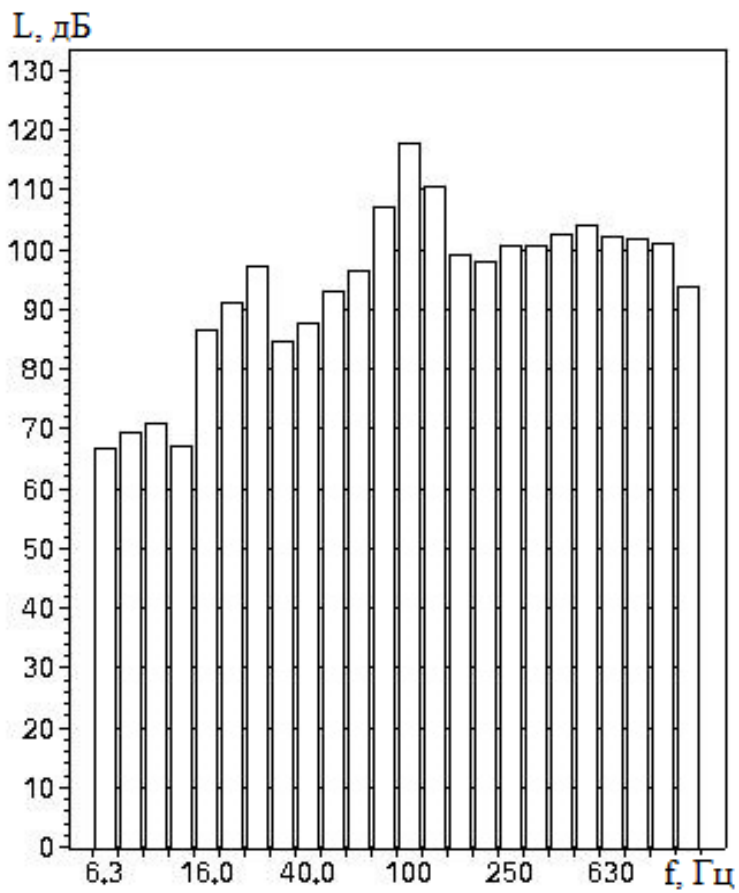

Рис. 6.27. Амплитудный спектр вибросигнала (оба двигателя, $\Omega_{\text {вс }}=18$ Гц)

Из спектров, представленных на рис. 6.16 и рис. 6.17 видно, что у обоих двигателей присутствует гармоника 22 Гц, что соответствует частоте вращения их роторов. Однако из этих же спектров следует, что уровень данной гармоники левого двигателя, в среднем, на четыре децибела выше. Здесь сказывается различие в моментах инерции. Из рис. 6.18 следует, что синхронизация происходит на той же частоте, на которой работает каж- 
дый из двигателей, но ее уровень выше, чем у каждого из них в отдельности, в среднем, на пять децибел.

Сравнивая спектры, представленные на рис. 6.16 и рис. 6.23, следует, что, уменьшая момент инерции эксцентрика для левого двигателя уменьшается и уровень вибрации основания на пять децибел. То же справедливо и для правого двигателя, уменьшая момент инерции эксцентрика посредством уменьшения неуравновешенной массы, уменьшается и уровень вибрации основания (рис. 6.17 и рис. 6.23). Но здесь уровень главной гармоники понизился на шесть децибел. Также амплитуда колебаний при синхронизации роторов двигателей с меньшими моментами инерции эксцентриков меньше, чем при синхронизации роторов двигателей с большими моментами инерции эксцентриков (рис. 6.18 и рис. 6.23). И в первом и во втором случаях с различными моментами инерции синхронизация осуществляется по правому двигателю, так как он при совместной их работе включался первым, устанавливался его рабочий режим, и только потом включался левый двигатель. Здесь эффект синхронизации проявлялся в явном виде. Синхронизация осуществлялась по тому двигателю, который уже имел установившийся режим работы, хотя момент инерции на его валу был меньше. Таким образом, уменьшая момент инерции эксцентриков роторов двигателей, уменьшается и амплитуда колебаний основания, что естественно ведет к снижению уровня вибрации и шума. Однако амплитуда колебаний при синхронизации роторов двигателей с меньшими моментами инерции эксцентриков возрастает на большую величину по сравнению с амплитудой колебаний, измеренной при синхронизации роторов двигателей с большими моментами инерции эксцентриков (рис. 6.18 и рис. 6.24).

При включенном вибростенде, также как и при выключенном вибростенде, при уменьшении момента инерции эксцентриков роторов на каждом из двигателей, амплитуды колебаний уменьшаются, как при работе каждого из двигателей отдельно (рис. 6.19, рис. 6.20, рис. 6.25, рис. 6.26), так и при совместной работе обоих двигателей, вступивших в режим синхронизации (рис. 6.21 и рис. 6.27). Следует отметить, что при включенном вибростенде время переходных процессов от момента включения двигателей до установки их стационарного режима работы возрастает, в среднем, на 30\%. Кроме того, увеличивается потребление энергии на 50\% и более. Это свидетельствует о наличии потенциального барьера при разгоне электродвигателей на вибрирующем основании.

Амплитуда колебаний при синхронизации роторов двигателей выше, чем при работе каждого из двигателей отдельно, при условии, что вибростенд выключен (рис. 6.16 - рис. 6.18, рис. 6.22 - рис. 6.24). Что свидетель- 
ствует о негативном влиянии синхронизации и увеличении уровня вибрации. При включении же вибростенда амплитуда колебаний основания при синхронизации роторов двигателей не превышает минимального из значений амплитуд колебаний основания при работе каждого из двигателей отдельно (рис. 6.19 - рис. 6.21, рис. 6.25 - рис. 6.27).

Из рис. 6.21 видно, что уровень вибрации основной гармоники 22 Гц при синхронизации роторов двигателей на работающем вибростенде уменьшился, по сравнению с уровнем вибрации, измеренным при синхронизации роторов двигателей на неработающем вибростенде на 8 дБ (рис. 6.18). При этом уровни низкочастотных гармоник от 6 до 20 Гц увеличились на 15-20 дБ, что соответствует энергетическому перераспределению за счет возможных биений. Здесь же видно возросшее насыщение высокочастотными гармониками спектра от 100 до 800 Гц, обусловленное нелинейными эффектами при работе вибростенда (рис. 6.21, рис. 6.27).

Для экспериментальной проверки изложенной концепции на вибрационном стенде закреплялись асинхронные электродвигатели с номинальной мощностью 250 Вт, измерялось значение пускового тока и время переходных процессов установления номинального режима работы двигателей при различных частотах действующей на них вибрации. Частота вибростенда изменялась от 10 до 60 Гц с шагом 5 Гц.

Стендовые испытания асинхронных электродвигателей показали следующее:

- на частотах вибрации 40-45 Гц потребляемый пусковой ток возрастал до 3 А, при номинальном токе 0,95 А;

- время переходных процессов возрастало в пять раз, что свидетельствует о явлениях синхронизации частоты при разгоне электродвигателей;

- в спектре выходного сигнала появлялась низкочастотная составляющая 1-3 Гц, которая является диагностическим признаком биений.

Биения, обусловленные фазовой рассогласованностью электродвигателей, являются наиболее негативными факторами действия вибрации на окружающую среду. Наиболее заметно это действие в системах, насыщенных мощным энергетическим оборудованием на мобильных объектах - в наземном и подземном электротранспорте. Синхронизация приводит не только к генерации низкочастотных гармоник, она способствует снижению экономичности и возрастанию энергозатрат электротранспорта.

При закреплении электродвигателей на платформе с гидроопорами их пусковой ток на частотах вибростенда 40-45 Гц превышал номинальный не более чем на 50\%. Таким образом, потребляемый электродвигате- 
лем пусковой ток при закреплении его на гидроопорах снижается в четыре раза.

В переходных режимах работы силовых агрегатов (электродвигателей) возникают процессы синхронизации и захватывания частоты. Суть этих эффектов состоит в том, что несколько объектов, совершающих при отсутствии взаимодействия колебательные или вращательные движения с различными частотами (угловыми скоростями), при наличии даже весьма слабых связей (взаимодействий), начинают двигаться с одинаковыми или соизмеримыми частотами (угловыми скоростями», причем устанавливаются определенные фазовые соотношения между колебаниями и вращениями [76]. Такие эффекты экспериментально наблюдались при исследовании вибрационных полей электровоза, в переходных режимах работы электродвигателей.

В работе [40] проведен анализ применения гидроопор для гашения вибраций возбуждаемых силовыми агрегатами электровоза. Средний уровень виброактивности с использованием гидроопор снижался на 20 дБ, что соответствует снижению потребляемой мощности при разгоне на два порядка.

Затянутый пуск второго асинхронного двигателя, установленного на общем основании с первым двигателем, работающем в номинальном режиме может быть объяснен следующим рис. 6.28. На рис. 6.28 показано 1 - механическая характеристика второго асинхронного двигателя, 2 момент, создаваемый вибрациями общего основания при вращении первого асинхронного двигателя. Вращение асинхронного двигателя создает вибрации основания $a(t)$, которые можно измерить как вибрационное ускорение м/ $\mathrm{c}^{2}$. Тогда момент, создаваемый основанием, приведенный к валу двигателя $M_{\text {прив }}=r \cdot F$, где $r-$ расстояние до смещенного центра массы, вызванного эксцентриситетом; $F=a(t) \cdot\left(m_{\text {основ }}+m_{\text {д }}\right)$ - сила созданная вибрацией основания, $m_{\text {основ }}-$ масса основания, $m_{\text {д }}$ - суммарная масса двигателей установленных на основании. Если вибрацию основания $a(t)$ представить в виде суммы гармонических сигналов, то можно представить момент $M_{\text {прив }}$ как моменты на разных частотах.

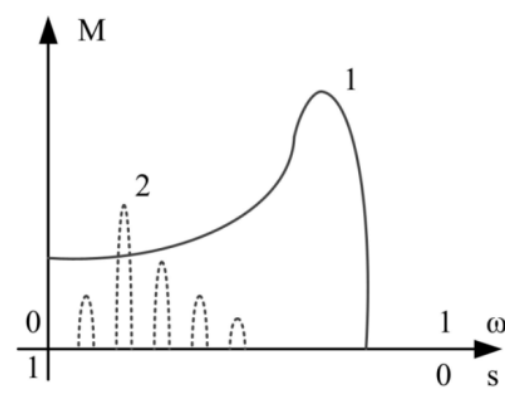

Рис. 6.28. Механическая характеристика асинхронного двигателя и момента, создаваемого вибрацией 


\section{4. Синтез комплексной системы ослабления вибраций электромеханического комплекса}

На рис 6.29 показана комплексная система, включающая виброзащитные гидроопоры с магнитореологическим преобразователем (ГО), электромеханический фильтр на основе ПЧ, активный фильтр гармоник (АФГ).

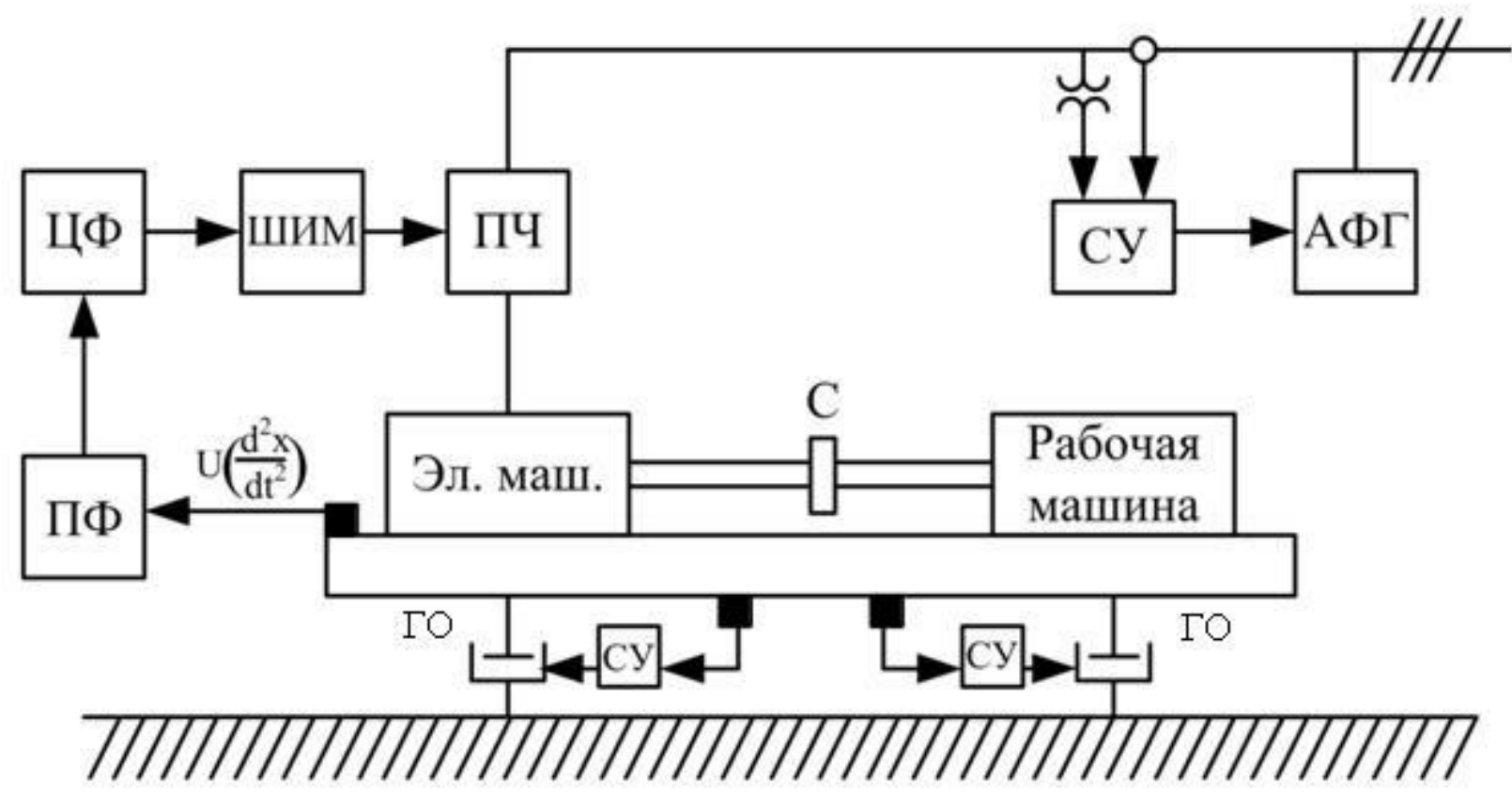

Рис. 6.29. Комплексная система ослабления вибраций:

- - акселерометр

Электрическая машина соединена через упругий элемент $C$ с рабочей машиной. Обе машины установлены на общей платформе, соединенным с основанием через гидроопоры.

1. Виброзащитные гидроопоры. При испытании были получены зависимости переходной жёсткости гидроопор от их частоты возбуждения [73].

Управление гидроопорой осуществляется от микропроцессорной системы управления (СУ). Сигнал с акселерометра (датчика вибраций) поступает на СУ, которая управляет жесткостью гидроопоры.

2. Электромеханический фильтр. В состав ПЧ входит инвертор напряжения, который формирует напряжение, питающее электрический двигатель таким образом, чтобы генерировать пульсации электромагнитного момента $\Delta M$, которые зависят от вибраций платформы. Сигнал с акселерометра обрабатывается с помощью преобразования Фурье, которое позволяет выбрать определенные частоты колебаний для генерации «антипульсаций» момента $\Delta M$. 
3. Активный фильтр гармоник выполняет функцию электромагнитной совместимости с сетью, а в случае если используется машина двойного питания или ПЧ - непосредственный ПЧ, активный фильтр гармоник снижает вибрации, вызванные высшими гармониками сетевого тока. Активный фильтр гармоник работает в режиме параллельного активного фильтра, его система управления основана на теории мгновенной мощности, которая позволяет компенсировать как высшие гармоники, так и реактивную мощность в соответствии с табл. 6.1.

Таблица 6.1

Результаты компенсации разных составляющих потребляемой неактивной мощности

\begin{tabular}{|c|c|c|c|c|}
\hline \multicolumn{4}{|c|}{$\begin{array}{l}\text { Составляющие мощ- } \\
\text { ности, подлежащие } \\
\text { компенсации }\end{array}$} & \multirow[t]{2}{*}{ Результат компенсации } \\
\hline $\bar{p}$ & $\tilde{p}$ & $\bar{q}$ & $\tilde{q}$ & \\
\hline- & - & + & + & $\begin{array}{l}\text { Компенсация реактивной мощности, в результате коэф- } \\
\text { фициент мощности равен } 1 \text {. Компенсация ВГ тока, свя- } \\
\text { занных с составляющей } \tilde{q}\end{array}$ \\
\hline - & - & + & - & $\begin{array}{l}\text { Компенсация реактивной мощности, в результате коэф- } \\
\text { фициент мощности равен } 1\end{array}$ \\
\hline- & + & - & - & $\begin{array}{l}\text { Компенсация ВГ тока, связанных с составляющей } \\
\tilde{p} . \text { Если первичный источник мощности содержит турбо- } \\
\text { генератор, то компенсация устранит пульсации электро- } \\
\text { магнитного (вращающего) момента на роторной оси } \\
\text { электрической машины }\end{array}$ \\
\hline - & + & - & + & $\begin{array}{l}\text { Компенсация ВГ, в результате компенсированный ток } \\
\text { синусоидален }\end{array}$ \\
\hline- & + & + & + & $\begin{array}{l}\text { Компенсация ВГ и реактивной мощности, ток сети сину- } \\
\text { соидален, компенсатор и нелинейная нагрузка представ- } \\
\text { ляют собой чисто активную нагрузку }\end{array}$ \\
\hline
\end{tabular}

Каждая из подсистем виброзащитного комплекса была описана ранее в тексте данной работы. Работоспособность этих подсистем доказана результатами экспериментов и моделирования. 


\section{ЗАКЛЮЧЕНИЕ}

Рассмотрены электромеханические комплексы в составе сети их электроснабжения, представлены математические модели наиболее распространенного электромеханического преобразователя - асинхронного двигателя. На основании моделей получены оценки зависимостей коэффициента мощности, пульсаций электромагнитного момента, искажения сетевого тока и падения напряжения в переходных процессах, при анализе которых сделан вывод о формировании структуры сети электроснабжения с организованным энергообменом посредством активных компенсирующих устройств.

Предложено использование активных фильтров гармоник в целях ослабления вибрации машин и негативного влияния на сеть гармоник потребляемого тока. Управление преобразователем частоты - активным выпрямителем и инвертором - позволяет компенсировать реактивную мощность, потребляемую из сети, обеспечивать фильтрацию сетевого тока и напряжения, а также создавать пульсации электромагнитного момента электрической машины в целях подавления нежелательных вибраций, т.е. реализовать электромеханический фильтр.

Результаты экспериментальных исследований эффектов, возникающих при синхронизации двух асинхронных двигателей, закрепленных на упругом основании, поясняют два основных варианта: синхронизация на неподвижном упругом основании; синхронизация при вибрирующем основании за счет сторонних внешних воздействий. Проведенный анализ спектров выявил информативные гармонические составляющие, позволяющие судить о порядке включения двигателей до синхронизации. В результате эксперимента было показано, что синхронизация осуществляется по тому двигателю, который ранее достиг стационарного режима. Обнаружено возрастание энергетического насыщения низкочастотных гармоник спектра при синхронизации двигателей на вибрирующем основании.

Описана интегральная система ослабления вибраций электромеханического комплекса, включающая в себя комплект виброзащитных гидроопор, электромеханический фильтр вибрационных колебаний на основе преобразователя частоты и активный фильтр гармоник. Микропроцессорная система управления позволяет контролировать жесткость гидроопор на резонансных частотах электромеханического комплекса, осуществлять преобразование Фурье и реализовать управление токами компенсации неактивных составляющих потребляемой из сети электрической мощности. 


\section{СПИСОК ЛИТЕРАТУРЫ}

1. Андронов, А.А. К математической теории захватывания / А.А. Андронов, А.А. Витт // Журн. прикл. физики. - 1930. - Т. 7. № 4. - С. 3-20.

2. Андронов, А.А. Собрание трудов. / А.А. Андронов, А.А. Витт. M.: АН CCCP, 1956. -538 c.

3. Анишев, Е.Ю. Опыт применения бесконтактных датчиков крутящего момента на испытательных стендах // Труды Нижегородского государственного технического университета им. Р.Е. Алексеева. - 2010. № 4(83). - С. 205-210.

4. Арнольд, В.И. Дополнительные главы теории обыкновенных дифференциальных уравнений / В.И. Арнольд. - М.: Наука, 1978. - 304 с.

5. Арриллага, Дж. Гармоники в электрических системах: пер. с англ. / Дж. Арриллага, Д. Бредли, П. Боджер. - М.: Энергоатомиздат, 1990. - $320 \mathrm{c}$.

6.Арфкен, Т. Математические методы в физике: пер. с анг. / Т. Арфкен. - М.: Атомиздат, 1970. - 412 с.

7. Бабаков, И.М. Теория колебаний. / И.М. Бабаков. - М.: Наука, 1968. $-560 \mathrm{c}$.

8. Бакланов, В.С. Анализ реактивных свойств динамических жесткостей и передаточных функций гидроопор / В.С. Бакланов, А.С. Горобцов, С.К. Карцов, А.В. Синев, В.В. Фролов // Проблемы машиностроения и надежности машин. - 1999. - №3. - С. 31-37.

9. Баранов, П.Р. Математическая модель асинхронного двигателя со встроенным электромагнитным приводом тормозного устройства // Известия Томского политехнического университета. - 2006. - Т. 309, № 1. - С. 159 - 163.

10.Барсуков, И.Б. Гармонические искажения при работе преобразователей частоты / И.Б. Барсуков, Е.В. Вдовенко, Е.В. Цыганов // Главный энергетик. - 2011. - №6. - С. 5-15.

11. Башарин, А.В. Управление электроприводами. / А.В. Башарин, В.А. Новиков, Г.Г. Соколовский. - Л.: Энергоиздат, 1982. - 392 с.

12. Башарин, А.В. Примеры расчета автоматизированного привода на ЭВМ. / А.В. Башарин, Ю.В. Постников. - Л.: Энергоатомиздпт, 1990. $-512 \mathrm{c}$.

13. Биргер, И.А. Расчет на прочность деталей машин. / И.А. Биргер, Б.Ф. Шор, Р.М. Шнейдерович. - М.: Машиностроение, 1966. - 616 с.

14. Бессонов, Л.А. Теоретические основы электротехники. / Л.А. Бессонов. - М.: Высшая школа, 1967. - 775 с.

15. Бессонов, Л.А. Теоретические основы электротехники. Электромагнитное поле. / Л.А. Бессонов. - М.: Высшая школа, 1978. - 232 с. 
16. Блехман, И.И. Синхронизация в природе и технике. / И.И. Блехман. - М.: Наука, 1971. - 352 с.

17.Блехман, И.И. Синхронизация динамических систем. / И.И. Блехман. - М.: Наука, 1971. - 896 с.

18. Блехман, И.И. Вибрационная механика. / И.И. Блехман. - М.: Физматлит, 1994. 391 с.

19. Блехман, И.И. Вибрации в технике, Т.2. Колебания нелинейных механических систем. / И.И. Блехман [и др.]. - М.: Машиностроение, 1979. $-351 \mathrm{c}$.

20.Борисов, Л.А. Борьба с шумом на производстве: справочник. / Л.А. Борисов [и др.]. - М.: Машиностроение, 1985. - 400 с.

21. Браславский, И.Я. Энергосберегающий асинхронный электропривод. / И.Я. Браславский, З.Ш. Ишматов, В.Н. Поляков. - М.: ACADEMA, 2004.- 243 c.

22. Вагин, Г.Я. Экономия энергии в промышленности: учеб. пособие. / Г.Я. Вагин, А.Б. Лоскутов; Нижегород. гос. техн. ун-т., - Н. Новгород, 1998. - 220 с.

23. Вагин, Г.Я. Электромагнитная совместимость в электроэнергетике: учебное пособие. / Г.Я. Вагин, А.Б. Лоскутов, А.А. Севостьянов; Нижегород. гос. техн. ун-т., - Н. Новгород, 2004. - 214 с.

24. Вегера, Ж.Г. Эффекты структурной организации коллоидных частиц и микрочастиц дисперсного немагнитного наполнителя в магнитной жидкости при ее взаимодействии с электрическим и магнитным полями: дис. ... канд. физ.-мат. наук. - Ставрополь, 2004. - 156 с.

25. Вибрация энергетических машин: справочное пособие / под ред. Н.В. Григорьева. - Л.: Машиностроение, 1974. - 464 с.

26. Висящев, А.Н. Качество электрической энергии и электромагнитная совместимость в электроэнергетических системах: учеб. пособие Ч. 1. / А.Н. Висящев. - Иркутск, 1997. - 187 с.

27. Висящев, А.Н. Качество электрической энергии и электромагнитная совместимость в электроэнергетических системах: учеб. пособие. Ч. 2. / А.Н. Висящев. - Иркутск, 1997. - 92 с.

28. Гордеев, Б.А. Причины возникновения фазовой синхронизации двух асинхронных двигателей в зависимости от параметров системы / Б.А. Гордеев, А.В. Леонтьева // Прикладная механика и технологии машиностроения: моделирование динамических систем сборник научных трудов. - Н. Новгород, 2011. - Вып. 3. - С. 80-90.

29. Гордеев, Б.А. Математические модели виброзащитных систем: монография / Б.А. Гордеев. - Н. Новгород: ННГАСУ, 2008. - 129 с. 
30. Гордеев, Б.А. Причины возникновения синхронизации в рельсовом транспорте / Б.А. Гордеев, А.Б. Гордеев, Д.А. Ковригин, А.В. Леонтьева // Приволжский научный журнал. - 2009. - № 4. - С. 47-53.

31. Гордеев, Б.А. Условия возникновения частотной синхронизации двух асинхронных двигателей в зависимости от характеристик основания / Б.А. Гордеев, А.В. Леонтьева // Вестник научно-технического развития. 2011.- №10(50). - С. 14-24.

32. Гордеев, Б.А. Устранение гистерезисных эффектов в ферромагнитных сердечниках электромеханических преобразователей гидравлических виброопор / Б.А. Гордеев, А.Н. Осмехин, С.Н. Охулков, А.С. Плехов // Вестник ИГЭУ. - 2013. - №5. - С. 64-68.

33. Гордеев, Б.А. Методы расчета основных параметров газогидравлических виброопор и результаты экспериментальных исследований / Б.А. Гордеев, Е.И. Абакумов // Прикладная механика и технологии машиностроения: тезисы докл. конф. - Н. Новгород, 1997. - С. 10-15.

34. Гордеев, Б.А. Применение газогидравлических виброопор в машиностроении / Б.А. Гордеев, Е.И. Абакумов // Проблемы машиностроения: тезисы докл. конф. - Н.Новгород, 1997. - С. 40-45.

35. Гордеев, Б.А. Установка с бесконтактным магнитореологическим преобразователем для измерения скорости магнитореологических жидкостей / Б.А. Гордеев, В.В. Бугайский, С.Н. Охулков, П.Н. Морозов // Прикладная механика и технология машиностроения: тезисы докл. конф. - Н. Новгород, 2005. - С. 86-100.

36. Гордеев, Б.А. Методы расчета демпфирующих характеристик газогидравлических виброопор транспортных средств / Б.А. Гордеев, А.И. Весницкий, Е.И. Абакумов // 4th International scientific conference of railway experts: тезисы докл. конф. (Vrnjacka Banja 2 - 4 Oct. 1997) - Vrnjacka Banja, 1997. - P. 325-328.

37. Гордеев, Б.А. Применение инерционных электрореологических трансформаторов в системах виброизоляции / Б.А. Гордеев, В.И. Ерофеев, А.В. Синев // Проблемы машиностроения и надежности машин. - 2003. №6. - C. 22-27.

38. Гордеев, Б.А. Взаимодействие силового агрегата моторкомпрессора электровоза с вибрационными полями в переходных режимах / Б.А. Гордеев [и др.]. // Проблемы машиностроения и надежности машин. - 2002. - № 4. - С. 105-111.

39. Гордеев, Б.А. Динамика протекания магнитореологической жидкости в дроссельных каналах при действии магнитных полей / Б.А. Гордеев [и др.]. // Проблемы машиностроения и надежности машин. - 2007. №2. - С. 95-99. 
40. Гордеев, Б.А. Системы виброзащиты с использованием инерционности и диссипации реологических сред. / Б.А. Гордеев [и др.]. - М.: Физматлит, 2004. - 173 с.

41. Гордеев, Б.А. Задача синхронизации вращения пары двигателей на упругом основании / Б.А. Гордеев, Д.А. Ковригин, А.В. Леонтьева // Вестник машиностроения. - 2011. - № 10. - С. 3-7.

42. Гордеев, Б.А. Особенности метрологического обеспечения проведения экспериментальных исследований динамики магнитореологических жидкостей / Б.А. Гордеев [и др.]. // Проблемы машиностроения и надежности машин. - 2008. - №1. - С. 95-99.

43. Гордеев, Б.А. Влияние остаточной магнитной индукции на амплитудно-частотные характеристики магнитореологических трансформаторов / Б. А. Гордеев [и др.]. // Вестник машиностроения. - 2014. №10. - С. 32-38.

44. Гордеев, Б.А. Течение и релаксация магнитореологической жидкости в дроссельных каналах гидроопор / Б.А. Гордеев [и др.]. // Вестник машиностроения. - 2015. - №7. - С.59-63.

45. Гордеев, Б.А. Физические основы и конструкция индукционного магнитореологического трансформатора гидроопор / Б.А. Гордеев [и др.]. // Прикладная механика и технология машиностроения. - 2011. №2. - С. 52-68.

46. Гордеев, Б.А. Оптимальное управление магнитореологическими трансформаторами гидроопор в системах виброзащиты / Б.А. Гордеев [и др.]. // Прикладная механика и технология машиностроения. - 2011. №2. - С. 31-42.

47. Дейс, Д.А. Электромагнитная совместимость в электроэнергетике: учеб. пособие. / Д.А. Дейс. - Чита: ЧитГУ, 2008. - 171 с.

48. Дмитриев, С.М. Алгоритмы управления активными фильтрами гармоник в составе электроприводов переменного тока / С.М. Дмитриев [и др.]. // Труды Нижегородского государственного технического университета им. Р.Е. Алексеева. - 2012. - № 2 (95). - С. 206-214.

49. Жгун, Д.В. Электромагнитная совместимость высоковольтной техники: учеб. пособие. / Д.В. Жгун. - Томск: Томский политехнич. университет, 2008. - 150 с.

50.Жежеленко, И.В. Высшие гармоники в системах электроснабжения промпредприятий / И.В. Жежеленко, - 4-е изд., перераб. и доп. - М.: Энергоатомиздат, 2000. - 331 с.

51.Жежеленко, И.В. Показатели качества электроэнергии и их контроль на промышленных предприятиях / И.В. Жежеленко, Ю.Л. Саенко, 3-е изд., перераб. и доп. - М.: Энергоатомиздат, 2000. - 252 с. 
52. Зайцев, А.И. Силовая промышленная электроника. / А.И. Зайцев, А.С. Плехов. - Воронеж: Научная книга, 2008. - 231 с.

53. Зинов ьев, Г.С. Основы силовой электроники: учебник. Ч.1. / Г.С. Зиновьев. - Новосибирск: НГТУ, 1999. - 199 с.

54. Зинов ьев, Г.С. Основы силовой электроники: учебник. Ч.2. / Г.С. Зиновьев.- Новосибирск: НГТУ, 2000. - 197 с.

55. Ильинский, Н.Ф. Основы электропривода. / Н.Ф. Ильинский. М.: МЭИ, 2000. - $141 \mathrm{c.}$

56.Ильинский, Н.Ф. Общий курс электропривода. / Н.Ф. Ильинский, В.Ф. Козаченко. - М.: Энергоатомиздат, 1992. - 544 с.

57. Калыгин, В.Г. Промышленная экология: учеб. пособие. / В. Г. Калыгин. - М.: Академия, 2004. - 432 с.

58. Кашканов, А.О. Нагружающее устройство для исследования энергосберегающего электропривода / А.О. Кашканов, А.С. Плехов, В.Г. Титов // Актуальные проблемы электроэнергетики: тезисы докл. Всероссийской конф. - Н. Новгород, 2011. - С.55-60

59. Кашканов, А.О. Энергосбережение на основе компенсационного преобразователя / А.О. Кашканов, А.С. Плехов, С.А. Фомин // Актуальные проблемы электроэнергетики: тезисы докл. Всероссийской конф. - Н. Новгород, 2009. - С. 177-179

60. Ключев, В.И. Теория электропривода. / В.И. Ключев. - М.: Энергоатомиздат, 1998. - 704 с.

61. Колосов, Ю.В. Защита от вибрации и шума на производстве: учеб. пособие. / Ю.В. Колосов, В.В. Барановский. - СПб: СПбГУ ИТМО, 2011. $-38 \mathrm{c}$.

62. Кононенко, В.О. Нелинейные колебания механических систем. / В.О. Кононенко. - Киев: Наук. думка, 1980. - 382 с.

63. Копылов, И.П. Математическое моделирование электрических машин. / И.П. Копылов, - 3-е изд., перераб. и доп. - М.: Высшая школа, 2001. - $327 \mathrm{c}$.

64. Копылов, И.П. Справочник по электрическим машинам: Т.1 / под общ. ред. И.П. Копылова, Б.К. Клокова. - М.: Энергоатомиздат, 1988. $-456 \mathrm{c}$.

65. Кухаркин, Е.С. Инженерная электрофизика. Техническая электродинамика: учеб. для вузов / Е.С. Кухаркин, - 2-е изд. перераб. и доп. М.: Высшая школа, 1978. - 520 с.

66. Левитанов, С.Д. К теории магнитоупругого преобразователя крутящего момента // Известия вузов. Электромеханика. - 1977. №3. - C. 304-310. 
67. Левинтов, С.Д. Бесконтактные магнитоупругие датчики крутящего момента / С.Д. Левинтов, А.М. Борисов. - М.: Энергоатомиздат, 1984. $-88 \mathrm{c}$.

68. Липкин, Б.Ю. Электроснабжение промышленных предприятий / Б.Ю. Липкин. - М.: Высшая школа, 1990. - 366 с.

69. Маквецов, Е.Н. Механические воздействия и защита радиоэлектронной аппаратуры: учебник / Е.Н. Маквецов, А.М. Тартаковский. - М.: Радио и связь, 1993. - 200 с.

70. Малсугенов, О.В. Каплеструйное движение магнитной жидкости в электрическом и магнитном полях: дис. ... канд. физ.-мат. наук. - Ставрополь, 2003. - $158 \mathrm{c}$.

71. Нагаев, Р.Ф. Квазиконсервативные синхронизирующиеся системы. / Р.Ф. Нагаев. - СПб.: Наука, 1996. - 252 с.

72.Немцов, М.В. Справочник по расчету параметров катушек индуктивности. / М.В. Немцов. - М.: Энергоатомиздат, 1989. - 192 с.

73. Охулков, С.Н. Разработка метода расчёта и конструкции магнитореологических трансформаторов гидроопор: дисс. ... канд. физ.-мат. наук. - Н. Новгород, 2011. - 225 с.

74. Охулков, С.Н. Расчет магнитореологических трансформаторов при ламинарном движении рабочей среды / С.Н. Охулков // Вторая Всероссийская конференция по волновой динамике машин и конструкций: тезисы докл. конф. - Н. Новгород, 2007. - С. 102-107.

75. Первачев, С.В. Радиоавтоматика: учебник для вузов. / С.В. Первачев. - М.: Радио и связь, 1982. - 296 с.

76. Пиковский, А. Синхронизация: фундаментальное нелинейное явление. / А. Пиковский, М. Розенблюм, Ю. Куртс. - М.: Техносфера, 2003 - 496 c.

77. Плехов, А.С. Энергосберегающие полупроводниковые источники реактивной мощности / А.С. Плехов [и др.]. // Промышленная энергетика. - 2012. - №5. - C. 47-51

78. Плехов, А.С. Активный фильтр гармоник сетевого напряжения / А.С. Плехов, Д.Ю. Титов // Будущее технической науки: тезисы докл. Международной конф. (Н. Новгород, 18 мая, 2011 г.). - Н. Новгород, 2011. - C. 111.

79. Плехов, А.С. Выбор силовой схемы активного фильтра гармоник / А.С. Плехов, Д.Ю. Титов // Актуальные проблемы электроэнергетики: тезисы докл. Всероссийской конф. (Н. Новгород, 20 декабря, 2012 г.). - Н. Новгород, 2012. - С. 50-54.

80. Плехов, А.С. Использование вейвлет преобразования для формирования тока задания активного фильтра гармоник / А.С. Плехов, Д.Ю. 
Титов // Будущее технической науки: тезисы докл. Международной конф. (Н. Новгород, 20 мая, 2013 г.). - Н. Новгород, 2013, С.115-116.

81. Плехов, А.С. Исследование алгоритмов управления активными фильтрами гармоник / А.С. Плехов, Д.Ю. Титов // Будущее технической науки: тезисы докл. Международной конф. (Н. Новгород, 12 мая, 2012 г.). - Н. Новгород, 2012. - С. 78.

82. Плехов, А.С. Определение емкости конденсатора в цепи постоянного тока активного фильтра гармоник / А.С. Плехов, Д.Ю. Титов // Актуальные проблемы электроэнергетики: тезисы докл. Всероссийской конф. (Н. Новгород, 22 декабря, 2013 г.). - Н. Новгород, 2013. - С. 163-167.

83. Плехов, А.С. Расчет емкости конденсатора в цепи постоянного тока активного фильтра гармоник / А.С. Плехов, Е.А. Чернов, Д.Ю. Титов // Инженерный вестник Дона. - 2014. - Т.28, №1. - С. 37.

84. Плехов, А.С. Структура и алгоритмы управления энергосберегающих компенсационных преобразователей / А.С. Плехов, К.А. Бинда, Д.Ю. Титов // Вестник Ивановского государственного энергетического университета. - 2013. - №2. - С. 56-61.

85. Поздеев, А.А. Электромагнитные и электромеханические процессы в частотно регулируемых асинхронных электроприводах. / А.А. Поздеев. - Чебоксары: Чувашский государственный университет, 1998. $172 \mathrm{c}$.

86. Поляков, В.С. О защите оборудования электрических сетей от феррорезонансных перенапряжений. / В.С. Поляков. - Л.-М.: Энергоатомиздат, Ленингр. Отд-ие, 1986. - 110 с.

87. Полянин, А.Д. Краткий справочник для инженеров и студентов: Высшая математика. Теоретическая механика. Сопротивление материалов. / А.Д. Полянин [и др.]. - М.: Международная программа образования, 1996. -432 с.

88. Синеев, А.В. Компенсация реактивной мощности «три в одном» или панацея от всех бед / А.В. Синеев // Электротехнический рынок. 2008. - №1(19). - С. 62-65.

89. Сливинская, А.Г. Электромагниты и постоянные магниты. / А.Г. Сливинская. - М.: Энергия, 1972. - 248 с.

90. Тимошенко, С.П. Колебания в инженерном деле. / С.П. Тимошенко. - М.: Наука, 1967. - 444 с.

91. Титов, В.Г. Итерационный алгоритм оптимального управления компенсационными преобразователями / В.Г. Титов [и др.]. // Инженерный вестник Дона. - 2013. - №4. - С. 12. 
92. Титов, В.Г. Управление энергосберегающими полупроводниковыми преобразователями / В.Г. Титов [и др.]. // Инженерный вестник Дона. - 2013. - №4. - С. 11.

93. Тихомиров, В.А. Сравнительный анализ гармонического состава сетевого тока управляемых выпрямителей и преобразователей частоты // В.А. Тихомиров, С.В. Хватов // Труды Нижегородского государственного технического университета им. Р.Е. Алексеева. - 2011. - №3 (90). - С. 204215.

94. Тихомиров, В.А. Сравнительный анализ гармонического состава сетевого тока управляемых выпрямителей и преобразователей частоты / В.А. Тихомиров, С.В. Хватов // Труды Нижегородского государственного технического университета им Р.Е.Алексеева. - 2011. - №3. - С. 201-214.

95. Федоров, А.А. Основы электроснабжения предприятий. / А.А. Федоров. - М.: Энергия, 1984. - 200 с.

96. Федоров, А.А. Основы электроснабжения промышленных предприятий: учебник для вузов. - 4-е изд., перераб. и доп. / А.А. Федоров, В.В. Каменева. - М.: Энергоатомиздат, 1984. - 472 с.

97. Фёдоров, О.В. Электропривод в промышленности: монография. / О.В. Фёдоров, А.С. Сарваров, Ю.В. Шевырёв. - М.: Изд-во ИНФРМ-М, 2008. - $150 \mathrm{c}$.

98. Фираго, Б.И. Регулируемые электроприводы переменного тока / Б.И. Фираго, Л.Б. Павлячик. - Мн.: Техноперспектива, 2006. - 363 с.

99. Фридман, В.М. Об одном приближенном методе определения частот колебаний. - В кн.: Колебания в турбомашинах. М.: изд-во АН CCCP, 1956.

100.Фролов, К.В. Колебания машин с ограниченной мощностью источника энергии и переменными параметрами // Нелинейные колебания и переходные процессы в машинах. - М.: Наука, 1972. - С. 5-16.

101.Фролов, К.В. Гидроупругие технологии виброизоляции прогрессивное направление в виброзащите мобильных машин / К.В. Фролов [и др.]. // Приводная техника. - 2000. - №6. - С. 13-21.

102.Хакен, Г. Синергетика. / Г. Хакен. - М.: Мир, 1980. - 406 с.

103.Хватов, О.С. Имитационная модель дизель-генераторной электростанции с переменной скоростью вращения на базе синхронного генератора / О.С. Хватов [и др.]. // Эксплуатация морского транспорта. 2012. - №1. - С. 61-66.

104.Хватов, О.С. Дизель-генераторная электростанция с переменной частотой вращения вала / О.С. Хватов, А.Б. Дарьенков, И.М. Тарасов // Вестник ИГЭУ. - 2012. -№2. - С. 53-56. 
105.Ходжаев, К.Ш. Резонансные и нерезонансные случаи в задаче о возбуждении механических колебаний / К.Ш. Ходжаев // Прикладная математика и механика. - 1968. - Т. 32, №1. - С. 85-100.

106. Чаплыгин, Е.Е. Теория мощности в силовой электронике: учеб. пособие. / Е.Е. Чаплыгин, Н. Г. Калугин. - М.: Московский энергетический институт, 2006. - 56 с.

107. Челомей, В.Н. Вибрации в технике: Колебания машин, конструкций и их элементов: справочник в 6-ти т. / В.Н. Челомей, Ф.М. Диментберга, К.С. Колесникова. - М.: Машиностроение, 1980. - 544 с.

108. Чивенков, А.И. Расширение функциональных возможностей инвертора напряжения систем интеграции возобновляемых источников энергии и промышленной сети / А.И. Чивенков [и др.]. // Инженерный вестник Дона. - 2013. - №1. - С. 43.

109. Шидловский, А.К. Высшие гармоники в низковольтных электрических сетях. / А.К. Шидловский, А.Ф. Жаркин. - Киев: Наукова Думка, 2005. - 211 с.

110. Шубов, И.Г. Шум и вибрация электрических машин. / И.Г. Шубов, - 2-е изд., перераб. и доп. - Л.: Энергоатомиздат. Ленингр. отд-ние, 1986. $-208 \mathrm{c}$.

111. Шульман, 3.П. Магнитореологический эффект. / 3.П. Шульман, В.И. Кордонский. - Минск: Наука и техника, 1982. - 184 с.

112.Яворский, Б.М. Справочник по физике. / Б.М. Яворский, А.А. Детлаф. - М.: Наука, 1964. - 847 с.

113. Abdul Rahman, N.F.A. A new approach for single-phase shunt active power filter (SSAPF) operation / Abdul Rahman N.F.A., Mohammad Noor S.Z. // Power Engineering and Renewable Energy (ICPERE), 2012. pp. 1 - 6.

114. Akaqi, H. Instantaneous power theory and applications to power conditioning / H. Akaqi, E.H. Watanabe, M. Aredes. - IEEE PRESS. 2007. $-389 \mathrm{p}$.

115.Gennensseaux, A. Research for new vibration isolation technique from hydro-mounts / A. Gennensseaux // Proceedings of SAE noise and vibration conference, 1993. - №931324.

116.Appleton, E.V. The automatic synchronization of triode oscillator / E.V. Appleton // Proc. Cambridge Phil. Soc. - 1922, V. - 21. - p. 231-248.

117. Blekhman, I.I. Synchronization and chaotization in interacting dynamical systems / I.I. Blekhman, P.S. Landa, M.G. Rosenblum // Appl. Mech. Rev. - 1995. - V.11., №.1. - P. 733-752.

118. da Silva, S.A.O. A single-phase UPS system with harmonic suppression and reactive power compensation / S.A.O. da Silva, R.A. Modesto, A.F. 
Neto, S.G. de Souza Cervantes // Power Electronics Conference, 2009. - pp. 558-563.

119. da Silva, S.A.O. A three-phase line-interactive UPS system implementation with series-parallel active power-line conditioning capabilities / S.A.O. da Silva, P.F. Donoso-Garcia, P.C. Cortizo, P.F. Seixas // Industry Applications, IEEE Transactions on. - 2002. - V.38, I.6, - pp. 1581-1590.

120. Dayi, Li. A novel series hybrid single-phase active power filter / L. Dayi, C. Qiaofu, J. Zhengchun, K. Jianxing, X. Yali // Power Electronics and Motion Control Conference, 2004. - pp. 242-245.

121.Erofeev, V.I. Electromechanic installations vibration acceleration protection system / V.I. Erofeev, A.S. Plehov, D.U. Titov // International Conference on Informatics, Networking and Intelligent Computing (16-17 November 2014, Shenzhen), 2014. - pp. 75-77. DOI: 10.1201/b18413-17.

122.Feng, N.S. Simulation of vibration signals from a rolling element bearing defect. / N.S. Feng, E.J. Hahn, R.B. Randall. - Sydney: University of new south wales, 2004.

123. European Copper Institute "European power quality survey", 2002.

124. IEEE C57.110-2008: IEEE recommended practice for establishing transformer capability when supplying non-sinusoidal load currents. 2008.

125. Melin, P.E. Unified Power Quality Conditioner based on current source converters for harmonic mitigation using a decoupled control strategy / P.E. Melin, J.R. Espinoza, C.R. Baier, C.R. Baier, E.E. Espinosa // IECON 2011 - 37th Annual Conference on IEEE Industrial Electronics Society, 2011. pp. 4152 - 4157.

126. Meng, Chao A novel control strategy for three-phase shunt active power filter using a Lyapunov function / Chao Meng, Lin Zhang Lin, Yongqiang Hong, Junbin Lin // Power Electronics and Motion Control Conference (IPEMC), 2012. - pp. 2754 - 2759.

127.Pennacchi, P. Nonlinear effects due to electromechanical interaction in generators with smooth poles / P. Pennacchi // Electrical Engineering. 2005. - V.88. - pp. 13-24.

128. Rahman, N.F. An analysis of shunt active filter performance using multiple number of power switches / N.F. Rahman // Electrical Machines and Systems (ICEMS), 2010. - pp. 123-127.

129. Silva, V. Real time digital control system for a single-phase shunt active power filter / V. Silva, J.G. Pinto, J. Cabral, J.L. Afonso, A. Tavares // Industrial Informatics (INDIN), 2012. - pp. 869 - 874.

130. Terciyanli, A. Current Source Converter based Active Power Filter for mitigation of harmonics at the interface of distribution and transmission systems / A. A. Terciyanli, T. Avci, I. Yilmaz, C. Ermis, N. Kose, A. Acik, A. 
Kalaycioglu, Y. Akkaya, I. Cadirci, M. Ermis // Energy Conversion Congress and Exposition (ECCE), 2010. - pp. 320-327.

131. Tinghsu, S. Suppression control method for torque vibration of AC motor utilizing repetitive controller with Fourier transform / S. Tinghsu, S. Hattori, M. Ishida, T. Hori // IEEE Transactions on Industry Applications. 2002. - V.38, I. 5. - pp. 1316 - 1325.

132. Van der Pol B. Forced oscillations in a circuit with non-linear resistance / B. Van der Pol // Phil. Mag. - 1927, V. 3. - pp. 64-80.

133. VLT Active Filter AAF00x Operating Instructions - URL: http://www.vlt-

drives.com.ua/usersimage/File/files/VLT\%20Low\%20Harmonic/AAF00x_Ope rating\%20Instructions_MG90V202.pdf (дата обращения 09.02.2015)

134. Xiaoyu, W.A comparative study on voltage-source control and current-source control of series active power filter / W. Xiaoyu, L. Jmjun, Y. Chang, W. Zhaoan // Applied Power Electronics Conference and Exposition, 2006. - pp. 100-107. 


\title{
Охуков Сергей Николаевич \\ Плехов Александр Сергеевич \\ Титов Дмитрий Юрьевич \\ Шевырёв Юрий Вадимович
}

\section{МЕТОДЫ И УСТРОЙСТВА ОСЛАБЛЕНИЯ ВИБРАЦИИ ЭЛЕКТРОМЕХАНИЧЕСКИХ КОМПЛЕКСОВ}

\author{
Редактор Н.Н. Максимова \\ Компьютерный набор Д.Ю. Титов
}

Подписано в печать 10.12.2016. Формат 60x84 1/16. Бумага офсетная. Печать офсетная. У сл. печ. л. 14,0.

Тираж 500 экз. Заказ 